\title{
Economic Evaluation of $\mathrm{CO}_{2}$ Storage and Sink Enhancement Options
}

\author{
Final Technical Report \\ Reporting Period Start Date: April 1, 2002 \\ Reporting Period End Date: February 28, 2003
}

\author{
Principal Authors: \\ Bert Bock, Tennessee Valley Authority \\ Richard Rhudy, Electric Power Research Institute \\ Howard Herzog, Massachusetts Institute of Technology \\ Michael Klett, Parsons Infrastructure and Technology \\ John Davison, IEA GHG R\&D Programme \\ Danial G. De La Torre Ugarte, University of Tennessee \\ Dale Simbeck, SFA Pacific
}

Prime Contractor: TVA, P.O. Box 1010, Muscle Shoals, AL 35662

Subcontractors:

Parsons Infrastructure and

Technology, Inc.

1 Meridian Boulevard, Suite 2B-1

Wyomissing, PA 19610

\author{
Massachusetts Institute of Technology \\ MIT Energy Laboratory \\ Room E40-471 \\ Cambridge, MA 02139 \\ IEA Greenhouse Gas R\&D \\ Programme \\ CRE Group Ltd., Stoke Orchard \\ Cheltenham, Gloucestershire \\ GL52 4RZ, United Kingdom \\ SFA Pacific \\ 444 Castro Street, Suite 920 \\ Mountain View, CA 94041
}

University of Tennessee

Agricultural Policy Analysis Center

310 Morgan Hall

Knoxville, TN 37996

Electric Power Research Institute

P.O. Box 10412

Palo Alto, CA 94303

February 2003

DE-FC26-00NT40937

Submitted by TVA Public Power Institute 


\section{DISCLAIMER}

This report was prepared as an account of work sponsored by an agency of the United States Government. Neither the United States Government nor any agency thereof, nor any other employees, makes any warranty, express or implied, or assumes any legal liability or responsibility for the accuracy, completeness, usefulness of any information, apparatus, product, or process disclosed, or represents that its use would not infringe privately owned rights. Reference herein to any specific commercial product, process, or service by trade name, trademark, manufacturer, or otherwise does not necessarily constitute or imply its endorsement, recommendation, or favoring by the United States Government or any agency thereof. The views and opinions of authors expressed herein do not necessarily state or reflect tho se of the United States Government or any agency thereof. 


\section{ABSTRACT}

This project developed life-cycle costs for the major technologies and practices under development for $\mathrm{CO}_{2}$ storage and sink enhancement. The technologies evaluated included options for storing captured $\mathrm{CO}_{2}$ in active oil reservoirs, depleted oil and gas reservoirs, deep aquifers, coal beds, and oceans, as well as the enhancement of carbon sequestration in forests and croplands. The capture costs for a nominal $500 \mathrm{MW}_{\mathrm{e}}$ integrated gasification combined cycle plant from an earlier study were combined with the storage costs from this study to allow comparison among capture and storage approaches as well as sink enhancements.

\section{Background}

In order to plan for potential $\mathrm{CO}_{2}$ mitigation mandates, energy companies need better cost information on $\mathrm{CO}_{2}$ mitigation options, especially storage and sink enhancement options that involve non-energy company operations. One of the major difficulties in evaluating $\mathrm{CO}_{2}$ storage and sink enhancement options is obtaining consistent, transparent, accurate, and comparable economics.

\section{Objective}

To develop consistent, transparent, accurate, and comparable economics of direct and indirect sequestration of $\mathrm{CO}_{2}$ to allow comparison between alternatives.

\section{Approach}

An international group of experts developed economic premises and cost evaluations to allow the comparison of a wide range of $\mathrm{CO}_{2}$ sequestration options. The project team calculated material balances, developed equipment lists and prices, and estimated installation costs. Economic evaluations for this project were estimated to \pm 25 to 30 percent, with the ability to modify values to be relatively site-specific. The economics of sequestration in this project are consistent with economics of advanced power generation with $\mathrm{CO}_{2}$ capture that the Electric Power Research Institute is developing for DOE. The economic framework also includes life cycle analysis for the various sequestration options - all greenhouse gas emissions from cradle to grave were estimated and considered in the analysis. The economic analysis used spreadsheet models that are flexible enough to allow a wide variation in the range of parameters to be evaluated and the sensitivity cases to be run. The carbon equivalent (CE) life-cycle greenhouse gas (LC GHG) emissions avoided by the capture and storage options assume $\mathrm{CO}_{2}$ capture and injection into storage reservoirs during the 20 -year book life of the capture and storage plants and storage of injected $\mathrm{CO}_{2}$ for another 80 years. 


\section{Results}

Costs for the base cases ranged from $\$-43$ to $39 /$ tonne of $\mathrm{CO}_{2}$ equivalent $\mathrm{LC} \mathrm{GHG}$ avoided. The forestry options are the least expensive except for the U.S. Pine case. Several forestry options would generate a positive return on investment. Next least expensive are the active oil reservoir and coal bed options followed by most of the cropland options. The other capture and storage options tend to be more expensive.

Base-case forest and cropland areas required to offset LC GHG emissions avoided by base-case $\mathrm{CO}_{2}$ capture and storage are generally ten times more for cropland than forest land.

\section{Limits on Interpretation}

Making these comparisons was a challenge due to the differences between direct and indirect cases. The resulting numbers should only be used as a relative indication of cost. Site-specific characteristics could significantly change the outcome of the comparisons. In this study, the forestry options are very attractive along with capture using active oil reservoirs for storage. Other factors, such as land availability and storage option location and capacity will also play a significant part in which options make the most sense at a given site.

The current work should be considered only a starting point. Better cost information and improvements to processes are likely to be developed and need to be incorporated into updates of this information. In addition, there are plans to update and add to portions of the current work to answer questions that arose but were beyond the scope of the current effort. For example, what happens to the costs if the power plant operates for longer than the plant book life? Also, how do the economics look for other power generation options? These and other questions will be evaluated in updates to this work. 


\section{ACKNOWLEDGMENTS}

The Tennessee Valley Authority would like to thank the Sequestration Product Line at the U.S. Department of Energy National Energy Technology Laboratory for their primary funding of this project and for their technical input and guidance.

We would like to thank EPRI (especially Richard Rhudy) for co-funding and significant roles in proposal and report preparation in addition to technical support throughout the project.

In addition to the lead investigators listed on the cover page, we would like to thank Gemma Heddle of MIT for her extensive and effective involvement in assessment of the $\mathrm{CO}_{2}$ storage options, J. David Wallace of TVA for his outstanding assistance in development of spreadsheet models for this project, and Chad Hellwinckel of the University of Tennessee for his valuable contributions in assessing the cropland options. 


\section{EXECUTIVE SUMMARY}

\section{Introduction}

In order to plan for potential $\mathrm{CO}_{2}$ mitigation mandates, energy companies need better information on the costs of alternative $\mathrm{CO}_{2}$ mitigation options, especially storage and sink enhancement options that involve non-energy company operations. One of the major difficulties in evaluating $\mathrm{CO}_{2}$ storage and sink enhancement options is obtaining consistent, transparent, accurate, and comparable economics. This project compares the economics of major technologies and practices under development for $\mathrm{CO}_{2}$ storage and sink enhancement, including options for storing captured $\mathrm{CO}_{2}$, such as active oil reservoirs, depleted oil and gas reservoirs, deep aquifers, coal beds, and oceans, as well as the enhancement of biological sinks such as forests and croplands.

The primary funding source for the project was the Department of Energy (DOE). The Tennessee Valley Authority (TVA) and the Electric Power Research Institute (EPRI) also provided additional funds. An international group of experts was assembled to develop the technology/ practice designs, the economic premises, and cost evaluations. TVA was the prime contractor for this project, responsible for overall completion of the effort. EPRI organized efforts to select specific sequestration processes to be evaluated for captured $\mathrm{CO}_{2}$ and coordinated the efforts of consultants from MIT, SFA Pacific, and the IEA Greenhouse Gas Programme to develop and refine the framework for the economic evaluations. MIT and Parsons Infrastructure and Technology developed process designs for captured $\mathrm{CO}_{2}$ storage processes and helped TVA develop economic models for comparing technologies and practices. The University of Tennessee Agricultural Policy Research Center, in collaboration with TVA, evaluated the economics of enhancing $\mathrm{CO}_{2}$ sequestration in croplands. The IEA Greenhouse Gas Programme and the Edinburgh Centre for Carbon Management (ECCM) developed the concept design for evaluating the forest sequestration options.

\section{Economic Framework}

Most of the cost comparisons to date have concentrated on $\mathrm{CO}_{2}$ capture, with the assumption that $\mathrm{CO}_{2}$ sequestration is a small part of these costs. In addition, these comparisons have used information supplied from studies of specific technologies, and the variability in costs due to variability in assumptions and lack of visibility into assumptions lessens the usefulness of the results. In the case of sequestration, virtually no comparative economic evaluations of processes have been done. 
Methodologies for developing economic comparisons are generally available. They range from very detailed \pm 10 percent for site-specific evaluations, where final decisions are made between options, to very general economics with little insight into the economic premises that were used to develop the economics. The latter is usually a simplification of more detailed economics for very high-level comparisons. In some cases, probability analyses are included to help evaluate risks. This usually adds significantly to the complexity of the model and the time to develop results. The model may use simplified economics to allow probability analysis without making the model too complex to run in a reasonable time.

The economic evaluations developed for this project are between the ranges described above and are typical of prior EPRI economics where a \pm 25 to 30 percent estimate is made, with the ability to modify values to be relatively site-specific. Material balances are made, equipment lists and pricing are developed, and installation costs are estimated. These types of evaluations are intended to be transparent, consistent, and comparable. They are consistent with the EPRI economics of advanced power generation with $\mathrm{CO}_{2}$ capture being developed for DOE. Probability analysis was not included to keep the results consistent with other EPRI studies.

The economic framework also included life cycle analysis for the various sequestration options. This means that all greenhouse gas emissions from cradle to grave were estimated and considered in the analysis. The economic analysis used spreadsheet models that are flexible enough to allow a wide variation in the range of parameters to be evaluated and the sensitivity cases to be run. The $\mathrm{CO}_{2}$ storage options were sized to accommodate the $\mathrm{CO}_{2}$ from our base case capture plant (see the design basis in the $\mathrm{CO}_{2}$ capture, transport and storage section). In addition, the amount of forest and cropland required to sequester the same amount of $\mathrm{CO}_{2}$ over a 100-year planning horizon was calculated.

\section{Concepts Evaluated}

The potential processes and concepts to be evaluated were initially prioritized, and the concepts were placed into three categories - (1) included, (2) may be included but more information is needed before a final decision can be made, and (3) not included due to the lack of good information at this time. Because one of the most unique aspects of this work is the comparison between storage of captured $\mathrm{CO}_{2}$ and sink enhancement, it was felt that at least one of each type should be included. The list of concepts and their final status is presented in Table ES-1. 
Table ES-1

Concepts status

\begin{tabular}{|l|l|}
\hline \multicolumn{1}{|c|}{ Included } & \multicolumn{1}{c|}{ Not Included } \\
\hline Aquifers & Ocean Fertilization \\
\hline Oil Reservoirs & Mineralization \\
\hline $\begin{array}{l}\text { Depleted Oil and Gas } \\
\text { Reservoirs }\end{array}$ & \\
\hline Ocean Storage & \\
\hline Forests & \\
\hline Croplands & \\
\hline Coal Beds & \\
\hline
\end{tabular}

In the case of ocean fertilization and mineralization, it is felt that at this time there is not enough reasonable information to develop a meaningful concept description and that these processes should not be included until more R\&D is performed.

The following three sections cover the results of the cases for (1) $\mathrm{CO}_{2}$ capture, transport and storage, (2) forestry, and (3) croplands. The last section presents the comparisons between cases.

\section{$\mathrm{CO}_{2}$ Capture, Transport and Storage}

\section{Overview}

This section summarizes the basis of design, methodology, and results for calculating the costs for transport and storage of captured $\mathrm{CO}_{2}$. Additional details and background information are contained in Chapters 3-9. At the end of this section, the capture costs from the DOE/EPRI study referenced in the next section are combined to get the capture, transport and storage costs.

In conjunction with overland transport via pipeline, the following storage options were evaluated:

- Enhanced oil recovery

- Enhanced coalbed methane recovery

- Depleted oil reservoir storage

- Depleted gas reservoir storage

- Deep saline aquifer storage

- Ocean storage via pipeline

- Ocean storage via tanker

For each option, a baseline conceptual design was generated. From the baseline conceptual design, capital and O\&M costs, and an economic analysis with several figures of merits were developed in a spreadsheet format. These were then used to develop sensitivity analyses and life cycle analyses, again in a spreadsheet format. 


\section{Design Basis}

A nominal $500 \mathrm{MW}_{\mathrm{e}}$ gross integrated gasification combined cycle (IGCC) plant operating at an 80 percent capacity factor was utilized as the production source of $\mathrm{CO}_{2}$. This was based on the DOE/EPRI's recent study on the "Evaluation of Innovative Fossil Fuel Power Plants with $\mathrm{CO}_{2}$ Removal" . Table ES-2 shows a summary of the parameters used in this study taken from the DOE/EPRI report for Case 3a, "IGCC with $\mathrm{CO}_{2}$ Removal".

1 "Evaluation of Innovative Fossil Fuel Power Plants with $\mathrm{CO}_{2}$ Removal," EPRI Report No. 1000316, Interim Report, December 2000, Cosponsors: U.S. Department of Energy/Office of Fossil Energy and U.S. Department of Energy/NETL, EPRI Project Manager N. A. H. Holt. 
Table ES-2

Summary of parameters for IGCC power plant with $\mathrm{CO}_{2}$ removal

\begin{tabular}{|c|c|c|}
\hline Parameter & Unit & Value \\
\hline Thermal Input, HHV & $10^{6} \mathrm{Btu} / \mathrm{h}$ & 3,723 \\
\hline Gross Power Output & MW & 490.4 \\
\hline Net Power Output & MW & 403.5 \\
\hline Efficiency, HHV & $\%$ & 37.0 \\
\hline Capacity Factor & $\%$ & 80 \\
\hline \multirow[t]{2}{*}{$\mathrm{CO}_{2}$ Captured } & $t / d$ & 7,389 \\
\hline & million scm/d & 3.76 \\
\hline $\mathrm{CO}_{2}$ Emitted & $\mathrm{kg} / \mathrm{kWh}$ & 0.073 \\
\hline $\mathrm{CO}_{2}$ Avoided in Capture & $t / d$ & 6,246 \\
\hline $\mathrm{CO}_{2}$ Capture Cost & $\$ /$ captured & 14.55 \\
\hline $\mathrm{CO}_{2}$ Capture Cost & $\$ / t$ avoided in capture & 17.21 \\
\hline Plant Life & $y$ & 20 \\
\hline Capital Charge Factor & $\%$ & 15.0 \\
\hline Fuel Cost & $\$ / G J$ & 1.18 \\
\hline Fuel Real Esc. Rate & $\% / y$ & 0.00 \\
\hline Fuel Levelization Factor & & 1.00 \\
\hline TPC & $\$ / \mathrm{kW}$ & 1,642 \\
\hline Fixed O\&M & $\$ / k W-y$ & 32.98 \\
\hline Variable O\&M & $\$ / M W h$ & 3.90 \\
\hline Heat Rate, HHV & $\mathrm{kJ} / \mathrm{kWh}$ & 9,727 \\
\hline Capital & $\$ / M W h$ & 35.04 \\
\hline O\&M & $\$ / M W h$ & 8.61 \\
\hline Fuel & $\$ / M W h$ & 11.44 \\
\hline LCOE & $\$ / M W h$ & 55.08 \\
\hline
\end{tabular}

$10^{6} \mathrm{Btu}=1.06 \mathrm{GJ}$

In the case of the ocean storage options, it is assumed that three IGCC power plants supply $\mathrm{CO}_{2}$ to a shoreline collection point. It was felt that this provided a more realistic evaluation for this option. Based on this, the ocean storage systems need to be designed to handle three times the quantity of $\mathrm{CO}_{2}$, i.e. 11.29 million scm (22,167 tonnes), as opposed to 3.76 million scm (7,389 tonnes), of $\mathrm{CO}_{2}$ per day. 
A pipeline specification of ( $152 \mathrm{bar},-40^{\circ} \mathrm{C}$ dewpoint, $\mathrm{N}_{2}<300 \mathrm{ppmv}, \mathrm{O}_{2}<40 \mathrm{ppmv}, \mathrm{Ar}<10 \mathrm{ppmv}$ ) was used for the quality of the $\mathrm{CO}_{2}$. The DOE/EPRI study is consistent with this except for the $\mathrm{CO}_{2}$ pressure. The DOE/EPRI study was based on compressing the $\mathrm{CO}_{2}$ to 83 bar. This study includes additional compression to 152 bar.

\section{Methodology}

\section{Pipeline Transport}

The pipeline inlet $\mathrm{CO}_{2}$ pressure is set equal to $152 \mathrm{bar}$, which is equivalent to the pressure of the $\mathrm{CO}_{2}$ supplied by the base case IGCC plant. Based on a recommendation that the pipeline $\mathrm{CO}_{2}$ pressure not be allowed to fall below 103 bar, this latter value is used for the pipeline outlet $\mathrm{CO}_{2}$ pressure. The maximum allowable pressure drop per unit length (?P/?L) is found as the difference between the pipeline inlet and outlet $\mathrm{CO}_{2}$ pressures divided by the pipeline length. The pipeline diameter is then calculated using the equations for pressure drop and head loss due to frictional resistance in a pipe, assuming turbulent flow.

Land construction cost data for natural gas pipelines was used to estimate construction costs for $\mathrm{CO}_{2}$ pipelines. The cost data found for natural gas pipelines consists of cost estimates filed with the United States' Federal Energy Regulatory Commission (FERC), and reported in the Oil and Gas Journal. A regression analysis on this data yields a pipeline construction cost of $\$ 20,989 / \mathrm{in} / \mathrm{km}(\$ 33,853 / \mathrm{in} / \mathrm{mile})$. O\&M costs are estimated to be $\$ 3,100 / \mathrm{km}(\$ 5,000 / \mathrm{mile})$, independent of pipeline diameter.

The total annual cost per tonne of $\mathrm{CO}_{2}$ is found by annualizing the construction cost using a capital charge rate of 15 percent per year and adding this to the annual O\&M cost. Figure ES-1 shows the cost per tonne of $\mathrm{CO}_{2}$ per $100 \mathrm{~km}$ as a function of $\mathrm{CO}_{2}$ mass flow rate. Economies of scale are reached with annual $\mathrm{CO}_{2}$ flow rates in excess of 10 million tonnes per year. At these rates, transport costs are less than $\$ 1$ per tonne of $\mathrm{CO}_{2}$ per $100 \mathrm{~km}$. Note that the annual flows evaluated in this study, corresponding to the IGCC plant described above, are 2.16 million tonnes per year (7,389 tonnes per day with an $80 \%$ capacity factor). 


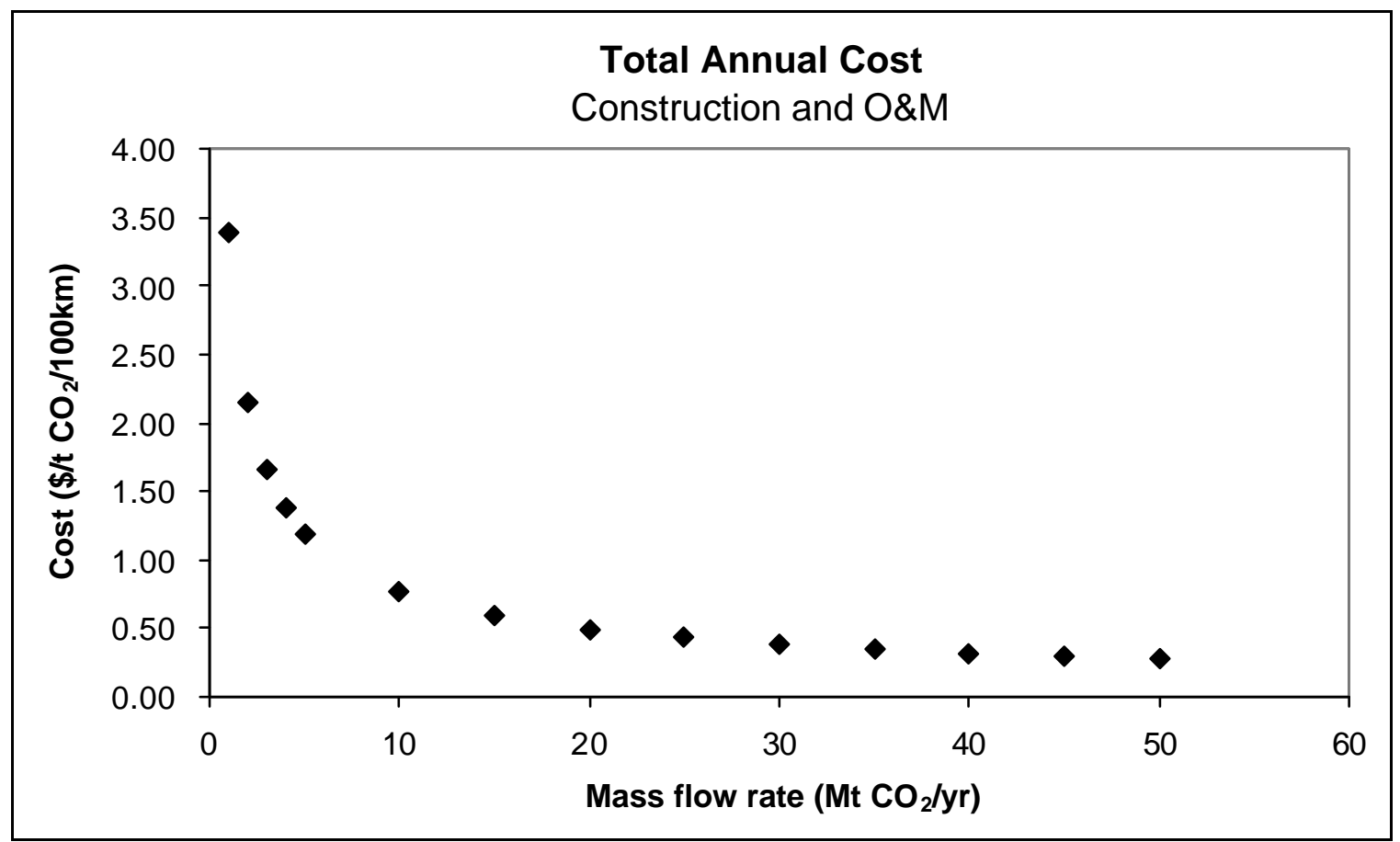

Figure ES-1

Cost for $\mathrm{CO}_{2}$ transport via pipeline as a function of $\mathrm{CO}_{2}$ mass flow rate

Note that these costs are not on a $\mathrm{CO}_{2}$ equivalent life cycle greenhouse gas basis. This information was developed using an MIT pipeline model. Transport values used for the rest of the transport and storage cases are on an equivalent life cycle greenhouse gas basis.

\section{Enhanced Oil Recovery}

For specific projects, the complex interactions between the injected $\mathrm{CO}_{2}$ and reservoir oil would be modeled to assess the likely performance of a proposed $\mathrm{CO}_{2}$-EOR project. Based on the output of this modeling, the cost of the proposed $\mathrm{CO}_{2}$ flood is calculated. However, for our purposes of developing general costing algorithms, 'rules of thumb' are used to define the engineering parameters needed to estimate the cost of a $\mathrm{CO}_{2}$-EOR project. These 'rules of thumb' have been derived based on information from experts in the field and the literature.

The method used for costing the EOR process can be split up into a number of steps. The illustration presented here uses numbers from our base case (see Table ES-3). First, the average amount of enhanced oil produced per day for the given $\mathrm{CO}_{2}$ mass flow rate is determined using a $\mathrm{CO}_{2}$ effectiveness factor of 170 standard cubic meters $\left(6,000\right.$ standard cubic feet) of new $\mathrm{CO}_{2}$ per bbl of enhanced oil. Second, the number of production wells is found by dividing this total amount of enhanced oil produced per day by an assumed average of $40 \mathrm{bbl}$ of enhanced oil per day being produced at each well. Third, a ratio of producers to injectors of 1 to 1.1 is used to calculate the number of injection wells from the number of production wells. Fourth, the capital cost of the $\mathrm{CO}_{2}$ recycle plant is determined based on a maximum $\mathrm{CO}_{2}$ recycle ratio of 3 , with an average recyc le ratio of 1.1 being used for the plant's O\&M costs. Finally, the capital and O\&M costs associated with the wells and the field equipment are calculated. 
The EIA 'Costs and Indices for Domestic Oil and Gas Field Equipment and Production Operations, ${ }^{2}$ report was used as the basis for field equipment and production operations costs. Costs and indices for additional secondary oil recovery equipment and its operation were provided for a representative lease, located in west Texas. This lease, or module, comprises 10 production wells, 11 water injection wells and 1 disposal well, and the wells are nominally 4,000 feet, or 1,219 m, deep.

Table ES-3 below defines three cases, a base case, a high cost case, and a low cost case. We analyzed typical EOR operating data to determine a base case and range for each critical variable. These values were then used to define the cases described in Table ES-3. Costs for EOR and the other $\mathrm{CO}_{2}$ storage options assessed in this project were calculated on a $\mathrm{CO}_{2}$ equivalent life-cycle (LC) GHG avoided basis as described in Chapter 2.

Table ES-3

EOR case descriptions and costing results

\begin{tabular}{|c|c|c|c|c|}
\hline Parameter & Units & $\begin{array}{l}\text { EOR } \\
\text { Base Case }\end{array}$ & $\begin{array}{l}\text { EOR } \\
\text { High Cost Case }\end{array}$ & $\begin{array}{l}\text { EOR } \\
\text { Low Cost } \\
\text { Case }\end{array}$ \\
\hline $\mathrm{CO}_{2}$ Effectiveness & scm/bbl enhanced oil & 170 & 227 & 85 \\
\hline $\begin{array}{l}\text { Oil Production per } \\
\text { Well }\end{array}$ & bbl enhanced oil/d/well & 40 & 20 & 70 \\
\hline $\begin{array}{l}\text { Maximum Recycle } \\
\text { Ratio }\end{array}$ & & 3 & 4 & 1 \\
\hline Oil Price & $\$ / b b l$ & 15 & 12 & 20 \\
\hline Depth & $m$ & 1,219 & 2,438 & 610 \\
\hline Pipeline Distance & $\mathrm{km}$ & 100 & 300 & 0 \\
\hline $\begin{array}{l}\text { Previous } \\
\text { Waterflooding }\end{array}$ & & Yes & No & Yes \\
\hline Total Oil Production* & bbl enhanced oil/d & 22,142 & 16,582 & 44,285 \\
\hline $\begin{array}{l}\text { Number of } 10 / 11 \text { Well } \\
\text { Modules* }\end{array}$ & & 56 & 83 & 64 \\
\hline New $\mathrm{CO}_{2}{ }^{*}$ & scm/day/module & 68,000 & 45,000 & 59,000 \\
\hline $\begin{array}{l}\text { Maximum Recycled } \\
\mathrm{CO}_{2}{ }^{*}\end{array}$ & scm/day/module & 204,000 & 182,000 & 59,000 \\
\hline $\begin{array}{l}\text { Levelized Annual } \mathrm{CO}_{2} \\
\text { Net Storage Cost }{ }^{\star}\end{array}$ & $\begin{array}{l}\text { \$/tonne } \mathrm{CO}_{2} \text { eq. } \mathrm{LC} \\
\mathrm{GHG} \text { avoided }\end{array}$ & $(12.21)$ & 73.84 & $(91.26)$ \\
\hline
\end{tabular}

* calculated

2 Energy Information Administration (Office of Oil and Gas), "Costs and Indices for Domestic Oil and Gas Field Equipment and Production Operations," [Online document], Mar. 2000, [cited Jan. 2002], Available HTTP:

http://www.eia.doe.gov/oil_gas/natural_gas/data_publications/cost_indices/c_i.html 


\section{Enhanced Coalbed Methane Recovery}

As in the case of the $\mathrm{CO}_{2}$-EOR concept design, 'rules of thumb' are used to define the engineering parameters needed to estimate the cost of a $\mathrm{CO}_{2}-\mathrm{ECBMR}$ project. The illustration presented here uses numbers from our base case (see Table ES-4). First, the total amount of enhanced $\mathrm{CBM}$ produced per day for the given $\mathrm{CO}_{2}$ mass flow rate is determined using a $\mathrm{CO}_{2}$ effectiveness factor of two $\mathrm{scm} \mathrm{CO}_{2}$ per scm of enhanced CBM. Second, the number of production wells is found by dividing this total amount of enhanced CBM produced per day by an assumed 14,000 scm of enhanced CBM per day being produced at each well. Third, a ratio of producers to injectors of 1 to 1 is used to calculate the number of injection wells from the number of production wells. Fourth, it is assumed that no recycling of $\mathrm{CO}_{2}$ is required. Finally, the cost of drilling and equipping the required production and injection wells is calculated.

Prior to acquiring a lease position, geological expenditures, geophysical expenditures, and engineering-based feasibility studies are often conducted. In addition, outlays are generally required for obtaining the lease and its associated permits. These front-end costs will vary greatly but may range from $\$ 20,000$ to $\$ 30,000$ per well for a commercial project. For this study, a cost of $\$ 25,000$ per well is assumed.

All of the other field costs, except for the well drilling cost, are based on data contained in the EIA 'Costs and Indices for Domestic Oil and Gas Field Equipment and Production Operations' report. A representative ECBMR lease, or module, comprising $10 \mathrm{CO}_{2}$ injection wells and 10 producing wells with dewatering facilities is used for the design basis. The $10 \mathrm{CO}_{2}$ injection wells are drilled to a depth of $610 \mathrm{~m}$ and equipped with a battery of lease equipment, which includes distribution lines, headers, electrical service, and controls. The 10 producing wells, also drilled to a depth of $610 \mathrm{~m}$, are equipped with beam balanced/sucker rod dewatering.

The well drilling cost is calculated based on a relationship derived from data contained in the '1998 Joint Association Survey (JAS) on Drilling Costs' report. ${ }^{3}$ This relationship between well depth and drilling cost is shown in Figure ES-2. To determine the relationship, regression analysis was performed on drilling cost data for onshore gas and oil wells. The total well drilling cost is found by multiplying the cost of drilling a single well for the given reservoir depth, taken from the graph, by the required number of wells.

\footnotetext{
3 American Petroleum Institute - Policy Analysis and Statistics Department, "1998 Joint Association Survey on Drilling Costs," [Online document], Nov. 1999, Available HTTP:
}

http://www.api.org/axs -api/products/joint.htm 


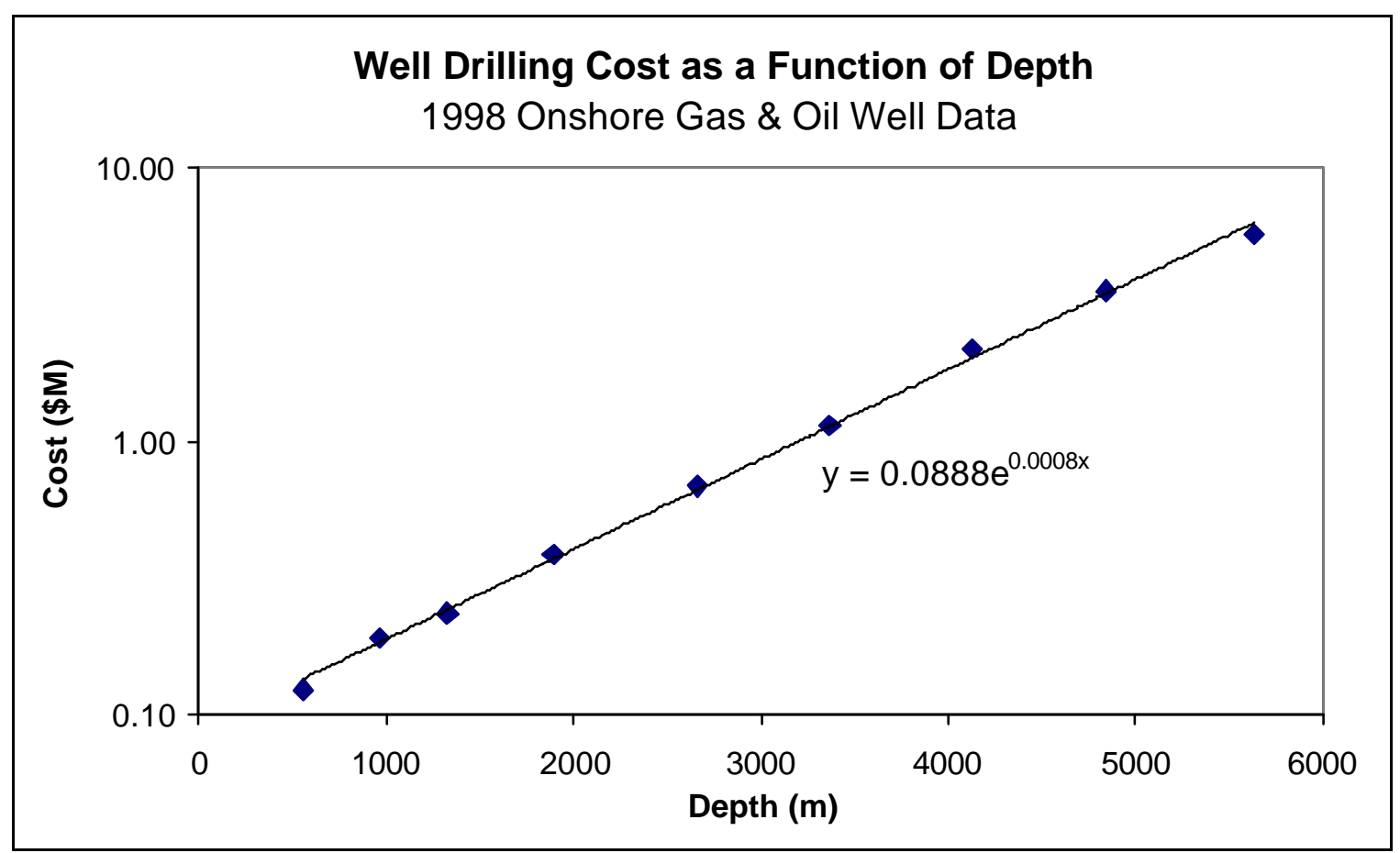

Figure ES-2

Well drilling cost as a function of depth

Table ES-4 defines a base case, a high cost case, and a low cost case derived from an analysis of typical ECBMR operating data.

Table ES-4

ECBMR case descriptions and costing results

\begin{tabular}{|c|c|c|c|c|}
\hline Parameter & Units & $\begin{array}{l}\text { ECBMR } \\
\text { Base Case }\end{array}$ & $\begin{array}{l}\text { ECBMR } \\
\text { High Cost } \\
\text { Case }\end{array}$ & $\begin{array}{l}\text { ECBMR } \\
\text { Low Cost } \\
\text { Case }\end{array}$ \\
\hline $\mathrm{CO}_{2}$ Effectiveness & $\begin{array}{l}\text { scm/scm enhanced } \\
\text { CBM }\end{array}$ & 2 & 10 & 1.5 \\
\hline $\begin{array}{l}\text { CBM Production per } \\
\text { Well }\end{array}$ & $\begin{array}{l}\text { scm enhanced } \\
\text { CBM/d/well }\end{array}$ & 14,000 & 3,000 & 30,000 \\
\hline Gas Price & $\$ / 10^{6} \mathrm{Btu}$ & 2 & 1.80 & 3 \\
\hline Depth & $\mathrm{m}$ & 610 & 1,219 & 610 \\
\hline Pipeline Distance & $\mathrm{km}$ & 100 & 300 & 0 \\
\hline Total CBM Production* & $\begin{array}{l}\text { million scm enhanced } \\
\mathrm{CBM} / \mathrm{d}\end{array}$ & 1.88 & 0.38 & 2.51 \\
\hline $\begin{array}{l}\text { Number of } 10 / 10 \text { Well } \\
\text { Modules }{ }^{*}\end{array}$ & & 135 & 126 & 84 \\
\hline Number of $\mathrm{CO}_{2}$ Wells ${ }^{*}$ & & 135 & 126 & 84 \\
\hline New $\mathrm{CO}_{2}{ }^{*}$ & $\mathrm{scm} / \mathrm{d} /$ well & 28,000 & 30,000 & 45,000 \\
\hline $\begin{array}{l}\text { Levelized Annual } \mathrm{CO}_{2} \\
\text { Net Storage Cost }\end{array}$ & $\begin{array}{l}\$ / \text { tonne } \mathrm{CO}_{2} \text { eq. LC } \\
\text { GHG avoided }\end{array}$ & $(5.59)$ & 18.88 & $(25.72)$ \\
\hline
\end{tabular}

* calculated 


\section{Depleted Gas and Oil Reservoir/Aquifer Storage}

Depleted natural gas and oil reservoirs, and deep saline aquifers, differ quite substantially from one another in terms of typical values of reservoir parameters such as pressure, thickness, depth, and permeability. The processes that govern the rate at which $\mathrm{CO}_{2}$ can be injected at a well, and thus the number of wells required, are however essentially identical for the three types of reservoir. Given this, the same costing methodology is applied to each of the three geologic $\mathrm{CO}_{2}$ storage options.

The cost model for the geologic $\mathrm{CO}_{2}$ storage options can be broken down into a number of components. First, there is a relationship for calculating the number of wells required for a given $\mathrm{CO}_{2}$ flow rate, $\mathrm{CO}_{2}$ downhole injection pressure, and set of reservoir parameters. Second, an iterative procedure is used to take into account the interdependent relationship between $\mathrm{CO}_{2}$ downhole injection pressure and well number. Third, a set of capital and O\&M cost factors are used to determine cost based on well number.

The well number calculation requires inputs for $\mathrm{CO}_{2}$ mass flow rate, $\mathrm{CO}_{2}$ downhole injection pressure, and reservoir pressure, thickness, depth, and permeability. The relationship shown in Figure ES-3 is used to determine $\mathrm{CO}_{2}$ injectivity from $\mathrm{CO}_{2}$ mobility ${ }^{4} \mathrm{CO}_{2}$ injectivity is defined as the mass flow rate of $\mathrm{CO}_{2}(\mathrm{~m})$ that can be injected per unit of reservoir thickness (h) and per unit of downhole pressure difference $\left(\mathrm{P}_{\text {inj }}-\mathrm{P}_{\text {res }}\right) . \mathrm{CO}_{2}$ mobility is defined as the $\mathrm{CO}_{2}$ absolute permeability divided by the $\mathrm{CO}_{2}$ viscosity. Given the $\mathrm{CO}_{2}$ injectivity, the $\mathrm{CO}_{2}$ injection rate per well (Q) can be calculated as

$$
\mathrm{Q}=\mathrm{CO}_{2} \text { injectivity } \times \mathrm{h} \times\left(\mathrm{P}_{\mathrm{inj}}-\mathrm{P}_{\text {res }}\right)
$$

Finally, the number of wells required (n) is given by

$$
\mathrm{n}=\mathrm{m} / \mathrm{Q}
$$

\footnotetext{
${ }^{4}$ Law, D. and S. Bachu, "Hydrogeological and numerical analysis of $\mathrm{CO}_{2}$ disposal in deep aquifers in the Alberta sedimentary basin,” Energy Convers. Mgmt., 37:6-8, pp. 1167-1174, 1996.
} 


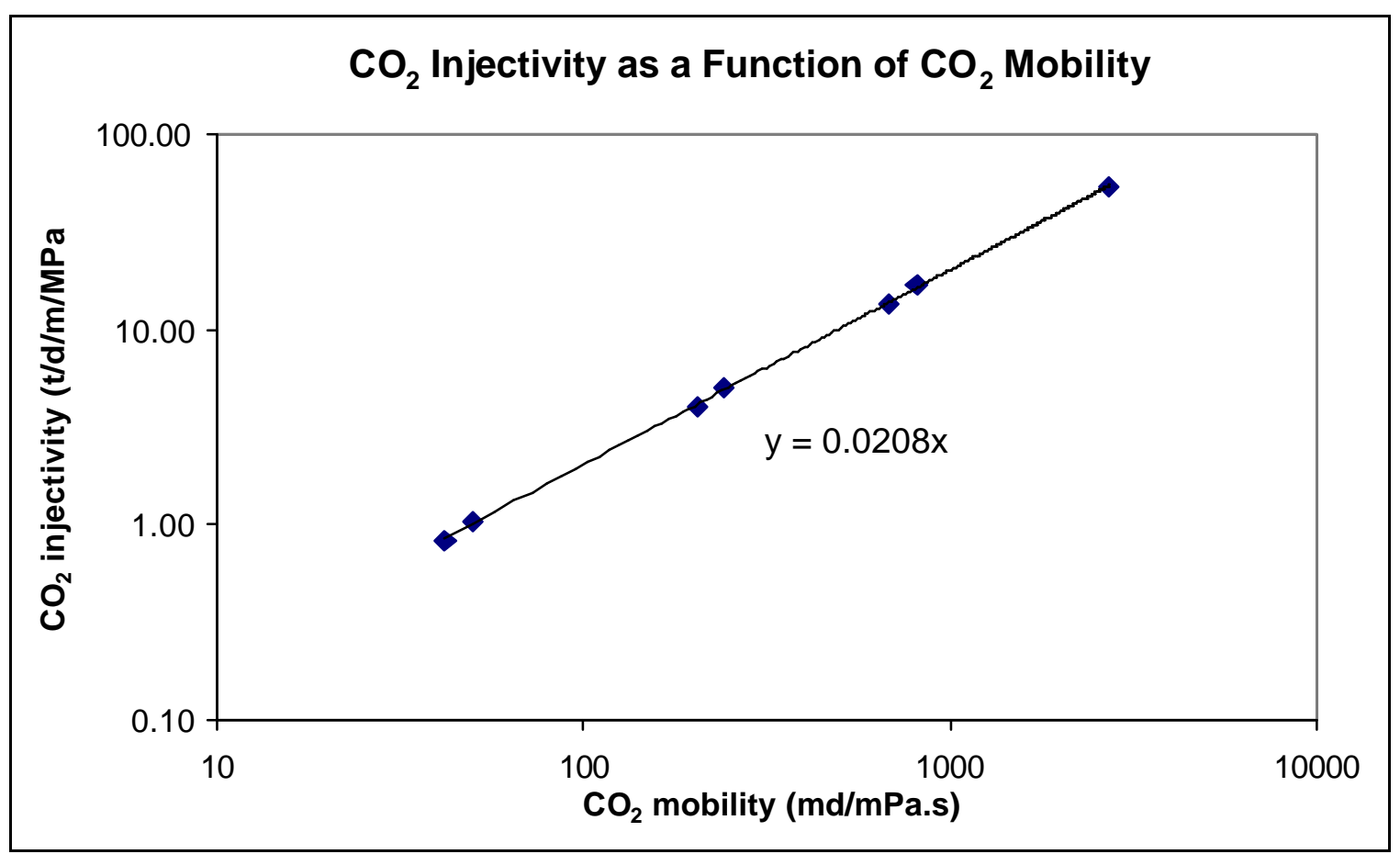

Figure ES-3

$\mathrm{CO}_{2}$ injectivity as a function of $\mathrm{CO}_{2}$ mobility

The capital cost for site screening and evaluation is based on an estimate given in a recent study by the Battelle Memorial Institute. ${ }^{5}$ This study estimated the costs for preliminary site screening and candidate evaluation at $\$ 1,685,000$.

All of the other costs, except for the well drilling cost, are calculated based on values given in the EIA 'Costs and Indices for Domestic Oil and Gas Field Equipment and Production Operations' report. Average lease equipment costs and O\&M costs were developed on a per well basis. In the case of the injection equipment and surface maintenance, these average cost values are adjusted to take into account the number of wells. Similarly, the average cost value for subsurface maintenance is adjusted to take into account the well depth. These capital and O\&M cost factors/functions are given in Table ES-5.

\footnotetext{
5 Smith, L.A. et al, "Engineering and Economic Assessment of Carbon Dioxide Sequestration in Saline Formations," presented at the First National Conference on Carbon Sequestration, May 14-17, 2001, Washington D.C.
} 
Table ES-5

Capital and O\&M cost estimation factors/functions

\begin{tabular}{|c|c|c|}
\hline Parameter & Unit & Value \\
\hline \multicolumn{3}{|l|}{ CAPITAL COSTS } \\
\hline $\begin{array}{l}\text { Injection Equipment } \\
\text { (Flowlines \& Connections) }\end{array}$ & $\$ /$ well & $43,600^{*}\left(7,389 /\left(280^{*} \text { Number_of_wells }\right)\right)^{\wedge} 0.5$ \\
\hline \multicolumn{3}{|l|}{ O\&M COSTS } \\
\hline Normal Daily Expenses & $\$ /$ well & 6,700 \\
\hline Consumables & $\$ /$ well & 17,900 \\
\hline $\begin{array}{l}\text { Surface Maintenance } \\
\text { (Repair \& Services) }\end{array}$ & $\$ /$ well & $13,600^{*}\left(7,389 /\left(280^{*} \text { Number_of_wells }\right)\right)^{\wedge} 0.5$ \\
\hline $\begin{array}{l}\text { Subsurface Maintenance } \\
\text { (Repair \& Services) }\end{array}$ & $\$ /$ well & 5,000*Well_depth/1219 \\
\hline
\end{tabular}

The well drilling cost is calculated based on the relationship derived from data contained in the '1998 Joint Association Survey (JAS) on Drilling Costs' report.

Table ES-6, Table ES-7, and Table ES-8 define a base case, a high cost case, and a low cost case derived from an analysis of typical data for depleted gas reservoirs, depleted oil reservoirs, and deep, brine aquifers, respectively.

Table ES-6

Depleted Gas Reservoir Case Descriptions and Costing Results

\begin{tabular}{|c|c|c|c|c|}
\hline Parameter & Units & $\begin{array}{l}\text { Gas } \\
\text { Reservoir } \\
\text { Base Case }\end{array}$ & $\begin{array}{l}\text { Gas } \\
\text { Reservoir } \\
\text { High Cost } \\
\text { Case }\end{array}$ & $\begin{array}{l}\text { Gas } \\
\text { Reservoir } \\
\text { Low Cost } \\
\text { Case }\end{array}$ \\
\hline Pressure & $\mathrm{MPa}$ & 3.5 & 6.9 & 2.1 \\
\hline Thickness & $\mathrm{m}$ & 31 & 15 & 61 \\
\hline Depth & $\mathrm{m}$ & 1,524 & 3,048 & 610 \\
\hline Permeability & md & 1 & 0.8 & 10 \\
\hline Pipeline Distance & $\mathrm{km}$ & 100 & 300 & 0 \\
\hline Injection Rate per Well ${ }^{\star}$ & $t / d$ & 156 & 57 & 2,975 \\
\hline Number of Wells* & & 48 & 129 & 3 \\
\hline $\begin{array}{l}\text { Levelized Annual } \mathrm{CO}_{2} \\
\text { Storage Cost }{ }^{\star}\end{array}$ & $\begin{array}{l}\$ / \text { tonne } \mathrm{CO}_{2} \text { eq. LC } \\
\mathrm{GHG} \text { avoided }\end{array}$ & 4.87 & 19.43 & 1.20 \\
\hline
\end{tabular}

* calculated 
Table ES-7

Depleted oil reservoir case descriptions and costing results

\begin{tabular}{|l|l|l|l|l|}
\hline & Units & $\begin{array}{l}\text { Oil Reservoir } \\
\text { Base Case }\end{array}$ & $\begin{array}{l}\text { Oil Reservoir } \\
\text { High Cost } \\
\text { Case }\end{array}$ & $\begin{array}{l}\text { Oil Reservoir } \\
\text { Low Cost } \\
\text { Case }\end{array}$ \\
\hline Pressure & $\mathrm{MPa}$ & 13.8 & 20.7 & 3.5 \\
\hline Thickness & $\mathrm{m}$ & 43 & 21 & 61 \\
\hline Depth & $\mathrm{m}$ & 1,554 & 2,134 & 1,524 \\
\hline Permeability & $\mathrm{md}$ & 5 & 5 & 19 \\
\hline Pipeline Distance & $\mathrm{km}$ & 100 & 300 & 0 \\
\hline Injection Rate per Well & $\mathrm{t} / \mathrm{d}$ & 360 & 115 & 5,690 \\
\hline Number of Wells* & & 21 & 65 & 2 \\
\hline $\begin{array}{l}\text { Levelized Annual } \mathbf{C O}_{2} \\
\text { Storage Cost }\end{array}$ & $\begin{array}{l}\text { \$/tonne } \mathrm{CO}_{2} \text { eq. LC } \\
\text { GHG avoided }\end{array}$ & 3.82 & 11.16 & 1.21 \\
\hline
\end{tabular}

* calculated

Table ES-8

Deep, brine aquifer case descriptions and costing results

\begin{tabular}{|l|l|l|l|l|}
\hline & Units & $\begin{array}{l}\text { Aquifer } \\
\text { Base Case }\end{array}$ & $\begin{array}{l}\text { Aquifer } \\
\text { High Cost } \\
\text { Case }\end{array}$ & $\begin{array}{l}\text { Aquifer } \\
\text { Low Cost } \\
\text { Case }\end{array}$ \\
\hline Pressure & $\mathrm{MPa}$ & 8.4 & 11.8 & 5.0 \\
\hline Thickness & $\mathrm{m}$ & 171 & 42 & 703 \\
\hline Depth & $\mathrm{m}$ & 1,239 & 1,784 & 694 \\
\hline Permeability & $\mathrm{md}$ & 22 & 0.8 & 585 \\
\hline Pipeline Distance & $\mathrm{km}$ & 100 & 300 & 0 \\
\hline Injection Rate per Well* & $\mathrm{t} / \mathrm{d}$ & 9,363 & 82 & 889,495 \\
\hline Number of Wells* & & 1 & 91 & 1 \\
\hline $\begin{array}{l}\text { Levelized Annual } \mathbf{C O}_{2} \\
\text { Storage Cost }\end{array}$ & $\begin{array}{l}\text { \$/tonne } \mathrm{CO}_{2} \text { eq. LC } \\
\text { GHG avoided }\end{array}$ & 2.93 & 11.71 & 1.14 \\
\hline
\end{tabular}

* calculated

\section{Ocean Via Pipeline}

The ocean pipeline storage option assumes that three IGCC power plants supply $\mathrm{CO}_{2}$ to a shoreline collection point. The $\mathrm{CO}_{2}$ is then transported via a subsea pipeline from the shoreline to a depth of 2,000 m, at which depth the $\mathrm{CO}_{2}$ is discharged into the deep ocean via a diffuser unit. The method used for calculating the cost of this process can be broken down into two steps. First, the diameter of the subsea pipeline is determined. It is then possible, as a second step, to calculate the capital and O\&M costs as well as the cost per tonne of $\mathrm{CO}_{2}$. 
The pipeline diameter is calculated using the same method as is used in the $\mathrm{CO}_{2}$ overland pipeline transport model. The only difference is the means by which the maximum allowable pressure drop per unit length (?P/?L) is determined. In the case of $\mathrm{CO}_{2}$ overland pipeline transport, the pressure drop per unit length is simply found as the difference between the pipeline $\mathrm{CO}_{2}$ inlet and outlet pressures divided by the pipeline length. The pipeline ocean $\mathrm{CO}_{2}$ storage model however requires that the pressure drop per unit length calculation also take into account the gravity head gain and diffuser head loss. In addition, it is necessary that the $\mathrm{CO}_{2}$ be discharged at a pressure equal to the hydrostatic pressure.

The cost of the subsea pipeline has been determined based on cost information contained in McDermott's phase II final report on 'Large-scale $\mathrm{CO}_{2}$ Transportation and Deep Ocean Sequestration. ${ }^{6}$ The capital cost of an injector unit, based on an estimate given in an IEA report, ${ }^{7}$ is taken to be $\$ 14.5$ million. The results are shown in Table ES-9.

Table ES-9

Ocean pipeline storage case descriptions and costing results

\begin{tabular}{|c|c|c|c|c|}
\hline Parameter & Units & $\begin{array}{l}\text { Ocean } \\
\text { Pipeline } \\
\text { Base Case }\end{array}$ & $\begin{array}{l}\text { Ocean } \\
\text { Pipeline } \\
\text { High Cost } \\
\text { Case }\end{array}$ & $\begin{array}{l}\text { Ocean } \\
\text { Pipeline } \\
\text { Low Cost } \\
\text { Case }\end{array}$ \\
\hline Pipeline Distance & $\mathrm{km}$ & 100 & 300 & 0 \\
\hline Offshore Distance & $\mathrm{km}$ & 100 & 300 & 50 \\
\hline $\begin{array}{l}\text { Pressure Drop per Unit } \\
\text { Length }^{*}\end{array}$ & $\mathrm{~Pa} / \mathrm{m}$ & 126 & 42 & 251 \\
\hline Pipe Diameter* & inches & 14.2 & 17.5 & 12.4 \\
\hline Nominal Pipe Size* & inches & 16 & 20 & 14 \\
\hline $\begin{array}{l}\text { Levelized Annual } \mathrm{CO}_{2} \\
\text { Storage Cost }\end{array}$ & $\begin{array}{l}\text { \$/tonne } \mathrm{CO}_{2} \text { eq. LC } \\
\mathrm{GHG} \text { avoided }\end{array}$ & 5.53 & 14.23 & 2.90 \\
\hline
\end{tabular}

* calculated, 1 inch $=0.0254 \mathrm{~m}$

\section{Ocean Via Tanker}

The storage option has been modeled based on design and cost information obtained from McDermott's Phase I and Phase $\mathrm{II}^{8}$ final reports on 'Large-scale $\mathrm{CO}_{2}$ Transportation and Deep Ocean Sequestration' as well as e-mail communications with the reports' author. The method

\footnotetext{
${ }^{6}$ Sarv, H., "Large-scale $\mathrm{CO}_{2}$ transportation and deep ocean sequestration - Phase II final report," McDermott Technology Inc., Ohio. Tech. Rep. DE-AC26-98FT40412, 2001.

7 Ormerod, B., "The disposal of carbon dioxide from fossil fuel fired power stations," IEA Greenhouse R\&D Programme, Cheltenham. Tech. Rep. IEAGHG/SR3, Jun. 1994.

${ }^{8}$ Sarv, H., "Large-scale $\mathrm{CO}_{2}$ transportation and deep ocean sequestration," McDermott Technology Inc., Ohio. Tech. Rep. DE-AC26-98FT40412, Mar. 1999.
} 
used for a conceptual design of this process can be broken down into a number of steps. First, the number of tankers required to transport the $\mathrm{CO}_{2}$ to the offshore platform is determined. Second, the diameter of the vertical pipe to carry the $\mathrm{CO}_{2}$ from the platform to the injection depth is calculated. Third, the amount of $\mathrm{CO}_{2}$ emitted by the tankers travelling to and from the offshore storage site, and emitted due to boil off, is found. It is then possible, as a final step, to calculate the capital cost of the tankers, port facility, offshore floating platform, and vertical pipe, and the non-fuel and fuel O\&M costs as well as the cost per tonne of $\mathrm{CO}_{2}$.

The total capital cost of the tanker ocean $\mathrm{CO}_{2}$ storage option comprises the capital cost of the three required tankers, the offshore floating platform, the port facility, and a 2,000-m long, 8-inch diameter vertical pipe. The total O\&M cost is calculated as the sum of the non-fuel and fuel O\&M costs. From e-mail communications with Hamid Sarv of McDermott Technology, Inc., it was learned that the total annual O\&M cost in the case studies was taken as the sum of 5.6 percent and 0.02 percent of the total tanker and non-tanker capital costs, respectively, where the fuel cost comprised 16.5 percent of the tanker O\&M cost. The non-fuel O\&M cost is calculated in the model as 4.7 percent of the total tanker capital cost, thus excluding the fuel cost, plus 0.02 percent of the total non-tanker capital costs. The fuel O\&M cost is determined as the product of the total annual fuel usage, found from multiplying the tanker fuel usage by the total annual distance traveled, and a diesel fuel price of $\$ 0.566 / \mathrm{gal}$.

The capital and O\&M cost estimation factors are summarized in Table ES-10. Table ES-11 defines a base case, a high cost case, and a low cost case for the ocean tanker storage option. 
Table ES-10

Capital and O\&M cost estimation factors for ocean tanker storage

\begin{tabular}{|c|c|c|c|}
\hline Parameter & Unit & Value & \\
\hline \multicolumn{4}{|l|}{ CAPITAL COSTS } \\
\hline Tanker & \$/tanker & $55,263,000$ & \\
\hline Offshore Platform & $\$$ & $200,000,000$ & \\
\hline Onshore Port Facility & $\$$ & $50,000,000$ & \\
\hline \multicolumn{4}{|l|}{ Vertical Pipeline: } \\
\hline Construction & $\$ / \mathrm{in} / \mathbf{k m}$ & 351,445 & \\
\hline $\begin{array}{l}\text { Towing to Offshore } \\
\text { Structure }\end{array}$ & $\$$ & 300,000 & \\
\hline $\begin{array}{l}\text { Upending, Securing \& } \\
\text { Anchoring }\end{array}$ & $\$$ & $3,000,000$ & \\
\hline $\begin{array}{l}\text { General Facilities, } \\
\text { Engineering, Permitting etc. }\end{array}$ & $\$$ & $\begin{array}{l}0.3^{\star}(\text { Tanker_capital_cost } \\
\text { Offshore_platform_capital_cost } \\
\text { Onshore_port_facility_capital_cost } \\
\text { Vertical_pipeline_capital_cost) }\end{array}$ & $\begin{array}{l}+ \\
+ \\
+\end{array}$ \\
\hline \multicolumn{4}{|l|}{ O\&M COSTS } \\
\hline Non-fuel & $\$ / y$ & $\begin{array}{l}\left.\text { (Tanker_capital_cost }{ }^{\star} 0.047\right) \\
\text { ((Offshore_platform_capital_cost } \\
\text { Onshore_port_facility_capital_cost } \\
\left.\text { Vertical_pipeline_capital_cost) }{ }^{\star} 0.02\right)\end{array}$ & $\begin{array}{l}+ \\
+ \\
+\end{array}$ \\
\hline Fuel & $\$ /$ gal & 0.566 & \\
\hline
\end{tabular}

1 inch $=0.0254 \mathrm{~m}, 1 \mathrm{gal}=3.79$ liters

Table ES-11

Ocean tanker storage case descriptions and costing results

\begin{tabular}{|c|c|c|c|c|}
\hline Parameter & Units & $\begin{array}{l}\text { Ocean Tanker } \\
\text { Base Case }\end{array}$ & $\begin{array}{l}\text { Ocean Tanker } \\
\text { High Cost } \\
\text { Case }\end{array}$ & $\begin{array}{l}\text { Ocean Tanker } \\
\text { Low Cost } \\
\text { Case }\end{array}$ \\
\hline Pipeline Distance & $\mathrm{km}$ & 100 & 300 & 0 \\
\hline Offshore Distance & $\mathrm{km}$ & 100 & 300 & 50 \\
\hline Boil Off & $\% / d$ & 1 & 2 & 0.5 \\
\hline Diesel Price & $\$ /$ gal & 0.566 & 0.8 & 0.45 \\
\hline Number of Tankers* & & 3 & 3 & 3 \\
\hline $\begin{array}{l}\text { Total Annual Fuel } \\
\text { Usage }^{\star}\end{array}$ & gal/y & 249,001 & 747,004 & 124,501 \\
\hline $\begin{array}{l}\mathrm{CO}_{2} \text { Emitted by } \\
\text { Tankers }{ }^{\star}\end{array}$ & $t / y$ & 2,395 & 7,186 & 1,198 \\
\hline $\mathrm{CO}_{2}$ Emitted by Boil Off* & $t / y$ & 53,362 & 139,415 & 24,638 \\
\hline $\begin{array}{l}\text { Levelized Annual } \mathrm{CO}_{2} \\
\text { Storage Cost }\end{array}$ & $\begin{array}{l}\$ / \text { tonne } \mathrm{CO}_{2} \text { eq. } \mathrm{LC} \\
\mathrm{GHG} \text { avoided }\end{array}$ & 17.64 & 22.79 & 15.76 \\
\hline
\end{tabular}

* calculated

$1 \mathrm{gal}=3.79$ liters

xxii 


\section{Summary of Results}

Figure ES-4 and Figure ES-5 summarize the results for the cost of the various carbon storage technologies analyzed in this study on a life-cycle greenhouse gas avoided basis. Figure ES-4 includes all the direct storage technologies, while Figure ES-5 expands the scale for storage technologies with no commercial by-products. The points on the graphs are for the base case conditions, while the bars represent the range between the high and low cost cases as outlined in the Tables above.

Several observations about these results are offered below:

- Excluding the more expensive ocean tanker option, the typical base case costs for $\mathrm{CO}_{2}$ storage (transport + injection) without oil or gas by-product credit is in the range of \$3-5.50 per tonne $\mathrm{CO}_{2}(\$ 11-20$ per tonne $\mathrm{C})$. The cost range can be characterized as $\$ 2-15$ per tonne $\mathrm{CO}_{2}$ (\$7-55 per tonne $\left.\mathrm{C}\right)$.

- With a by-product credit for the gas or oil, the credit will offset the storage costs in many instances. For example, in the base EOR case, one can afford to pay $\$ 12.21$ per tonne of $\mathrm{CO}_{2}$ and still breakeven (i.e., the costs equal the by-product credit).

- With an oil or gas by-product, the net costs have a large range. The parameters most responsible for this variability are the by-product (i.e., the gas or oil) price and the ratio of $\mathrm{CO}_{2}$ stored to the oil or gas produced. With more oil or gas produced per unit of $\mathrm{CO}_{2}$ stored, the lower net $\mathrm{CO}_{2}$ storage cost, but the less $\mathrm{CO}_{2}$ stored.

Finally, Table ES-12 combines the capture and compression costs from our base IGCC plant with the transport and injection costs to give a total cost of sequestration on an NPV basis. These costs can be compared with costs of $\mathrm{CO}_{2}$ sink enhancement via forestry and reducing tillage on cropland. 


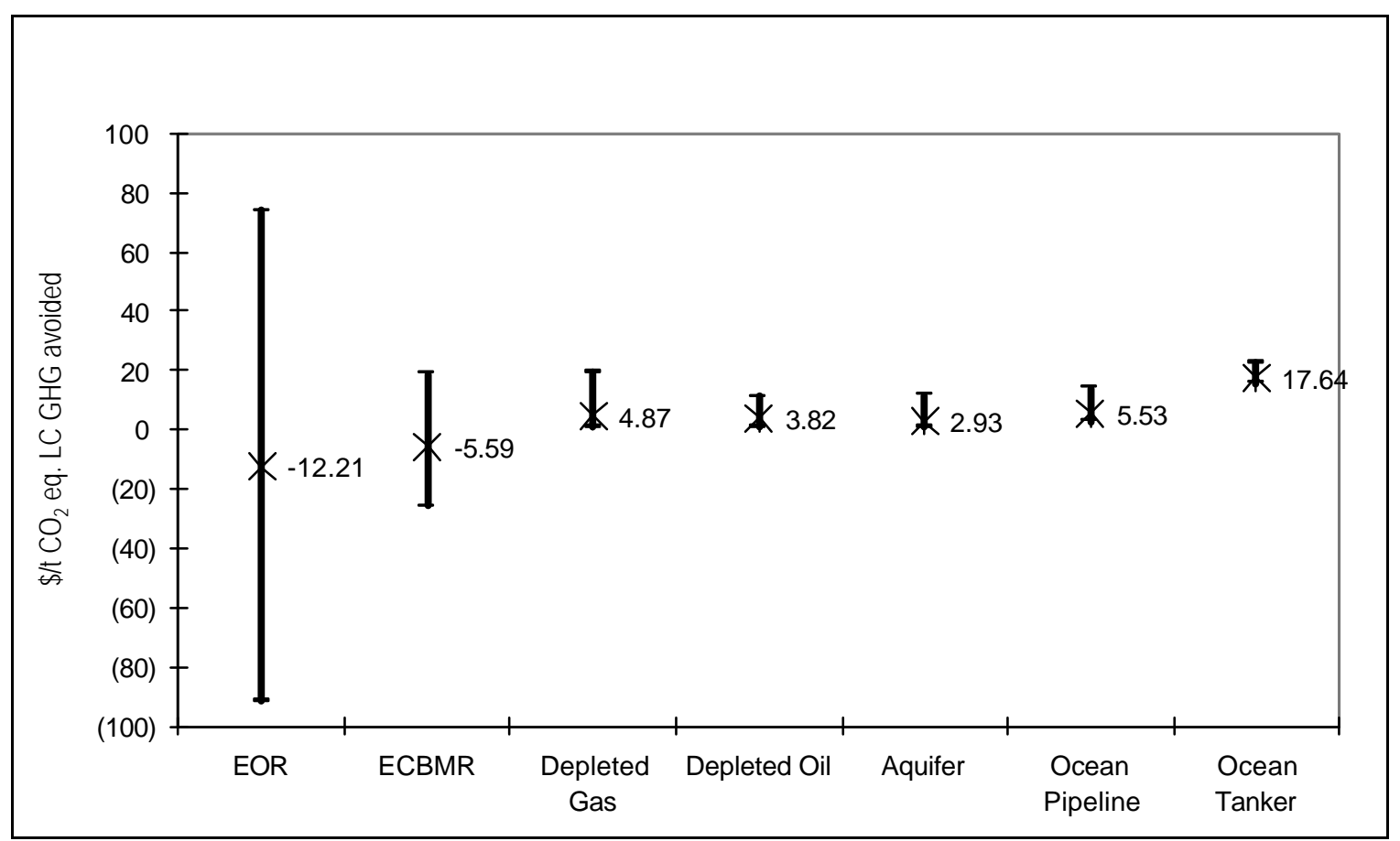

Figure ES-4

Levelized annual cost comparison of carbon sequestration technologies

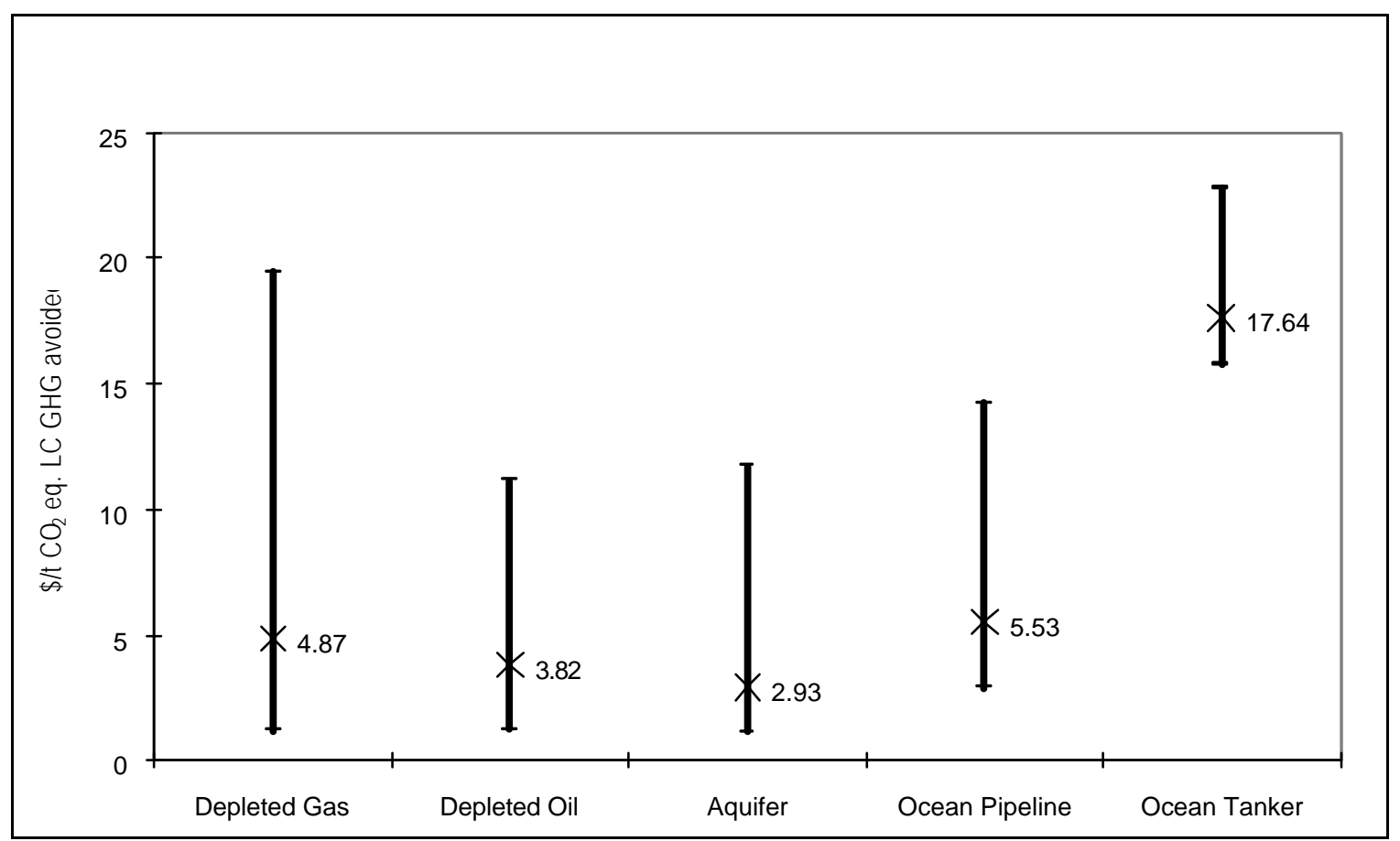

Figure ES-5

Levelized annual cost comparison of carbon sequestration technologies 
Table ES-12

$\mathrm{CO}_{2}$ Capture + Net Storage Costs: Base Cases, NPV Basis

\begin{tabular}{|l|c|c|}
\hline $\mathrm{CO}_{2}$ Storage Process & \multicolumn{2}{|c|}{ LC GHG avoided } \\
\hline & \$/tonne $\mathbf{C O}_{\mathbf{2}}$ eq. & \$/tonne C eq. \\
\hline Enhanced Oil Recovery & 4 & 15 \\
\hline $\begin{array}{l}\text { Enhanced Coalbed Methane } \\
\text { Recovery }\end{array}$ & 11 & 41 \\
\hline Depleted Gas Reservoir & 23 & 86 \\
\hline Depleted Oil Reservoir & 22 & 81 \\
\hline Deep Saline Aquifer & 21 & 77 \\
\hline Ocean Pipeline & 24 & 89 \\
\hline Ocean Tanker & 39 & 143 \\
\hline
\end{tabular}

\section{$\mathrm{CO}_{2}$ Sink Enhancement via Improved Forest Management}

\section{Basis and Approach}

Costs of the $\mathrm{CO}_{2}$ sink enhancement via improved forest management were estimated from an energy company perspective (i.e., the amount an energy company would have to pay forest product companies to manage their systems to sequester additional $\mathrm{CO}_{2}$ to serve as $\mathrm{CO}_{2}$ offsets for the company). From an energy company perspective, the cost of GHG emission offsets (\$/tonne C equivalent LC GHG avoided) from forestry options depends on the following: (1) levels of $\mathrm{CO}_{2}$ sink enhancement, (2) changes in GHG emissions other than from $\mathrm{CO}_{2}$ sink enhancement (e.g., from methane and nitrous oxide emissions), (3) reimbursement of forest management companies for net costs of changes in forest land area and/or management, (4) transaction costs for aggregating and brokering GHG credits, and (5) monitoring costs for assuring that contractual obligations are fulfilled.

The same financial parameters were used for forestry options as for $\mathrm{CO}_{2}$ capture and storage options included in this project. The rationale is that we assume that funding for both types of projects would come from an energy company seeking to receive credits for reducing GHG emissions. An energy company likely would use the same financial parameters for evaluating GHG abatement investments regardless of whether the investments involve $\mathrm{CO}_{2}$ capture and storage or $\mathrm{CO}_{2}$ sink enhancement. Costs of GHG mitigation ( $\$$ tonne $\mathrm{C}$ equivalent LC (life-cycle) GHG avoided) were calculated on an NPV basis with a 100-year planning horizon as described in detail in Chapter 2 and can be compared on an NPV basis with other $\mathrm{CO}_{2}$ storage and sink enhancement options that differ in timing of costs and timing of avoidance of GHG emissions.

Additional $\mathrm{C}$ can be sequestered in forests by establishing new plantations, restoring existing forests, or by avoiding deforestation. Cases representing a wide range of management types, trees, and geographic locations were included in this study (Table ES-13). All cases were 
assessed assuming medium productivity levels. Where data were available, cases were also assessed, assuming low and high productivity levels.

Table ES-13

Forestry case studies

\begin{tabular}{lll}
\hline Type of Management & Type of Trees & Country/region \\
\hline Plantation & Loblolly pine & USA (South) \\
Plantation & Douglas Fir & USA (Pacific NW) \\
Plantation & Spanish Cedar & Mexico \\
Restoration & Pine-oak & Mexico \\
Restoration & Miombo & Southern Africa \\
Agro-forestry & Mango-Tamarind & India (South) \\
Avoidance of deforestation & Various & Mexico
\end{tabular}

\section{Summary of Costs}

Costs (\$/tonne C equivalent) are presented in Figure ES-6 for medium productivity on an aboveground basis (costs/above-ground C) and a C equivalent life-cycle (LC) GHG avoided basis with product revenues (net costs after product revenues/aboveground $\mathrm{C}+$ below ground $\mathrm{C}+$ product $\mathrm{C}+$ non- $\mathrm{CO}_{2} \mathrm{GHG} \mathrm{C}$ equivalent). These two accounting bases bracket the costs $(\$ / \mathrm{Mg} \mathrm{C}$ equivalent) for each of the cases. The former accounting basis has most commonly been used in the past in order simplify monitoring and verification. The latter accounting basis is comparable with the basis used for $\mathrm{CO}_{2}$ storage options with revenues (e.g., enhanced oil recovery) and was used to calculate base-case costs. Base-case costs also assumed medium productivity. The Mango-Tamarind costs are relatively high on an aboveground basis because costs for the agoforestry system are high and no credit is taken for the relatively high value agricultural products. The Mango-Tamarind costs are relatively low on the aboveground $\mathrm{C}+$ below ground $\mathrm{C}+$ product $\mathrm{C}+$ non- $\mathrm{CO}_{2}$ GHG $\mathrm{C}$ equivalent basis because credit is taken for both more $\mathrm{C}$ and products that more than offset costs. 


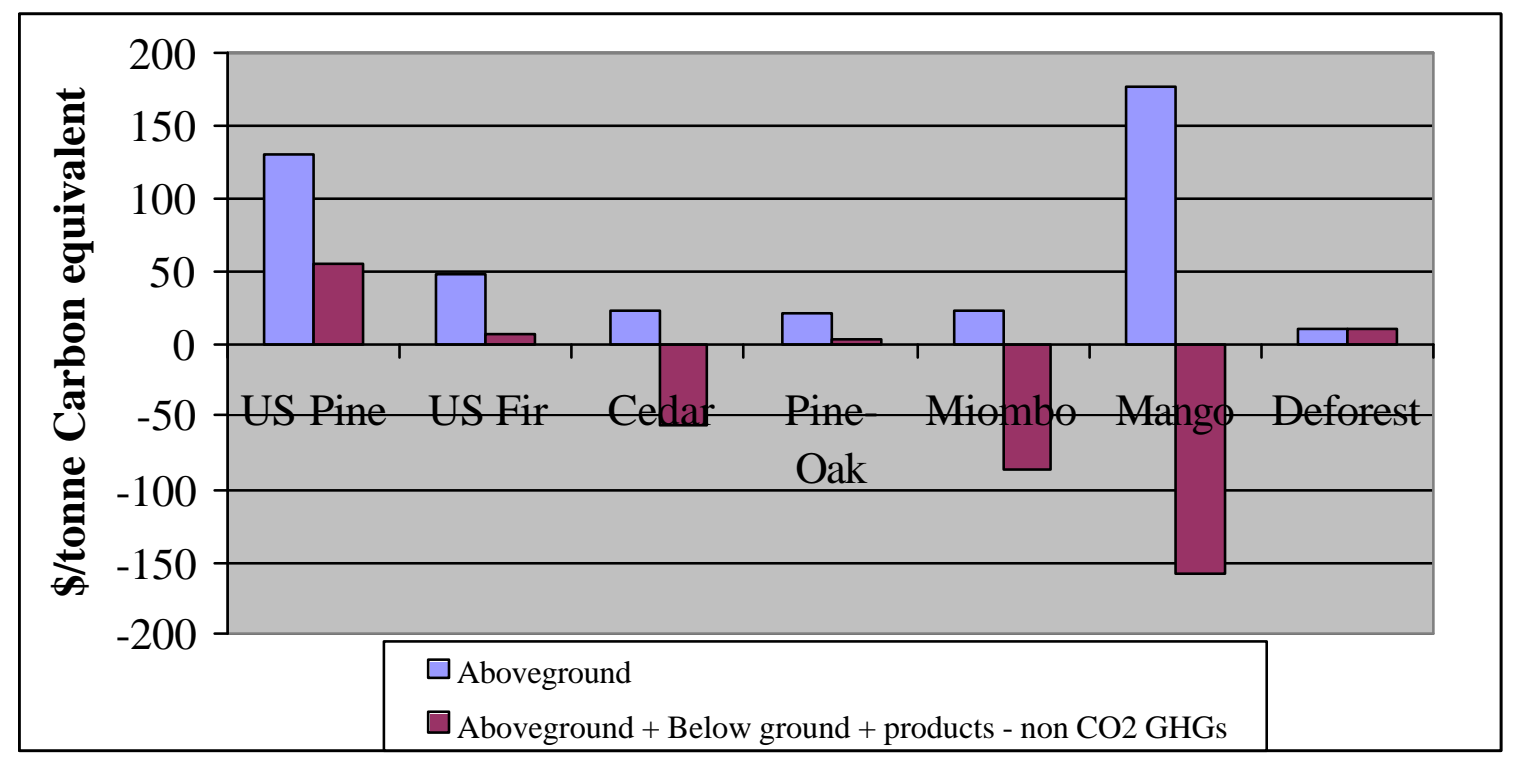

Figure ES-6

Forestry costs for medium productivity levels on two accounting bases

Costs are summarized in Table ES-14 for three productivity levels on both a $\mathrm{CO}_{2}$ equivalent LC GHG avoided and a C equivalent LC GHG avoided basis.

Table ES-14

Forestry costs for three productivity levels and $\mathrm{CO}_{2}$ and $\mathrm{C}$ bases

\begin{tabular}{|l|c|c|c|c|c|c|}
\hline Case & $\begin{array}{c}\text { Base Case- } \\
\text { Medium } \\
\text { Productivity }\end{array}$ & $\begin{array}{c}\text { Low Cost } \\
\text { Case-High } \\
\text { Productivity }\end{array}$ & $\begin{array}{c}\text { High Cost } \\
\text { Case-Low } \\
\text { Productivity }\end{array}$ & $\begin{array}{c}\text { Base Case- } \\
\text { Medium } \\
\text { Productivity }\end{array}$ & $\begin{array}{c}\text { Low Cost } \\
\text { Case-High } \\
\text { Productivity }\end{array}$ & $\begin{array}{c}\text { High Cost } \\
\text { Case-Low } \\
\text { Productivity }\end{array}$ \\
\hline US Pine & 15 & 11 & & 54 & 40 & \\
\hline USFir & 2 & 1 & & 7 & 3 & \\
\hline Cedar & $(15)$ & $(14)$ & $(11)$ & $(56)$ & $(51)$ & $(39)$ \\
\hline Pine-Oak & 1 & $(1)$ & 2 & 2 & $(3)$ & 6 \\
\hline Miombo & $(24)$ & & & $(87)$ & & \\
\hline Mango & $(43)$ & & & $(158)$ & & \\
\hline Deforest & 3 & & & 10 & & \\
\hline
\end{tabular}




\section{$\mathrm{CO}_{2}$ Sink Enhancement via Reducing Tillage on U.S. Cropland}

\section{Basis and Approach}

Reducing tillage on cropland slows the rate of organic matter decomposition and increases soil organic matter levels until a new equilibrium level is attained (typically about 20 to 30 years after shifting from intensive tillage to no tillage). Carbon is sequestered in the added soil organic matter, resulting in an increase in soil organic carbon (SOC). Reducing tillage reduces equipment and fuel use, increases herbicide use, and can affect the amount of nitrogen fertilizer required and $\mathrm{N}_{2} \mathrm{O}$ emissions from the soil; these factors combined with the added carbon sequestered in soil organic matter determine the life-cycle (LC) GHG emissions avoided by reducing tillage. Effects of reducing tillage on equipment, fuel, herbicide, and nitrogen (N) fertilizer use and on $\mathrm{N}_{2} \mathrm{O}$ emissions continue as long as the switch to reduced-tillage continues. Costs to an energy company are an adoption incentive to get farmers to switch from intensive tillage to moderate- or no-tillage, transaction costs for aggregating and brokering GHG credits, and monitoring costs for assuring that contractual obligations are met. Costs $(\$ /$ hectare) divided by the tonnes C equivale nt (CE) LC GHG avoided/hectare give the cost in \$/tonne CE LC GHG avoided.

The same financial parameters were used for cropland options as for $\mathrm{CO}_{2}$ capture and storage options included in this project. The rationale is that we assume that funding for both types of projects would come from an energy company seeking to receive credits for reducing GHG emissions. An energy company likely would use the same financial parameters for evaluating GHG abatement investments regardless of whether the investments involve $\mathrm{CO}_{2}$ capture and storage or $\mathrm{CO}_{2}$ sink enhancement. Costs of GHG mitigation (\$/tonne C equivalent LC (lifecycle) GHG avoided) were calculated on an NPV basis with a 100-year planning horizon as described in detail in Chapter 2 and can be compared on an NPV basis with other $\mathrm{CO}_{2}$ storage and sink enhancement options that differ in timing of costs and timing of avoidance of GHG emissions.

The following regional cropland cases were included in this study, the goal being to both (1) include cases representing the greatest amount of avoided GHG emissions that could be achieved by reducing tillage and (2) illustrate the range of amounts per hectare and costs of avoided GHG emissions that could be achieved by reducing tillage.

1. Chapter 19: Corn/soybean rotations in the Corn Belt being converted from intensive-till to either no-till or moderate-till. This case includes best-case and worst-case scenarios concerning effects of reducing tillage on $\mathrm{N}$ fertilizer requirements and on $\mathrm{N}_{2} \mathrm{O}$ emissions.

2. Chapter 20: Continuous corn cropping systems in the Corn Belt being converted from intensive-till to either no-till or moderate-till. This case includes best-case and worst-case scenarios concerning effects of reducing tillage on $\mathrm{N}$ fertilizer requirements and on $\mathrm{N}_{2} \mathrm{O}$ emissions.

3. Chapter 21: Wheat/fallow rotations in the western Great Plains being converted from intensive-till to no-till. This case includes variations in the amount of SOC sequestered and amount of $\mathrm{N}_{2} \mathrm{O}$ emissions due to reducing tillage. 
4. Chapter 22: Intensive-till cotton to no-till cotton in the southeastern U.S. This case includes variations in the amount of soil SOC sequestered and amount of $\mathrm{N}_{2} \mathrm{O}$ emissions due to reducing tillage.

\section{Summary of Costs}

Base-case costs of avoided $\mathrm{CO}_{2}$ are presented in Table ES-14 for the four regional cropping systems included in this study, assuming that an annual adoption incentive is paid for 5, 10, 15, or 20 years after switching to no-till. These costs are based on the assumption that, due to soil quality and crop yield benefits that develop over time, a farmer would continue the no-till practice after the adoption incentive stops.

Table ES-14

Base-case costs of $\mathrm{CO}_{2}$ sink enhancement on U.S. cropland: intensive-till to no- till

\begin{tabular}{ccccc}
\hline & Corn/soybean & Continuous corn & Wheat/fallow & Cotton \\
\hline $\begin{array}{c}\text { Incentive } \\
\text { period, years }\end{array}$ & \multicolumn{4}{c}{$\begin{array}{c}\text { Cost (NPV basis, 100-year planning horizon) } \\
\text { \$/tonne CE LC GHG avoided }\end{array}$} \\
\hline 5 & $30(8)^{1^{-}}$ & $30(8)$ & $32(9)$ & $54(15)$ \\
10 & $48(13)$ & $51(14)$ & $49(13)$ & $88(24)$ \\
15 & $62(17)$ & $66(18)$ & $61(17)$ & $113(31)$ \\
20 & $72(20)$ & $77(21)$ & $71(19)$ & $132(36)$ \\
\hline
\end{tabular}

1/ Values in parenthesis are \$/tonne $\mathrm{CO}_{2}$ equivalent LC GHG avoided

Inputs used to estimate the base-case costs of $\mathrm{CO}_{2}$ sink enhancement via reducing tillage on U.S. cropland are presented in Table ES-15. Costs in Table ES-15 assume that an adoption incentive is paid for 20 years.

Costs of $\mathrm{CO}_{2}$ abatement are similar for corn/soybean rotations and continuous corn because of two offsetting factors. Relative to corn/soybean rotations, switching to no-till continuous corn sequesters nearly twice as much additional carbon in soil organic matter but also requires twice as large an adoption incentive. With continuous corn, more carbon is sequestered in SOC mainly because more crop residues are produced and returned to the soil and a larger adoption incentive is required mainly because corn is less well adapted to no-till than are soybeans.

Costs of $\mathrm{CO}_{2}$ abatement are similar for corn/soybean rotations and wheat/fallow because of offsetting factors. Relative to corn/soybean rotations, switching to no-till wheat/fallow sequesters less additional carbon in soil organic matter but also requires a smaller adoption incentive and results in a decrease rather than in increase in $\mathrm{N}_{2} \mathrm{O}$ emissions. 
Table ES-15

Base-case inputs and costs of $\mathrm{CO}_{2}$ sink enhancement on U.S. cropland: intensive-till to no-till

\begin{tabular}{lcccc}
\hline & Corn & & Western \\
Region & Belt & Corn Belt & $\begin{array}{c}\text { Great } \\
\text { Plains }\end{array}$ & $\begin{array}{r}\text { SE } \\
\text { U.S. }\end{array}$ \\
\hline Cropping system & $\begin{array}{c}\text { Corn/ } \\
\text { soybean }\end{array}$ & $\begin{array}{c}\text { Continuous } \\
\text { corn }\end{array}$ & $\begin{array}{c}\text { Wheat/ } \\
\text { fallow }\end{array}$ & Cotton \\
\hline Quadratic SOC response curve & & & & \\
$\Delta$ SOCs, kg C/ha & 7221 & 13104 & & \\
E (slope factor) & 53.1 & 92.0 & & \\
kg SOC/ha/y & & & 200 & 300 \\
Years to new steady state (Ys) & 27 & 28 & 20 & 20 \\
Average annual increase in SOC (years 1 to Ys), kg C/ha/y & 267 & 468 & 200 & 300
\end{tabular}

GHG emissions from tillage-system inputs and $\mathrm{N}_{2} \mathrm{O}$ (years 1-100), $\mathrm{kg} \mathrm{CE} / \mathrm{ha} / \mathrm{y}$ :

\begin{tabular}{|c|c|c|c|c|}
\hline$\Delta$ Fuel use & -22.3 & -22.9 & -10.3 & -23.8 \\
\hline$\Delta$ Machinery maint., trans., and repair & -4 & -4 & -1.9 & -4.3 \\
\hline$\Delta \mathrm{N}$ fertilizer use & 0 & 0 & 0 & 0 \\
\hline$\Delta$ Herbicide use & 3 & 4 & 11.7 & 0 \\
\hline$\Delta$ Total GHG emissions from inputs & -23.3 & -22.7 & -0.5 & -28.1 \\
\hline$\Delta \mathrm{N}_{2} \mathrm{O}$ emissions from soil & 30.3 & 30.3 & -25.3 & 63.2 \\
\hline$\Delta$ Total GHG emissions & 7.0 & 7.6 & -25.8 & 35.1 \\
\hline \multicolumn{5}{|l|}{ Average LC GHG avoided (kg CE/ha/y) } \\
\hline Years 1 to Ys & 260 & 460 & 226 & 265 \\
\hline Years Ys to 100 & -7 & -8 & 26 & --35 \\
\hline $\begin{array}{l}\text { Total LC GHG avoided (years } 1-100 \text { ), } \\
\text { tonne CE/ha }\end{array}$ & 6.5 & 12.3 & 6.6 & 1.0 \\
\hline $\begin{array}{l}\text { NPV Total LC GHG avoided (years 1-100), } \\
\text { tonne CE/ha }\end{array}$ & 4.3 & 7.7 & 2.7 & 2.3 \\
\hline \multicolumn{5}{|l|}{ Costs, $\$ /$ ha/y } \\
\hline Transaction (year 1) & 5 & 5 & 5 & 5 \\
\hline Adoption incentive (years 1-20) & 25 & 50 & 15 & 25 \\
\hline Monitoring (years 1-100) & 1 & 1 & 1 & 1 \\
\hline Total costs (years $1-100), \$ /$ ha & 605 & 1105 & 405 & 605 \\
\hline NPV Total costs (years 1-100), \$/ha & 306 & 590 & 195 & 306 \\
\hline $\begin{array}{l}\text { Cost (NPV basis), \$/tonne CE LC GHG } \\
\text { avoided }\end{array}$ & 72 & 77 & 71 & 132 \\
\hline $\begin{array}{l}\text { Cost (NPV basis), } \$ \text { /tonne } \mathrm{CO}_{2} \text { equivalent } \\
\text { LC GHG avoided }\end{array}$ & 20 & 21 & 19 & 36 \\
\hline
\end{tabular}

With wheat/fallow, less carbon is sequestered in SOC mainly because less crop residue is produced and returned to the soil on an annual basis and a smaller adoption incentive is required 
because increases in wheat yields partially offset higher production costs with no-till. Mainly because of the dry climate in which wheat/fallow systems are used, switching to no-till wheat/fallow reduces $\mathrm{N}_{2} \mathrm{O}$ emissions whereas switching to no-till corn/soybeans increases $\mathrm{N}_{2} \mathrm{O}$ emissions.

Costs of $\mathrm{CO}_{2}$ abatement are significantly higher for cotton than for corn/soybean rotations, mainly because switching to no-till increases $\mathrm{N}_{2} \mathrm{O}$ emissions significantly more with cotton than with corn/soybean rotations. The greater increase in $\mathrm{N}_{2} \mathrm{O}$ emissions with no-till cotton than with no-till corn/soybeans is apparently due to the warmer, wetter climate in the southeastern U.S. where most of the cotton is grown.

Switching from intensive-till to no-till corn/soybean rotations or to no-till continuous corn can result in significantly higher $\mathrm{N}$ fertilizer requirements and $\mathrm{N}_{2} \mathrm{O}$ emissions unless $\mathrm{N}$ fertilizer is managed efficiently. This can greatly reduce the amount of GHG emissions avoided because production and use of $\mathrm{N}$ fertilizer is very energy intensive and $\mathrm{N}_{2} \mathrm{O}$ has a radiative forcing factor 296 times greater the $\mathrm{CO}_{2}$ on a mass basis. Effects of increases in $\mathrm{N}$ fertilizer rate and $\mathrm{N}_{2} \mathrm{O}$ emissions on LC GHG avoided and costs of GHG avoidance are discussed below.

Examples of the large effects of $\mathrm{N}$ rate and $\mathrm{N}_{2} \mathrm{O}$ emissions on amount of GHG emissions avoided and cost per tonne of GHG avoided are presented in Table ES-16. The scenarios in Table 3 are for switching from intensive-till to no-till in a corn/soybean rotation in the Corn Belt. No significant change in $\mathrm{N}_{2} \mathrm{O}$ emissions due switching from intensive-till to no-till is a possibility with good $\mathrm{N}$ management, especially on well-drained soils. The increases in $\mathrm{N}$ rate and $\mathrm{N}_{2} \mathrm{O}$ emissions in Table 3 due to switching from intensive-till to no-till are possibilities with poor $\mathrm{N}$ management. Amounts of GHG avoided range from 9.6 tonnes CE LC GHG avoided/ha (35.3 tonnes $\mathrm{CO}_{2}$ equivalent LC GHG avoided/ha) with a best-case $\mathrm{N}$ rate and $\mathrm{N}_{2} \mathrm{O}$ scenario to 3.0 tonnes CE LC GHG avoided/ha (-11.0 tonnes $\mathrm{CO}_{2}$ equivalent $\mathrm{LC}$ GHG avoided/ha) for a worst-case scenario. Costs on an NPV basis range from \$64/tonne CE LC GHG avoided (\$17/tonne $\mathrm{CO}_{2}$ equivalent LC GHG avoided) with a best-case $\mathrm{N}$ rate and $\mathrm{N}_{2} \mathrm{O}$ scenario to \$113/tonne CE LC GHG avoided (\$31/tonne $\mathrm{CO}_{2}$ equivalent LC GHG avoided) for a worst-case scenario. Differences between the best-case and worst-case scenarios regarding amount of GHG avoided are very large because the annual effects are manifested over the entire 100-year planning horizon. In order for reducing tillage on corn/soybean rotations to be a viable option for avoiding GHG emissions, $\mathrm{N}$ fertilizer will have to be managed efficiently so that the amount of $\mathrm{N}$ fertilizer used and the $\mathrm{N}_{2} \mathrm{O}$ emissions are not significantly increased. This conclusion is also applicable to continuous corn in the Corn Belt. 
Table ES-16

Effects of increases in $\mathrm{N}$ rate and $\mathrm{N}_{2} \mathrm{O}$ emissions on amounts and costs of avoided GHG via switching from intensive-till to no-till in a Corn/Soybean rotation

\begin{tabular}{|c|c|c|c|c|c|}
\hline \multicolumn{2}{|c|}{ ? $\mathrm{N}$ rate } & \multirow{2}{*}{$\begin{array}{c}\text { ? } \mathrm{N}_{2} \mathrm{O} \text { rate } \\
\mathrm{kg} / \mathrm{CE} / \mathrm{ha} / \mathrm{yr}\end{array}$} & \multirow{2}{*}{$\begin{array}{c}\text { Years 1-100 } \\
\text { tonne CE LC } \\
\text { GHG } \\
\text { avoided/ha }\end{array}$} & \multicolumn{2}{|c|}{ NPV basis, years 1-100 } \\
\hline $\mathrm{kg} \mathrm{N} / \mathrm{ha} / \mathrm{yr}$ & $\mathrm{kg} / \mathrm{CE} / \mathrm{ha} / \mathrm{yr}$ & & & $\begin{array}{c}\text { tonne CE LC } \\
\text { GHG } \\
\text { avoided/ha }\end{array}$ & $\begin{array}{c}\text { \$/tonne CE } \\
\text { LC GHG } \\
\text { avoided }^{1 /}\end{array}$ \\
\hline 0 & 0 & 0 & 9.6 & 4.8 & $64 \stackrel{2 !}{1}$ \\
\hline 0 & 0 & 30.3 & 6.5 & 4.3 & $72 \stackrel{3}{3}$ \\
\hline 25 & 14.4 & 63.5 & 1.8 & 3.5 & $88^{4 !}$ \\
\hline 50 & 28.8 & 96.6 & -3.0 & 2.7 & $113^{\frac{5}{}}$ \\
\hline $\begin{array}{l}\text { 1/ Assumes in } \\
\text { 2/ Base case } \\
\text { 3/ Base case. } \\
\text { 4/ Base case } \\
\text { 5/ Base case }\end{array}$ & $\begin{array}{l}\text { tive payment } \\
\text { ept for no cha } \\
\text { ept for an incr } \\
\text { ept for an ado }\end{array}$ & $\begin{array}{l}20 \text { years. } \\
\text { in } \mathrm{N}_{2} \mathrm{O} \text { emiss } \\
\text { nal increase ir } \mathrm{N} \text { rate du } \\
\text { nal incre }\end{array}$ & $\begin{array}{l}\text { ns due to switc } \\
\text { to switching fro } \\
\text { rate due to sy }\end{array}$ & $\begin{array}{l}\text { ng to no-till. } \\
\text { to no-till. } \\
\text { ching from to }\end{array}$ & \\
\hline
\end{tabular}

\section{Summary Comparisons and Conclusions}

Presented in this section are comparisons among options evaluated in this project and between $\mathrm{CO}_{2}$ capture, transport and storage and indirect capture by forests and cropland via reducing tillage.

\section{Direct Verses Indirect Sequestration}

Shown in Figure ES-7 is a comparison of all of the base case values in $\$ /$ tonne of $\mathrm{CO}_{2}$ equivalent LC GHG avoided on a NPV basis plotted from lowest to highest cost. 


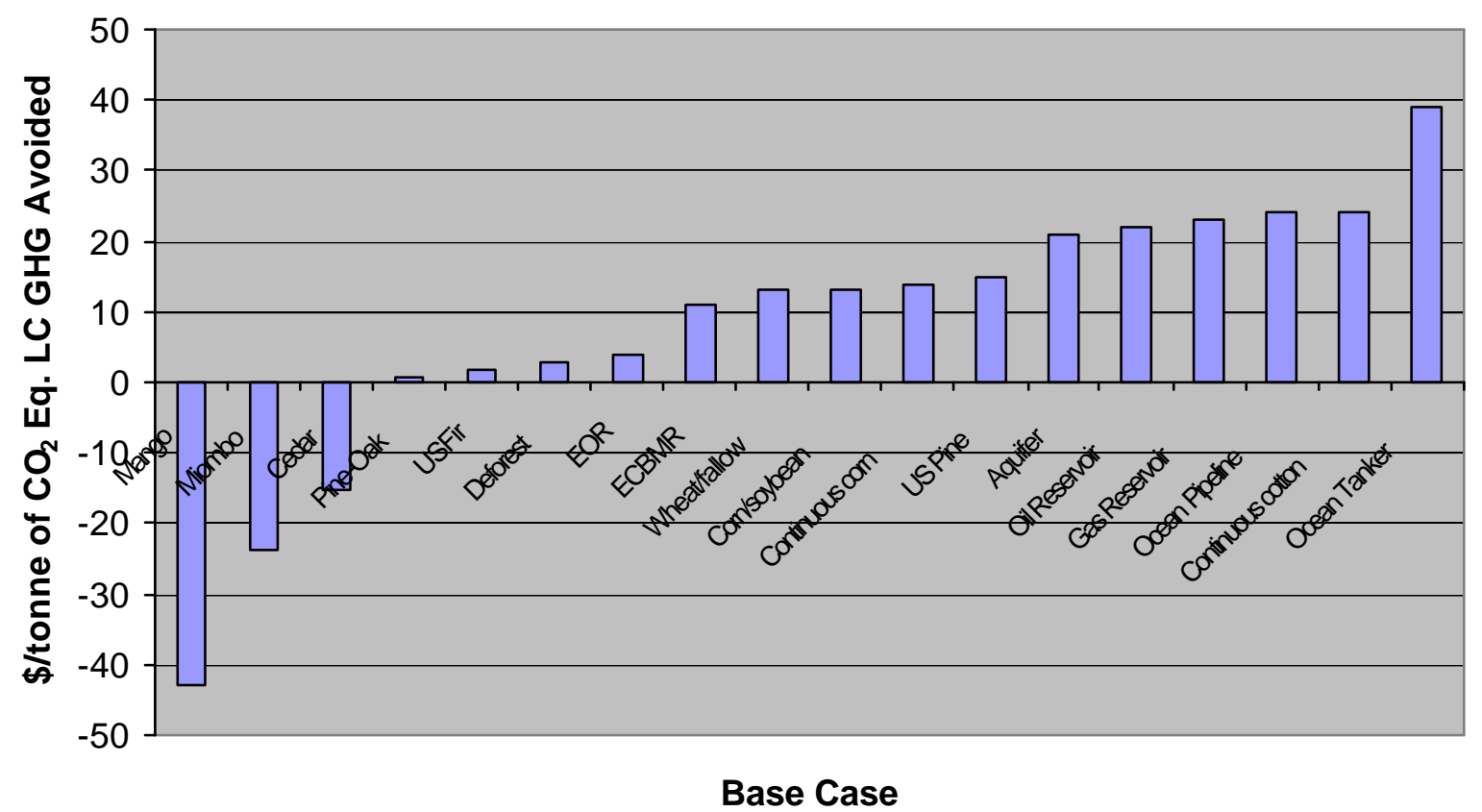

Figure ES-7

Comparison of direct and indirect sequestration cases.

As shown in Figure ES-7, all of the forestry options are the least expensive except for the US Pine case. Next are the EOR and ECBMR options followed by most of the cropland options. Figure ES-8 includes the available high and low cases. The main impact of these cases is on the cropland cases where the low cases would make them competitive with ECBMR and the high cases would make them about the same as the other geologic storage cases. 


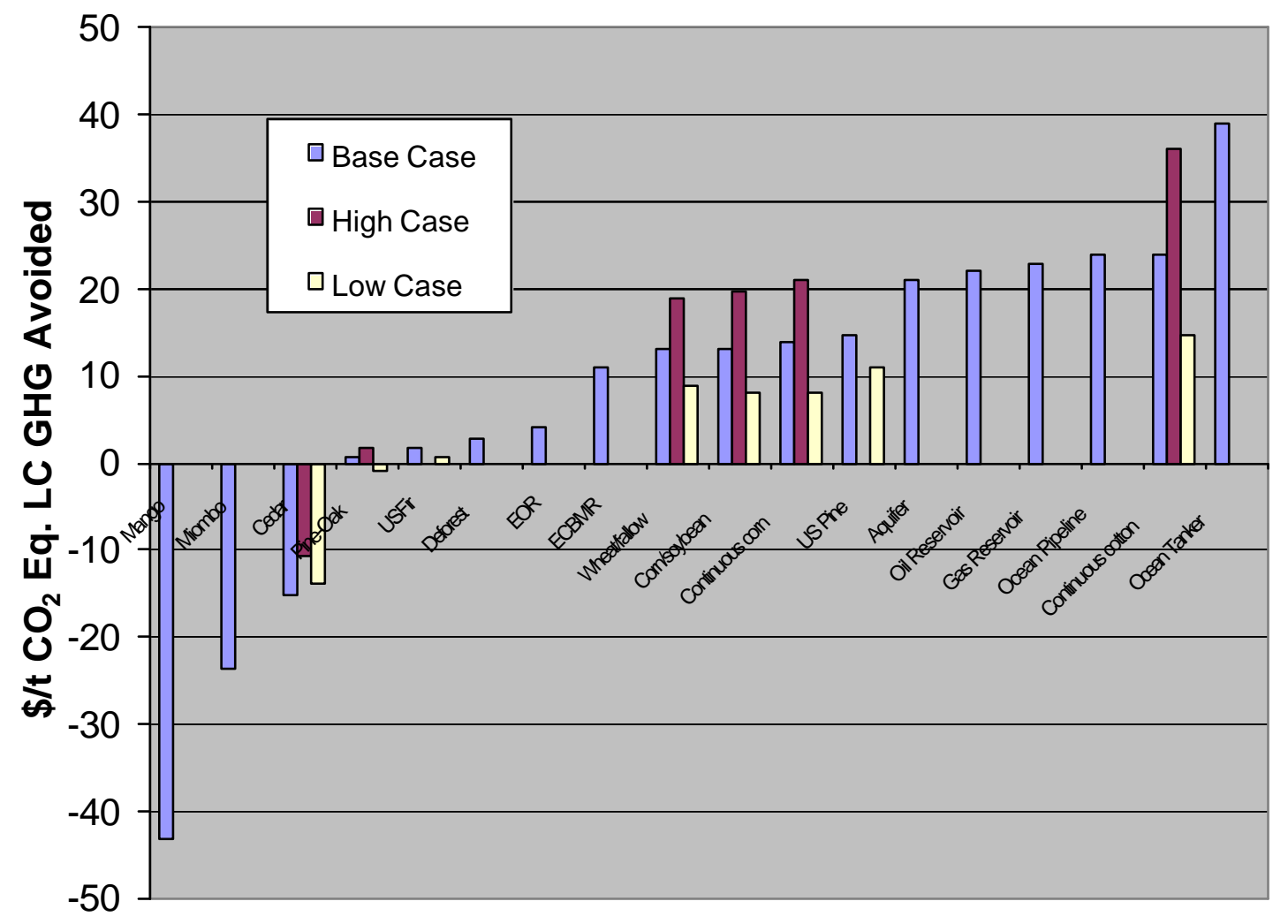

\section{Figure ES-8}

Comparison of direct and indirect sequestration cases including high and low cases

Base-case forest and cropland areas required to offset LC GHG emissions avoided by base-case $\mathrm{CO}_{2}$ capture and storage options are presented in Table ES-17. These land area equivalents are for a 100-year planning horizon. The carbon equivalent (CE) LC GHG emissions avoided by the capture and storage options assume $\mathrm{CO}_{2}$ capture and injection into storage reservoirs during the 20-year book life of the capture and storage plants and storage of injected $\mathrm{CO}_{2}$ for another 80 years. For the ocean storage options, the $\mathrm{CE}$ LC GHG avoided is reduced for leakage of $\mathrm{CO}_{2}$ throughout the 100-year storage period. Zero $\mathrm{CO}_{2}$ leakage is assumed for the other $\mathrm{CO}_{2}$ storage options. The CE LC GHG emissions avoided by the forest and cropland options assume that the improved forestry or cropland practices are maintained for 100 years. Generally, ten times or more cropland than forest land is required to offset the $\mathrm{CO}_{2}$ storage options. 
Table ES-17

Base-case forest and cropland areas required to offset LC GHG emissions avoided by base - $\mathrm{Case}^{\mathrm{CO}} \mathrm{CO}_{2} \mathrm{Capture}$ and storage options.

Equivalent Forestry / Cropland Area Required to

Offset Geologic \& Ocean Options
LC Avoided GHG Basis (100 year summation,

\begin{tabular}{|c|c|c|c|c|c|c|c|c|c|c|c|c|c|c|c|}
\hline $\begin{array}{l}\text { Forestry System - Medium Productivity } \\
\text { (Abovereblow ground } C \text {, non-CO2 GHGs, \& timber }\end{array}$ & & Aquifer Storage & 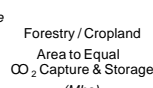 & Enhanced Oil & 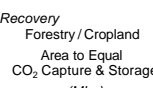 & $\int^{\text {Depleted Oil }}$ & $\begin{array}{l}\text { Reservoirs } \\
\text { Forestry / Cropland } \\
\text { Areat o Equal } \\
\mathrm{CO}_{2} \text { Capture \& S Storag }\end{array}$ & Depleted Gas F & 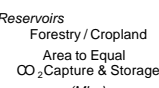 & Coal Bed Met & 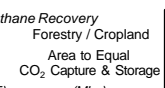 & $\left.\right|^{\text {ocean }}$ Pipelin & 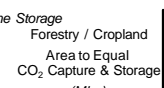 & ocean Tanker. & 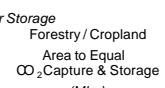 \\
\hline & tonne CEhs & (MtonneCE) & & & (Mha) & (Mitonne CE) & (Mha) & (Mtonne CE) & (Mha) & (Mtonne CE) & $=$ (Mha) & (Mtonne CE) & (Mha) & \begin{tabular}{|l} 
Mtonne \\
\end{tabular} & (Mha) \\
\hline Plantation, USA, Lobblolly Pine & 183.14 & 9.81 & 0.05 & 9.09 & 0.05 & 9.81 & 0.05 & 9.81 & 0.05 & 9.54 & 0.05 & 28.28 & 0.15 & 28.00 & 0.15 \\
\hline Plantation, USA, Douglas Fir & 452.65 & 9.81 & 0.02 & 9.09 & 0.02 & 9.81 & 0.02 & 9.81 & 0.02 & 9.54 & 0.02 & 28.28 & 0.06 & 28.00 & 0.06 \\
\hline Plantation (Taungya), Mexico, Spanish cedar & 277.40 & 9.81 & 0.04 & 9.09 & 0.03 & 9.81 & 0.04 & 9.81 & 0.04 & 9.54 & 0.03 & 28.28 & 0.10 & 28.00 & 0.10 \\
\hline Restoration, Mexico, Pine-oak & 183.39 & 9.81 & 0.05 & 9.09 & 0.05 & 9.81 & 0.05 & 9.81 & 0.05 & 9.54 & 0.05 & 28.28 & 0.15 & 28.00 & 0.15 \\
\hline Restoration, Southern Africa, Miombo & 59.26 & 9.81 & 0.17 & 9.09 & 0.15 & 9.81 & 0.17 & 9.81 & 0.17 & 9.54 & 0.16 & 28.28 & 0.48 & 28.00 & 0.47 \\
\hline Agro- forestry, Southern India, Mango- tamarind & 71.53 & 9.81 & 0.14 & 9.09 & 0.13 & 9.81 & 0.14 & 9.81 & 0.14 & 9.54 & 0.13 & 28.28 & 0.40 & 28.00 & 0.39 \\
\hline Avoidance of deforestation, Mexico, Various & 207.66 & 9.81 & 0.05 & 9.09 & 0.04 & 9.81 & 0.05 & 9.81 & 0.05 & 9.54 & 0.05 & 28.28 & 0.14 & 28.00 & 0.13 \\
\hline $\begin{array}{l}\text { Cropland System } \\
\text { Tww Year Corrs Soybean Rotation } \\
\text { (Intensive-til to Nov-til) }\end{array}$ & 6.51 & 9.81 & 1.51 & 9.09 & 1.39 & 9.81 & 1.51 & 9.81 & 1.51 & 9.54 & 1.46 & 28.28 & 4.34 & 28.00 & 4.30 \\
\hline 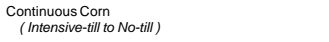 & 12.33 & 9.81 & 0.80 & 9.09 & 0.74 & 9.81 & 0.80 & 9.81 & 0.80 & 9.54 & 0.77 & 28.28 & 2.29 & 28.00 & 2.27 \\
\hline $\begin{array}{l}\text { Continuous Cotton } \\
\text { (Intensive-til to o Notili) }\end{array}$ & 0.99 & 9.81 & 9.90 & 9.09 & 9.18 & 9.81 & 9.90 & 9.81 & 9.90 & 9.54 & 9.64 & 28.28 & 28.56 & 28.00 & 28.28 \\
\hline $\begin{array}{l}\text { Two Year Wheat/ Fallow Rotation } \\
\text { (Intensive-tilit o No-till) }\end{array}$ & 6.58 & 9.81 & 1.49 & 9.09 & 1.38 & 9.81 & 1.49 & 9.81 & 1.49 & 9.54 & 1.45 & 28.28 & 4.30 & 28.00 & 4.26 \\
\hline
\end{tabular}




\section{Conclusions}

Making these comparisons was a challenge due to the differences between direct and indirect cases. The resulting numbers should only be used as a relative indication of cost. Site-specific characteristics could significantly change the outcome of the comparisons. In this study, the forestry options are very attractive along with capture using EOR for storage. Other factors, such as land availability and storage option location and capacity will also play a significant part in which options make the most sense at a given site.

The current work should only be considered a starting point. Better cost information and improvements to processes are likely to be developed and need to be incorporated into updates of this information. In addition, there are plans to update and add to portions of the current work to answer questions that arose but were beyond the scope of the current effort. For example, what happens to the costs if the power plant operates for longer than the plant book life? Also, how do the economics look for other power generation options? These and other questions will be evaluated in updates to this work. 


\section{CONTENTS}

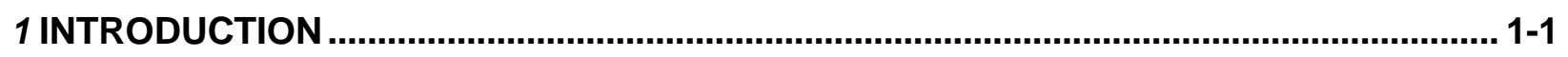

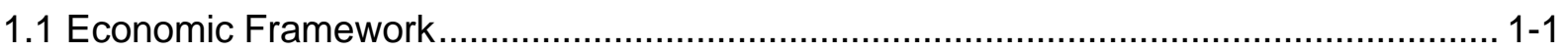

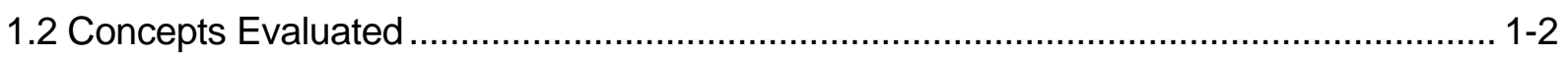

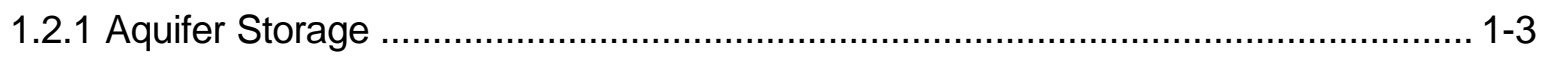

1.2.2 Oil Reservoir Storage with Enhanced Oil Recovery (EOR) ................................. 1-5

1.2.3 Depleted Oil and Gas Reservoir Storage ......................................................... 1-7

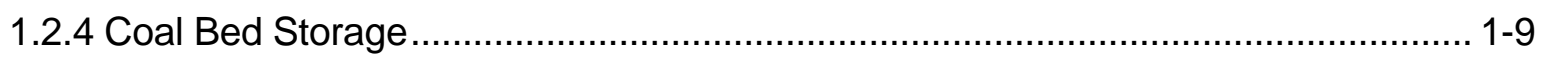

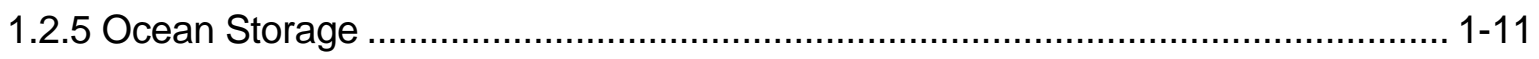

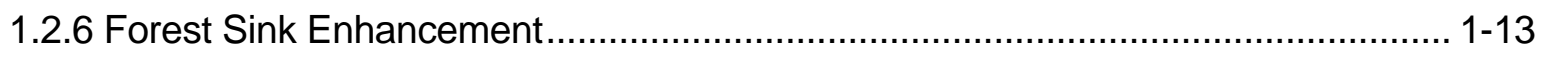

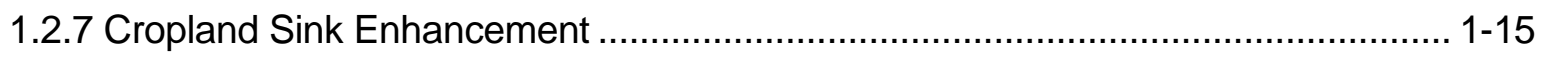

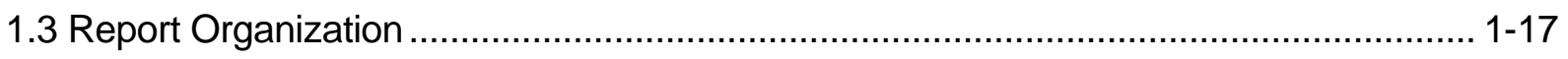

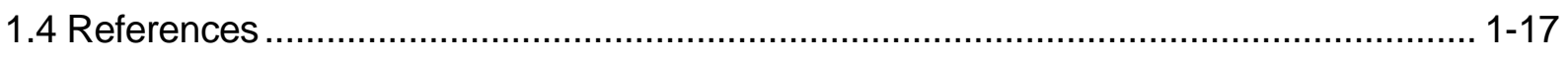

\section{METHODOLOGIES FOR CALCULATING THE COST OF CAPTURING AND}

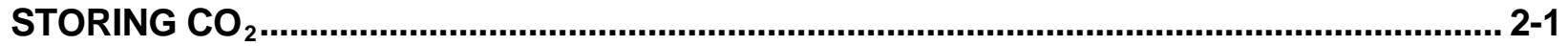

2.1 Revenue Requirement Methodology ……................................................................. 2-1

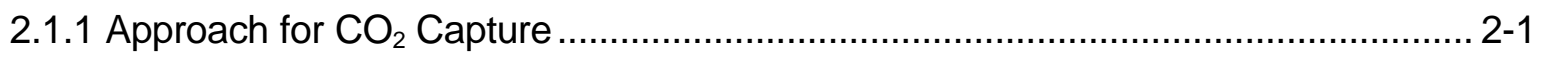

2.1.2 Adjustment for $\mathrm{CO}_{2}$ Storage ...................................................................... 2-3

2.1.3 Adjustment of Levelized Carrying Charge Factor as a Function of Discount Rate

2.1.4 Impact of $\mathrm{CO}_{2}$ Storage Costs on Cost of Electricity .......................................... 2-4

2.2 Capture Costs on $\mathrm{CO}_{2}$ Captured, $\mathrm{CO}_{2}$ Avoided, and Life-Cycle GHG Avoided Bases.

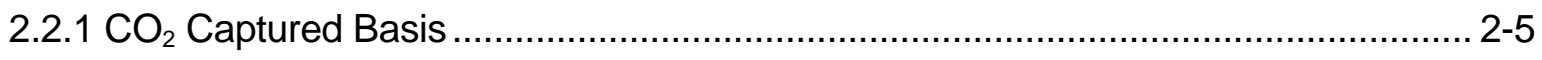

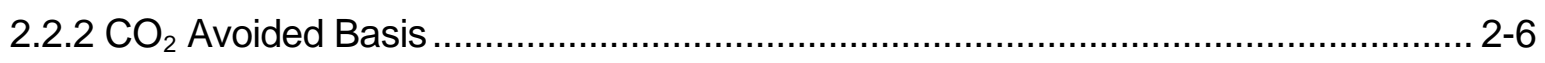

2.2.3 LC GHG Avoided Basis.................................................................................. 2-7

2.3 Combining Capture and Storage Costs.............................................................. 2-7

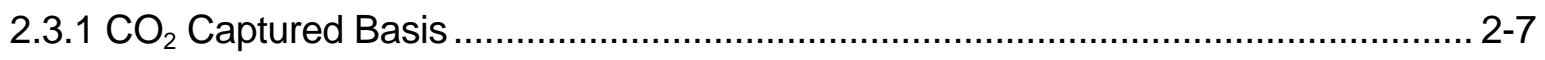

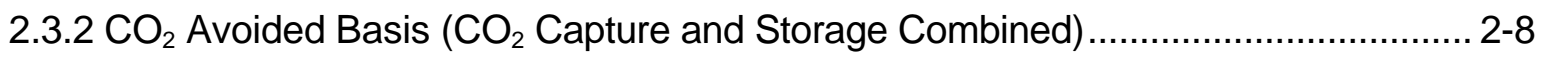


2.3.2 $\mathrm{CO}_{2}$ Avoided Basis ( $\mathrm{CO}_{2}$ Capture and Storage Combined).

2.3.3 GHG Avoided in $\mathrm{CO}_{2}$ Capture and Storage Processes Combined on a

Life-Cycle (LC) Basis.

2.3.4 Costs of $\mathrm{CO}_{2}$ Storage on a Life-Cycle GHG Avoided Basis (Storage Only) .......... 2-10

2.4 Comparing the Economics of $\mathrm{CO}_{2}$ Storage and Sink Enhancement Options

Differing in Timing and Permanence of Sequestration

2.5 References

3STORING CAPTURED $\mathrm{CO}_{2}$ - BASIS \& APPROACH.................................................... 3-1

3.1 Technologies Evaluated.......................................................................................

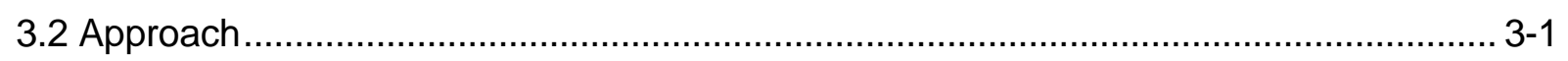

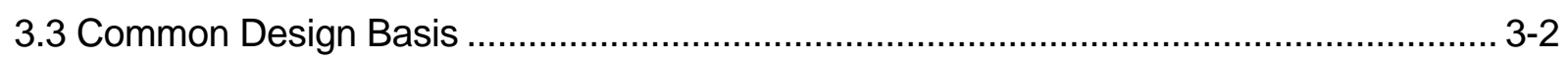

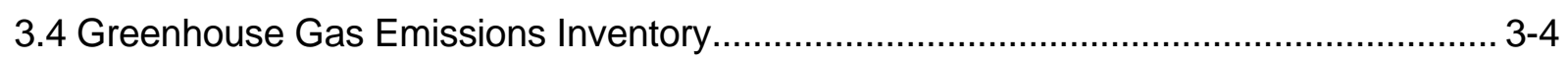

3.4.1 Emissions from Deep Mining ……………………................................. 3-5

3.4.2 Emissions from Rail Transport.................................................................... 3-6

3.4.3 Emissions from the Operation of the Power Plant............................................ 3-6

3.4.4 Emissions from the Construction and Decommissioning of the Power Plant .......... 3-6

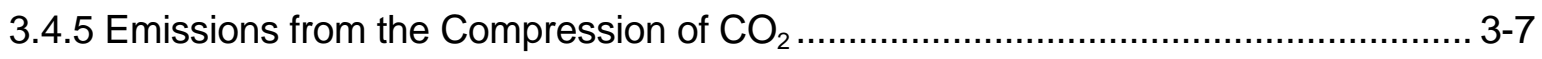

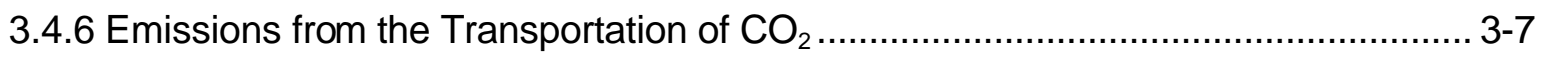

3.4.7 Emissions from the $\mathrm{CO}_{2}$ Storage Options ………….................................... 3-7

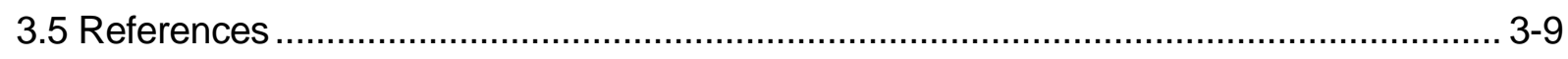

4 PIPELINE TRANSPORT

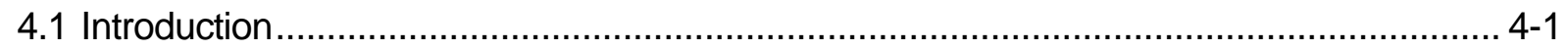

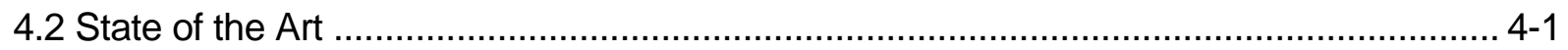

4.3 Process Description ........................................................................................ 4-4

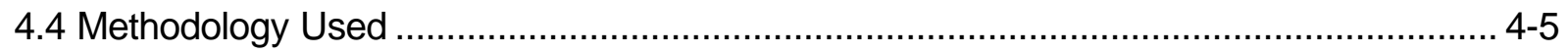

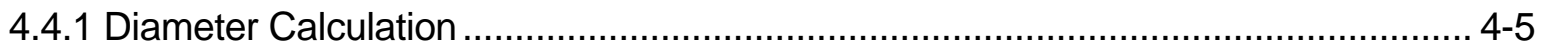

4.4.2 Cost Calculations ...................................................................................... 4-7

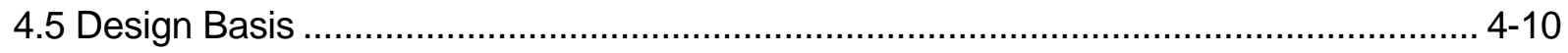

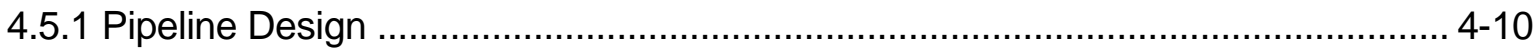

4.5.2 Capital and O\&M Cost Inputs ………………….......................................... 4-11

4.6 MIT Model Results ...................................................................................... 4-11

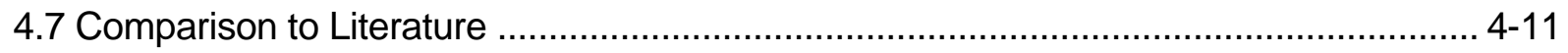

4.7.1 Studies Used in Model Evaluation .......................................................... 4-11

4.7.2 Comparison of Values from Model and Studies .............................................. 4-12 
4.8 References

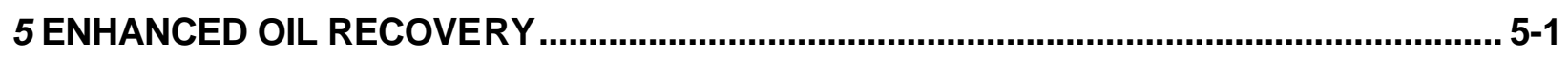

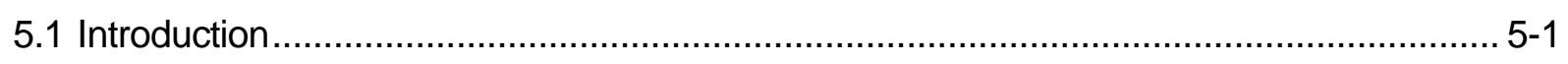

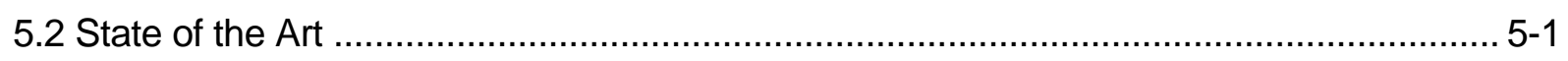

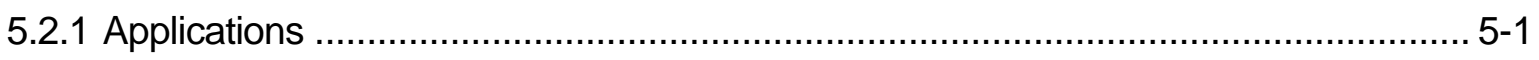

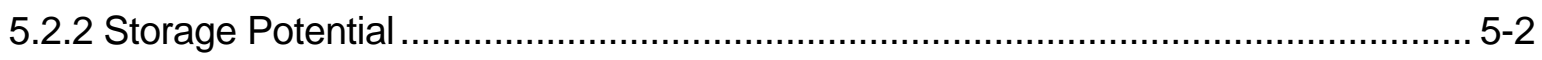

5.2.3 Storage Mechanics....................................................................................... 5-3

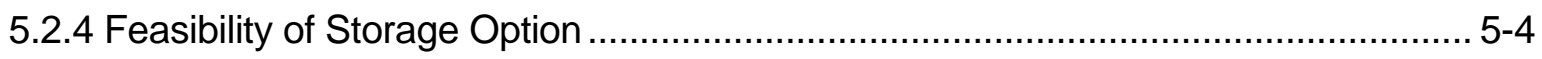

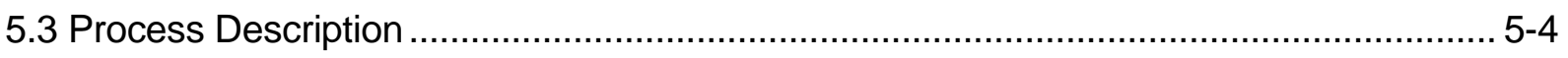

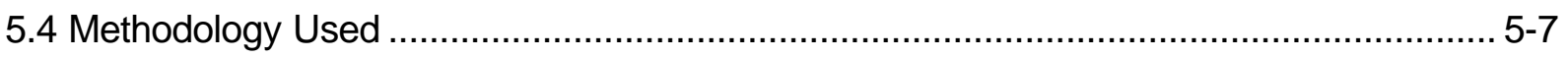

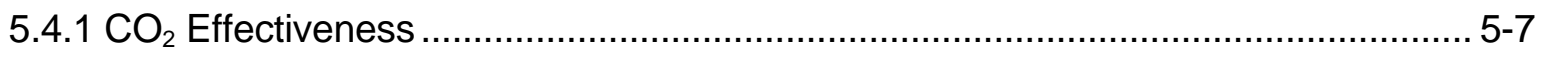

5.4.2 Rate of Enhanced Oil Production at Producer................................................... 5-9

5.4.3 Ratio of Producers to Injectors.................................................................... 5-10

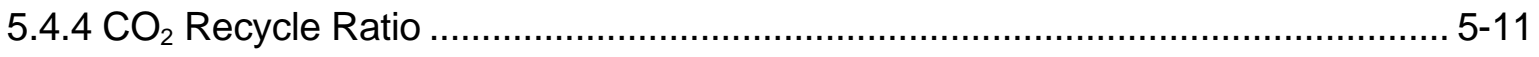

5.4.5 Reworking of Existing Wells....................................................................... 5-11

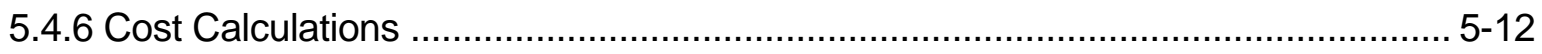

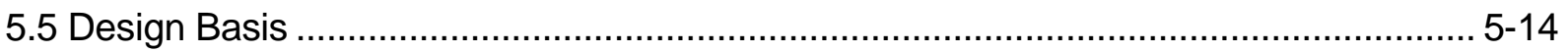

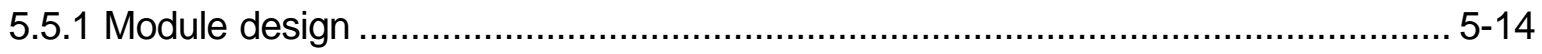

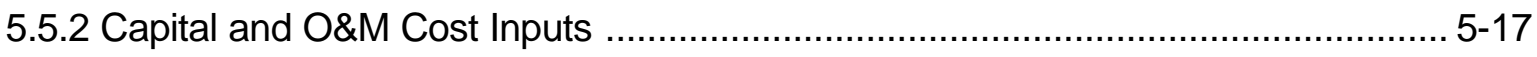

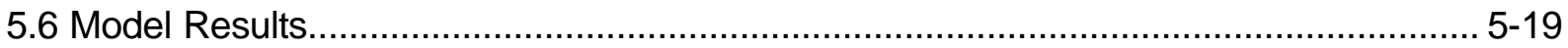

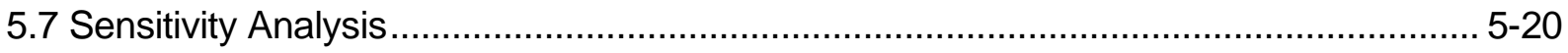

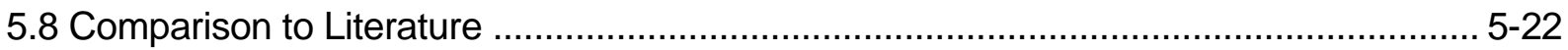

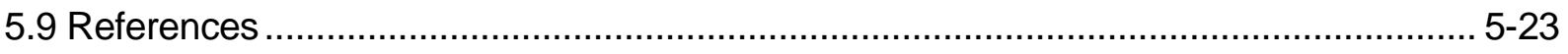

6 ENHANCED COALBED METHANE

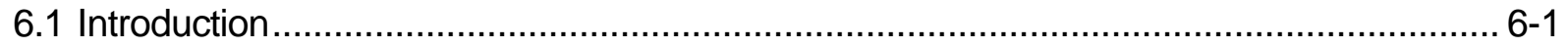

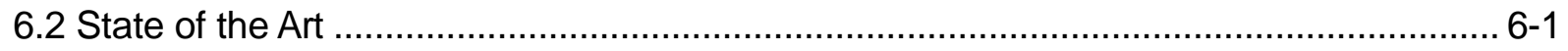

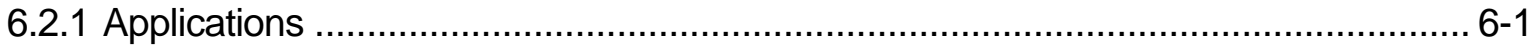

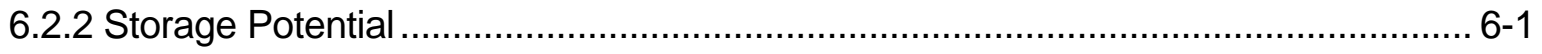

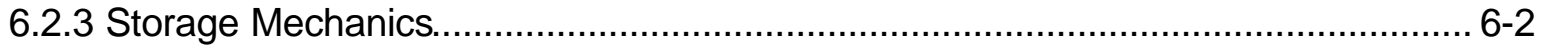

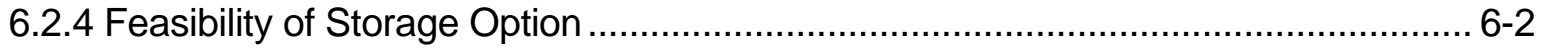

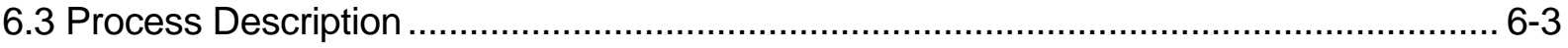

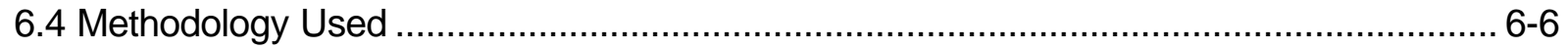

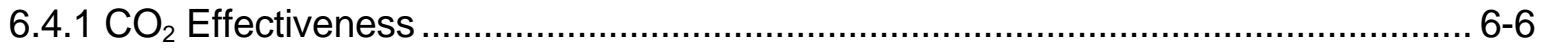


6.4.2 Rate of Enhanced CBM Production ................................................................. 6-6

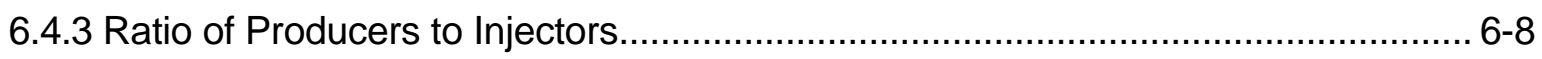

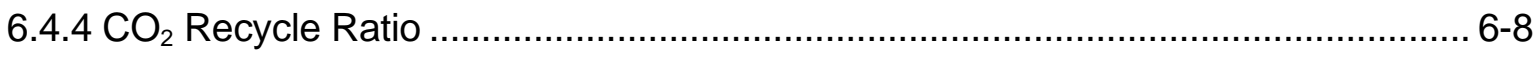

6.4.5 Drilling and Equipping of Production and Injection Wells .................................... 6-8

6.4.6 Cost Calculations ...................................................................................... 6-9

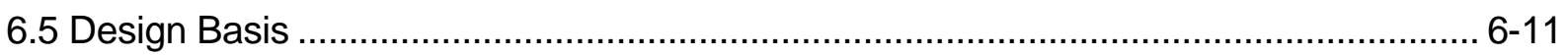

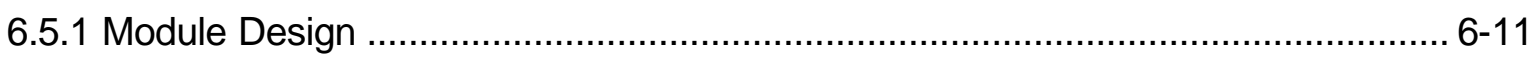

6.5.2 Capital and O\&M Cost Inputs ................................................................. 6-14

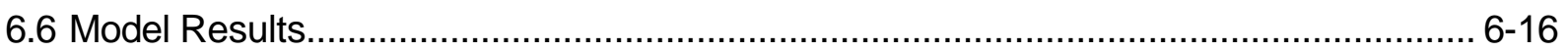

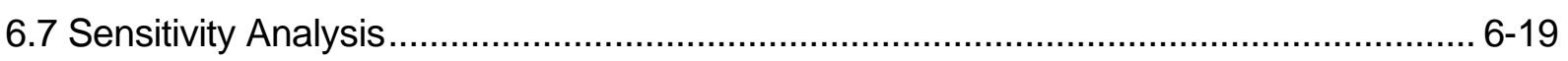

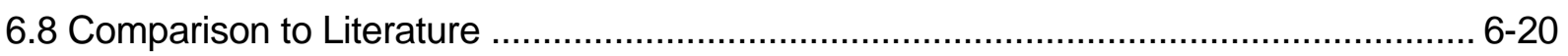

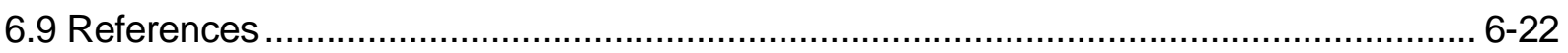

7DEPLETED GAS AND OIL RESERVOIR/AQUIFER STORAGE........................................ 7-1

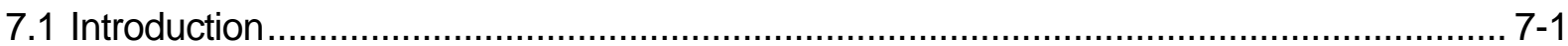

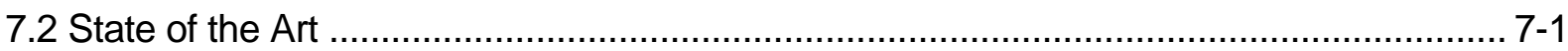

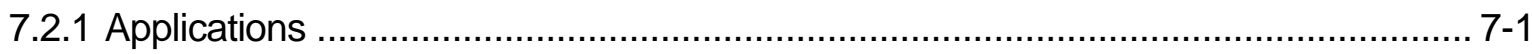

7.2.2 Storage Potential ..............................................................................................

Depleted Natural Gas Reservoirs ........................................................................ 7-1

Depleted Oil Reservoirs .................................................................................

Deep Saline Aquifers......................................................................................

7.2.3 Storage Mechanics......................................................................................

7.2.4 Storage Option Feasibility .......................................................................... $7-3$

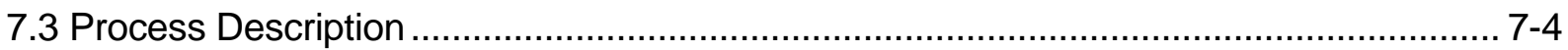

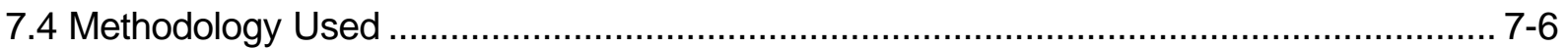

7.4.1 Well Number Calculation .............................................................................. 7-7

7.4.2 $\mathrm{CO}_{2}$ Downhole Injection Pressure Calculation …………................................... 7-8

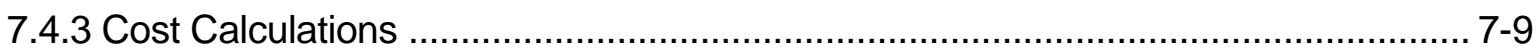

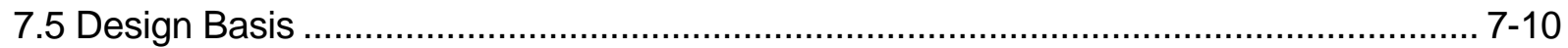

7.5.1 Reservoir Parameters and Well Numbers for Base and Sensitivity Cases ........... 7-10

7.5.2 Capital and O\&M Cost Inputs .................................................................... 7-14

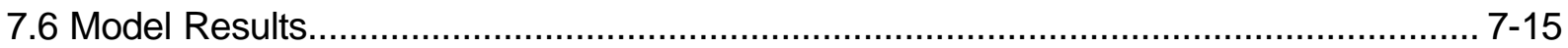

7.6.1 Depleted Gas Reservoir: Spreadsheet Orientation and Typical Costs ................. 7-15

7.6.2 Depleted Oil Reservoir: Spreadsheet Orientation and Typical Costs .................. 7-17

7.6.3 Aquifer Storage: Spreadsheet Orientation and Typical Costs .............................. 7-20 


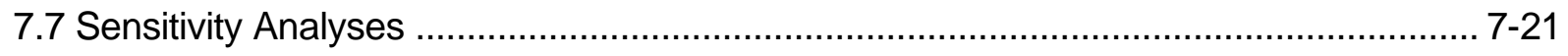

7.7.1 Depleted Gas Reservoir ..............................................................................

7.7.2 Depleted Oil Reservoir ............................................................................ 7-23

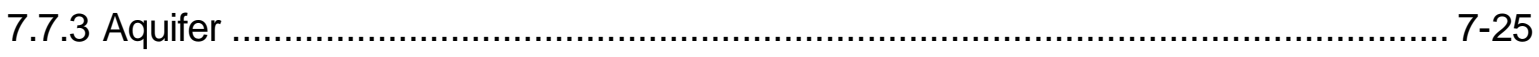

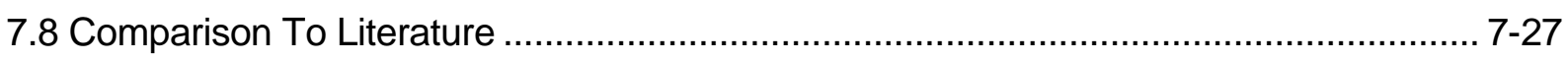

7.8.1 Studies Used in Model Evaluation ................................................................ 7-27

7.8.2 Comparison of Values from Model and Studies ……...................................... 7-27

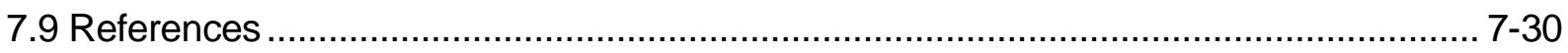

8 OCEAN VIA PIPELINE

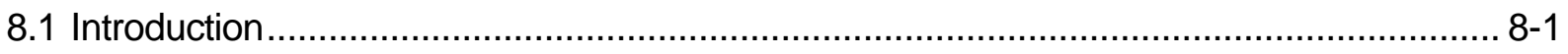

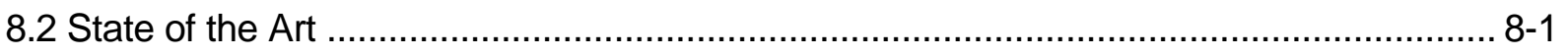

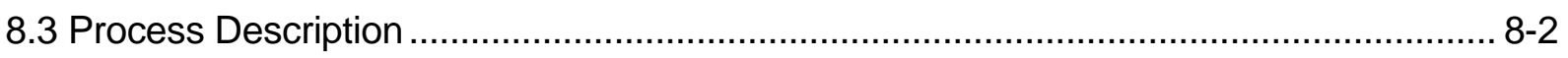

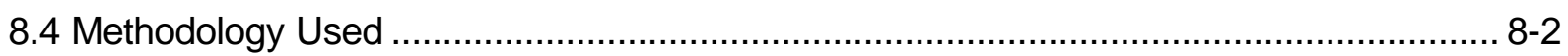

8.4.1 Diameter Calculation ..................................................................................... 8-3

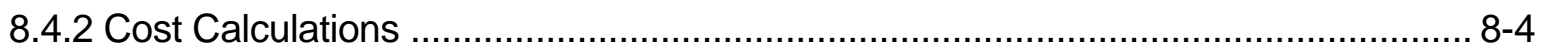

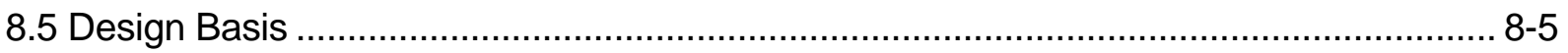

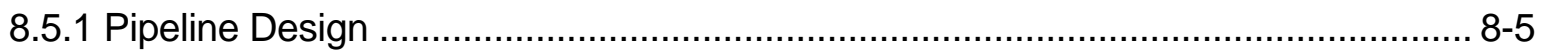

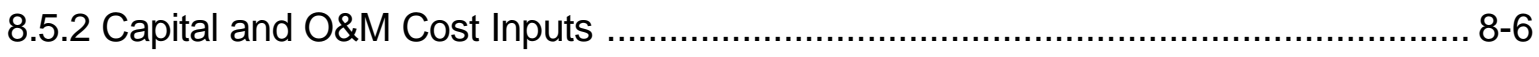

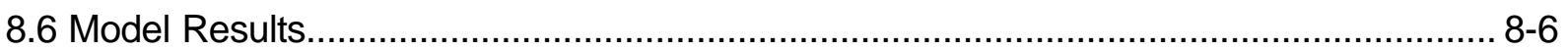

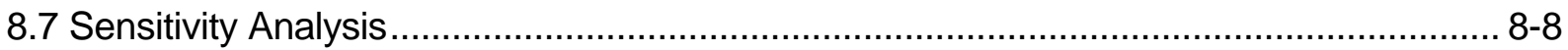

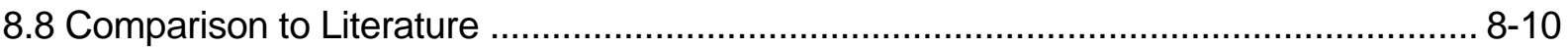

8.8.1 Studies Used in Model Evaluation ............................................................ 8-10

8.8.2 Comparison of Values from Model and Studies ……....................................... 8-11

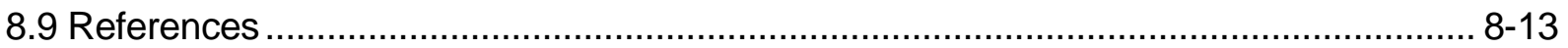

9 OCEAN VIA TANKER

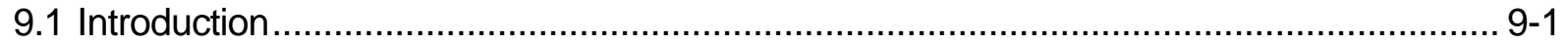

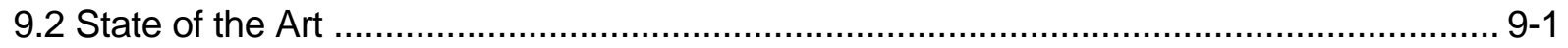

9.3 Process Description ............................................................................................ 9 -

9.4 Methodology Used ......................................................................................... 9-1

9.4.1 Tanker Number Calculation ......................................................................... 9-2

9.4.2 Vertical Pipe Diameter Calculation ............................................................... 9-2

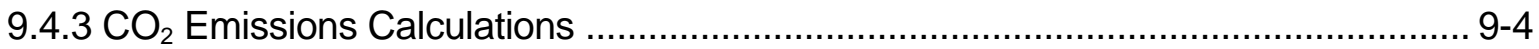

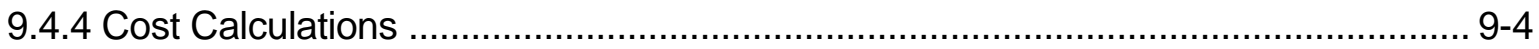




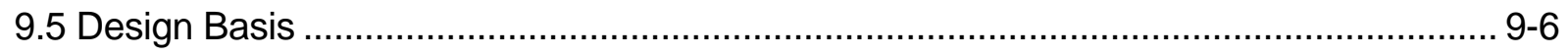

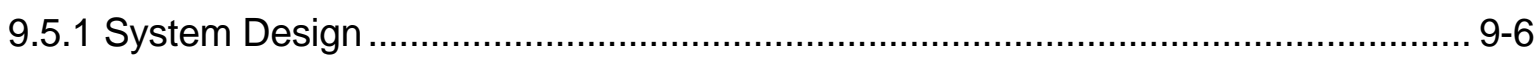

9.5.2 Capital and O\&M Cost Inputs ………………................................................ 9-7

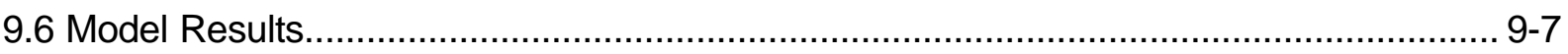

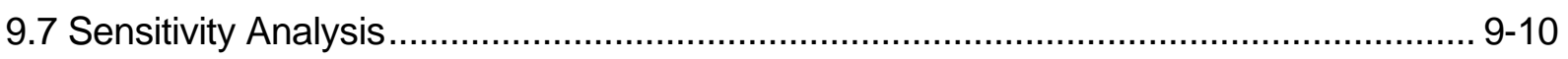

9.8 Comparison to Literature …………................................................................. 9-11

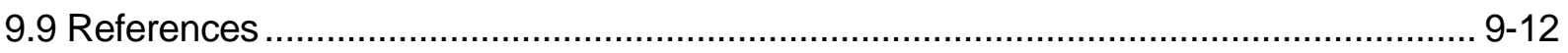

$10 \mathrm{CO}_{2}$ SINK ENHANCEMENT IN FORESTS—BASIS AND APPROACH ........................ 10-1

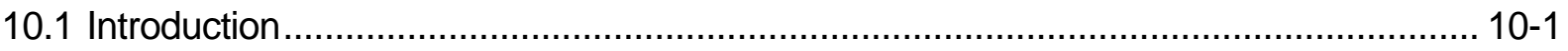

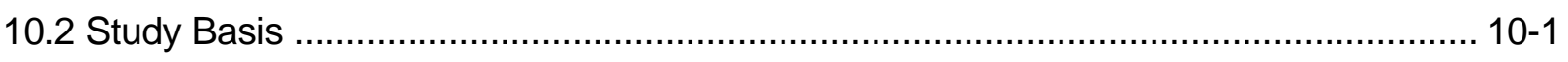

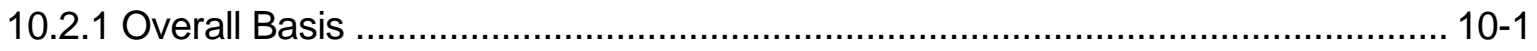

10.2.2 Carbon Sink Enhancement ........................................................................ 10-2

10.2.3 Reduction in Emissions Resulting from Use of Wood and Biomass....................10-2

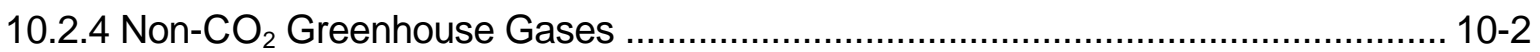

10.2.5 Ancillary Benefits ................................................................................... 10-2

10.2.6 Concerns and Uncertainties ..................................................................... 10-3

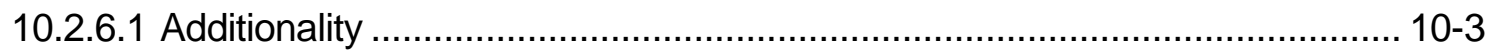

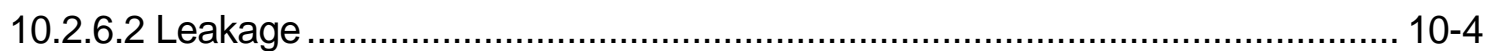

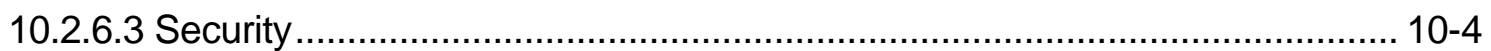

10.2.6.4 Non-Greenhouse Gas Effects ............................................................... 10-5

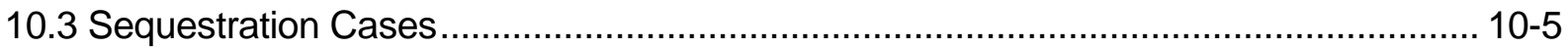

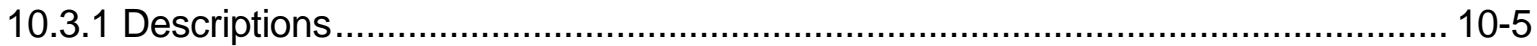

10.3.2 Quantities of Carbon Sequestered .............................................................. 10-6

10.3.2.1 Above-Ground Carbon ........................................................................... 10-7

10.3.2.2 Below-Ground Carbon ........................................................................ 10-8

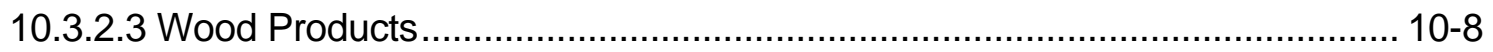

10.3.3 Non- $\mathrm{CO}_{2}$ Greenhouse Gases ............................................................... 10-9

10.3.3.1 Nitrous Oxide from Forests and Baseline Land Uses ............................. 10-10

10.3.3.2 Methane from Forests and Baseline Land Uses .................................... 10-10

10.3.3.3 Net Emissions of Nitrous Oxide and Methane From Forestry................... 10-11

10.3.3.4 Emissions From Biomass Burning ........................................................ 10-11

10.3.3.5 Other Atmospheric Emissions........................................................... 10-12

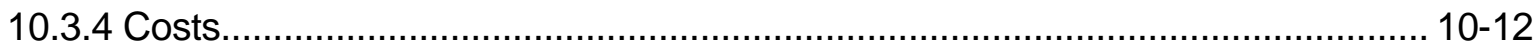

10.3.4.1 Establishment and Maintenance ..................................................... 10-12 


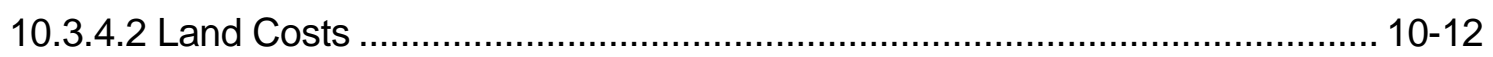

10.3.4.3 Timber Revenues ............................................................................... 10-13

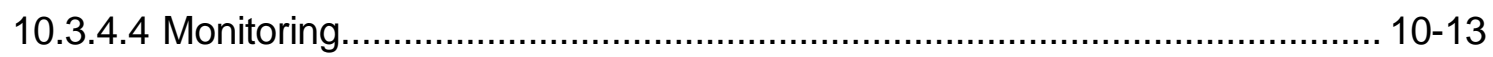

10.3.4.5 Financial Parameters ....................................................................... 10-13

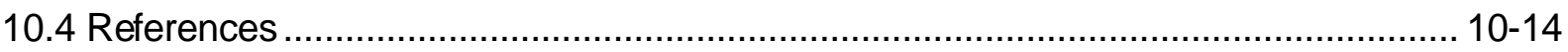

11 CASE 1: SOUTHERN U.S. LOBLOLLY PINE PLANTATIONS........................................11-1

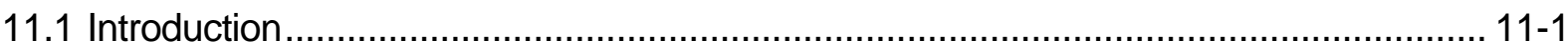

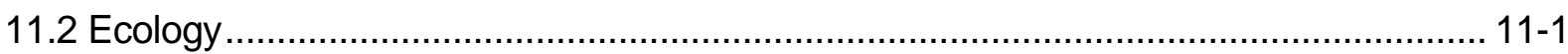

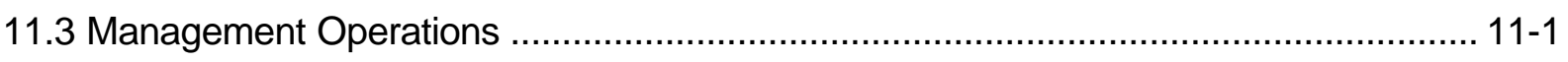

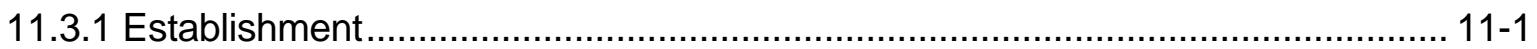

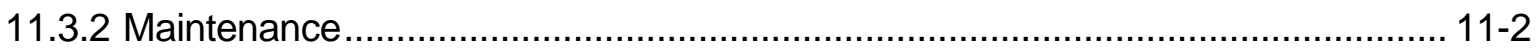

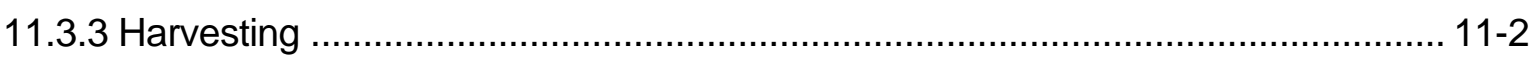

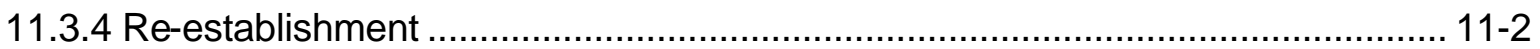

11.3.5 Classification of Productivity ..........................................................................

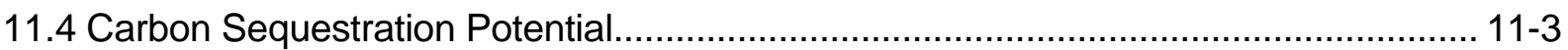

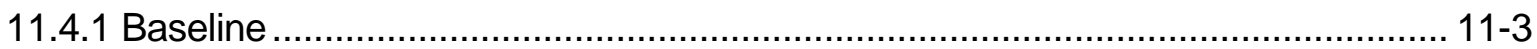

11.4.2 Carbon Uptake and Storage by Pinus Taeda................................................ 11-3

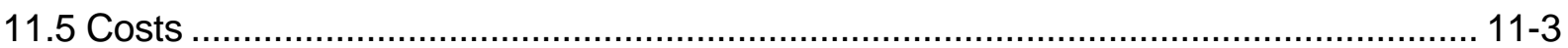

11.5.1 Establishment and Maintenance...................................................................11-3

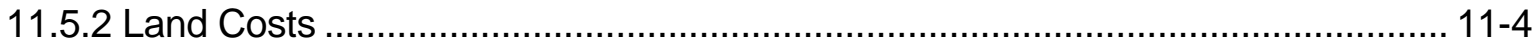

11.5.3 Potential Income.................................................................................... 11-4

11.6 Summary of Model Inputs and Results ............................................................ 11-4

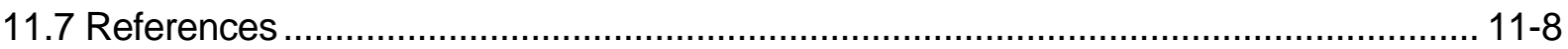

12 CASE 2: PACIFIC NORTHWEST DOUGLAS FIR PLANTATIONS …..............................12-1

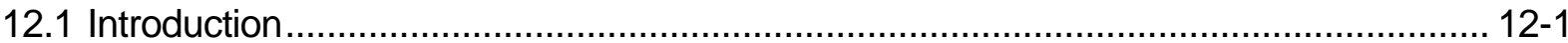

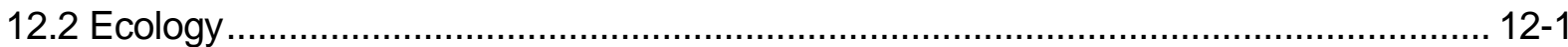

12.3 Management Operations …………………….................................................... 12-1

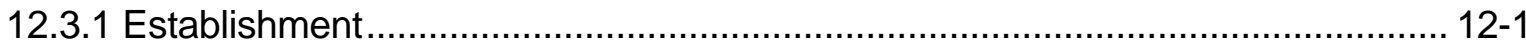

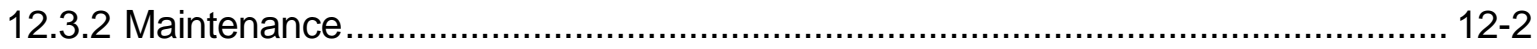

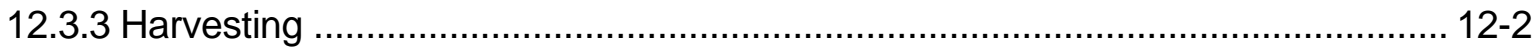

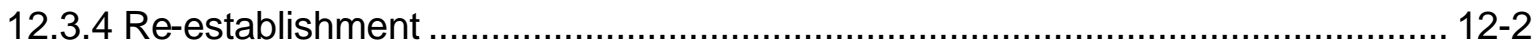

12.4 Classification of Productivity ............................................................................ 12-2

12.5 Carbon Sequestration Potential........................................................................ 12-3

xliii 


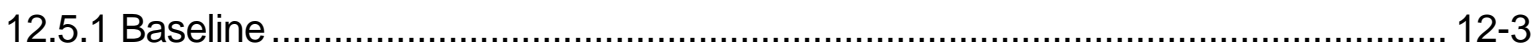

12.5.2 Carbon Uptake and Storage by Pseduotsuga Menziesii.................................. 12-3

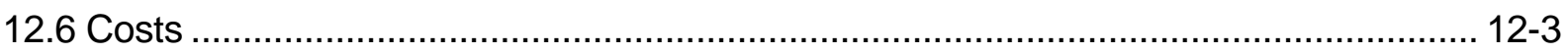

12.6.1 Establishment and Maintenance........................................................... 12-3

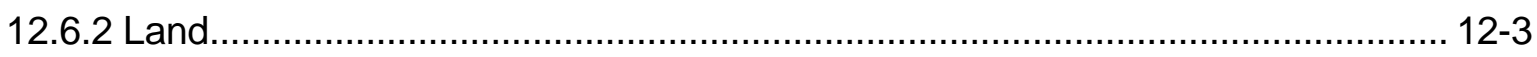

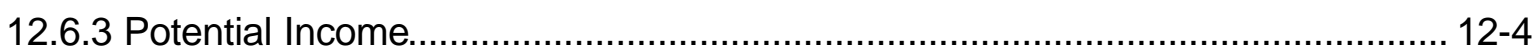

12.7 Summary of Model Inputs and Results ........................................................... 12-4

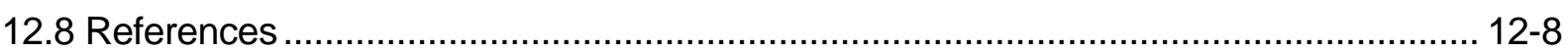

\section{CASE 3: SPANISH CEDAR PLANTATIONS IN MEXICO USING THE TAUNGYA}

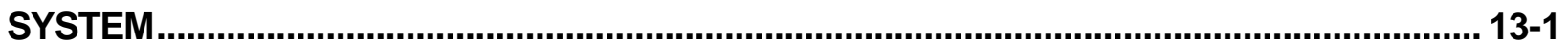

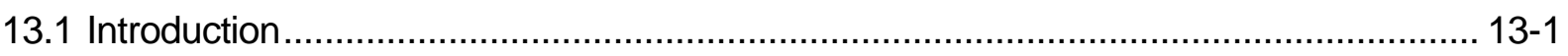

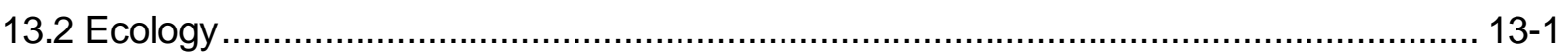

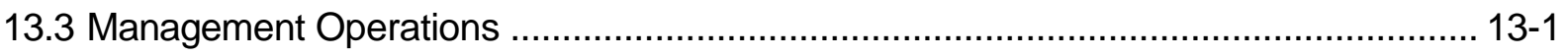

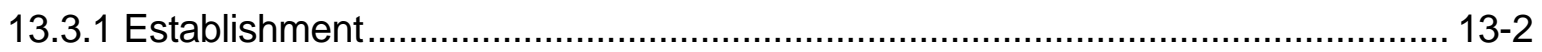

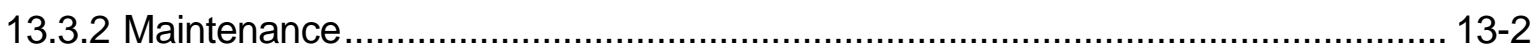

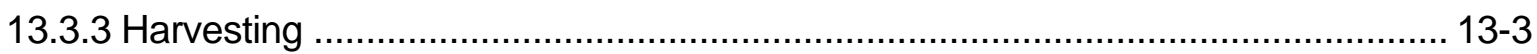

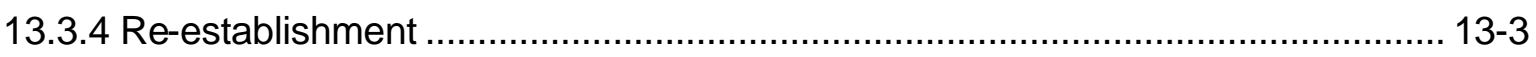

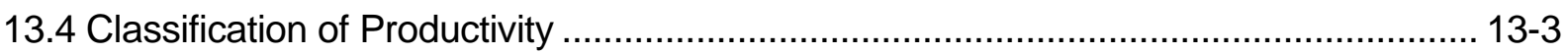

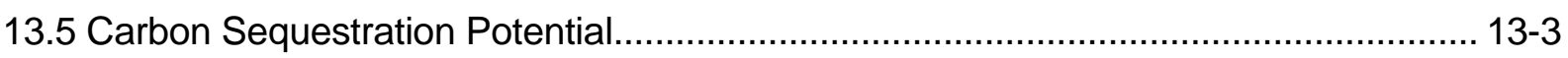

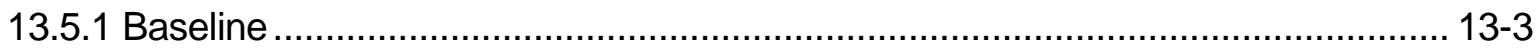

13.5.2 Carbon Uptake and Storage by Cedrela Odorata .......................................... 13-4

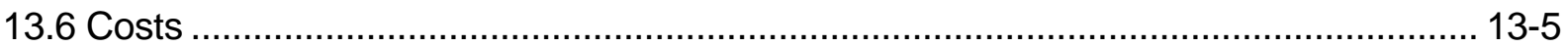

13.6.1 Establishment and Maintenance................................................................ 13-5

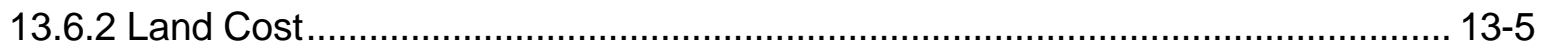

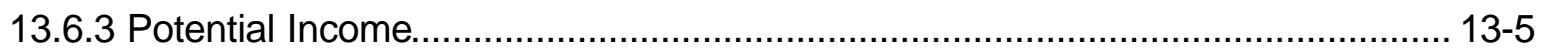

13.7 Summary of Model Inputs and Results............................................................... 13-5

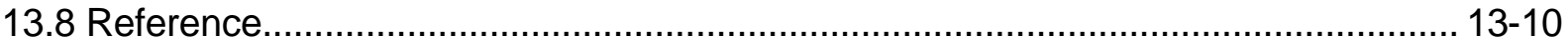

14 CASE 4: RESTORATION OF DEGRADED PINE-OAK WOODLAND IN CHIAPAS, MEXICO THROUGH ENRICHMENT PLANTING WITH PINUS OOCARPA.......................... 14-1

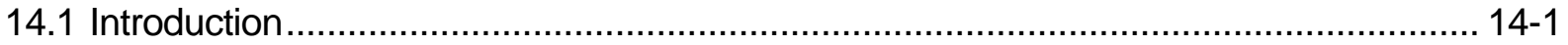

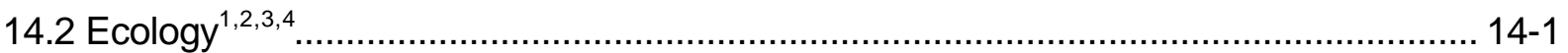

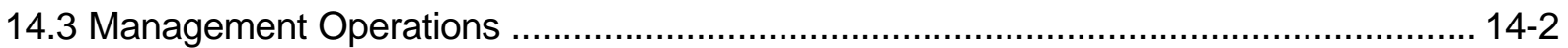

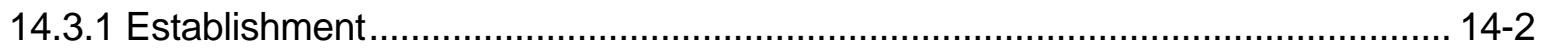

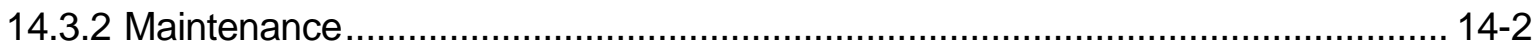




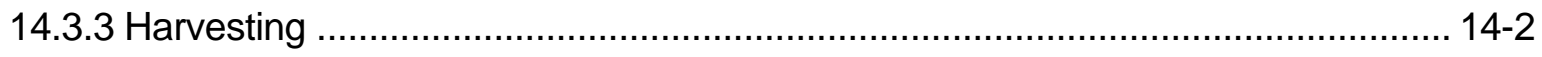

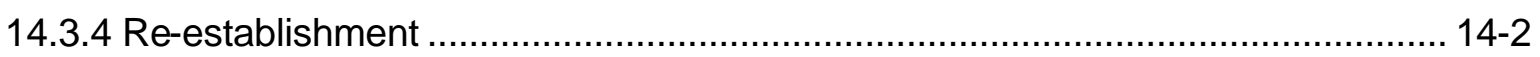

14.4 Classification of Productivity .................................................................................

14.5 Carbon Sequestration Potential....................................................................... 14-3

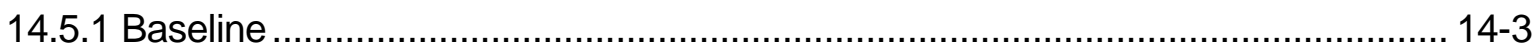

14.5.2 Carbon Uptake by the Regenerating Forest............................................... 14-4

14.6 Costs:

14.6.1 Establishment and Maintenance.............................................................. 14-5

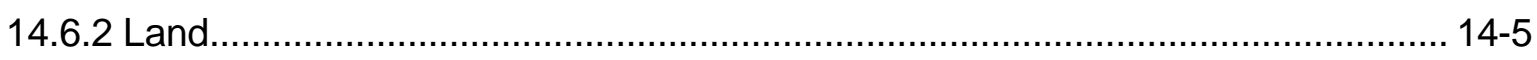

14.6.3 Potential Income........................................................................................

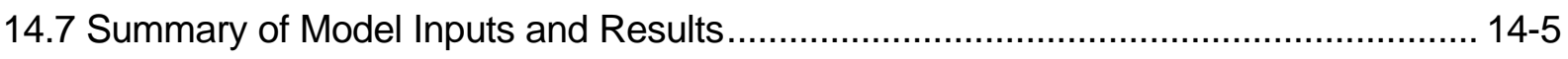

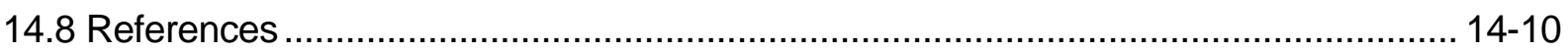

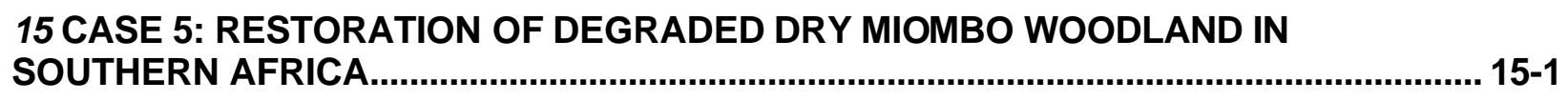

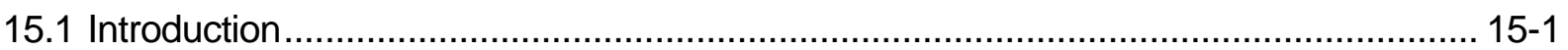

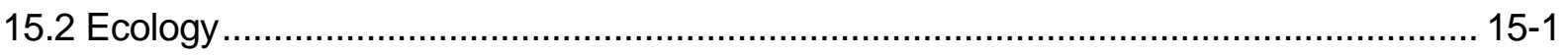

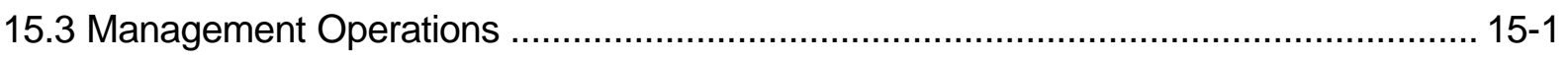

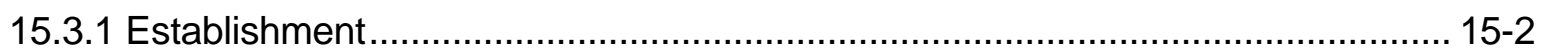

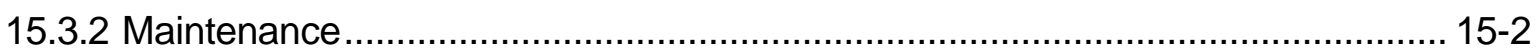

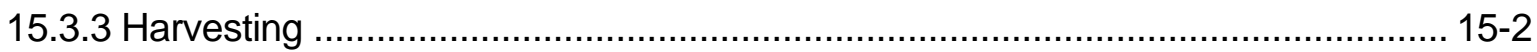

15.3.4 Re-establishment ............................................................................... 15-2

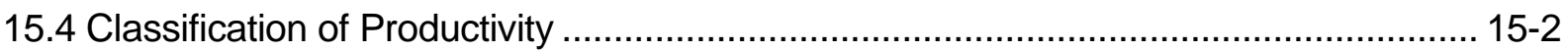

15.5 Carbon Sequestration Potential............................................................................ 15-2

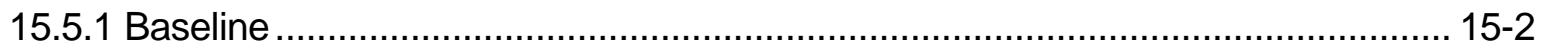

15.5.2 Carbon Uptake and Storage in Miombo Woodland......................................... 15-3

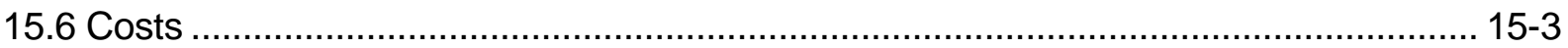

15.6.1 Establishment and Maintenance.................................................................. 15-3

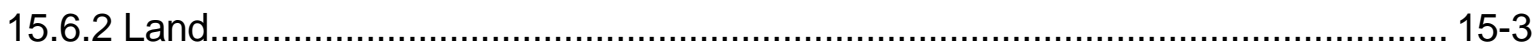

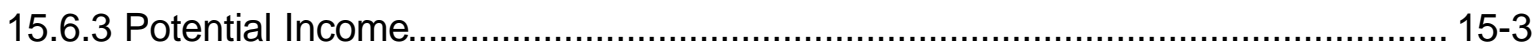

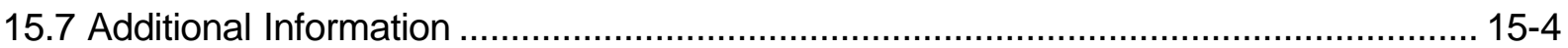

15.8 Summary of Model Inputs and Results......................................................... 15-4

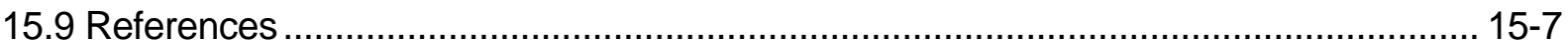




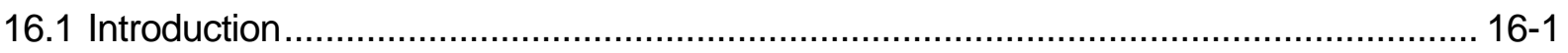

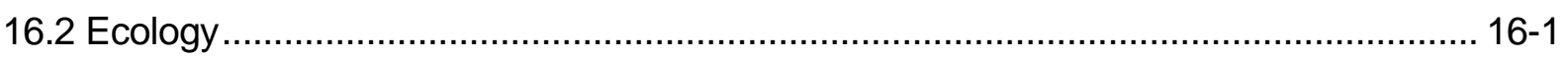

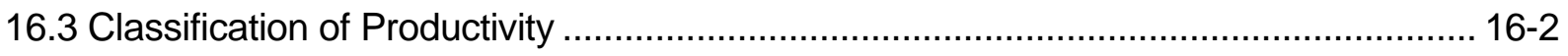

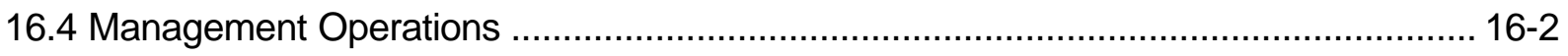

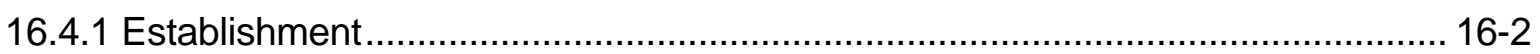

16.4.2 Harvesting/Replanting ......................................................................... 16-3

16.5 Carbon Sequestration Potential....................................................................... 16-3

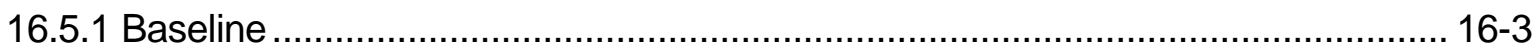

16.5.2 Carbon Uptake and Storage by Orchards ................................................... 16-3

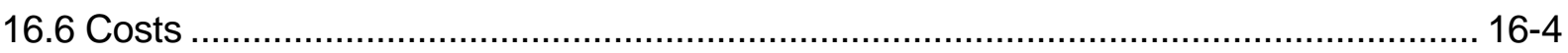

16.6.1 Establishment and Maintenance................................................................ 16-4

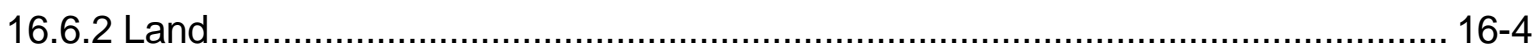

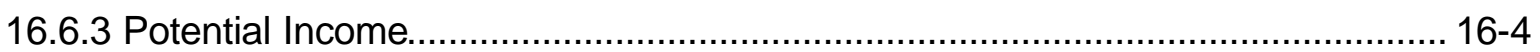

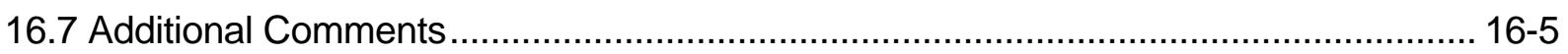

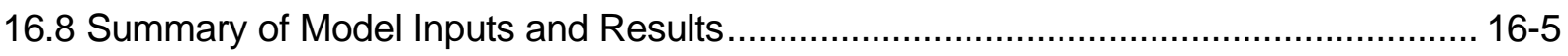

16.9 References / Information Sources ........................................................................ 16-8

17 CASE 7: AVOIDANCE OF DEFORESTATION IN CHIAPAS, MEXICO ............................17-1

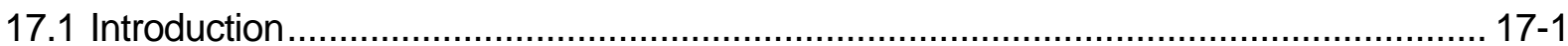

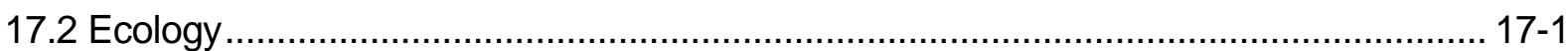

17.3 Carbon Sequestration Potential...................................................................... 17-2

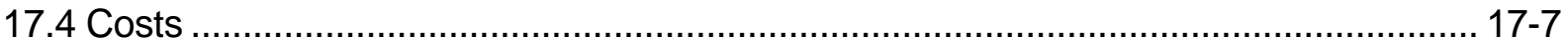

17.4.1 Establishment and Maintenance................................................................. 17-7

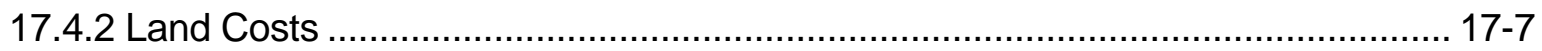

17.4.3 Potential Income....................................................................................

17.5 Summary of Model Inputs and Results ............................................................ 17-8

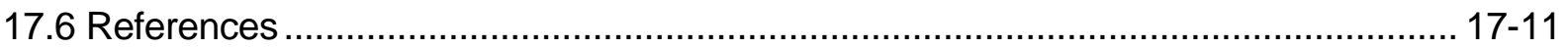

18 ECONOMICS OF $\mathrm{CO}_{2}$ SINK ENHANCEMENT VI A REDUCING TILLAGE ON U.S.

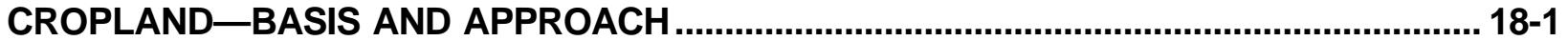

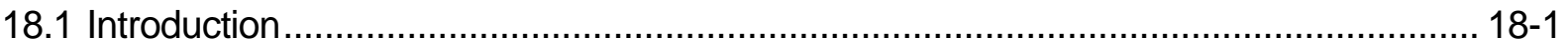

18.2 Tillage-System Definitions ......................................................................... 18-1

18.3 Effects of Tillage-System on the Amount of Carbon Stored in Soil Organic Matter .... 18-3

18.4 Regions With Greatest Potential for Increasing Soil Organic Carbon ........................ 18-5

18.5 Current Levels of Conservation-Tillage Adoption................................................ 18-8

18.5.1 Corn and Soybeans in the Corn Belt ........................................................ 18-8 


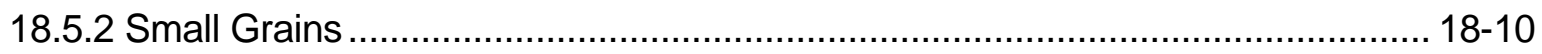

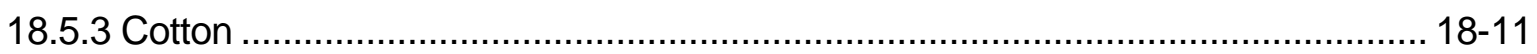

18.6 GHG Effects in Addition to Carbon Storage in Soil Organic Matter ......................... 18-12

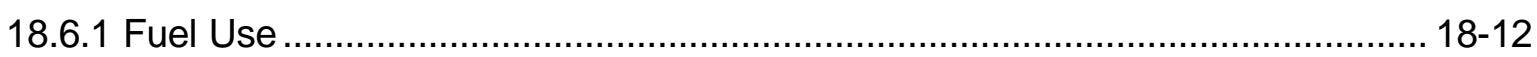

18.6.2 Machinery Required ......................................................................... 18-13

18.6.3 N Fertilizer Use.................................................................................... 18-13

18.6.4 Herbicide Use.................................................................................... 18-13

18.6.5 $\mathrm{N}_{2} \mathrm{O}$ Emissions From Soil...................................................................... 18-13

18.7 Costs of Reducing Tillage as a Means of Offsetting Utility GHG Emissions ............. 18-14

18.8 Cropland Case Studies Included in This Project................................................. 18-16

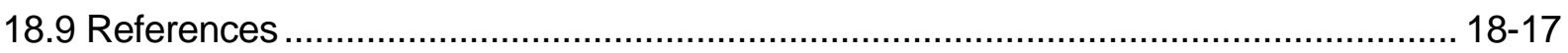

19 CORN/SOYBEAN ROTATIONS IN THE U.S. CORN BELT ….........................................19-1

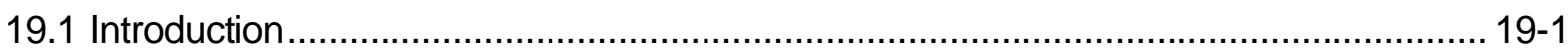

19.2 Corn/Soybean Rotation (Base Cases) …………............................................. 19-1

19.2.1 Increases in Soil Organic Carbon ............................................................. 19-3

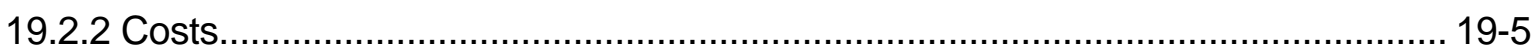

19.2.3 GHG Effects in Addition to Carbon Storage in Soil Organic Matter.................... 19-5

19.2.3.1 Fuel Use ......................................................................................... 19-5

19.2.3.2 Machinery Manufacture, Transportation, and Repair ................................. 19-6

19.2.3.3 Nitrogen Fertilizer Use .................................................................... 19-7

19.2.3.4 Herbicide Use................................................................................ 19-10

19.2.3.5 $\mathrm{N}_{2} \mathrm{O}$ Emissions from Soil................................................................. 19-10

19.2.3.6 Summary of Avoided GHG Emissions.................................................. 19-12

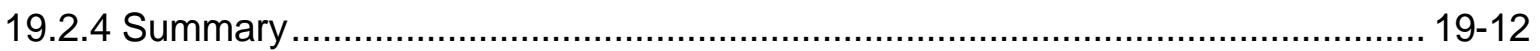

19.2.5 Sensitivity Summary........................................................................... 19-14

19.3 Corn/Soybean Rotations (Poor N Management Scenario) …................................... 19-15

19.3 Corn/Soybean Rotations (Poor N Management Scenario) ...................................... 19-16

19.3.1 Nitrogen Fertilizer Use ........................................................................ 19-17

19.3.2 Summary of Avoided GHG Emissions..................................................... 19-19

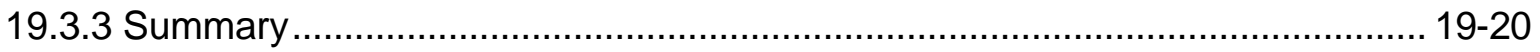

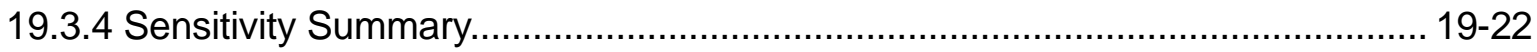

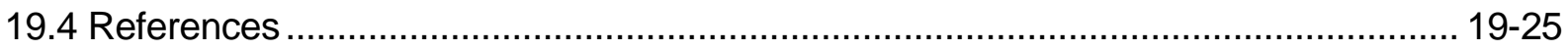

20 CONTINUOUS CORN IN THE U.S. CORN BELT .......................................................... 20-1 


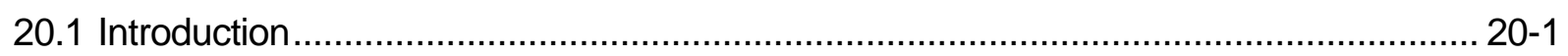

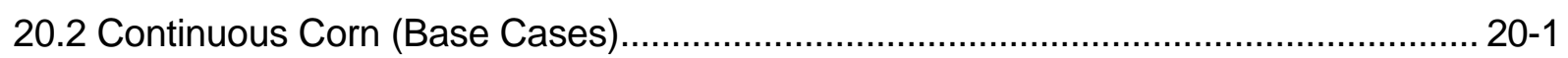

20.2.1 Increases in Soil Organic Carbon ........................................................... 20-3

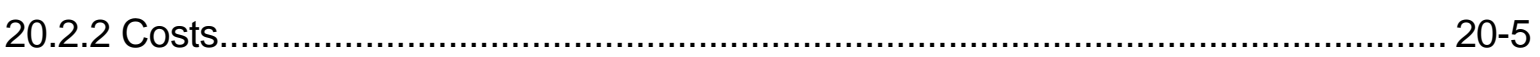

20.2.3 GHG Effects in Addition to Carbon Storage in Soil Organic Matter................... 20-5

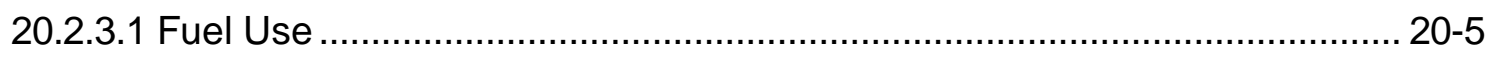

20.2.3.2 Machinery Manufacture, Transportation, and Repair ............................... 20-6

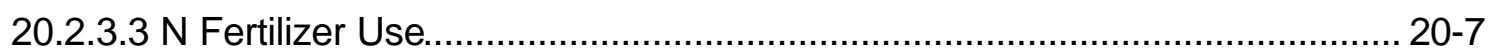

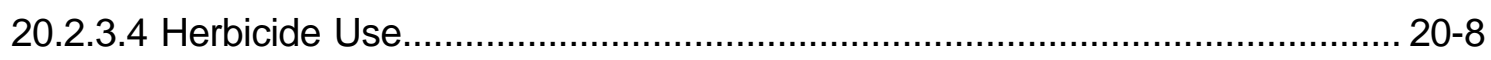

20.2.3.5 $\mathrm{N}_{2} \mathrm{O}$ Emissions from Soil......................................................................... 20-8

20.2.3.6 Summary of Avoided GHG Emissions................................................. 20-10

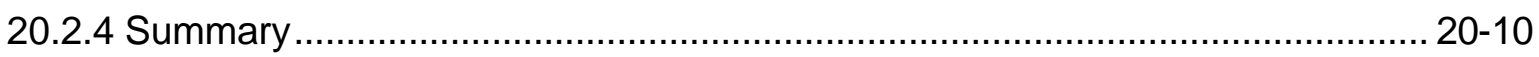

20.2.5 Sensitivity Summary............................................................................ 20-12

20.3 Continuous Corn (Poor N Management Scenario) ............................................. 20-13

20.3 Continuous Corn (Poor N Management Scenario) ............................................ 20-14

20.3.1 N Fertilizer Use.............................................................................. 20-15

20.3.2 Summary of Avoided GHG Emissions....................................................... 20-17

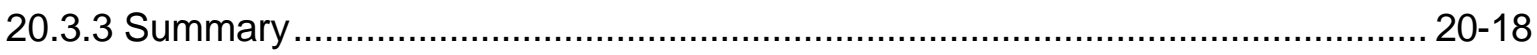

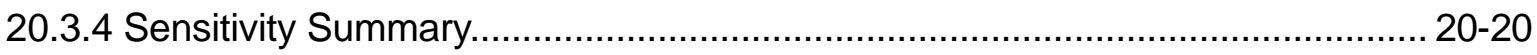

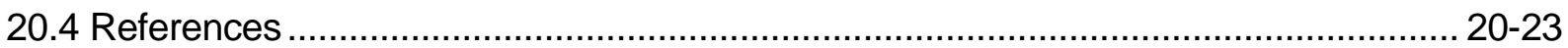

21 WHEAT/FALLOW IN THE WESTERN GREAT PLAINS ............................................... 21-1

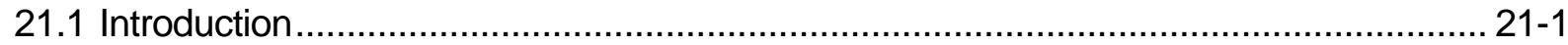

21.2 Wheat/Fallow (Base Cases) ……...................................................................... 21-1

21.2.1 Increases in Soil Organic Carbon ................................................................. 21-1

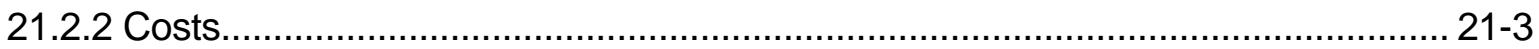

21.2.3 GHG Effects in Addition to Carbon Storage in Soil Organic Matter ....................21-4

21.2.3.1 Fuel Use .................................................................................... 21-4

21.2.3.2 Machinery Manufacture, Transportation, and Repair ................................. 21-4

21.2.3.3 N Fertilizer Use........................................................................ 21-5

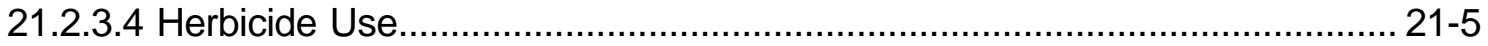

21.2.3.5 $\mathrm{N}_{2} \mathrm{O}$ Emissions from Soil............................................................. 21-5

21.2.3.6 Summary of Avoided GHG Emissions................................................ 21-6

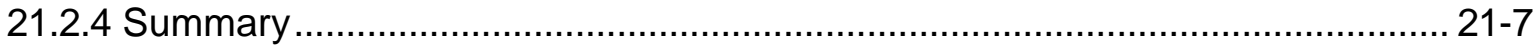

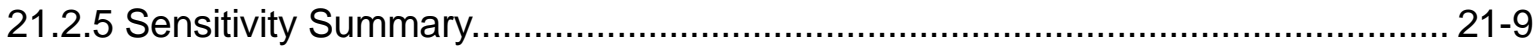

xlviii 
21.3 Wheat/Fallow (Sensitivity Cases with No Tillage Effect on $\mathrm{N}_{2} \mathrm{O}$ Emissions)............ 21-10

21.3 Wheat/Fallow (Sensitivity Cases with No Tillage Effect on $\mathrm{N}_{2} \mathrm{O}$ Emissions).............21-11

21.3.1 Summary of Avoided GHG Emissions.................................................... 21-11

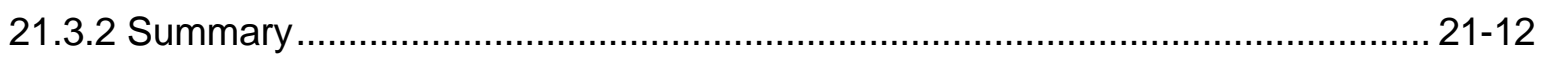

21.3.3 Sensitivity Summary........................................................................ $21-12$

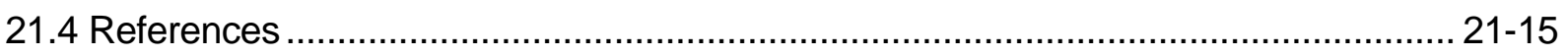

22 COTTON IN THE SOUTHEASTERN UNITED STATES ................................................. 22-1

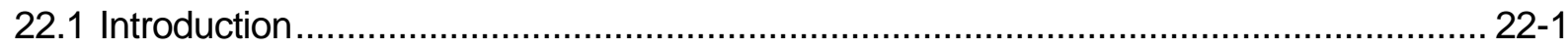

22.2 Cotton (Base Cases) .......................................................................................... 22-1

22.2.1 Increases in Soil Organic Carbon .............................................................. 22-1

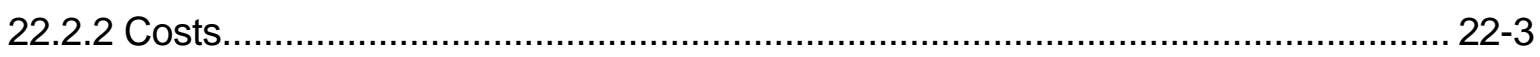

22.2.3 GHG Effects in Addition to Carbon Storage in Soil Organic Matter .................... 22-4

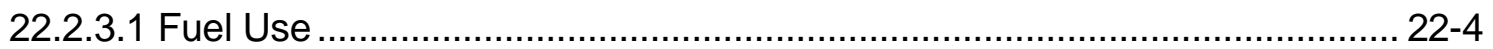

22.2.3.2 Machinery Manufacture, Transportation, and Repair ................................ 22-5

22.2.3.3 N Fertilizer Use..................................................................................... 22-5

22.2.3.4 Herbicide Use...................................................................................... $22-5$

22.2.3.5 $\mathrm{N}_{2} \mathrm{O}$ Emissions from Soil....................................................................... 22-5

22.2.3.6 Summary of Avoided GHG Emissions..................................................... 22-6

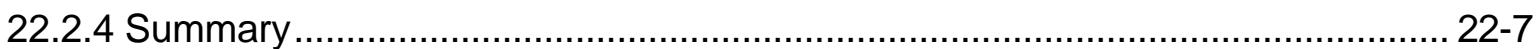

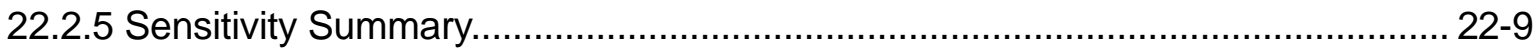

22.3 Cotton (Sensitivity Cases with No Tillage Effect on $\mathrm{N}_{2} \mathrm{O}$ Emissions) .......................22-10

22.3 Cotton (Sensitivity Cases with No Tillage Effect on $\mathrm{N}_{2} \mathrm{O}$ Emissions) .......................22-11

22.3.1 Summary of Avoided GHG Emissions........................................................ 22-11

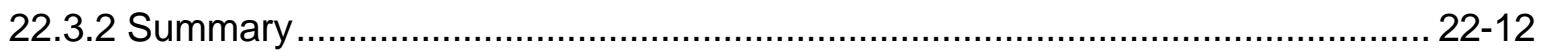

22.3.3 Sensitivity Summary.............................................................................. $22-12$

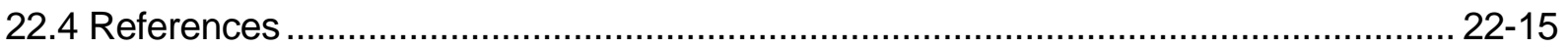

23 SUMMARY COMPARISONS AND CONCLUSIONS...................................................... 23-1

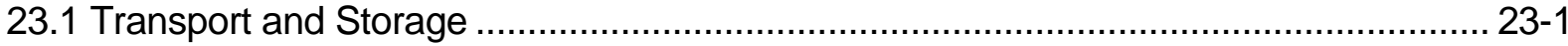

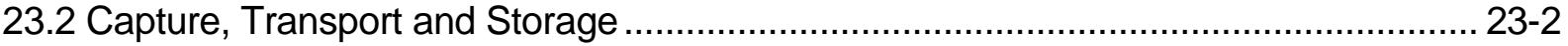

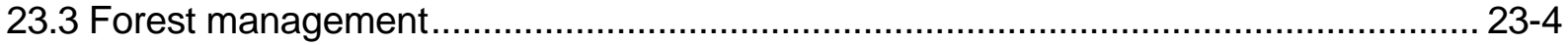

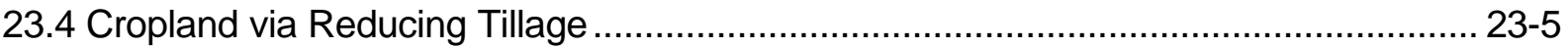

23.5 Direct Verses Indirect Sequestration ..................................................................... 23-7

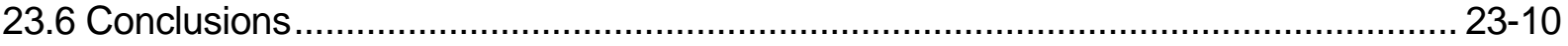

xlix 


\section{A DETAILED LIFE-CYCLE GHG EMISSIONS AVOIDED VIA CAPTURING AND}

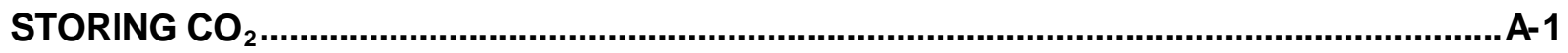

$B$ EXPLANATION OF PROCESS INPUT AND SUMMARY SPREADSHEETS....................... 1

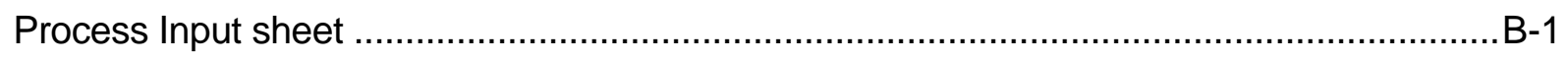

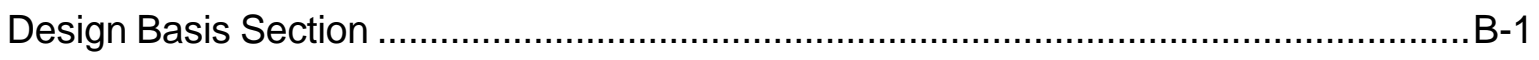

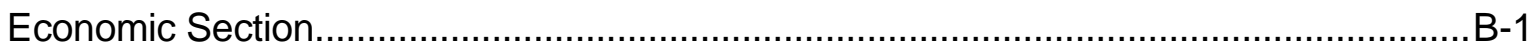

EOR and ECBMR Storage Options Only..........................................................

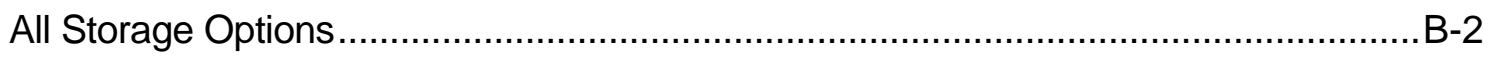

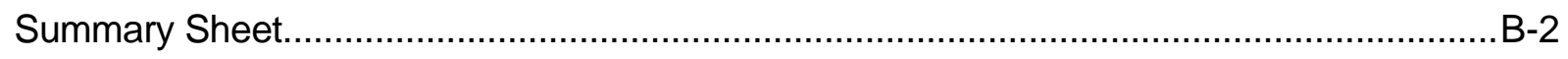

Summary Sheet Section 1 - Levelized Annual $\mathrm{CO}_{2}$ Storage Costs (years 1-20) .............. B-2

Summary Sheet Section 2 - Levelized Annual $\mathrm{CO}_{2}$ Capture and Net Storage Costs

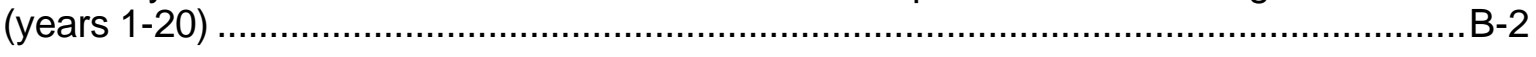

Summary Sheet Section $3-\mathrm{CO}_{2}$ Capture and Storage Costs, NPV Basis (years 1-

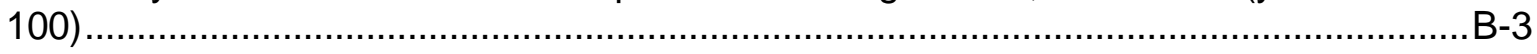

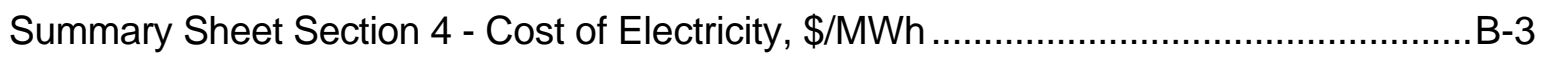

C STATUS AND COSTS OF EXISTING FORESTRY SEQUESTRATION PROJECTS............-1

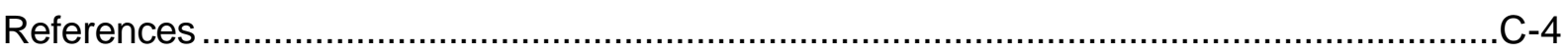


D PUBLISHED COSTS OF FORESTRY CARBON SEQUESTRATION

References

\section{E ESTIMATING ECONOMIC INCENTIVES REQUIRED TO ACHIEVE ADOPTION OF CONSERVATION-TILLAGE SYSTEMS IN SELECTED REGIONS OF THE UNITED STATES}

Background $\mathrm{E}-1$

Budgeting Case Study Tillage Systems E-2

Estimating the Incentives to Adopt Reduced-Tillage Practices. E-2

Analytical Procedure E-3

Discussion of Incentive Level Results E-7

Sensitivity of Incentives to Changes in Revenue E-8

References Cited. $\mathrm{E}-11$

Attachment E-1 of Appendix E: Budget and Yield Sources E-13

Attachment E-2 of Appendix E: Site Selection E-16

Attachment E-3 of Appendix E: Yield Comparisons

FESTIMATING STATE-LEVEL SOC RESPONSES.

References

References

$\mathrm{F}-10$ 


\section{LIST OF FIGURES}

Figure 1-1 Preliminary Block Diagram for Aquifer Storage Concept .................................. 1-3

Figure 1-2 Preliminary Block Diagram for EOR Concept ................................................ 1-5

Figure 1-3 Preliminary Block Diagram for Depleted Oil and Gas Reservoir Storage ................1-7

Figure 1-4 Preliminary Block Diagram for Coal Bed Storage Concept ................................... 1-9

Figure 1-5 Preliminary Block Diagram for Ocean Storage Concept.................................1-11

Figure 1-6 Preliminary Block Diagram for Forest Storage Concept .................................1-13

Figure 1-7 Preliminary Block Diagram for Cropland Sink Concept .....................................1-15

Figure 2-1 Carrying charge factor vs. after-tax discount rate (based on constant dollar

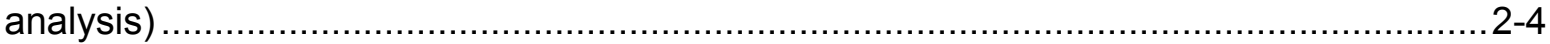

Figure 2-2 Relationships among $\mathrm{CO}_{2}$ produced, captured, and avoided when comparing

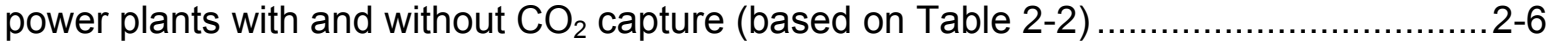

Figure 2-3 Relationships among GHG produced, $\mathrm{CO}_{2}$ captured, and $\mathrm{GHG}$ avoided on a LC basis for $\mathrm{CO}_{2}$ capture and storage (via EOR) combined; based on Tables 2-2 and $2-3$

Figure 3-1 Carbon dioxide pressure enthalpy diagram ..................................................

Figure 4-1 Pipeline transport cost model overview diagram ......................................... $4-5$

Figure 4-2 Diameter for the base case as a function of $\mathrm{CO}_{2}$ mass flow rate ......................... 4-6

Figure 4-3 Breakdown of pipeline cost on a dollar per mile basis ..................................... 4-7

Figure 4-4 Breakdown of pipeline cost on a percentage of total cost basis ............................ 4-8

Figure 4-5 Regression analysis of pipeline construction cost data ...................................... 4-9

Figure 4-6 Total cost per tonne of $\mathrm{CO}_{2}$ for the base case as a function of $\mathrm{CO}_{2}$ mass flow rate.

Figure 4-7 Comparison of pipe diameter values ....................................................... 4-13

Figure 4-8 Comparison of pipeline capital cost values ................................................. 4-14

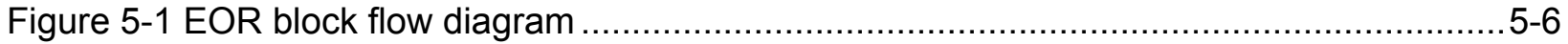

Figure 5-2 EOR cost model overview diagram .......................................................... $5-8$

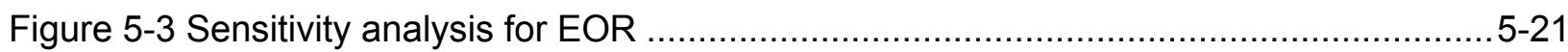

Figure 6-1 ECBMR block flow diagram ........................................................................ $6-5$

Figure 6-2 ECBMR cost model overview diagram ........................................................ $6-7$

Figure 6-3 Well drilling cost as a function of depth ..................................................... $6-9$

Figure 6-4 Sensitivity analysis for ECBMR ................................................................. 6-19

Figure 7-1 Depleted oil, gas, and aquifer block flow diagram ........................................ 7-5

Figure $7-2$ Geologic storage cost model overview diagram ............................................... 


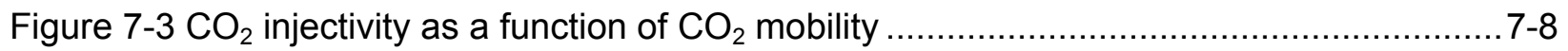

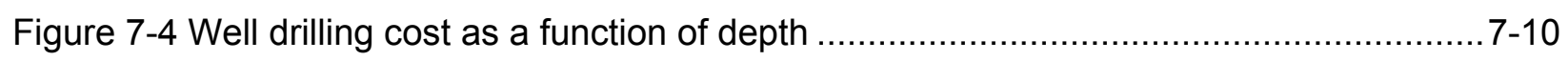

Figure 7-5 Sensitivity analysis for depleted gas reservoir .............................................. $7-22$

Figure 7-6 Sensitivity analysis for depleted oil reservoir .......................................... $7-24$

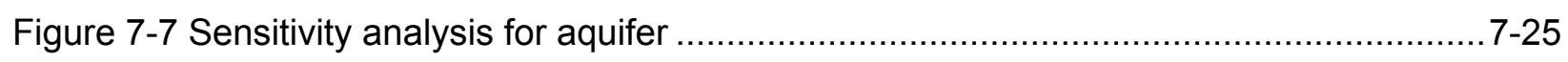

Figure $7-8$ Comparison of $\mathrm{CO}_{2}$ injectivity values.................................................... $7-28$

Figure $7-9$ Comparison of onshore well drilling cost values......................................... $7-28$

Figure 7-10 Comparison of offshore well drilling cost values........................................... $7-29$

Figure 8-1 Cumulative distribution of population and power plant $\mathrm{CO}_{2}$ emissions .................. 8-2

Figure 8-2 Ocean pipeline cost model overview diagram ............................................. 8-3

Figure 8-3 Diameter for the base case as a function of $\mathrm{CO}_{2}$ mass flow rate ........................8-4

Figure 8-4 Comparison of pipe diameter values ......................................................... 8 811

Figure 8-5 Comparison of subsea pipeline capital cost values ...................................... 8-12

Figure 9-1 Ocean tanker cost model overview diagram .............................................. 9-3

Figure 9-2 Sensitivity analysis for ocean tanker ..................................................... $9-10$

Figure 10-1 Quantities of carbon sequestered (medium productivity sites) .........................10-7

Figure 10-2 Carbon sequestered in Spanish Cedar plantations at different site

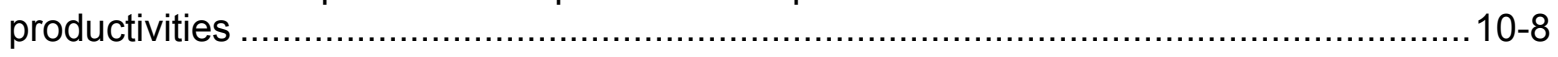

Figure 10-3 Carbon sequestered in vegetation, soil etc. and timber products (Spanish

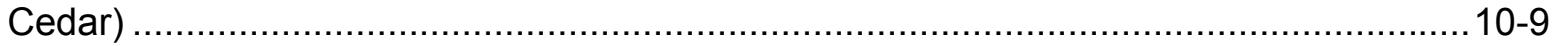

Figure 17-1 Emissions from land use change in Chiapas, Mexico, over 20 years from

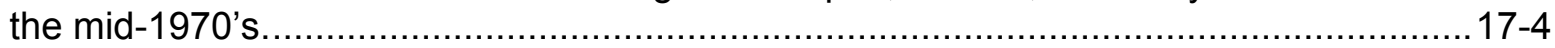

Figure 17-2 Map of two key causal factors in land-use change: Distance to roads and

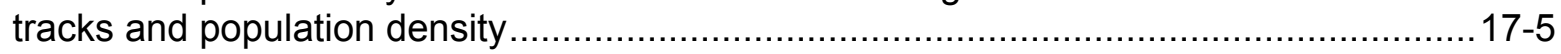

Figure 17-3 Regional baseline for 2000 to 2020, showing expected emissions tc/ha ............ 17-6

Figure 18-1 Mechanisms by which conservation-tillage systems affect the amount of carbon that remains stored in soil organic matter

Figure 18-2 Increases in soil organic carbon (SOC) via switching from intensive-till to notill.

Figure 18-3 Trends in soil organic carbon (SOC) in the central corn belt ............................18-5

Figure 18-4 Counties with more than 20,000 hectares of cropland ..................................18-6

Figure 18-5 Simulated changes in soil organic carbon (SOC) as affected by tillage and cropping systems in eastern Colorado ............................................................18-7

Figure 18-6 Simulated changes in soil organic carbon (SOC) as affected by tillage and cropping systems in central Indiana....

Figure 19-1 State SOC response curves for switching from intensive-till to no-till (NT) or moderate-till (MT) in lowa and Indiana.

Figure 20-1 State SOC response curves for switching from intensive-till to no-till (NT) or moderate-till (MT) in lowa and Indiana

Figure 23-1 $\mathrm{CO}_{2}$ transport and storage cost comparison on a levelized annual $\$ / \mathrm{t}$ of $\mathrm{CO}_{2}$ equivalent life cycle greenhouse gas avoided basis 
Figure 23-2 $\mathrm{CO}_{2}$ capture, transport and storage cost comparison on a NPV \$/t of $\mathrm{CO}_{2}$ equivalent life cycle greenhouse gas avoided basis

Figure 23-3 Forestry cost comparison on a NPV $\$ / t$ of $\mathrm{CO}_{2}$ equivalent life cycle greenhouse gas avoided basis

Figure 23-4 Cropland cases NPV \$/t CO $\mathrm{CO}_{2}$ equivalent life cycle greenhouse gas avoided basis.

Figure 23-5 Comparison of direct and indirect sequestration cases.

Figure 23-6 Comparison of direct and indirect sequestration cases including high and low cases.

Figure F-1 Quadratic regression and transformation procedure for SOC response to reducing tillage

Figure F-2 Linear relationship between $\mathrm{E}$ and $\triangle \mathrm{SOC}$ for the Indiana data from Table F-1

Figure F-3 Linear relationship between $\mathrm{E}$ and $\Delta \mathrm{SOCs}$ for the lowa data from Table F-2 F-3 


\section{LIST OF TABLES}

Table 1-1 Concepts Status $1-2$

Table 1-2 Rationale for Including Aquifers in the Economic Study...................................... 1-4

Table 1-3 Rationale for Including EOR in the Economic Study .......................................... 1-6

Table 1-4 Rationale for Including Depleted Oil and Gas Reservoirs in the Economic Study

Table 1-5 Rationale for Including Coal Bed Storage in the Economic Study ......................... 1-10

Table 1-6 Rationale for Including Ocean Storage in the Economic Study ............................ 1-12

Table 1-7 Rationale for Including Forest Sinks in the Economic Study ................................ 1-14

Table 1-8 Rationale for Including Cropland Sinks in the Economic Study ............................ 1-16

Table 2-1 Financial parameters for calculating the levelized carrying charge factor ................. 2-2

Table 2-2 Calculation of $\mathrm{CO}_{2}$ capture costs on $\mathrm{CO}_{2}$ captured and $\mathrm{CO}_{2}$ avoided bases ${ }^{*}$........... 2-5

Table 2-3 Summary of Enhanced Oil Recovery on a LC GHG avoided basis ........................ 2-8

Table 2-4 Greenhouse gas emissions from $\mathrm{CO}_{2}$ storage operations ................................ 2-11

Table 3-1 Summary of parameters for IGCC power plant with $\mathrm{CO}_{2}$ removal.......................... 3-3

Table 3-2 Typical composition of recovered coal mine gas .................................................. 3-5

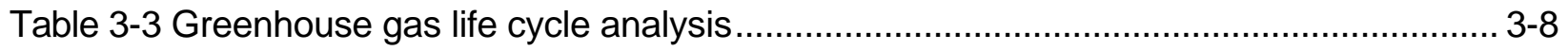

Table 4-1 $\mathrm{CO}_{2}$ pipelines in the United States ................................................................. 4-2

Table 4-2 Design bases for pipeline transport .............................................................. 4-10

Table 4-3 Capital and O\&M cost inputs for the pipeline transport base and sensitivity

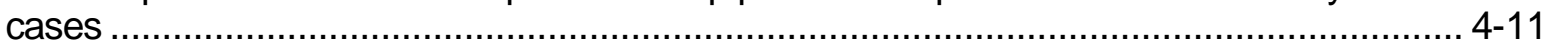

Table 4-4 Overland pipelines' characteristics ............................................................. 4-12

Table 5-1 Six largest $\mathrm{CO}_{2}$-EOR projects ${ }^{1}$...................................................................... 5-2

Table 5-2 Estimated $\mathrm{CO}_{2}$ effectiveness for selected $\mathrm{CO}_{2}$-EOR projects ${ }^{5,6} \ldots \ldots \ldots \ldots \ldots \ldots \ldots \ldots \ldots . . . .5-9$

Table 5-3 Average enhanced oil production per day per well for six largest $\mathrm{CO}_{2}$-EOR

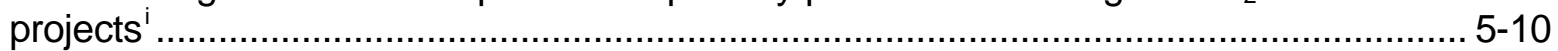

Table 5-4 Ratio of producers to injectors for selected $\mathrm{CO}_{2}$-EOR projects ${ }^{5,6} \ldots \ldots \ldots \ldots \ldots \ldots \ldots \ldots . . . .5-11$

Table 5-5 Capital and O\&M cost estimation factors........................................................ 5-13

Table 5-6 Design basis for the EOR base case..................................................... 5-15

Table 5-7 Recycle compressor's parameters and cost.................................................. 5-16

Table 5-8 Lease equipment .................................................................................... 5-17

Table 5-9 Capital and O\&M cost inputs for the EOR base case ..................................... 5-18

Table 5-10 Process input sheet for base case EOR .......................................................... 5-19 
Table 5-11 Summary sheet for base case EOR …….................................................... 5-20

Table 5-12 EOR base, high cost and low cost cases ..................................................... 5-21

Table 5-13 Results for EOR base, high cost and low cost cases ........................................ 5-22

Table 5-14 EOR cost estimation functions ${ }^{15}$................................................................... 5-22

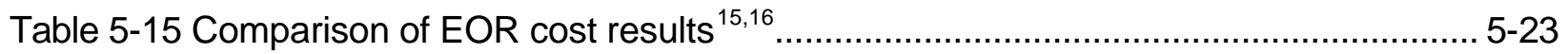

Table 6-1 Capital and O\&M cost estimation factors...................................................... 6-10

Table 6-2 Design basis for ECBMR base case.......................................................... 6-12

Table 6-3 ECBMR gathering compressor design basis ................................................... 6-12

Table 6-4 ECBMR sales gas compressor design basis.................................................. 6-13

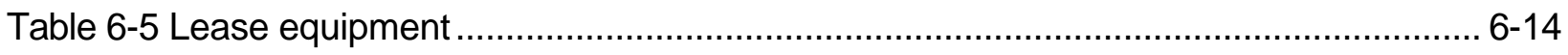

Table 6-6 Capital and O\&M cost inputs for the ECBMR base case..................................... 6-15

Table 6-7 Process input sheet for base case ECBMR ………........................................... 6-17

Table 6-8 Summary sheet for base case ECBMR ……................................................. 6-18

Table 6-9 ECBMR base, high cost and low cost cases ..................................................... 6-20

Table 6-10 Results for ECBMR base, high cost and low cost cases .................................... 6-20

Table 6-11 $\mathrm{CO}_{2}$-ECBMR cost estimates from Wong, et al. ${ }^{5}$............................................ 6-21

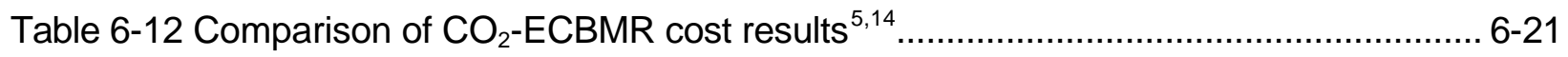

Table 7-1 Capital and O\&M cost estimation factors/functions ........................................... 7-9

Table 7-2 Natural gas and oil reservoir property data.................................................... 7-10

Table 7-3 Design bases for natural gas reservoir storage option ........................................... 7-11

Table 7-4 Design bases for oil reservoir storage option .................................................... 7-11

Table 7-5 Aquifer property data .............................................................................

Table 7-6 Incomplete sets of aquifer property data ……............................................. 7-13

Table 7-7 Design bases for aquifer storage option ........................................................ 7-14

Table 7-8 Capital and O\&M cost inputs for gas and oil reservoir, and aquifer base cases ..... 7-15

Table 7-9 Process input sheet for base case depleted gas reservoir................................... 7-16

Table 7-10 Summary sheet for base case depleted gas reservoir ..................................... 7-17

Table 7-11 Process input sheet for depleted oil reservoir base case.................................. 7-18

Table 7-12 Summary sheet for depleted oil reservoir base case ........................................ 7-19

Table 7-13 Process input sheet for aquifer storage base ............................................... 7-20

Table 7-14 Summary sheet for the aquifer storage base case.......................................... 7-21

Table 7-15 Depleted gas reservoir base, high cost and low cost cases .............................. 7-22

Table 7-16 Results for depleted gas reservoir base, high cost and low cost cases................ 7-23

Table 7-17 Depleted oil reservoir base, high cost and low cost cases................................ 7-24

Table 7-18 Results for depleted oil reservoir base, high cost and low cost cases .................. 7-25

Table 7-19 Aquifer base, high cost and low cost cases............................................... 7-26

Table 7-20 Results for aquifer base, high cost and low cost cases.................................... 7-26

Table 7-21 Injection schemes' characteristics .................................................................. 7-27

Table 8-1 Capital and O\&M cost estimation factors.......................................................... 8-5 
Table 8-2 Design basis for ocean storage via pipeline ..................................................... 8-5

Table 8-3 Capital and O\&M cost inputs for the ocean pipeline base case................................ 8-6

Table 8-4 Process input sheet for the ocean pipeline base case............................................ 8-7

Table 8-5 Summary sheet for the ocean pipeline base case.............................................. 8-8

Table 8-6 Ocean pipeline base, high cost and low cost cases ............................................... 8-9

Table 8-7 Results for ocean pipeline base, high cost and low cost cases ............................. 8-10

Table 8-8 Subsea pipelines' characteristics............................................................... 8-10

Table 9-1 Capital and O\&M cost estimation factors.............................................................. 9-5

Table 9-2 Design basis for ocean storage via tanker .......................................................... 9-6

Table 9-3 Capital and O\&M cost inputs for the ocean tanker base case ................................ 9-7

Table 9-4 Process input sheet for the ocean tanker base case ......................................... 9-8

Table 9-5 Summary sheet for the ocean tanker base case.................................................. 9-9

Table 9-6 Ocean tanker base, high cost and low cost cases ............................................. 9-11

Table 9-7 Results for ocean tanker base, high cost and low cost cases................................ 9-11

Table 10-1 Summary of forestry sequestration cases ..................................................... 10-6

Table 10-2 Global $\mathrm{N}_{2} \mathrm{O}$ sources ............................................................................... 10-10

Table 10-3 Forest and baseline $\mathrm{N}_{2} \mathrm{O}$ And $\mathrm{CH}_{4}$ emissions........................................... 10-11

Table 11-1 Productivity classes for Loblolly Pine in the southern United States .....................11-2

Table 11-2 Expected carbon storage from Loblolly Pine plantations over 100 years .............. 11-3

Table 11-3 Forestry input variables for Loblolly Pine ....................................................... 11-5

Table 11-4 Forestry summary of results for Loblolly Pine medium productivity case .............. 11-6

Table 11-5 Forestry summary of results for Loblolly Pine high productivity case ................... 11-7

Table 12-1 Productivity classes for Douglas Fir in pacific northwest USA............................ 12-2

Table 12-2 Expected carbon storage from Douglas Fir plantations over 100 years ............... 12-3

Table 12-3 Forestry input variables for Douglas Fir ........................................................ 12-5

Table 12-4 Forestry summary of results for Douglas Fir medium productivity case................ 12-6

Table 12-5 Forestry summary of results for Douglas Fir high productivity case .................... 12-7

Table 13-1 Productivity classes for Spanish Cedar in central America.................................. 13-3

Table 13-2 Components of baseline carbon stock (tC)...................................................... 13-4

Table 13-3 Expected carbon storage from Spanish Cedar over 100 years ............................ 13-4

Table 13-4 Forestry input variables for Spanish Cedar .................................................... 13-6

Table 13-5 Forestry summary of results for Spanish Cedar medium productivity case.......... 13-7

Table 13-6 Forestry summary of results for Spanish Cedar low productivity case ................. 13-8

Table 13-7 Forestry summary of results for Spanish Cedar high productivity case................ 13-9

Table 14-1 Productivity classes for Pinus Oocarpa in Chiapas, Mexico .................................. 14-3

Table 14-2 Components of baseline carbon stock (tC)..................................................... 14-4

Table 14-3 Expected carbon storage from Pine-Oak forest enriched with Pinus Oocarpa over 100 years ................................................................................................... 14-4

Table 14-4 Forestry input variables for Pine-Oak .......................................................... 14-6 
Table 14-5 Forestry summary of results for Pine-Oak medium productivity case.

Table 14-6 Forestry summary of results for Pine-Oak low productivity case... 14-8

Table 14-7 Forestry summary of results for Pine-Oak high productivity case. 14-9

Table 15-1 Expected carbon storage from restoration of Miombo woodland over 100 years.

Table 15-2 Forestry input variables for Miombo. 15-5

Table 15-3 Forestry summary of results for Miombo medium productivity case. 15-6

Table 16-1 Productivity factors for mixed orchards of Tamarind and Mango. $16-2$

Table 16-2 Expected carbon storage from Mango-Tamarind agro-forestry over $100 \mathrm{y}$ 16-4

Table 16-3 Forestry input variables for Mango-Tamarind. 16-6

Table 16-4 Forestry summary of results for Mango-Tamarind medium productivity case...... 16-7

Table 17-1 Percentage of above-ground carbon lost from 1976 to 1996.

Table 17-2 Predicted annual rate of deforestation (\%).

Table 17-3 Forestry input values for avoidance of deforestation.

Table 17-4 Forestry summary of results for Avoidance of Deforestation medium productivity case

Table 18-1 Adoption of conservation-tillage practices in the eastern corn belt and midsouth U.S.

Table 18-2 Adoption of conservation-tillage practices in the western corn belt $18-10$

Table 18-3 Adoption of conservation-tillage practices in major small grain states in year 2000 .

Table 18-4 Adoption of conservation-p in major cotton states in year 2000

Table 19-1 Effects of switching from intensive-till to no- or moderate-till on SOC, GHG Emissions, and costs of life-cycle (LC) avoided GHG emissions--Indiana and lowa state averages for Corn/Soybean rotation.

Table 19-2 Example process and economic input variables for switching from intensivetill to no-till for corn/soybean rotation in Indiana...

Table 19-3 Reductions in fuel use and associated carbon emissions by switching from intensive-till to no-till in a corn/soybean rotation

Table 19-4 Reductions in fuel use and associated carbon emissions by switching from intensive-till to moderate-till in a corn/soybean rotation.

Table 19-5 Mean N rates for corn in the ten major U.S. corn producing states-- $1995^{13}$

Table 19-6 Example spreadsheet output for estimating herbicide carbon equivalent emissions for corn/soybean rotation.

Table 19-7 Example spreadsheet output for carbon equivalent emissions from changes in $\mathrm{N}_{2} \mathrm{O}$ emissions for corn/soybean rotation when changing from intensive-till to notill

Table 19-8 Example spreadsheet output summarizing changes in GHG emissions for corn/soybean rotation when changing from intensive-till to no-till ....

Table 19-9 Example spreadsheet output summarizing costs and life-cycle (LC) avoided $\mathrm{GHG}$ on a carbon equivalent (CE) basis for corn/soybean rotation when changing from intensive-till to no-till . 
Table 19-10 Corn/soybean rotation sensitivity summary.

Table 19-11 Effects of switching from intensive-till using $150 \mathrm{~kg} \mathrm{~N} / \mathrm{ha}$ to no- till using 175 or $200 \mathrm{~kg} \mathrm{~N} / \mathrm{ha}$ on GHG emissions and costs of life-cycle (LC) avoided GHG emissions - Indiana Corn/Soybean rotations

Table 19-12 Corn/soybean carbon emissions associated with important combinations of $\mathrm{N}$ source and placement.

Table 19-13 Corn/soybean overall increase in $\mathrm{N}_{2} \mathrm{O}$ emissions due to both switching from intensive-till to no-till and increasing $\mathrm{N}$ fertilizer use

Table 19-14 Corn/soybean example spreadsheet output summarizing changes in GHG emissions due to switching from intensive-till to no-till and increasing $N$ fertilizer use .. 19-20

Table 19-15 Corn/soybean example spreadsheet output summarizing costs and lifecycle (LC) avoided GHG on a carbon equivalent (CE) basis when changing from intensive-till to no-till and increasing $\mathrm{N}$ fertilizer use

Table 19-16 Corn/soybean example spreadsheet sensitivity summary output when changing from intensive-till to no-till and increasing $\mathrm{N}$ fertilizer use

Table 19-17 Effects of increases in $\mathrm{N}$ rate and $\mathrm{N}_{2} \mathrm{O}$ emissions on amounts and costs of avoided GHG via switching from intensive-till to no-till in a Corn/Soybean rotation

Table 20-1 Effects of switching from intensive-till to no- or moderate-till on SOC, GHG emissions, and costs of life-cycle (LC) avoided GHG emissions--Indiana and lowa state averages for Continuous Corn

Table 20-2 Example process and economic input variables for switching from intensivetill to no-till for continuous corn in Indiana.....

Table 20-3 Reductions in fuel use and associated carbon emissions by switching from intensive-till to no-till in continuous corn ...................................................................... 20-6

Table 20-4 Reductions in fuel use and associated carbon emissions by switching from intensive-till to moderate-till in continuous corn

Table 20-5 Example spreadsheet output for estimating herbicide carbon equivalent emissions for continuous corn

Table 20-6 Example spreadsheet output for carbon equivalent emissions from changes in $\mathrm{N}_{2} \mathrm{O}$ emissions for continuous corn when changing from intensive-till to no-till

Table 20-7 Example spreadsheet output summarizing changes in GHG emissions for continuous corn when changing from intensive-till to no-till.

Table 20-8 Costs and life-cycle (LC) avoided GHG on a carbon equivalent (CE) basis for continuous corn when changing from intensive-till to no-till

Table 20-9 Continuous corn sensitivity summary. 20-13

Table 20-10 Effects of switching from intensive-till Using $150 \mathrm{~kg} \mathrm{~N} / \mathrm{ha}$ to no- till Using 175 or $200 \mathrm{~kg} \mathrm{~N} / \mathrm{ha}$ on GHG emissions and costs of life-cycle (LC) avoided GHG emissions - Indiana Continuous Corn.

Table 20-11 Continuous corn carbon emissions associated with important combinations of $\mathrm{N}$ source and placement.

Table 20-12 Continuous corn overall increase in $\mathrm{N}_{2} \mathrm{O}$ emissions due to both switching from intensive-till to no-till and increasing $\mathrm{N}$ fertilizer use...... 
Table 20-13 Continuous sorn example spreadsheet output summarizing changes in GHG emissions due to switching from intensive-till to no-till and increasing N fertilizer use.

Table 20-14 Continuous corn costs and life-cycle (LC) avoided GHG on a carbon equivalent (CE) basis when changing from intensive-till to no-till and increasing $\mathrm{N}$ fertilizer use.

Table 20-15 Continuous corn example spreadsheet sensitivity summary output when changing from intensive-till to no-till and increasing $\mathrm{N}$ fertilizer use.....

Table 20-16 Effects of increases in $\mathrm{N}$ rate and $\mathrm{N}_{2} \mathrm{O}$ emissions on amounts and costs of avoided GHG via switching from intensive-till to no-Continuous Corn

Table 21-1 Effects of switching from intensive-till to no-till on SOC, GHG emissions, and costs of life-cycle (LC) avoided GHG emissions-Wheat/Fallow in the western great plains

Table 21-2 Example process and economic input variables for switching from intensivetill to no-till for wheat/fallow rotation

Table 21-3 Reductions in fuel use and associated carbon emissions by switching from intensive-till to no-till in a wheat/fallow rotation

Table 21-4 Example spreadsheet output for estimating herbicide carbon equivalent emissions for wheat/fallow rotation.

Table 21-5 Example spreadsheet output for carbon equivalent emissions from changes in $\mathrm{N}_{2} \mathrm{O}$ emissions for wheat/fallow rotation when changing from intensive-till to no-till .... 21-6

Table 21-6 Example spreadsheet output summarizing changes in GHG emissions for wheat/fallow rotation when changing from intensive-till to no-till

Table 21-7 Example spreadsheet output summarizing costs and life-cycle (LC) avoided GHG on a carbon equivalent (CE) basis for wheat/fallow rotation when changing from intensive-till to no-till.

Table 21-8 Wheat/fallow rotation sensitivity summary.

Table 21-9 Wheat/fallow example spreadsheet output summarizing changes in GHG emissions due to switching from intensive-till to no-till with no change in $\mathrm{N}_{2} \mathrm{O}$ emissions

Table 21-10 Wheat/fallow costs and life-cycle (LC) avoided GHG on a carbon equivalent (CE) basis when changing from intensive-till to no-till with no change in $\mathrm{N}_{2} \mathrm{O}$ emissions

Table 21-11 Wheat/fallow example spreadsheet sensitivity summary output when changing from intensive-till to no-till with no change in $\mathrm{N}_{2} \mathrm{O}$ emissions

Table 22-1 Effects of switching from intensive-till to no-till on SOC, GHG emissions, and costs of life-cycle (LC) avoided GHG emissions-Cotton in the southeastern United States....

Table 22-2 Example process and economic input variables for switching from intensivetill to no-till for cotton

Table 22-3 Reductions in fuel use and associated carbon emissions by switching from intensive-till to no-till for cotton

Table 22-4 Example spreadsheet output for estimating herbicide carbon equivalent emissions for cotton 
Table 22-5 Example spreadsheet output for carbon equivalent emissions from changes in $\mathrm{N}_{2} \mathrm{O}$ emissions for cotton when changing from intensive-till to no-till .

Table 22-6 Example spreadsheet output summarizing changes in GHG emissions for cotton when changing from intensive-till to no-till...

Table 22-7 Example spreadsheet output summarizing costs and life-cycle (LC) avoided GHG on a carbon equivalent (CE) basis for cotton when changing from intensive-till to no-till.

Table 22-8 Cotton rotation sensitivity summary.....

Table 22-9 Cotton example spreadsheet output summarizing changes in GHG emissions due to switching from intensive-till to no-till with no change in $\mathrm{N}_{2} \mathrm{O}$ emissions

Table 22-10 Cotton costs and life-cycle (LC) avoided GHG on a carbon equivalent (CE) basis when changing from intensive-till to no-till with no change in $\mathrm{N}_{2} \mathrm{O}$ emissions ...... 22-13

Table 22-11 Cotton example spreadsheet sensitivity summary output when changing from intensive-till to no-till with no change in $\mathrm{N}_{2} \mathrm{O}$ emissions....

Table 23-1 $\mathrm{CO}_{2}$ transport and storage cost comparison on a levelized annual $\mathrm{CO}_{2}$ equivalent life cycle greenhouse gas avoided basis

Table 23-2 $\mathrm{CO}_{2}$ capture, transport and storage cost comparison on a NPV equivalent life cycle greenhouse gas avoided basis

Table 23-3 Forestry cases NPV cost comparison (LC equivalent greenhouse gas avoided, including above and below ground carbon and timber products \& revenues).

Table 23-4 Cropland cases NPV equivalent life cycle greenhouse gas avoided basis 23-6

Table 23-5 Base-case forest and cropland areas required to offset LC GHG emissions avoided by base-case $\mathrm{CO}_{2}$ capture and storage options.

Table A-1 EOR base case detailed analysis of LC GHG emissions avoided.

Table A-2 ECBMR base case detailed analysis of LC GHG emissions avoided ..................... A-3

Table A-3 Aquifer storage base case detailed analysis of LC GHG emissions avoided.......... A-4

Table A-4 Depleted oil reservoir base case detailed analysis of LC GHG emissions avoided.

Table A-5 Depleted gas reservoir base case detailed analysis of LC GHG emissions avoided.

Table A-6 Ocean pipeline storage base case detailed analysis of LC GHG emissions avoided.

Table A-7 Ocean tanker storage base case detailed analysis of LC GHG emissions avoided.

Table C-1 Forestry sequestration projects initiated until mid-1998 ......................................2

Table D-1 Published costs of forestry carbon sequestration ...............................................

Table E-1 Yield mean, standard deviation, and coefficient of variation and variable costs at selected sites.

Table E-2 Incentive levels under base yields and prices .................................................... E-6

Table E-3 Base yields and revenues by experimental site and rotation.................................. E-9

Table E-4 Base prices........................................................................................................ E-10

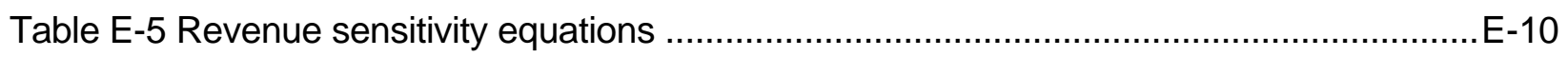


Table F-1 Increases in SOC due to switching from intensive-till to no-till or moderate till in Indiana.

Table F-2 Increases in SOC due to switching from intensive-till to no-till or moderate-till in lowa 


\section{1 \\ INTRODUCTION}

In order to plan for potential $\mathrm{CO}_{2}$ mitigation mandates, energy companies need better cost information on $\mathrm{CO}_{2}$ mitigation options, especially storage and sink enhancement options that involve non-energy company operations. One of the major difficulties in evaluating $\mathrm{CO}_{2}$ storage and sink enhancement options is obtaining consistent, transparent, accurate, and comparable economics. This project compares the economics of major technologies and practices under development for $\mathrm{CO}_{2}$ storage and sink enhancement, including options for storing captured $\mathrm{CO}_{2}$, such as active oil reservoirs, depleted oil and gas reservoirs, deep aquifers, coal beds, and oceans, as well as the enhancement of biological sinks such as forests and croplands.

The primary funding source for the project was the Department of Energy (DOE), with the Tennessee Valley Authority (TVA) and the Electric Power Research Institute (EPRI) also providing additional funds. An international group of experts in this area was assembled to develop the technology/practice designs, the economic premises, and cost evaluations. TVA was the prime for this project, responsible for overall completion of the effort. EPRI organized efforts to select specific sequestration processes to be evaluated for captured $\mathrm{CO}_{2}$ and coordinated the efforts of consultants from the MIT, SFA Pacific, and the IEA Greenhouse Gas Programme and the Edinburgh Centre for Carbon Management (ECCM) to develop and refine the framework for the economic evaluations. MIT and Parsons Infrastructure and Technology developed process designs for captured $\mathrm{CO}_{2}$ storage processes and helped TVA develop economic models for comparing technologies and practices. The University of Tennessee Agricultural Policy Research Center, in collaboration with TVA, evaluated the economics of enhancing $\mathrm{CO}_{2}$ sequestration in croplands. The IEA Greenhouse Gas Programme developed the concept design for evaluating the forest sequestration options.

\subsection{Economic Framework}

Most of the cost comparisons to date have concentrated on $\mathrm{CO}_{2}$ capture, with the assumption that $\mathrm{CO}_{2}$ sequestration is a small part of these costs. In addition, these comparisons have used information supplied from studies of specific technologies, and the variability in costs due to variability in assumptions and lack of visibility into assumptions lessens the usefulness of the results. In the case of sequestration, virtually no comparative economic evaluations of processes have been done.

Methodologies for developing economic comparisons are generally available. They range from very detailed \pm 10 percent for site-specific evaluations, where final decisions are made between options, to very general economics with little insight into the economic premises that were used to develop the economics. The latter is usually a simplification of more detailed economics for 
very high-level comparisons. In some cases, probability analyses are included to help evaluate risks. This usually adds significantly to the complexity of the model and the time to develop results. The model may use simplified economics to allow probability analysis without making the model too complex to run in a reasonable time.

The economic evaluations developed for this project are between the ranges described above and are typical of prior EPRI economics where a \pm 25 to 30 percent estimate is made, with the ability to modify values to be relatively site-specific. Material balances are made, equipment lists and pricing are developed, installation costs are estimated, and contingencies are estimated for project and process uncertainties. These types of evaluations are intended to be transparent, consistent, and comparable. They are consistent with the EPRI economics of advanced power generation with $\mathrm{CO}_{2}$ capture being developed for DOE. Probability analysis was not included to keep the results consistent with other EPRI studies.

The economic framework also included life-cycle analysis for the various sequestration options. This means that all greenhouse gas emissions from cradle to grave were estimated and considered in the analysis. The economic analysis used spreadsheet models that are flexible enough to allow a wide variation in the range of parameters to be evaluated and the sensitivity cases to be run. The $\mathrm{CO}_{2}$ storage options were sized to accommodate the $\mathrm{CO}_{2}$ from our basecase capture plant (see the design basis in Chapter 3). In addition, the amount of forest and cropland required to sequester the same amount of $\mathrm{CO}_{2}$ over a 100-year planning horizon was calculated.

\subsection{Concepts Evaluated}

The potential processes and concepts to be evaluated were initially prioritized, and the concepts were placed into three categories - (1) included, (2) may be included but more information is needed before a final decision can be made, and (3) not included due to the lack of good information at this time. Because one of the most unique aspects of this work is the comparison between storage of captured $\mathrm{CO}_{2}$ and sink enhancement, it was felt that at least one of each type should be included. The list of concepts and their final status is presented in Table 1-1.

\section{Table 1-1 \\ Concepts Status}

\begin{tabular}{|l|l|}
\hline \multicolumn{1}{|c|}{ Included } & \multicolumn{1}{c|}{ Not Included } \\
\hline Oil Reservoirs & Mineralization \\
\hline $\begin{array}{l}\text { Depleted Oil and Gas } \\
\text { Reservoirs }\end{array}$ & \\
\hline Ocean Storage & \\
\hline Forests & \\
\hline Croplands & \\
\hline Coal Beds & \\
\hline
\end{tabular}


In the case of ocean fertilization and mineralization, it is felt that at this time, there is not enough reasonable information to develop a meaningful concept description and that these processes should not be included until more R\&D is performed.

\subsubsection{Aquifer Storage}

Shown below is the preliminary block diagram for the Aquifer Storage concept. This concept is simple in application. The complexity comes from deciding on the nature of the distribution and number of wells.

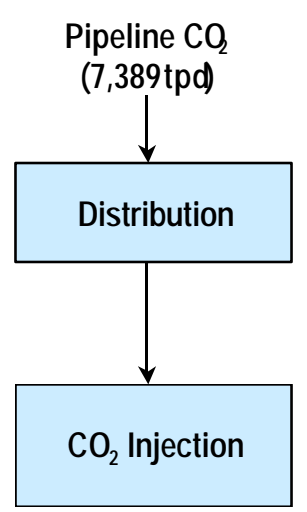

\section{Figure 1-1}

Preliminary Block Diagram for Aquifer Storage Concept

The rationale for including the aquifer concept in the economic evaluation is summarized in Table 1-2 below. This concept has the largest storage capacity of all the concepts, except the ocean, and is widespread throughout the United States. In addition, it is at commercial scale, although not in the United States. Sufficient data is believed to be available. 
Table 1-2

Rationale for Including Aquifers in the Economic Study

\begin{tabular}{|c|c|c|c|c|c|c|}
\hline Merits & $\begin{array}{l}\text { Potential } \\
\text { Challenges }\end{array}$ & Applicability & $\begin{array}{l}\text { Technical } \\
\text { Maturity }\end{array}$ & Data Availability & $\begin{array}{c}\text { Industrial } \\
\text { Acceptance }\end{array}$ & $\begin{array}{c}\text { Compatibility } \\
\text { With Power } \\
\text { Systems }\end{array}$ \\
\hline $\begin{array}{l}\text { - Best potential } \\
\mathrm{CO}_{2} \text { storage } \\
\text { capacity of all } \\
\text { geological } \\
\text { storage options } \\
\text { - Retention time } \\
\text { predicted to be } \\
\text { thousands of } \\
\text { years } \\
\text { - Offshore } \\
\text { aquifers } \\
\text { eliminate most } \\
\text { safety concerns }\end{array}$ & $\begin{array}{l}\text { - Understanding } \\
\text { risk of } \\
\text { catastrophic or } \\
\text { slow release of } \\
\mathrm{CO}_{2}\end{array}$ & $\begin{array}{l}\text { - Ubiquitous and } \\
\text { large, so } \\
\text { widespread } \\
\text { availability }\end{array}$ & $\begin{array}{l}\text { - Some } \\
\text { experience of } \\
\text { aquifer storage } \\
\text { for chemicals, } \\
\text { etc. } \\
\text { - Little actual } \\
\text { experience for } \\
\text { this specific } \\
\text { application }\end{array}$ & $\begin{array}{l}\text { - Many studies on } \\
\text { this storage } \\
\text { option } \\
\text { - Specific } \\
\text { reservoir } \\
\text { characterization } \\
\text { is lacking }\end{array}$ & $\begin{array}{l}\text { - Commercial } \\
\text { application- } \\
\mathrm{CO}_{2} \text { has been } \\
\text { injected into the } \\
\text { Utsira formation } \\
\text { under the North } \\
\text { Sea since } \\
\text { August 1996, as } \\
\text { part of the } \\
\text { Sleipner Vest } \\
\text { project } \\
\text { - Accepted for } \\
\text { materials other } \\
\text { than } \mathrm{CO}_{2}\end{array}$ & - Excellent \\
\hline
\end{tabular}




\subsubsection{Oil Reservoir Storage with Enhanced Oil Recovery (EOR)}

Shown below is the preliminary block diagram for the EOR storage concept.

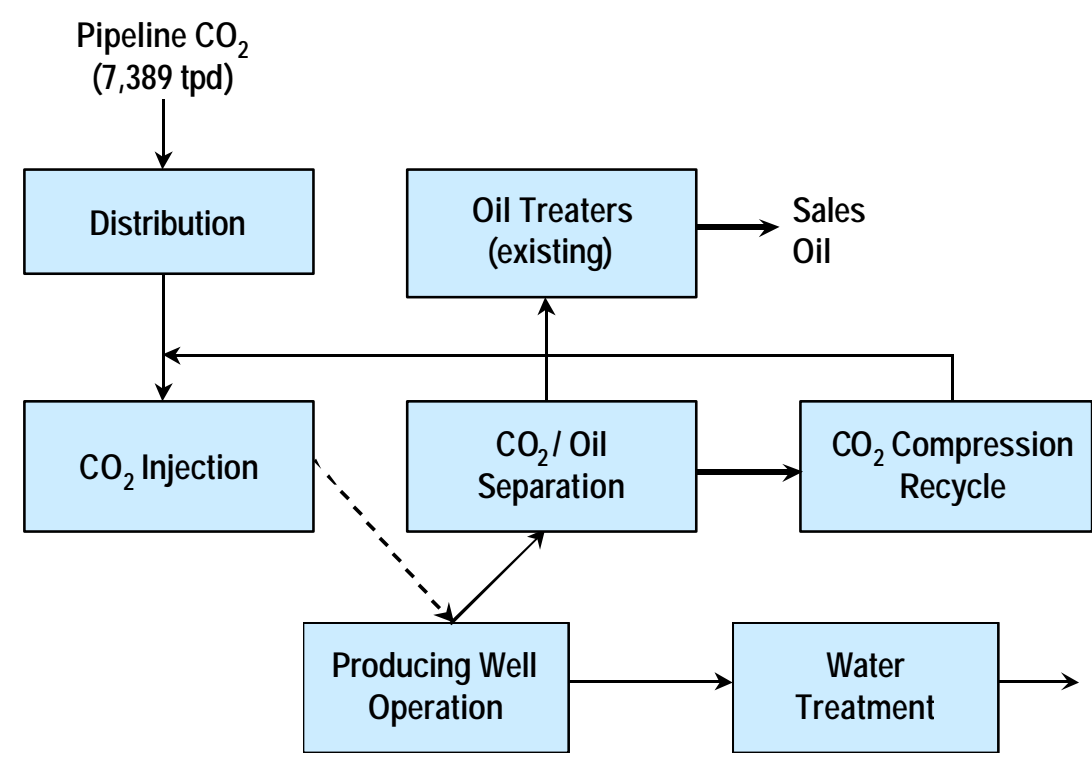

\section{Figure 1-2}

Preliminary Block Diagram for EOR Concept

The rationale for including the EOR concept in the economic evaluation is summarized in Table 1-3 below. While this concept has a more limited storage capacity and is not as widespread, it is likely to be an early application due to the potential for low-cost storage. It is also commercial in the United States. However, it has not been optimized for maximum $\mathrm{CO}_{2}$ storage, and its compatibility with power systems is of some concern. Sufficient data is believed to be available. 
Table 1-3

Rationale for Including EOR in the Economic Study

\begin{tabular}{|c|c|c|c|c|c|c|}
\hline Merits & $\begin{array}{l}\text { Potential } \\
\text { Challenges }\end{array}$ & Applicability & $\begin{array}{l}\text { Technical } \\
\text { Maturity }\end{array}$ & Data Availability & $\begin{array}{l}\text { Industrial } \\
\text { Acceptance }\end{array}$ & $\begin{array}{c}\text { Compatibility } \\
\text { With Power } \\
\text { Systems }\end{array}$ \\
\hline $\begin{array}{l}\text { - Oil by-product } \\
\text { makes option } \\
\text { economically } \\
\text { attractive } \\
\text { - Not considered } \\
\text { to involve any } \\
\text { undue risks to } \\
\text { man or the } \\
\text { natural } \\
\text { environment } \\
\text { - Injection of } \mathrm{CO}_{2} \\
\text { done } \\
\text { commercially } \\
\text { today }\end{array}$ & $\begin{array}{l}\text { - Could often be } \\
\text { cheaper to } \\
\text { obtain } \mathrm{CO}_{2} \text { from } \\
\text { natural sources } \\
\text { - Global storage } \\
\text { capacity may be } \\
\text { limited (e.g., to } \\
65 \mathrm{Gt} \mathrm{C})(2) \\
\text { - For today's } \\
\text { blowdown, } \\
\text { reservoir } \\
\text { operations need } \\
\text { to store } \mathrm{CO}_{2} \\
\text { under pressure }\end{array}$ & $\begin{array}{l}\text { - Limited to areas } \\
\text { where there are } \\
\text { active oil fields }\end{array}$ & $\begin{array}{l}\text { - EOR practiced } \\
\text { on a significant } \\
\text { scale for last } \\
25 \text { years }\end{array}$ & - Excellent & $\begin{array}{l}\text { - EOR is widely } \\
\text { used, in } 1998 \\
\text { more than } 65 \text { oil } \\
\text { fields in the U.S. } \\
\text { were being } \\
\text { injected with } \\
\mathrm{CO}_{2} \\
\text { - Industry actively } \\
\text { investigating the } \\
\text { option of using } \\
\text { captured } \mathrm{CO}_{2}\end{array}$ & $\begin{array}{l}\text { - Oil operations } \\
\text { require } \\
\text { continuous } \\
\text { supply (versus } \\
\text { intermittent) } \\
\text { - Issues with } \\
\text { fluctuation in the } \\
\text { quantity of } \mathrm{CO}_{2} \\
\text { needed over } \\
\text { time }\end{array}$ \\
\hline
\end{tabular}




\subsubsection{Depleted Oil and Gas Reservoir Storage}

Shown in Figure 1-3 is the preliminary block diagram for the Depleted Oil and Gas Reservoir Storage concept.

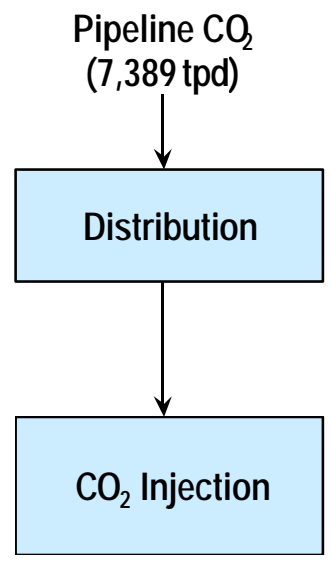

Figure 1-3

Preliminary Block Diagram for Depleted Oil and Gas Reservoir Storage

The rationale for including the Depleted Oil and Gas Reservoir Storage concept in the economic evaluation is summarized in Table 1-4 below. This concept is similar to the EOR, except the storage location is simply used for storage without recovery of oil or gas. Since the storage location has a known integrity, it should be relatively straightforward to use. The gas reservoirs may be the easiest since gas should be depleted and the reservoir can just be repressurized. The data is believed to be sufficient, since it is so similar to EOR. 
Table 1-4

Rationale for Including Depleted Oil and Gas Reservoirs in the Economic Study

\begin{tabular}{|c|c|c|c|c|c|c|}
\hline Merits & $\begin{array}{l}\text { Potential } \\
\text { Challenges }\end{array}$ & Applicability & $\begin{array}{l}\text { Technical } \\
\text { Maturity }\end{array}$ & Data Availability & $\begin{array}{l}\text { Industrial } \\
\text { Acceptance }\end{array}$ & $\begin{array}{c}\text { Compatibility } \\
\text { With Power } \\
\text { Systems }\end{array}$ \\
\hline $\begin{array}{l}\text { - Global storage } \\
\text { capacity as } \\
\text { much as } 140 \mathrm{Gt} \\
\mathrm{C} \text { for disused } \\
\text { gas fields and } \\
40 \mathrm{Gt} \mathrm{C} \text { for } \\
\text { disused oil fields } \\
(3) \\
\text { - Reservoirs have } \\
\text { proven } \\
\text { containment } \\
\text { over geological } \\
\text { timeframes } \\
\text { - Knowledge } \\
\text { about reservoir } \\
\text { already exists }\end{array}$ & $\begin{array}{l}\text { - Today very few } \\
\text { reservoirs } \\
\text { depleted } \\
\text { - Understanding } \\
\text { risk of } \\
\text { catastrophic or } \\
\text { slow release of } \\
\mathrm{CO}_{2}\end{array}$ & $\begin{array}{l}\text { - Limited to areas } \\
\text { where there are } \\
\text { disused oil and } \\
\text { gas reservoirs }\end{array}$ & $\begin{array}{l}\text { - Uses similar } \\
\text { technology to } \\
\text { EOR }\end{array}$ & - Good & $\begin{array}{l}\text { - No commercial } \\
\text { scheme } \\
\text { involving such } \\
\text { fields as yet } \\
\text { exists } \\
\text { - May be liability } \\
\text { issues }\end{array}$ & $\begin{array}{l}\text { - May need } \\
\text { multiple } \\
\text { reservoirs for } \\
\text { large power } \\
\text { plants }\end{array}$ \\
\hline
\end{tabular}




\subsubsection{Coal Bed Storage}

Shown below is a preliminary block diagram for the Coal Bed Storage concept.

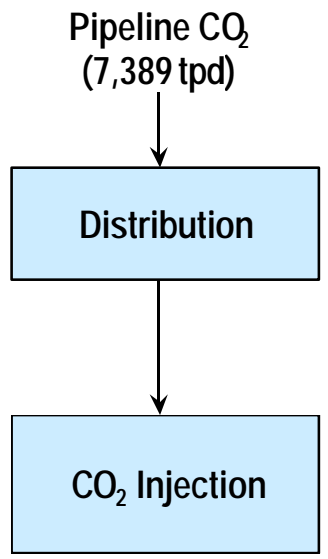

Figure 1-4

Preliminary Block Diagram for Coal Bed Storage Concept

The rationale for including the Coal Bed Storage concept in the economic evaluation is summarized in Table 1-5 below. While the data is limited, $\mathrm{CH}_{4}$ by-product production credits and significant coal deposits make a good argument for inclusion. Data availability is limited. 
Table 1-5

Rationale for Including Coal Bed Storage in the Economic Study

\begin{tabular}{|c|c|c|c|c|c|c|}
\hline Merits & $\begin{array}{l}\text { Potential } \\
\text { Challenges }\end{array}$ & Applicability & $\begin{array}{l}\text { Technical } \\
\text { Maturity }\end{array}$ & Data Availability & $\begin{array}{c}\text { Industrial } \\
\text { Acceptance }\end{array}$ & $\begin{array}{c}\text { Compatibility } \\
\text { With Power } \\
\text { Systems }\end{array}$ \\
\hline $\begin{array}{l}\text { - } \mathrm{CH}_{4} \text { by-product } \\
\text { makes option } \\
\text { economically } \\
\text { attractive } \\
\text { - } \mathrm{CO}_{2} \text { strongly } \\
\text { sequestered by } \\
\text { adsorption on } \\
\text { coal matrix } \\
\text { - Worldwide large } \\
\text { coal deposits } \\
\text { means } \\
\text { potentially large } \\
\mathrm{CO}_{2} \text { storage } \\
\text { capacity }\end{array}$ & $\begin{array}{l}\text { - Enhanced gas } \\
\text { recovery (EGR) } \\
\text { methods for coal } \\
\text { bed } \mathrm{CH}_{4} \\
\text { exploitation } \\
\text { require further } \\
\text { refinement }\end{array}$ & $\begin{array}{l}\text { - Unclear as to } \\
\text { how many types } \\
\text { of coal } \\
\text { formations will } \\
\text { be practical to } \\
\text { use for coal bed } \\
\mathrm{CH}_{4} \text { production }\end{array}$ & $\begin{array}{l}\text { - Injection of } \mathrm{CO}_{2} \\
\text { into coal beds } \\
\text { already used to } \\
\text { enhance } \mathrm{CH}_{4} \\
\text { recovery, } \\
\text { although } \\
\text { process is still at } \\
\text { an early stage of } \\
\text { development }\end{array}$ & - Limited & - Well accepted & $\begin{array}{l}\text { - Could be used } \\
\text { to develop a } \\
\text { zero greenhouse } \\
\text { gas emissions } \\
\text { power plant } \\
\text { fueled by } \\
\text { coalbed } \mathrm{CH}_{4} \text {, } \\
\text { where waste } \\
\mathrm{CO}_{2} \text { produced } \\
\text { by plant is } \\
\text { injected into } \\
\text { coalbed } \mathrm{CH}_{4} \\
\text { reservoirs to } \\
\text { produce more } \\
\mathrm{CH}_{4}\end{array}$ \\
\hline
\end{tabular}




\subsubsection{Ocean Storage}

Shown in Figure 1-5 is a preliminary block diagram for the Ocean Storage concept.
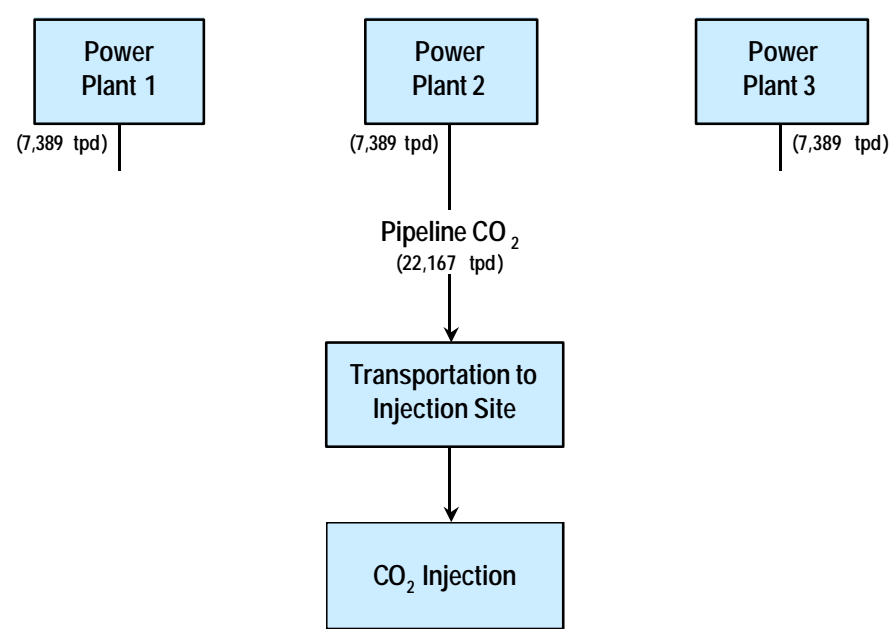

Figure 1-5

Preliminary Block Diagram for Ocean Storage Concept

The rationale for including the Ocean Storage concept in the economic evaluation is summarized in Table 1-6 below. The ocean has the largest storage capacity of any of the concepts, and much work has been done to study ways to store $\mathrm{CO}_{2}$ in the ocean. Sufficient data should be available. 
Table 1-6

Rationale for Including Ocean Storage in the Economic Study

\begin{tabular}{|c|c|c|c|c|c|c|}
\hline Merits & $\begin{array}{l}\text { Potential } \\
\text { Challenges }\end{array}$ & Applicability & $\begin{array}{c}\text { Technical } \\
\text { Maturity }\end{array}$ & Data Availability & $\begin{array}{l}\text { Industrial } \\
\text { Acceptance }\end{array}$ & $\begin{array}{c}\text { Compatibility } \\
\text { With Power } \\
\text { Systems }\end{array}$ \\
\hline $\begin{array}{l}\text { - Largest potential } \\
\text { sink for } \mathrm{CO}_{2} \text {, } \\
\text { storage capacity } \\
\text { estimated to be } \\
\text { upwards of } \\
1000 \mathrm{Gt} \mathrm{C} \mathrm{(4)} \\
\text { - Leaks do not } \\
\text { pose safety } \\
\text { issues }\end{array}$ & $\begin{array}{l}\text { - Could have a } \\
\text { negative impact } \\
\text { on local marine } \\
\text { environment } \\
\text { - Significant legal } \\
\text { and jurisdictional } \\
\text { issues to be } \\
\text { overcome } \\
\text { - Negatively } \\
\text { perceived by } \\
\text { non- } \\
\text { governmental } \\
\text { organizations } \\
\text { (NGOs) } \\
\text { - Retention time, } \\
\text { on the order of } \\
\text { hundreds of } \\
\text { years, less than } \\
\text { for underground } \\
\text { storage }\end{array}$ & $\begin{array}{l}\text { - Best suited to } \\
\text { countries } \\
\text { situated } \\
\text { adjacent to } \\
\text { ocean trenches } \\
\text { and that do not } \\
\text { have access to } \\
\text { suitable } \\
\text { underground } \\
\text { reservoirs, for } \\
\text { example, Japan } \\
\text { - Populated areas } \\
\text { are near } \\
\text { coastlines }\end{array}$ & $\begin{array}{l}\text { - Much } \\
\text { experience from } \\
\text { offshore } \\
\text { exploration/ } \\
\text { production is } \\
\text { applicable }\end{array}$ & - Modest & $\begin{array}{l}\text { - Not well } \\
\text { perceived } \\
\text { compared to } \\
\text { geological } \\
\text { storage options } \\
\text { - Field experiment } \\
\text { to take place off } \\
\text { the coast of } \\
\text { Hawaii in } 2001 \text {, } \\
\text { this should help } \\
\text { to reduce some } \\
\text { of the } \\
\text { uncertainties }\end{array}$ & $\begin{array}{l}\text { - Excellent for } \\
\text { plants situated } \\
\text { on coastline }\end{array}$ \\
\hline
\end{tabular}




\subsubsection{Forest Sink Enhancement}

Shown in Figure 1-6 is a preliminary block diagram for the Forest Sink Enhancement concept.

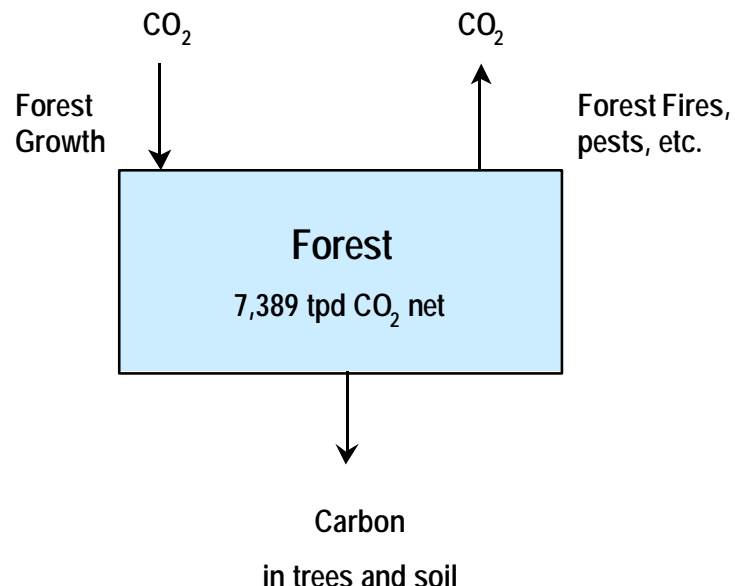

Figure 1-6

Preliminary Block Diagram for Forest Storage Concept

The rationale for including the Forest Sink Enhancement concept in the economic evaluation is summarized in Table 1-7 below. Forests are generally considered the lowest-cost storage option, and a great deal of work has been done on them. This is the basic sink comparison to be made with the captured storage concept. A number of concerns still remain, and matching the economics will be difficult. Sufficient data should be available. 
Table 1-7

Rationale for Including Forest Sinks in the Economic Study

\begin{tabular}{|c|c|c|c|c|c|c|}
\hline Merits & $\begin{array}{l}\text { Potential } \\
\text { Challenges }\end{array}$ & Applicability & $\begin{array}{l}\text { Technical } \\
\text { Maturity }\end{array}$ & Data Availability & $\begin{array}{c}\text { Industrial } \\
\text { Acceptance }\end{array}$ & $\begin{array}{l}\text { Compatibility } \\
\text { with power } \\
\text { systems }\end{array}$ \\
\hline $\begin{array}{l}\text { - Low cost } \\
\text { - Significant forest } \\
\text { available } \\
\text { - Provides funding } \\
\text { and employment } \\
\text { in rural areas } \\
\text { and developing } \\
\text { countries } \\
\text { - Preservation of } \\
\text { biodiversity }\end{array}$ & $\begin{array}{l}\text { - Monitoring and } \\
\text { verification of } \\
\text { carbon storage } \\
\text { - Opportunities for } \\
\text { fraud } \\
\text { - "Leakage" } \\
\text { minimization } \\
\text { - Short-term } \\
\text { storage } \\
\text { - Risks of forest } \\
\text { loss through } \\
\text { fires, pests, and } \\
\text { social factors }\end{array}$ & $\begin{array}{l}\text { - Particularly } \\
\text { applicable to } \\
\text { areas of low } \\
\text { population with } \\
\text { few other land } \\
\text { use options } \\
\text { - Changes to } \\
\text { albedo may } \\
\text { make forests } \\
\text { less effective in } \\
\text { high latitudes } \\
\text { - Global capacity } \\
\text { limited and costs } \\
\text { increase } \\
\text { substantially as } \\
\text { less favorable } \\
\text { sites are used }\end{array}$ & $\begin{array}{l}\text { - Forestry is } \\
\text { technically } \\
\text { mature } \\
\text { - Land owners } \\
\text { and farmers } \\
\text { need to be } \\
\text { educated on } \\
\text { merits of forestry } \\
\text { for carbon } \\
\text { storage } \\
\text { - Monitoring and } \\
\text { verification } \\
\text { services offered } \\
\text { but further } \\
\text { developments } \\
\text { would be } \\
\text { beneficial to } \\
\text { increase } \\
\text { accuracy and } \\
\text { reduce costs }\end{array}$ & $\begin{array}{l}\text { - Good } \\
\text { - Current projects } \\
\text { small and may } \\
\text { not be } \\
\text { representative of } \\
\text { large schemes } \\
\text { - Current large- } \\
\text { scale projects } \\
\text { are mainly } \\
\text { deforestation } \\
\text { avoidance }\end{array}$ & $\begin{array}{l}\text { - Still being } \\
\text { debated at the } \\
\text { COP } 6 \text { meeting } \\
\text { - Considered the } \\
\text { easy, low-cost } \\
\text { option } \\
\text { - Some } \\
\text { companies } \\
\text { already buying } \\
\text { forestry carbon } \\
\text { credits } \\
\text { - Still concerns } \\
\text { over "leakage" } \\
\text { and risks }\end{array}$ & $\begin{array}{l}\text { - Applicable to all } \\
\text { power systems } \\
\text { since there is no } \\
\text { direct link to the } \\
\text { power plant }\end{array}$ \\
\hline
\end{tabular}




\subsubsection{Cropland Sink Enhancement}

Shown in Figure 1-7 is a preliminary block diagram for the Cropland Sink Enhancement concept. The cropland concept involves enhancing soil carbon sequestration by switching from conventional to conservation-tillage systems and improving residue management.

Conservation-tillage systems use less intensive tillage, often no tillage, and leave at least 30 percent of the crop residues on the soil surface. Conservation-tillage systems also sometimes include a winter cover crop that remains on the soil surface to reduce soil erosion. The winter cover crop is not harvested and adds additional crop residue to soil organic matter.

General parameters for estimating the net cost of switching to conservation-tillage systems are presented in the block diagram below. The net cost of switching to conservation-tillage systems is the change in cost of tillage-system inputs, plus or minus the change in revenue and risk from changes in crop yield.

General parameters for estimating the additional $\mathrm{CO}_{2}$ sequestered in soil organic matter are also presented in the block diagram. These parameters are (1) the increase in crop residue carbon added to soil organic matter, (2) the reduced rate of soil organic matter decomposition to $\mathrm{CO}_{2}$, and (3) the reduced soil erosion and the associated reduction of $\mathrm{CO}_{2}$ emitted from eroded soil.

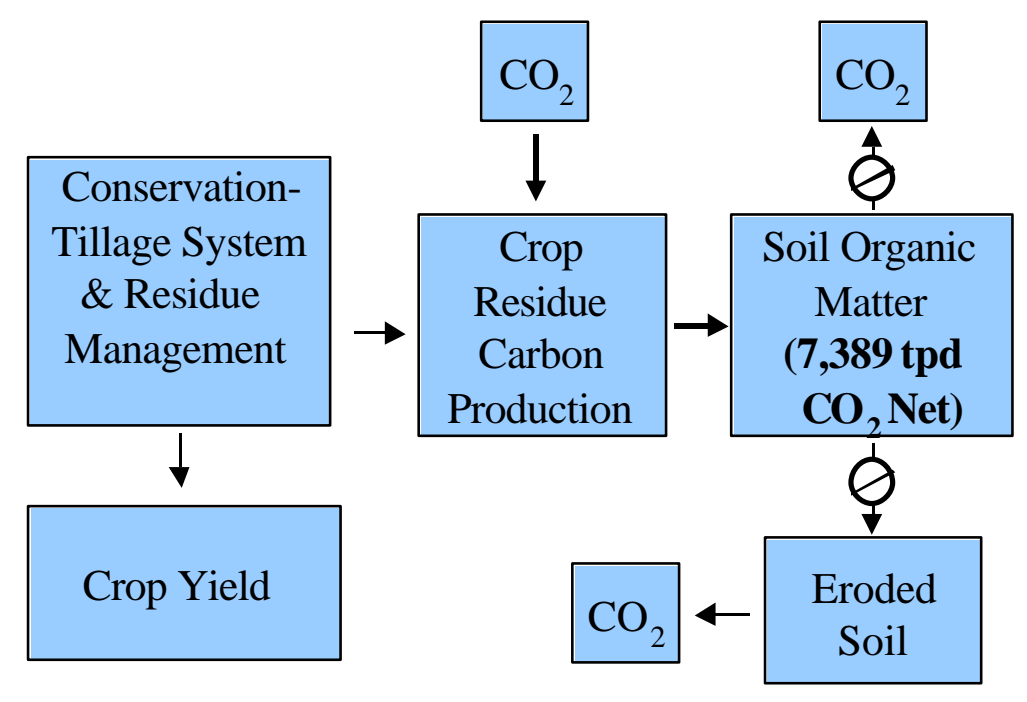

\section{Figure 1-7}

Preliminary Block Diagram for Cropland Sink Concept

The rationale for including the Cropland Sink Enhanceme nt concept in the economic evaluation is summarized in Table 1-8 below. The cropland component of this project will estimate added costs of converting from conventional-tillage systems to conservation-tillage systems that sequester additional carbon in soil organic matter. Increased adoption of conservation-tillage systems and improved residue management accounts for about one-half of the potential for reducing greenhouse (GHG) emissions from U.S. croplands. The remaining one-half of the potential for reducing GHG emissions from U.S. croplands is highly fragmented and beyond the scope and resources of this project. 
Table 1-8

Rationale for Including Cropland Sinks in the Economic Study

\begin{tabular}{|c|c|c|c|c|c|c|}
\hline Merits & $\begin{array}{l}\text { Potential } \\
\text { Challenges }\end{array}$ & Applicability & $\begin{array}{c}\text { Technical } \\
\text { Maturity }\end{array}$ & Data Availability & $\begin{array}{c}\text { Industrial } \\
\text { Acceptance }\end{array}$ & $\begin{array}{l}\text { Compatibility } \\
\text { with power } \\
\text { systems }\end{array}$ \\
\hline $\begin{array}{l}\text { - Relatively low } \\
\text { projected } \\
\text { cost/ton of } \mathrm{CO}_{2} \\
\text { - Collateral } \\
\text { benefits of } \\
\text { conservation } \\
\text { tillage- } \\
\text { improved soil } \\
\text { quality, reduced } \\
\text { soil erosion, } \\
\text { improved water- } \\
\text { use efficiency, } \\
\text { improved crop } \\
\text { productivity } \\
\text { where well } \\
\text { adapted }\end{array}$ & $\begin{array}{l}\text { - Possible need } \\
\text { for periodic use } \\
\text { of conventional } \\
\text { tillage to } \\
\text { maintain crop } \\
\text { productivity, } \\
\text { resulting in } \\
\text { partial loss of } \\
\text { sequestered } \\
\mathrm{CO}_{2} \\
\text { - Possible } \\
\text { reversion to } \\
\text { conventional } \\
\text { tillage due to } \\
\text { changes in land } \\
\text { ownership } \\
\text { - Resistance to } \\
\text { including } \\
\text { biological sinks } \\
\text { in GHG polices } \\
\text { - Poorly } \\
\text { developed } \\
\text { infrastructure for } \\
\text { CO }{ }_{2} \text { credits and } \\
\text { markets } \\
\text { infrastructure }\end{array}$ & $\begin{array}{l}\text { Excellent in well- } \\
\text { drained soils, } \\
\text { water deficient } \\
\text { cropping } \\
\text { systems, and } \\
\text { highly erosive } \\
\text { soils } \\
\text { - Moderately good } \\
\text { in most other } \\
\text { cropping } \\
\text { systems }\end{array}$ & $\begin{array}{l}\text { - Conservation } \\
\text { tillage systems } \\
\text { under } \\
\text { development } \\
\text { since early } \\
1970 \text { s } \\
\text { - } ~ 35 \% \text { adoption } \\
\text { achieved to date } \\
\text { in U.S. } \\
\text { - Technology } \\
\text { ready for rapid } \\
\text { adoption, given } \\
\text { additional } \\
\text { economic } \\
\text { incentives }\end{array}$ & $\begin{array}{l}\text { - Good for costs } \\
\text { of tillage } \\
\text { systems } \\
\text { - Moderately good } \\
\text { for } \mathrm{CO}_{2} \\
\text { sequestration } \\
\text { rates } \\
\text { - Lacking for } \\
\text { equilibrium } \\
\text { levels of } \\
\text { sequestered } \\
\text { carbon and time } \\
\text { to equilibrium } \\
\text { - Good for } \mathrm{CO}_{2} \\
\text { emissions } \\
\text { factors } \\
\text { associated with } \\
\text { tillage-system } \\
\text { inputs }\end{array}$ & $\begin{array}{l}\text { - Generally good } \\
\text { farmer } \\
\text { acceptance } \\
\text { because of } \\
\text { collateral } \\
\text { benefits } \\
\text { - Somewhat } \\
\text { greater } \\
\text { economic risk to } \\
\text { farmers } \\
\text { - May require } \\
\text { moderate } \\
\text { adoption } \\
\text { incentives to } \\
\text { achieve rapid } \\
\text { additional } \\
\text { adoption }\end{array}$ & $\begin{array}{l}\text { - Good } \\
\text { compatibility via } \\
\text { combining farm- } \\
\text { level } \mathrm{CO}_{2} \\
\text { sequestration } \\
\text { credits into } \\
\text { bundles of } \\
\text { sufficient size to } \\
\text { match power } \\
\text { project needs }\end{array}$ \\
\hline
\end{tabular}


In conventionat-tillage systems, soil is plowed or otherwise thoroughly tilled, and all of the crop residues are mixed with soil. In contrast, conservation-tillage systems involve less intensive tillage (often no tillage), leave 30 percent or more of the crop residues on the soil surface, and sequester additional carbon in soil organic matter that otherwise would be emitted to the atmosphere as $\mathrm{CO}_{2}$. In addition to sequestering more carbon, conservation-tillage systems also have lower emissions associated with production and use of tillage-system inputs, dramatically reduce soil erosion and $\mathrm{CO}_{2}$ emissions from eroded soil, improve soil quality, and conserve soil water by reducing water runoff and evaporation from the soil.

\subsection{Report Organization}

Presented in Chapter 2 is a summary of the methodology used in developing the costs. Chapters 3-9 contain the information on the captured $\mathrm{CO}_{2}$ storage concepts. Chapters 10-17 contain the information on the forestry options. Chapters 18-22 contain the information on the croplands options. Chapter 23 contains the summary comparisons between options and conclusions.

\subsection{References}

1 DOE/EPRI. 2000. Evaluation of innovative fossil-fuel power plants with $\mathrm{CO}_{2}$ removal. EPRI., Palo Alto, California; U.S. Department of Energy-Office of Fossil Energy, Germantown, Maryland, and U.S. Department of Energy/NETL, Pittsburgh, Pennsylvania: 1000316. 


\section{METHODOLOGIES FOR CALCULATING THE COST OF CAPTURING AND STORING $\mathrm{CO}_{2}$}

General procedures for calculating the cost of capturing and storing $\mathrm{CO}_{2}$ are overviewed in this chapter. They include:

- Calculating costs using revenue requirement methodology

- Defining the three cost bases used in this report: $\mathrm{CO}_{2}$ captured, $\mathrm{CO}_{2}$ avoided, and $\mathrm{CO}_{2}$ equivalent life-cycle (LC) greenhouse gas (GHG) avoided

- Combining $\mathrm{CO}_{2}$ capture and storage costs

- Accounting for differences in timing of $\mathrm{CO}_{2}$ sequestration profiles and for leaking reservoirs

Specific procedures are provided in Chapter 3.

\subsection{Revenue Requirement Methodology}

Costs of storing captured $\mathrm{CO}_{2}$ were calculated using the same general approach as for $\mathrm{CO}_{2}$ capture costs that have already been calculated by EPRI and DOE for several power plant $\mathrm{CO}_{2}$ capture technologies ${ }^{1}$. This allowed $\mathrm{CO}_{2}$ capture and storage costs to be combined on an equal basis.

\subsubsection{Approach for $\mathrm{CO}_{2}$ Capture}

In the DOE/EPRI project, EPRI revenue requirement (RR) methodology was used ${ }^{2}$. Revenue requirement methodology is used for regulated economics (i.e., return on equity and debt are set at regulated levels) and focuses on minimizing annual revenue requirements, whereas unregulated economics focus on maximizing return on investment. With regulated economics, utilities are allowed to charge a price for electricity that recovers revenue requirements for prudent investments. A levelized RR (\$/yr) was calculated for each year of the 20-year plant book life as follows:

Levelized RR = Levelized Carrying Charge $($ LCC $)+$ Expenses

$=$ Levelized annual cost of electricity 
where LCC $=$ Total Plant Cost (or TPC) $\mathrm{x}$ Levelized Carrying Charge Factor (or LCCF), and Expenses include O\&M and fuel costs. The TPC includes process facilities capital, general facilities capital, engineering and home office overhead, project and process contingencies, and miscellaneous expenses generally included under owners costs.

A levelized revenue requirement was calculated for an integrated gasification combined cycle (IGCC) plant without $\mathrm{CO}_{2}$ capture (Case $3 \mathrm{~b}$ of reference 1) and for the same IGCC plant converted to capture $\mathrm{CO}_{2}$ (Case 3a of reference 1) as shown in Equation 1. A value of 0.15 for the LCCF was based on assumptions specified in the DOE/EPRI report for return on debt, return on equity, federal and state income taxes, book depreciation, property taxes, and insurance. The same financial parameters and associated LCCF of 0.15 were used for calculating the base case for cost of storing captured $\mathrm{CO}_{2}$. Assumptions for return on debt, return on equity, and federal and state income taxes are presented in Table 2-1.

The cost of electricity (COE) for the capture and non-capture power plants was calculated based on their respective LCC and expenses. The difference in COE $(\$ / \mathrm{MWh})$ for capture and noncapture IGCC plants was used as a basis for calculating the cost of $\mathrm{CO}_{2}$ captured (more details provided in Section 2.2).

Table 2-1

Financial parameters for calculating the levelized carrying charge factor

\begin{tabular}{|c|c|c|c|c|c|}
\hline & & & $\begin{array}{l}\text { Current } \\
\text { dollars }\end{array}$ & \multicolumn{2}{|c|}{ Constant dollars } \\
\hline & $\begin{array}{l}\text { Percent } \\
\text { of total }\end{array}$ & Cost, \% & Return, \% & Cost, \% & Return, \% \\
\hline Debt & 45 & 9.0 & 4.05 & 5.83 & 2.62 \\
\hline Preferred stock & 10 & 8.5 & 0.85 & 5.34 & 0.53 \\
\hline Common stock & 45 & 12.0 & 5.40 & 8.74 & 3.93 \\
\hline Total annual return & 100 & & 10.30 & & 7.09 \\
\hline Inflation rate, $\%$ & & 3.00 & & & \\
\hline Federal tax, \% & & 34.00 & & & \\
\hline State tax, \% & & 4.15 & & & \\
\hline Federal and state tax, \% & & 38.00 & & & \\
\hline \multicolumn{6}{|l|}{ Discount rates } \\
\hline After tax & & & 8.76 & & 6.09 \\
\hline Before tax & & & 10.3 & & 7.09 \\
\hline
\end{tabular}




\subsubsection{Adjustment for $\mathrm{CO}_{2}$ Storage}

In calculating the costs of storing captured $\mathrm{CO}_{2}$, the RR methodology for $\mathrm{CO}_{2}$ capture was generalized to accommodate options for enhanced revenues from $\mathrm{CO}_{2}$ storage. These adjustments were required because $\mathrm{CO}_{2}$ storage options such as enhanced oil recovery (EOR) and enhanced coal bed methane recovery (ECBMR) generate revenues that at least partially offset the cost of $\mathrm{CO}_{2}$ storage. This required that the $\mathrm{RR}$ methodology for $\mathrm{CO}_{2}$ capture be generalized as follows:

$$
\begin{aligned}
\text { Levelized RR } & =\mathrm{LCC}+\mathrm{O} \& \mathrm{M} \text { costs }- \text { Enhanced revenues } \\
& =\text { Levelized annual net cost of storing } \mathrm{CO}_{2}
\end{aligned}
$$

A positive net storage cost equals the breakeven $\mathrm{CO}_{2}$ tipping fee for EOR. A negative net storage cost equals the breakeven $\mathrm{CO}_{2}$ purchase price for EOR.

\subsubsection{Adjustment of Levelized Carrying Charge Factor as a Function of Discount Rate}

Costs of capturing and storing $\mathrm{CO}_{2}$ were calculated on a constant 1999 dollar basis. Financial parameters in Table 2-1 result in a LCC factor of 0.150 and an after-tax discount rate ( $\mathrm{r}$ ) of 6.09 percent on a constant-dollar basis. Discounted costs and revenues were used to compare $\mathrm{CO}_{2}$ storage and sink enhancement options differing in timing of costs and in timing and permanence of $\mathrm{CO}_{2}$ storage and sink enhancement (see Section 2.4). The discount rate used in Section 2.4 calculations needs to be consistent with the LCC factor. The discount rate and LCC factor are related by Equation (3).

$$
\text { LCC factor }=0.0738+0.01 r+0.0004 r^{2}
$$

Equation (3) is based on the regression in Figure 2-1. Levelized carrying charge factors were calculated for the range of after-tax discount rates (r) in Figure 2-1 by varying return to debt and equity and holding other financial parameters constant. Procedures from reference 2 were used for these calculations. 


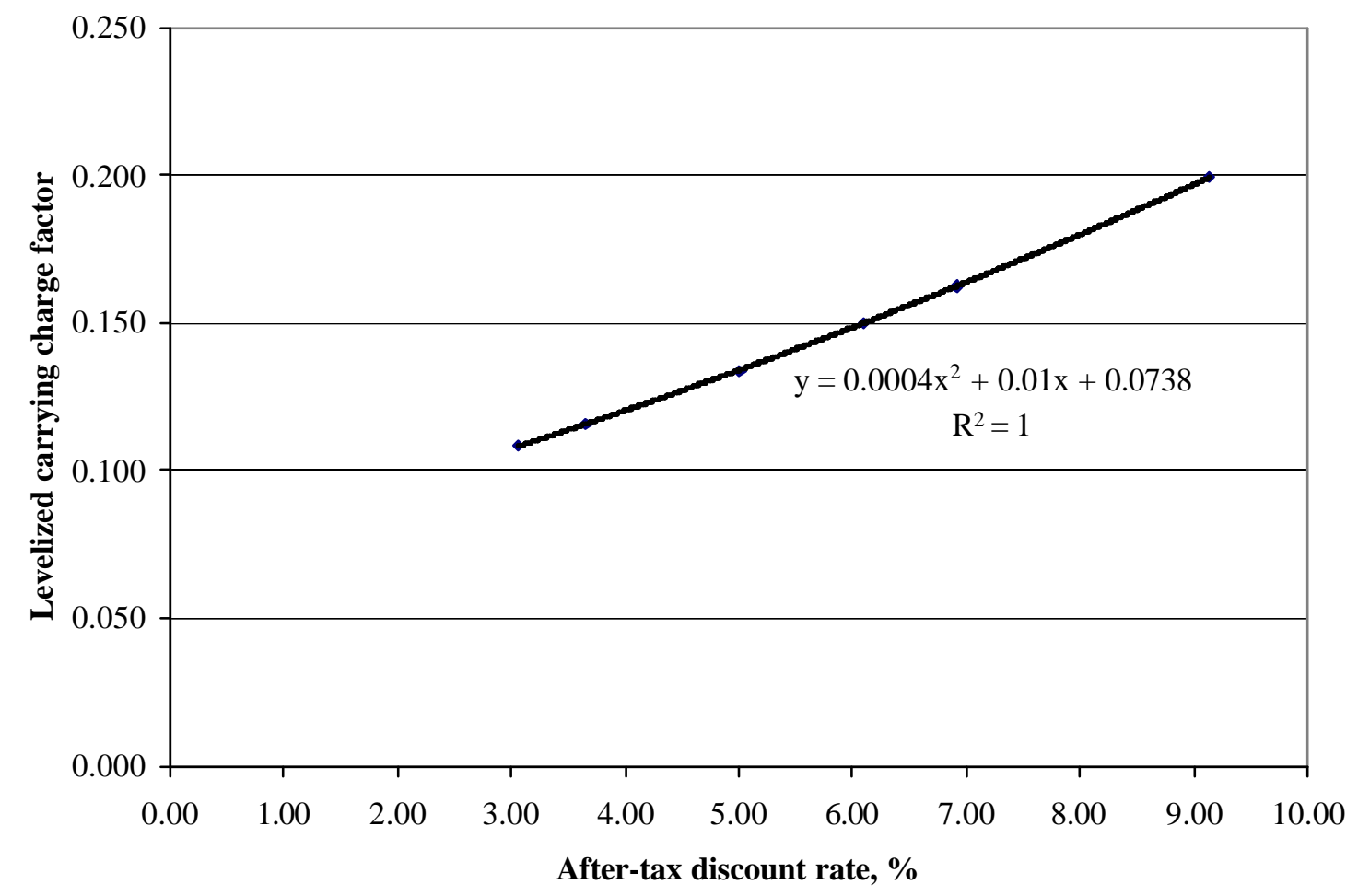

Figure 2-1

Carrying charge factor vs. after-tax discount rate (based on constant dollar analysis)

\subsubsection{Impact of $\mathrm{CO}_{2}$ Storage Costs on Cost of Electricity}

The $\mathrm{COE}$ for the IGCC $\mathrm{CO}_{2}$ capture plant was adjusted for the net cost of $\mathrm{CO}_{2}$ storage (i.e., storage costs minus enhanced oil or gas revenues). The increase in $\mathrm{COE}$ due to $\mathrm{CO}_{2}$ storage was calculated by dividing the total revenue requirement for $\mathrm{CO}_{2}$ storage by the total $\mathrm{MWh}$ of electricity produced. Consistent with revenue requirement methodology, $\mathrm{CO}_{2}$ storage operations were assumed to be owned by a regulated utility or reimbursed by a regulated utility for net storage costs (including return on equity), in which case enhanced oil or gas revenues were assumed to have no impact on income taxes. The reason is that regulated utilities are allowed to charge a price for electricity that recovers revenue requirements for prudent investments. Within this context, enhanced oil or gas revenues reduce the revenue requirement for $\mathrm{CO}_{2}$ storage, and thereby, reduce any increase in electricity prices that a regulated utility would be allowed to charge to cover $\mathrm{CO}_{2}$ storage costs. The end result is no additional income tax burden beyond that built into the carrying charge. In some EOR and ECBMR scenarios, enhanced oil or gas revenues are large enough to result in a negative revenue requirement for storing $\mathrm{CO}_{2}$.

In these cases, it was assumed that the negative revenue requirement would be used to:

- Eliminate the increase in electricity prices that a regulated utility would normally be allowed to charge to cover $\mathrm{CO}_{2}$ storage costs, and 
- Reduce part of the increase in electricity prices that a regulated utility would normally be allowed to charge to cover $\mathrm{CO}_{2}$ capture costs.

\subsection{Capture Costs on $\mathrm{CO}_{2}$ Captured, $\mathrm{CO}_{2}$ Avoided, and Life-Cycle GHG Avoided Bases}

\subsection{1 $\mathrm{CO}_{2}$ Captured Basis}

The cost per tonne of $\mathrm{CO}_{2}$ captured was calculated by subtracting the cost of electricity (COE, $\$ / \mathrm{MWh}$ ) for the IGCC reference plant without $\mathrm{CO}_{2}$ capture from the COE for the IGCC plant with $\mathrm{CO}_{2}$ capture and dividing by the amount of $\mathrm{CO}_{2}$ captured (tonne/MWh). Assuming no losses of captured $\mathrm{CO}_{2}$ during transport and storage, this calculation also provides the capture cost per tonne of $\mathrm{CO}_{2}$ stored. Inputs for calculating $\mathrm{CO}_{2}$ capture costs on a $\mathrm{CO}_{2}$ captured basis are presented in Table 2-2. For this case, the $\mathrm{CO}_{2}$ capture cost on a $\mathrm{CO}_{2}$ captured basis $=(55.08$ 43.98)/0.763 = \$14.55/tonne $\mathrm{CO}_{2}$ captured.

Table 2-2

Calculation of $\mathrm{CO}_{2}$ capture costs on $\mathrm{CO}_{2}$ captured and $\mathrm{CO}_{2}$ avoided bases

Based on IGCC example from DOE/EPRI report ${ }^{1}$

\begin{tabular}{|c|c|c|}
\hline & Capture plant & Reference $\mathrm{p}$ \\
\hline COE, $\$ / M W h$ & 55.08 & 43.98 \\
\hline $\mathrm{CO}_{2}$ produced, tonne/MWh & 0.836 & 0.718 \\
\hline $\mathrm{CO}_{2}$ captured, tonne/MWh & 0.763 & 0.000 \\
\hline Direct $\mathrm{CO}_{2}$ emitted, tonne/MWh & 0.073 & 0.718 \\
\hline $\begin{array}{l}\text { LC GHG emitted, tonne } \mathrm{CO}_{2} \text { eq./MWh } \\
\text { (see Table 3) }\end{array}$ & 0.111 & 0.750 \\
\hline
\end{tabular}

Cost, $\mathrm{CO}_{2}$ captured basis:

Costs

$\mathrm{CO}_{2}$ capture cost $\left(\mathrm{CO}_{2}\right.$ captured basis), $\$$ /tonne $\mathrm{CO}_{2}$ captured

14.55

Costs, $\mathrm{CO}_{2}$ avoided basis:

$\mathrm{CO}_{2}$ capture cost $\left(\mathrm{CO}_{2}\right.$ avoided basis), $\$$ /tonne $\mathrm{CO}_{2}$ avoided

$\mathrm{CO}_{2}$ capture cost ( $\mathrm{LC} \mathrm{GHG}$ avoided basis), $\$$ /tonne $\mathrm{CO}_{2}$ eq. avoided

17.37

-Assumes $80 \%$ capacity factor. 


\subsection{2 $\mathrm{CO}_{2}$ Avoided Basis}

The primary difference in capturing $\mathrm{CO}_{2}$ for commercial markets versus capturing $\mathrm{CO}_{2}$ for sequestration is the role of energy. In the former case, energy is a commodity, and all we care about is its price. In the latter case, using energy generates more $\mathrm{CO}_{2}$ emissions, which is precisely what we want to avoid. We can account for this "energy penalty" by calculating costs on a $\mathrm{CO}_{2}$ avoided basis. As shown in Figure 2-2, due to the extra energy required to capture $\mathrm{CO}_{2}$, the amount of $\mathrm{CO}_{2}$ emissions avoided is always less than the amount of $\mathrm{CO}_{2}$ captured. Therefore, capturing $\mathrm{CO}_{2}$ for purposes of sequestration requires more emphasis on reducing energy inputs than in traditional commercial processes.

\section{$\mathrm{CO}_{2}$ Avoided during $\mathrm{CO}_{2}$ Capture}

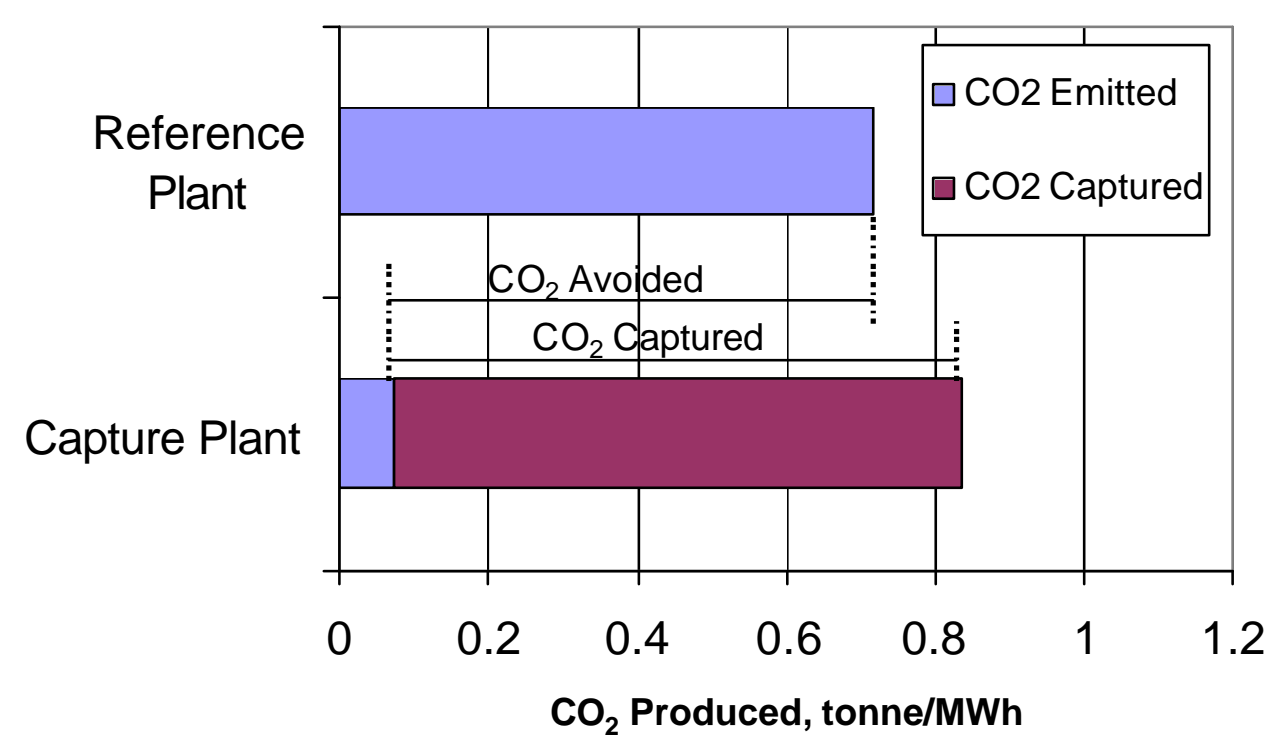

\section{Figure 2-2}

Relationships among $\mathrm{CO}_{2}$ produced, captured, and avoided when comparing power plants with and without $\mathrm{CO}_{2}$ capture (based on Table 2-2)

The cost per tonne of $\mathrm{CO}_{2}$ avoided in the $\mathrm{CO}_{2}$ capture process was calculated with Equation(4) from the EPRI/DOE report ${ }^{1}$ :

Cost of $\mathrm{CO}_{2}$ Avoided $=\frac{\left(\$ / M W h_{\text {withcapture }}\right)-\left(\$ / M W h_{\text {withoutcapture }}\right)}{\left(\text { tonne } \mathrm{CO}_{2} \text { emitted } \text { withoutcapture }_{\text {en }} / \mathrm{MWh}\right)-\left(\text { tonne } \mathrm{CO}_{2} \text { emitted } \text { withcapture }_{\text {enWh }}\right)}$

Inputs for calculating $\mathrm{CO}_{2}$ capture costs on a $\mathrm{CO}_{2}$ avoided basis are presented in Table 2-2. For this case, the cost of $\mathrm{CO}_{2}$ avoided $=(55.08-43.98) /(0.718-0.073)=\$ 17.21 /$ tonne $\mathrm{CO}_{2}$ avoided. 


\subsubsection{LC GHG Avoided Basis}

The calculation of $\mathrm{CO}_{2}$ capture costs on a life-cycle greenhouse gas (LC GHG) avoided basis is the same as in the previous section except that the terms in the denominator of Equation (4) are tonne $\mathrm{CO}_{2}$ equivalent $\mathrm{LC} \mathrm{GHG}$ emitted/MWh instead of tonne $\mathrm{CO}_{2}$ directly emitted from the power plant/MWh. Life-cycle GHG emissions are greater than direct $\mathrm{CO}_{2}$ emissions for two reasons. First, greenhouse gases in addition to $\mathrm{CO}_{2}$ were included in the analysis. Second, the system boundaries were expanded to include coal mining and manufacture and transportation, construction, and decommissioning of power plant equipment in addition to GHG emissions from power plant operations; this boundary expansion was required because of the energy penalty and associated added coal required for $\mathrm{CO}_{2}$ capture and because of the energy use associated with added equipment required for $\mathrm{CO}_{2}$ capture. Inputs for calculating $\mathrm{CO}_{2}$ capture costs on a LC GHG avoided basis are presented in Table 2-3. For this case, the cost of GHG avoided on a LC GHG basis $=(55.05-43.98) /(0.111-0.750)=\$ 17.37 /$ tonne $\mathrm{CO}_{2}$ equivalent $\mathrm{LC}$ GHG avoided. Calculation of LC GHG emissions (values in the denominator of the equation in the previous sentence) is illustrated in Table 2-3. The 100-year warming potentials used are from the recent Intergovernmental Panel on Climate Change (IPCC) report ${ }^{7}$.

\subsection{Combining Capture and Storage Costs}

The previous section described the bases based only on capture costs and emissions. In this section, we describe how these bases are modified to also consider storage costs and emissions. In addition, we describe the methodology for reporting storage costs alone on a LC GHG avoided basis.

\subsection{1 $\mathrm{CO}_{2}$ Captured Basis}

Costs associated with $\mathrm{CO}_{2}$ compression, transportation, and storage are included in the cost of electricity ( $\mathrm{COE}, \$ / \mathrm{MWh}$ ) from a $\mathrm{CO}_{2}$ capture plant. The cost per tonne of $\mathrm{CO}_{2}$ captured is calculated by subtracting the $\mathrm{COE}$ for the reference power plant without $\mathrm{CO}_{2}$ capture from the $\mathrm{COE}$ for the power plant with $\mathrm{CO}_{2}$ capture, including costs for compression, transportation, and storage, and dividing the difference by the amount of $\mathrm{CO}_{2}$ captured (tonne/MWh). 
Table 2-3

Summary of Enhanced Oil Recovery on a LC GHG avoided basis

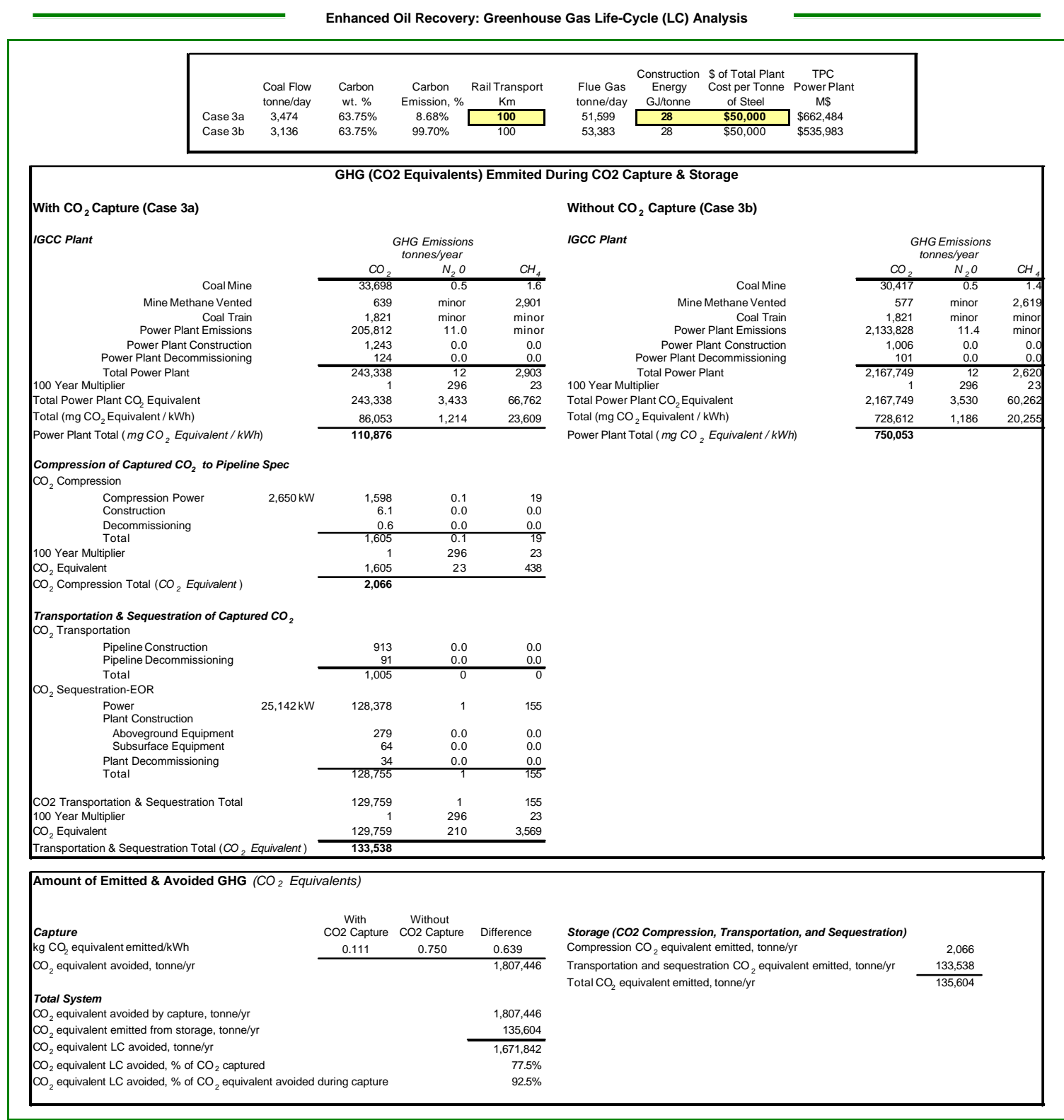




\subsection{2 $\mathrm{CO}_{2}$ Avoided Basis $\left(\mathrm{CO}_{2}\right.$ Capture and Storage Combined)}

In addition to the inclusion of $\mathrm{CO}_{2}$ compression, transportation, and storage costs as described in section 2.3.1 above, this basis also considers the $\mathrm{CO}_{2}$ emitted during $\mathrm{CO}_{2}$ storage. Referencing Equation 4 , including storage costs on a $\mathrm{CO}_{2}$ avoided cost basis will increase the $\$ / \mathrm{MWh}_{\text {with capture }}$ and the tonne $\mathrm{CO}_{2}$ emitted/MWh $\mathrm{Mith}_{\text {capture }}$ terms.

\subsubsection{GHG Avoided in $\mathrm{CO}_{2}$ Capture and Storage Processes Combined on a Life-Cycle (LC) Basis}

The concept of GHG emissions avoided on a LC GHG basis for capture and storage combined is illustrated in Figure 2-3. The LC GHG emissions from the reference and capture power plants were discussed in Section 2.2.3, and emissions levels from the reference and capture power plants are presented in Tables 2-2 and 2-3. The red bars in Figure 2-3 are the LC GHG emissions in addition to the direct $\mathrm{CO}_{2}$ emissions from the reference and capture power plants. The LC GHG emissions avoided via $\mathrm{CO}_{2}$ capture and storage combined are calculated as the LC GHG emitted from the reference plant (blue plus red bars) minus the LC GHG emitted from the capture plant and storage operation combined (blue plus red plus yellow bars).

To get the cost per tonne of LC GHG avoided via the capture and storage processes combined, the combined annual net cost of capturing and storing $\mathrm{CO}_{2}$ was divided by the annual tonnes of $\mathrm{CO}_{2}$ equivalent $\mathrm{GHG}$ avoided via capture and storage processes combined. For the EOR example in Table 2-3, the annual combined net cost of $\mathrm{CO}_{2}$ capture and storage was $\$ 6.70$ million (data not shown). The annual tonnes of $\mathrm{CO}_{2}$ equivalent $\mathrm{GHG}$ avoided in capture and storage processes combined was 1.67 million (see next paragraph for details). Dividing annual costs by annual tonnes gave a net cost of $\$ 4.01 /$ tonne $\mathrm{CO}_{2}$ equivalent $\mathrm{GHG}$ avoided by capture and storage combined.

The difference in LC GHG emissions from the reference and capture plants is $0.750-0.111=0.639$ tonnes $\mathrm{CO}_{2}$ equivalent/MWh (Table 2-3). This difference in LC GHG emissions was multiplied by the $\mathrm{MWh} / \mathrm{year}$ for the capture plant to get the annual tonnes of $\mathrm{CO}_{2}$ equivalent $\mathrm{GHG}$ avoided via the capture process $\left(1,807,446\right.$ tonnes $\mathrm{CO}_{2}$ equivalent $\mathrm{LC} \mathrm{GHG}$ avoided/yr). The LC GHG emissions from EOR $\mathrm{CO}_{2}$ storage were 135,606 tonnes $\mathrm{CO}_{2}$ equivalent LC GHG/yr, resulting in 1,807,466-135,606 = 1,671,840 tonnes $\mathrm{CO}_{2}$ equivalent $\mathrm{LC} \mathrm{GHG}$ avoided/yr for the $\mathrm{CO}_{2}$ capture and storage processes combined. 


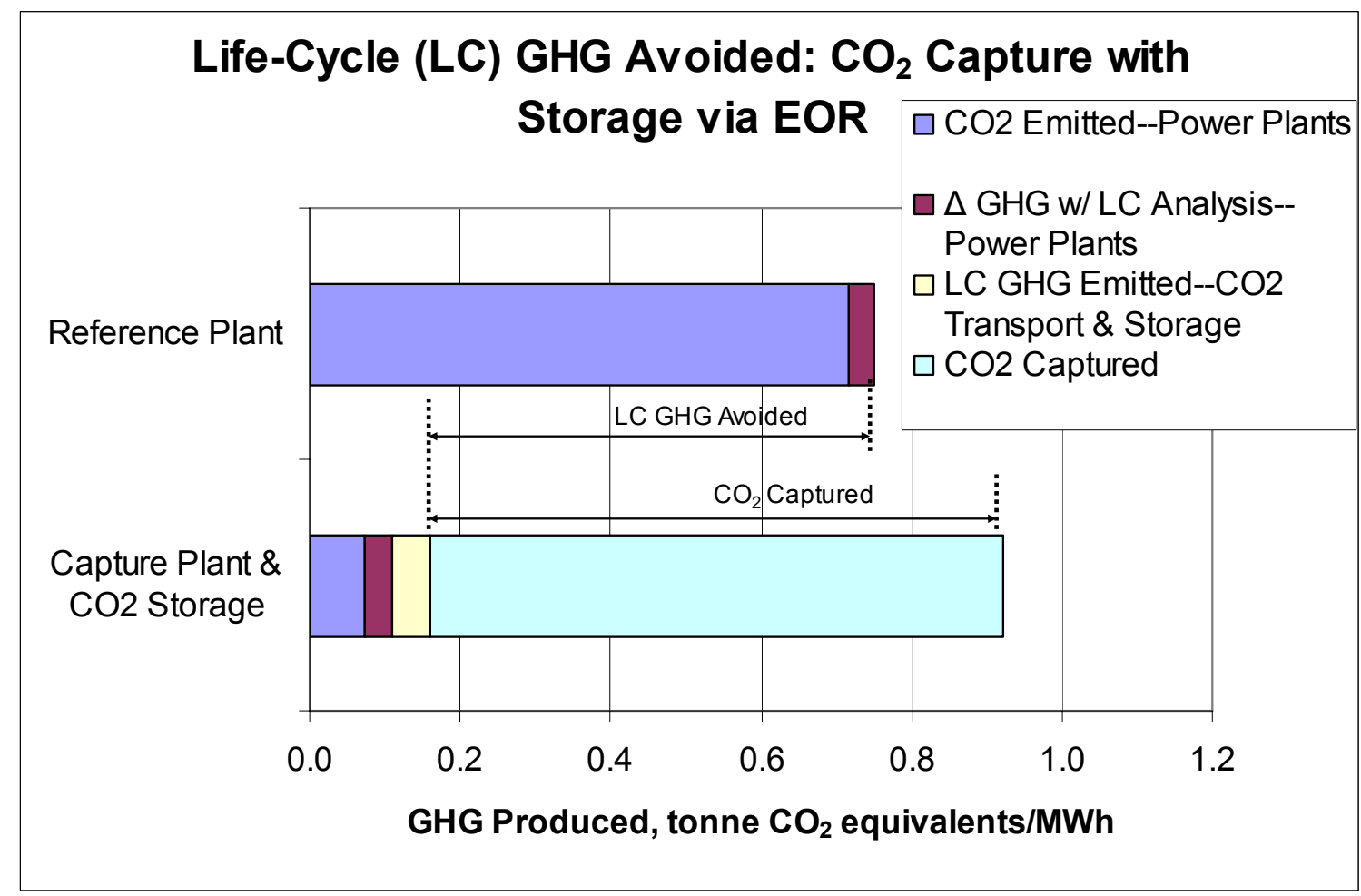

Figure 2-3

Relationships among GHG produced, $\mathrm{CO}_{2}$ captured, and GHG avoided on a LC basis for $\mathrm{CO}_{2}$ capture and storage (via EOR) combined; based on Tables 2-2 and 2-3

In the case of ocean storage, the portion of injected $\mathrm{CO}_{2}$ predicted to leak back out of the ocean (3.1 percent in 100 years from an MIT model) was subtracted from the GHG emissions avoided during the $\mathrm{CO}_{2}$ capture and storage processes to get a net GHG emissions avoided. For all other cases, the storage location leakage was assumed to be zero. The net GHG emissions avoided was used to calculate the cost of $\mathrm{CO}_{2}$ capture and storage on a LC GHG avoided basis.

\subsubsection{Costs of $\mathrm{CO}_{2}$ Storage on a Life-Cycle GHG Avoided Basis (Storage Only)}

The cost per tonne of $\mathrm{CO}_{2}$ stored was calculated on a life-cycle $\mathrm{GHG}$ avoided basis (storage system only) by dividing the total annual revenue requirement for $\mathrm{CO}_{2}$ storage by the difference between annual tonnes $\mathrm{CO}_{2}$ stored and $\mathrm{LC} \mathrm{GHG}$ emitted due to the storage operation (i.e., $\mathrm{CO}_{2}$ compression, transportation, and sequestration). Examples of $\mathrm{LC} \mathrm{GHG}$ emissions from $\mathrm{CO}_{2}$ storage operations are presented for base cases in Table 2-4. This analysis included LC GHG emitted from energy consumption during equipment manufacture, transportation, construction, and decommissioning, and during the storage operation. Detailed LC GHG emissions from EOR storage (base case) are presented in Figure 2-3. Detailed LC GHG emissions from all the basecase $\mathrm{CO}_{2}$ storage options in Table 2-4 are presented in Appendix A. 
Table 2-4

Greenhouse gas emissions from $\mathrm{CO}_{2}$ storage operations

\begin{tabular}{|c|c|c|}
\hline $\mathrm{CO}_{2}$ Storage Option & $\begin{array}{c}\text { Direct } \mathrm{CO}_{2} \\
\text { emitted }\end{array}$ & $\begin{array}{l}\text { Total LC GHG emitted } \\
\text { (includes direct } \mathrm{CO}_{2} \\
\text { emissions) }\end{array}$ \\
\hline & \multicolumn{2}{|c|}{ million tonnes $\mathrm{CO}_{2}$ eq./y } \\
\hline \multicolumn{3}{|c|}{ Storage of $\mathrm{CO}_{2}$ from one power plant at $80 \%$ capacity factor : } \\
\hline Enhanced oil recovery & 0.130 & 0.136 \\
\hline Enhanced coalbed methane recovery & 0.049 & 0.052 \\
\hline Deep saline aquifers & 0.002 & 0.003 \\
\hline Depleted oil reservoirs & 0.002 & 0.003 \\
\hline Depleted gas reservoirs & 0.002 & 0.003 \\
\hline \multicolumn{3}{|c|}{ Storage of $\mathrm{CO}_{2}$ from three power plants at $80 \%$ capacity factor ${ }^{* *}:$} \\
\hline Ocean pipeline & 0.008 & 0.013 \\
\hline Ocean tanker & 0.061 & 0.064 \\
\hline \multicolumn{3}{|c|}{$\begin{array}{l}\text { Assumes } 100 \mathrm{~km} \text { from power plant to storage operation and storage of } 2.158 \text { million } \\
\text { tonnes } \mathrm{CO}_{2} / \mathrm{y}\end{array}$} \\
\hline \multicolumn{3}{|c|}{$\begin{array}{l}\text { ** Assumes } 100 \mathrm{~km} \text { from power plant to ocean shore and } 100 \mathrm{~km} \text { from shore to ocean } \\
\text { injection point; and storage of } 6.474 \text { million tonnes } \mathrm{CO}_{2} / \mathrm{y} \text {. }\end{array}$} \\
\hline
\end{tabular}

\subsection{Comparing the Economics of $\mathrm{CO}_{2}$ Storage and Sink Enhancement Options Differing in Timing and Permanence of Sequestration}

Carbon dioxide storage and sink enhancement options differ greatly in timing of costs, the uptake or sequestration of $\mathrm{CO}_{2}$ and, in some cases, leakage of $\mathrm{CO}_{2}$ back into the atmosphere.

For options involving storage of captured $\mathrm{CO}_{2}$, the primary costs and amounts of $\mathrm{CO}_{2}$ stored are levelized over the book life of the $\mathrm{CO}_{2}$ capture and storage plants which is assumed to be 20 years in this project. With storage of captured $\mathrm{CO}_{2}$, there are also relatively small monitoring costs after 20 years, and in some cases, there may be additional transaction costs after 20 years. In some cases such as ocean storage, there are leaks of $\mathrm{CO}_{2}$ back to the atmosphere that occur after 20 years. The costs and $\mathrm{CO}_{2}$ sink enhancement for forestry projects usually extend over at least a 50- to 100-year period. In cropland systems involving reduction of tillage to achieve $\mathrm{CO}_{2}$ sink enhancement, primary costs in the form of annual farmer adoption incentives will likely be required for 5 to 20 years after a farmer switches to a reduced-tillage system. Sink enhancement occurs over approximately the first 20 to 40 years after switching to reduced tillage practices, and changes in GHG emissions associated with crop production inputs such as reduced fuel use continue for as long as the reduced-tillage system is used. Monitoring costs, and perhaps 
additional transaction costs, will continue for as long as the reduced-tillage system is used. If a farmer permanently switches back to a more intensive tillage system because of crop production problems, the $\mathrm{CO}_{2}$ sink reduces in size, resulting in $\mathrm{CO}_{2}$ loss back to the atmosphere.

The differences in timing and permanence discussed above present a significant challenge in comparing the economics of diverse options such as storage of captured $\mathrm{CO}_{2}$ and $\mathrm{CO}_{2}$ sink enhancement in forests and cropland. There have been many suggestions on how to handle this challenge $^{4,6}$. Removals and emissions/leaks are treated as separate events. The idea is that when one removes a ton of $\mathrm{CO}_{2}$, one receives the going price of $\mathrm{CO}_{2}$. When a ton of $\mathrm{CO}_{2}$ is released, the owner of this $\mathrm{CO}_{2}$ must then purchase a credit from elsewhere at the going price. $\mathrm{CO}_{2}$ prices will be set as a result of government policy either through market mechanisms (e.g., a cap and trade system) or in the form of a tax (e.g., a carbon tax). As long as $\mathrm{CO}_{2}$ can be emitted in the atmosphere for free, there will be no incentive to sequester $\mathrm{CO}_{2}$ on a large-scale.

In order to implement this approach, one must make explicit assumptions concerning $\mathrm{CO}_{2}$ prices and discount rates. We argue that no matter what methodology one adopts, they all must make assumptions about how to deal with $\mathrm{CO}_{2}$ prices and discount rates. Some methods seem to avoid this task by making these assumptions implicitly. We prefer to confront the issue of the longterm value of $\mathrm{CO}_{2}$ storage and sink enhancement and the discount rate directly as these are values, that while admittedly highly uncertain, where one can appeal to an underlying rationale.

The mathematical formulation for comparing the value and cost of $\mathrm{CO}_{2}$ storage and sink enhancement options differing in timing of costs and in timing and permanence of storage and sink enhancement is shown below. This approach provides a breakeven $\mathrm{CO}_{2}$ price $(\$ /$ tonne of $\mathrm{CO}_{2}$ sequestered) for each $\mathrm{CO}_{2}$ storage and sink enhancement option that reflects differences in timing of costs and in timing and permanence of $\mathrm{CO}_{2}$ storage and sink enhancement. If the calculated breakeven $\mathrm{CO}_{2}$ price is less than the market $\mathrm{CO}_{2}$ price, then the proposed project has favorable economics. However, if the calculated breakeven $\mathrm{CO}_{2}$ price is greater than the market $\mathrm{CO}_{2}$ price, then the proposed project is not economical. The breakeven carbon price is very project specific and care must be taken when trying to generalize the results beyond a given project. In this study, we look specifically at sequestration in conjunction with an IGCC power plant. Extrapolating the results to other types of power plants is not necessarily valid.

The net present value (NPV) of the revenues from $\mathrm{CO}_{2}$ storage and sink enhancement options differing in timing and permanence is calculated as follows ${ }^{3}$ :

$$
N P V=\sum_{t=0}^{t=100} p(t) a(t)(1+r)^{-t}
$$

where $\mathbf{p}$ is the $\mathrm{CO}_{2}$ price (\$/tonne), $\mathbf{a}$ is the abatement or avoided emissions (tonnes/yr), $\mathbf{r}$ is the discount rate, and $\mathbf{t}$ is time (yrs). Based on the assessment of cases with constant and variable $\mathrm{CO}_{2}$ prices, we concluded that considering variable $\mathrm{CO}_{2}$ prices is beyond the scope of this project. Assuming a constant $\mathrm{CO}_{2}$ price $\left(\mathrm{p}_{\mathrm{o}}\right)$ results in the following form of Equation (5): 


$$
N P V=p_{o} \sum_{t=0}^{t=100} a(t)(1+r)^{-t}
$$

The relative value of $\mathrm{CO}_{2}$ offsets differing in timing and permanence is compared by setting the NPV of $\mathrm{CO}_{2}$ abatement as calculated in Equation (6) equal to the discounted cost (c) of achieving the $\mathrm{CO}_{2}$ offset and solving for a constant breakeven price as follows ${ }^{5}$ :

$$
p_{o} \sum_{t=0}^{t=100} a(t)(1+r)^{-t}=\sum_{t=0}^{t=100} c(t)(1+r)^{-t}
$$

and

Breakeven $p_{o}=\frac{\sum_{0}^{t=100} c(t)(1+r)^{-t}}{\sum_{t=0}^{100} a(t)(1+r)^{-t}}=$ Cost of $\mathrm{CO}_{2}$ sequestration

Equation (8) is used in this project to compare breakeven prices (i.e., costs) for $\mathrm{CO}_{2}$ storage and sink enhancement options differing in timing of costs and in timing and permanence of $\mathrm{CO}_{2}$ storage and sink enhancement. Note that computationally a(t) appears to be discounted in Equation (8); however, the discount term in the denominator actually arises from discounting $\mathrm{CO}_{2}$ revenues as shown in Equation (5).

In this project, Equation (8) is used with a planning horizon of 100. This planning horizon is long enough to reflect typical project life cycles for all the $\mathrm{CO}_{2}$ storage and sink enhancement options included in this project.

Equation (8) reduces to a ratio of total $\mathrm{CO}_{2}$ abatement costs to total avoided emissions for cases in which annual $\mathrm{CO}_{2}$ storage costs and annual avoided emissions are in the same proportion over time. For the $\mathrm{CO}_{2}$ capture and storage options in this project, $\mathrm{CO}_{2}$ abatement costs and $\mathrm{CO}_{2}$ avoided emissions are levelized over time for years 1-20. This means that for years 1-20 of the $\mathrm{CO}_{2}$ capture and storage options, the breakeven price is the same on a discounted and a nondiscounted basis. However, when monitoring and/or transaction costs are included for years 21-100, the breakeven price is affected by discounting. For forestry and cropland options, the breakeven price is significantly affected by discounting.

The 6.09 percent after-tax discount rate (constant dollar basis) used for capture and storage of $\mathrm{CO}_{2}$ (Table 2-1) was also used in base cases for cropland and forestry $\mathrm{CO}_{2}$ sink enhancement options. The rationale for using the same discount rate for the $\mathrm{CO}_{2}$ capture/storage and $\mathrm{CO}_{2}$ sink enhancement options is that funding for both types of projects would come from an electric utility seeking to receive credits for reducing GHG emissions. A utility likely would use the same discount rate for evaluating GHG abatement investments regardless of whether the investments involve $\mathrm{CO}_{2}$ capture and storage or $\mathrm{CO}_{2}$ sink enhancement. 


\subsection{References}

1 DOE/EPRI. 2000. Evaluation of innovative fossil fuel power plants with $\mathrm{CO}_{2}$ removal. EPRI, Palo Alto, California; U.S. Department of Energy-Office of Fossil Energy, Germantown, Maryland, and U.S. Department of Energy/NETL, Pittsburgh, Pennsylvania: 1000316.

2 EPRI. 1999. TAG ${ }^{\circledR}$ Technical assessment guide: Volume 3, Revision 8: Fundamentals and methods electricity supply. Palo Alto, California. TR-100281-V3R8.

3 Herzog, Howard, Ken Caldeira, and John Reilly. 2002. An issue of permanence: Assessing the effectiveness of ocean and carbon sequestration. In review.

4 Marland, G., K. Fruit, and R. Sedjo. 2002. Accounting for sequestered carbon: The question of permanence. Environmental Science \& Policy. In press.

5 McCarl, Bruce A., Uwe Schnider, Brian Murray, Jimmy Williams, and Ronald D. Sands. 2001. Economic potential of greenhouse gas emission reductions: Comparative role for soil sequestration in agriculture and forestry. First National Conference on Carbon Sequestration. http://www.netl.doe.gov/publications/proceedings/01/carbon_seq/4c3.pdf.

6 Noble, I., M. Apps, R. Houghton, D. Lashof, W. Makundi, D. Murdiyarso, B. Murray, W. Sombroek, and R. Valentini. 2000. Implications of different definitions and generic issues. In: Watson, R. T., I. R. Noble, B. Bolin, N. H. Ravindranath, D. J. Verado, and D. J. Dokkens (eds.). Land use, land use change, and forestry. Cambridge University Press, Cambridge, United Kingdom, pp. 53-156.

7 Ramaswamy, V., O. Boucher, J. Haigh, D. Hanglustaine, J. Haywood, G. Myhre, T. Nakajima, G. Y. Shi, and S. Solomon. "Radiative Forcing of Climate Change." 2001. In: Climate Change 2001: The Scientific Basis. Contribution of Working Group I to the Third Assessment Report of the Intergovernmental Panel on Climate Change.

J. T. Houghton, Y. Ding, D. J. Griggs, M. Noguer, P. J. van der Linden, X. Dai, K. Maskell, and C. A. Johnson (eds.). Cambridge University Press, Cambridge, United Kingdom and New York, New York, USA, 881 pp., 2001. 


\section{STORING CAPTURED $\mathrm{CO}_{2}-$ BASIS \& APPROACH}

\subsection{Technologies Evaluated}

The following transportation and injection processes for captured $\mathrm{CO}_{2}$ were evaluated in this study:

- Overland pipeline transport (Chapter 4)

- Enhanced oil recovery (Chapter 5)

- Enhanced coalbed methane recovery (Chapter 6)

- Depleted oil reservoir storage (Chapter 7)

- Depleted gas reservoir storage (Chapter 7)

- Deep saline aquifer storage (Chapter 7)

- Ocean storage via pipeline (Chapter 8)

- Ocean storage via tanker (Chapter 9)

For the processes of ocean fertilization and mineralization, it was determined that there was not enough information at this time to develop meaningful conceptual designs and cost estimates. Therefore, these were not included in the evaluations pending more R\&D.

Initially, the same was thought to be true for coalbed methane. However, a recent IEA Greenhouse Gas R\&D Programme Report ${ }^{1}$ assessed the potential of enhanced coalbed methane recovery with $\mathrm{CO}_{2}$ sequestration and concluded, "Injection of carbon dioxide into deep coal seams has the potential to enhance coal-bed methane recovery, while simultaneously sequestering carbon dioxide. Analysis of production operations from the world's first carbon dioxide-enhanced coal-bed methane demonstration plant, in the San Juan Basin, indicates that the process is technically and economically feasible. A recent pilot scheme in Alberta, Canada, should also help to confirm the technical and economic data of this process." Thus, while there is still uncertainty about the effectiveness of $\mathrm{CO}_{2}$ in enhancing the recovery of coalbed methane, the potential is such that it was included in the study.

\subsection{Approach}

Two key areas for all the geologic storage options are the injection/production wells and field equipment/production operations. Two annual surveys, "Joint Association Survey on Drilling Costs", and "Costs and Indices for Domestic Field Equipment and Production Operations"3, 
have for many years tracked costs for drilling and operating domestic oil and gas fields. These costs are disaggregated by depth, regions, well type, and production rate. Our options were tied as closely as possible to these surveys to provide both up-to-date costs and indices that measure the increase or decrease in costs from year to year.

A key area for all the options, including the ocean storage options, is the pipeline used to transport the captured $\mathrm{CO}_{2}$. The MIT Pipeline Transport Model, developed by the MIT Energy Laboratory, ${ }^{4}$ was used for pipeline sizing and costs.

For each option, a baseline conceptual design was generated based on the assumptions discussed below. From the baseline conceptual design, capital, O\&M costs, and an economic analysis with several figures of merits were developed in a spreadsheet format. These were then used to develop sensitivity analyses and life cycle analyses, again in a spreadsheet format.

\subsection{Common Design Basis}

A nominal $500 \mathrm{MW}_{\mathrm{e}}$ gross integrated gasification combined cycle (IGCC) plant operating at an 80 percent capacity factor was utilized as the production source of $\mathrm{CO}_{2}$. This was based on the DOE/EPRI's recent study on the "Evaluation of Innovative Fossil Fuel Power Plants with $\mathrm{CO}_{2}$ Removal." Table 3-1 shows a summary of the parameters used in this study taken from the DOE/EPRI report for Case 3a, "IGCC with $\mathrm{CO}_{2}$ Removal." 
Table 3-1

Summary of parameters for IGCC power plant with $\mathrm{CO}_{2}$ removal

\begin{tabular}{|c|c|c|}
\hline Parameter & Unit & Value \\
\hline Thermal Input, HHV & $10^{6} \mathrm{Btu} / \mathrm{h}$ & 3,723 \\
\hline Gross Power Output & MW & 490.4 \\
\hline Net Power Output & MW & 403.5 \\
\hline Efficiency, HHV & $\%$ & 37.0 \\
\hline Capacity Factor & $\%$ & 80 \\
\hline \multirow[t]{2}{*}{$\mathrm{CO}_{2}$ Captured } & $t / d$ & 7,389 \\
\hline & million scm/d & 3.76 \\
\hline $\mathrm{CO}_{2}$ Emitted & $\mathrm{kg} / \mathrm{kWh}$ & 0.073 \\
\hline $\mathrm{CO}_{2}$ Avoided in Capture & $t / d$ & 6,246 \\
\hline $\mathrm{CO}_{2}$ Capture Cost & $\$ /$ captured & 14.55 \\
\hline $\mathrm{CO}_{2}$ Capture Cost & $\begin{array}{l}\$ / t \text { avoided in } \\
\text { capture }\end{array}$ & 17.21 \\
\hline Plant Life & $y$ & 20 \\
\hline Capital Charge Factor & $\%$ & 15.0 \\
\hline Fuel Cost & \$/GJ & 1.18 \\
\hline Fuel Real Esc. Rate & $\% / y$ & 0.00 \\
\hline Fuel Levelization Factor & & 1.00 \\
\hline TPC & $\$ / \mathrm{kW}$ & 1,642 \\
\hline Fixed O\&M & $\$ / \mathrm{kWy}$ & 32.98 \\
\hline Variable O\&M & $\$ / M W h$ & 3.90 \\
\hline Heat Rate, HHV & $\mathrm{kJ} / \mathrm{kWh}$ & 9,727 \\
\hline Capital & $\$ / M W h$ & 35.04 \\
\hline O\&M & $\$ / M W h$ & 8.61 \\
\hline Fuel & $\$ / M W h$ & 11.44 \\
\hline $\begin{array}{l}\text { Levelized cost of } \\
\text { Energy (LCOE) }\end{array}$ & $\$ / M W h$ & 55.08 \\
\hline
\end{tabular}

The baseline IGCC plant produces two streams of $\mathrm{CO}_{2}$ from the double-stage Selexol acid gas removal process. One stream is at 3.4 bar (50 psia), while the second stream produced at 1.0 bar (15 psia) is boosted to 3.4 bar (50 psia). The combined 3.4 bar (50 psia) $\mathrm{CO}_{2}$ streams are further 
compressed and dehydrated in a multi-stage, intercooled compressor to 83 bar (1,200 psia). The amount of $\mathrm{CO}_{2}$ recovered from the IGCC plant that must be sequestered is 7,389 tonnes per day.

The existing pipeline specification $\left(152 \mathrm{bar},-40^{\circ} \mathrm{C}\right.$ dewpoint, $\mathrm{N}_{2}<300 \mathrm{ppmv}, \mathrm{O}_{2}<40 \mathrm{ppmv}$, $\mathrm{Ar}<10 \mathrm{ppmv}$ ) was used for the quality of the $\mathrm{CO}_{2}$. The DOE/EPRI study is consistent with this except for the $\mathrm{CO}_{2}$ pressure. The DOE/EPRI study was based on compressing the $\mathrm{CO}_{2}$ to 83 bar, although a sensitivity study at 152 bar was done. Our study includes additional compression to 152 bar.

Referring to Figure $3-1$, the $\mathrm{CO}_{2}$ at 83 bar $(1200$ psia $)$ and $41^{\circ} \mathrm{C}\left(105^{\circ} \mathrm{F}\right)$ is above and to the liquid side of the critical point $31.1^{\circ} \mathrm{C}\left(88^{\circ} \mathrm{F}\right)$ and 73.0 bar $(1073 \mathrm{psi})$. By increasing pressure to $152 \mathrm{bar}(2200 \mathrm{psi})$ and $38^{\circ} \mathrm{C}\left(100^{\circ} \mathrm{F}\right)$ or less, the pipeline pressure can drop to about $103 \mathrm{bar}$ (1500 psi) before recompression, and the $\mathrm{CO}_{2}$ mass is ensured of retaining flow properties approximating a liquid. This boost compression adds an additional power requirement of $2,650 \mathrm{~kW}$. The $\mathrm{CO}_{2}$ stream is dried to a $-40^{\circ} \mathrm{C}$ dewpoint and contains $\mathrm{N}_{2}<300 \mathrm{ppmv}$, $\mathrm{O}_{2}<40$ ppmv, and $\mathrm{Ar}<10$ ppmv to prevent corrosion.

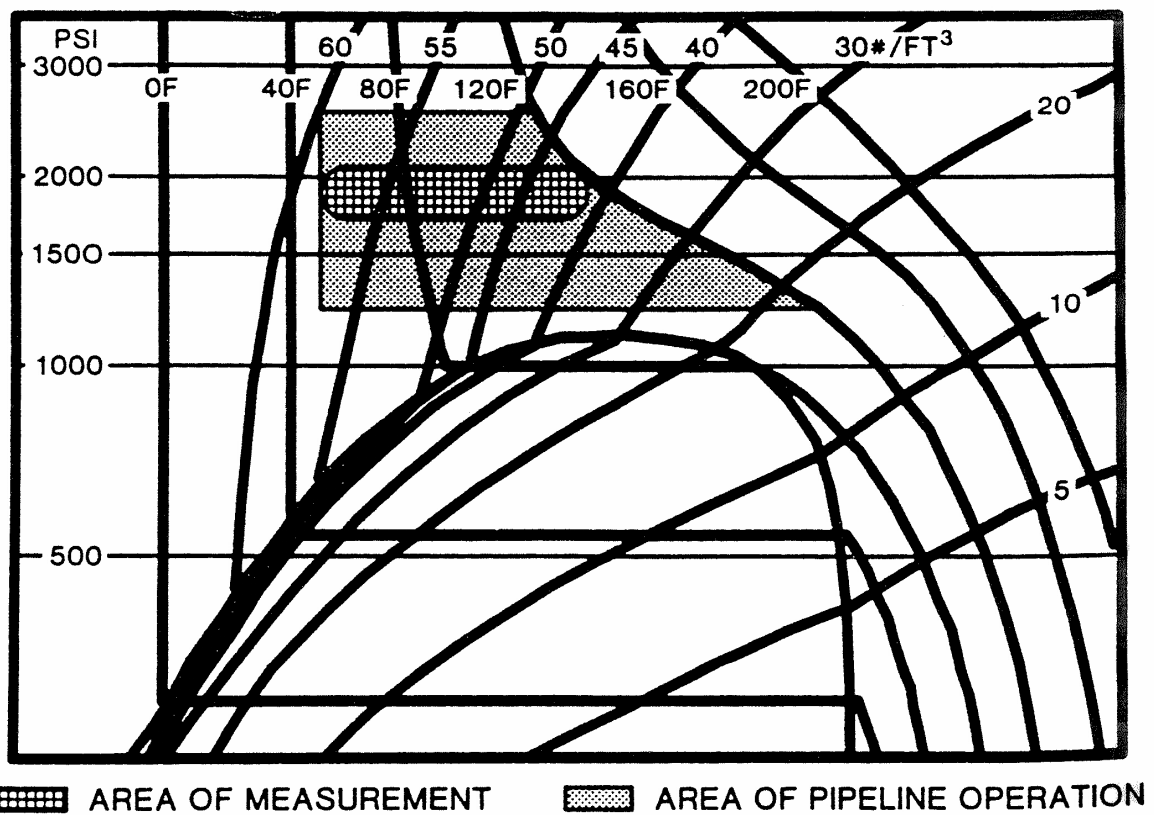

Figure 3-1

Note: ${ }^{\circ} \mathrm{C}=\left({ }^{\circ} \mathrm{F}-32\right) / 1.8,1 \mathrm{bar}=14.5 \mathrm{psi}$

Carbon dioxide pressure enthalpy diagram

\subsection{Greenhouse Gas Emissions Inventory}

The atmospheric greenhouse gas emissions for the full fuel cycle including coal mining, transportation, power conversion, and carbon sequestration for the EOR option are listed in Table 3-3. The emissions are presented in terms of tonnes per year of the gases emitted. These figures are based on the heat and material balance data for Case $3 \mathrm{a}$ presented in the DOE/EPRI recent study on the "Evaluation of Innovative Fossil Fuel Power Plants with $\mathrm{CO}_{2}$ Removal.", 
Case 3a was based on an IGCC power system with an output of $404 \mathrm{MW}_{\mathrm{e}}$ and a HHV efficiency of 37.0 percent. Over 90 percent of the carbon in the coal was captured and sequestered as 7,389 tonnes per day of $\mathrm{CO}_{2}$ (2.16 million tonnes per year). Annual emissions were based on a capacity factor of 80 percent.

Many of the assumptions for emissions from mining, coal transport, and construction, which are discussed below, were taken from previous studies, especially the ETSU study. ${ }^{6}$ The emissions from the power plant were based on DOE/EPRI Case 3a material balance and emissions estimate. $^{5}$

\subsubsection{Emissions from Deep Mining}

Based on DOE/EPRI Case 3a, the total coal feed to the IGCC plant is 1.01 million tonnes per year. The deep-mined coal source in the U.S. is expected to have high methane content. The methane content of coal mines can vary widely over short distances. In addition to the methane contained in the coal seams, methane also seeps from the strata surrounding the coal mine. The amount of pure $\mathrm{CH}_{4}$ released is expected to be about $10 \mathrm{Nm}^{3} /$ tonnes of coal mined. ${ }^{7}$ This gas is partly recovered, mixed with air and other gases to give a total apparent gas release of about twice this flow rate. Table 3-2 gives the typical composition of gas recovered from a coal mine.

Table 3-2

Typical composition of recovered coal mine gas

\begin{tabular}{|l|c|}
\hline Gas & \% Volume \\
\hline $\mathrm{CH}_{4}$ & 50 \\
\hline VOCs & 2 \\
\hline $\mathrm{O}_{2}$ & 7 \\
\hline $\mathrm{N}_{2}$ & 37 \\
\hline $\mathrm{CO}_{2}$ & 4 \\
\hline
\end{tabular}

For underground mining, methane collection of some of the gas is feasible and is required as a safety precaution. The gas is collected as a combustible fuel gas containing variable proportions of air up to 65 percent. The remainder of the released gas is removed from the mine in ventilation air in which the methane content is kept below 0.5 percent. The fraction of the total methane gas that can be recovered as a combustible fuel gas is site specific. For the purpose of this study, it is assumed that 60 percent of the methane released can be collected as combustible gas and burned usefully to generate power or is flared ${ }^{7}$.

On the basis of the analysis of mine methane and 60 percent collection, the atmospheric emissions of unburned gas associated with the production of one tonne of clean coal is $2.86 \mathrm{~kg}$ of $\mathrm{CH}_{4}$ and $0.63 \mathrm{~kg}$ of $\mathrm{CO}_{2}$. 
If it is assumed that all of the collected methane is sufficiently consistent in quality to be burned in an open-cycle gas turbine operating at 33 percent efficiency for power generation, then 60 percent of the power requirements of the mine $(38 \mathrm{kWh} /$ tonne of coal) would be generated.

The balance of the power would be generated from natural gas. The emissions will be the products of combustion of $11.2 \mathrm{~kg} \mathrm{CH}_{4}$ and $0.50 \mathrm{~kg}$ of VOCs per tonne of clean coal. This combustion will yield $33.2 \mathrm{~kg}$ of $\mathrm{CO}_{2}$ per tonne of coal. Emissions of $\mathrm{CH}_{4}$ and $\mathrm{N}_{2} \mathrm{O}$ from burning mine gas are calculated based on the EPA emission factors for gas turbines resulting in emissions of $\mathrm{CH}_{4}$ of $3.4 \times 10^{-3} \mathrm{lb} /$ tonne of coal and $\mathrm{N}_{2} \mathrm{O}$ of $1.2 \times 10^{-3} \mathrm{lb} /$ tonne of coal. ${ }^{8}$

\subsubsection{Emissions from Rail Transport}

The fuel consumption for rail transport of coal in the U.S. is $0.25 \mathrm{MJ} /$ tonne-kilometer. $^{9}$ For the IGCC case, based on the transport over $100 \mathrm{~km}$ of 1.01 million tonnes per year of U.S. coal, the total annual fuel energy consumption would be $25.36 \mathrm{TJ}$ corresponding to 571 tonnes per year of diesel oil. The corresponding emissions, based on carbon content of 87 percent, would be 1821 tonnes per year of $\mathrm{CO}_{2}$. Other emissions are calculated from EPA emission factors for locomotives. ${ }^{10}$

\subsubsection{Emissions from the Operation of the Power Plant}

The power plant data for IGCC is based on $\mathrm{CO}_{2}$ abatement by shift conversion and scrubbing of $\mathrm{CO}_{2}$ from the fuel gas prior to the combustion of hydrogen in a gas turbine. The $\mathrm{CO}_{2}$ emissions are derived from the mass balance data reported in Reference 1. $\mathrm{N}_{2} \mathrm{O}$ content of the IGCC gas turbine exhaust is estimated to be 0.5 ppm. ${ }^{6}$ The $\mathrm{N}_{2} \mathrm{O}$ emissions were calculated from the design flow rate of stack gas of $510 \mathrm{Nm}^{3} / \mathrm{s}$, which is equivalent to $12.9 \times 10^{9} \mathrm{Nm}^{3} /$ year. Since there are no hydrocarbons in the gas turbine fuel, the gas turbine exhaust will be free from methane.

\subsubsection{Emissions from the Construction and Decommissioning of the Power Plant}

The bulk construction materials required for power plants are essentially steel, cement, and aggregate. The energy requirements of these commodities are reported as about 22,5 , and $0.12 \mathrm{GJ} /$ tonne respectively. ${ }^{6,11}$ The amount of material required for the construction of power plants is broadly proportional to the size and complexity of the power plant, which is in turn proportional to its cost. Analysis of the data available ${ }^{6}$ showed typical steel, cement, and aggregate consumption in the ratio 1:1:6; therefore, the overall construction energy requirement for a power plant is estimated to be about $28 \mathrm{GJ} /$ tonne of steel used in the plant.

Analysis of plant cost information ${ }^{6}$ indicates a steel utilization in power plant projects of the order of one tonne of steel per $\$ 50,000$ of total investment. On the basis of this rule of thumb, the energy requirement for construction of the IGCC power plant is estimated to be about 404,000 GJ. Other energy consumption on the construction site is assumed to be trivial in comparison with the energy requirement of the construction materials. 
To determine the emissions associated with the energy expended in making the steel and cement, it is assumed that gas will be used to supply the energy for making construction materials. The total energy consumption in construction corresponds to 1.5 percent of the annual energy consumption of the power plant. The associated emissions are assumed to be equivalent to the emissions from natural gas combustion. ${ }^{12}$ In addition, 0.4 tonnes of $\mathrm{CO}_{2}$ is emitted from the manufacture of one tonne of cement. Therefore, an additional 6,000 tonnes of $\mathrm{CO}_{2}$ arises from this source.

The decommissioning of the power plant at the end of its useful life will involve some expenditure of energy depending on the use that is made of the site. There will be some recycling of steel from the decommissioning operation that is a less energy intensive operation than the making of new steel; therefore, an energy credit could accrue. For the purpose of this study, it is assumed that there will be a net energy consumption for decommissioning equal to a nominal 10 percent of the energy consumed in the construction of the power plant. Emissions for decommissioning are, therefore, calculated on the basis of 10 percent of the emissions from the construction of the power plant.

For the purpose of the development of a single emissions inventory, the emissions associated with power plant construction and decommissioning are presented as if the emissions were produced continuously over the 20-year lifetime of the plant.

\subsubsection{Emissions from the Compression of $\mathrm{CO}_{2}$}

Emissions for the power used for compression are based on the power plant's life cycle emissions. The emissions from the construction and decommissioning of the $\mathrm{CO}_{2}$ compression unit located at the power plant were based on the same assumptions as were used for the power plant.

\subsubsection{Emissions from the Transportation of $\mathrm{CO}_{2}$}

The amount of steel for the pipeline construction was based on the amount of steel needed for the size pipe used, $97.3 \mathrm{~kg}$ per $\mathrm{m}(65.4 \mathrm{lb}$ per $\mathrm{ft})$ for the 12 -inch pipe. The emissions from the construction and decommissioning of the pipeline were based on the same energy assumptions (28 GJ/tonne of steel used) as were used for the power plant.

\subsubsection{Emissions from the $\mathrm{CO}_{2}$ Storage Options}

Emissions for the power used for storage are based on the power plant's life-cycle emissions. The emissions from the construction and decommissioning of the $\mathrm{CO}_{2}$ storage systems were based on the same assumptions as were used for the power plant. In the case of ocean storage via tanker, it was also necessary to consider the $\mathrm{CO}_{2}$ emitted by the tankers and due to boil off. The methodology used to calculate the $\mathrm{CO}_{2}$ emitted from these sources is described in Section 9.4.3. 
Table 3-3

Greenhouse gas life-cycle analysis

\begin{tabular}{|c|c|c|c|}
\hline \multicolumn{4}{|l|}{ With $\mathrm{CO}_{2}$ Capture (Case 3a) } \\
\hline \multirow[t]{2}{*}{ IGCC Plant } & \multicolumn{3}{|c|}{$\begin{array}{c}\text { GHG Emissions } \\
\text { tonnes/year }\end{array}$} \\
\hline & $\mathrm{CO}_{2}$ & $\mathrm{~N}_{2} \mathrm{O}$ & $\mathrm{CH}_{4}$ \\
\hline Coal Mine & 33,698 & 0.5 & 1.6 \\
\hline Mine Methane Vented & 639 & minor & 2,901 \\
\hline Coal Train & 1,821 & minor & minor \\
\hline Power Plant Emissions & 205,812 & 11.0 & minor \\
\hline Power Plant Construction & 1,243 & 0.0 & 0.0 \\
\hline Power Plant Decommissioning & 124 & 0.0 & 0.0 \\
\hline Total Power Plant & 243,338 & 12 & 2,903 \\
\hline 100 Year Multiplier & 1 & 296 & 23 \\
\hline Total Power Plant $\mathrm{CO}_{2}$ Equivalent & 243,338 & 3,433 & 66,762 \\
\hline Total (mg CO 2 Equivalent / kWh) & 86,053 & 1,214 & 23,609 \\
\hline Power Plant Total ( $m g \mathrm{CO}_{2}$ Equivalent / $\mathrm{kWh}$ ) & 110,876 & & \\
\hline \multicolumn{4}{|l|}{ Compression of Captured $\mathrm{CO}_{2}$ to Pipeline Spec } \\
\hline \multicolumn{4}{|l|}{$\mathrm{CO}_{2}$ Compression } \\
\hline Compression Power & 1,598 & 0.1 & 19 \\
\hline Construction & 6.1 & 0.0 & 0.1 \\
\hline Decommissioning & 0.6 & 0.0 & 0.0 \\
\hline Total & 1,605 & 0.1 & 19 \\
\hline 100 Year Multiplier & 1 & 296 & 23 \\
\hline $\mathrm{CO}_{2}$ Equivalent & 1,605 & 23 & 441 \\
\hline $\mathrm{CO}_{2}$ Compression Total $\left(\mathrm{CO}_{2}\right.$ Equivalent $)$ & 2,068 & & \\
\hline \multirow{2}{*}{\multicolumn{4}{|c|}{$\begin{array}{l}\text { Transportation \& Sequestration of Captured } \mathrm{CO}_{2} \\
\mathrm{CO}_{2} \text { Transportation }\end{array}$}} \\
\hline & & & \\
\hline Pipeline Construction & 913 & 0.0 & 0.0 \\
\hline Pipeline Decommissioning & 91 & 0.0 & 0.0 \\
\hline Total & 1,005 & 0 & 0 \\
\hline \multicolumn{4}{|l|}{$\mathrm{CO}_{2}$ Sequestration-EOR } \\
\hline Power & 128,378 & 1 & 155 \\
\hline \multicolumn{4}{|l|}{ Plant Construction } \\
\hline Aboveground Equipment & 279 & 0.0 & 0.0 \\
\hline Subsurface Equipment & 64 & 0.0 & 0.0 \\
\hline Plant Decommissioning & 34 & 0.0 & 0.0 \\
\hline Total & 128,755 & 1 & 155 \\
\hline CO2 Transportation \& Sequestration Total & 129,759 & 1 & 155 \\
\hline 100 Year Multiplier & 1 & 296 & 23 \\
\hline $\mathrm{CO}_{2}$ Equivalent & 129,759 & 210 & 3,569 \\
\hline Transportation \& Sequestration Total $\left(\mathrm{CO}_{2}\right.$ Equivalent $)$ & 133,538 & & \\
\hline
\end{tabular}




\subsection{References}

1 "Enhanced Coal Bed Methane Recovery with $\mathrm{CO}_{2}$ Sequestration." IEA Greenhouse Gas R\&D Programme. Report Number PH3/3, August 1998.

2 "1998 Joint Association Survey on Drilling Costs." American Petroleum Institute, Policy Analysis and Statistics Department, November 1999. http://www.api.org/axsapi/products/joint.htm.

3 "Costs and Indices for Domestic Oil and Gas Field Equipment and Production Operations." Energy Information Administration, Office of Oil and Gas, March 2000. http://www.eia.doe.gov/oil_gas/natural_gas/data_publications/cost_indices/c_i.html.

4 “A Cost Model for Transport of Carbon Dioxide." The Energy Laboratory, Massachusetts Institute of Technology, January 2000.

5 "Evaluation of Innovative Fossil Fuel Power Plants with $\mathrm{CO}_{2}$ Removal." EPRI Report No. 1000316, Interim Report, December 2000. Cosponsors: U.S. Department of Energy/Office of Fossil Energy and U.S. Department of Energy/NETL, EPRI Project Manager N. A. H. Holt.

6 "Full Fuel Cycle Study on Power Generation Schemes Incorporating the Capture and Disposal of Carbon Dioxide." ETSU, United Kingdom, October 1994.

7 “Methane Emissions from Coal Mining.” IEA GHG Report PH2/5, June 1996.

8 Gas Turbine Emission Factors. http://www.epa.gov/ttn/chief/ap42/ch03/final/c03s01.pdf.

9 Khoury. "Coal Cleaning Technology." Edited by D. L. Khoury, Noyes Data Corporation, 1981.

10 Locomotive Emission Factors. http://www.epa.gov/oms/invntory/r92009.pdf.

11 Boustead, I., and G. F. Hancock. "Handbook of Industrial Energy Analysis." Wiley and Sons, 1979.

12 Gas Combustion Emission Factors, http://www.epa.gov/ttn/chief/ap42/ch01/final/c01s04.pdf. 


\section{4 \\ PIPELINE TRANSPORT}

\subsection{Introduction}

This chapter looks at the transport of $\mathrm{CO}_{2}$ via pipeline from the base case IGCC power plant to the injection site, for the geologic storage options, and the shoreline collection point, in the case of the ocean storage options.

\subsection{State of the Art}

Over 110 million standard cubic meters $(\mathrm{scm})$ per day of $\mathrm{CO}_{2}$ are transported by pipeline in the United States, frequently for distances greater than $100 \mathrm{~km}$. Details of currently operating $\mathrm{CO}_{2}$ pipelines in the United States are given in Table 4-1.,2,3,4,5,6 
Table 4-1

$\mathrm{CO}_{2}$ pipelines in the United States

\begin{tabular}{|c|c|c|c|c|c|c|}
\hline Name & Operator & Route & $\mathrm{CO}_{2}$ Source & $\begin{array}{c}\text { Length } \\
(\mathbf{k m})\end{array}$ & Diameter (in) & $\begin{array}{l}\text { Capacity (10 } \\
\text { scm per day) }\end{array}$ \\
\hline Cortez Pipeline $^{2}$ & $\begin{array}{c}\text { Kinder Morgan } \\
\mathrm{CO}_{2}\end{array}$ & $\begin{array}{c}\text { McElmo Dome } \\
\text { to Denver City } \\
\mathrm{CO}_{2} \mathrm{Hub}\end{array}$ & $\begin{array}{c}\text { Natural } \mathrm{CO}_{2} \\
\text { deposit }\end{array}$ & 311 & 30 & 28 \\
\hline $\begin{array}{l}\text { McElmo Creek } \\
\text { Pipeline }^{2}\end{array}$ & ExxonMobil & $\begin{array}{l}\text { McElmo Dome } \\
\text { to McElmo } \\
\text { Creek Unit (UT) }\end{array}$ & $\begin{array}{c}\text { Natural } \mathrm{CO}_{2} \\
\text { deposit }\end{array}$ & 25 & 8 & 2 \\
\hline Bravo Pipeline $^{2}$ & $\mathrm{BP}$ & $\begin{array}{c}\text { Bravo Dome to } \\
\text { Denver City } \mathrm{CO}_{2} \\
\mathrm{Hub}\end{array}$ & $\begin{array}{c}\text { Natural } \mathrm{CO}_{2} \\
\text { deposit }\end{array}$ & 135 & 20 & 11 \\
\hline $\begin{array}{l}\text { Sheep Mountain } \\
\mathrm{I}^{2}\end{array}$ & $\mathrm{BP}$ & $\begin{array}{l}\text { Sheep Mountain } \\
\text { Field to } \\
\text { Rosebud } \\
\text { connection with } \\
\text { Bravo Dome }\end{array}$ & $\begin{array}{c}\text { Natural } \mathrm{CO}_{2} \\
\text { deposit }\end{array}$ & 114 & 20 & 9 \\
\hline $\begin{array}{l}\text { Sheep Mountain } \\
\|^{2}\end{array}$ & $\mathrm{BP}$ & $\begin{array}{c}\text { Rosebud } \\
\text { connection to } \\
\text { Denver City } \mathrm{CO}_{2} \\
\mathrm{Hub} \text { and onward } \\
\text { to Seminole San } \\
\text { Andres Unit (TX) }\end{array}$ & $\begin{array}{c}\text { Natural } \mathrm{CO}_{2} \\
\text { deposit }\end{array}$ & 139 & 24 & 14 \\
\hline $\begin{array}{l}\text { Central Basin } \\
\text { Pipeline }^{2}\end{array}$ & $\begin{array}{l}\text { Kinder Morgan } \\
\mathrm{CO}_{2}\end{array}$ & $\begin{array}{c}\text { Denver City } \mathrm{CO}_{2} \\
\text { Hub to } \\
\text { McCamey, TX }\end{array}$ & - & - & 26,16 & 17 \\
\hline Este Pipeline $^{2}$ & ExxonMobil & $\begin{array}{c}\text { Denver City } \mathrm{CO}_{2} \\
\text { Hub to Salt } \\
\text { Creek, TX }\end{array}$ & - & 74 & 12,14 & 7 \\
\hline $\begin{array}{l}\text { Slaughter } \\
\text { Pipeline }^{2}\end{array}$ & ExxonMobil & $\begin{array}{c}\text { Denver City } \mathrm{CO}_{2} \\
\text { Hub to Hockley } \\
\text { County, TX }\end{array}$ & - & 25 & 12 & 5 \\
\hline $\begin{array}{l}\text { West Texas } \\
\text { Pipeline }^{2}\end{array}$ & Trinity Pipeline & $\begin{array}{c}\text { Denver City } \mathrm{CO}_{2} \\
\text { Hub to Reeves } \\
\text { County, TX }\end{array}$ & - & 79 & 12,8 & 3 \\
\hline
\end{tabular}




\section{Table 4-1 (continued)}

$\mathrm{CO}_{2}$ pipelines in the United States

\begin{tabular}{|c|c|c|c|c|c|c|}
\hline Name & Operator & Route & $\mathrm{CO}_{2}$ Source & $\begin{array}{c}\text { Length } \\
(\mathbf{k m})\end{array}$ & Diameter (in) & $\begin{array}{l}\text { Capacity }\left(10^{6}\right. \\
\text { scm per day) }\end{array}$ \\
\hline $\begin{array}{l}\text { Llano Lateral } \\
\text { Pipeline }^{2}\end{array}$ & Trinity Pipeline & $\begin{array}{c}\text { runs off Cortez } \\
\text { main line to } \\
\text { Llano, NM }\end{array}$ & $\begin{array}{c}\text { Natural } \mathrm{CO}_{2} \\
\text { deposit }\end{array}$ & 33 & 12,8 & 3 \\
\hline $\begin{array}{l}\text { Canyon Reef } \\
\text { Carriers } \\
\text { Pipeline }\end{array}$ & $\begin{array}{c}\text { Kinder Morgan } \\
\mathrm{CO}_{2}\end{array}$ & $\begin{array}{l}\text { McCamey, TX to } \\
\text { SACROC field }\end{array}$ & - & 87 & 16 & 7 \\
\hline $\begin{array}{l}\text { Val Verde } \\
\text { Pipeline } e^{5,6}\end{array}$ & PSCC & $\begin{array}{c}\text { connects } \\
\text { Mitchell, Gray } \\
\text { Ranch, Pucket } \\
\text { and Terrell gas } \\
\text { processing } \\
\text { facilities to } \\
\text { Canyon Reef } \\
\text { Carriers main } \\
\text { line }\end{array}$ & $\begin{array}{l}\text { Gas processing } \\
\text { facilities }\end{array}$ & 51 & 10 & 4 \\
\hline $\begin{array}{l}\text { Weyburn } \\
\text { Pipeline }^{3}\end{array}$ & $\begin{array}{c}\text { Dakota } \\
\text { Gasification } \\
\text { Company }\end{array}$ & $\begin{array}{c}\text { Great Plains } \\
\text { Synfuels plant } \\
\text { (Beulah, ND) to } \\
\text { Weyburn field } \\
\text { (Saskatchewan, } \\
\text { Canada) } \\
\end{array}$ & $\begin{array}{l}\text { Coal gasification } \\
\text { plant }\end{array}$ & 127 & 14,12 & 3 \\
\hline $\begin{array}{l}\text { Choctaw } \\
\text { Pipeline }^{4}\end{array}$ & $\begin{array}{c}\text { Denbury } \\
\text { Resources }\end{array}$ & $\begin{array}{c}\text { Jackson Dome } \\
\text { to Bayou } \\
\text { Choctaw Field, } \\
\text { LA } \\
\end{array}$ & $\begin{array}{c}\text { Natural } \mathrm{CO}_{2} \\
\text { deposit }\end{array}$ & 115 & 20 & 6 \\
\hline
\end{tabular}

1 in $=0.0254 \mathrm{~m}$ 
Transported $\mathrm{CO}_{2}$ is most commonly used for enhanced oil recovery (EOR). The use of $\mathrm{CO}_{2}$ for EOR is a proven technology with $72 \mathrm{CO}_{2}$ floods in the United States. ${ }^{7}$ Most of these floods are dependent upon naturally occurring $\mathrm{CO}_{2}$, which is obtained from high-pressure, high-purity underground deposits. The most important of these natural $\mathrm{CO}_{2}$ deposits, in decreasing order of current production, are the McElmo Dome, the Bravo Dome, the Sheep Mountain Field and the Jackson Dome. ${ }^{4,8}$ A small fraction of the $\mathrm{CO}_{2}$ supply comes from anthropogenic sources, including the Mitchell, Gray Ranch, Pucket and Terrell gas processing facilities in the southern Permian basin and the Great Plains coal gasification plant at Beulah, North Dakota. ${ }^{3,6}$

The operation of the Canyon Reef Carriers pipeline, one of the first $\mathrm{CO}_{2}$ pipelines constructed for EOR, provides a reference for future $\mathrm{CO}_{2}$ handling systems. Put into operation in 1972, it recorded only five failures (with no injuries) during its first twelve years of operation. Two failures were explosions at compressor stations that resulted from air (oxygen) being drawn into the suction line from the extraction plant stack line. In order to rectify the problem, the emergency shutdown system was adjusted so that the loss of positive pressure on the suction line would cause the compressors to come to an immediate halt. The three other failures were ruptures at the injection station due to localized 'hot spots' in the tubes of the direct-fired line heater. The first was attributed to the build-up of a corrosion product in a pipe that took place before its installation and was not removed by initial cleaning. The other two ruptures occurred near support brackets where the distribution of flow through the parallel tube arrangement was not equal. Provisions for better temperature monitoring and flow distribution in the heater were put in place to prevent further such accidents. ${ }^{9}$

An important technical consideration in the design of pipelines for transport of supercritical $\mathrm{CO}_{2}$ is that the $\mathrm{CO}_{2}$ remains above critical pressure. This can be achieved by means of recompression of the $\mathrm{CO}_{2}$ at certain points along the length of the pipeline. Recompression is often needed for pipelines over $150 \mathrm{~km}$ (90 miles) in length. It is important to note, however, that recompression may not be needed if a sufficient pipe diameter is used. For example, the Weyburn $\mathrm{CO}_{2}$ pipeline runs for $330 \mathrm{~km}$ (205 miles) from North Dakota to Saskatchewan, Canada, without recompression. ${ }^{10}$

A survey of North American pipeline project costs yields several pertinent observations. First, for a given pipeline diameter, the per unit distance cost of construction is generally lower the longer the pipeline. Second, pipelines built nearer populated areas tend to be more expensive. Finally, road, highway, river, or channel crossings and marshy or rocky terrain also greatly increase the cost. ${ }^{11}$

\subsection{Process Description}

The $\mathrm{CO}_{2}$ for pipeline transport is taken from Case $3 \mathrm{a}$ of the DOE/EPRI Report on $\mathrm{CO}_{2}$ removal from fossil fuel power plants. ${ }^{12}$ This case is used for the design basis since potential $\mathrm{CO}_{2}$ sources from a coal-based power plant would most probably be associated with an IGCC plant. $\mathrm{CO}_{2}$ recovery from IGCC is most economical because of the $\mathrm{CO}_{2}$ concentration in syngas at a high partial pressure, enabling the use of conventional recovery processes. The pipeline is to be designed to handle 3.76 million scm (7,389 tonnes) of $\mathrm{CO}_{2}$ per day. It is important to note that, 
since the capacity factor of the IGCC power plant is assumed to be 80 percent, this $\mathrm{CO}_{2}$ is only supplied 80 percent of the time.

The pipeline design must conform to the United States Department of Transportation (DOT) Codes 49 CFR 195, Transportation of Hazardous Liquids by Pipeline, and 49 CFR 192, Transportation of Natural and Other Gas by Pipeline: Minimum Federal Safety Standards.

\subsection{Methodology Used}

The first stage of the $\mathrm{CO}_{2}$ storage process involves the $\mathrm{CO}_{2}$ being transported via pipeline from the base case IGCC plant to the injection site, for the geologic storage options, and to the shoreline collection point, in the case of the ocean storage options. Overland distances of 100 and $300 \mathrm{~km}$, for the base and sensitivity cases respectively, are considered. The method used to calculate the cost of $\mathrm{CO}_{2}$ pipeline transport can be broken down into a couple of steps. First, the diameter of the pipeline is calculated. Next, based on the calculated diameter, the capital and $\mathrm{O} \& \mathrm{M}$ costs as well as the total cost per tonne of $\mathrm{CO}_{2}$ are found. An overview of the cost model is given in Figure 4-1. The diameter and cost calculations are explained in greater detail below.

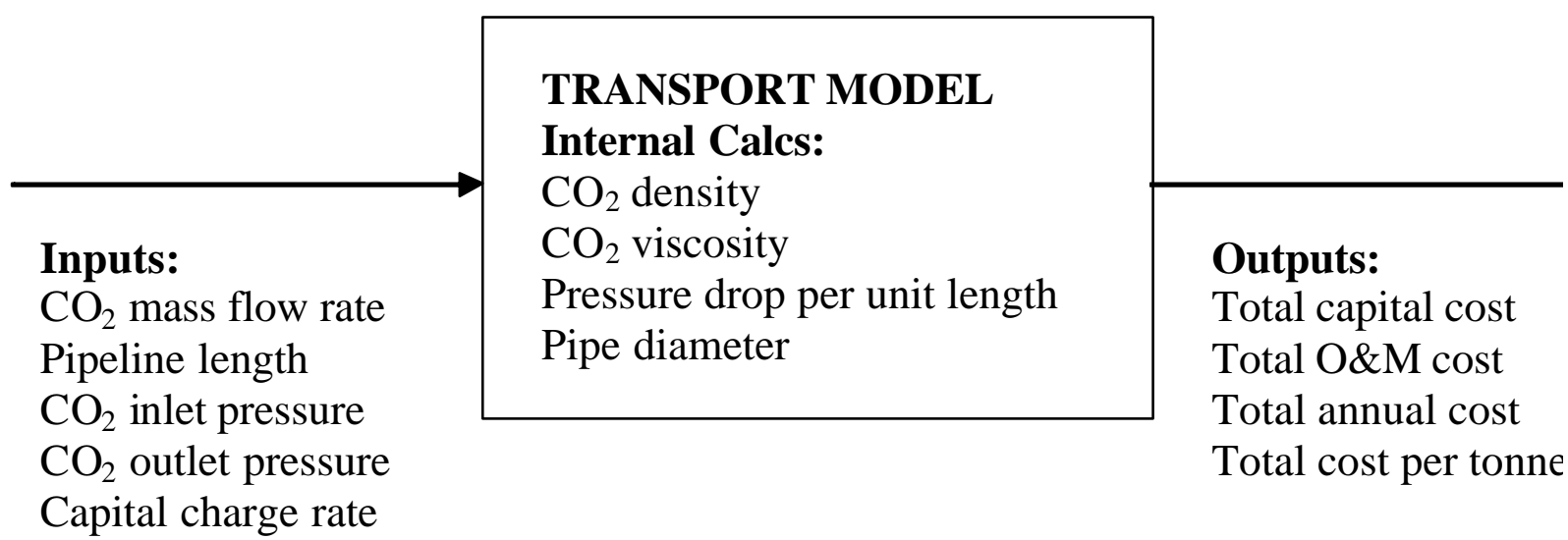

Figure 4-1

Pipeline transport cost model overview diagram

\subsubsection{Diameter Calculation}

The pipeline inlet $\mathrm{CO}_{2}$ pressure is set equal to $152 \mathrm{bar}$, which is equivalent to the pressure of the $\mathrm{CO}_{2}$ supplied by the base case IGCC plant. Based on a recommendation that the pipeline $\mathrm{CO}_{2}$ pressure not be allowed to fall below 103 bar, ${ }^{13}$ this latter value is used for the pipeline outlet $\mathrm{CO}_{2}$ pressure. The maximum allowable pressure drop per unit length $(\Delta \mathrm{P} / \Delta \mathrm{L})$ is found as the difference between the pipeline inlet and outlet $\mathrm{CO}_{2}$ pressures divided by the pipeline length.

Next, based on an assumed ambient temperature of $25^{\circ} \mathrm{C}$, the $\mathrm{CO}_{2}$ density and viscosity are calculated. The $\mathrm{CO}_{2}$ density $(\rho)$ is calculated to be $884 \mathrm{~kg} / \mathrm{m}^{3}$, using a correlation based on data from the National Institute of Standards and Technology (NIST) for a temperature range of 5 to 
$27^{\circ} \mathrm{C}$ and a pressure range of 80 to 140 bar. ${ }^{14}$ The $\mathrm{CO}_{2}$ viscosity $(\mu)$ is found, from a correlation published by Nihous and Bohn, ${ }^{15}$ to be $6.06 \times 10^{-5} \mathrm{~N}-\mathrm{s} / \mathrm{m}^{2}$.

The pipeline diameter is calculated using the equations for pressure drop and head loss due to frictional resistance in a pipe, assuming turbulent flow. This calculation uses an iterative procedure, which initially requires that the diameter be guessed. This guessed value is used to find the Reynolds number ( $\mathrm{Re}$ ) given by

$$
\operatorname{Re}=4 \mathrm{~m} / \pi \mu \mathrm{D}
$$

where $\mathrm{m}$ is the $\mathrm{CO}_{2}$ mass flow rate and $\mathrm{D}$ is the pipeline diameter. Based on this calculated Reynolds number and a roughness factor of $0.00015,{ }^{16}$ the Fanning friction factor (f) is then found using an empirical relationship based on the Moody chart. Combining the equations for pressure drop and head loss gives the simplified formula

$$
\mathrm{D}^{5}=32 \mathrm{fm}^{2} / \pi^{2} \rho(\Delta \mathrm{P} / \Delta \mathrm{L})
$$

from which the diameter is determined. This calculated value of diameter is then used for the next iteration, and so on. 1 in $=0.0254 \mathrm{~m}$

Figure 4-2 gives the diameter, calculated for the base case, as a function of $\mathrm{CO}_{2}$ mass flow rate.

Figure 4-2

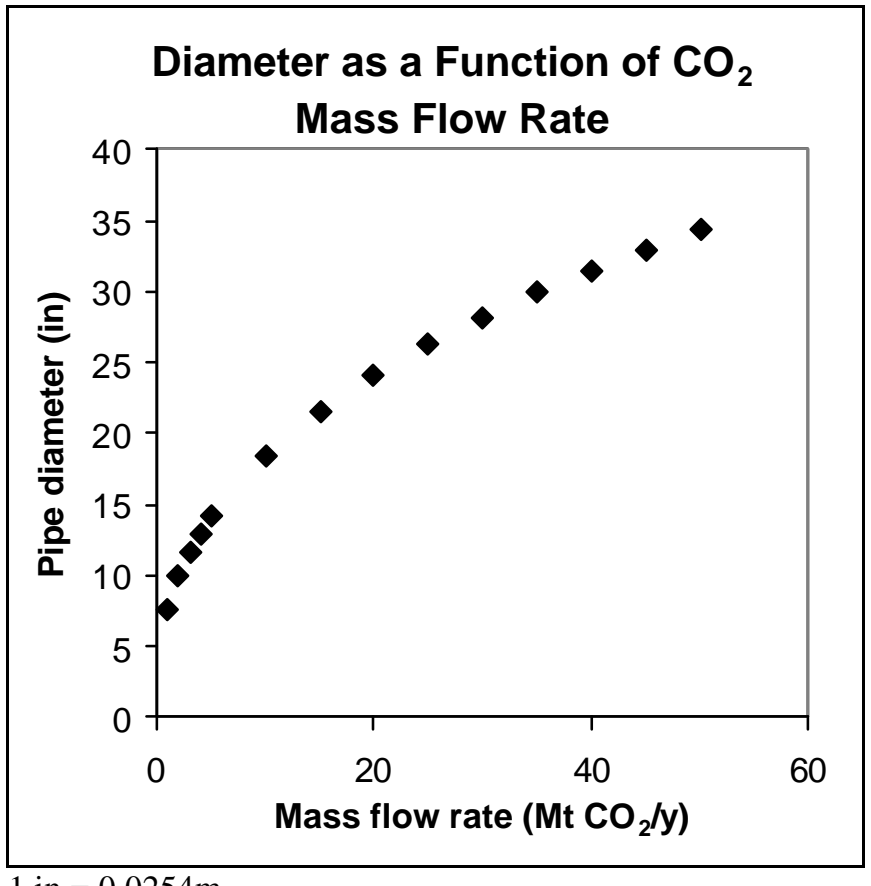

1 in $=0.0254 \mathrm{~m}$

Diameter for the base case as a function of $\mathrm{CO}_{2}$ mass flow rate 


\subsubsection{Cost Calculations}

The amount of cost data on $\mathrm{CO}_{2}$ pipelines in the open literature is very limited, but there is an abundance of cost data for natural gas pipelines. For this reason, land construction cost data for natural gas pipelines were used to estimate construction costs for $\mathrm{CO}_{2}$ pipelines. This is adequate given that there is little difference between land construction costs for these two types of pipeline. ${ }^{8}$ It is worth noting, though, that $\mathrm{CO}_{2}$ pipelines might be slightly more expensive because of the greater wall thickness needed to contain the $\mathrm{CO}_{2}$, which is transported at higher pressures.

The cost data found for natural gas pipelines consists of cost estimates filed with the United States' Federal Energy Regulatory Commission (FERC), and reported in the Oil and Gas Journal. ${ }^{11,17}$ Figure 4-3 gives the breakdown of costs on a dollar per mile basis for four pipeline diameters: $8,16,24$ and 30 inches $(0.20,0.41,0.61$, and $0.76 \mathrm{~m})$. Costs are broken down into material, labor, right-of-way (ROW) and miscellaneous components. Materials can include line pipe, pipe coating, cathodic protection and telecommunications equipment. Right-of-way costs include obtaining the right-of-way and allowing for damages. Miscellaneous costs generally cover surveying, engineering, supervision, contingencies, allowances for funds used during construction, administration and overheads, and regulatory filing fees.

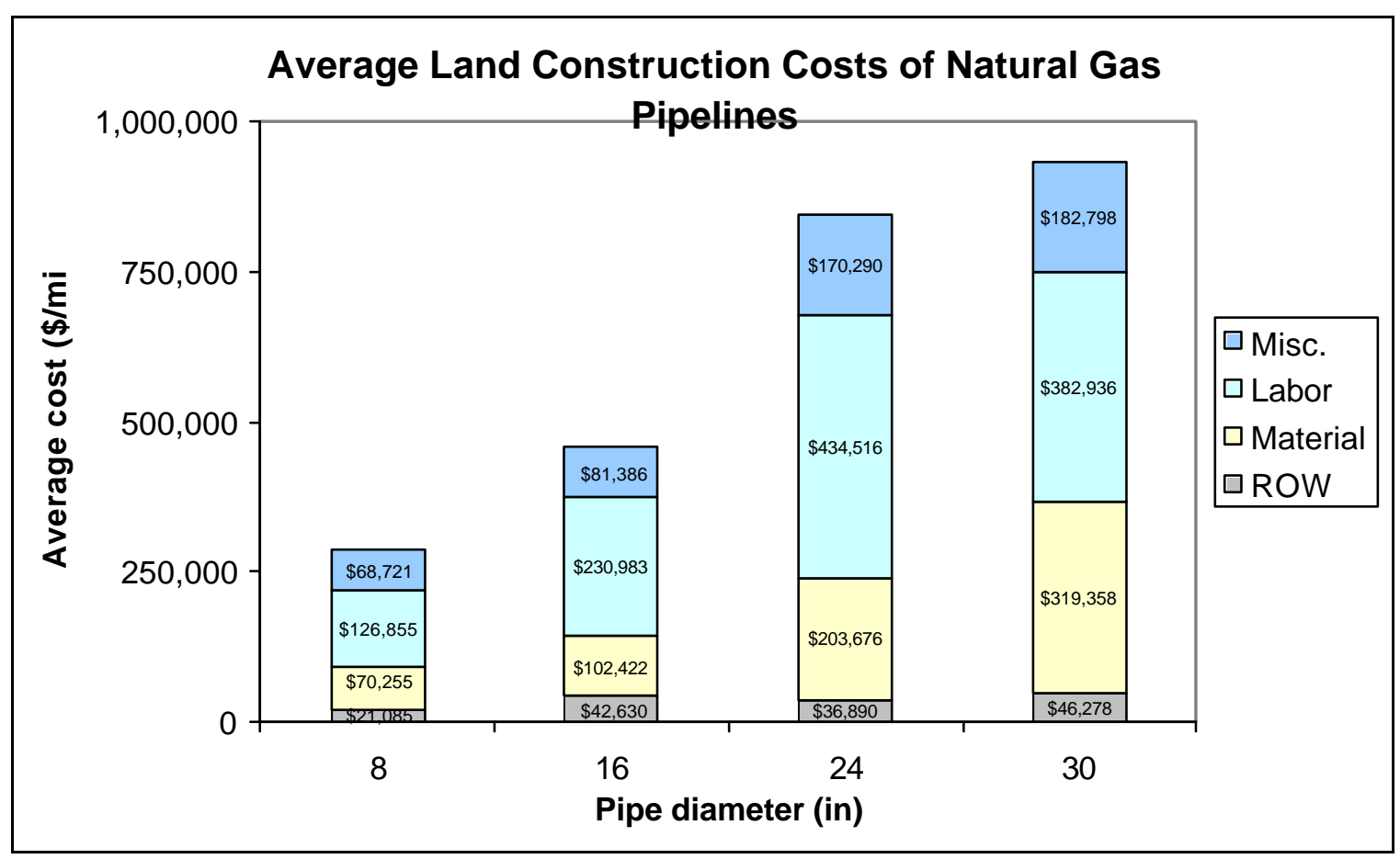

1 in $=0.0254 \mathrm{~m}, 1 \mathrm{mi}=1.61 \mathrm{~km}$

\section{Figure 4-3}

Breakdown of pipeline cost on a dollar per mile basis

A breakdown of costs on a percentage of total cost basis is given in Figure 4-4. The graph suggests that right-of-way costs can be estimated at $5 \%$ of total costs, while labor, material, and 
miscellaneous costs appear to be random percentages of total costs. It is also important to note that each of these costs is independent of pipeline diameter.

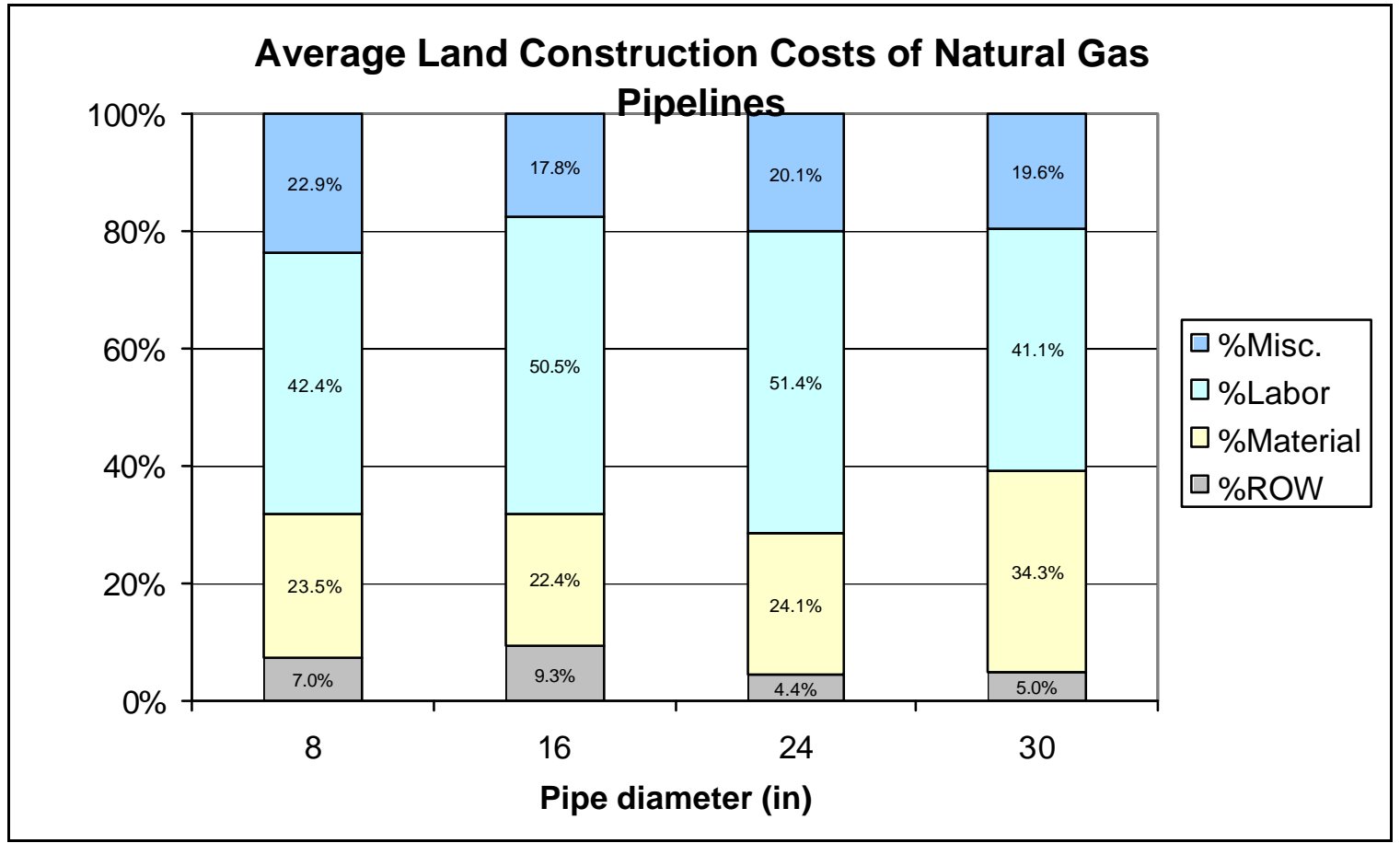

1 in $=0.0254 \mathrm{~m}$

Figure 4-4

Breakdown of pipeline cost on a percentage of total cost basis

Total costs in dollars per mile are plotted against pipeline diameter in Figure 4-5. A regression line fit to this data yields a pipeline construction cost of $\$ 20,989 / \mathrm{in} / \mathrm{km}(\$ 33,853 / \mathrm{in} / \mathrm{mile})$. According to an industry expert ${ }^{13}$ the construction cost for $\mathrm{CO}_{2}$ pipelines should be close to $\$ 12,400 / \mathrm{in} / \mathrm{km}(\$ 20,000 / \mathrm{in} / \mathrm{mile})$. One possible reason for this lower $\mathrm{CO}_{2}$ pipeline construction cost estimate is that $\mathrm{CO}_{2}$ pipelines are currently constructed in sparsely populated areas. Another is that the rock in New Mexico and West Texas where most $\mathrm{CO}_{2}$ pipelines have been laid is easy to dig in. It is important to note that neither cost figure includes recompression costs. 


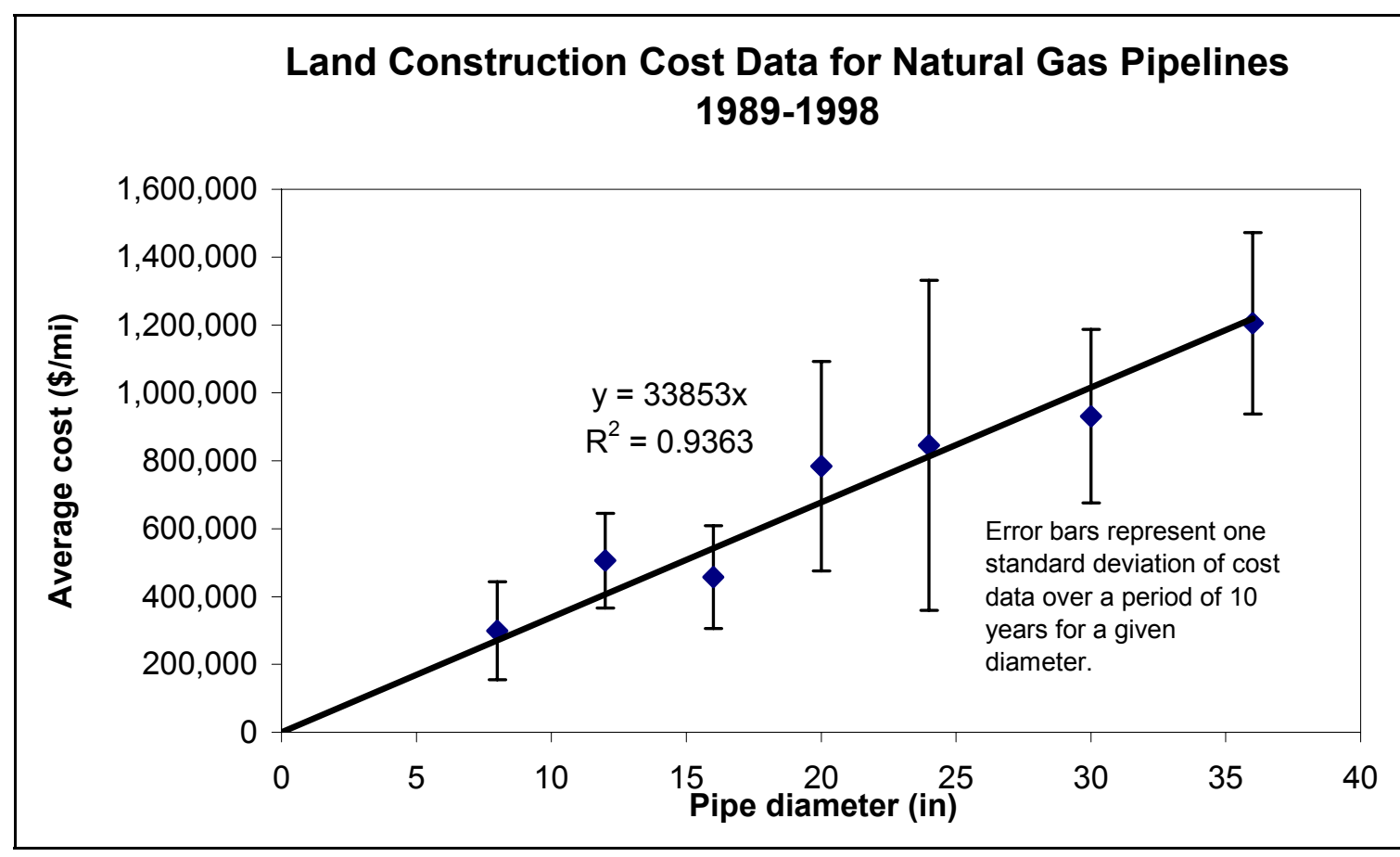

Figure 4-5

$1 \mathrm{in}=0.0254 \mathrm{~m}, 1 \mathrm{mi}=1.61 \mathrm{~km}$

Regression analysis of pipeline construction cost data

It has been reported that it costs about $\$ 40,000$ to $\$ 60,000$ per month to operate $480 \mathrm{~km}$ (300 miles) of pipeline and that this figure should be doubled to account for associated overhead costs. ${ }^{13}$ Taking the higher value to be on the conservative side, O\&M costs are estimated to be $\$ 3,100 / \mathrm{km}(\$ 5,000 / \mathrm{mile})$ per year, independent of pipeline diameter. It should be noted that this O\&M cost estimate does not account for pumping or its associated costs.

Total pipeline construction cost is found using the $\$ 20,989 / \mathrm{in} / \mathrm{km}(\$ 33,853 / \mathrm{in} / \mathrm{mile})$ cost factor. Applying the O\&M cost factor of $\$ 3,100 / \mathrm{km}(\$ 5,000 /$ mile), gives the respective total O\&M costs. Finally, the total annual cost per tonne of $\mathrm{CO}_{2}$ is found by annualizing the construction cost using a capital charge rate of 15 percent per year and adding this to the annual O\&M cost. Figure 4-6 shows the cost per tonne of $\mathrm{CO}_{2}$, calculated for the base case, as a function of $\mathrm{CO}_{2}$ mass flow rate. 


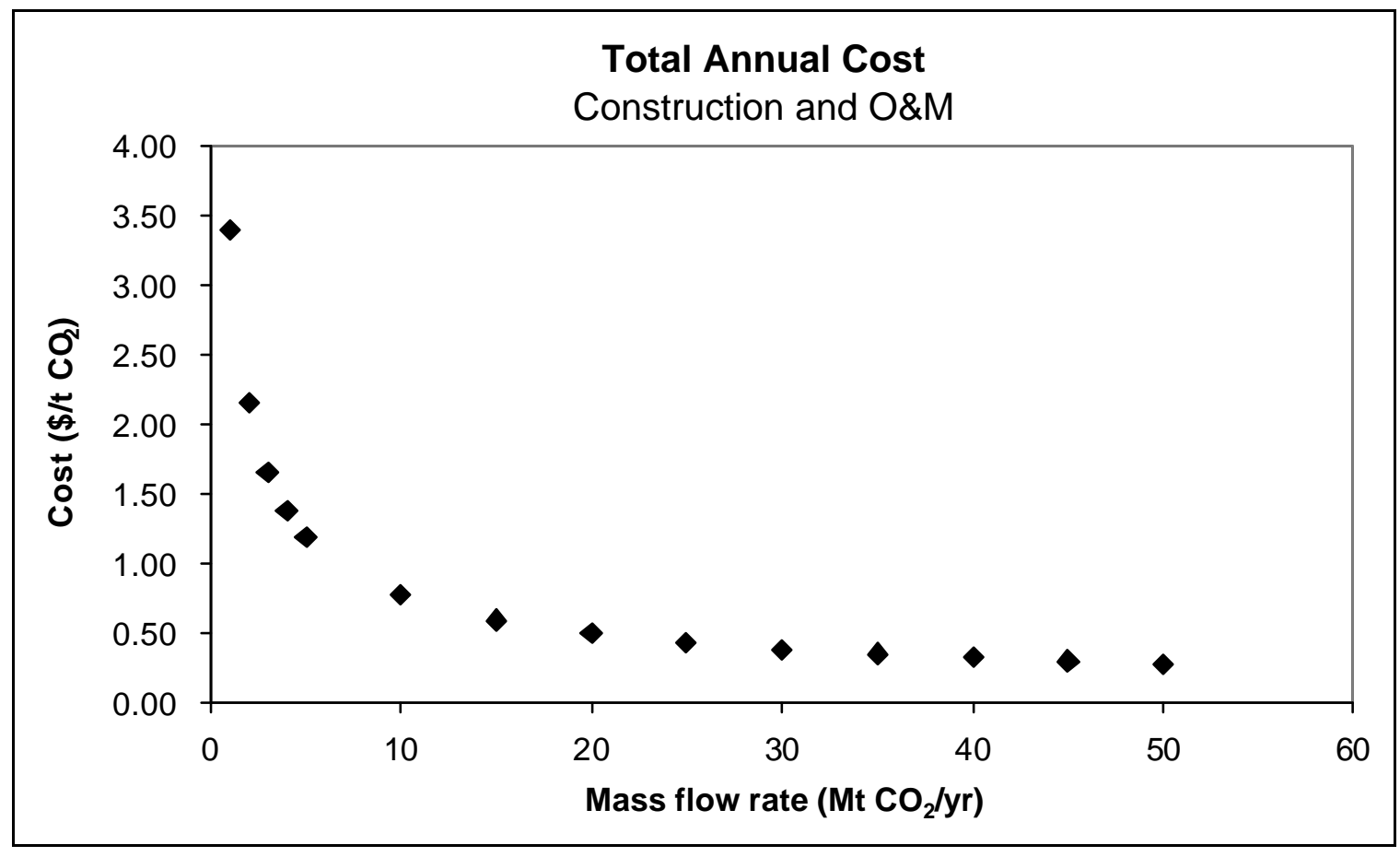

Figure 4-6

Total cost per tonne of $\mathrm{CO}_{2}$ for the base case as a function of $\mathrm{CO}_{2}$ mass flow rate

\subsection{Design Basis}

\subsubsection{Pipeline Design}

The methodology described in Section 4.4.1 was used to determine pressure drop per unit length and pipeline diameter for the base and sensitivity cases. The design bases for pipeline transport are summarized in Table 4-2.

Table 4-2

Design bases for pipeline transport

\begin{tabular}{|l|c|c|c|}
\hline Parameter & Unit & $\begin{array}{c}\text { Pipeline Transport } \\
\text { Base Case }\end{array}$ & $\begin{array}{c}\text { Pipeline Transport } \\
\text { Sensitivity Case }\end{array}$ \\
\hline Pipeline Length & $\mathrm{km}$ & 100 & 300 \\
\hline $\mathrm{CO}_{2}$ Inlet Pressure & $\mathrm{MPa}$ & 15.2 & 15.2 \\
\hline $\mathrm{CO}_{2}$ Outlet Pressure & $\mathrm{MPa}$ & 10.3 & 10.3 \\
\hline $\begin{array}{l}\text { Pressure Drop per } \\
\text { Unit Length* }\end{array}$ & $\mathrm{Pa} / \mathrm{m}$ & 49 & 16 \\
\hline Pipe Diameter $^{*}$ & inches & 11.2 & 13.8 \\
\hline Nominal Pipe Size & inches & 12 & 16 \\
\hline
\end{tabular}

* calculated

1 in $=0.0254 \mathrm{~m}$ 


\subsubsection{Capital and O\&M Cost Inputs}

The capital and O\&M costs of the pipeline, for the base and sensitivity cases, were calculated using the methodology described in Section 4.4.2. Table 4-3 shows the results.

Table 4-3

Capital and O\&M cost inputs for the pipeline transport base and sensitivity cases

\begin{tabular}{|l|c|c|c|}
\hline Parameter & Unit & $\begin{array}{c}\text { Pipeline Transport } \\
\text { Base } \mathbf{( 1 0 0} \mathbf{~ k m}) \text { Case }\end{array}$ & $\begin{array}{c}\text { Pipeline Transport } \\
\text { Sensitivity (300 km) } \\
\text { Case }\end{array}$ \\
\hline Pipe Diameter & inches & 11.2 & 13.8 \\
\hline \hline Capital Cost & $\$$ & $23,500,000$ & $87,100,000$ \\
\hline O\&M Cost & $\$$ & 310,000 & 930,000 \\
\hline
\end{tabular}

The total cost of constructing the pipeline is $\$ 23.5$ and $\$ 87.1$ million for the 100 and $300 \mathrm{~km}$ cases, respectively. The construction cost of the $300 \mathrm{~km}$ pipeline is more than three times the cost of the $100 \mathrm{~km}$ pipeline due to the fact that a larger diameter pipe is required, i.e. a 16-inch as opposed to 12 -inch pipe.

\subsection{MIT Model Results}

Based on the model developed by MIT, the respective values of total cost per tonne of $\mathrm{CO}_{2}$ for the base and sensitivity cases are $\$ 1.78$ and $\$ 6.49$. These are converted to $\mathrm{CO}_{2}$ equivalent LC GHG avoided bases in Chapters 5-9 when they are combined with the storage concepts.

\subsection{Comparison to Literature}

\subsubsection{Studies Used in Model Evaluation}

Data related to overland pipeline transport of $\mathrm{CO}_{2}$ were taken from the studies listed in Table 4-4. 
Table 4-4

Overland pipelines' characteristics

\begin{tabular}{|c|c|c|c|c|c|}
\hline Study & $\begin{array}{l}\mathrm{CO}_{2} \text { flow } \\
\text { rate }(\mathrm{Mt} / \mathrm{yr})\end{array}$ & $\begin{array}{c}\text { Initial } \mathrm{CO}_{2} \\
\text { pressure } \\
\text { (bar) }\end{array}$ & $\begin{array}{l}\text { Diameter } \\
\text { (m) }\end{array}$ & $\begin{array}{c}\text { Length } \\
(\mathbf{k m})\end{array}$ & $\begin{array}{c}\text { Recompression } \\
\text { station } \\
\text { included }\end{array}$ \\
\hline IEA aquifer ${ }^{18}$ & 3.90 & 208 & 0.400 & 30 & No \\
\hline $\begin{array}{l}\text { IEA depleted } \\
\text { reservoir }^{18}\end{array}$ & 3.16 & 110 & 0.400 & 50 & No \\
\hline British Coal $^{19}$ & 3.63 & 136 & 0.350 & 425 & Yes \\
\hline Weyburn $^{10}$ & 2.00 & 170 & 0.305 & 127 & No \\
\hline
\end{tabular}

A pumping station is required for the 'British Coal' $\mathrm{CO}_{2}$ pipeline, of which only the onshore section is considered here, due to its extreme length. For the purpose of comparing the capital cost of this pipeline with that determined by the model, the pumping station was ignored. It should also be noted that cost data were not available for the 'Weyburn' pipeline.

\subsubsection{Comparison of Values from Model and Studies}

The graph below in Figure 4-7 shows pipe diameter as a function of $\mathrm{CO}_{2}$ mass flow rate. Also shown in the figure, is the value of pipe diameter, for a specific $\mathrm{CO}_{2}$ mass flow rate, given in each of the four studies. The model's calculation of pipe diameter can be seen to strongly agree with this studies' estimate. 


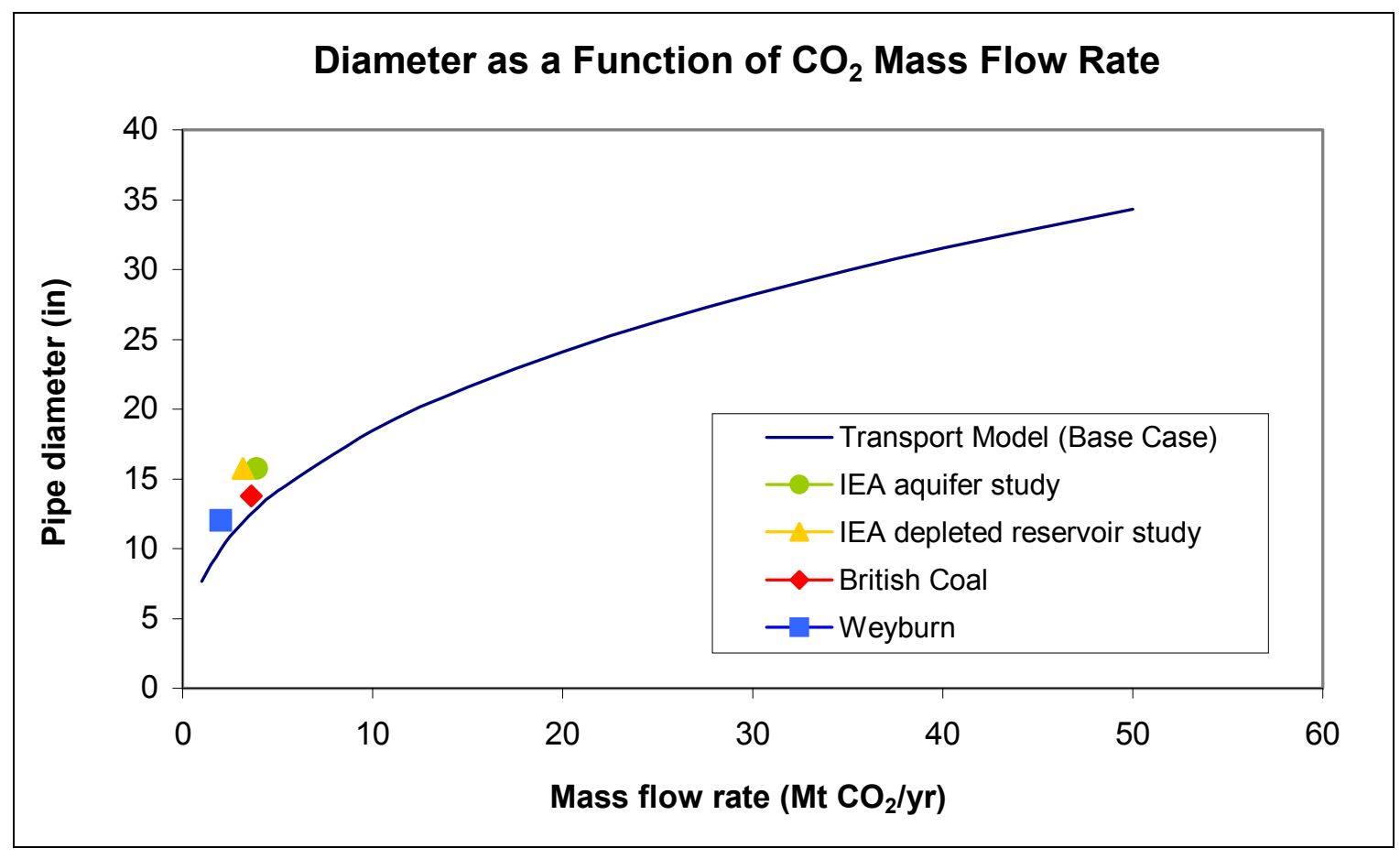

Figure 4-7

Comparison of pipe diameter values

Figure 4-8 shows the estimated capital costs of the pipeline versus mass flow rate, and a comparison with three other studies. Our model shows generally lower costs, especially when compared to the 'British Coal' study. The discrepancy can be attributed to the additional costs associated with pipelines located in the more populated areas of Europe as opposed to North America. 


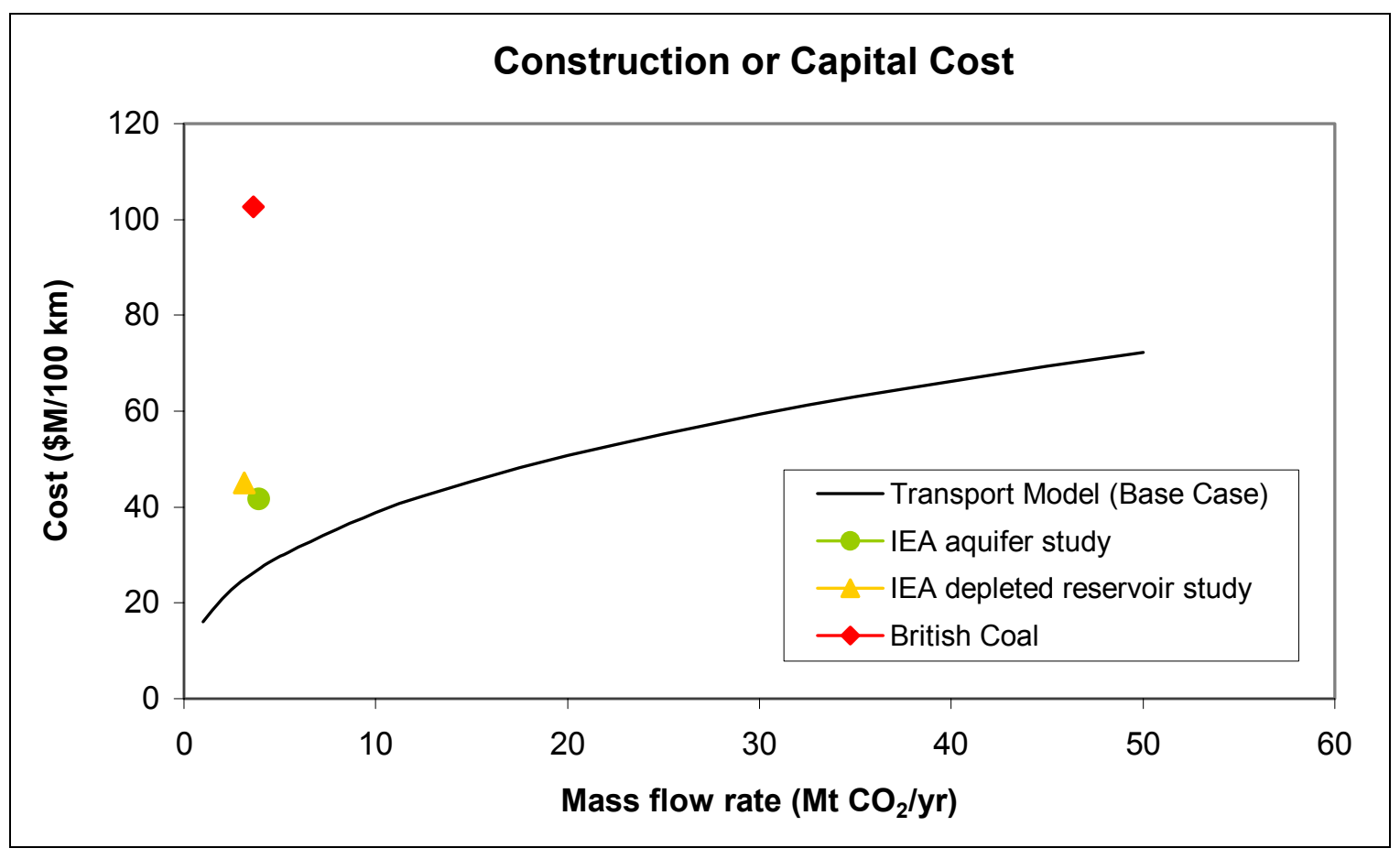

Figure 4-8

Comparison of pipeline capital cost values 


\subsection{References}

1 Moritis, G., "Future of EOR \& IOR: New companies, infrastructure, projects reshape landscape for $\mathrm{CO}_{2}$ EOR in U.S.," Oil \& Gas Journal, May 14, 2001.

2 Kinder Morgan $\mathrm{CO}_{2}$ Company, " $\mathrm{CO}_{2}$ Transportation," [Online document], 2001, [cited Apr. 2002], Available HTTP:

http://www.kne.com/co2/transport.cfm

3 International Energy Agency Greenhouse Gas R\&D Programme (IEAGHG), "Weyburn $\mathrm{CO}_{2}$-EOR Project," [Online document], 2001, [cited Apr. 2002], Available HTTP: http://www.ieagreen.org.uk/weyburn4.htm

4 Stevens, S.H., J.M. Pearce and A.A.J. Rigg, "Natural analogs for geologic storage of $\mathrm{CO}_{2}$ : An integrated global research program," presented at the First National Conference on Carbon Sequestration, Washington D.C., May 15-17, 2001.

5 Petro Source Corporation, "Val Verde $\mathrm{CO}_{2}$ pipeline completes construction and begins operations," [Online document], 1998, [cited Apr. 2002], Available HTTP: http://www.petrosource.com/news_ValVer.htm

6 “Enhanced Oil Recovery Scoping Study,” EPRI, Palo Alto, CA. Tech. Rep. 113836, 1999.

7 "OGJ Special - Worldwide EOR survey 2000," Oil \& Gas Journal, pp. 44-61, Mar. 20, 2000.

8 Kinder Morgan $\mathrm{CO}_{2}$ Company, " $\mathrm{CO}_{2}$ Supply," [Online document], 2001, [cited Jan. 2002], Available HTTP:

http://www.kne.com/co2/supply.cfm

9 Gill, T.E., "Canyon Reef Carriers Inc. $\mathrm{CO}_{2}$ pipeline: Description of 12 years of operation," presented at the ASME Pipeline Engineering Symposium, 1985.

10 Hattenbach, R.P., Wilson, M. and K. Brown, "Capture of carbon dioxide from coal combustion and its utilization for enhanced oil recovery," in Greenhouse Gas Control Technologies, Elsevier Science, New York, 1999, pp. 217-221.

11 True, W.R., "Weather, construction inflation could squeeze North American pipelines," Oil \& Gas Journal, Aug. 31, 1998.

12 "Evaluation of Innovative Fossil Fuel Power Plants with $\mathrm{CO}_{2}$ Removal," EPRI Report No. 1000316, Interim Report, December 2000, Cosponsors: U.S. Department of Energy/Office of Fossil Energy and U.S. Department of Energy/NETL, EPRI Project Manager N. A. H. Holt.

Available HTTP: http://www.netl.doe.gov/coalpower/gasification/pubs/pdf/EpriReport.pdf 
13 Fox, Chuck, e-mail communication, Dec. 30, 1999.

14 Herzog, H., "Conceptual design of pipeline operations and control".

15 Nihous and Bohn, "Principles of heat transfer".

16 Perry, R.H. and D.W. Green, "Perry's Chemical Engineers' Handbook - Seventh Edition," 1997.

17 True, W.R., "U.S. gas pipelines improve operations, want to expand," Oil \& Gas Journal, Nov. 26, 1990.

18 Ormerod, W., "The disposal of carbon dioxide from fossil fuel fired power stations," IEA Greenhouse R\&D Programme, Cheltenham. Tech. Rep. IEAGHG/SR3, Jun. 1994.

19 Summerfield, I.R., S.H. Goldthorpe, N. Williams and A. Sheikh, "Costs of $\mathrm{CO}_{2}$ disposal options," Energy Convers. Mgmt, vol. 34, no. 9-11, pp. 1105-1112, 1993. 


\section{5 \\ ENHANCED OIL RECOVERY}

\subsection{Introduction}

This chapter deals with the storage of $\mathrm{CO}_{2}$ in depleted oil reservoirs where enhanced oil production results in a value-added product. The use of depleted oil reservoirs for $\mathrm{CO}_{2}$ storage without enhanced production is treated separately in Chapter 7.

\subsection{State of the Art}

\subsubsection{Applications}

There were a total of 84 commercial or research-level applications of enhanced oil recovery using $\mathrm{CO}_{2}$ floods $\left(\mathrm{CO}_{2}\right.$-EOR) worldwide in 2000. The amount of enhanced oil production from these $\mathrm{CO}_{2}$-EOR projects during that year averaged 200,772 barrels (bbl) of oil per day ${ }^{\mathrm{a}}$, which is only a very small amount ( 0.3 percent) of that year's total worldwide oil production of 67.2 million bbl of oil per day. The United States account for 72 of the 84 projects, or 96 percent of worldwide enhanced oil production from $\mathrm{CO}_{2}$ floods, and is as such the world leader in the use of $\mathrm{CO}_{2}$-EOR technology. Currently, Turkey is the only other country with a commercialscale application of $\mathrm{CO}_{2}$-EOR, with Canada and Trinidad having only pilot-scale projects. ${ }^{1,2}$

Enhanced oil production from the $72 \mathrm{CO}_{2}$ floods in the United States in 2000 was 192,209 bbl of oil per day, which is equivalent to 5 percent of total U.S. oil production during the same period. Most of these $\mathrm{CO}_{2}$ floods (53) are located in the southwestern United States within the Permian basin of western Texas and eastern New Mexico. The next largest concentrations of $\mathrm{CO}_{2}$ floods in the United States are in the Rocky Mountain and Mid-continent regions. The details of the six largest $\mathrm{CO}_{2}$-EOR projects in 2000 are given in Table 5-1. It should be noted that these six projects are all situated in the United States and that together they accounted in 2000 for 47 percent of worldwide enhanced oil production from $\mathrm{CO}_{2}$ floods. ${ }^{1,2}$

\footnotetext{
${ }^{\text {a }}$ Only the oil recovered due to the $\mathrm{CO}_{2}$ flood is included here as enhanced oil production. Quoted enhanced oil production figures may thus account for only a fraction of the total amount of oil produced during the tertiary recovery process.
} 
Table 5-1

Six largest $\mathrm{CO}_{2}$-EOR projects

\begin{tabular}{|l|c|c|c|c|c|c|}
\hline Operator & Field & Basin/Region & $\begin{array}{c}\text { Area } \\
\mathbf{k m}^{2} \text { ) }\end{array}$ & $\begin{array}{c}\text { Production } \\
\text { Wells }\end{array}$ & $\begin{array}{c}\text { Injection } \\
\text { Wells }\end{array}$ & $\begin{array}{c}\text { EOR } \\
\text { Production } \\
\text { (bbl/d) }\end{array}$ \\
\hline Altura & $\begin{array}{c}\text { Wasson } \\
\text { (Denver) }\end{array}$ & Permian & 113 & 735 & 385 & 29,000 \\
\hline $\begin{array}{l}\text { Amerada } \\
\text { Hess }\end{array}$ & $\begin{array}{c}\text { Seminole } \\
\text { (Main) }\end{array}$ & Permian & 64 & 408 & 160 & 25,900 \\
\hline Chevron & $\begin{array}{c}\text { Rangely } \\
\text { Weber Sand }\end{array}$ & $\begin{array}{c}\text { Rocky } \\
\text { Mountain }\end{array}$ & 61 & 341 & 209 & 11,208 \\
\hline ExxonMobil & Salt Creek & Permian & 49 & 137 & 100 & 9,300 \\
\hline $\begin{array}{l}\text { Devon } \\
\text { Energy }\end{array}$ & SACROC & Permian & 202 & 325 & 57 & 9,000 \\
\hline Altura & Wasson (ODC) & Permian & 32 & 293 & 290 & 9,000 \\
\hline
\end{tabular}

Currently, there is no commercial-scale $\mathrm{CO}_{2}$-EOR project that utilizes $\mathrm{CO}_{2}$ from a power plant. In the 1980s, there were three small-scale $\mathrm{CO}_{2}$-EOR projects that utilized $\mathrm{CO}_{2}$ from gas boiler power plants. These plants were shut down when the price of oil dropped in the mid-1980s, making this source of $\mathrm{CO}_{2}$ too expensive. ${ }^{3}$ The main obstacle to the utilization of this source of $\mathrm{CO}_{2}$ for EOR is its significant cost of capture. Most of the $\mathrm{CO}_{2}$-EOR projects, particularly those located in the Permian basin, are dependent upon naturally occurring $\mathrm{CO}_{2}$, which is obtained from high-pressure, high-purity underground deposits. The most important of these natural $\mathrm{CO}_{2}$ deposits, in decreasing order of size, are the McElmo Dome, the Bravo Dome, and the Sheep Mountain Field. ${ }^{4}$ A small fraction of the Permian basin $\mathrm{CO}_{2}$ supply has also come from anthropogenic sources, namely the Mitchell, Gray Ranch, Pucket, and Terrell gas processing facilities in the southern Permian basin. In contrast, the Rocky Mountain and Mid-continent regions are almost wholly supplied by anthropogenic $\mathrm{CO}_{2}$ from gas processing and fertilizer production facilities. The Rangely Weber Sand $\mathrm{CO}_{2}$-EOR project, for example, is supplied by the La Barge gas processing plant in southwestern Wyoming and is as such the world's largest single sequestration site of anthropogenic $\mathrm{CO}_{2}{ }^{5}$

\subsubsection{Storage Potential}

The Weyburn Field in southeastern Saskatchewan, Canada, is the only $\mathrm{CO}_{2}$-EOR project to date that has been monitored specifically to understand $\mathrm{CO}_{2}$ sequestration. In the case of most $\mathrm{CO}_{2-}$ EOR projects, much of the $\mathrm{CO}_{2}$ injected into the oil reservoir should be considered as being only temporarily stored. This is because the decommissioning of an EOR project usually involves the "blowing down" of the reservoir pressure to maximize oil recovery. This "blowing down" results in $\mathrm{CO}_{2}$ being released ${ }^{\mathrm{b}}$, with a small but significant amount of the injected $\mathrm{CO}_{2}$ remaining

\footnotetext{
b $\mathrm{The} \mathrm{CO}_{2}$ from 'blow down' may be either vented or reused in other EOR fields.
} 
dissolved in the immobile oil. In the case of the Weyburn Field, no "blow-down" phase is planned, thereby allowing for permanent $\mathrm{CO}_{2}$ sequestration. Over the anticipated 25-year life of the project, it is expected that the injection of some 18 million tonnes of $\mathrm{CO}_{2}$ from the Dakota Gasification Facility in North Dakota will produce around 130 million bbl of enhanced oil. This has been calculated to be equivalent to, taking into account the $\mathrm{CO}_{2}$ emitted by the generation of electricity required, approximately 14 million tonnes of $\mathrm{CO}_{2}$ being prevented from reaching the atmosphere. 5,6

\subsubsection{Storage Mechanics}

Most $\mathrm{CO}_{2}$ floods achieve enhanced oil production through miscible, as opposed to immiscible, displacement. The six largest $\mathrm{CO}_{2}$-EOR projects described above, for example, are all miscible $\mathrm{CO}_{2}$ floods. Miscible displacement involves the injected $\mathrm{CO}_{2}$ mixing thoroughly with the oil in the reservoir whereas, in the case of immiscible displacement, the $\mathrm{CO}_{2}$ remains physically distinct from the oil. The type of displacement that occurs is dependent on the reservoir pressure and crude oil composition, with a reservoir depth greater than 1,200 $\mathrm{m}$ and an oil density less than $22^{\circ}$ API typically leading to miscible conditions. Miscible displacement leads to an ultimate recovery of about 7 to 15 percent of the original oil in place (OOIP). Immiscible displacement yields lower recoveries compared to miscible conditions, but can still achieve a high recovery rate due to oil swelling and viscosity reduction. Currently, only one large $\mathrm{CO}_{2}$-EOR project, located in Turkey, utilizes immiscible processes. However, it is expected that the number of immiscible $\mathrm{CO}_{2}$ floods will increase as the use of $\mathrm{CO}_{2}$-EOR becomes increasingly widespread. ${ }^{1,5,7,8,9}$

In $\mathrm{CO}_{2}$-EOR projects, it is most common for the $\mathrm{CO}_{2}$ to not be injected as a continuous gas stream, but for it to be alternated with water injection in a water-alternating-gas (WAG) process. This WAG process is carried out to help overcome the problem of high $\mathrm{CO}_{2}$ mobility that greatly reduces the effectiveness of $\mathrm{CO}_{2}$ flooding. This high $\mathrm{CO}_{2}$ mobility problem, caused by the $\mathrm{CO}_{2}$ having a lower density and viscosity than the reservoir oil, is responsible for the phenomena of gravity tonguing and viscous fingering. These phenomena are undesirable as they lead to injected $\mathrm{CO}_{2}$ flowing through areas that have already been swept. Taking advantage of the fact that water is less mobile than $\mathrm{CO}_{2}$, the WAG process is able to significantly improve the sweep efficiency through reducing $\mathrm{CO}_{2}$ mobility. This, in turn, results in improved oil recovery while also preventing early $\mathrm{CO}_{2}$ breakthrough in producing wells. The world's largest $\mathrm{CO}_{2}$-EOR project, Wasson (Denver), is an example of a WAG flood. ${ }^{5,9,10}$

\subsubsection{Feasibility of Storage Option}

The use of $\mathrm{CO}_{2}$ floods for EOR presents a very attractive $\mathrm{CO}_{2}$ storage option. Even without $\mathrm{CO}_{2}$ sequestration credits, most of the active $\mathrm{CO}_{2}$-EOR projects are profitable. In addition to a valueadded product, $\mathrm{CO}_{2}$-EOR has the advantage that it has been widely applied and is a proven technology. Furthermore, significant advances continue to be made in the computer simulation of $\mathrm{CO}_{2}$ flood performance. This $\mathrm{CO}_{2}$ storage option also has the added bonus that most oil fields have already undergone primary and secondary recovery prior to $\mathrm{CO}_{2}$ flooding. This means that certain components of the existing infrastructure, such as the wells, are able to be simply adapted 
for $\mathrm{CO}_{2}$ storage purposes. There is the downside that $\mathrm{CO}_{2}$ floods require significant additional infrastructure to handle the processing and recycling of $\mathrm{CO}_{2}$. On a positive note, however, the cost of anticorrosive equipment to deal with the problem of $\mathrm{CO}_{2}$ reacting with water to form carbonic acid has recently been reduced. ${ }^{5,7}$

\subsection{Process Description}

The $\mathrm{CO}_{2}$ for the EOR case is taken from Case $3 \mathrm{a}$ of the DOE/EPRI Report on $\mathrm{CO}_{2}$ removal from fossil fuel power plants. ${ }^{11}$ This case is used for the design basis since potential $\mathrm{CO}_{2}$ sources from a coal-based power plant would most probably be associated with an IGCC plant. $\mathrm{CO}_{2}$ recovery from IGCC is most economical because of the $\mathrm{CO}_{2}$ concentration in syngas at a high partial pressure, enabling the use of conventional recovery processes. The storage system is to be designed to handle 3.76 million scm (7,389 tonnes) of new $\mathrm{CO}_{2}$ per day. It is important to note that, since the capacity factor of the IGCC power plant is assumed to be 80 percent, this new $\mathrm{CO}_{2}$ is not available 20 percent of the time. Consideration of this issue is beyond the scope of the current project.

Figure 5-1 is a block flow diagram, indicating the overall flow and distribution of $\mathrm{CO}_{2}$ from the IGCC power plant to the EOR field. First, the $\mathrm{CO}_{2}$ leaving the plant is fed to an additional stage of compression to bring it up to the required pipeline inlet pressure. Second, the pipeline transports the $\mathrm{CO}_{2}$ a distance of $100 \mathrm{~km}$ to the EOR field, where it is mixed with recycled $\mathrm{CO}_{2}$ and injected into the EOR $\mathrm{CO}_{2}$ injection wells. Third, the oil produced at the EOR wells is separated from water and $\mathrm{CO}_{2}$ at the surface. Finally, the $\mathrm{CO}_{2}$ is dehydrated, compressed, and mixed with fresh incoming $\mathrm{CO}_{2}$.

The $\mathrm{CO}_{2}$ injection wells are an important component of the EOR field. These wells function as conduits for moving supercritical $\mathrm{CO}_{2}$ fluid from the surface down into the reservoir. The wells are regulated under the provisions of the Underground Injection Control (UIC) Program under the Federal Safe Drinking Water Act (SDWA) as either Class I or Class V wells. ${ }^{12}$

The EOR field also consists of a distribution system, which serves the following functions:

- Receives $\mathrm{CO}_{2}$ from the pipeline terminal and distributes it to the $\mathrm{EOR} \mathrm{CO}_{2}$ injection wells.

- Gathers oil from the EOR production wells and delivers it to the tank battery.

- Compresses separated $\mathrm{CO}_{2}$ and mixes it with pipeline $\mathrm{CO}_{2}$ for injection into EOR $\mathrm{CO}_{2}$ injection wells.

The oil from the EOR production wells is carried by small pipelines called flow lines to a part of the production site known as the tank battery. In addition to storage tanks, the tank battery contains equipment for preparing the oil before further distribution. The fluid coming out of nearly all wells is actually a mixture of oil, gas (in this case $\mathrm{CO}_{2}$ ), salt water, and sediment. First, most of the $\mathrm{CO}_{2}$ present is separated from the oil and water at 7 bar, recompressed and recycled, then re-injected to help maintain reservoir pressure, and thereby, production. Separation of the remaining mixture is accomplished in special tanks where the settling process 
separates water and oil, or it may be assisted by special equipment such as a heater treater. Vapor recovery units recover the remaining $\mathrm{CO}_{2}$, which is also recompressed and recycled.

Testing of the oil to determine its properties is conducted at the well site by taking samples of oil from the storage tanks. Today, oil volumes are measured with Lease Automatic Custody Transfer facilities (LACTs), which do most of the measuring, sampling, and testing without human intervention. Oil that has been completely prepared is stored in tanks at the well site until it is transported to the refinery.

Most $\mathrm{CO}_{2}$-EOR projects take place at fields that have already undergone secondary recovery, i.e. waterflooding. The modification of water-flooded fields for $\mathrm{CO}_{2}$ flooding involves:

- Makeover and equipping of injection wells

- Installation of $\mathrm{CO}_{2}$ distribution and recycle systems

- Provision of high-pressure injection equipment and related piping

- Replacement of selected production facilities

The production phase of the Weyburn field is expected to be more than 25 years. The Millennium Energy $\mathrm{CO}_{2}$ flood in West Texas has been going on since 1983. It is assumed that this flood has, like the power plant, a lifetime of 20 years. As a final note, the design/construction time is taken to be the same as the power plant, 4 years. 


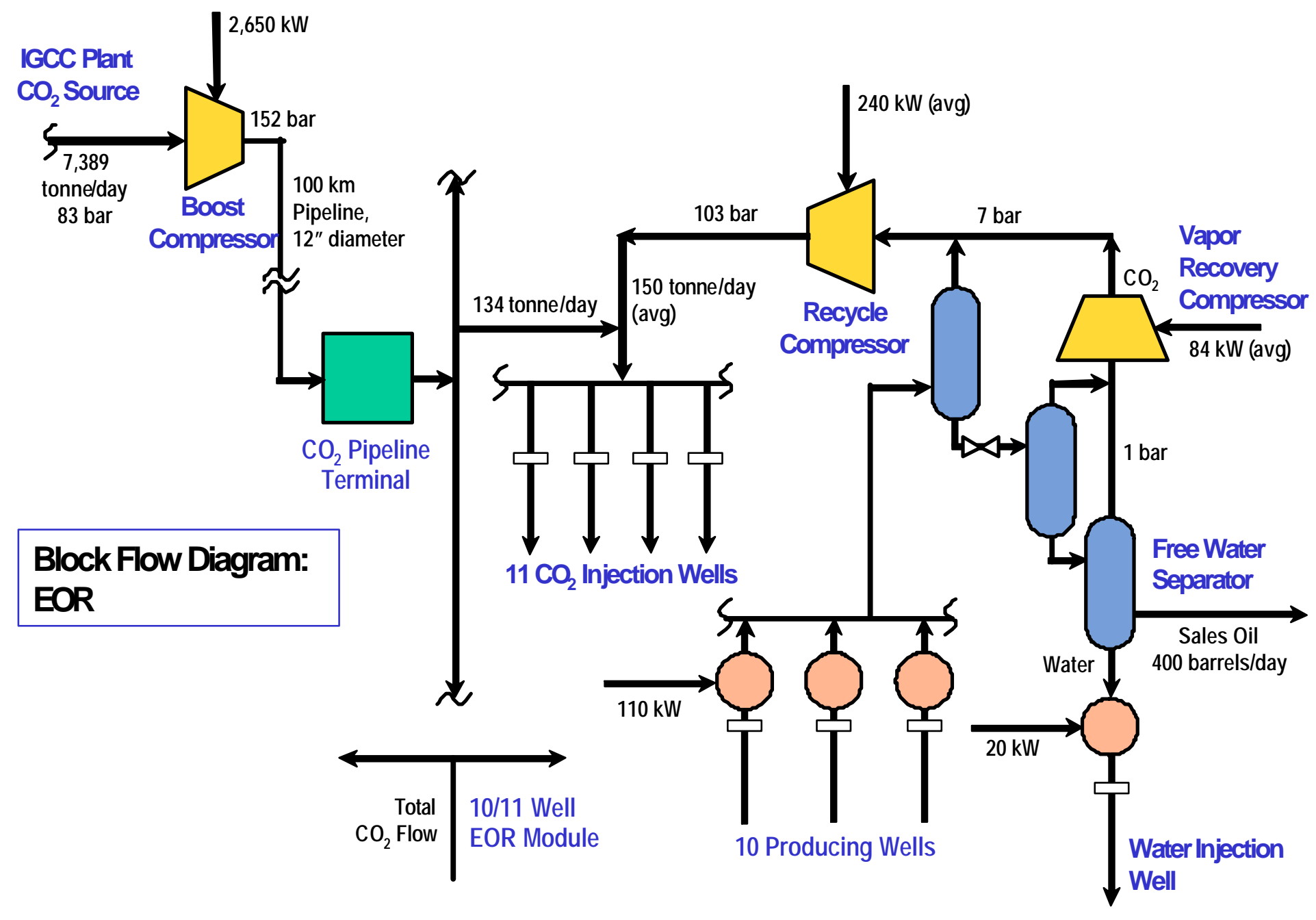

Figure 5-1

EOR block flow diagram 


\subsection{Methodology Used}

For specific projects, the complex interactions between the injected $\mathrm{CO}_{2}$ and reservoir oil would be modeled to assess the likely performance of a proposed $\mathrm{CO}_{2}-\mathrm{EOR}$ project. Based on the output of this modeling, the cost of the proposed $\mathrm{CO}_{2}$ flood is calculated. However, for our purposes of deve loping general costing algorithms, 'rules of thumb' are used to define the engineering parameters needed to estimate the cost of a $\mathrm{CO}_{2}$-EOR project. These 'rules of thumb' have been derived based on information from experts in the field and the literature.

The method used for costing the EOR process can be split up into a number of steps. First, the average amount of enhanced oil produced per day for the given $\mathrm{CO}_{2}$ mass flow rate is determined using a $\mathrm{CO}_{2}$ effectiveness factor of 170 standard cubic meters $(6,000$ standard cubic feet) of new $\mathrm{CO}_{2}$ per bbl of enhanced oil. Second, the number of production wells is found by dividing this total amount of enhanced oil produced per day by an assumed average of $40 \mathrm{bbl}$ of enhanced oil per day being produced at each well. Third, a ratio of producers to injectors of 1 to 1.1 is used to calculate the number of injection wells from the number of production wells. Fourth, the capital cost of the $\mathrm{CO}_{2}$ recycle plant is determined based on a maximum $\mathrm{CO}_{2}$ recycle ratio of 3, with an average recycle ratio of 1.1 being used for the plant's O\&M costs. Finally, the capital and O\&M costs associated with the wells and the field equipment are calculated. Figure 5-2 provides an overview of the cost model, with the assumptions made in each of these steps being discussed below in more detail.

\subsection{1 $\mathrm{CO}_{2}$ Effectiveness}

For the EOR-design basis, an average of $170 \mathrm{scm}(6,000 \mathrm{scf})$ of $\mathrm{CO}_{2}$ is taken to remain in the ground for each bbl of enhanced oil production. It is important to note, however, that the effectiveness of $\mathrm{CO}_{2}$-EOR varies both from one basin to another and within a basin itself. In the case of the Permian basin, Malcolm Wilson from the Petroleum Technology Research Center indicated that around 170 to $227 \mathrm{scm}\left(6,000\right.$ to 8,000 scf) of $\mathrm{CO}_{2}$ per bbl of enhanced oil would remain in the ground. ${ }^{13}$ In contrast, the $\mathrm{CO}_{2}$ effectiveness in the Weyburn Field, according to Ray Hattenbach from the Dakota Gasification Company, is closer to $85 \mathrm{scm}$ (3,000 scf) per bbl of enhanced oil. ${ }^{14}$ Given this, it was deemed necessary that the sensitivity of the cost of EOR to a range of $\mathrm{CO}_{2}$ effectiveness values be determined. Based on the rough estimates given above, and the values given in the literature (see Table 5-2), a range of 85 to $227 \mathrm{scm}$ (3,000 to 8,000 $\mathrm{scf}$ ) of $\mathrm{CO}_{2}$ per bbl of enhanced oil was chosen for the sensitivity calculation.

The $\mathrm{CO}_{2}$-EOR projects in Table 5-2 have illustrate the range of $\mathrm{CO}_{2}$ effectiveness. The projects chosen include two of the largest $\mathrm{CO}_{2}$ floods in the Permian basin. In addition, two other smaller $\mathrm{CO}_{2}$-EOR projects in this basin, namely Dollarhide (Devonian) and Vacuum, are provided as examples of $\mathrm{CO}_{2}$ floods displaying relatively high and low $\mathrm{CO}_{2}$ effectiveness, respectively. $\mathrm{CO}_{2}$-EOR projects located in the other two main $\mathrm{CO}_{2}$-flood regions are also included. These projects comprise the two largest $\mathrm{CO}_{2}$ floods in the Rocky Mountain region while, for the Midcontinent region, data was only available for two medium-sized floods. Finally, a last case study is made of the highly efficient $\mathrm{CO}_{2}$ flood at the Weyburn Field. 


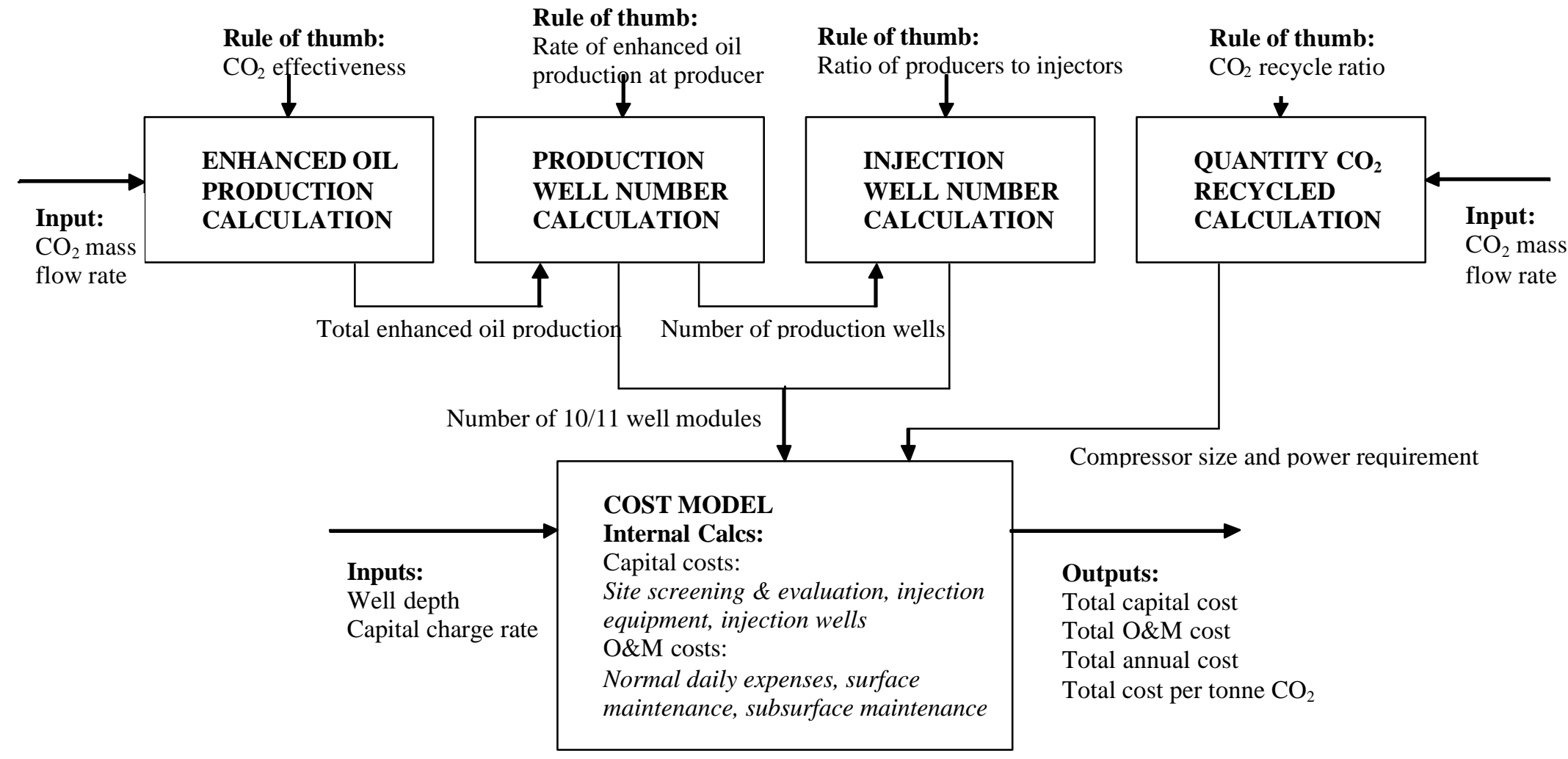

Figure 5-2

EOR cost model overview diagram 
Table 5-2

Estimated $\mathrm{CO}_{2}$ effectiveness for selected $\mathrm{CO}_{2}$-EOR projects ${ }^{5,6}$

\begin{tabular}{|c|c|c|c|c|c|}
\hline Operator & Field & Basin/Region & $\begin{array}{c}\text { Est. Ultimate } \\
\text { EOR } \\
\text { (million bbl) }\end{array}$ & $\begin{array}{l}\text { Est. Ultimate } \mathrm{CO}_{2} \\
\text { Sequestered } \\
\text { (giga scm) }\end{array}$ & $\begin{array}{c}\text { Est. } \mathrm{CO}_{2} \\
\text { Effectiveness } \\
(\mathrm{scm} / \mathrm{bbl})\end{array}$ \\
\hline Altura & $\begin{array}{l}\text { Wasson } \\
\text { (Denver) }\end{array}$ & Permian & 348 & 47 & 136 \\
\hline Devon Energy & SACROC & Permian & 169 & 26 & 153 \\
\hline Texaco & Vacuum & Permian & 33 & 3 & 94 \\
\hline Spirit Energy & $\begin{array}{c}\text { Dollarhide } \\
\text { (Devonian) }\end{array}$ & Permian & 28 & 5 & 177 \\
\hline Chevron & $\begin{array}{c}\text { Rangely } \\
\text { Weber Sand }\end{array}$ & $\begin{array}{c}\text { Rocky } \\
\text { Mountain }\end{array}$ & 136 & 17 & 127 \\
\hline Merit Energy & $\begin{array}{l}\text { Lost Soldier } \\
\text { (Tensleep) }\end{array}$ & $\begin{array}{c}\text { Rocky } \\
\text { Mountain }\end{array}$ & 24 & 3 & 117 \\
\hline Anadarko & $\begin{array}{c}\text { Northeast } \\
\text { Purdy }\end{array}$ & Mid-continent & 17 & 2 & 117 \\
\hline $\begin{array}{l}\text { Henry } \\
\text { Petroleum }\end{array}$ & Sho-Vel-Tum & Mid-continent & 10 & 3 & 292 \\
\hline PanCanadian & Weyburn & Saskatchewan & 130 & 9 & 70 \\
\hline
\end{tabular}

The $\mathrm{CO}_{2}$ effectiveness has been calculated for the above $\mathrm{CO}_{2}$-EOR projects by dividing the estimated total amount of $\mathrm{CO}_{2}$ to be sequestered, taken as being equal to 90 percent of the $\mathrm{CO}_{2}$ purchased, ${ }^{5}$ by the estimated total amount of enhanced oil to be recovered over the lifetime of the project. The resulting estimates of $\mathrm{CO}_{2}$ effectiveness are all, except for those for the Sho-VelTum and Weyburn Field $\mathrm{CO}_{2}$ floods, within the selected range of 85 to $227 \mathrm{scm}$ (3,000 to 8,000 scf) of $\mathrm{CO}_{2}$ per bbl of enhanced oil. In the case of the Sho-Vel-Tum flood, the use of the lessefficient immiscible displacement process to recover enhanced oil is the likely cause of the exceedingly high $\mathrm{CO}_{2}$ effectiveness value. ${ }^{1}$

\subsubsection{Rate of Enhanced Oil Production at Producer}

The average amount of enhanced oil produced per day per well over the 20-year life of the field is taken to be $40 \mathrm{bbl}$. Unfortunately, there is no industry 'rule of thumb' for the amount of enhanced oil production that should be allowed at each production well on a daily basis. This is primarily because, as explained below, such a value is not used in practice as a basis for determining the number of production wells required. Given this, a value equal to the average amount of enhanced oil produced per day per well at the Weyburn Field has been adopted. Based on the calculated values of average daily enhanced oil production per well for the six largest $\mathrm{CO}_{2}$-EOR projects, given in Table 5-3, this assumed base-case value of $40 \mathrm{bbl}$ would seem adequate and a sensitivity range of 20 to $70 \mathrm{bbl}$ appropriate. 
There is no evidence to suggest that the amount of enhanced oil produced per day per well is dependent on the basin in which the $\mathrm{CO}_{2}$ flood is located. The values of average daily enhanced oil production per well for the six largest $\mathrm{CO}_{2}$-EOR projects, all but one of which are located in the Permian basin, can therefore be considered typical. The fact that the average of these enhanced oil production per well values is $44 \mathrm{bbl}$, which is very close to the assumed base-case value of $40 \mathrm{bbl}$, is reassuring.

Table 5-3

Average enhanced oil production per day per well for six largest $\mathrm{CO}_{2}$-EOR projects ${ }^{1}$

\begin{tabular}{|l|c|c|c|c|c|}
\hline Operator & Field & Basin/Region & $\begin{array}{c}\text { Production } \\
\text { Wells }\end{array}$ & $\begin{array}{c}\text { EOR } \\
\text { Production } \\
\text { (bbl/day) }\end{array}$ & $\begin{array}{c}\text { EOR } \\
\text { Production } \\
\text { (bbl/day/well) }\end{array}$ \\
\hline Altura & $\begin{array}{c}\text { Wasson } \\
\text { (Denver) }\end{array}$ & Permian & 735 & 29,000 & 40 \\
\hline Amerada Hess & $\begin{array}{c}\text { Seminole } \\
\text { (Main) }\end{array}$ & Permian & 408 & 25,900 & 64 \\
\hline Chevron & $\begin{array}{c}\text { Rangely Weber } \\
\text { Sand }\end{array}$ & $\begin{array}{c}\text { Rocky } \\
\text { Mountain }\end{array}$ & 341 & 11,208 & 33 \\
\hline ExxonMobil & Salt Creek & Permian & 137 & 9,300 & 68 \\
\hline Devon Energy & SACROC & Permian & 325 & 9,000 & 28 \\
\hline Altura & Wasson (ODC) & Permian & 293 & 9,000 & 31 \\
\hline
\end{tabular}

It should be noted that the EOR industry determines the number of production wells based, not on an optimal level of enhanced oil production per day per well, but rather, on a required well spacing. This required spacing of wells, set by a state's gas and oil commission, can vary significantly. The required spacing in one state might be one well per $0.08 \mathrm{~km}^{2}$ (20 acres), while in another it might be one well per $1.30 \mathrm{~km}^{2}$ (320 acres). It has not been possible here to calculate the well numbers using this method, as doing so would require that the typical amount of enhanced oil produced per acre be known. ${ }^{14}$

\subsubsection{Ratio of Producers to Injectors}

A ratio of producers to injectors of 1 to 1.1 is used in the EOR concept design. Since this ratio depends largely on the injection strategy used, it is important to note here that use of WAG injection is assumed. For WAG injection, the 'rule of thumb' is that there be a rough balance between producers and injectors. The specific choice of a 1 to 1.1 ratio can be attributed to the fact that modules comprising 10 production and 11 injection wells are used as the basis for costing in the EIA's 'Costs and Indices for Domestic Oil and Gas Field Equipment and Production Operations' report and this report is used here for cost data. ${ }^{13,14}$

Table 5-4 gives the ratio of producers to injectors for each of the six largest $\mathrm{CO}_{2}$-EOR projects. It can be seen that, for those projects using the WAG process, the number of production and injection wells is roughly equal. However, this is not the case for the Seminole (Main) and SACROC projects for which $\mathrm{CO}_{2}$ is injected continuously. The Lost Soldier (Tensleep) $\mathrm{CO}_{2-}$ EOR project, the second largest in the Rocky Mountain region, is also included in the table as it provides an example of a $\mathrm{CO}_{2}$ flood having a producer to injector ratio of 1 to 1.1 . 
Table 5-4

Ratio of producers to injectors for selected $\mathrm{CO}_{2}$-EOR projects ${ }^{5,6}$

\begin{tabular}{|l|c|c|c|c|c|c|}
\hline Operator & Field & Basin/Region & $\begin{array}{c}\text { Injection } \\
\text { Strategy }\end{array}$ & $\begin{array}{c}\text { Production } \\
\text { Wells }\end{array}$ & $\begin{array}{c}\text { Injection } \\
\text { Wells }\end{array}$ & $\begin{array}{c}\text { Producers: } \\
\text { Injectors }\end{array}$ \\
\hline Altura & $\begin{array}{c}\text { Wasson } \\
\text { (Denver) }\end{array}$ & Permian & WAG & 735 & 385 & $1.9: 1$ \\
\hline $\begin{array}{l}\text { Amerada } \\
\text { Hess }\end{array}$ & $\begin{array}{c}\text { Seminole } \\
\text { (Main) }\end{array}$ & Permian & Continuous & 408 & 160 & $2.6: 1$ \\
\hline Chevron & $\begin{array}{c}\text { Rangely } \\
\text { Weber Sand }\end{array}$ & $\begin{array}{c}\text { Rocky } \\
\text { Mountain }\end{array}$ & WAG & 341 & 209 & $1.6: 1$ \\
\hline ExxonMobil & Salt Creek & Permian & WAG & 137 & 100 & $1.4: 1$ \\
\hline $\begin{array}{l}\text { Devon } \\
\text { Energy }\end{array}$ & $\begin{array}{c}\text { SACROC } \\
\text { Altura }\end{array}$ & $\begin{array}{c}\text { Permian } \\
\text { (ODSO) }\end{array}$ & Continuous & 325 & 57 & $5.7: 1$ \\
\hline \hline Merit Energy & $\begin{array}{c}\text { Lost Soldier } \\
\text { (Tensleep) }\end{array}$ & $\begin{array}{c}\text { Rocky } \\
\text { Mountain }\end{array}$ & WAG & 54 & 60 & $1: 1.1$ \\
\hline
\end{tabular}

\subsection{4 $\mathrm{CO}_{2}$ Recycle Ratio}

The $\mathrm{CO}_{2}$ recycle ratio is taken to have an average value of 1.1. ${ }^{15}$ This value is used to calculate the power requirements of the $\mathrm{CO}_{2}$ recycle plant. The $\mathrm{CO}_{2}$ recycle ratio increases over the lifetime of the $\mathrm{CO}_{2}$ flood, from effectively zero to its maximum value, as the amount of $\mathrm{CO}_{2}$ produced with the oil at the production wells increases while the amount of oil produced decreases. This increase in the recycle ratio is well illustrated in the case of the Rangely Weber Sand $\mathrm{CO}_{2}$-EOR project. During the first 10 years of $\mathrm{CO}_{2}$ flooding, 9 giga scm of net $\mathrm{CO}_{2}$ purchases and 10 giga scm of recycled $\mathrm{CO}_{2}$ were injected, giving an average recycle ratio of 1.1. In contrast, the recycle ratio in 1998 was close to 2.8 , with an average of 1.2 million scm per day of net $\mathrm{CO}_{2}$ purchases and 3.3 million scm per day of recycled $\mathrm{CO}_{2}$ being injected. ${ }^{5}$

\subsubsection{Reworking of Existing Wells}

It is assumed that only the reworking of existing wells, as opposed to the drilling of new wells, is required. The maturity of the field and the choice of injection strategy together determine whether or not extra wells are needed. For the purpose of the EOR-concept design, the assumptions are made that the field has undergone primary and secondary flooding and that the $\mathrm{CO}_{2}$ flood uses WAG injection. A field that has been subject to secondary flooding, i.e., waterflooding, has both production and injection wells. For WAG injection, it is adequate to assume that no additional injection wells are required. While the concept design as such requires that no extra wells be drilled, it is important to note that the existing production and injection wells and production surface facilities need to be reworked for the changed reservoir conditions. Also, it is necessary to provide the appropriate injection surface facilities. ${ }^{13,14}$ 


\subsubsection{Cost Calculations}

The total capital cost comprises the injection and production equipment costs, and the cost of refurbishing the existing wells. The O\&M costs include normal daily expenses, and surface and subsurface maintenance costs.

The EIA 'Costs and Indices for Domestic Oil and Gas Field Equipment and Production Operations' report ${ }^{16}$ includes a scenario for secondary oil recovery using water flooding. Costs and indices for additional secondary oil recovery equipment and its operation are provided for a representative lease, located in west Texas. This lease, or module, comprises 10 production wells, 11 water injection wells and 1 disposal well, and the wells are nominally 4,000 feet, or $1,219 \mathrm{~m}$, deep. This scenario was modified for $\mathrm{CO}_{2}$ flooding, and used as the basis for field equipment and production operations costs. The capital and O\&M costs on a per module basis, as well as the cost of power on a per kilowatt-hour basis, are given in Table 5-5. 
Table 5-5

Capital and O\&M cost estimation factors

\begin{tabular}{|c|c|c|}
\hline Parameter & Unit & Value \\
\hline \multicolumn{3}{|l|}{ CAPITAL COSTS } \\
\hline \multicolumn{3}{|l|}{ Injection Equipment: } \\
\hline Recycle \& Vapor Compressors & $\$ /$ module & $1,773,000$ \\
\hline Plant & $\$ /$ module & 113,600 \\
\hline Distribution Lines & $\$ /$ module & 77,200 \\
\hline Header & $\$ /$ module & 61,100 \\
\hline Electrical Service & $\$ /$ module & 97,400 \\
\hline \multicolumn{3}{|l|}{ Producing Equipment: } \\
\hline Tubing Replacement & $\$ /$ module & 90,800 \\
\hline Rods \& Pumps & $\$ /$ module & 41,000 \\
\hline Equipment & $\$ /$ module & 405,000 \\
\hline Makeover of Existing Wells & $\$ /$ module & 605,000 \\
\hline \multicolumn{3}{|l|}{ O\&M COSTS } \\
\hline \multicolumn{3}{|l|}{ Normal Daily Expenses: } \\
\hline Supervision \& Overhead & $\$ /$ module & 53,100 \\
\hline Labor & $\$ /$ module & 62,600 \\
\hline Consumables & $\$ /$ module & 7,500 \\
\hline Operative Supplies & $\$ /$ module & 7,700 \\
\hline Pumping \& Field Power & $\$ / k W h$ & 0.044 \\
\hline Recycle Compressor Power & $\$ / \mathrm{kWh}$ & 0.044 \\
\hline \multicolumn{3}{|c|}{ Surface Maintenance (Repair \& Services): } \\
\hline Labor (roustabout) & $\$ /$ module & 32,200 \\
\hline Supplies \& Services & $\$ /$ module & 44,300 \\
\hline Equipment Usage & $\$ /$ module & 16,300 \\
\hline Other & $\$ /$ module & 2,300 \\
\hline \multicolumn{3}{|c|}{ Subsurface Maintenance (Repair \& Services): } \\
\hline Workover Rig Services & $\$ /$ module & 46,400 \\
\hline Remedial Services & $\$ /$ module & 15,100 \\
\hline Equipment Repair & $\$ /$ module & 11,200 \\
\hline Other & $\$ /$ module & 9,900 \\
\hline
\end{tabular}




\subsection{Design Basis}

\subsubsection{Module design}

The EOR design is tied as closely as possible to the EIA 'Costs and Indices for Domestic Oil and Gas Field Equipment and Production Operations' report ${ }^{16}$ in order to make use of the cost data. This report is a continuation of the EIA series on equipment and operating costs, and cost indices for oil and gas leases. In addition to cost comparisons within the petroleum industry, the reported data are often used to assess the economic effects of specific plans and policies relating to the industry. Standardization of this data has occurred over the past 23 years.

The costs and cost indices provided in this report are for representative 10-well lease operations, with equipment and operating procedures designed by EIA staff engineers. As previously mentioned, each EOR lease has 10 producing wells, 11 injection wells, and 1 disposal well, and the wells are nominally 4,000 feet, or 1,219 m, deep. The design criteria have taken into account the predominant methods of operation in each region. Individual items of equipment have been priced by using price lists and by communication with the manufacturer or supplier of the item in each region. Freight and installation costs have been determined based on regional rates. All costs presented in the report are current to their year and are not adjusted for inflation.

The base case design is based on a $\mathrm{CO}_{2}$ effectiveness factor of $170 \mathrm{scm}(6,000 \mathrm{scf})$ per bbl of enhanced oil and an enhanced oil production rate of $40 \mathrm{bbl}$ per day per well. From the design flow rate of 3.76 million scm (7,389 tonnes) of $\mathrm{CO}_{2}$ per day, the total enhanced oil production is calculated using the $\mathrm{CO}_{2}$ effectiveness factor to be 22,142 bbl. Dividing this total enhanced oil production by the enhanced oil production rate per well, the required number of production wells is found to be 554. Given a producer to injector ratio of 1 to 1.1, 609 injection wells are required. In keeping the design consistent with the EIA modular approach, the EOR field for the base case therefore consists of 56 10/11 well modules. Finally, the quantities of new $\mathrm{CO}_{2}$ and $\mathrm{CO}_{2}$ to be recycled, assuming a maximum recycle ratio of 3, per module are 68,000 and 204,000 scm per day, respectively. Table 5-6 summarizes the base case for EOR. 
Table 5-6

Design basis for the EOR base case

\begin{tabular}{|l|c|c|}
\hline Parameter & Unit & EOR Base Case \\
\hline \multirow{2}{*}{$\mathbf{C O}_{2}$ Effectiveness } & scf/bbl enhanced oil & 6,000 \\
\cline { 2 - 3 } & scm/bbl enhanced oil & 170 \\
\hline Oil Production per Well & bbl enhanced oil/day/well & 40 \\
\hline Total Oil Production* & bbl enhanced oil/day & 22,142 \\
\hline Number of Production Wells ${ }^{*}$ & & 554 \\
\hline Number of Injection Wells & & 609 \\
\hline Number of 10/11 Well Modules & & 56 \\
\hline New $\mathbf{C O}_{2}{ }^{*}$ & & 68,000 \\
\hline Maximum Recycled $\mathbf{C O}_{2}{ }^{*}$ & $\mathrm{scm} / \mathrm{d} /$ module & 204,000 \\
\hline Well Depth & $\mathrm{scm} / \mathrm{d} /$ module & 1,219 \\
\hline
\end{tabular}

* calculated

A key component of the EOR field is the recycle compressor as it requires a large amount of energy, and capital investment. The compressor use is initially minimal but, after 20 years of operation, it is assumed that the ratio of $\mathrm{CO}_{2}$ produced with the enhanced oil production to the new $\mathrm{CO}_{2}$ will reach the maximum value of 3 .

The compressor is sized to handle all of the $\mathrm{CO}_{2}$ that is recycled in the $10 / 11$ well module. The actual compressor is a Superior Model WG74, sized by Cooper Energy Services and priced by Gas Packagers, Inc. To meet the $\mathrm{CO}_{2}$ recycle requirements of the 10/11 well module, two compressors, each delivering $71 \mathrm{scm}$ per minute are required. The base cost for each compressor was adjusted by Parsons to include shipping, foundations, installation and a cooling system. Table 5-7 gives the recycle compressor's parameters and cost. 
Table 5-7

Recycle compressor's parameters and cost

\begin{tabular}{|c|c|c|c|}
\hline Parameter & Unit & $\begin{array}{l}\text { Individual } \\
\text { Compressor }\end{array}$ & $\begin{array}{c}\text { Total for } 10 / 11 \\
\text { Module }\end{array}$ \\
\hline Maximum $\mathrm{CO}_{2}$ to be Compressed & $\mathrm{scm} / \mathrm{d}$ & 102,000 & 204,000 \\
\hline Compressor Type & & Reciprocating & Reciprocating \\
\hline \multirow[t]{2}{*}{ Suction Pressure } & bar & 7 & 7 \\
\hline & psia & 100 & 100 \\
\hline \multirow[t]{2}{*}{ Discharge Pressure } & bar & 103 & 103 \\
\hline & psia & 1,500 & 1,500 \\
\hline Compressor Displacement & $\mathrm{scm} / \mathrm{min}$ & 71 & 142 \\
\hline Overall Compression Ratio & & 14.7 & 14.7 \\
\hline Number of Stages & & 2 & 2 \\
\hline Horsepower & & 4.2 & 4.2 \\
\hline Connected Horsepower & & 500 & 1,000 \\
\hline Maximum Power Consumption & $\mathrm{kW}$ & 319 & 638 \\
\hline Average Power Consumption & $\mathrm{kW}$ & 120 & 240 \\
\hline Power Consumption & $\begin{array}{c}\mathrm{kW} / \text { thous and } \\
\mathrm{scm} / \mathrm{d}\end{array}$ & 3.1 & 3.1 \\
\hline Capital Cost per Compressor & $\$ /$ compressor & 737,000 & $1,473,000$ \\
\hline Total Compressor Cost & $\$$ & & $82,500,000$ \\
\hline
\end{tabular}

A summary of the lease equipment required for the EOR design is given in Table 5-8. 
Table 5-8

Lease equipment

\begin{tabular}{|l|c|c|}
\hline $\begin{array}{l}\text { Equipment } \\
\text { Description }\end{array}$ & Specification & Quantity \\
\hline Tubing & 2.375 inch, Grade J-55 & $40,000 \mathrm{ft}$ \\
\hline Sucker Rod & API Class K & $40,000 \mathrm{ft}$ \\
\hline Pump Rod & API Type RWBC & 10 \\
\hline Pumping Unit & API Size M160D 173-74, 12 hp & 10 \\
\hline Oil Flowline & 2.375 inch, PVC & $16,000 \mathrm{ft}$ \\
\hline Manifold & 10 valves, 2 inch 3-way & 1 \\
\hline Production Separator & $\begin{array}{c}\text { Vertical, 30 inch } \times 10 \text { feet, 2,700 } \\
\text { barrels per day of fluid, 5.7 million } \\
\text { scf/day gas }\end{array}$ \\
\hline Vapor Compressor & 500 scf/min, 0-100 psig, $115 \mathrm{hp}$ & 1 \\
\hline Test Separator & 1.0 bbl/d & 1 \\
\hline Oil Storage Tank & 2,000 bbls & 2 \\
\hline Water Disposal Pump & Quintuplex, 1,000 psi, 20 hp & 1 \\
\hline Water Disposal Line & 2.375 in, 2,500 psi yield & $2,000 \mathrm{ft}$ \\
\hline LACT Unit & 2,000 bbl/d & 1 \\
\hline
\end{tabular}

$1 \mathrm{in}=0.0254 \mathrm{~m}, 1 \mathrm{hp}=746 \mathrm{~J} / \mathrm{s}, 1 \mathrm{ft}=0.305 \mathrm{~m}, 1 \mathrm{cf}=0.028 \mathrm{~cm}, 1 \mathrm{psig}=0.069 \mathrm{bar}$

\subsubsection{Capital and O\&M Cost Inputs}

All of the capital and O\&M costs, except for the power costs, are found by multiplying the per module costs, given in Table 5-5, by the required number of modules, as detailed in Section 5.5.1. In the case of the pumping and field, and recycle compressor, power costs, the costs per kilowatt-hour are multiplied by 8,760, the total hours of operation per year, and the respective power requirement. Table 5-10 summarizes the model inputs for the capital and O\&M costs for the base case EOR design. 
Table 5-9

Capital and O\&M cost inputs for the EOR base case

\begin{tabular}{|l|c|}
\hline Parameter & Input \\
\hline Number of Modules & 56 \\
\hline \hline CAPITAL COSTS & \\
\hline Injection Equipment: & $\$ 99,300,000$ \\
\hline Recycle \& Vapor Compressors & $\$ 6,360,000$ \\
\hline Injection Plant Confines & $\$ 4,320,000$ \\
\hline Distribution Lines & $\$ 3,420,000$ \\
\hline Header & $\$ 5,450,000$ \\
\hline Electrical Service & $\$ 33,900,000$ \\
\hline Makeover of Existing Injection Wells \\
\hline Producing Equipment: & $\$ 5,080,000$ \\
\hline Tubing Replacement & $\$ 2,300,000$ \\
\hline Rods \& Pumps & $\$ 22,700,000$ \\
\hline Equipment & $\$ 182,800,000$ \\
\hline Subtotal & $\$ 27,000,000$ \\
\hline \hline O\&M COSTS & $\$ 846,000$ \\
\hline Normal Daily Expenses: & $\$ 27,000$ \\
\hline Supervision \& Overhead & $\$ 2,970,000$ \\
\hline Labor & $\$ 3,510,000$ \\
\hline Consumables & $\$ 420,000$ \\
\hline Operative Supplies & $\$ 431,000$ \\
\hline Pumping \& Field Power (7,196 kW) & $\$ 2,770,000$ \\
\hline Recycle Compressor Power (17,946 kW) & $\$ 1,910,000$ \\
\hline Surface Maintenance (Repair \& Services): \\
\hline Labor (roustabout) & $\$ 129,000$ \\
\hline Supplies \& Services & \\
\hline Equipment Usage & \\
\hline Other & \\
\hline Subsurface Maintenance (Repair \& Services): \\
\hline Workover Rig Services & \\
\hline Remedial Services & \\
\hline Equipment Repair & \\
\hline Other & \\
\hline Subtotal & \\
\hline
\end{tabular}




\subsection{Model Results}

This section presents costs for $\mathrm{CO}_{2}$ capture and storage for EOR for the base case, described in Section 5.5.1. The storage costs comprise transaction, transportation (from Chapter 4), injection and monitoring costs. These costs are combined with capture costs from the IGCC power plant referred to earlier. The results, which include the revenue generated from the sale of the enhanced oil produced, are given on several bases as described in Chapter 2. Appendix B provides a detailed description of these spreadsheets.

The Process Input sheet for the base case is presented in Table 5-10.

Table 5-10

Process input sheet for base case EOR

Enhanced Oil Recovery Input Variables

\begin{tabular}{|c|c|}
\hline $\begin{array}{l}\text { Design Basis } \\
\text { IGCC Plant }\end{array}$ & \\
\hline Capacity Factor & $80 \%$ \\
\hline Pipeline Distance & $100 \mathrm{~km}$ \\
\hline Pipeline Distance & 62 miles \\
\hline Nominal pipe size (in) & 12 \\
\hline $\mathrm{CO}_{2}$ Storage & \\
\hline Well Depth $(m)$ & 1,219 \\
\hline Well Depth (ft) & 4,000 \\
\hline $\mathrm{CO}_{2}$ Effectiveness (scm/bbl) & 170 \\
\hline $\mathrm{CO}_{2}$ Effectiveness (scf/bbl) & 6,000 \\
\hline $\begin{array}{l}\text { Oil Production (bbl/day/well) } \\
\text { Maximum Recycle Ratio }\end{array}$ & $\begin{array}{r}40 \\
3.0 \\
\end{array}$ \\
\hline Previous Waterflooding & $\square$ \\
\hline
\end{tabular}

Economic

IGCC Plant (Case 3a)

$\mathrm{CO}_{2}$ Capture Cost (\$/tonne captured)

COE Including $\mathrm{CO}_{2}$ Capture Cost $(\$ / \mathrm{MWh})$

$\$ 14.55$

$\$ 55.08$

$\mathrm{CO}_{2}$ Storage

\begin{tabular}{ll} 
Wellhead Oil Price $(\$ / \mathrm{bbl})$ & $\$ 15.00$ \\
\hline
\end{tabular}

Oil Royalty

Oil Credit ( $\$ / b b l)$

Break Even Oil Price to Offset $\mathrm{CO}_{2}$ Storage Costs $(\$ / \mathrm{bbl})$

Years 1-20

$12.5 \%$

$\$ 13.13$

Years 1-100, NPV Basis

IGCC Plant \& $\mathrm{CO}_{2}$ Storage

After-Tax Discount Rate

Levelized Carrying Charge Factor

1 inch $=0.0254 \mathrm{~m}$

The Summary sheet for the base case is presented in Table 5-11. This summary assumes a Wellhead Oil Price of $\$ 15.00 / \mathrm{bbl}$ and an Oil Royalty of 12.5 percent. 
Table 5-11

Summary sheet for base case EOR

Enhanced Oil Recovery Summary

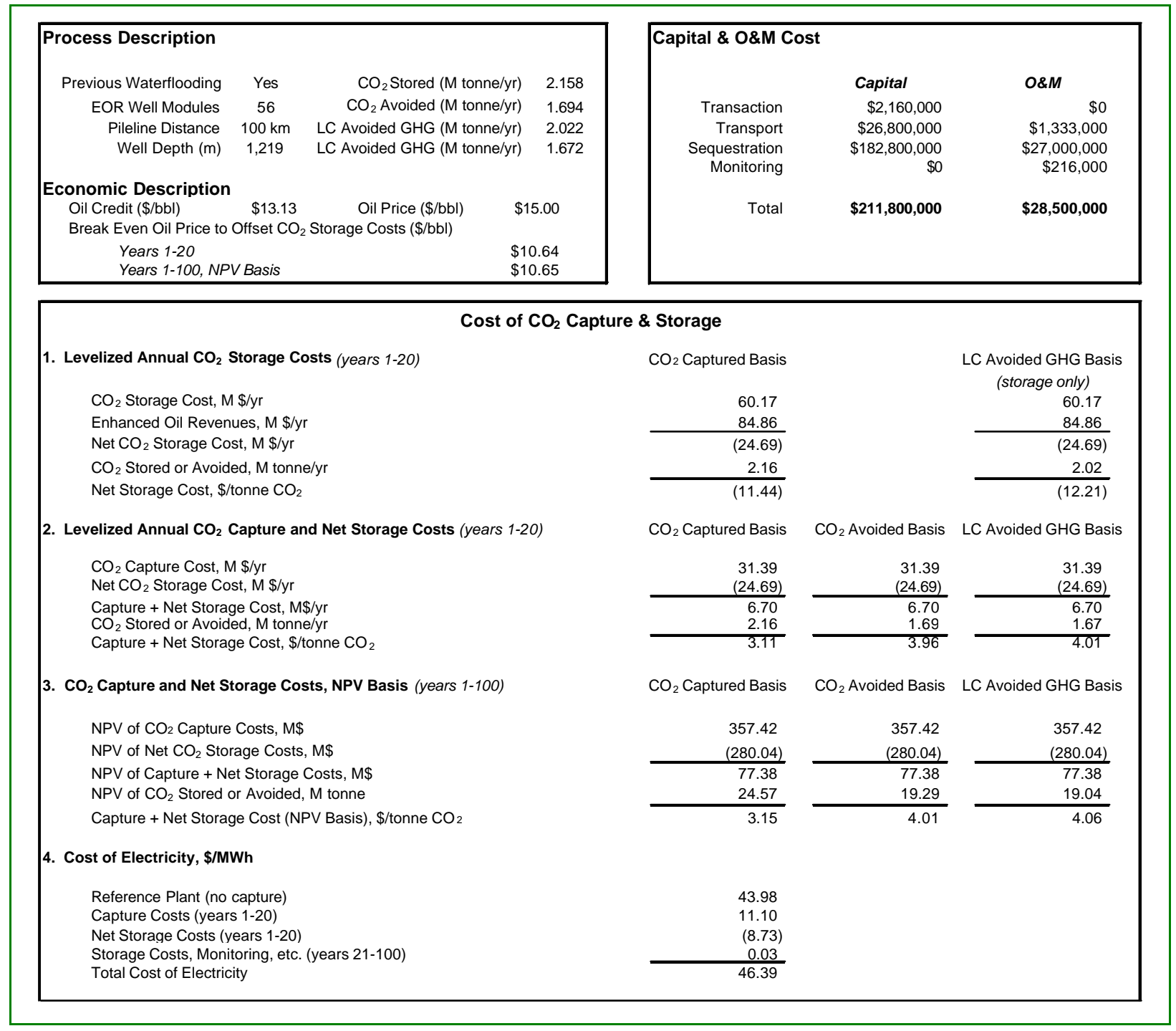

\subsection{Sensitivity Analysis}

The sensitivity of the $\mathrm{CO}_{2}$ storage cost for EOR is determined for six key parameters as well as for the case of no previous waterflooding. It can be seen in Figure 5-3 that increases in well depth, $\mathrm{CO}_{2}$ effectiveness, recycle ratio and pipeline distance cause an increase in the cost of storage, while increases in oil production rate and oil price decrease the storage cost. More noteworthy, the figure shows that changes in oil price have the greatest effect on storage cost, followed closely by changes in $\mathrm{CO}_{2}$ effectiveness. As is to be expected, the case of no previous waterflooding results in an upward shift in the cost. 


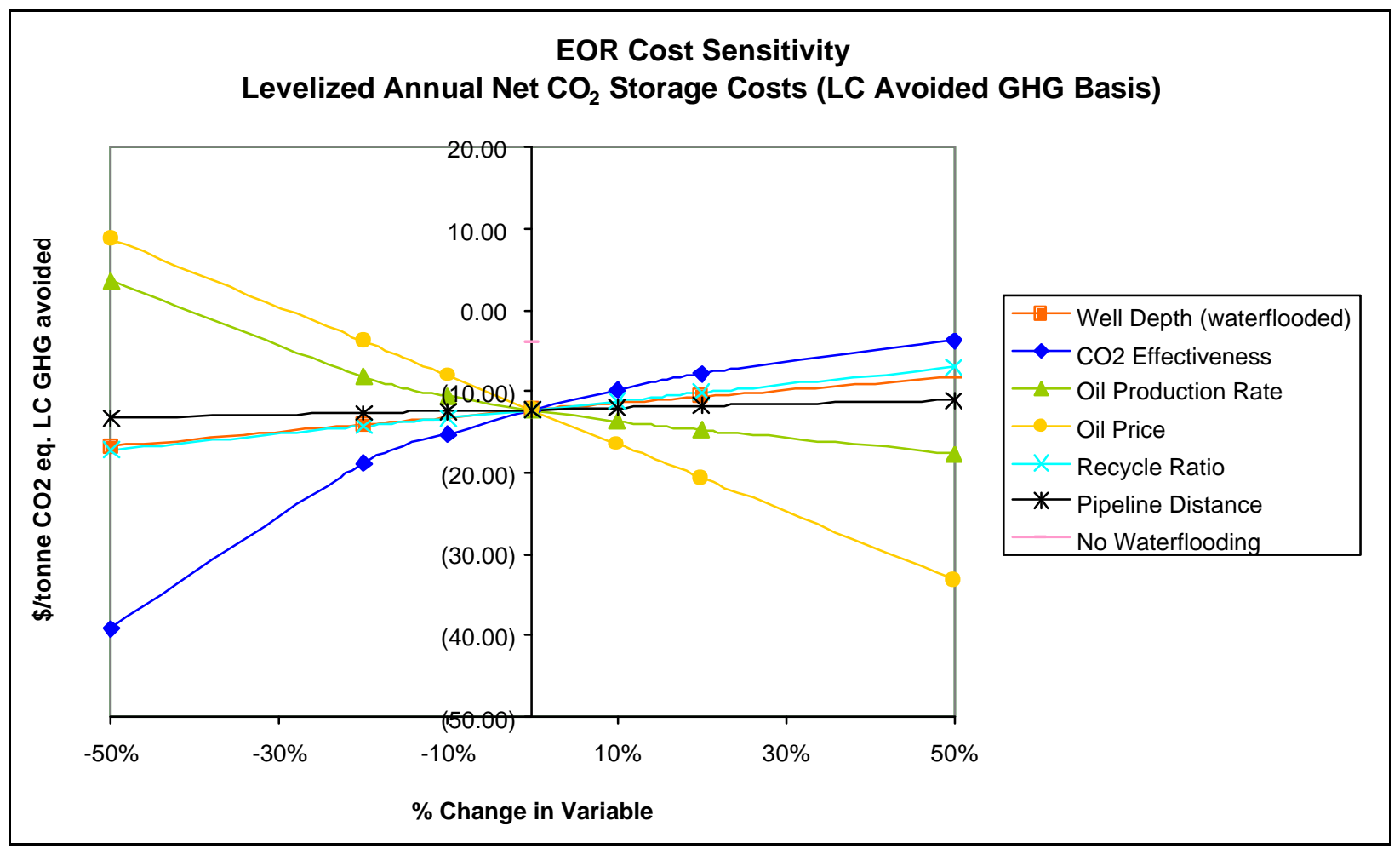

Figure 5-3

Sensitivity analysis for EOR

High and low cost cases have been chosen for EOR, and are presented together with the base case in Table 5-12. The price of oil at the wellhead is taken to have a low-end value of $\$ 12$ per $\mathrm{bbl}$ and a ceiling price of $\$ 20$ per bbl. For the high and low cost values for each of the six key parameters, the percentage change in the value from the base case is shown. This is done to illustrate the fact that the range in the values of some parameters is expected to be greater than for others. The table also shows that the high cost case assumes no previous waterflooding, while the low cost case assumes the field has been waterflooded as for the base case.

Table 5-12

EOR base, high cost and low cost cases

\begin{tabular}{|l|c|c|c|c|c|c|}
\hline Parameter & Units & \multicolumn{2}{c|}{$\begin{array}{c}\text { EOR } \\
\text { Base Case }\end{array}$} & \multicolumn{2}{|c|}{ High Cost Case } & \multicolumn{2}{c|}{ Low Cost Case } \\
\hline $\mathbf{C O}_{2}$ Effectiveness & scm/bbl enhanced oil & 170 & 227 & $+34 \%$ & 85 & $-50 \%$ \\
\hline Oil Production per Well & bbl enhanced oil/d/well & 40 & 20 & $-50 \%$ & 70 & $+75 \%$ \\
\hline Maximum Recycle Ratio & & 3 & 4 & $+33 \%$ & 1 & $-67 \%$ \\
\hline Oil Price & $\$ / b b l$ & 15 & 12 & $-20 \%$ & 20 & $+33 \%$ \\
\hline Depth & $\mathrm{m}$ & 1,219 & 2,438 & $+100 \%$ & 610 & $-50 \%$ \\
\hline Pipeline Distance & $\mathrm{km}$ & 100 & 300 & $+200 \%$ & 0 & $-100 \%$ \\
\hline Previous Waterflooding & & Yes & No & - & Yes & - \\
\hline
\end{tabular}


The results for the high and low cost cases as well as the base case are given in Table 5-13. The $\mathrm{CO}_{2}$ storage cost for EOR can be seen to be widely different for the high and low cost cases. In reality, a $\mathrm{CO}_{2}$-EOR project with parameter values approaching those of the high cost case would not be carried out.

Table 5-13

Results for EOR base, high cost and low cost cases

\begin{tabular}{|l|l|c|c|c|}
\hline Parameter & Units & $\begin{array}{c}\text { EOR } \\
\text { Base Case }\end{array}$ & $\begin{array}{c}\text { EOR } \\
\text { High Cost Case }\end{array}$ & $\begin{array}{c}\text { EOR } \\
\text { Low Cost Case }\end{array}$ \\
\hline Total Oil Production & $\begin{array}{c}\text { bbl enhanced } \\
\text { oil/d }\end{array}$ & 22,142 & 16,582 & 44,285 \\
\hline Number of 10/11 Well Modules & 56 & 83 & 64 \\
\hline New $\mathrm{CO}_{2}$ & $\mathrm{scm} / \mathrm{d} /$ module & 68,000 & 45,000 & 59,000 \\
\hline Maximum Recycled $\mathrm{CO}_{2}$ & $\mathrm{scm} / \mathrm{d} / \mathrm{module}$ & 204,000 & 182,000 & 59,000 \\
\hline $\begin{array}{l}\text { Levelized Annual } \mathrm{Net}_{\mathbf{C O}} \\
\text { Storage Cost }\end{array}$ & $\begin{array}{c}\$ / \text { tonne } \mathrm{CO}_{2} \text { Eq. } \\
\mathrm{LC} \mathrm{GHG} \\
\text { Avoided }\end{array}$ & $(12.21)$ & 73.84 & $(91.26)$ \\
\hline
\end{tabular}

\subsection{Comparison to Literature}

A comparison is made between the costs obtained for the EOR base-case design using the EIA 'Costs and Indices for Domestic Oil and Gas Field Equipment and Production Operations' report and those calculated using cost estimation functions provided by Reference 15 . The relevant cost functions are shown in Table 5-14.

Table 5-14 EOR cost estimation functions ${ }^{15}$

\begin{tabular}{|c|c|c|}
\hline Item & Unit & Value \\
\hline \multicolumn{3}{|l|}{ CAPITAL COSTS } \\
\hline Workover of existing injector & $\$$ & $5 * \operatorname{depth}(\mathrm{ft})+35,000$ \\
\hline Workover of existing producer & $\$$ & 40,000 \\
\hline Provision of injection surface facilities & $\$ /$ well & 22,000 \\
\hline Workover of production surface facilities & $\$ /$ well & 10,000 \\
\hline $\mathrm{CO}_{2}$ recycle plant & $\$$ & $\begin{array}{c}457,000 * \mathrm{CO}_{2} \text { recycled (million } \\
\text { scf per day) }\end{array}$ \\
\hline \multicolumn{3}{|l|}{ O\&M COSTS } \\
\hline $\mathrm{CO}_{2}$ recycle compression operating costs & $\$ / y$ & $\begin{array}{c}200 * \mathrm{CO}_{2} \text { recycled (million scf } \\
\text { per day) }{ }^{*} 365\end{array}$ \\
\hline
\end{tabular}


Using these cost functions, the capital and O\&M costs of EOR for the base-case design were calculated. Table 5-15 shows the results of these calculations together with the previously determined base-case EOR costs.

Table 5-15

Comparison of EOR cost results ${ }^{15,16}$

\begin{tabular}{|c|c|c|c|}
\hline Item & Unit & This Study & Using Cost Functions \\
\hline \multicolumn{4}{|l|}{ CAPITAL COSTS } \\
\hline Workover of injectors & $\$$ & $33,900,000$ & $33,495,000$ \\
\hline Provision of injection surface facilities & $\$$ & $13,190,000$ & $13,398,000$ \\
\hline Total cost injection equipment & $\$$ & $47,090,000$ & $46,893,000$ \\
\hline Workover of producers & $\$$ & $27,780,000$ & $22,160,000$ \\
\hline $\begin{array}{l}\text { Workover of production surface } \\
\text { facilities }\end{array}$ & $\$$ & $2,300,000$ & $5,540,000$ \\
\hline Total cost production equipment & $\$$ & $30,080,000$ & $27,700,000$ \\
\hline $\mathrm{CO}_{2}$ recycle plant & $\$$ & $105,660,000$ & $182,354,000$ \\
\hline Total Capital Cost & $\$$ & $182,800,000$ & $256,947,000$ \\
\hline \multicolumn{4}{|l|}{ O\&M COSTS } \\
\hline $\begin{array}{l}\mathrm{CO}_{2} \text { recycle compression operating } \\
\text { costs }\end{array}$ & $\$ / y r$ & $12,232,000$ & $14,540,000$ \\
\hline TOTAL O\&M COSTS & $\$ / y r$ & $27,000,000$ & - \\
\hline
\end{tabular}

Except for the $\mathrm{CO}_{2}$ recycle plant, it can be seen from the table that the cost of the EOR base-case design is very similar for the two sets of cost data. The $\mathrm{CO}_{2}$ recycle plant costs were not included in the EIA report and were developed from vendor quotations and in-house data. It is concluded that using the EIA report for costs was reliable, given the uncertainties and variation in the data.

\subsection{References}

1 “OGJ Special - Worldwide EOR survey 2000," Oil \& Gas Journal, pp. 44-61, Mar. 20, 2000.

2 “OGJ Special - Worldwide production,” Oil \& Gas Journal, pp. 126-157, Dec. 24, 2001.

3 Herzog, H., "An introduction to $\mathrm{CO}_{2}$ separation and capture technologies," Energy Laboratory Working Paper, 1999. 
4 Kinder Morgan $\mathrm{CO}_{2}$ Company, “ $\mathrm{CO}_{2}$ Supply,” [Online document], 2001, [cited Jan. 2002], Available HTTP: http://www.kne.com/co2/supply.cfm

5 “Enhanced Oil Recovery Scoping Study,” EPRI, Palo Alto, CA. Tech. Rep. 113836, 1999.

6 Brown, K., W. Jazrawi, R. Moberg and M. Wilson, "Role of enhanced oil recovery in carbon sequestration - The Weyburn Monitoring Project, a case study," presented at the First National Conference on Carbon Sequestration, Washington DC, May 14-17, 2001.

7 Moritis, G., "Future of EOR \& IOR: New companies, infrastructure, projects reshape landscape for $\mathrm{CO}_{2}$ EOR in U.S.," Oil \& Gas Journal, May 14, 2001.

8 Marle, C.M., "Oil entrapment and mobilization," In Basic Concepts in Enhanced Oil Recovery Processes, M. Baviere, Eds. Elsevier Applied Science, 1991, pp. 3-39.

9 Klins, M.A. and C.P. Bardon, "Carbon dioxide flooding," In Basic Concepts in Enhanced Oil Recovery Processes, M. Baviere, Eds. Elsevier Applied Science, 1991, pp. 215-240.

10 Morel, D., "Miscible gas flooding," In Basic Concepts in Enhanced Oil Recovery Processes, M. Baviere, Eds. Elsevier Applied Science, 1991, pp. 185-214.

11 "Evaluation of Innovative Fossil Fuel Power Plants with CO2 Removal," EPRI Report No. 1000316, Interim Report, December 2000, Cosponsors: U.S. Department of Energy/Office of Fossil Energy and U.S. Department of Energy/NETL, EPRI Project Manager N. A. H. Holt.

Available HTTP:

http://www.netl.doe.gov/coalpower/gasification/pubs/pdf/EpriReport.pdf

12 Smith, L.A. et al, "Engineering and economic assessment of carbon dioxide sequestration in saline formations," presented at the First National Conference on Carbon Sequestration, Washington DC, May 14-17, 2001.

13 Wilson, Malcolm, personal communication, Sep. 24, 2001.

14 Hattenbach, Ray, personal communication, Sep. 24, 2001.

15 "Is my field a candidate for $\mathrm{CO}_{2}$ flooding?," Center for Energy and Economic Diversification (CEED), Odessa, TX. CEED CO 2 flooding shortcourse no. 2, 1995.

16 Energy Information Administration - Office of Oil and Gas, "Costs and Indices for Domestic Oil and Gas Field Equipment and Production Operations," [Online document], Mar. 2000, Available HTTP:

http://www.eia.doe.gov/oil_gas/natural_gas/data_publications/cost_indices/c_i.html 


\section{ENHANCED COALBED METHANE}

\subsection{Introduction}

This chapter looks at the injection of $\mathrm{CO}_{2}$ into deep coal seams as a means of enhancing coalbed methane production while simultaneously sequestering $\mathrm{CO}_{2}$.

\subsection{State of the Art}

\subsubsection{Applications}

The injection of $\mathrm{CO}_{2}$ into deep, unmineable coal seams to enhance coal-bed methane production $\left(\mathrm{CO}_{2}\right.$-ECBMR $)$ is a relatively recent technology. It was not until 1996 that the world's first, and to date only, pilot-scale application of $\mathrm{CO}_{2}$-ECBMR began operation. In contrast, EOR using $\mathrm{CO}_{2}$ floods $\left(\mathrm{CO}_{2}\right.$-EOR) is a mature technology with over three decades of commercial-scale application. The one $\mathrm{CO}_{2}$-ECBMR project, comprising nine coal-bed methane (CBM) production and four $\mathrm{CO}_{2}$ injection wells, is located in the southwestern United States within the Allison production unit of the San Juan basin and is operated by Burlington Resources, the United States' largest producer of coal-bed methane. Analysis of operations at the Allison unit has shown the $\mathrm{CO}_{2}$-ECBMR process to be technically and economically feasible. ${ }^{1,2,3}$

\subsubsection{Storage Potential}

CBM production has become an increasingly important component of natural gas supply in the United States during the last decade. In 2000, approximately 40 billion standard cubic meters (scm) of CBM was produced, accounting for about 7 percent of the nation's total natural gas production. The most significant CBM production, some 85 percent of the total, occurs in the San Juan basin of southern Colorado and northern New Mexico. Another 10 percent is produced in the Black Warrior basin of Alabama and the remaining 5 percent comes from rapidly developing Rocky Mountain coal basins, namely the Uinta basin in Utah, the Raton basin in Colorado and New Mexico, and the Powder River basin in Wyoming. ${ }^{1,4}$

Essentially all current CBM production utilizes primary recovery methods. Primary recovery involves pumping off large volumes of formation water to lower reservoir pressure and cause methane desorption from the coal. Primary production of CBM recovers only 20 to 60 percent of original gas-in-place (OGIP), where this varies depending on reservoir properties such as coal seam permeability and gas saturation, and operational practices such as well spacing. In comparison, over 90 percent of the OGIP can theoretically be recovered using $\mathrm{CO}_{2}$-ECBMR. 
Furthermore, $\mathrm{CO}_{2}$-ECBMR can accelerate $\mathrm{CBM}$ recovery, providing greater real value for a given reserve. ${ }^{1,2}$

Significant potential for $\mathrm{CO}_{2}$-ECBMR exists worldwide. In order for $\mathrm{CO}_{2}$-ECBMR to be successfully applied, reservoirs must have laterally continuous and permeable coal seams, concentrated seam geometry, and minimal faulting and reservoir compartmentalization. In the United States, the geologically most favorable reservoirs are located within the San Juan, Uinta, and Raton basins, while additional potential exists in the Greater Green River and Appalachian basins. A number of coal basins in Australia, Russia, China, India, Indonesia, and other countries have also been identified as having large $\mathrm{CO}_{2}$-ECBMR potential. Indeed, the total worldwide potential for $\mathrm{CO}_{2}$-ECBMR, taking into consideration only those reservoirs where $\mathrm{CO}_{2}$-ECBMR could be profitably developed without $\mathrm{CO}_{2}$ sequestration credits or free or reduced-cost $\mathrm{CO}_{2}$ supplies, is estimated at around two trillion scm of $\mathrm{CBM}$, with about 7.1 billion tonnes of associated $\mathrm{CO}_{2}$ sequestration potential. ${ }^{5}$

\subsubsection{Storage Mechanics}

Four patents have been issued over the past two decades relating to the $\mathrm{CO}_{2}$-ECBMR process. Each of these patents is based on the principle that $\mathrm{CO}_{2}$ is adsorbed more readily onto the coal matrix than methane. Specifically, $\mathrm{CO}_{2}$-ECBMR involves injected $\mathrm{CO}_{2}$ being adsorbed at the expense of methane, which having been displaced can be recovered as a free gas at production wells. Sorption isotherm measurements in the laboratory indicate that two unit volumes of $\mathrm{CO}_{2}$ are required to displace one unit volume of methane. This ratio of $\mathrm{CO}_{2}$ effectiveness is however expected to vary in the field according to the thermal maturity of the coal. ${ }^{1,2,5,6}$

A successful demonstration of $\mathrm{CO}_{2}$-ECBMR technology has been provided by the Allison unit pilot project. Prior to $\mathrm{CO}_{2}$ injection, $\mathrm{CBM}$ was produced within the unit using conventional pressure-depletion methods. Since the start of $\mathrm{CO}_{2}$ injection, enhanced $\mathrm{CBM}$ production has been observed. A marked increase in water production was also observed initially, signaling improved sweep of bypassed reservoir areas that should lead to higher ultimate gas recovery. Finally, there has been negligible $\mathrm{CO}_{2}$ breakthrough, despite around one billion scf of $\mathrm{CO}_{2}$ being injected each year since the project began in 1996. The injected $\mathrm{CO}_{2}$ comes from the McElmo Dome, which is a natural $\mathrm{CO}_{2}$ deposit in southwestern Colorado. ${ }^{1,2,3}$

\subsubsection{Feasibility of Storage Option}

$\mathrm{CO}_{2}$-ECBMR presents an attractive option for the sequestering of $\mathrm{CO}_{2}$. Like $\mathrm{CO}_{2}$-EOR, it has the distinct advantage over other $\mathrm{CO}_{2}$ storage options that it sequesters $\mathrm{CO}_{2}$ while also generating a value-added product. While $\mathrm{CO}_{2}$-ECBMR as a technology is still in the development stage and has not been widely applied, it has been successfully demonstrated in a pilot-scale application. Also, given the broad similarities between the two, the technology required to implement $\mathrm{CO}_{2}$-ECBMR in the field can be largely based on that used for $\mathrm{CO}_{2}$-EOR operations. The fact that $\mathrm{CO}_{2}$ is adsorbed onto the coal surface means that there should be little risk of leakage of $\mathrm{CO}_{2}$ from the reservoir. Also on a positive note, coal, and so CBM, typically 
lies at relatively shallow depths so that well drilling and completion costs are generally lower than for other geologic options.

On the downside, $\mathrm{CO}_{2}$-ECBMR is a very energy intensive process, requiring significant electricity both for pumping large volumes of formation water to the surface and for compressing the produced methane to a suitable pressure for pipeline transport and sale. Another disadvantage is that the large volumes of formation water produced by $\mathrm{CO}_{2}-\mathrm{ECBMR}$ are most often saline and need to be disposed of in an environmentally acceptable manner.

\subsection{Process Description}

Figure 6-1 is a block flow diagram, indicating the overall flow and distribution of $\mathrm{CO}_{2}$ from the IGCC plant to the ECBMR field. First, the $\mathrm{CO}_{2}$ leaving the plant is fed to an additional stage of compression to bring it up to the required pipeline inlet pressure. Second, the pipeline transports the $\mathrm{CO}_{2}$ a distance of $100 \mathrm{~km}$ to the ECBMR field, where it is injected into the ECBMR $\mathrm{CO}_{2}$ wells. Third, the ECBMR product is dewatered, and dry gas from the ECBMR wells is compressed to the gathering line pressure. Finally, the gas from the gathering line is then further compressed for sale to a nearby pipeline.

The source and quantity of $\mathrm{CO}_{2}$ supplied to the ECBMR field is the same as for the EOR storage option. It should also be noted that the pipeline outlet pressure of 103 bar is assumed to be at or above the required surface injection pressure.

Very simple vertical wells from 300 to $1,200 \mathrm{~m}$ in total depth are common to this type of production. These wells produce gas at very low pressures; wellhead pressures of between 2 to 3 bar are common. ${ }^{7}$ Because these wells are generally operated at low backpressures (assuming 1.7 bar), compression is required to increase the wellhead pressure to the gas gathering line pressure of 4.5 bar. The gathered gas is then further compressed to 25.1 bar for delivery to a nearby pipeline.

Developing an ECBMR lease for production involves:

- Lease acquisition activities

- Drilling and equipping production/injection wells

- Installation of high-pressure injection equipment and related piping

- Installation of ECBMR production equipment and facilities

- Installation of product gas compressors

The ECBMR field is a grass-roots facility, which has not produced CBM in the past. The ECBMR field therefore requires a new distribution and injection/ECBMR production system, which serves the following purposes:

- Receives $\mathrm{CO}_{2}$ from the pipeline terminal and distributes it to the $\mathrm{ECBMR} \mathrm{CO}_{2}$ injection wells. 
- Gathers gas from the ECBMR production wells and delivers it to a central gas/liquid separator.

- Dewaters the ECBMR production wells and conveys water to a central disposal well.

- Compresses the separated gas to 4.5 bar for distribution to a regional gathering line.

- Compresses the gathered gas to 25.1 bar for sale to a nearby pipeline.

Most coal-bed methane reservoirs are low-pressure water-bearing gas reservoirs. Under conditions of high water saturation, the water volume and the hydrostatic pressure must be reduced by artificial lift to initiate gas desorption and flow to the wellbore. ${ }^{8}$ This dewatering process produces large quantities of saline water that must be disposed of carefully. In the Warrior Basin, water is usually piped to a central treatment facility and disposed into a surface stream. In the San Juan Basin, because of the higher total dissolved solids in the water, disposal wells are used. ${ }^{9}$ For this study, the use of disposal wells is assumed.

A productive life span of 20 to 30 years is typical for coalbed methane fields. ${ }^{10}$ The life of this field is assumed to be the same as that of the power plant, 20 years. As a final note, the design/construction time is taken to be the same as the power plant, 4 years. 


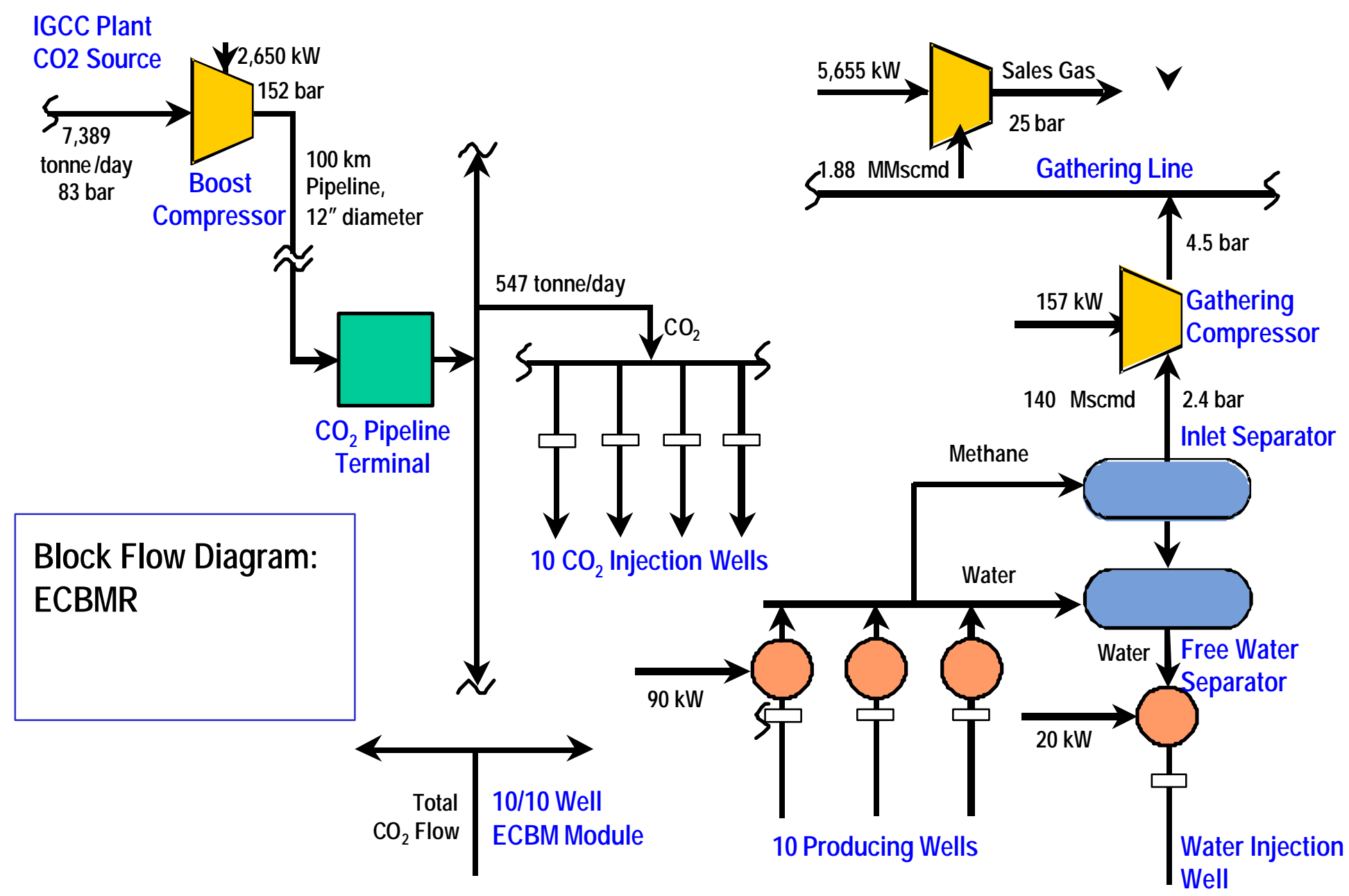

\section{Figure 6-1}

ECBMR block flow diagram 


\subsection{Methodology Used}

As in the case of the $\mathrm{CO}_{2}$-EOR concept design, 'rules of thumb' are used to define the engineering parameters needed to estimate the cost of a $\mathrm{CO}_{2}-\mathrm{ECBMR}$ project. As for $\mathrm{CO}_{2}-\mathrm{EOR}$, the method for costing the $\mathrm{CO}_{2}$-ECBMR process is also split up into a number of steps. First, the total amount of enhanced $\mathrm{CBM}$ produced per day for the given $\mathrm{CO}_{2}$ mass flow rate is determined using a $\mathrm{CO}_{2}$ effectivene ss factor of two $\mathrm{scm} \mathrm{CO}_{2}$ per scm of enhanced CBM. Second, the number of production wells is found by dividing this total amount of enhanced CBM produced per day by an assumed 14,000 scm of enhanced CBM per day being produced at each well. Third, a ratio of producers to injectors of 1 to 1 is used to calculate the number of injection wells from the number of production wells. Fourth, it is assumed that no recycling of $\mathrm{CO}_{2}$ is required. Finally, the cost of drilling and equipping the required production and injection wells is calculated. An overview of the cost model is provided in Figure 6-2.

\subsection{1 $\mathrm{CO}_{2}$ Effectiveness}

For the design basis, it is assumed that $2 \mathrm{scm}$ of $\mathrm{CO}_{2}$ needs to be injected to produce $1 \mathrm{scm}$ of enhanced CBM. This $\mathrm{CO}_{2}$ effectiveness ratio is based on the results of sorption isotherm measurements carried out on bituminous coals in the laboratory. These measurements indicate that coal can adsorb roughly twice as much $\mathrm{CO}_{2}$ by volume as methane. This may vary, however, as a result of other physical processes active within a coal reservoir. Based on data collected in the field, one source ${ }^{11}$ has reported the amount of $\mathrm{CO}_{2}$ injected to $\mathrm{CBM}$ produced as being between 1.5 and 2 while another ${ }^{12}$ has reported it as being closer to 3 than 2 . It is important to note that the ratio is also dependent on the thermal maturity of the coal and that it can be as high as 10 to 1 for sub-bituminous coals. Based on these values, a range of 1.5 to $10 \mathrm{scm}$ of $\mathrm{CO}_{2}$ per scm of enhanced CBM was chosen for the sensitivity analysis. ${ }^{1,2,5}$

\subsubsection{Rate of Enhanced CBM Production}

The amount of enhanced CBM produced per day at each well is taken to be $14,000 \mathrm{scm}$. As in the case of EOR, there is no industry 'rule of thumb' for the production at each well on a daily basis. Instead, the CBM production rate depends on reservoir parameters such as coal seam permeability, gas saturation and thickness, and operational practices such as the recovery method used and well spacing. ${ }^{13}$

The variation in the CBM production rate that results from different values of reservoir parameters can be seen from a comparison of values for the San Juan and Black Warrior basins. Average production in the San Juan basin exceeds 23,000 scm per day per well, with many wells in the most productive area averaging over $85,000 \mathrm{scm}$ per day. In contrast, the Black Warrior basin wells average $3,400 \mathrm{scm}$ per day, reflecting the fact that this basin has lower permeability, thinner coal seams. 


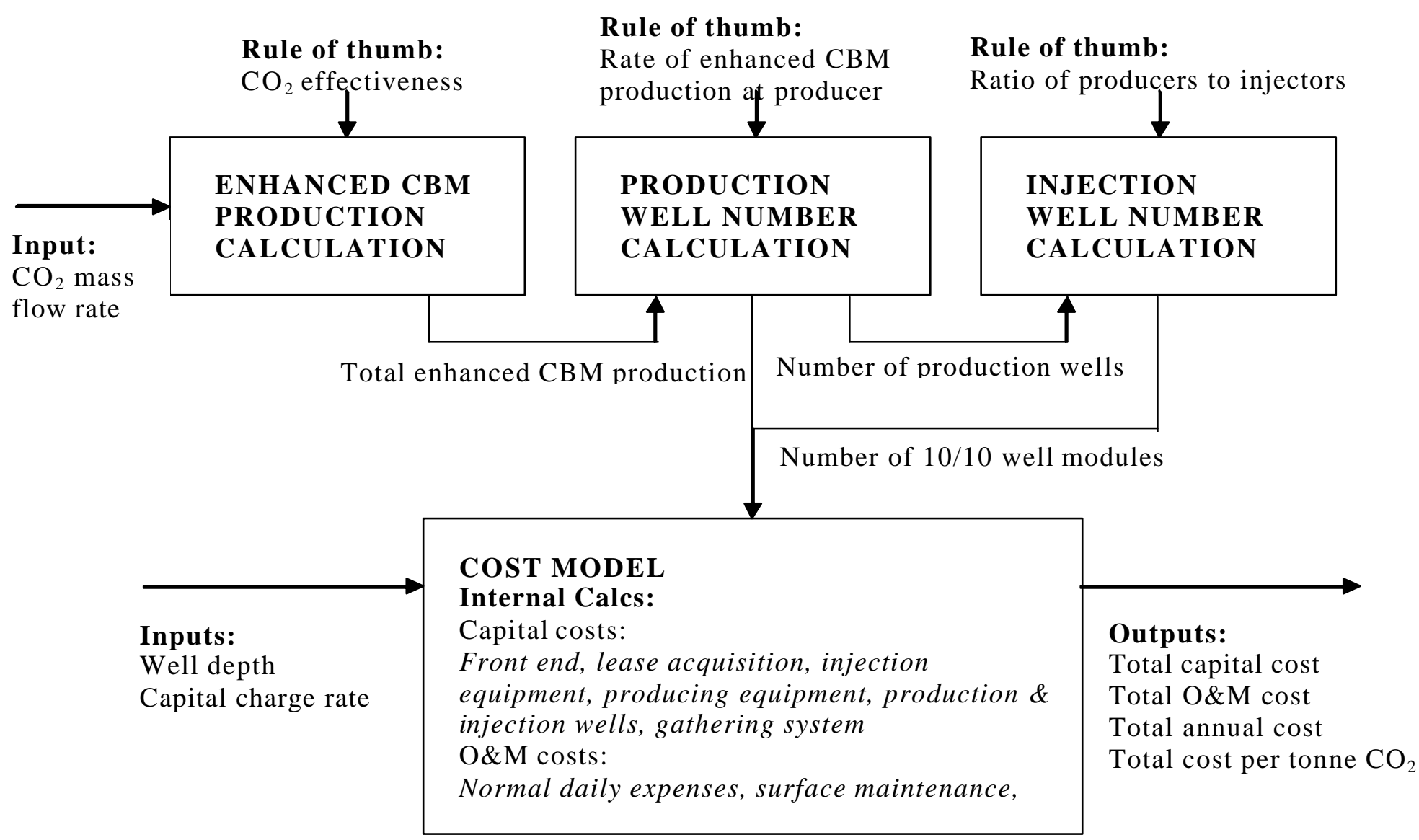

Figure 6-2

ECBMR cost model overview diagram 
The effect of the recovery method on the CBM production rate is evident from a look at the production history of the \#115 well within the Allison unit of the San Juan basin. Prior to $\mathrm{CO}_{2}$ injection, the \#115 well had been a sub-average performer, with a CBM production rate of $14,000 \mathrm{scm}$ per day. However, following $\mathrm{CO}_{2}$ injection, the daily $\mathrm{CBM}$ production rate rose sharply to $37,000 \mathrm{scm} .^{2,13}$

Based on the values given above for projects without $\mathrm{CO}_{2}$ injection as well as the Allison unit $\mathrm{CO}_{2}$-ECBMR pilot project, and advice from experts in the field ${ }^{11,12}$, the assumed base-case value of 14,000 scm of enhanced CBM per day per well was chosen. A sensitivity analysis range of 3,000 to 30,000 scm of enhanced CBM per day per well was also chosen. It is important to note that the values for the base-case and sensitivity range were chosen to be somewhat lower than those values quoted for the San Juan basin. This is simply because the San Juan basin, being the world's most prolific basin for CBM, is expected to have higher CBM production rates than other coal basins with $\mathrm{CO}_{2}$-ECBMR potential.

\subsubsection{Ratio of Producers to Injectors}

A ratio of producers to injectors of 1 to 1 is assumed for the $\mathrm{CO}_{2}-\mathrm{ECBMR}$ concept design. It is an industry standard for production and injection wells to be arranged in a five-spot configuration, where this entails each injector being surrounded by four producers. This well configuration is used in the case of the Allison unit $\mathrm{CO}_{2}$-ECBMR pilot project, which comprises nine $\mathrm{CBM}$ production and four $\mathrm{CO}_{2}$ injection wells. The ratio of producers to injectors resulting from the five-spot configuration for this small number of wells is just over 2 to 1 . However, as the number of production and injection wells increases, a repeating five-spot configuration results and the ratio of producers to injectors steadily approaches 1 to 1 . For the $\mathrm{CO}_{2}$-ECBMR concept design, which comprises a relatively large number of wells, a ratio of producers to injectors of 1 to 1 is therefore used.

\subsection{4 $\mathrm{CO}_{2}$ Recycle Ratio}

The $\mathrm{CO}_{2}$-ECBMR concept design assumes that $\mathrm{CO}_{2}$ breakthrough at the production wells is negligible and that there is, therefore, no need for $\mathrm{CO}_{2}$ recycling. At the Allison unit, breakthrough of $\mathrm{CO}_{2}$ has been minimal during the life of the project. Following almost five years of injection, the $\mathrm{CO}_{2}$ concentration in the produced gas was about 0.6 percent, which is only slightly above pre-injection levels of 0.4 percent. $^{3}$

\subsubsection{Drilling and Equipping of Production and Injection Wells}

The cost of the $\mathrm{CO}_{2}$-ECBMR process is calculated based on both production and injection wells needing to be drilled and equipped. If a coal bed is viewed primarily as a source of CBM, it makes more economic sense to partially deplete the reservoir of $\mathrm{CBM}$ before injecting $\mathrm{CO}_{2}$. However, in the case that the primary role of the coal bed is as a repository for $\mathrm{CO}_{2}$, early use of $\mathrm{CO}_{2}$-ECBMR is favored. Given that the concern here is $\mathrm{CO}_{2}$ sequestration, it is assumed for the 
purpose of the concept design that no CBM production has taken place at the coal bed prior to $\mathrm{CO}_{2}$ injection. This assumption implies that production and injection wells need to be provided. ${ }^{5}$

\subsubsection{Cost Calculations}

The total capital cost comprises front end and lease acquisition, injection and production equipment, well drilling and gathering system costs. The O\&M costs include normal daily expenses, and surface and subsurface maintenance costs.

Prior to acquiring a lease position, geological expenditures, geophysical expenditures, and engineering-based feasibility studies are often conducted. In addition, outlays are generally required for obtaining the lease and its associated permits. These front-end transaction costs will vary greatly but may range from $\$ 20,000$ to $\$ 30,000$ per well for a commercial project. ${ }^{9}$ For this study, a cost of $\$ 25,000$ per well is assumed.

All of the other field costs, except for the well drilling cost, are based on data contained in the EIA 'Costs and Indices for Domestic Oil and Gas Field Equipment and Production Operations' report. ${ }^{14}$ A representative ECBMR lease, or module, comprising $10 \mathrm{CO}_{2}$ injection wells and 10 producing wells with dewatering facilities is used for the design basis. The $10 \mathrm{CO}_{2}$ injection wells are drilled to a depth of $610 \mathrm{~m}$ and equipped with a battery of lease equipment, which includes distribution lines, headers, electrical service, and controls. The 10 producing wells, also drilled to a depth of $610 \mathrm{~m}$, are equipped with beam balanced/sucker rod dewatering.

The well drilling cost is calculated based on a relationship derived from data contained in the '1998 Joint Association Survey (JAS) on Drilling Costs' report. ${ }^{15}$ This relationship between well depth and drilling cost is shown in Figure 6-3.

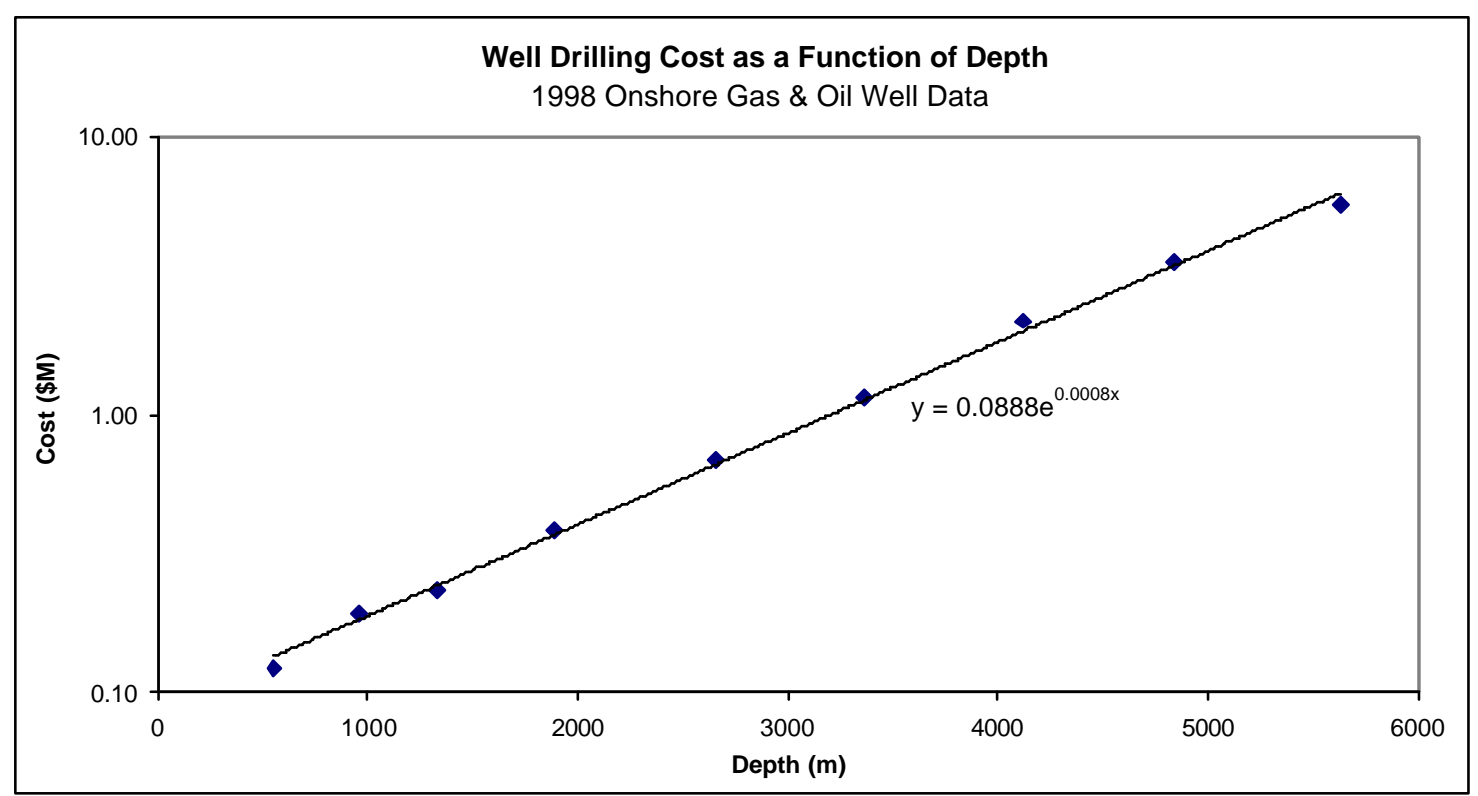

Figure 6-3

Well drilling cost as a function of depth 
The field equipment and well drilling capital costs, and the associated O\&M costs, are shown on a per module basis in Table 6-1. This table also gives the power costs associated with the gathering and sales gas compressors on a per kilowatt-hour basis.

Table 6-1

Capital and O\&M cost estimation factors

\begin{tabular}{|c|c|c|}
\hline Parameter & Unit & Value \\
\hline \multicolumn{3}{|l|}{ CAPITAL COSTS } \\
\hline \multicolumn{3}{|l|}{ Injection Equipment: } \\
\hline Plant & $\$ /$ module & 104,455 \\
\hline Distribution Lines & $\$ /$ module & 70,182 \\
\hline Header & $\$ /$ module & 55,545 \\
\hline Electrical Service & $\$ /$ module & 87,818 \\
\hline \multicolumn{3}{|l|}{ Producing Equipment: } \\
\hline Tubing & $\$ /$ module & 40,800 \\
\hline Rods \& Pumps & $\$ /$ module & 39,200 \\
\hline Pumping Equipment & $\$ /$ module & 340,000 \\
\hline \multicolumn{3}{|l|}{ Gathering System: } \\
\hline Flowlines & $\$ /$ module & 42,500 \\
\hline Manifold & $\$ /$ module & 42,600 \\
\hline Gathering Compressor & $\$ /$ module & 105,000 \\
\hline Sales Gas Compressor & $\$ /$ module & $3,970,000$ \\
\hline \multicolumn{3}{|l|}{ Lease Equipment: } \\
\hline Producing Separator & $\$ /$ module & 12,400 \\
\hline Storage Tanks & $\$ /$ module & 76,600 \\
\hline Accessory Equipment & $\$ /$ module & 35,800 \\
\hline Disposal System & $\$ /$ module & 96,700 \\
\hline Production \& Injection Wells & $\$ /$ module & $1,446,601$ \\
\hline \multicolumn{3}{|l|}{ O\&M COSTS } \\
\hline \multicolumn{3}{|l|}{ Normal Daily Expenses: } \\
\hline Supervision \& Overhead & $\$ /$ module & 50,245 \\
\hline Labor & $\$ /$ module & 39,936 \\
\hline Consumables & $\$ /$ module & 7,664 \\
\hline Operative Supplies & $\$ /$ module & 4,518 \\
\hline Auto Usage & $\$ /$ module & 7,900 \\
\hline Pumping \& Field Power & $\$ / k W h$ & 0.044 \\
\hline Gathering Compressor & $\$ / \mathrm{kWh}$ & 0.044 \\
\hline
\end{tabular}


Table 6-1 (continued)

Capital and O\&M cost estimation factors

\begin{tabular}{|l|c|c|}
\hline Parameter & Unit & Value \\
\hline Sales Gas Compressor & $\$ / \mathrm{kWh}$ & 0.044 \\
\hline \multicolumn{2}{|l|}{ Surface Maintenance (Repair \& Services): } \\
\hline Labor (roustabout) & $\$ /$ module & 18,282 \\
\hline Supplies \& Services & \$/module & 27,182 \\
\hline Equipment Usage & \$/module & 7,064 \\
\hline Other & $\$ /$ module & 2,782 \\
\hline Subsurface Maintenance (Repair \& Services): \\
\hline Workover Rig Services & \$/module & 30,518 \\
\hline Remedial Services & \$/module & 8,145 \\
\hline Equipment Repair & \$/module & 7,400 \\
\hline Other & \$/module & 6,764 \\
\hline
\end{tabular}

\subsection{Design Basis}

\subsubsection{Module Design}

The ECBMR design is tied as closely as possible to the EIA 'Costs and Indices for Domestic Oil and Gas Field Equipment and Production Operations' report ${ }^{14}$ in order to make use of the cost data. This report is described in detail in Section 5.5.1.

The base case design is based on a $\mathrm{CO}_{2}$ effectiveness factor of $2 \mathrm{scm}$ per scm of enhanced CBM and an enhanced CBM production rate of $14,000 \mathrm{scm}$ per day per well. From the design flow rate of 3.76 million $\mathrm{scm}$ (7,389 tonnes) of $\mathrm{CO}_{2}$ per day, the total enhanced $\mathrm{CBM}$ production is calculated using the $\mathrm{CO}_{2}$ effectiveness factor to be 1.88 million scm. Dividing this total enhanced CBM production by the enhanced CBM production rate per well, the required number of production wells is found to be 135 . Given a producer to injector ratio of 1 to 1,135 injection wells are required. In keeping the design consistent with the EIA modular approach, the ECBMR field for the base case therefore consists of 14 10/10 well modules. Finally, a well depth of $610 \mathrm{~m}$, which is slightly more than the average depth of the CBM wells reported in the '1998 JAS on Drilling Costs' report, is selected as typical. Table 6-2 summarizes the base case for ECBMR. 
Table 6-2

Design basis for ECBMR base case

\begin{tabular}{|l|c|c|}
\hline Parameter & Unit & ECBMR Base Case \\
\hline $\mathrm{CO}_{2}$ Effectiveness & scm/scm enhanced CBM & 2.0 \\
\hline CBM Production per Well & scm enhanced CBM/d/well & 14,000 \\
\hline Total CBM Production* & million scm enhanced CBM/d & 1.88 \\
\hline Number of CBM Wells* & & 135 \\
\hline Number of $\mathrm{CO}_{2}$ Wells* & & 135 \\
\hline New $\mathrm{CO}_{2}^{*}$ & $\mathrm{scm} / \mathrm{d} /$ well & 28,000 \\
\hline Well Depth & $\mathrm{m}$ & 610 \\
\hline
\end{tabular}

Each ECBMR field requires a gathering line compressor to transfer dewatered methane from the 10 producing wells to a connecting pipeline. The methane from the wells is fed to a common pipe at 1.7 bar and compressed to 4.5 bar. Table 6-3 indicates the basis for the gathering compressor design and the compressor requirements.

Table 6-3

ECBMR gathering compressor design basis

\begin{tabular}{|l|c|c|}
\hline Parameter & Unit & Value \\
\hline Maximum Methane Rate & thousand scm/d & 140 \\
\hline Suction Pressure & bar & 2.4 \\
\cline { 2 - 3 } & psia & 24.7 \\
\hline Discharge Pressure & bar & 4.5 \\
\cline { 2 - 3 } & psia & 64.7 \\
\hline Compressor Displacement & $\mathrm{cmm}$ & 41 \\
\hline Compression Ratio & & 1.875 \\
\hline Compressor Configuration & & 210 \\
\hline Maximum Horsepower & & 157 \\
\hline Maximum Connected & $\mathrm{kW}$ & 105,000 \\
\hline Power & & \\
\hline Compressor Cost & $\$$ & Rotor Driven Reciprocating \\
\hline
\end{tabular}


A second compressor is required for sending the gathered gas from all the modules though a common sales gas line to a nearby pipeline. The gas must be compressed to $25.1 \mathrm{bar}$ for transfer to the pipeline. Table 6-4 indicates the basis for the sales gas compressor design and the compressor requirements.

\section{Table 6-4}

ECBMR sales gas compressor design basis

\begin{tabular}{|l|c|c|}
\hline Parameter & Unit & Value \\
\hline Maximum Methane Rate & million scm/d & 1.88 \\
\hline Suction Pressure & bar & 4.5 \\
\cline { 2 - 3 } & psia & 64.7 \\
\hline \multirow{2}{*}{ Discharge Pressure } & bar & 25.1 \\
\cline { 2 - 3 } & psia & 364.7 \\
\hline Compressor Displacement & $\mathrm{cmm}$ & 291 \\
\hline Compression Ratio & & 5.637 \\
\hline Compressor Configuration & & 7,580 \\
\hline Maximum Horsepower & $\mathrm{kW}$ & 5,655 \\
\hline $\begin{array}{l}\text { Maximum Connected } \\
\text { Power }\end{array}$ & $\$$ & $3,970,000$ \\
\hline $\begin{array}{l}\text { Sales Gas Compressor } \\
\text { Cost }\end{array}$ & & \\
\hline
\end{tabular}

A summary of lease equipment required for the ECBMR design is given in Table 6-5. 
Table 6-5

Lease equipment

\begin{tabular}{|l|c|c|}
\hline $\begin{array}{l}\text { Equipment } \\
\text { Description }\end{array}$ & Specification & Quantity \\
\hline Tubing & 2.375 inch, Grade J-55 & $20,000 \mathrm{ft}$ \\
\hline Sucker Rod & API Class K & $20,000 \mathrm{ft}$ \\
\hline Pump Rod & API Type RWBC & 10 \\
\hline Pumping Unit & API Size M160D 173-74, 20 hp & 10 \\
\hline Flowline & 4 inch, Schedule 40 Steel & $16,000 \mathrm{ft}$ \\
\hline Manifold & 10 valves, 2 inch 3-way & 1 \\
\hline Production Separator & Vertical, 30 inch $\times 10$ feet, 5.0 million & 1 \\
\hline Storage Tank & 50,000 gallon & 2 \\
\hline Water Disposal Pump & Quintuplex, 1,000 psi, 20 hp & 1 \\
\hline Water Disposal Line & 3 inch, Schedule 40 Steel & $2,000 \mathrm{ft}$ \\
\hline Gas Meter & million scf/d & 1 \\
\hline
\end{tabular}

$1 \mathrm{in}=0.0254 \mathrm{~m}, 1 \mathrm{hp}=746 \mathrm{~J} / \mathrm{s}, 1 \mathrm{ft}=0.305 \mathrm{~m}, 1 \mathrm{cf}=0.028 \mathrm{~cm}, 1 \mathrm{psig}=0.069 \mathrm{bar}$,

\subsubsection{Capital and O\&M Cost Inputs}

All of the capital and O\&M costs, except for the power costs, are found by multiplying the per module costs, given in Table 6-1, by the required number of modules, as detailed in Section 6.5.1. In the case of the gathering compressor and sales gas compressor power costs, the costs per kilowatt-hour are multiplied by 8,760 , the total hours of operation per year, and the respective power requirement. Table 6-6 summarizes the model inputs for the capital and O\&M costs for the base case EOR design. 
Table 6-6

Capital and O\&M cost inputs for the ECBMR base case

\begin{tabular}{|c|c|}
\hline Parameter & Input \\
\hline \multicolumn{2}{|l|}{ Number of Modules } \\
\hline \multicolumn{2}{|l|}{ CAPITAL COSTS } \\
\hline Front End \& Lease Acquisition Costs & $\$ 6,750,000$ \\
\hline \multicolumn{2}{|l|}{ Injection Equipment: } \\
\hline Plant & $\$ 1,410,000$ \\
\hline Distribution Lines & $\$ 947,000$ \\
\hline Header & $\$ 750,000$ \\
\hline Electrical Service & $\$ 1,190,000$ \\
\hline \multicolumn{2}{|l|}{ Producing Equipment: } \\
\hline Tubing & $\$ 551,000$ \\
\hline Rods \& Pumps & $\$ 529,000$ \\
\hline Pumping Equipment & $\$ 4,590,000$ \\
\hline \multicolumn{2}{|l|}{ Gathering System: } \\
\hline Flowlines & $\$ 574,000$ \\
\hline Manifold & $\$ 575,000$ \\
\hline Gathering Compressor & $\$ 1,420,000$ \\
\hline Sales Gas Compressor & $\$ 3,970,000$ \\
\hline \multicolumn{2}{|l|}{ Lease Equipment: } \\
\hline Producing Separator & $\$ 167,000$ \\
\hline Storage Tanks & $\$ 1,030,000$ \\
\hline Accessory Equipment & $\$ 483,000$ \\
\hline Disposal System & $\$ 1,310,000$ \\
\hline Production \& Injection Wells & $\$ 39,100,000$ \\
\hline Subtotal & $\$ 65,300,000$ \\
\hline \multicolumn{2}{|l|}{ O\&M COSTS } \\
\hline \multicolumn{2}{|l|}{ Normal Daily Expenses: } \\
\hline Supervision \& Overhead & $\$ 678,000$ \\
\hline Labor & $\$ 539,000$ \\
\hline Consumables & $\$ 103,000$ \\
\hline Operative Supplies & $\$ 61,000$ \\
\hline Auto Usage & $\$ 107,000$ \\
\hline Pumping \& Field Power (1,485 kW) & $\$ 572,000$ \\
\hline
\end{tabular}


Table 6-6 (continued)

Capital and O\&M cost inputs for the ECBMR base case

\begin{tabular}{|l|c|}
\hline Parameter & Input \\
\hline Gathering Compressor (2,120 kW) & $\$ 817,000$ \\
\hline Sales Gas Compressor Power (6,654 kW) & $\$ 2,180,000$ \\
\hline Surface Maintenance (Repair \& Services): \\
\hline Labor (roustabout) & $\$ 247,000$ \\
\hline Supplies \& Services & $\$ 367,000$ \\
\hline Equipment Usage & $\$ 95,400$ \\
\hline Other & $\$ 37,600$ \\
\hline Subsurface Maintenance (Repair \& Services): \\
\hline Workover Rig Services & $\$ 412,000$ \\
\hline Remedial Services & $\$ 110,000$ \\
\hline Equipment Repair & $\$ 100,000$ \\
\hline Other & $\$ 91,300$ \\
\hline Subtotal & $\$ 6,520,000$ \\
\hline
\end{tabular}

\subsection{Model Results}

This section presents costs for $\mathrm{CO}_{2}$ capture and storage for ECBMR for the base case, described in Section 6.5. The storage costs comprise transaction, transportation, injection and monitoring costs. These costs are combined with capture costs from an IGCC power plant. The results, which include the revenue generated from the sale of the enhanced CBM produced, are given on several bases as described in Chapter 2. Appendix B provides a detailed description of these spreadsheets.

The Process Input sheet for the base case is presented in Table 6-7. 
Table 6-7

Process input sheet for base case ECBMR

\section{Enhanced Coal Bed Methane Input Variables}

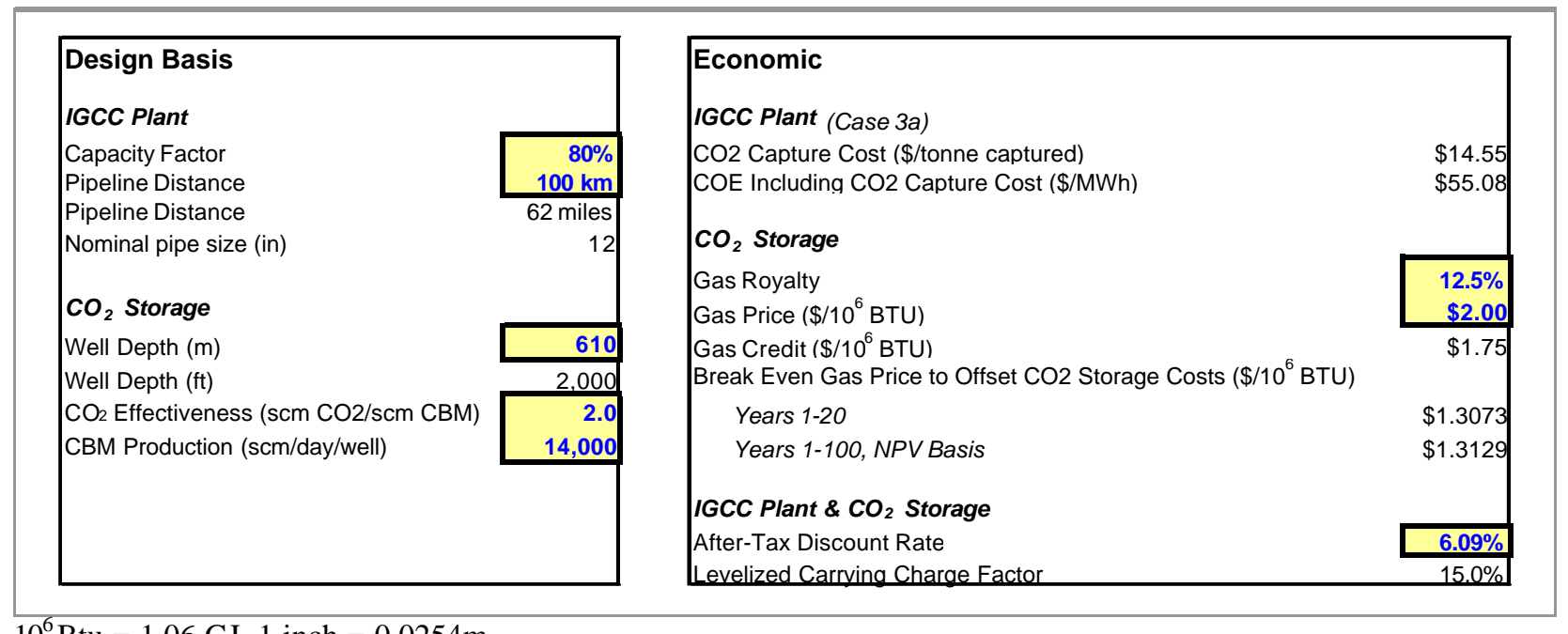

$10^{6} \mathrm{Btu}=1.06 \mathrm{GJ}, 1 \mathrm{inch}=0.0254 \mathrm{~m}$

The Summary sheet for the base case is presented in Table 6-8. This summary assumes a Gas Price of $\$ 1.90 /$ giga joule ( $\$ 2.00 /$ million Btu) and a Gas Royalty of 12.5 percent. 
Table 6-8

Summary sheet for base case ECBMR

Enhanced Coal Bed Methane Summary

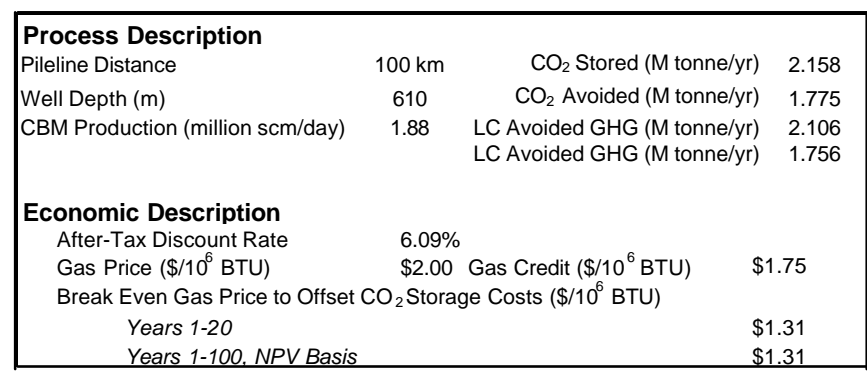

\begin{tabular}{|crr|}
\hline Capital \& O\&M Cost & & \\
& & \\
& Capital & O\&M \\
Transaction & $\$ 2,160,000$ & $\$ 0$ \\
Transport & $\$ 26,800,000$ & $\$ 1,333,000$ \\
Sequestration & $\$ 65,300,000$ & $\$ 6,520,000$ \\
Monitoring & $\$ 0$ & $\$ 216,000$ \\
Total & $\$ 94,300,000$ & $\$ 8,100,000$ \\
& & \\
& & \\
\hline
\end{tabular}

\section{Cost of $\mathrm{CO}_{2}$ Capture \& Storage}

1. Levelized Annual $\mathrm{CO}_{2}$ Storage Costs (years 1-20)

$\mathrm{CO}_{2}$ Storage Cost, $\mathrm{M} \$ / \mathrm{yr}$

Gas Revenues, M \$/yr

Net $\mathrm{CO}_{2}$ Storage Cost, M $\$ / y r$

$\mathrm{CO}_{2}$ Stored or Avoided, $\mathrm{M}$ tonne/yr

Net Storage Cost, $\$$ /tonne $\mathrm{CO}_{2}$

2. Levelized Annual $\mathrm{CO}_{2}$ Capture and Net Storage Costs (years 1-20)

$\mathrm{CO}_{2}$ Capture Cost, $\mathrm{M} \$ / \mathrm{yr}$

Net $\mathrm{CO}_{2}$ Storage Cost, $\mathrm{M} \$ / \mathrm{yr}$

Capture + Net Storage Cost, $\mathrm{M} \$ / \mathrm{yr}$

$\mathrm{CO}_{2}$ Stored or Avoided, M tonne/yr

Capture + Net Storage Cost, $\$$ /tonne $\mathrm{CO}_{2}$

3. $\mathrm{CO}_{2}$ Capture and Net Storage Costs, NPV Basis (years 1-100)

NPV of $\mathrm{CO}_{2}$ Capture Costs, M\$

$\mathrm{NPV}$ of $\mathrm{Net} \mathrm{CO}_{2}$ Storage Costs, M\$

NPV of Capture + Net Storage Costs, M\$

$\mathrm{NPV}$ of $\mathrm{CO}_{2}$ Stored or Avoided, M tonne

Capture + Net Storage Cost (NPV Basis), $\$ /$ tonne $\mathrm{CO}_{2}$

4. Cost of Electricity, \$/MWh

Reference Plant (no capture)

Capture Costs (years 1-20)

Net Storage Costs (years 1-20)

Storage Costs, Monitoring, etc. (years 21-100)

Total Cost of Electricity
$\mathrm{CO}_{2}$ Captured Basis

$\begin{array}{r}22.20 \\ 33.96 \\ \hline(11.76) \\ 2.16 \\ \hline(5.45)\end{array}$

$\mathrm{CO}_{2}$ Captured Basis

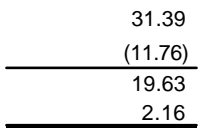

$\frac{2.16}{9.10}$

$\mathrm{CO}_{2}$ Captured Basis
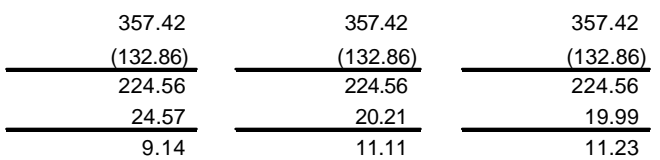

$\mathrm{CO}_{2}$ Avoided Basis

LC Avoided GHG Basis

LC Avoided GHG Basis (storage only)

22.20

33.96

(11.76)

$\frac{2.11}{(5.59)}$

$\mathrm{CO}_{2}$ Avoided Basis LC Avoided GHG Basis

1.76

.86)

9.99

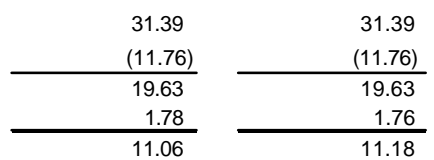




\subsection{Sensitivity Analysis}

The sensitivity of the $\mathrm{CO}_{2}$ storage cost for ECBMR is determined for five key parameters: well depth, $\mathrm{CO}_{2}$ effectiveness, $\mathrm{CBM}$ production rate, gas price and pipeline distance. It can be seen in Figure 6-4 that increases in well depth, $\mathrm{CO}_{2}$ effectiveness and pipeline distance cause an increase in the cost of storage, while increases in CBM production rate and gas price decrease the storage cost. More noteworthy, the figure shows that changes in gas price have the greatest effect on storage cost, followed closely by changes in $\mathrm{CO}_{2}$ effectiveness.

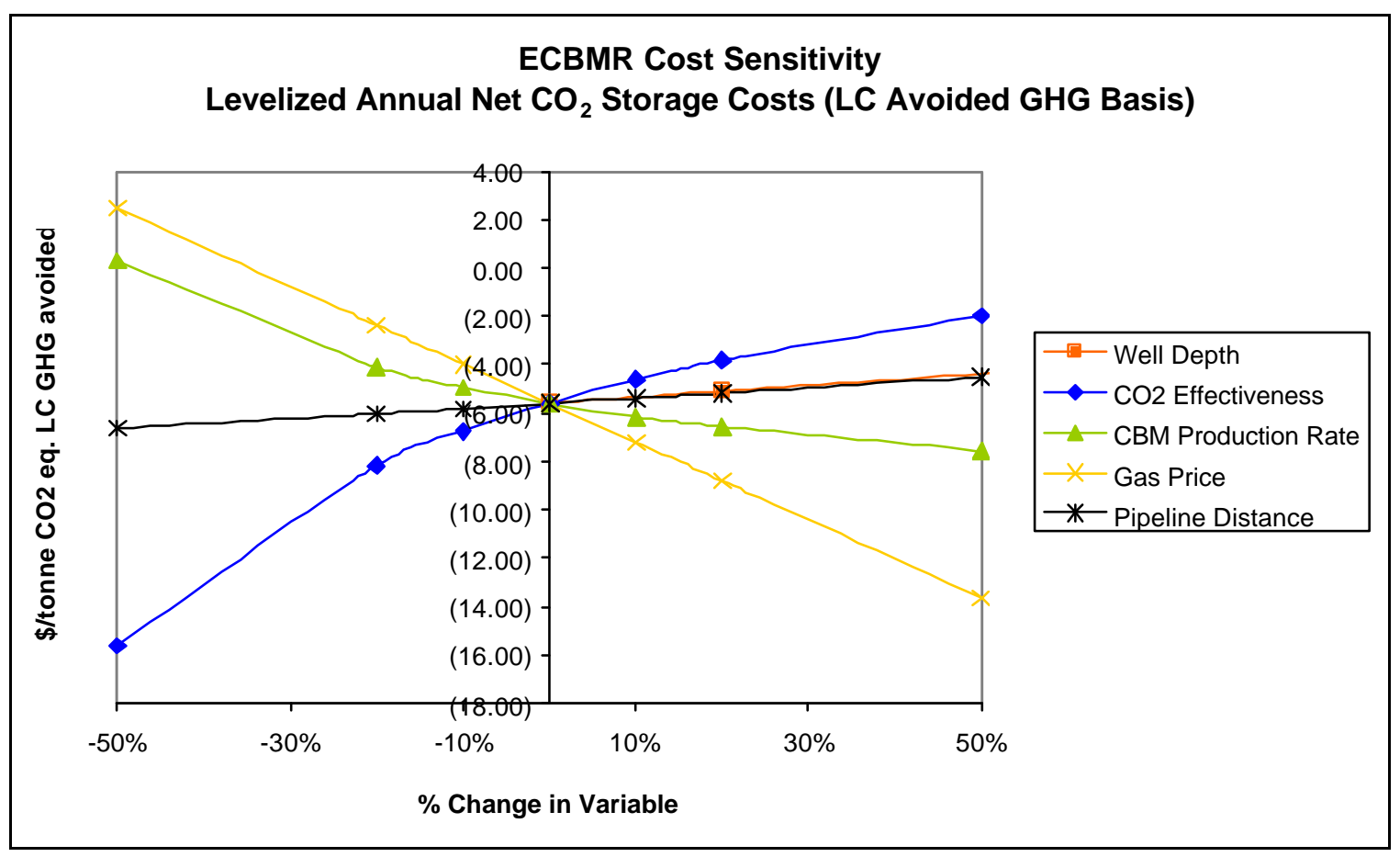

Figure 6-4

Sensitivity analysis for ECBMR

High and low cost cases have been chosen for ECBMR, and are presented together with the base case in Table 6-9. The price of gas at the wellhead is taken to have a low-end value of $\$ 1.80$ per giga joule and a ceiling price of $\$ 3$ per giga joule. For the high and low cost values for each of the five key parameters, the percentage change in the value from the base case is shown. This is done to illustrate the fact that the range in the values of some parameters is expected to be greater than for others. 
Table 6-9

ECBMR base, high cost and low cost cases

\begin{tabular}{|l|c|c|c|c|c|c|}
\hline Parameter & Units & $\begin{array}{c}\text { ECBMR } \\
\text { Base } \\
\text { Case }\end{array}$ & \multicolumn{2}{|c|}{$\begin{array}{c}\text { ECBMR } \\
\text { High Cost Case }\end{array}$} & \multicolumn{2}{c|}{$\begin{array}{c}\text { ECBMR } \\
\text { Low Cost Case }\end{array}$} \\
\hline $\begin{array}{l}\mathbf{C O}_{2} \\
\text { Effectiveness }\end{array}$ & $\begin{array}{c}\text { scm/scm enhanced } \\
\text { CBM }\end{array}$ & 2 & 10 & $+400 \%$ & 1.5 & $-33 \%$ \\
\hline $\begin{array}{l}\text { CBM } \\
\text { Production } \\
\text { per Well }\end{array}$ & $\begin{array}{c}\text { scm enhanced } \\
\text { CBM/d/well }\end{array}$ & 14,000 & 3,000 & $-79 \%$ & 30,000 & $+114 \%$ \\
\hline Gas Price & \$/giga joule & 2 & 1.80 & $-10 \%$ & 3 & $+50 \%$ \\
\hline Depth & $\mathrm{m}$ & 610 & 1,219 & $+100 \%$ & 610 & $0 \%$ \\
\hline $\begin{array}{l}\text { Pipeline } \\
\text { Distance }\end{array}$ & $\mathrm{km}$ & 100 & 300 & $+200 \%$ & 0 & $-100 \%$ \\
\hline
\end{tabular}

The results for the high and low cost cases as well as the base case are given in Table 6-10. The $\mathrm{CO}_{2}$ storage cost for ECBMR can be seen to be widely different for the high and low cost cases. In reality, a $\mathrm{CO}_{2}$-ECBMR project with parameter values approaching those of the high cost case would not be carried out.

Table 6-10

Results for ECBMR base, high cost and low cost cases

\begin{tabular}{|l|l|c|c|c|}
\hline Parameter & Units & $\begin{array}{c}\text { ECBMR } \\
\text { Base Case }\end{array}$ & $\begin{array}{c}\text { ECBMR } \\
\text { High Cost } \\
\text { Case }\end{array}$ & $\begin{array}{c}\text { ECBMR } \\
\text { Low Cost } \\
\text { Case }\end{array}$ \\
\hline Total CBM Production & $\begin{array}{c}\text { (million scm } \\
\text { enhanced } \\
\text { CBM/d) }\end{array}$ & 1.88 & 0.38 & 2.51 \\
\hline Number of CBM Wells & & 135 & 126 & 84 \\
\hline Number of $\mathrm{CO}_{2}$ Wells & 135 & 126 & 84 \\
\hline New $\mathrm{CO}_{2}$ & scm/d/well & 28,000 & 30,000 & 45,000 \\
\hline $\begin{array}{l}\text { Levelized Annual Net } \\
\mathrm{CO}_{2} \text { Storage Cost }\end{array}$ & $\begin{array}{c}\$ / \text { tonne } \mathrm{CO}_{2} \\
\text { Eq. LC GHG } \\
\text { Avoided }\end{array}$ & $(5.59)$ & 18.88 & $(25.72)$ \\
\hline
\end{tabular}

\subsection{Comparison to Literature}

A comparison is made between the costs obtained in this study for the $\mathrm{CO}_{2}$-ECBMR base case design and those calculated using cost estimates from a paper by Wong, et al. ${ }^{5}$ The costs for this 
study were based on the EIA 'Costs and Indices for Domestic Oil and Gas Field Equipment and Production Operations' report ${ }^{14}$ and the API 'Joint Association Survey on Drilling Costs'

report ${ }^{15}$. Wong, et al., cost estimates are given for a conceptual 50-well pair $\mathrm{CO}_{2}$-ECBMR field development in the Alberta Plains region and are shown in Table 6-11. It is to be noted that the well drilling and completion cost estimates are based on a reservoir depth of 1,280 m.

Table 6-11

$\mathrm{CO}_{2}$-ECBMR cost estimates from Wong, et al. ${ }^{5}$

\begin{tabular}{|l|c|c|}
\hline Item & Unit & Value \\
\hline \multicolumn{3}{|l|}{ CAPITAL COSTS } \\
\hline Wells: & \$/well pair & 346,840 \\
\hline Drilling & \$/well pair & 113,390 \\
\hline Completion & \$/well pair & 113,390 \\
\hline Equipment: & \$/well pair & 6,670 \\
\hline Tie-in & \multicolumn{3}{|l}{} \\
\hline Stimulation & \$/well pair/yr & 21,344 \\
\hline \hline O\&M CoSTS
\end{tabular}

Using these cost estimates, the capital, the well surface, and subsurface maintenance, costs of $\mathrm{CO}_{2}$-ECBMR were calculated for the 1,219 $\mathrm{m}$ case design. Table 6-12 shows the results of these calculations together with the previously determined $\mathrm{CO}_{2}$-ECBMR costs from this study. It should be noted that the latter, in order to make the results comparable, have been given for a reservoir depth of 1,219 $\mathrm{m}$ and do not include the front end lease expense of the sales gas compressor.

Table 6-12 Comparison of $\mathrm{CO}_{2}$-ECBMR cost results ${ }^{5,14}$

\begin{tabular}{|l|c|c|c|}
\hline Item & Unit & This Study & $\begin{array}{c}\text { Using Cost } \\
\text { Estimates }\end{array}$ \\
\hline CAPITAL COSTS & $\$$ & $63,600,000$ & $62,131,000$ \\
\hline Total cost of wells & $\$$ & $17,980,000$ & $16,208,000$ \\
\hline Total cost of equipment & $\$$ & $81,580,000$ & $78,339,000$ \\
\hline Subtotal & & \\
\hline \hline O\&M COSTS & $\$ / y$ & $2,204,000$ & $2,881,000$ \\
\hline Well maintenance & $\$ / y$ & $7,660,000$ & not reported \\
\hline Subtotal
\end{tabular}

This comparison shows that the cost of the $\mathrm{CO}_{2}$-ECBMR design is very similar for the two sets of cost data. 


\subsection{References}

1 "Enhanced Oil Recovery Scoping Stud y,” EPRI, Palo Alto, CA. Tech. Rep. 113836, 1999.

2 Stevens, S.H., D. Spector and P. Riemer, "Enhanced coalbed methane recovery using $\mathrm{CO}_{2}$ injection: Worldwide resource and CO2 sequestration potential," presented at the 1998 SPE International Conference and Exhibition, Beijing, China, May 2-6, 1998.

3 Reeves, S., "Geologic sequestration of $\mathrm{CO} 2$ in deep, unmineable coalbeds: An integrated research and commercial-scale field demonstration project," presented at the First National Conference on Carbon Sequestration, Washington DC, May 14-17, 2001.

4 Energy Information Administration (EIA), "U.S. Crude Oil, Natural Gas, and Natural Gas Liquids Reserves 2000 Annual Report," [Online document], Dec. 2001, [cited Feb. 2002], Available HTTP:

http://www.eia.doe.gov/oil_gas/natural_gas/data_publications/crude_oil_natural_gas_reserv es/cr.html

5 Wong, S., W.D. Gunter and M.J. Mavor, "Economics of $\mathrm{CO}_{2}$ sequestration in coalbed methane reservoirs," presented at the 2000 SPE/CERI Gas Technology Symposium, Calgary, Alberta Canada, Apr. 3-5, 2000.

6 Hamelinck, C.N., A.P.C. Faaij, G.J. Ruijg, D. Jansen, H. Pagnier, F. van Bergen, K. Wolf, O. Barzandji, H. Bruining and H. Schreurs, "Potential for $\mathrm{CO}_{2}$ sequestration and enhanced coalbed methane production in the Netherlands," [Online document], Mar. 2001, [cited Feb. 2002], Available HTTP:

http://www.chem.uu.nl/nws/www/publica/e2001-07.pdf

7 http://www.spe-uk.org/uk/supporters/supportersfr.html

8 "Dewatering systems and techniques for coalbed methane wells," GRI-81/0159, August 1983.

9 "Enhanced coal bed methane recovery with CO2 sequestration," IEA Greenhouse Gas R\&D Programme, Report Number PH3/3, August 1998.

10 Pashin, J.C., et al, "Enhanced coalbed methane recovery through sequestration of carbon dioxide: Potential for a market-based environmental solution in the Black Warrior Basin of Alabama, First National Conference on Carbon Sequestration, May 14-17, 2001, Washington, DC.

11 Reeves, Scott, e-mail communication, Jan. 5, 2002.

12 Wong, Sam, e-mail communication, Dec. 3, 2002. 
13 Stevens, S.H., J.A Kuuskraa and R.A. Schraufnagel, "Technology spurs growth of U.S. coal-bed methane," Oil \& Gas Journal, Jan. 1, 1996.

14 Energy Information Administration (Office of Oil and Gas), "Costs and Indices for Domestic Oil and Gas Field Equipment and Production Operations," [Online document], Mar. 2000, [cited Jan. 2002], Available HTTP:

http://www.eia.doe.gov/oil_gas/natural_gas/data_publications/cost_indices/c_i.html

15 American Petroleum Institute - Policy Analysis and Statistics Department, "1998 Joint Association Survey on Drilling Costs," [Online document], Nov. 1999, Available HTTP: http://www.api.org/axs-api/products/joint.htm 


\section{7 \\ DEPLETED GAS AND OIL RESERVOIR/AQUIFER STORAGE}

\subsection{Introduction}

The $\mathrm{CO}_{2}$ sequestration options considered here include $\mathrm{CO}_{2}$ storage in depleted natural gas and oil reservoirs, and deep saline aquifers. Geologic $\mathrm{CO}_{2}$ storage options with value-added products, specifically EOR and ECBMR, are treated separately.

\subsection{State of the Art}

\subsubsection{Applications}

The first, and to date only, commercial-scale project dedicated to geologic $\mathrm{CO}_{2}$ storage is in operation at the Sleipner West field. Sleipner West is a natural gas/condensate field operated by Statoil and located in the North Sea about $250 \mathrm{~km}$ off the coast of Norway. The natural gas produced at the field has a $\mathrm{CO}_{2}$ content of about 9 percent which, to meet commercial specifications, must be reduced to 2.5 percent. It is standard practice in natural gas production for the byproduct $\mathrm{CO}_{2}$ to be vented to the atmosphere. At Sleipner, however, the $\mathrm{CO}_{2}$ is compressed and injected via a single well into the Utsira Formation, a 250-m-thick aquifer located at a depth of $800 \mathrm{~m}$ below the seabed. About one million tonnes of $\mathrm{CO}_{2}$ have been sequestered annually at Sleipner since October 1996, with a total of 20 million tonnes of $\mathrm{CO}_{2}$ expected to be sequestered over the lifetime of the project. A second scheme, which would involve about 0.7 million tonnes per year of $\mathrm{CO}_{2}$ produced at the Snohvit gas field in the Barents Sea off northern Norway being injected into a deep sub-sea formation, is planned. ${ }^{1,2,3,4,5}$

\subsubsection{Storage Potential}

\section{Depleted Natural Gas Reservoirs}

One type of geologic reservoir with significant potential for $\mathrm{CO}_{2}$ sequestration is the abandoned natural gas field. Nearly all of the volume of abandoned gas fields should be available for $\mathrm{CO}_{2}$ storage. The first reason for this is that the exploitation of a gas field normally extracts up to 95 percent of the available gas. The second is that only a very small fraction of the abandoned reservoir's pore space is likely to be invaded by formation water because water is more viscous than low-pressure methane. In the unlikely case that an abandoned reservoir does become water saturated, due to the reservoir being highly permeable and/or having been abandoned for many 
years prior to $\mathrm{CO}_{2}$ injection, the reservoir will be similar to an aquifer. It should be noted here that abandoned gas fields are quite widespread, with an estimated 98 to 133 giga tonnes of total carbon sequestration potential. ${ }^{1,2,6,7,8}$

In active natural gas fields, it has been proposed that $\mathrm{CO}_{2}$ injection could prolong the economic life of a field by maintaining reservoir pressure longer than would otherwise be possible. It is important to note that, to date, there have been no demonstrations of $\mathrm{CO}_{2}$-enhanced gas production. Furthermore, this technology is unlikely to be implemented in the future due to the fact that it risks contaminating the hydrocarbon reserve. For these reasons, $\mathrm{CO}_{2}$ injection into active gas fields is not considered here as a geologic $\mathrm{CO}_{2}$ storage option. ${ }^{1,6,7}$

\section{Depleted Oil Reservoirs}

The other type of hydrocarbon reservoir in which $\mathrm{CO}_{2}$ could possibly be sequestered is the depleted oil field. In the case of the depleted oil field, it is important to note that production ceases not because all the oil has been recovered but rather because the field is no longer economic to produce. It is typical for primary production to result in only about 30 percent of the original oil in place (OOIP) being recovered. Even in fields in which secondary recovery by waterflooding has taken place, around 50 percent of the OOIP may remain in the reservoir.

\section{Deep Saline Aquifers}

Deep saline aquifers have the greatest $\mathrm{CO}_{2}$ sequestration potential, with these reservoirs being the most widespread and having the largest volumes. The latter is very important given that, unlike exhausted hydrocarbon reservoirs where the reservoir pressure has been very substantially reduced by the production of reservoir fluids, the pressure in aquifers is hydrostatic or greater. In order to ensure that the fracture pressure of an aquifer is not exceeded, it is necessary that $\mathrm{CO}_{2}$ injection wells be located in regions of high permeability and that the total amount of $\mathrm{CO}_{2}$ injected be limited. Modeling suggests that an average of around only two percent of the pore volume of an aquifer can be safely occupied by $\mathrm{CO}_{2}$, but this number is highly uncertain. ${ }^{1}$

To give an illustration of the aquifer volumes needed to store the $\mathrm{CO}_{2}$ emissions from power plants, the aquifer volume required for the $\mathrm{CO}_{2}$ captured at the base-case IGCC plant was determined. Calculating the total quantity of $\mathrm{CO}_{2}$ to be supplied by the base-case plant over its 20 -year lifetime to be $43 \mathrm{Mt}$ and assuming a supercritical $\mathrm{CO}_{2}$ density of $0.7 \mathrm{~kg} / \mathrm{m}^{3}$, it is found that an aquifer with an effective pore volume of approximately $0.0617 \mathrm{~km}^{3}$ is needed. Given a realistic effective porosity of 30 percent and a storage efficiency of two percent, this is equivalent to a total aquifer volume of about $10.28 \mathrm{~km}^{3}$. This can be visualized as a circularshaped aquifer with a diameter of $11.4 \mathrm{~km}$ and a thickness of $100 \mathrm{~m} .{ }^{1,8}$

$\mathrm{CO}_{2}$ can be sequestered in either of two types of deep saline aquifer. The first type of aquifer is directly analogous to a hydrocarbon field, where the reservoir acts as a geologic trap. It should also be possible to inject the $\mathrm{CO}_{2}$ into aquifers that do not have lateral seals. An impermeable caprock to prevent the buoyant $\mathrm{CO}_{2}$ from escaping vertically and a down-directed flow regime to transport the $\mathrm{CO}_{2}$ away from the surface should theoretically be sufficient to provide secure $\mathrm{CO}_{2}$ 
storage. ${ }^{9,10}$ This possibility vastly increases the total potential $\mathrm{CO}_{2}$ sequestration capacity of aquifers. A lack of information about aquifers that are not located near where oil and gas exploration has taken place has led to greatly varying estimates of global $\mathrm{CO}_{2}$ storage potential. An assessment of the varying estimates has, however, suggested that the global storage potential lies somewhere between 100 and 3,000 giga tonnes of carbon. ${ }^{1,8,11}$

\subsubsection{Storage Mechanics}

$\mathrm{CO}_{2}$ is stored in geologic formations by a number of different trapping mechanisms, with the exact mechanisms depending on the formation type. To make full use of storage capacity, the $\mathrm{CO}_{2}$ should be stored in a dense or supercritical phase, i.e., above the critical pressure of 7.4 $\mathrm{MPa}$. For a hydrostatic pressure gradient of $10.5 \mathrm{MPa} / \mathrm{km}$, this condition is met at depths below about $700 \mathrm{~m}$. At $800-\mathrm{m}$ depth, the density of supercritical $\mathrm{CO}_{2}$ is $740 \mathrm{~kg} / \mathrm{m}^{3}$. Since the $\mathrm{CO}_{2}$ under these pressure and temperature conditions will still be less dense than formation water, the $\mathrm{CO}_{2}$ will naturally rise to the top of the reservoir and a trap is needed to ensure that it does not reach the surface. In oil and gas reservoirs, as well as aquifers directly analogous to hydrocarbon fields, geologic traps immobilize the $\mathrm{CO}_{2}$. In the case of aquifers with no distinct geologic traps, however, an impermeable caprock above the underground reservoir is needed. This forces the $\mathrm{CO}_{2}$ to be entrained in the groundwater flow and is known as hydrodynamic trapping. ${ }^{1,7,8,10}$

Two other very important trapping mechanisms are solubility and mineral trapping. Solubility and mineral trapping involve the dissolution of $\mathrm{CO}_{2}$ into fluids, and the reaction of $\mathrm{CO}_{2}$ with minerals present in the host formation to form stable, solid compounds like carbonates, respectively. These latter two mechanisms are particularly important in the case of the aquifer with no lateral seals. As the $\mathrm{CO}_{2}$ moves through the reservoir along the flowpath, it comes into contact with uncarbonated formation water and reactive minerals. A proportion of the $\mathrm{CO}_{2}$ dissolves in the formation water and some of this dissolved $\mathrm{CO}_{2}$ becomes permanently fixed by reactions with minerals in the host rock. If the flowpath is long enough, the $\mathrm{CO}_{2}$ might all dissolve or become fixed by mineral reactions before it reaches the basin margin, essentially becoming permanently trapped in the reservoir. ${ }^{1,3,9,10}$

\subsubsection{Storage Option Feasibility}

The injection of $\mathrm{CO}_{2}$ into geologic formations is a promising $\mathrm{CO}_{2}$ sequestration option. First, the technology for injecting $\mathrm{CO}_{2}$ into exhausted hydrocarbon reservoirs and deep saline aquifers already exists. Oil producers in the Permian Basin of western Texas and eastern New Mexico, and in the Rocky Mountain and Mid-continent regions have been injecting $\mathrm{CO}_{2}$ for EOR for more than 25 years. Underground natural gas storage projects also provide a considerable base of relevant geologic and engineering experience. Second, even though no direct economic benefits are derived, it should be noted that the $\mathrm{CO}_{2}$ sequestration potential associated with the injection of $\mathrm{CO}_{2}$ into exhausted oil and natural gas reservoirs and deep saline aquifers greatly exceeds that of EOR and ECBMR using $\mathrm{CO}_{2}$ floods. ${ }^{7}$

Exhausted hydrocarbon reservoirs have the advantage over aquifers that these fields are proven long-term traps, their geology is well characterized, and their existing surface and subsurface 
infrastructures could readily be converted for $\mathrm{CO}_{2}$ distribution and injection. On the downside, the locating and sealing of abandoned wells could present an ongoing challenge. Aquifers, however, have a larger $\mathrm{CO}_{2}$ capacity, are more widespread and are generally located closer to $\mathrm{CO}_{2}$ emission sources. ${ }^{6,7,8,11}$

\subsection{Process Description}

Figure 7-1 is a block flow diagram, indicating the overall flow and distribution of $\mathrm{CO}_{2}$ from the IGCC plant to the depleted gas and oil fields, and aquifer. Developing a depleted reservoir or aquifer for $\mathrm{CO}_{2}$ storage involves:

- Screening and evaluation of sites

- Drilling and equipping injection wells

- Installation of high-pressure injection equipment and related piping

Equipment must be available at the injection site to accept pressurized $\mathrm{CO}_{2}$ from the pipeline, and transfer it to the injection well at the flow rate and pressure required for injection. The primary components include piping to distribute $\mathrm{CO}_{2}$ to the injection wells, $\mathrm{CO}_{2}$ flow controls equipment, and equipment to monitor well condition.

The source and quantity of $\mathrm{CO}_{2}$ supplied to the field is the same as for the EOR storage option, i.e. the system must be able to handle 3.76 million $\mathrm{scm}$ (7,389 tonnes) of $\mathrm{CO}_{2}$ per day. Determining the required $\mathrm{CO}_{2}$ pressure at the top of the well requires consideration of the pressure required at the bottom of the well to force $\mathrm{CO}_{2}$ into the injection zone, the pressure increase in the pipe due to the height of the $\mathrm{CO}_{2}$ column, and the pressure loss due to flow in the pipe. Moving the $\mathrm{CO}_{2}$ into the reservoir requires raising the $\mathrm{CO}_{2}$ sufficiently above the in situ pressure to provide a driving force, but not so high as to risk hydrofracturing the injection interval. ${ }^{12}$ It was decided that the pipeline delivery pressure, 103 bar, is adequate for injection.

The $\mathrm{CO}_{2}$ injection wells are as described in Section 5.3. For geologic $\mathrm{CO}_{2}$ storage, these wells are equipped with a battery of lease equipment that includes distribution lines, headers, electrical service and controls. This equipment enables the $\mathrm{CO}_{2}$ to be taken from the pipeline terminal and injected at a pressure that maintains the downhole injection point pressure.

As a final note, it is assumed that this facility, like the power plant, has a lifetime and design/construction time of 20 and 4 years, respectively. 


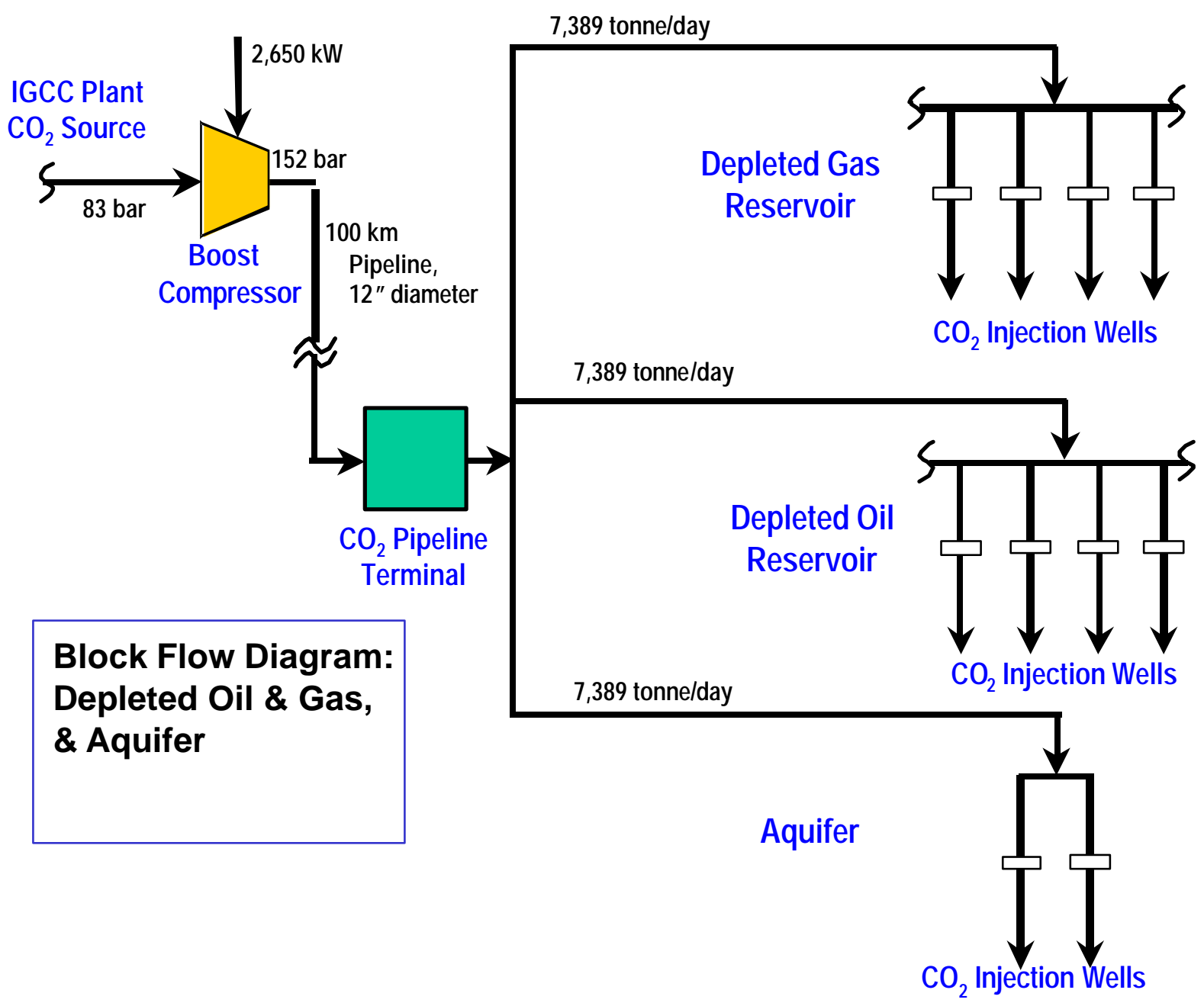

Figure 7-1

Depleted oil, gas, and aquifer block flow diagram 


\subsection{Methodology Used}

Depleted natural gas and oil reservoirs, and deep saline aquifers, differ quite substantially from one another in terms of typical values of reservoir parameters such as pressure, thickness, depth, and permeability. The processes that govern the rate at which $\mathrm{CO}_{2}$ can be injected at a well, and thus the number of wells required, are however essentially identical for the three types of reservoir. Given this, the same costing method is applied to each of the three geologic $\mathrm{CO}_{2}$ storage options.

The cost model for the geologic $\mathrm{CO}_{2}$ storage options can be broken down into a number of components. First, there is a relationship for calculating the number of wells required for a given $\mathrm{CO}_{2}$ flow rate, $\mathrm{CO}_{2}$ downhole injection pressure, and set of reservoir parameters. Second, an iterative procedure is used to take into account the interdependent relationship between $\mathrm{CO}_{2}$ downhole injection pressure and well number. Third, a set of capital and O\&M cost factors are used to determine cost based on well number. Each of these components, illustrated in the

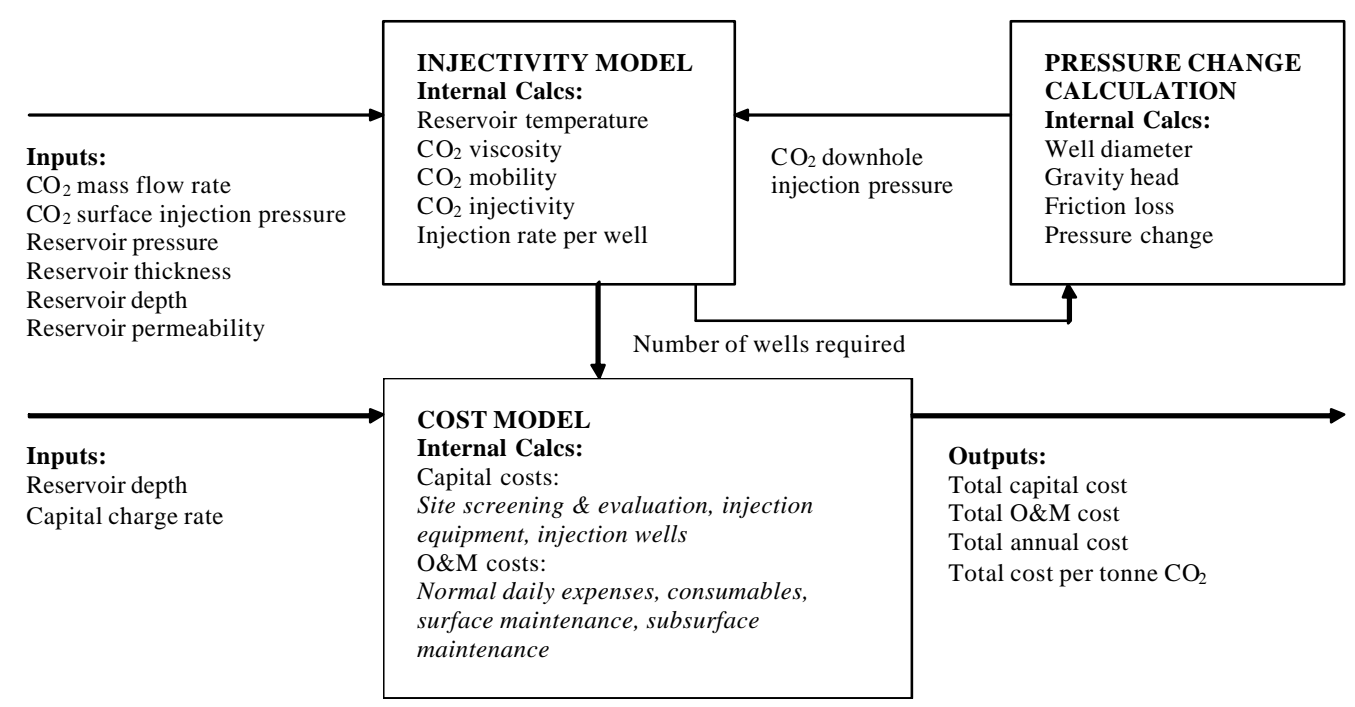

overview diagram in Figure 7-2 is described below in greater detail.

\section{Figure 7-2}

Geologic storage cost model overview diagram

The value of a particular reservoir parameter, where the same type of geological reservoir is being considered, can vary significantly. This variation is important because it has the potential to greatly affect the cost estimate of the geologic $\mathrm{CO}_{2}$ storage option. In order to take account of this variation, base and sensitivity cases are run for each of the three storage options. These design bases, which comprise different sets of reservoir parameters, are detailed in Section 7.5.1. 


\subsubsection{Well Number Calculation}

The well number calculation requires inputs for $\mathrm{CO}_{2}$ mass flow rate, $\mathrm{CO}_{2}$ downhole injection pressure, and reservoir pressure, thickness, depth, and permeability. Given the depth of the reservoir, reservoir temperature is calculated assuming a surface temperature of $15^{\circ} \mathrm{C}$ and a geothermal gradient of $25^{\circ} \mathrm{C} / \mathrm{km}$. The viscosity of the $\mathrm{CO}_{2}\left(\mu_{\mathrm{CO} 2}\right)$ is then calculated based on a correlation published by McHugh and Krukonis. ${ }^{13}$ Next, the absolute permeability $\left(\mathrm{k}_{\mathrm{a}}\right)$ is found from

$$
\mathrm{k}_{\mathrm{a}}=\left(\mathrm{k}_{\mathrm{h}} \times \mathrm{k}_{\mathrm{v}}\right)^{0.5}
$$

where $\mathrm{k}_{\mathrm{v}}=$ the vertical permeability and is equal to 0.3 times the horizontal permeability and $\mathrm{k}_{\mathrm{h}}$ $=$ the given horizontal permeability. ${ }^{14}$

A relationship, derived by Law and Bachu, ${ }^{14}$ is used to determine $\mathrm{CO}_{2}$ injectivity from $\mathrm{CO}_{2}$ mobility. This relationship is shown in Figure 7-3. The equation for $\mathrm{CO}_{2}$ injectivity is

$$
\mathrm{CO}_{2} \text { injectivity }=0.0208 \times \mathrm{CO}_{2} \text { mobility }
$$

where $\mathrm{CO}_{2}$ injectivity is equal to the mass flow rate of $\mathrm{CO}_{2}(\mathrm{~m})$ that can be injected per unit of reservoir thickness $(\mathrm{h})$ and per unit of downhole pressure difference $\left(\mathrm{P}_{\mathrm{inj}}-\mathrm{P}_{\text {res }}\right)$, and $\mathrm{CO}_{2}$ mobility equals the $\mathrm{CO}_{2}$ absolute permeability $\left(\mathrm{k}_{\mathrm{a}}\right)$ divided by the $\mathrm{CO}_{2}$ viscosity $\left(\mu_{\mathrm{CO} 2}\right)$. Given the $\mathrm{CO}_{2}$ injectivity, the $\mathrm{CO}_{2}$ injection rate per well $\left(\mathrm{Q}_{\mathrm{CO} / \text { well }}\right)$ can be found from

$$
\mathrm{Q}_{\mathrm{CO} 2 / \text { well }}=\mathrm{CO}_{2} \text { injectivity } \times \mathrm{h} \times\left(\mathrm{P}_{\mathrm{inj}}-\mathrm{P}_{\text {res }}\right)
$$

Finally, the number of wells required (n) is given by

$$
\mathrm{n}=\mathrm{m} / \mathrm{Q}_{\mathrm{CO} 2 / \mathrm{well}}
$$




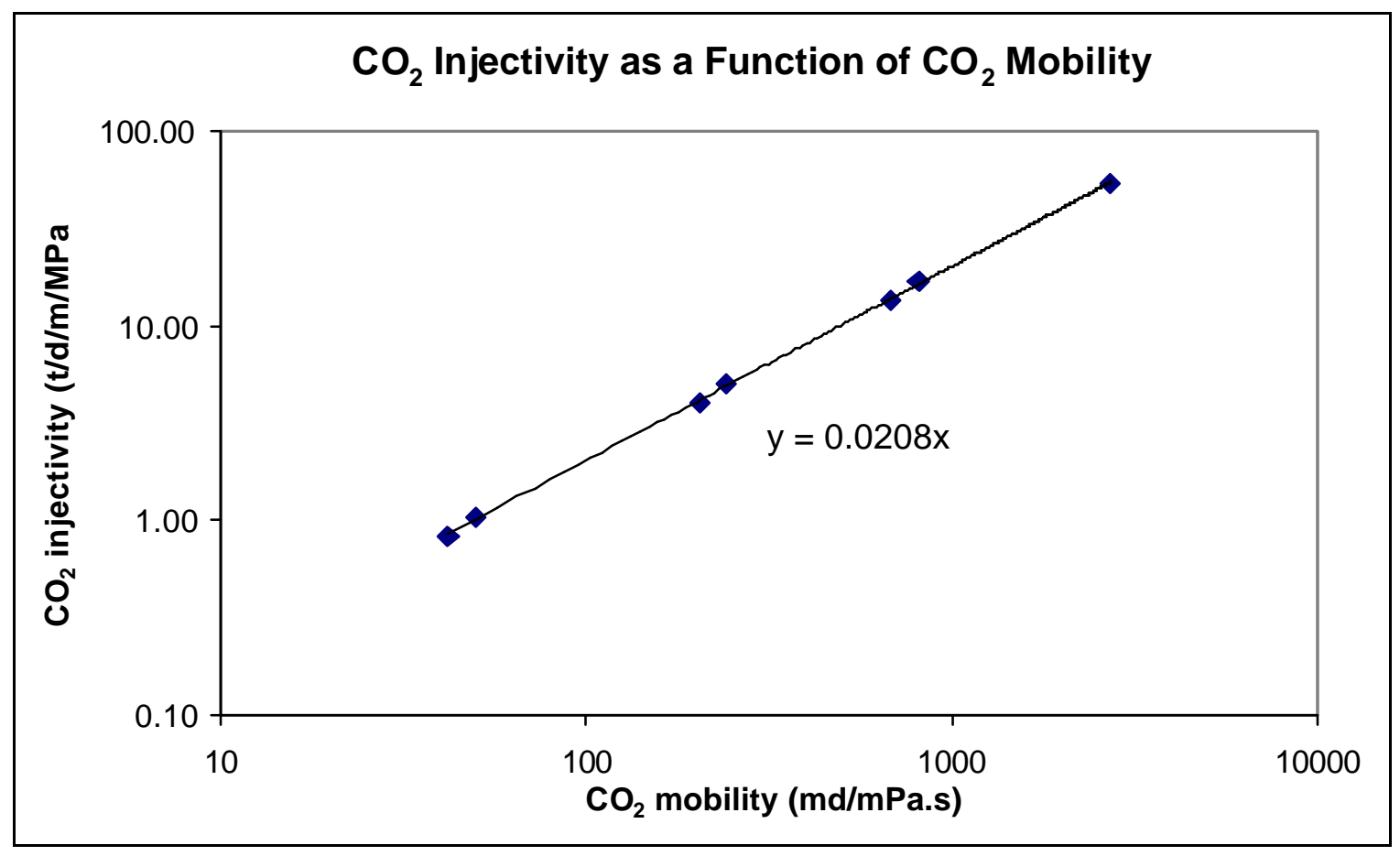

Figure 7-3

$\mathrm{CO}_{2}$ injectivity as a function of $\mathrm{CO}_{2}$ mobility

\subsection{2 $\mathrm{CO}_{2}$ Downhole Injection Pressure Calculation}

The surface $\mathrm{CO}_{2}$ injection pressure is equal to the $10.3 \mathrm{MPa}$ minimum $\mathrm{CO}_{2}$ pipeline outlet pressure used in the design of the pipeline for $\mathrm{CO}_{2}$ transport. Based on this value, no additional recompression of $\mathrm{CO}_{2}$ is required at the wellhead. A typical well diameter of $0.059 \mathrm{~m}$ is used for the injection pipe.

An iterative procedure is used to calculate the $\mathrm{CO}_{2}$ downhole injection pressure and the required number of wells. This is because downhole injection pressure and well number are mutually dependent. Downhole injection pressure is found by adding the pressure increase due to the gravity head to the surface pressure and then subtracting from this the pressure decrease due to friction loss, which depends on the velocity of $\mathrm{CO}_{2}$ in each well. Well number, on the other hand, is determined by $\mathrm{CO}_{2}$ injectivity, which is dependent on the difference between the downhole injection and reservoir pressures.

It is important to note that, for the aquifer base and low-cost cases, it is necessary to increase the pipe diameter to 0.1 and $0.5 \mathrm{~m}$, respectively. This is because smaller diameters in these cases result in unacceptable friction losses. 


\subsubsection{Cost Calculations}

The total capital cost comprises site screening and evaluation, injection equipment and well drilling costs, while the total O\&M cost includes the costs of normal daily operations, consumables, and surface and subsurface maintenance.

The capital cost for site screening and evaluation is based on an estimate given in a recent study by the Battelle Memorial Institute. ${ }^{15}$ This study estimated the costs for preliminary site screening and candidate evaluation at $\$ 1,685,000$.

All of the other costs, except for the well drilling cost, are calculated based on values given in the EIA 'Costs and Indices for Domestic Oil and Gas Field Equipment and Production Operations' report. ${ }^{12}$ Average lease equipment costs and O\&M costs were developed on a per well basis. In the case of the injection equipment and surface maintenance, the average cost values are factored by 0.5 to take into account the number of wells and thus the size/complexity of the surface equipment. Similarly, the average cost value for subsurface maintenance is adjusted to take into account the well depth. These capital and O\&M cost factors/functions are given in Table 7-1.

Table 7-1

Capital and $O \& M$ cost estimation factors/functions

\begin{tabular}{|c|c|c|}
\hline Parameter & Unit & Value \\
\hline \multicolumn{3}{|l|}{ CAPITAL COSTS } \\
\hline $\begin{array}{l}\text { Injection Equipment } \\
\text { (Flowlines \& Connections) }\end{array}$ & $\$ /$ well & $43,600^{*}\left(7,389 /\left(280^{*} \text { Number_of_wells }\right)\right)^{\wedge} 0.5$ \\
\hline \multicolumn{3}{|l|}{ O\&M COSTS } \\
\hline Normal Daily Expenses & $\$ /$ well & 6,700 \\
\hline Consumables & $\$ /$ well & 17,900 \\
\hline $\begin{array}{l}\text { Surface Maintenance } \\
\text { (Repair \& Services) }\end{array}$ & $\$ /$ well & $13,600^{*}\left(7,389 /\left(280^{*} \text { Number_of_wells }\right)\right)^{\wedge} 0.5$ \\
\hline $\begin{array}{l}\text { Subsurface Maintenance } \\
\text { (Repair \& Services) }\end{array}$ & $\$ /$ well & 5,000*Well_depth/1219 \\
\hline
\end{tabular}

The well drilling cost is calculated based on a relationship derived from data contained in the '1998 Joint Association Survey (JAS) on Drilling Costs' report. ${ }^{16}$ This relationship between well depth and drilling cost is shown in Figure 7-4. To determine the relationship, regression analysis was performed on drilling cost data for onshore gas and oil wells. The total well drilling cost is found by multiplying the cost of drilling a single well for the given reservoir depth, taken from the graph, by the required number of wells. 


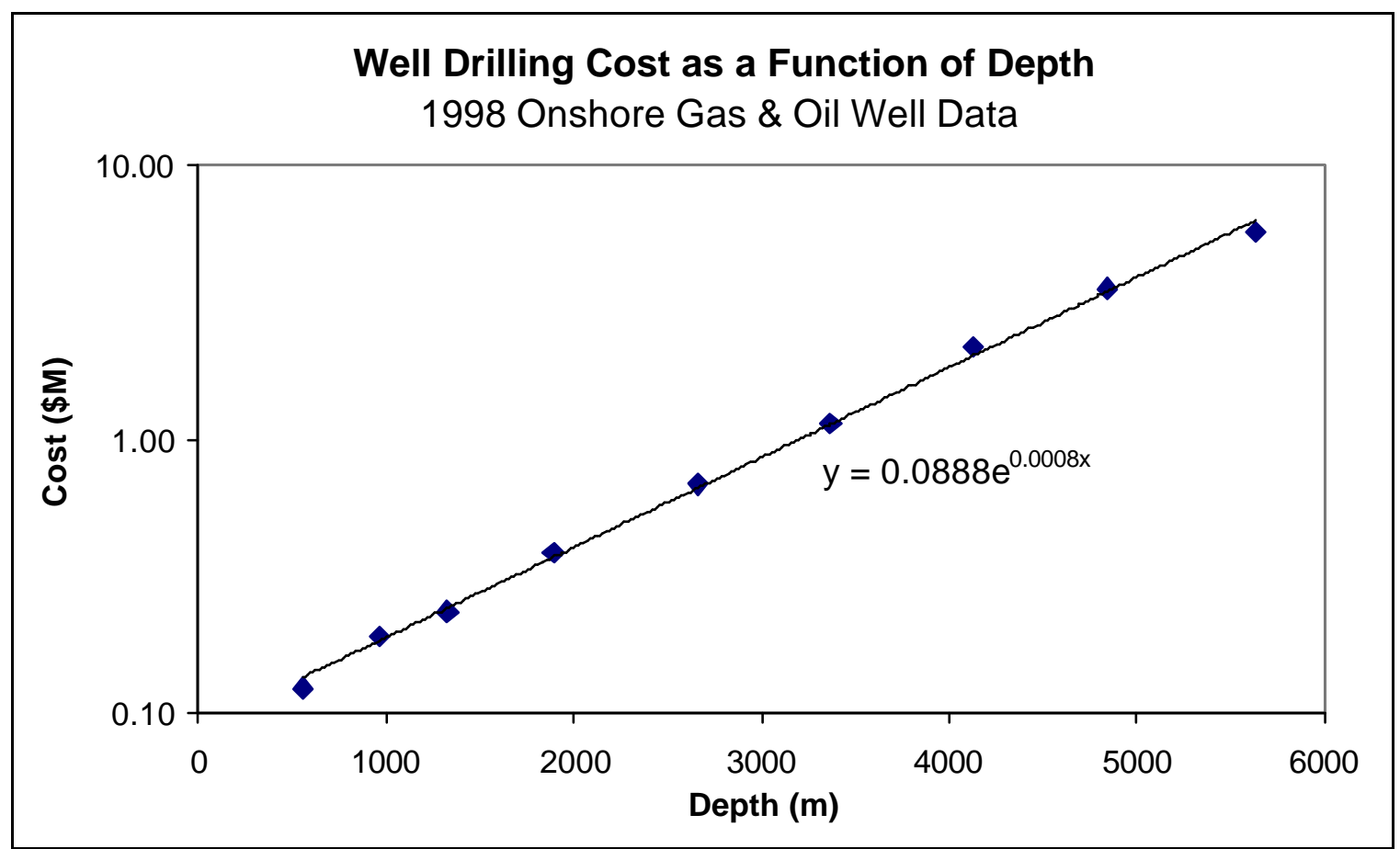

Figure 7-4

Well drilling cost as a function of depth

\subsection{Design Basis}

\subsubsection{Reservoir Parameters and Well Numbers for Base and Sensitivity Cases}

Typical, as well as a range of values for, reservoir properties of exhausted natural gas and oil fields, as suggested by Vello Kuuskraa of Advanced Resources International, ${ }^{17}$ are given in Table 7-2. It should be noted that these values are representative of the properties of gas and oil reservoirs found in the Permian Basin.

Table 7-2

Natural gas and oil reservoir property data

\begin{tabular}{|l|c|c|c|c|c|}
\hline Parameter & Units & $\begin{array}{c}\text { Gas } \\
\text { Reservoir } \\
\text { Typical }\end{array}$ & $\begin{array}{c}\text { Gas } \\
\text { Reservoir } \\
\text { Range }\end{array}$ & $\begin{array}{c}\text { Oil Reservoir } \\
\text { Typical }\end{array}$ & $\begin{array}{c}\text { Oil Reservoir } \\
\text { Range }\end{array}$ \\
\hline Pressure & $\mathrm{MPa}$ & 3.45 & $2.07-6.89$ & 13.78 & $3.45-20.7$ \\
\hline Thickness & $\mathrm{m}$ & 30.5 & $15.24-61.0$ & 42.7 & $21.3-61.0$ \\
\hline Depth & $\mathrm{m}$ & 1524 & $610-3048$ & 1554 & $1524-2134$ \\
\hline Permeability & $\mathrm{md}$ & 1 & $0.01-100$ & 5 & $5-19$ \\
\hline
\end{tabular}


Based on these reservoir parameter values, a base case as well as high-cost and low-cost cases were selected for both the depleted gas and oil reservoir options. It should be noted that, in the case of the gas reservoir, the range of permeability values considered was limited to give a practical number of wells. The parameter values for each of the base, high-cost and low-cost cases, as well as the corresponding number of wells required, are given for the gas and oil reservoir storage options in Table 7-32 and Table 7-4, respectively.

Table 7-3

Design bases for natural gas reservoir storage option

\begin{tabular}{|l|c|c|c|c|}
\hline Parameter & Units & $\begin{array}{c}\text { Gas Reservoir } \\
\text { Base Case }\end{array}$ & $\begin{array}{c}\text { Gas Reservoir } \\
\text { High Cost Case }\end{array}$ & $\begin{array}{c}\text { Gas Reservoir } \\
\text { Low Cost Case }\end{array}$ \\
\hline Pressure & $\mathrm{MPa}$ & 3.5 & 6.9 & 2.1 \\
\hline Thickness & $\mathrm{m}$ & 31 & 15 & 61 \\
\hline Depth & $\mathrm{m}$ & 1,524 & 3,048 & 610 \\
\hline Permeability & $\mathrm{md}$ & 1 & 0.8 & 10 \\
\hline Injection Rate per Well* & $\mathrm{t} / \mathrm{d}$ & 154 & 58 & 2,985 \\
\hline Number of Wells* & & 48 & 127 & 3 \\
\hline
\end{tabular}

* calculated

\section{Table 7-4}

Design bases for oil reservoir storage option

\begin{tabular}{|l|c|c|c|c|}
\hline Parameter & Units & $\begin{array}{c}\text { Oil Reservoir } \\
\text { Base Case }\end{array}$ & $\begin{array}{c}\text { Oil Reservoir } \\
\text { High Cost Case }\end{array}$ & $\begin{array}{c}\text { Oil Reservoir } \\
\text { Low Cost Case }\end{array}$ \\
\hline Pressure & $\mathrm{MPa}$ & 13.8 & 20.7 & 3.5 \\
\hline Thickness & $\mathrm{m}$ & 43 & 21 & 61 \\
\hline Depth & $\mathrm{m}$ & 1,554 & 2,134 & 1,524 \\
\hline Permeability & $\mathrm{md}$ & 5 & 5 & 19 \\
\hline Injection Rate per Well $^{*}$ & $\mathrm{t} / \mathrm{d}$ & 358 & 116 & 5,720 \\
\hline Number of Wells* & & 21 & 64 & 2 \\
\hline
\end{tabular}

* calculated

The aquifer base and sensitivity cases are based on aquifer property data given in the literature, ${ }^{8,14}$ including data obtained from the Bureau of Economic Geology's website. ${ }^{18}$ This property data is presented in Table 7-5. In addition, the calculated values of well number are shown. It can be seen from this table that aquifer properties, and thus the number of wells that would be required and the cost, can vary considerably. 
Table 7-5

Aquifer property data

\begin{tabular}{|l|c|c|c|c|c|}
\hline Aquifer & $\begin{array}{c}\text { Pressure } \\
(\mathbf{M P a})\end{array}$ & $\begin{array}{c}\text { Thickness } \\
(\mathbf{m})\end{array}$ & $\begin{array}{c}\text { Depth } \\
(\mathbf{m})\end{array}$ & $\begin{array}{c}\text { Permeability } \\
(\mathbf{m d})\end{array}$ & $\begin{array}{c}\text { Number of } \\
\text { wells }\end{array}$ \\
\hline Sleipner West & 9.0 & 184 & 1,020 & 10 & 2 \\
\hline IEA Study Aquifer & 11.3 & 55 & 1,459 & 13 & 6 \\
\hline $\begin{array}{l}\text { Glauconitic Sandstone, } \\
\text { Albert Basin }\end{array}$ & 12.4 & 13 & 1,480 & 30 & 11 \\
\hline $\begin{array}{l}\text { Repetto Formation, Los } \\
\text { Angeles Basin }\end{array}$ & 6.9 & 800 & 2,400 & 250 & 1 \\
\hline Arbuckle Group, Oklahoma & 2.1 & 600 & 2,400 & 0.005 & 418 \\
\hline $\begin{array}{l}\text { Paluxy Sandstone, East } \\
\text { Texas Basin }\end{array}$ & 10.3 & 75 & 1,000 & 400 & 1 \\
\hline $\begin{array}{l}\text { Jasper Interval, East Texas } \\
\text { Gulf Coast }\end{array}$ & 8.4 & 1,500 & 800 & 100 & 1 \\
\hline $\begin{array}{l}\text { Pottsville Formation, Black } \\
\text { Warrior Basin }\end{array}$ & 6.9 & 1,100 & 500 & 15 & 1 \\
\hline $\begin{array}{l}\text { Cedar Key Dolomite, } \\
\text { Central Florida Region }\end{array}$ & 1.0 & 325 & 1,000 & 15 & 1 \\
\hline
\end{tabular}

Incomplete sets of data for 13 aquifers were also available from the Bureau of Economic Geology. This data is shown in Table 7-6. 
Table 7-6

Incomplete sets of aquifer property data

\begin{tabular}{|l|c|c|c|c|}
\hline Aquifer & $\begin{array}{c}\text { Pressure } \\
\text { (MPa) }\end{array}$ & $\begin{array}{c}\text { Thickness } \\
(\mathbf{m})\end{array}$ & $\begin{array}{c}\text { Depth } \\
(\mathbf{m})\end{array}$ & $\begin{array}{c}\text { Permeability } \\
\text { (md) }\end{array}$ \\
\hline $\begin{array}{l}\text { Glen Canyon Group, Sevier/Kaiparowitz } \\
\text { Basin }\end{array}$ & & 175 & 2,000 & \\
\hline Morrison Formation, San Juan Basin & & 250 & 1,600 & \\
\hline Fox Hills Sandstone, Power River Basin & & 175 & 800 & \\
\hline Madison Group, Williston Basin & & 250 & 1,400 & \\
\hline Lyons Sandstone, Denver Basin & & 300 & 2,000 & \\
\hline Granite Wash, Palo Duro Basin & 9.1 & 800 & 1,000 & \\
\hline Woodbine Formation, East Texas Basin & 12.4 & 100 & 1,000 & \\
\hline Frio Formation, Texas Gulf Coast & & 500 & 800 & 500 \\
\hline St. Peter Sandstone, Illinois Basin & 5.3 & 50 & 50 & \\
\hline Mt. Simon Formation, Michigan Basin & 11.4 & 100 & 100 & \\
\hline $\begin{array}{l}\text { Tuscaloosa Group, Alabama Gulf Coastal } \\
\text { Plain }\end{array}$ & 10.9 & 40 & 40 & \\
\hline Oriskany Formation, Appalachian Basin & 10.0 & 5 & 5 & \\
\hline $\begin{array}{l}\text { Lower Potomac Group, Eastern Coastal } \\
\text { Plain }\end{array}$ & 6.9 & 225 & 225 & \\
\hline
\end{tabular}

The data given in these two tables were used in a statistical analysis to determine suitable base, high-cost and low-cost cases for the aquifer storage option. The calculation of the values of aquifer pressure and depth for the base, high-cost and low-cost cases used standard statistical functions. In the case of aquifer thickness and permeability, however, a logarithmic regression was necessary. This was due to the fact that the values of these two latter variables varied by more than two orders of magnitude.

The base values for aquifer pressure and depth were based on the arithmetic mean. The highcost values of each of these parameters were then taken as the mean plus the standard deviation and the low-cost values as the mean minus the standard deviation. This corresponds to an increase in pressure and depth causing an increase in cost, and a decrease in these parameters causing a reduction in cost. The values for thickness and permeability were calculated in a similar manner, but taking into account that a reduction in these parameters increases the cost and an increase reduces the cost. The final value for each parameter for each of the base, highcost and low-cost cases is given Table 7-7. The number of wells required for each of these cases is also shown. 
Table 7-7

Design bases for aquifer storage option

\begin{tabular}{|l|c|c|c|c|}
\hline Parameter & Units & $\begin{array}{c}\text { Aquifer } \\
\text { Base Case }\end{array}$ & $\begin{array}{c}\text { Aquifer } \\
\text { High Cost Case }\end{array}$ & $\begin{array}{c}\text { Aquifer } \\
\text { Low Cost Case }\end{array}$ \\
\hline Pressure & $\mathrm{MPa}$ & 8.4 & 11.8 & 5.0 \\
\hline Thickness & $\mathrm{m}$ & 171 & 42 & 703 \\
\hline Depth & $\mathrm{m}$ & 1,239 & 1,784 & 694 \\
\hline Permeability & $\mathrm{md}$ & 22 & 0.8 & 585 \\
\hline Injection Rate per Well* & $\mathrm{t} / \mathrm{d}$ & 9,363 & 82 & 889,495 \\
\hline Number of Wells* & & 1 & 91 & 1 \\
\hline
\end{tabular}

Reservoirs that are thick, shallow, and have high permeability require a smaller number of wells and, therefore, have a lower storage cost. A higher reservoir pressure results in lower injectivity (not desired), but higher $\mathrm{CO}_{2}$ densities (desired). Therefore, a moderate pressure is optimal. In general, the permeability is the most critical parameter in determining costs.

It is important to note that the injection rate per well of 889,495 tonnes of $\mathrm{CO}_{2}$ per day for the low cost case was calculated without setting any limit on the well diameter. Indeed, this injection rate requires a well diameter of $0.5 \mathrm{~m}$, which is too large to be used in practice. Given that the standard well diameter used for the other cases for each of the geologic options is 0.059 $\mathrm{m}$, it would seem reasonable to limit the diameter to double this at $0.120 \mathrm{~m}$. This would give a maximum flow rate of around 25,100 tonnes of $\mathrm{CO}_{2}$ per day.

\subsubsection{Capital and O\&M Cost Inputs}

The capital cost of site screening and evaluation is assumed equal $(\$ 1,685,000)$ for each of the three geologic storage options. The other capital and O\&M costs are calculated using the cost estimation factors/functions given in Section 7.4.3. Based on the respective values of well depth and required number of wells, as detailed in Section 7.5.1, it is possible to determine the costs on a per well basis for each of the storage options. These per well costs are then multiplied by the total number of wells. The model inputs for the capital and O\&M costs for the base cases are given in Table 7-8. 
Table 7-8

Capital and O\&M cost inputs for gas and oil reservoir, and aquifer base cases

\begin{tabular}{|l|c|c|c|}
\hline Parameter & Gas Reservoir & Oil Reservoir & Aquifer \\
\hline Number of Wells & 48 & 21 & 1 \\
\hline \hline CAPITAL COSTS & \multicolumn{3}{|l|}{} \\
\hline $\begin{array}{l}\text { Screening and Evaluation of } \\
\text { Sites }\end{array}$ & $\$ 1,685,000$ & $\$ 1,685,00$ & $\$ 1,685,000$ \\
\hline $\begin{array}{l}\text { Injection Equipment } \\
\text { (Flowlines \& Connections) }\end{array}$ & $\$ 1,552,000$ & $\$ 1,026,000$ & $\$ 224,000$ \\
\hline Injection Wells & $\$ 14,426,000$ & $\$ 6,465,000$ & $\$ 239,000$ \\
\hline Subtotal & $\$ 17,700,000$ & $\$ 9,180,000$ & $\$ 2,150,000$ \\
\hline \hline O\&M COSTS & $\$ 322,000$ & $\$ 141,000$ & $\$ 7,000$ \\
\hline Normal Daily Expenses & $\$ 859,000$ & $\$ 376,000$ & $\$ 18,000$ \\
\hline Consumables & $\$ 484,000$ & $\$ 320,000$ & $\$ 70,000$ \\
\hline $\begin{array}{l}\text { Surface Maintenance } \\
\text { (Repair \& Services) }\end{array}$ & $\$ 300,000$ & $\$ 134,000$ & $\$ 5,000$ \\
\hline $\begin{array}{l}\text { Subsurface Maintenance } \\
\text { (Repair \& Services) }\end{array}$ & $\$ 1,970,000$ & $\$ 970,000$ & $\$ 100,000$ \\
\hline Subtotal & & & \\
\hline
\end{tabular}

\subsection{Model Results}

This section presents costs for $\mathrm{CO}_{2}$ capture and storage for the base cases described in Section 7.5. The storage costs comprise transaction, transportation, injection and monitoring costs. These costs are combined with capture costs from an IGCC power plant. The results are given on several bases as described in Chapter 2. Appendix B provides a detailed description of these spreadsheets.

\subsubsection{Depleted Gas Reservoir: Spreadsheet Orientation and Typical Costs}

The Process Input sheet for the depleted gas reservoir base case is presented in Table 7-9. 
Table 7-9

Process input sheet for base case depleted gas reservoir

\begin{tabular}{|c|c|c|c|}
\hline Design Basis & & Economic & \\
\hline IGCC Plant & & IGCC Plant (Case 3a) & \\
\hline Capacity Factor & $80 \%$ & $\mathrm{CO}_{2}$ Capture Cost (\$/tonne captured) & $\$ 14.55$ \\
\hline Pipeline Distance & $100 \mathrm{~km}$ & COE Including $\mathrm{CO}_{2}$ Capture Cost ( $\left.\$ / \mathrm{MWh}\right)$ & $\$ 55.08$ \\
\hline Pipeline Distance & 62 miles & & \\
\hline Nominal pipe size (in) & 12 & IGCC Plant \& $\mathrm{CO}_{2}$ Storage & \\
\hline & & After-Tax Discount Rate & $6.09 \%$ \\
\hline $\mathrm{CO}_{2}$ Storage & & Levelized Carrying Charge Factor & $15.0 \%$ \\
\hline $\begin{array}{l}\text { Design Basis } \\
\text { Well Depth }(\mathrm{m})\end{array}$ & $\begin{array}{r}\text { Base Cost Case } \\
1,524\end{array}$ & & \\
\hline Reservoir Pressure (MPa) & $\begin{array}{r}1,0<4 \\
3.5\end{array}$ & & \\
\hline Thickness (m) & 31 & & \\
\hline Permeability (md) & 1.0 & & \\
\hline Iniection Rate Per Well (tonne/dav) & 156 & & \\
\hline
\end{tabular}

The Summary sheet for the depleted gas reservoir base case is presented in Table 7-10. 
Table 7-10

Summary sheet for base case depleted gas reservoir

\section{Depleted Gas Reservoir Summary}

\begin{tabular}{|ccrc|}
\hline \multicolumn{2}{|l}{ Process Description } & & \\
Pileline Distance & $100 \mathrm{~km}$ & $\mathrm{CO}_{2}$ Stored (M tonne/yr) & 2.158 \\
Design Basis: & Base Cost Case & $\mathrm{CO}_{2}$ Avoided (M tonne/yr) & 1.822 \\
& & LC Avoided GHG (M tonne/yr) & 2.154 \\
& LC Avoided GHG (M tonne/yr) & 1.804 \\
Economic Description & & \\
After-Tax Discount Rate & $6.09 \%$ & \\
& &
\end{tabular}

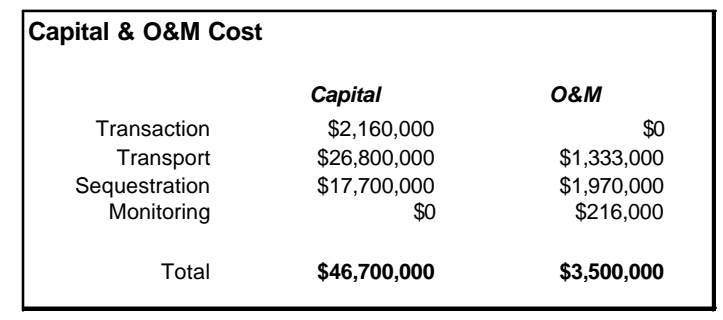

Cost of $\mathrm{CO}_{2}$ Capture \& Storage

1. Levelized Annual $\mathrm{CO}_{2}$ Storage Costs (years 1-20)

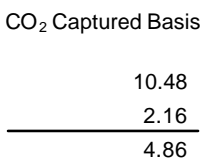

LC Avoided GHG Basis (storage only)

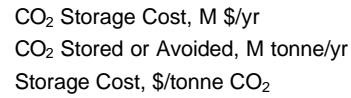

$\mathrm{CO}_{2}$ Captured Basis

$\mathrm{CO}_{2}$ Avoided Basis LC Avoided GHG Basis
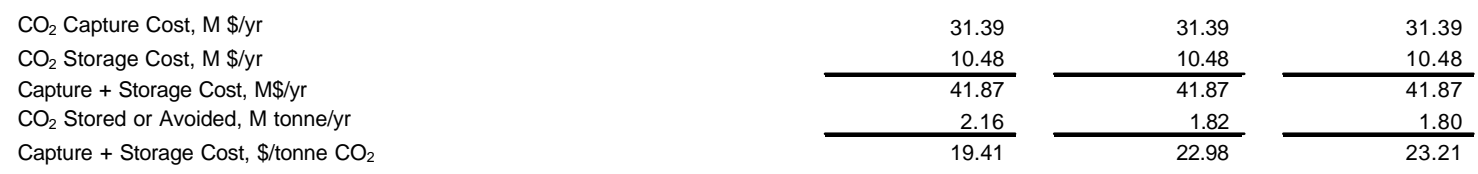

3. $\mathrm{CO}_{2}$ Capture and Net Storage Costs, NPV Basis (years 1-100)

NPV of $\mathrm{CO}_{2}$ Capture Costs, M\$

$\mathrm{NPV}$ of $\mathrm{CO}_{2}$ Storage Costs, M\$

NPV of Capture + Storage Costs, M\$

NPV of $\mathrm{CO}_{2}$ Stored or Avoided, M tonne

Capture + Storage Cost (NPV Basis), $\$ /$ tonne $\mathrm{CO}_{2}$

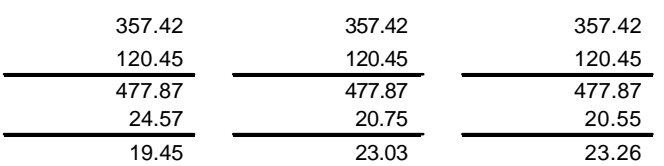

4. Cost of Electricity, $\$ / M W h$
Reference Plant (no capture)
Capture Costs (years 1-20)
Storage Costs (years 1-20)
Storage Costs, Monitoring, etc. (years 21-100)
Total Cost of Electricity

$\begin{array}{r}43.98 \\ 11.10 \\ 3.71 \\ 0.03 \\ \hline 58.82\end{array}$

\subsubsection{Depleted Oil Reservoir: Spreadsheet Orientation and Typical Costs}

The Process Input sheet for the depleted oil reservoir base case is presented in Table 7-11. 
Table 7-11

Process input sheet for depleted oil reservoir base case

\begin{tabular}{|c|c|c|c|}
\hline Design Basis & & Economic & \\
\hline IGCC Plant & & IGCC Plant (Case 3a) & \\
\hline Capacity Factor & $80 \%$ & $\mathrm{CO}_{2}$ Capture Cost (\$/tonne captured) & $\$ 14.55$ \\
\hline Pipeline Distance & $100 \mathrm{~km}$ & COE Including $\mathrm{CO}_{2}$ Capture Cost $(\$ / \mathrm{MWh})$ & $\$ 55.08$ \\
\hline Pipeline Distance & 62 miles & & \\
\hline Nominal pipe size (in) & 12 & $\begin{array}{l}\text { IGCC Plant \& } \mathrm{CO}_{2} \text { Storage } \\
\text { After-Tax Discount Rate }\end{array}$ & $6.09 \%$ \\
\hline $\mathrm{CO}_{2}$ Storage & & Levelized Carrying Charge Factor & $15.0 \%$ \\
\hline $\begin{array}{l}\text { Design Basis } \\
\text { Well Depth (m) } \\
\text { Reservoir Pressure (MPa) }\end{array}$ & $\begin{array}{r}\text { Base Cost Case } \\
1,554 \\
13.8\end{array}$ & & \\
\hline $\begin{array}{l}\text { Thickness (m) } \\
\text { Permeability (md) } \\
\text { Iniection Rate Per Well (tonne/day) }\end{array}$ & $\begin{array}{r}43 \\
5.0 \\
360 \\
\end{array}$ & & \\
\hline
\end{tabular}

The Summary sheet for the depleted oil reservoir base case is presented in Table 7-12. 
Table 7-12

Summary sheet for depleted oil reservoir base case

\section{Depleted Oil Reservoir Summary}
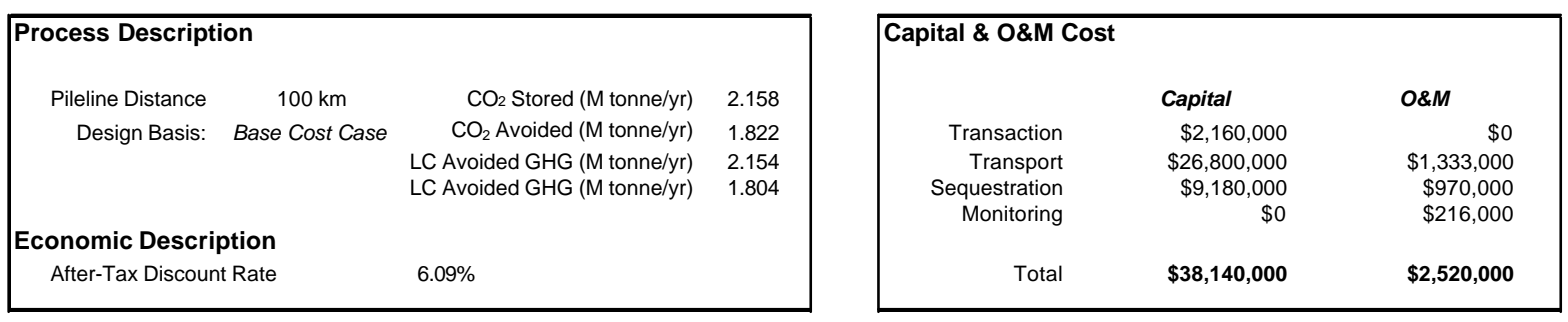

\section{Cost of $\mathrm{CO}_{2}$ Capture \& Storage}

1. Levelized Annual $\mathrm{CO}_{2}$ Storage Costs (years 1-20)

$\mathrm{CO}_{2}$ Storage Cost, $\mathrm{M} \$ / \mathrm{yr}$

$\mathrm{CO}_{2}$ Stored or Avoided, $\mathrm{M}$ tonne/yr

Storage Cost, \$/tonne $\mathrm{CO}_{2}$

2. Levelized Annual $\mathrm{CO}_{2}$ Capture and Storage Costs (years 1-20)

$\mathrm{CO}_{2}$ Capture Cost, $\mathrm{M} \$ / \mathrm{yr}$

$\mathrm{CO}_{2}$ Storage Cost, $\mathrm{M} \$ / \mathrm{yr}$

Capture + Storage Cost, $\mathrm{M} \$ / \mathrm{yr}$

$\mathrm{CO}_{2}$ Stored or Avoided, $\mathrm{M}$ tonne/yr

Capture + Storage Cost, $\$$ tonne $\mathrm{CO}_{2}$

3. $\mathrm{CO}_{2}$ Capture and Storage Costs, NPV Basis (years 1-100)

NPV of $\mathrm{CO}_{2}$ Capture Costs, $\mathrm{M} \$$

$\mathrm{NPV}$ of $\mathrm{CO}_{2}$ Storage Costs, $\mathrm{M} \$$

NPV of Capture + Storage Costs, M\$

$\mathrm{NPV}$ of $\mathrm{CO}_{2}$ Stored or Avoided, $\mathrm{M}$ tonne

Capture + Storage Cost (NPV Basis), \$/tonne $\mathrm{CO}_{2}$

4. Cost of Electricity, $\$ / M W h$

Reference Plant (no capture)

Capture Costs (years 1-20)

Storage Costs (years 1-20)

Storage Costs, Monitoring, etc. (years 21-100)

Total Cost of Electricity
$\mathrm{CO}_{2}$ Captured Basis

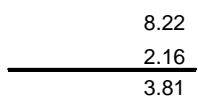

$\mathrm{CO}_{2}$ Captured Basis

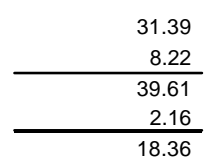

$\mathrm{CO}_{2}$ Captured Basis
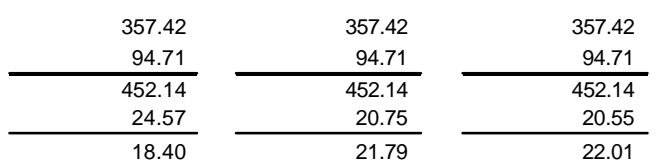

$\mathrm{CO}_{2}$ Avoided Basis

LC Avoided GHG Basis

8.22

2.15

$\mathrm{CO}_{2}$ Avoided Basis LC Avoided GHG Basis

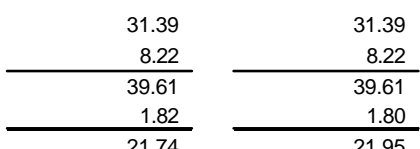

21.95

LC Avoided GHG Basis

57.42 (storage only) 


\subsubsection{Aquifer Storage: Spreadsheet Orientation and Typical Costs}

The Process Input sheet for the aquifer storage base case is presented in Table 7-13.

Table 7-13

Process input sheet for aquifer storage base

\begin{tabular}{|c|c|c|c|}
\hline Design Basis & & Economic & \\
\hline IGCC Plant & & IGCC Plant (Case 3a) & \\
\hline Capacity Factor & $80 \%$ & $\mathrm{CO}_{2}$ Capture Cost (\$/tonne captured) & $\$ 14.55$ \\
\hline Pipeline Distance & $100 \mathrm{~km}$ & COE Including $\mathrm{CO}_{2}$ Capture Cost ( $\left.\$ / \mathrm{MWh}\right)$ & $\$ 55.08$ \\
\hline Pipeline Distance & 62 miles & & \\
\hline Nominal pipe size (in) & 12 & IGCC Plant \& $\mathrm{CO}_{2}$ Storage & $6.09 \%$ \\
\hline $\mathrm{CO}_{2}$ Storage & & Levelized Carrying Charge Factor & $15.0 \%$ \\
\hline $\begin{array}{l}\text { Design Basis } \\
\text { Well Depth }(m)\end{array}$ & $\begin{array}{r}\text { Base Cost Case } \\
1,239\end{array}$ & & \\
\hline Reservoir Pressure (MPa) & 8.4 & & \\
\hline Thickness (m) & 171 & & \\
\hline Permeability (md) & 22.0 & & \\
\hline Injection Rate Per Well (tonne/day) & 6,452 & & \\
\hline
\end{tabular}

The Summary sheet for the aquifer storage base case is presented in Table 7-14. 
Table 7-14

Summary sheet for the aquifer storage base case

Aquifer Storage Summary
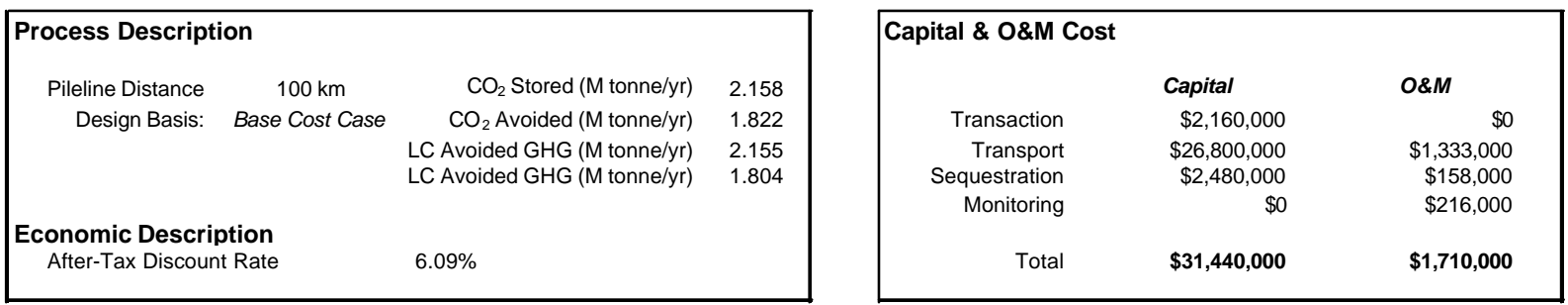

Cost of $\mathrm{CO}_{2}$ Capture \& Storage

1. Levelized Annual $\mathrm{CO}_{2}$ Storage Costs (years 1-20)

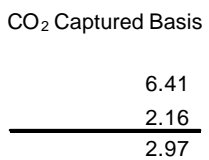

LC Avoided GHG Basis (storage only)

$\mathrm{CO}_{2}$ Storage Cost, $\mathrm{M} \$ / \mathrm{yr}$

$\mathrm{CO}_{2}$ Stored or Avoided, $\mathrm{M}$ tonne/yr

Storage Cost, $\$ /$ tonne $\mathrm{CO}_{2}$

2.16

2. Levelized Annual $\mathrm{CO}_{2}$ Capture and Storage Costs (years 1-20)

$\mathrm{CO}_{2}$ Captured Basis

$\mathrm{CO}_{2}$ Avoided Basis LC Avoided GHG Basis

$\mathrm{CO}_{2}$ Capture Cost, $\mathrm{M} \$ / \mathrm{yr}$

$\mathrm{CO}_{2}$ Storage Cost, $\mathrm{M} \$ / \mathrm{yr}$

Capture + Storage Cost, $\mathrm{M} \$ / \mathrm{yr}$

$\mathrm{CO}_{2}$ Stored or Avoided, $\mathrm{M}$ tonne/yr

Capture + Storage Cost, $\$$ tonne $\mathrm{CO}_{2}$
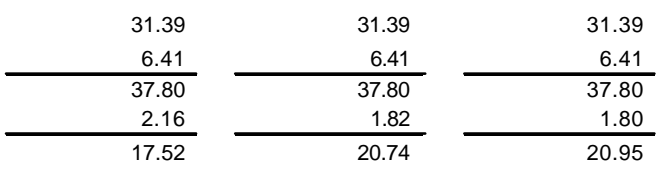

3. $\mathrm{CO}_{2}$ Capture and Net Storage Costs, NPV Basis (years 1-100)

$\mathrm{CO}_{2}$ Captured Basis

$\mathrm{CO}_{2}$ Avoided Basis LC Avoided GHG Basis

NPV of $\mathrm{CO}_{2}$ Capture Costs, M\$

NPV of $\mathrm{CO}_{2}$ Storage Costs, M\$

NPV of Capture + Storage Costs, M\$

NPV of $\mathrm{CO}_{2}$ Stored or Avoided, M tonne

Capture + Storage Cost (NPV Basis), \$/tonne $\mathrm{CO}_{2}$

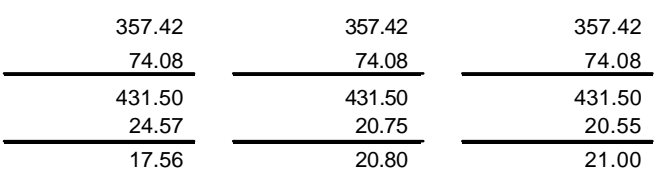

4. Cost of Electricity, $\$ / M W h$

Reference Plant (no capture)

Capture Costs (years 1-20)

Storage Costs (years 1-20)

Storage Costs, Monitoring, etc. (years 21-100)

Total Cost of Electricity

2.27

0.03
57.38

\subsection{Sensitivity Analyses}

\subsubsection{Depleted Gas Reservoir}

The sensitivity of the $\mathrm{CO}_{2}$ storage cost for the depleted gas reservoir option is determined for five key parameters: well depth, pressure, thickness, permeability and pipeline distance. It can be seen in Figure 7-5 that increases in well depth, reservoir pressure and pipeline distance cause an increase in the cost of storage, while increases in reservoir thickness and permeability decrease the storage cost. More noteworthy, the figure shows that, for the chosen base case values, changes in thickness and permeability have the greatest effect on storage cost. 


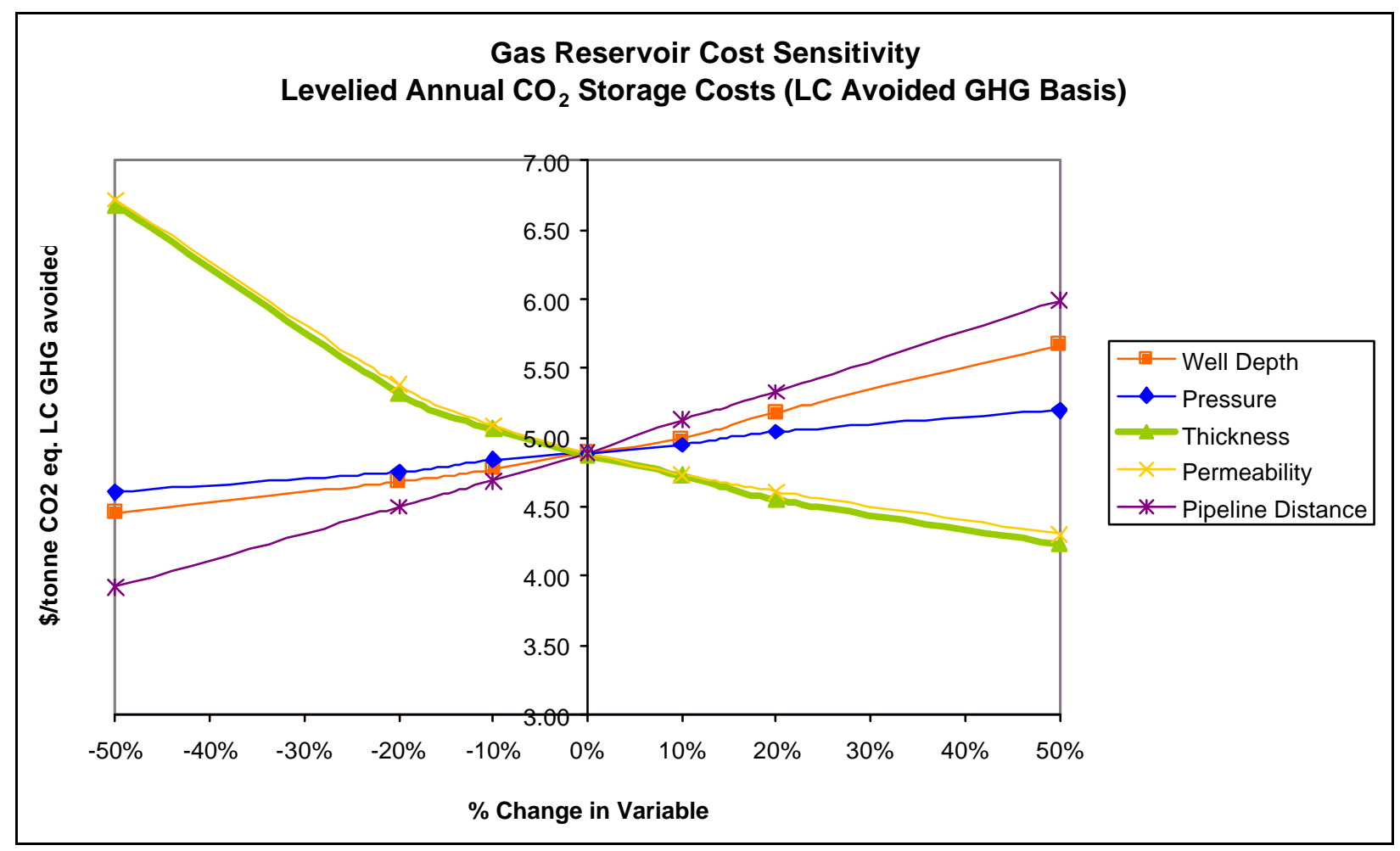

Figure 7-5

Sensitivity analysis for depleted gas reservoir

High and low cost cases have been chosen for the depleted gas reservoir option, and are presented together with the base case in Table 7-15. For the high and low cost values for each of the five key parameters, the percentage change in the value from the base case is shown. This is done to illustrate the fact that the range in the values of some parameters is expected to be greater than for others.

Table 7-15

Depleted gas reservoir base, high cost and low cost cases

\begin{tabular}{|l|c|c|c|c|c|c|}
\hline Parameter & Units & $\begin{array}{c}\text { Gas Reservoir } \\
\text { Base Case }\end{array}$ & \multicolumn{2}{|c|}{$\begin{array}{c}\text { Gas Reservoir } \\
\text { High Cost Case }\end{array}$} & \multicolumn{2}{c|}{$\begin{array}{c}\text { Gas Reservoir } \\
\text { Low Cost Case }\end{array}$} \\
\hline Pressure & $\mathrm{MPa}$ & 3.5 & 6.9 & $+97 \%$ & 2.1 & $-40 \%$ \\
\hline Thickness & $\mathrm{m}$ & 31 & 15 & $-52 \%$ & 61 & $+97 \%$ \\
\hline Depth & $\mathrm{m}$ & 1,524 & 3,048 & $+100 \%$ & 610 & $-60 \%$ \\
\hline Permeability & $\mathrm{md}$ & 1 & 0.8 & $-20 \%$ & 10 & $+900 \%$ \\
\hline Pipeline Distance & $\mathrm{km}$ & 100 & 300 & $+200 \%$ & 0 & $-100 \%$ \\
\hline
\end{tabular}


The results for the high and low cost cases as well as the base case are given in Table 7-16. The range of $\mathrm{CO}_{2}$ storage cost for the depleted gas reservoir option varies by about a factor of 20 for the high and low cost cases.

Table 7-16

Results for depleted gas reservoir base, high cost and low cost cases

\begin{tabular}{|l|l|c|c|c|}
\hline Parameter & Units & $\begin{array}{c}\text { Gas } \\
\text { Reservoir } \\
\text { Base Case }\end{array}$ & $\begin{array}{c}\text { Gas Reservoir } \\
\text { High Cost Case }\end{array}$ & $\begin{array}{c}\text { Gas } \\
\text { Reservoir } \\
\text { Low Cost } \\
\text { Case }\end{array}$ \\
\hline Injection Rate per Well & $\mathrm{t} / \mathrm{d}$ & 156 & 57 & 2,975 \\
\hline Number of Wells & 48 & 129 & 3 \\
\hline $\begin{array}{l}\text { Levelized Annual } \mathrm{CO}_{2} \text { Storage } \\
\text { Cost }\end{array}$ & $\begin{array}{l}\$ \text { /tonne } \mathrm{CO}_{2} \\
\text { Eq. LC GHG } \\
\text { avoided }\end{array}$ & 4.87 & 19.43 & 1.20 \\
\hline
\end{tabular}

\subsubsection{Depleted Oil Reservoir}

The sensitivity of the $\mathrm{CO}_{2}$ storage cost for the depleted gas reservoir option is determined for the same five key parameters as used in the case of the depleted oil reservoir. It can be seen in Figure 7-6 that increases in reservoir pressure and pipeline distance cause an increase in the cost of storage, while increases in well depth, reservoir thickness and permeability decrease the storage cost. In contrast to the depleted gas reservoir option, increased well depth results in a decrease in the number of wells required, the resulting decrease in cost of which outweighs the increase in well drilling cost. The figure shows that, for the chosen base case values, changes in pressure have the greatest effect on storage cost. 


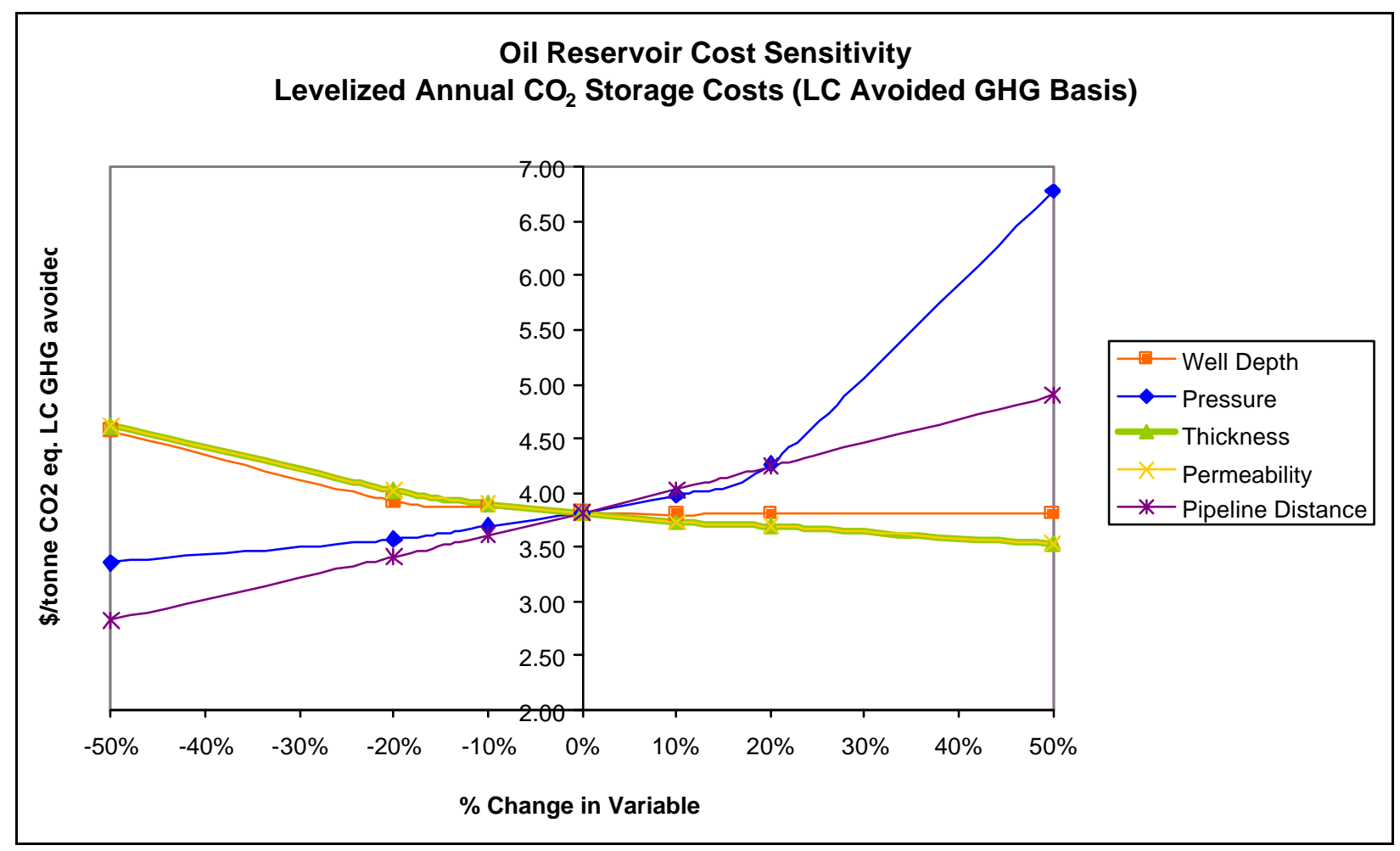

Figure 7-6

Sensitivity analysis for depleted oil reservoir

High and low cost cases have been chosen for the depleted oil reservoir option, and are presented together with the base case in Table 7-17. For the high and low cost values for each of the five key parameters, the percentage change in the value from the base case is shown.

Table 7-17

Depleted oil reservoir base, high cost and low cost cases

\begin{tabular}{|l|c|c|c|c|c|c|}
\hline Parameter & Units & $\begin{array}{c}\text { Oil Reservoir } \\
\text { Base Case }\end{array}$ & \multicolumn{2}{|c|}{$\begin{array}{c}\text { Oil Reservoir } \\
\text { High Cost Case }\end{array}$} & \multicolumn{2}{c|}{$\begin{array}{c}\text { Oil Reservoir } \\
\text { Low Cost Case }\end{array}$} \\
\hline Pressure & $\mathrm{MPa}$ & 13.8 & 20.7 & $+50 \%$ & 3.5 & $-75 \%$ \\
\hline Thickness & $\mathrm{m}$ & 43 & 21 & $-51 \%$ & 61 & $+42 \%$ \\
\hline Depth & $\mathrm{m}$ & 1,554 & 2,134 & $+37 \%$ & 1,524 & $-29 \%$ \\
\hline Permeability & $\mathrm{md}$ & 5 & 5 & $0 \%$ & 19 & $+280 \%$ \\
\hline $\begin{array}{l}\text { Pipeline } \\
\text { Distance }\end{array}$ & $\mathrm{km}$ & 100 & 300 & $+200 \%$ & 0 & $-100 \%$ \\
\hline
\end{tabular}

The results for the high and low cost cases as well as the base case are given in Table 7-18. The range of the $\mathrm{CO}_{2}$ storage cost for the depleted oil reservoir option differ by about a factor of 10 for the high and low cost cases. 
Table 7-18

Results for depleted oil reservoir base, high cost and low cost cases

\begin{tabular}{|l|l|c|c|c|}
\hline Parameter & Units & $\begin{array}{c}\text { Oil } \\
\text { Reservoir } \\
\text { Base Case }\end{array}$ & $\begin{array}{c}\text { Oil Reservoir } \\
\text { High Cost } \\
\text { Case }\end{array}$ & $\begin{array}{c}\text { Oil Reservoir } \\
\text { Low Cost Case }\end{array}$ \\
\hline Injection Rate per Well & $\mathrm{t} / \mathrm{d}$ & 360 & 115 & 5,690 \\
\hline Number of Wells & 21 & 65 & 2 \\
\hline $\begin{array}{l}\text { Levelized Annual } \mathrm{CO}_{2} \text { Storage } \\
\text { Cost }\end{array}$ & $\begin{array}{l}\$ / \text { tonne } \mathrm{CO}_{2} \\
\text { Eq. LC GHG } \\
\text { avoided }\end{array}$ & 3.82 & 11.16 & 1.21 \\
\hline
\end{tabular}

\subsubsection{Aquifer}

The sensitivity of the $\mathrm{CO}_{2}$ storage cost for the aquifer option is determined for the same five key parameters as for the other geologic storage options. It can be seen in Figure 7-7 that, for the range of values considered, the storage cost is only sensitive to pipeline distance. This is because, for the base case values chosen, the value of $\mathrm{CO}_{2}$ injectivity is very high. This in turn results in only one well being required, where this is relatively insensitive to changes in reservoir properties.

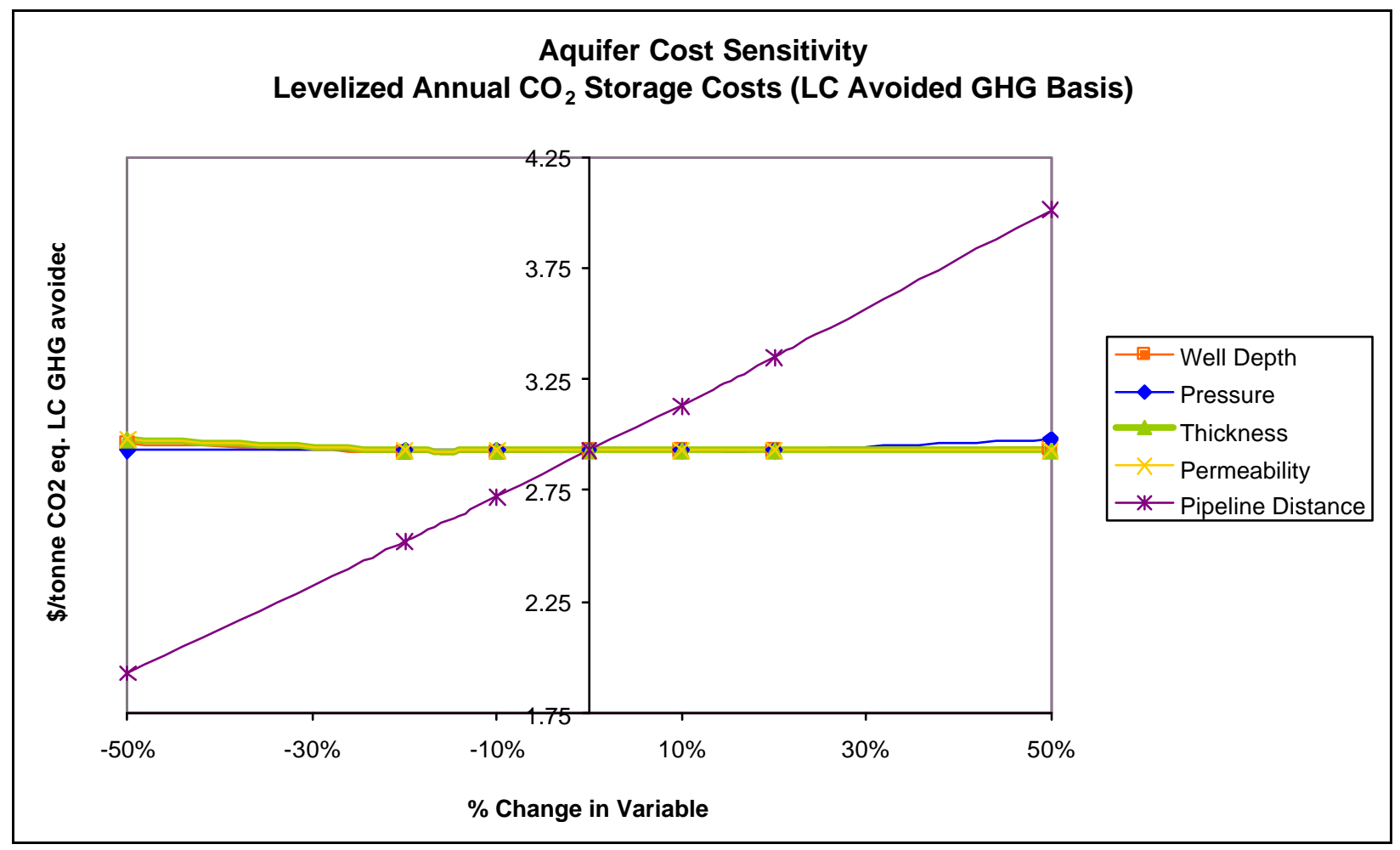

Figure 7-7

Sensitivity analysis for aquifer 
High and low cost cases have been chosen for the aquifer option, and are presented together with the base case in Table 7-19. For the high and low cost values for each of the five key parameters, the percentage change in the value from the base case is shown. As compared to the depleted gas and oil reservoir options, thickness and permeability can vary to a far greater degree.

Table 7-19

Aquifer base, high cost and low cost cases

\begin{tabular}{|l|c|c|c|c|c|c|}
\hline Parameter & Units & $\begin{array}{c}\text { Aquifer } \\
\text { Base Case }\end{array}$ & \multicolumn{2}{c|}{$\begin{array}{c}\text { Aquifer } \\
\text { High Cost Case }\end{array}$} & \multicolumn{2}{c|}{$\begin{array}{c}\text { Aquifer } \\
\text { Low Cost Case }\end{array}$} \\
\hline Pressure & $\mathrm{MPa}$ & 8.4 & 11.8 & $+40 \%$ & 5.0 & $-40 \%$ \\
\hline Thickness & $\mathrm{m}$ & 171 & 42 & $-75 \%$ & 703 & $+311 \%$ \\
\hline Depth & $\mathrm{m}$ & 1,239 & 1,784 & $+44 \%$ & 694 & $-44 \%$ \\
\hline Permeability & $\mathrm{md}$ & 22 & 0.8 & $-96 \%$ & 585 & $+2559 \%$ \\
\hline $\begin{array}{l}\text { Pipeline } \\
\text { Distance }\end{array}$ & $\mathrm{km}$ & 100 & 300 & $+200 \%$ & 0 & $-100 \%$ \\
\hline
\end{tabular}

The results for the high and low cost cases as well as the base case are given in Table 7-20. The range of $\mathrm{CO}_{2}$ storage cost for the aquifer option differ by about a factor of 10 for the high and low cost cases.

Table 7-20

Results for aquifer base, high cost and low cost cases

\begin{tabular}{|l|c|c|c|c|}
\hline Parameter & Units & $\begin{array}{c}\text { Aquifer } \\
\text { Base } \\
\text { Case }\end{array}$ & $\begin{array}{c}\text { Aquifer } \\
\text { High Cost } \\
\text { Case }\end{array}$ & $\begin{array}{c}\text { Aquifer } \\
\text { Low Cost } \\
\text { Case }\end{array}$ \\
\hline Injection Rate per Well & $\mathrm{t} / \mathrm{d}$ & 9,363 & 82 & 889,495 \\
\hline Number of Wells & 1 & 91 & 1 \\
\hline $\begin{array}{l}\text { Levelized Annual } \mathrm{CO}_{2} \text { Storage } \\
\text { Cost }\end{array}$ & $\begin{array}{l}\text { \$/tonne } \mathrm{CO}_{2} \\
\text { Eq. LC GHG } \\
\text { avoided }\end{array}$ & 2.93 & 11.71 & 1.14 \\
\hline
\end{tabular}

It is important to note that an aquifer could have a value of permeability equal to or 2 or 3 orders of magnitude less than the base case value. A reduction in the permeability of this magnitude would in turn cause a dramatic increase in the $\mathrm{CO}_{2}$ storage cost. For example, for the base case, reducing the base case permeability value from 22 to 0.22 md gives a storage cost of $\$ 5.37$, while a permeability of 0.022 md gives a cost of $\$ 25.23$. Similarly, as the thickness of the reservoir approaches zero, the storage cost skyrockets. 


\subsection{Comparison To Literature}

\subsubsection{Studies Used in Model Evaluation}

Injection scheme details and reservoir properties as well as cost data were collected from the studies listed in Table 7-21. All of the studies are concerned with the injection of $\mathrm{CO}_{2}$ into a saline aquifer, except for the 'IEA depleted reservoir' study that looks at storing $\mathrm{CO}_{2}$ in an exhausted gas reservoir.

Table 7-21

Injection schemes' characteristics

\begin{tabular}{|c|c|c|c|c|c|c|c|c|}
\hline Study & $\begin{array}{l}\mathrm{CO}_{2} \\
\mathrm{Flow} \\
\text { Rate } \\
(\mathrm{t} / \mathrm{d})\end{array}$ & $\begin{array}{c}\text { Downhole } \\
\text { Injection } \\
\text { Pressure } \\
\text { (MPa) }\end{array}$ & $\begin{array}{c}\text { Reservoir } \\
\text { Pressure } \\
\text { (MPa) }\end{array}$ & $\begin{array}{l}\text { Thickness } \\
(\mathrm{m})\end{array}$ & $\begin{array}{l}\text { Depth } \\
\text { (m) }\end{array}$ & $\begin{array}{l}\text { Permeability } \\
\quad \text { (md) }\end{array}$ & $\begin{array}{l}\text { Number } \\
\text { of Wells }\end{array}$ & Location \\
\hline IEA aquifer ${ }^{8}$ & 10,685 & 28.0 & 11.3 & 55 & 1,459 & 13 & 6 & Onshore \\
\hline $\begin{array}{l}\text { IEA depleted } \\
\text { reservoir }\end{array}$ & 8,560 & 10.4 & 3.0 & - & 2,500 & 100 & 4 & Onshore \\
\hline Elsamprojekt $^{19}$ & 3,770 & - & - & - & 1,100 & - & 12 & Onshore \\
\hline GEODISC $^{20}$ & 15,780 & 17.4 & 17.2 & 400 & 1,600 & 300 & 4 & Offshore \\
\hline $\begin{array}{l}\text { Sleipner } \\
\text { West }^{21}\end{array}$ & 2,740 & 11.0 & 9.0 & 184 & 1,020 & 10 & 1 & Offshore \\
\hline
\end{tabular}

The aquifer in both the 'GEODISC' and 'Sleipner West' studies is located offshore, in a depth of water of 100 and $80 \mathrm{~m}$ respectively. Due to certain reservoir properties not being specified, a benchmark for $\mathrm{CO}_{2}$ injectivity cannot be obtained from either of the 'IEA depleted reservoir' or the 'Elsamprojekt' studies. It should also be noted that cost data are not available for the 'Sleipner West' project.

\subsubsection{Comparison of Values from Model and Studies}

Figure 7-8 shows that, for $\mathrm{CO}_{2}$ injectivity, the value calculated by the model generally agrees with the value used in each of the studies. Indeed, the same relationship between $\mathrm{CO}_{2}$ mobility and injectivity, as is used in the model, has been used in the 'GEODISC' study $^{22}$ and possibly also the 'IEA aquifer' study. In the case of the 'Sleipner West' study, it should be noted the model at least underestimates, rather than overestimates, the injectivity. 


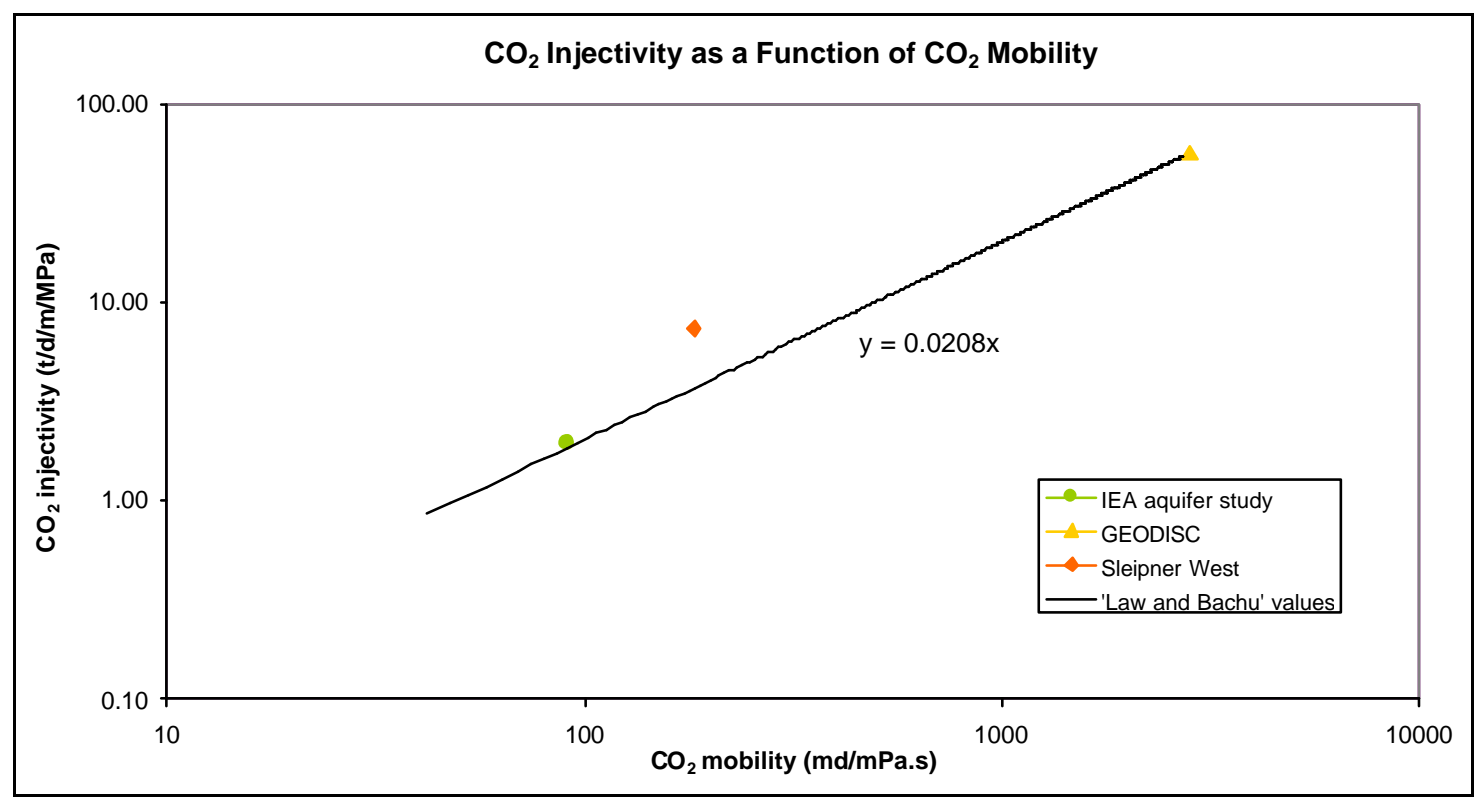

Figure 7-8

Comparison of $\mathrm{CO}_{2}$ injectivity values

A comparison of well drilling cost as calculated by the model and given in various studies is shown in Figure 7-9. The drilling cost in three of the studies can be seen to be about four times that calculated by the model, with the value in the 'GEODISC' study being exceedingly higher. The significant difference between the model's and the 'GEODISC' study's drilling cost can be attributed in part to the aquifer in the latter being located offshore. The drilling costs in the other three studies, one of which is based on conditions in Europe and the other two on those in Canada, are likely higher due to less drilling activity in these regions.

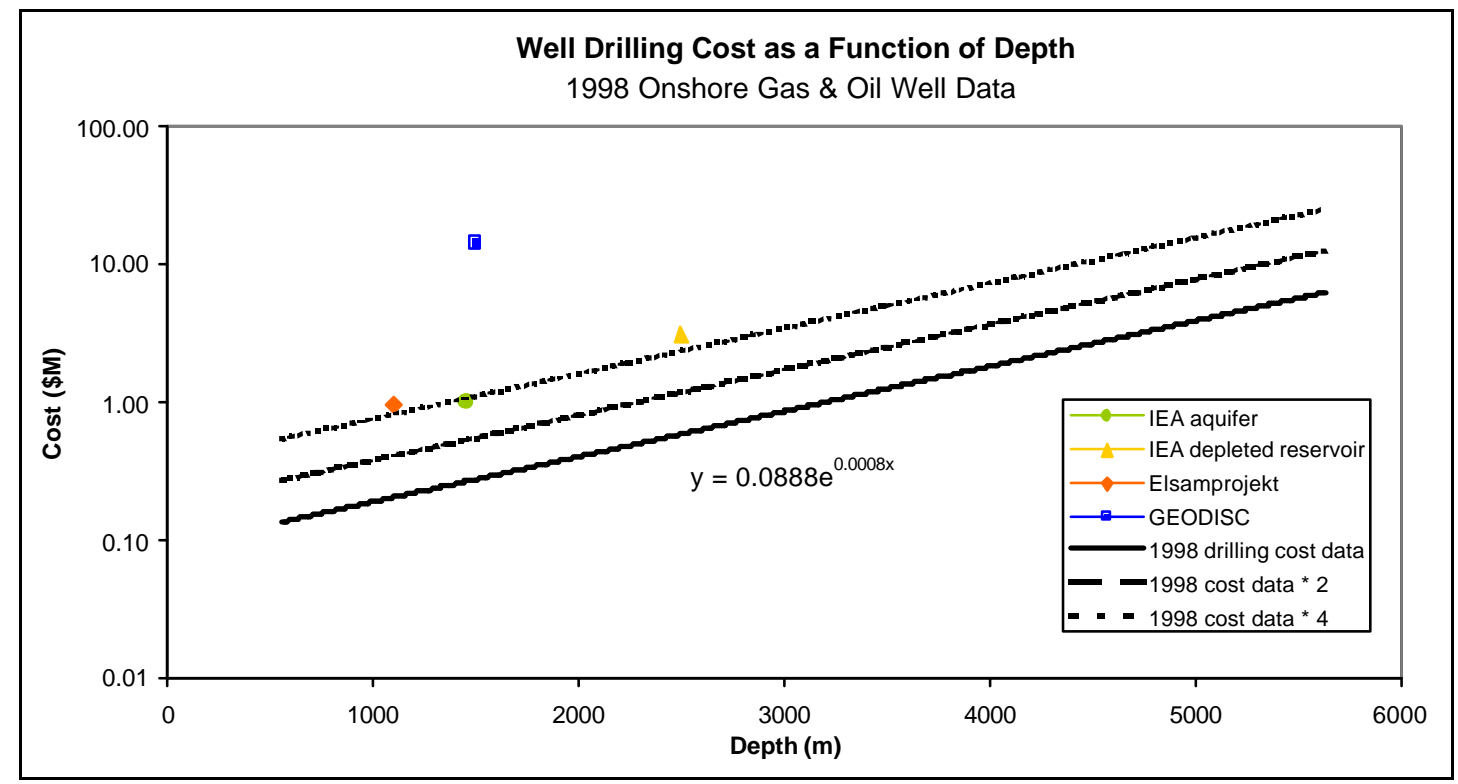

Figure 7-9

Comparison of onshore well drilling cost values 
Injecting $\mathrm{CO}_{2}$ into an offshore reservoir can be expected to be significantly more expensive than for a reservoir in an onshore location. Firstly, offshore drilling costs are higher. This can be seen from a comparison of Figure 7-10, which gives the cost of offshore well drilling based on 1998 JAS data for offshore gas and oil wells, with Figure 7-9. From Figure 7-10 it can also be seen that the offshore well drilling cost given in the 'GEODISC' study is about four times the JAS value. Secondly, $\mathrm{CO}_{2}$ injection into an offshore reservoir requires that a platform be installed. The cost of a platform depends primarily on the water depth and the number of wells it accommodates, with an unmanned platform with ten wells in a water depth of around 100 and $200 \mathrm{~m}$ costing around $\$ 4$ million and $\$ 6.5$ million per meter water depth, respectively ${ }^{20}$. If $\mathrm{CO}_{2}$ injection into offshore reservoirs were to be considered, these factors would need to be taken into account.

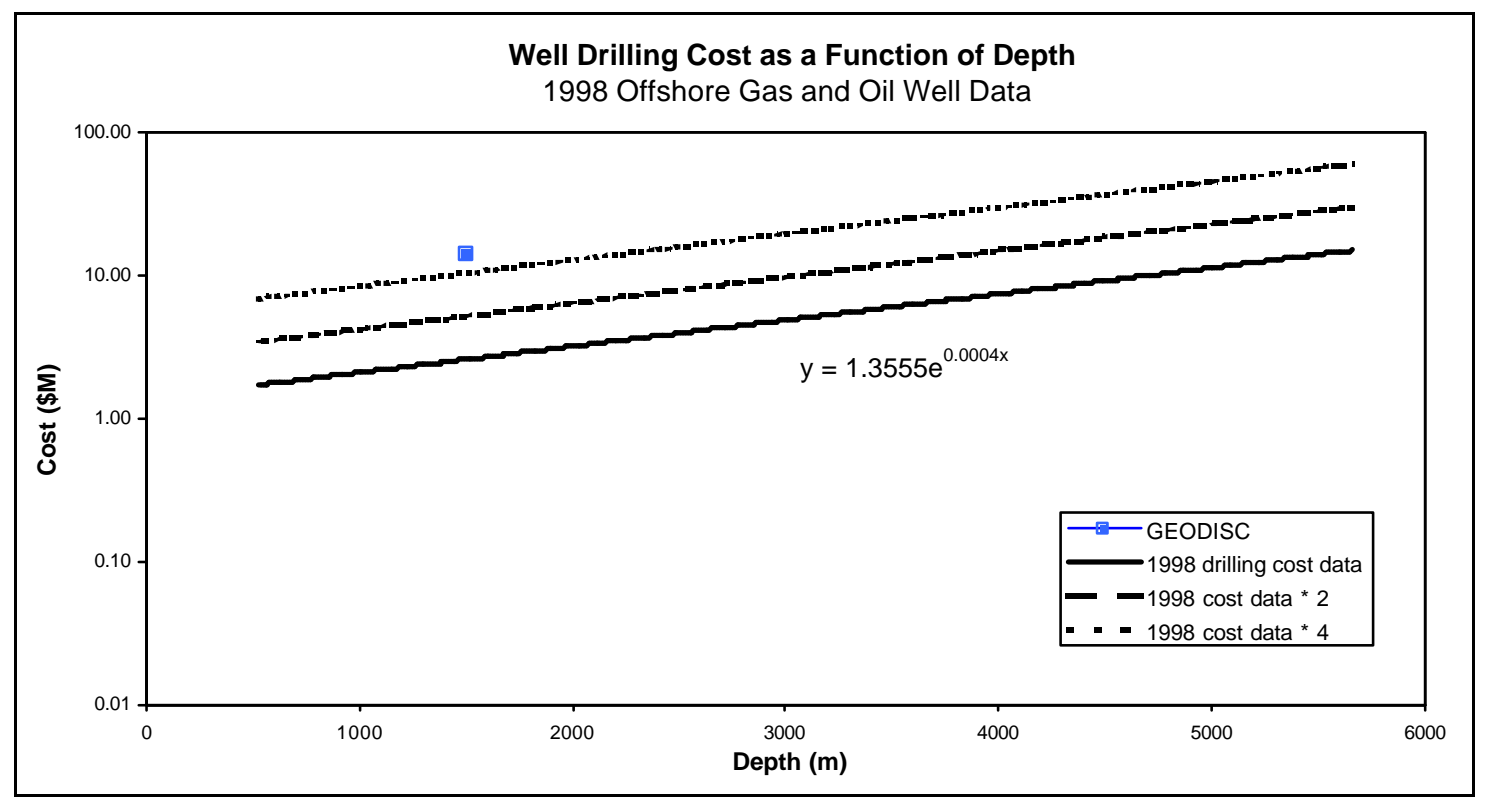

Figure 7-10

Comparison of offshore well drilling cost values 


\subsection{References}

1 Holloway, S., J.P. Heederik, L.G.H. van der Meer, I. Czernichowski-Lauriol, R. Harrison, E. Lindeberg, I.R. Summerfield, C. Rochelle, T. Schwarzkopf, O. Kaarstad and B. Berger, "The underground disposal of carbon dioxide," Summary report for the Joule II Project CT92-0031, 1996.

2 Royal Commission on Environmental Pollution, "Energy - The changing climate," [Online document], Jun. 2000, [cited Mar. 2002], Available HTTP:

http://www. Rcep.org.uk/newenergy.html

3 Herzog, H., "What future for carbon capture and sequestration?" Environmental Science and Technology, 35:7, pp. 148A-153A, Apr. 1, 2001.

4 International Energy Agency Greenhouse Gas R\&D Programme (IEAGHG), "CO2 storage in saline aquifers," [Online document], Jan. 2002, [cited Mar. 2002], Available HTTP:

http://www.ieagreen.org.uk/sacshome.htm

5 Kaarstad, Olav, e-mail communication, Sep. 29, 2001.

6 Stevens, S., V. Kuuskraa and J. Gale, "Sequestration of CO2 in depleted oil and gas fields: Global capacity, costs and barriers," presented at the Fifth International Conference on Greenhouse Gas Control Technologies (GHGT-5), Cairns, Australia, Aug. 13-16, 2000.

7 U.S. Department of Energy (Offices of Science and Fossil Energy), "Carbon sequestration Research and development," [Online document], Dec. 1999, [cited Mar. 2002], Available HTTP:

http://www.ornl.gov/carbon_sequestration/

8 Ormerod, W., "The disposal of carbon dioxide from fossil fuel fired power stations," Tech. Rep. IEAGHG/SR3, Jun. 1994.

9 Gunter, W.D., Bachu, S., Law, D.H.-S., Marwaha, V., Drysdale, D.L., Macdonald, D.L. and T.J. McCann, "Technical and economic feasibility of $\mathrm{CO} 2$ disposal in aquifers within the Alberta sedimentary basin," Energy Convers. Mgmt., 37:6-8, pp. 1135-1142, 1996.

10 Hitchon, B. (editor), "Aquifer disposal of carbon dioxide: Hydrodynamics and mineral trapping - proof of concept," 1996.

11 Stevens, S. and J. Gale, "Geologic CO2 sequestration may benefit upstream industry," Oil and Gas Journal, May 15, 2000.

12 Energy Information Administration - Office of Oil and Gas, "Costs and Indices for Domestic Oil and Gas Field Equipment and Production Operations," [Online document], Mar. 2000, Available HTTP: 
http://www.eia.doe.gov/oil_gas/natural_gas/data_publications/cost_indices/c_i.html

13 McHugh, M. and V. Krukonis, "Supercritical fluid extraction: principles and practice," 1986.

14 Law, D. and S. Bachu, "Hydrogeological and numerical analysis of CO2 disposal in deep aquifers in the Alberta sedimentary basin," Energy Convers. Mgmt., 37:6-8, pp. 1167-1174, 1996.

15 Smith, L.A. et al, "Engineering and Economic Assessment of Carbon Dioxide Sequestration in Saline Formations," presented at the First National Conference on Carbon Sequestration, May 14-17, 2001, Washington D.C.

16 American Petroleum Institute - Policy Analysis and Statistics Department, "1998 Joint Association Survey on Drilling Costs," [Online document], Nov. 1999, Available HTTP: http://www.api.org/axs-api/products/joint.htm

17 Kuuskraa, Vello, e-mail communication, Mar. 28, 2001.

18 Bureau of Economic Geology (The University of Texas at Austin), "Carbon dioxide sequestration - Study areas," [Online document], 2000, [cited Dec. 2001], Available HTTP: http://www.beg.utexas.edu/environqlty/co2seq/co2data.htm

19 Krom, T.D., F.L. Jacobsen and K.H. Ipsen, "Aquifer based carbon dioxide disposal in Denmark," Energy Convers. Mgmt., 34:9-11, pp. 933-940, 1993.

20 Allinson, G. and V. Nguyen, "The economics of CO2 sequestration in Australia," presented at the Fifth International Conference on Greenhouse Gas Control Technologies, Cairns, Australia, 2000.

21 Steefel, C., "Intercomparison of simulation models for $\mathrm{CO} 2$ disposal in underground storage reservoirs - Test problem 7: CO2 injection into a 2-D layered brine formation," [Online document], [cited Apr. 2001], Available HTTP:

http://esd.lbl.gov/GEOSEQ/code/testprob_7.html

22 Nguyen, Victor, personal communication, Jul. 17, 2001. 


\section{8 \\ OCEAN VIA PIPELINE}

\subsection{Introduction}

This chapter looks at the injection of $\mathrm{CO}_{2}$ into the deep ocean via a pipeline laid on the seabed.

\subsection{State of the Art}

The direct injection of $\mathrm{CO}_{2}$ into the ocean requires starting with a fairly concentrated stream of $\mathrm{CO}_{2}$ and delivering it to locations in the ocean where it will be effectively sequestered for hundreds of years, if not longer. To accomplish this, the $\mathrm{CO}_{2}$ needs to be injected below the thermocline at depths greater than 1000 meters. ${ }^{1}$ The $\mathrm{CO}_{2}$ may be injected at moderate depths of 1,000 to $2,000 \mathrm{~m}$ or at depths greater than $3,000 \mathrm{~m}$. The $\mathrm{CO}_{2}$ can be sequestered either by dissolution in the water column or by the formation of $\mathrm{CO}_{2}$ hydrates, which are solid, ice-like compounds.

Led by offshore exploration and production activities of the oil and gas industry, great strides have been made in the development of undersea offshore technology. It is becoming routine for work to be done at depths approaching 2,000 m (6,600 feet). Work at much greater depths, even approaching $10,000 \mathrm{~m}$, is possible at reduced scales and/or time horizons, as has been shown in deep drilling and other scientific programs. However, there are still many technical challenges in going deep at large scales for extended times. Therefore, as a first step, it appears that the best strategy is to discharge the $\mathrm{CO}_{2}$ below the thermocline at moderate depths of 1,000 to $2,000 \mathrm{~m}^{2}$

The technology to proceed with this option is available. There is however a lack of information regarding how to adequately optimize the costs, determine the effectiveness of the sequestration and understand the resulting changes in the biogeochemical cycles of the oceans. This storage option is also limited by the fact that it is best suited to large, stationary $\mathrm{CO}_{2}$ sources with access to deep-sea sequestration sites - sources that may account for only about 15 to 20 percent of our anthropogenic $\mathrm{CO}_{2}$ emissions.

Figure 8-1 illustrates that about 18 percent of worldwide power plant emissions are within a 400 $\mathrm{km}$ offshore distance of 1,500 m water depth. Given that power plant $\mathrm{CO}_{2}$ emissions account for about 35 percent of total anthropogenic $\mathrm{CO}_{2}$ emissions, about 6 to 6.5 percent of $\mathrm{CO}_{2}$ emissions could be sequestered in the deep ocean from coastal power plants. 


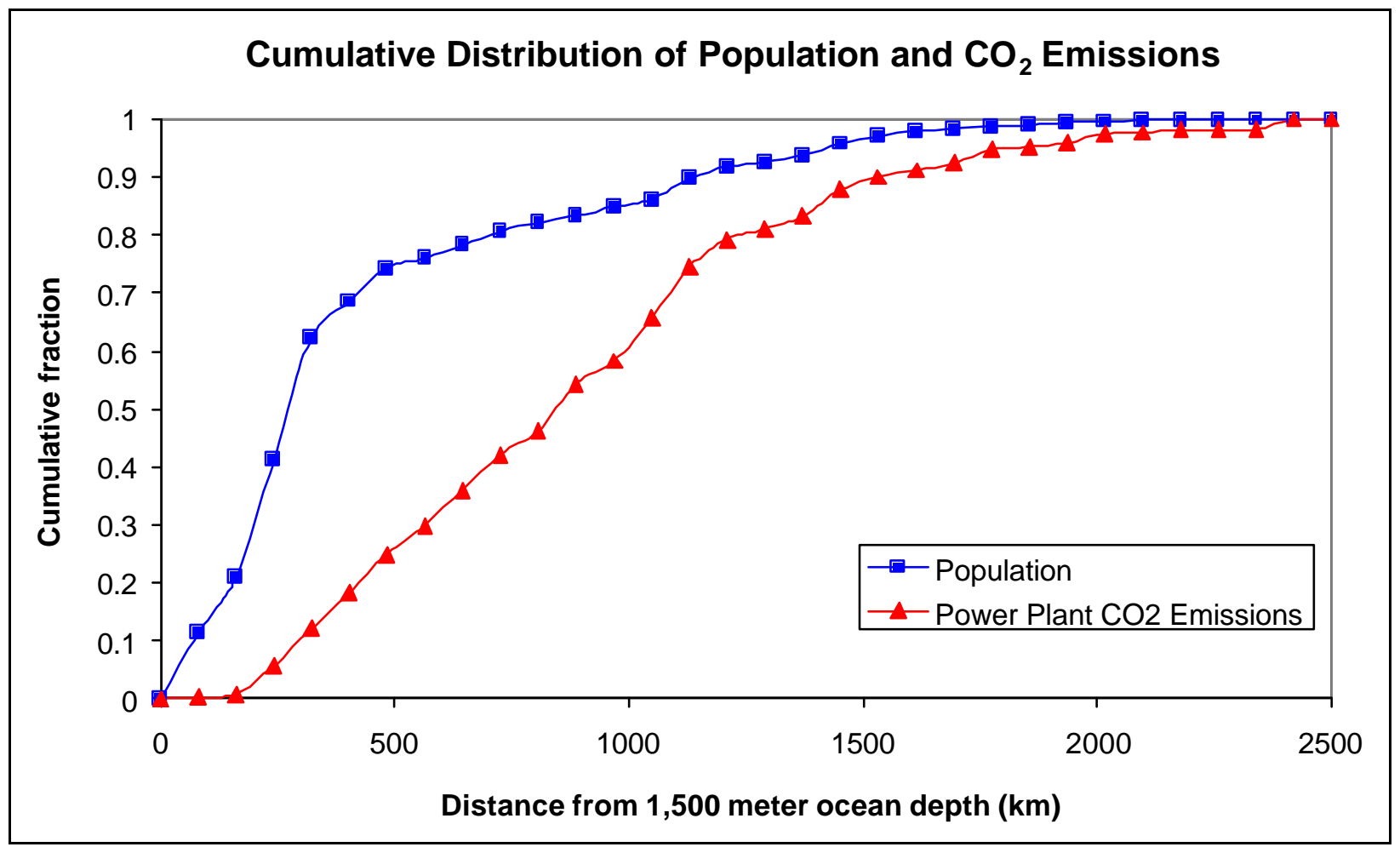

Figure 8-1

Cumulative distribution of population and power plant $\mathrm{CO}_{2}$ emissions

\subsection{Process Description}

To make a more realistic case, it is assumed that three IGCC power plants supply $\mathrm{CO}_{2}$ to a single ocean pipeline. Based on this, the ocean pipeline system needs to be designed to handle three times the quantity of $\mathrm{CO}_{2}$, i.e. 11.29 million scm (22,167 tonnes), as opposed to 3.76 million scm (7,389 tonnes) of $\mathrm{CO}_{2}$ per day. At the shoreline collection point, additional compression is needed to bring the $\mathrm{CO}_{2}$ up to the ocean pipeline's required inlet pressure of 152 bar. As a final note, it is assumed that this facility, like the power plant, has a lifetime and design/construction time of 20 and 4 years, respectively.

\subsection{Methodology Used}

The ocean pipeline storage option involves transporting the $\mathrm{CO}_{2}$ via a subsea pipeline from the shoreline to a depth of 2,000 m, at which depth the $\mathrm{CO}_{2}$ is discharged into the deep ocean via a diffuser unit. An offshore distance of $100 \mathrm{~km}$, for the base case, is considered. The method used for calculating the cost of this process can be broken down into a couple of steps. First, the diameter of the subsea pipeline is determined. It is then possible, as a second step, to calculate the capital and O\&M costs as well as the cost per tonne of $\mathrm{CO}_{2}$. These two steps are explained in greater detail below. Figure 8-2 gives an overview of the ocean pipeline cost model. 
OCEAN PIPELINE MODEL

Internal Calcs:

$\mathrm{CO}_{2}$ outlet pressure

Gravity head

Inputs:

$\mathrm{CO}_{2}$ mass flow rate

Pressure drop per unit length

Pipe diameter

Capital costs:

Injection depth

$\mathrm{CO}_{2}$ inlet pressure

Diffuser head loss

Pipeline, injector unit, boost compressor

O\&M costs:

Subsea maintenance, boost compressor

power \& maintenance

Outputs:

Total capital cost

Total O\&M cost

Total annual cost

Total cost per tonne $\mathrm{CO}_{2}$

\section{Figure 8-2 \\ Ocean pipeline cost model overview diagram}

\subsubsection{Diameter Calculation}

The pipeline diameter is calculated using the same method, described in Section 4.4.1, as is used in the $\mathrm{CO}_{2}$ overland pipeline transport model. The only difference is the means by which the maximum allowable pressure drop per unit length (?P/?L) is determined. In the case of $\mathrm{CO}_{2}$ overland pipeline transport, the pressure drop per unit length is simply found as the difference between the pipeline $\mathrm{CO}_{2}$ inlet and outlet pressures divided by the pipeline length. The pipeline ocean $\mathrm{CO}_{2}$ storage model however requires that the pressure drop per unit length calculation also take into account the gravity head gain and diffuser head loss. In addition, it is necessary that the $\mathrm{CO}_{2}$ be discharged at a pressure equal to the hydrostatic pressure.

The pipeline $\mathrm{CO}_{2}$ inlet pressure for the subsea pipeline is set at 152 bar, the same as the outlet value in the land-based cases. Given that the $\mathrm{CO}_{2}$ outlet pressure for the overland pipelines is set at 103 bar, this requires the use of booster pumps. The required pipeline outlet pressure, taken to be equal to the hydrostatic pressure of water at a depth of $2,000 \mathrm{~m}$, is calculated to be approximately 200 bar. A diffuser head loss of 20 bar is then assumed. Next, calculating the average value of $\mathrm{CO}_{2}$ specific gravity over both the 0 to $1,000 \mathrm{~m}$-depth and 1,000 to 2,000 $\mathrm{m}$ depth intervals, and adding the respective $\mathrm{CO}_{2}$ pressure head gains, gives a gravity head of 194 bar. Based on the set inlet pressure, assumed diffuser head loss and the calculated values of outlet pressure and gravity head, maximum allowable pressure drops per unit length for the base and sensitivity cases are found. Finally, the equations for pressure drop and head loss due to frictional resistance in a pipe, assuming turbulent flow, are used to determine the respective diameters. Figure 8-3 gives the calculated pipe diameter, for the base case, as a function of $\mathrm{CO}_{2}$ mass flow rate. 


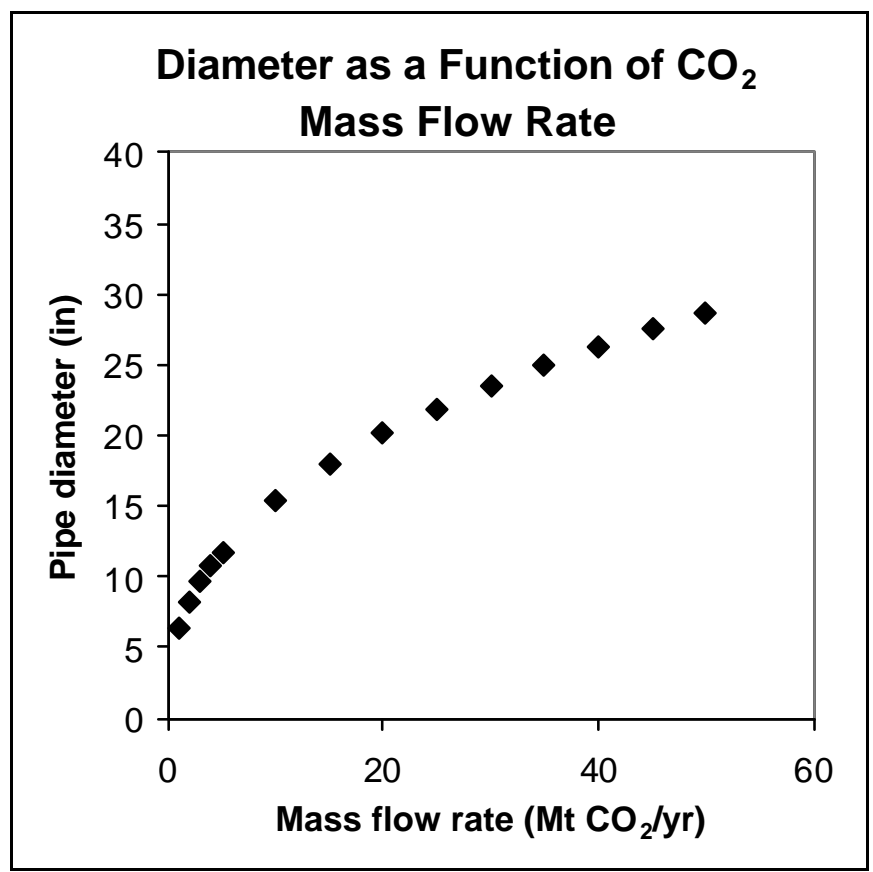

Figure 8-3

1 inch $=0.254$ meters

Diameter for the base case as a function of $\mathrm{CO}_{2}$ mass flow rate

\subsubsection{Cost Calculations}

The cost of the subsea pipeline has been determined based on cost information contained in McDermott's phase II final report on 'Large-scale $\mathrm{CO}_{2}$ Transportation and Deep Ocean Sequestration. ${ }^{3}$ Based on McDermott's total capital cost of \$3,224.5 million for six 30-inch, $500-\mathrm{km}$ long pipelines, a capital cost factor of $\$ 35,749 / \mathrm{in} / \mathrm{km}(\$ 57,659 / \mathrm{in} / \mathrm{mi})$ is calculated. The total annual O\&M cost for the six pipelines was found by McDermott to be $\$ 75,400,000$, where this excludes the cost of pump operation. ${ }^{4}$ Based on this figure, an O\&M cost factor of $\$ 25,078 / \mathrm{yr} / \mathrm{km}(\$ 40,448 / \mathrm{yr} / \mathrm{mi})$ is calculated. The capital cost of an injector unit, based on an estimate given in an IEA report, ${ }^{5}$ is taken to be $\$ 14.5$ million.

The capital and yearly maintenance costs of the boost compressor are estimated at $\$ 9,355,000$ and $\$ 432,000$, respectively. The cost of the power used by the compressor is taken to be $\$ 0.055$ per kilowatt-hour. These costs together with the costs associated with the subsea pipeline and injector unit are summarized in Table 8-1. 
Table 8-1

Capital and O\&M cost estimation factors

\begin{tabular}{|l|c|c|}
\hline Parameter & Unit & Value \\
\hline CAPITAL COSTS & $\$ / \mathrm{in} / \mathrm{km}$ & 35,749 \\
\hline Subsea Pipeline & $\$$ & $14,500,000$ \\
\hline Injector Unit & $\$$ & $9,355,000$ \\
\hline Boost Compressor & \multicolumn{2}{|}{} \\
\hline \hline O\&M COSTS & $\$ / \mathrm{y} / \mathrm{km}$ & 25,078 \\
\hline Subsea Maintenance & $\$ / \mathrm{kWh}$ & 0.055 \\
\hline Boost Compressor Power & $\$$ & 432,000 \\
\hline $\begin{array}{l}\text { Boost Compressor } \\
\text { Maintenance }\end{array}$ &
\end{tabular}

\subsection{Design Basis}

\subsubsection{Pipeline Design}

The methodology described in Section 8.4.1 was used to determine pressure drop per unit length and pipeline diameter for the base case. The design basis for ocean storage via pipeline is summarized in Table 8-2.

Table 8-2

Design basis for ocean storage via pipeline

\begin{tabular}{|l|c|c|}
\hline Parameter & Unit & $\begin{array}{c}\text { Ocean Pipeline } \\
\text { Base Case }\end{array}$ \\
\hline Subsea Pipeline Length & $\mathrm{km}$ & 100 \\
\hline Injection Depth & $\mathrm{m}$ & 2,000 \\
\hline $\mathbf{C O}_{2}$ Inlet Pressure & $\mathrm{MPa}$ & 15.2 \\
\hline $\mathbf{C O}_{2}$ Outlet Pressure${ }^{*}$ & $\mathrm{MPa}$ & 20.0 \\
\hline Gravity Head $^{*}$ & $\mathrm{MPa}$ & 19.4 \\
\hline Diffuser Head Loss $^{*}$ & $\mathrm{MPa}$ & 2.0 \\
\hline Pressure Drop per Unit Length $^{*}$ & $\mathrm{~Pa} / \mathrm{m}$ & 126 \\
\hline Pipe Diameter* $^{*}$ & inches & 14.2 \\
\hline Nominal Pipe Size $^{*}$ & inches & 16 \\
\hline
\end{tabular}

\footnotetext{
* calculated

1 inch $=0.0254$ meters
} 
The calculated nominal pipe size for the base case is 16 inches $(0.41$ meters $)$. This pipe diameter is larger than the 12 -inch diameter ( 0.30 meters) for the case of $\mathrm{CO}_{2}$ overland pipeline transport. This is despite the value of maximum allowable pressure drop per unit length also being larger. This can be explained by the fact that the design $\mathrm{CO}_{2}$ mass flow rate used here is 11.29 million $\operatorname{scm}(22,167$ tonnes) per day as opposed to 3.76 million scm (7,389 tonnes) per day.

\subsubsection{Capital and O\&M Cost Inputs}

The capital and O\&M costs of ocean storage via pipeline for the base case are calculated using the methodology described in Section 8.4.2. The results are shown in Table 8-3.

Table 8-3

Capital and O\&M cost inputs for the ocean pipeline base case

\begin{tabular}{|l|c|c|}
\hline Parameter & Unit & $\begin{array}{c}\text { Ocean Pipeline } \\
\text { Base Case }\end{array}$ \\
\hline Subsea Pipe Diameter & inches & 14.2 \\
\hline \hline Subsea Pipeline & $\$$ & $50,900,000$ \\
\hline Injector Unit & $\$$ & $14,500,000$ \\
\hline Boost Compressor & $\$$ & $9,355,000$ \\
\hline Subtotal & $\$$ & $74,755,000$ \\
\hline \hline Subsea Maintenance & $\$$ & $2,507,776$ \\
\hline $\begin{array}{l}\text { Boost Compressor } \\
\text { Power (5,650 kW) }\end{array}$ & $\$$ & $2,726,000$ \\
\hline $\begin{array}{l}\text { Boost Compressor } \\
\text { Maintenance }\end{array}$ & $\$$ & 432,000 \\
\hline Subtotal & $\$$ & $5,665,776$ \\
\hline
\end{tabular}

1 inch $=0.0254$ meters

\subsection{Model Results}

This section presents costs for $\mathrm{CO}_{2}$ capture and storage for the base case described in Section 8.5. The storage costs comprise transaction, transportation, injection and monitoring costs. These costs are combined with capture costs from an IGCC power plant. The results are given on several bases as described in Chapter 2. Appendix B provides a detailed description of each of the spreadsheets.

The Process Input sheet for the ocean pipeline base case is presented in Table 8-4. 
Table 8-4

Process input sheet for the ocean pipeline base case

Ocean Pipeline Storage Input Variables

Design Basis

IGCC Plant

Capacity Factor

Land Pipeline Distance

Land Pipeline Distance

Nominal pipe size (in)

$\mathrm{CO}_{2}$ Storage

Injection Depth $(\mathrm{m})$

Ocean Pipeline Distance

Ocean Pipeline Distance

Nominal ocean pipe size (in)

\section{Economic}

IGCC Plant (Case 3a)

$\mathrm{CO}_{2}$ Capture Cost (\$/tonne captured)

$\$ 14.55$

$\$ 55.08$

$100 \mathbf{~ k m ~ C O E ~ I n c l u d i n g ~} \mathrm{CO}_{2}$ Capture Cost $(\$ / \mathrm{MWh})$

$6.09 \%$

IGCC Plant \& $\mathrm{CO}_{2}$ Storage

After-Tax Discount Rate

$15.0 \%$

1 inch $=0.0254$ meters 
The Summary sheet for the ocean pipeline base case is presented in Table 8-5.

Table 8-5

Summary sheet for the ocean pipeline base case

\section{Ocean Pipeline Storage Summary}
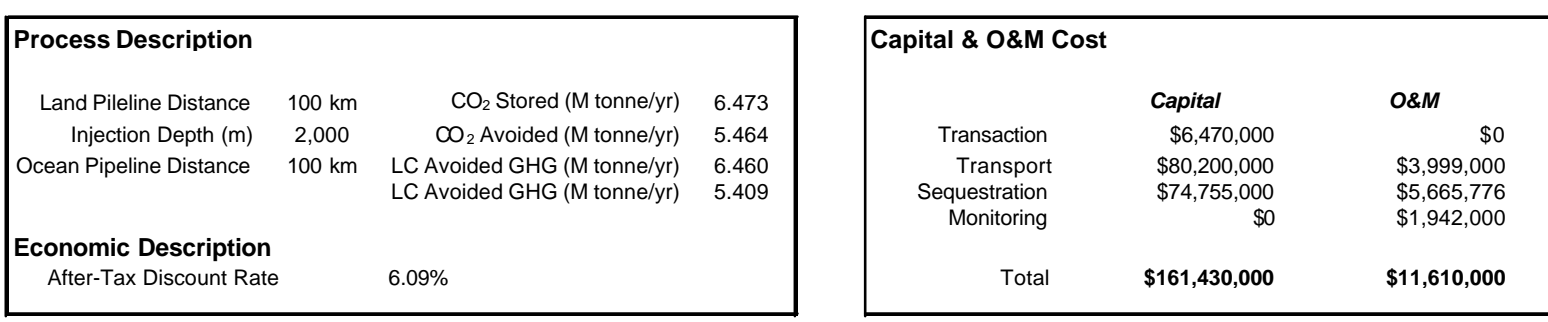

Cost of $\mathrm{CO}_{2}$ Capture \& Storage

1. Levelized Annual $\mathrm{CO}_{2}$ Storage Costs (years 1-20)

$\mathrm{CO}_{2}$ Captured Basis

$\mathrm{CO}_{2}$ Storage Cost, $\mathrm{M} \$ / \mathrm{yr}$

$\mathrm{CO}_{2}$ Stored or Avoided, M tonne/yr

Storage Cost, $\$$ /tonne $\mathrm{CO}_{2}$

2. Levelized Annual $\mathrm{CO}_{2}$ Capture and Storage Costs (years 1-20)

$\mathrm{CO}_{2}$ Capture Cost, $\mathrm{M} \$ / \mathrm{yr}$

$\mathrm{CO}_{2}$ Storage Cost, $\mathrm{M} \$ / \mathrm{yr}$

Capture + Storage Cost, $\mathrm{M} \$ / \mathrm{yr}$

$\mathrm{CO}_{2}$ Stored or Avoided, $\mathrm{M}$ tonne/yr

Capture + Storage Cost, $\$$ /tonne $\mathrm{CO}_{2}$

3. $\mathrm{CO}_{2}$ Capture and Storage Costs, NPV Basis (years 1-100)

NPV of $\mathrm{CO}_{2}$ Capture Costs, M\$

NPV of $\mathrm{CO}_{2}$ Storage Costs, M\$

NPV of Capture + Storage Costs, M\$

$\mathrm{NPV}$ of $\mathrm{CO}_{2}$ Stored or Avoided, $\mathrm{M}$ tonne

Capture + Storage Cost (NPV Basis), \$/tonne $\mathrm{CO}_{2}$

4. Cost of Electricity, $\$ / M W h$

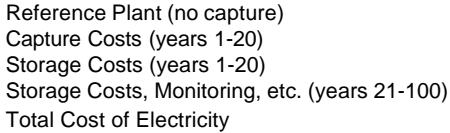

Total Cost of Electricity

$\mathrm{CO}_{2}$ Captured Basis
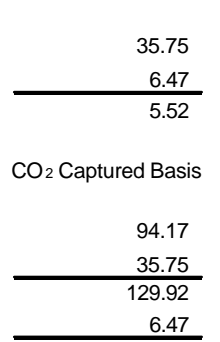

20.07

$\mathrm{CO}_{2}$ Captured Basis

$\mathrm{CO}_{2}$ Avoided Basis

LC Avoided GHG Basis
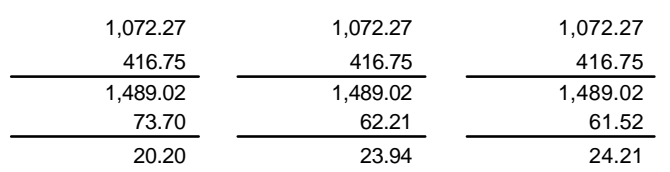

\subsection{Sensitivity Analysis}

The sensitivity of the $\mathrm{CO}_{2}$ storage cost for the ocean pipeline option is determined for offshore and pipeline distance. It can be seen in Figure 8-4 that an increase in both offshore and pipeline distance increases the storage cost. The storage cost is more sensitive to pipeline distance than offshore distance due to the fact that the ocean pipeline cost includes a fixed injector unit cost. 


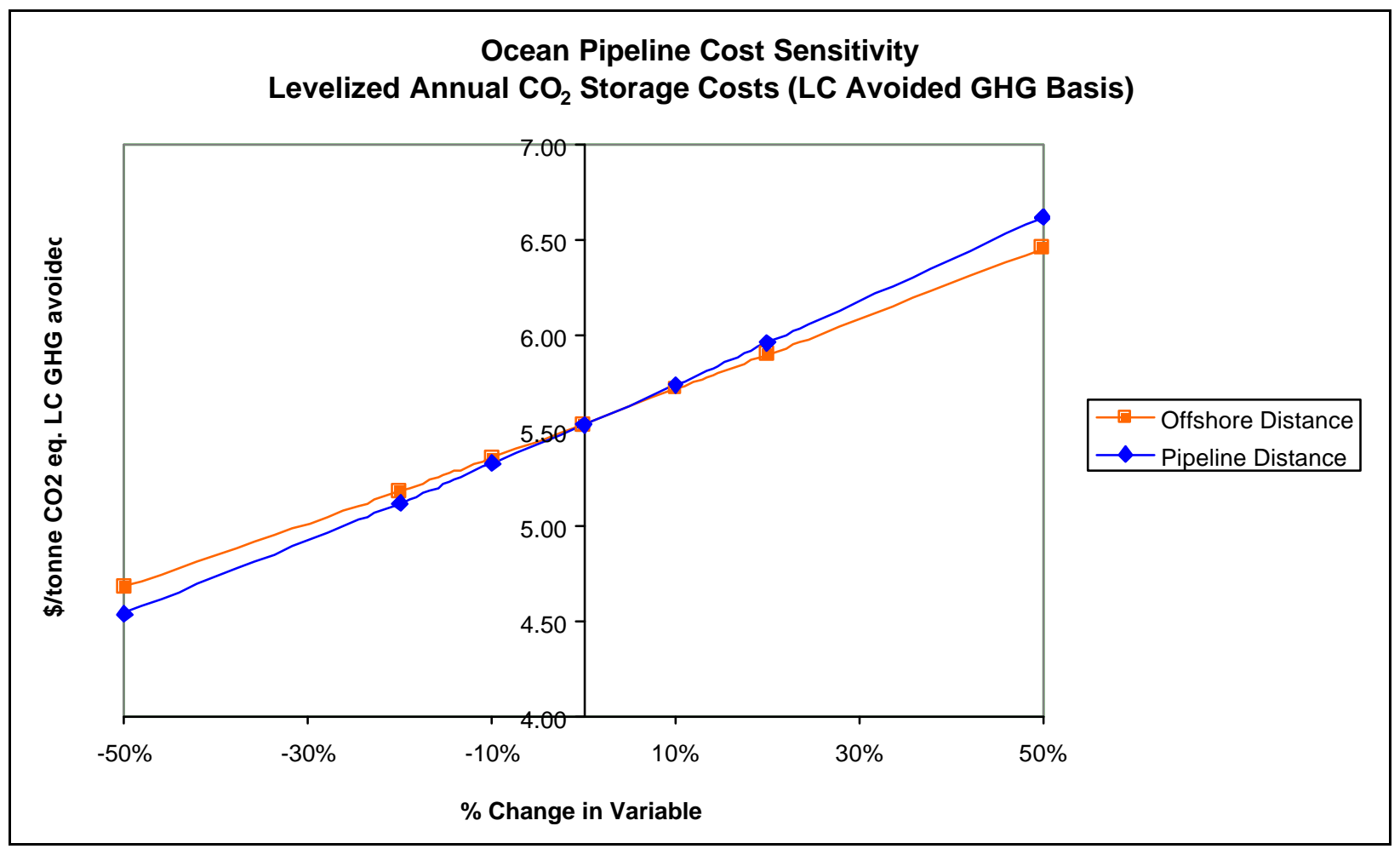

Figure 8-4

Sensitivity analysis for ocean pipeline

High and low cost cases have been chosen for the ocean pipeline option, and are presented together with the base case in Table 8-6.

Table 8-6

Ocean pipeline base, high cost and low cost cases

\begin{tabular}{|l|c|c|c|c|c|c|}
\hline Parameter & Units & $\begin{array}{c}\text { Ocean Pipeline } \\
\text { Base Case }\end{array}$ & \multicolumn{2}{|c|}{$\begin{array}{c}\text { Ocean Pipeline } \\
\text { High Cost Case }\end{array}$} & \multicolumn{2}{|c|}{$\begin{array}{c}\text { Ocean Pipeline } \\
\text { Low Cost Case }\end{array}$} \\
\hline Pipeline Distance & $\mathrm{km}$ & 100 & 300 & $+200 \%$ & 0 & $-100 \%$ \\
\hline Offshore Distance & $\mathrm{km}$ & 100 & 300 & $+200 \%$ & 50 & $-50 \%$ \\
\hline
\end{tabular}

The results for the high and low cost cases as well as the base case are given in Table 8-7. The $\mathrm{CO}_{2}$ storage cost for the ocean pipeline option differ by about a factor of 5 for the high and low cost cases. 
Table 8-7

Results for ocean pipeline base, high cost and low cost cases

\begin{tabular}{|l|c|c|c|c|}
\hline Parameter & Units & $\begin{array}{c}\text { Ocean Pipeline } \\
\text { Base Case }\end{array}$ & $\begin{array}{c}\text { Ocean Pipeline } \\
\text { High Cost Case }\end{array}$ & $\begin{array}{c}\text { Ocean Pipeline } \\
\text { Low Cost Case }\end{array}$ \\
\hline $\begin{array}{l}\text { Pressure Drop per } \\
\text { Unit Length }\end{array}$ & $\mathrm{Pa} / \mathrm{m}$ & 126 & 42 & 251 \\
\hline Pipe Diameter & inches & 14.2 & 17.5 & 12.4 \\
\hline Nominal Pipe Size & inches & 16 & 20 & 14 \\
\hline $\begin{array}{l}\text { Levelized Annual } \\
\mathrm{CO}_{2} \text { Storage Cost }\end{array}$ & $\begin{array}{l}\text { \$/tonne CO } \\
\text { Eq. LC GHG } \\
\text { avoided }\end{array}$ & 5.53 & 14.23 & 2.90 \\
\hline
\end{tabular}

1 inch $=0.0254$ meters

\subsection{Comparison to Literature}

\subsubsection{Studies Used in Model Evaluation}

The studies given in Table 8-8 all contain design and cost information for the transport of $\mathrm{CO}_{2}$ by subsea pipeline. In all cases, except the 'GEODISC' study, the pipeline is to be used for the purpose of injecting $\mathrm{CO}_{2}$ into the ocean. 'GEODISC' looks at subsea pipeline $\mathrm{CO}_{2}$ transport in the context of storing the gas in an offshore aquifer.

Table 8-8

Subsea pipelines' characteristics

\begin{tabular}{|c|c|c|c|c|c|c|}
\hline Study & $\begin{array}{c}\mathrm{CO}_{2} \text { flow } \\
\text { rate }(\mathrm{Mt} / \mathrm{y})\end{array}$ & $\begin{array}{c}\text { Initial } \mathrm{CO}_{2} \\
\text { pressure } \\
\text { (bar) }\end{array}$ & $\begin{array}{c}\text { Diamete } \\
\quad r(m)\end{array}$ & $\begin{array}{l}\text { Lengt } \\
\text { h (km) }\end{array}$ & $\begin{array}{l}\text { Injection } \\
\text { depth } \\
\text { (m) }\end{array}$ & $\begin{array}{c}\text { Recompress } \\
\text { on station } \\
\text { included }\end{array}$ \\
\hline IEA Ocean ${ }^{6}$ & 19.00 & $\begin{array}{c}74 \text { (liquid } \\
\left.\mathrm{CO}_{2}\right)\end{array}$ & 0.800 & 100 & 500 & Ignored \\
\hline British Coal ${ }^{7}$ & 3.63 & 136 & 0.350 & 517 & 2,000 & Yes \\
\hline GEODISC $^{8}$ & 5.67 & 205 & 0.660 & 200 & 100 & No \\
\hline McDermott $^{9}$ & $\begin{array}{l}200 \text { (total) } \\
33.3 \text { (each) }\end{array}$ & 130 & $\begin{array}{c}0.760(6 \\
\text { pipes) }\end{array}$ & 500 & 3,000 & Yes \\
\hline UMass $^{10}$ & 8.20 & 140 & 0.600 & 200 & 1,000 & No \\
\hline
\end{tabular}

It should be noted that in the 'McDermott' study there is a large quantity of $\mathrm{CO}_{2}$, taken to be the emissions from forty $500 \mathrm{MW}_{\mathrm{e}}$ coal-burning power stations, being injected into the ocean. This large quantity of $\mathrm{CO}_{2}, 200 \mathrm{Mt} / \mathrm{y}$, is determined in the study to require the use of one 
1.63-m-diameter pipe or six 0.760-m-diameter pipes. For purposes of making a diameter comparison with the model, taking into account its inability to allow for bundling, one $0.760 \mathrm{~m}$ diameter pipe carrying $33.3 \mathrm{Mt} / \mathrm{yr}$ of $\mathrm{CO}_{2}$ is assumed. It should be noted that a cost comparison is not made with the 'McDermott' study due to the fact that this study was used as a basis for costing.

The 'GEODISC' and 'IEA ocean' studies require the installation of a subsea pipeline up to a maximum depth of 100 and $500 \mathrm{~m}$, respectively. The installation of these pipelines, at these relatively shallow depths, requires only the use of a 'S-lay' barge and does, as such, lie within the capabilities of existing technology. However, in the case of the 'UMass', 'British Coal,' and 'McDermott' studies, which require pipeline installation at depths of 1000, 2000, and $3000 \mathrm{~m}$, respectively, a combination of ' $\mathrm{S}$-lay' and ' $\mathrm{J}$-lay' techniques is needed. In addition, in the case of 'British Coal', as for 'McDermott,' modifications to the existing 'J-lay' barge would be necessary. As this upgrade would only be a one-time cost, it is not included in the cost analysis.

The 'British Coal' study, like 'McDermott', requires a shore-based pumping station to transport the $\mathrm{CO}_{2}$ a long distance. The cost of this pumping station is not included in the total cost of the scheme, calculated for the purpose of comparing the study value with the model output. The requirement of a pumping station in the 'IEA Ocean' study is ignored as this study deals with liquid, not supercritical, $\mathrm{CO}_{2}$.

\subsubsection{Comparison of Values from Model and Studies}

The graph below in Figure 8-4 shows pipe diameter as a function of $\mathrm{CO}_{2}$ mass flow rate. Also shown in the figure is the value of pipe diameter given in each of the five studies.

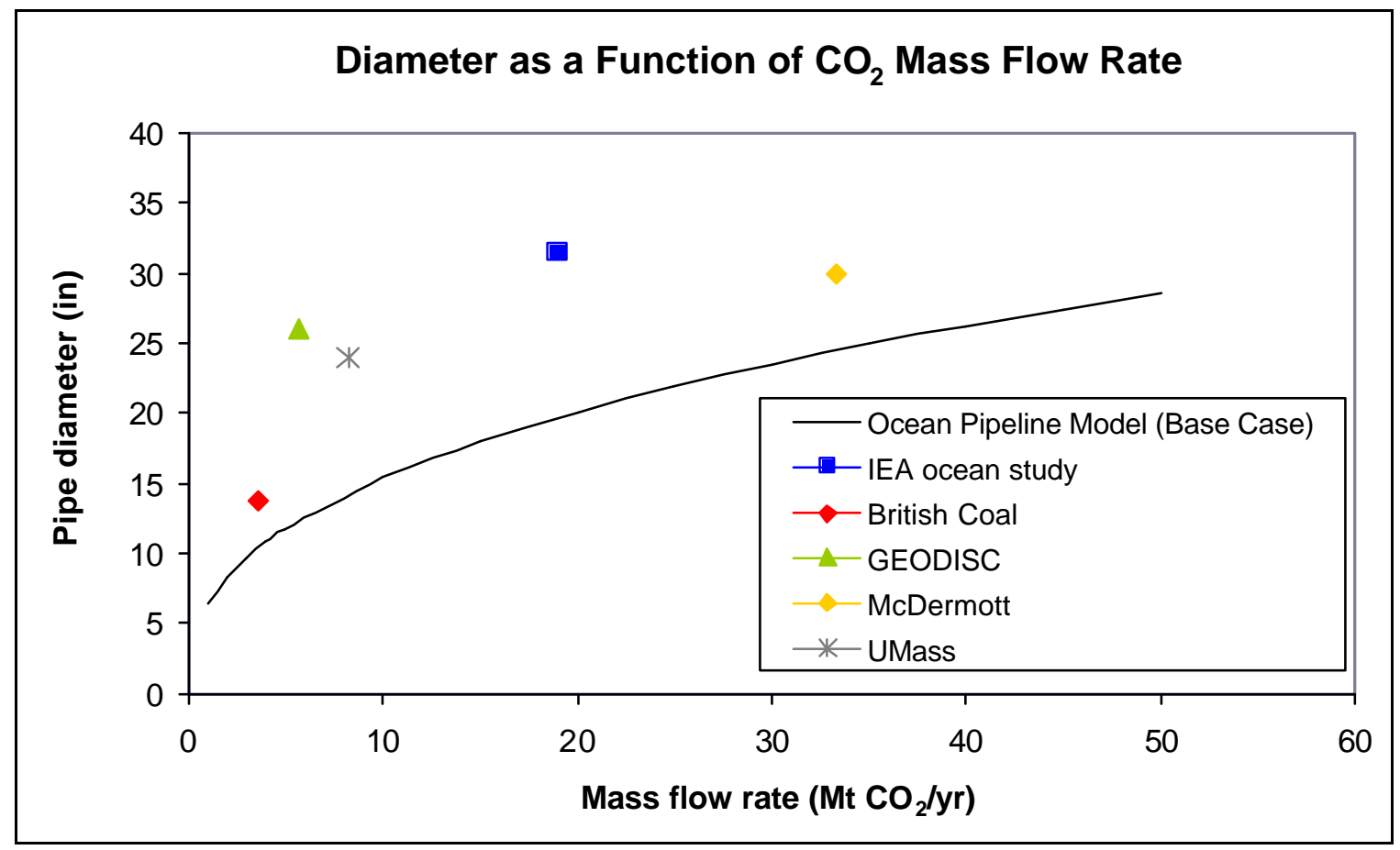


Figure 8-4

Comparison of pipe diameter values

Figure 8-5 shows the capital cost of the subsea pipeline as calculated by the model, where this excludes the cost of the boost compressor and transaction costs, as a function of $\mathrm{CO}_{2}$ mass flow rate. As for pipe diameter, the capital cost values given in the studies are reasonably close to those calculated by the model considering the uncertainties in the data.

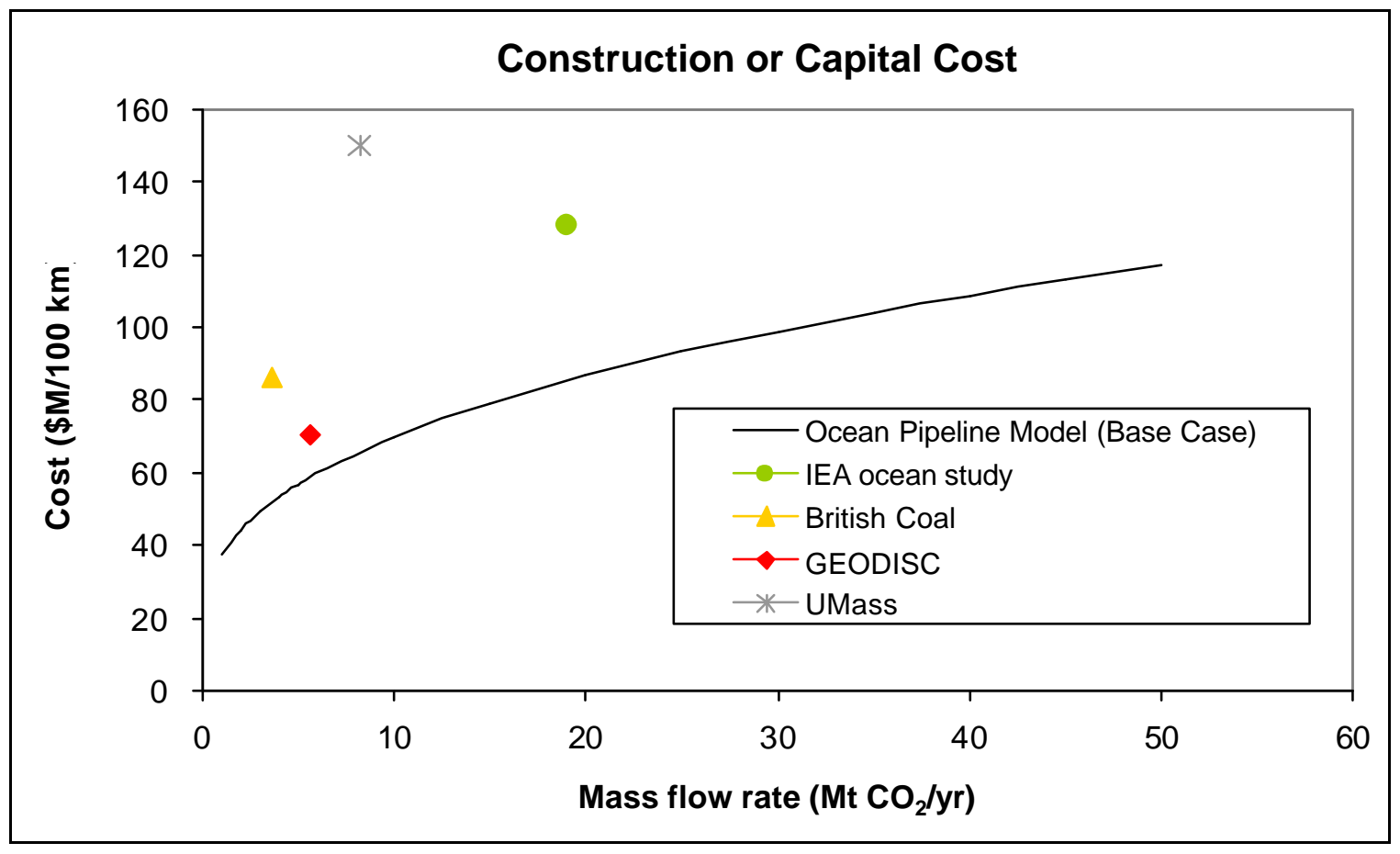

Figure 8-5

Comparison of subsea pipeline capital cost values 


\subsection{References}

1 Herzog, H., "Ocean Sequestration of $\mathrm{CO}_{2}$ : An Overview," presented at the Fourth International Conference on Greenhouse Gas Control Technologies, Interlaken, Switzerland, August 30-September 2, 1998.

2 "Carbon Sequestration Research and Development," Chapter 3, Ocean Sequestration, http://www.fe.doe.gov/coal_power/sequestration/reports/rd/chap5.pdf

3 Sarv, $\mathrm{H}$., "Large-scale $\mathrm{CO}_{2}$ transportation and deep ocean sequestration - Phase II final report,” McDermott Technology Inc., Ohio. Tech. Rep. DE-AC26-98FT40412, 2001.

4 Sarv, H., e-mail communication, Jan. 14, 2002.

5 Ormerod, B., "The disposal of carbon dioxide from fossil fuel fired power stations," IEA Greenhouse R\&D Programme, Cheltenham. Tech. Rep. IEAGHG/SR3, Jun. 1994.

6 Ormerod, W., "The disposal of carbon dioxide from fossil fuel fired power stations," IEA Greenhouse R\&D Programme, Cheltenham. Tech. Rep. IEAGHG/SR3, Jun. 1994.

7 Summerfield, I.R., S.H. Goldthorpe, N. Williams and A. Sheikh, "Costs of $\mathrm{CO}_{2}$ disposal options," Energy Convers. Mgmt, vol. 34, no. 9-11, pp. 1105-1112, 1993.

8 Allinson, G. and V. Nguyen, "The economics of $\mathrm{CO}_{2}$ sequestration in Australia," presented at Fifth International Conference on Greenhouse Gas Control Technologies Cairns, Australia, 2000.

9 Sarv, H., "Large-scale $\mathrm{CO}_{2}$ transportation and deep ocean sequestration," McDermott Technology Inc., Ohio. Tech. Rep. DE-AC26-98FT40412, Mar. 1999.

10 Golomb, D., "Transport systems for ocean disposal of $\mathrm{CO}_{2}$ and their environmental effects," Energy Convers. Mgmt, vol. 38, suppl., pp. 279-286, 1997. 


\section{9 \\ OCEAN VIA TANKER}

\subsection{Introduction}

The ocean storage via tanker option involves transporting the $\mathrm{CO}_{2}$ by refrigerated tanker from a port facility to an offshore floating platform, where the $\mathrm{CO}_{2}$ is injected into the deep ocean through a vertical pipe.

\subsection{State of the Art}

To date, there have been no commercial or pilot-scale applications of this ocean storage option. The use of tankers to transport $\mathrm{CO}_{2}$ to an offshore floating platform is however within the current state of technology. All that is required is that existing floating platforms and so-called 'semirefrigerated' tankers that transport pressurized liquid chemicals, such as ammonia and liquid natural gas, be adapted for the purpose. ${ }^{1}$

Ocean storage via tanker would only be desirable where $\mathrm{CO}_{2}$ was to be injected into the deep ocean at a great distance, say $800 \mathrm{~km}$, from the shoreline, in which case it would be more economical than the subsea pipeline option. It does also have the advantage that it would allow for easy relocation of the injection site.

\subsection{Process Description}

It is assumed, as in the case of ocean storage via pipeline, that three IGCC power plants supply $\mathrm{CO}_{2}$ to the shoreline collection point. Based on this, the ocean tanker system needs to be designed to handle three times the quantity of $\mathrm{CO}_{2}$, i.e., 11.29 million scm (22,167 tonnes), as opposed to 3.76 million scm (7,389 tonnes) of $\mathrm{CO}_{2}$ per day. As a final note, it is assumed that this facility, like the power plant, has a lifetime and design/construction time of 20 and 4 years, respectively.

\subsection{Methodology Used}

The storage option has been modeled based on design and cost information obtained from McDermott's Phase I and Phase II final reports on 'Large-scale $\mathrm{CO}_{2}$ Transportation and Deep Ocean Sequestration' ${ }^{1,2}$ as well as e-mail communications with the reports' author. ${ }^{3,4}$ The method used for a conceptual design of this process can be broken down into a number of steps. First, the number of tankers required to transport the $\mathrm{CO}_{2}$ to the offshore platform is determined. Second, the diameter of the vertical pipe to carry the $\mathrm{CO}_{2}$ from the platform to the injection 
depth is calculated. Third, the amount of $\mathrm{CO}_{2}$ emitted by the tankers traveling to and from the offshore storage site, and emitted due to boil off, is found. It is then possible, as a final step, to calculate the capital cost of the tankers, port facility, offshore floating platform, and vertical pipe, and the non-fuel and fuel O\&M costs as well as the cost per tonne of $\mathrm{CO}_{2}$. These steps are described in greater detail below. An overview of the ocean tanker cost model is given in Figure 9-1.

\subsubsection{Tanker Number Calculation}

The number of tankers required is determined based on the use of tankers able to carry $22,000 \mathrm{~m}^{3}$ of $\mathrm{CO}_{2}$ at $7 \mathrm{bar}$ and minus $50^{\circ} \mathrm{C}$. A tanker of this description is, according to McDermott, within the current state of shipbuilding technology. The aforementioned temperature and pressure properties of $\mathrm{CO}_{2}$ give a $\mathrm{CO}_{2}$ density of $1155 \mathrm{~kg} \mathrm{per} \mathrm{m}{ }^{3}$ and a tanker capacity, in terms of weight, of 25,410 tonnes of $\mathrm{CO}_{2}$. Given this latter tanker $\mathrm{CO}_{2}$ capacity, it is found from the design $\mathrm{CO}_{2}$ flow rate of 22,167 tonnes per day that the loading time for each tanker will be approximately 27.5 hours. The unloading time, which unlike the loading time is not dependent on the $\mathrm{CO}_{2}$ flow rate from the plant, is taken to be about six hours. Assuming a tanker speed of $33 \mathrm{~km}$ per hour, it is then possible to calculate the time taken for a round trip and the amount of time for which a tanker is not at the $\mathrm{CO}_{2}$ collection point. Finally, this calculated value of time not at the collection point enables the number of tankers required to be en route at any given time to be determined. For the base case, it is found that two tankers would be needed. An additional tanker is, however, added, bringing the total number required to three, to allow for tanker downtime.

\subsubsection{Vertical Pipe Diameter Calculation}

The same method as is used for pipe sizing in the subsea pipeline ocean $\mathrm{CO}_{2}$ storage model, described in Section 8.4.1, is used to calculate the diameter of the vertical pipe. The required pipe outlet pressure, taken to be equal to the hydrostatic pressure of water at a depth of 2,000 m, is calculated to be approximately 200 bar. Next, calculating the average value of $\mathrm{CO}_{2}$ specific gravity over both the 0 to 1,000 -m-depth and 1,000- to 2,000-m-depth intervals, and adding the respective $\mathrm{CO}_{2}$ pressure head gains, gives the gravity head. Based on the set inlet pressure of 152 bar and these calculated values of outlet pressure and gravity head, a maximum allowable pressure drop per unit length of 7,281 Pa per $\mathrm{m}$ is then found. Finally, the diameter is determined from the equations for pressure drop and head loss due to frictional resistance in the pipe, assuming turbulent flow. For the base case, a nominal 8-inch-diameter vertical pipe is required. 


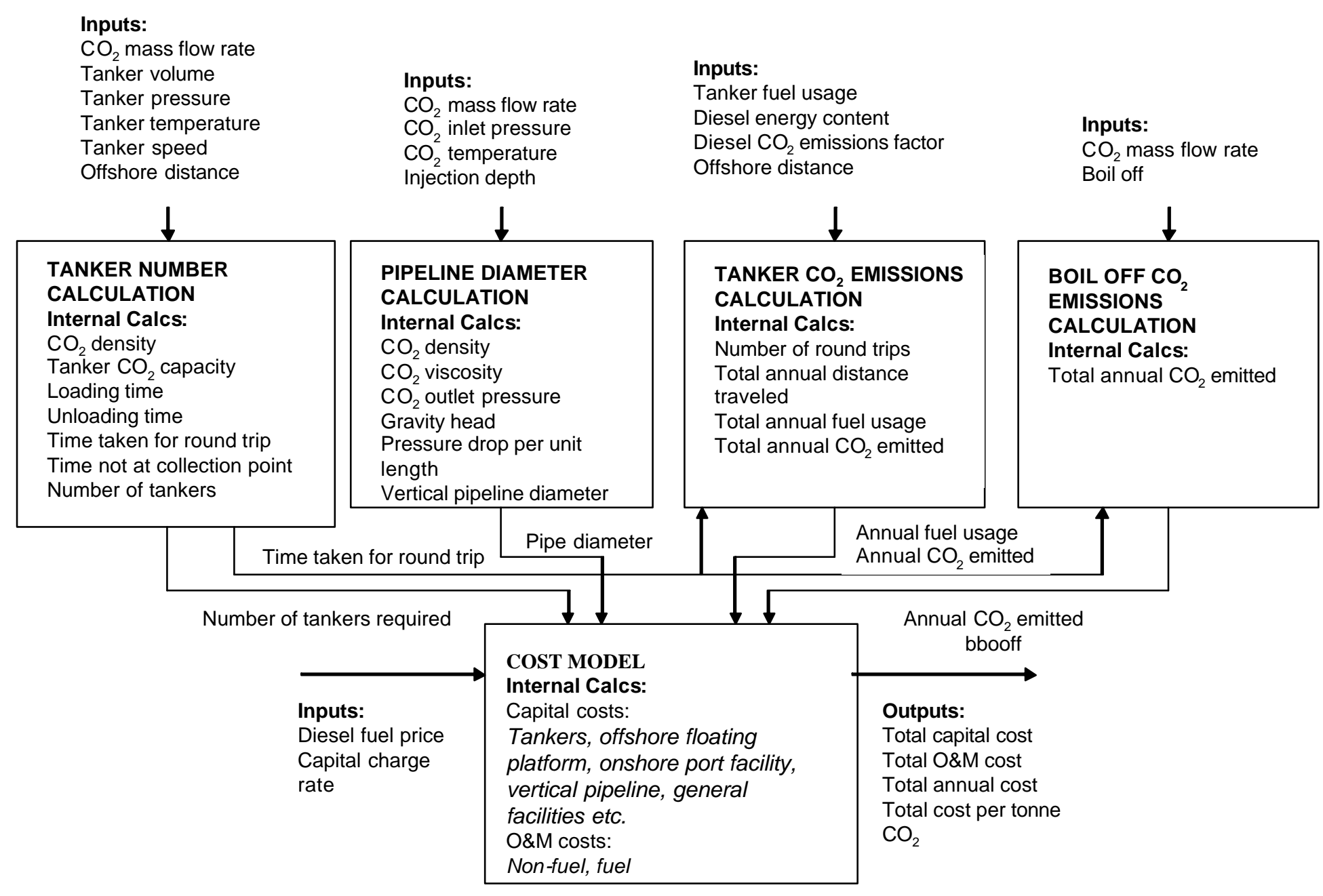

Figure 9-1

Ocean tanker cost model overview diagram 


\subsection{3 $\mathrm{CO}_{2}$ Emissions Calculations}

The quantity of $\mathrm{CO}_{2}$ to be emitted by the tankers needs to be determined. This requires that the quantity of fuel used by a $22,000 \mathrm{~m}^{3}$-tanker, in terms of gallons per $\mathrm{km}$, first be calculated. In order to do this, it was necessary to refer to the small tanker case study given in the McDermott reports. In this case study, the total capital cost of the required $3822,000-\mathrm{m}^{3}$ tankers is $\$ 2,100$ million. According to Hamid Sarv of McDermott, the annual tanker O\&M cost was estimated as being equal to 5.6 percent of the tanker capital cost, of which the tanker fuel cost comprised 16.5 percent. Based on these percentages, the tanker fuel cost is equal to $\$ 19.4$ million per year. Given that the price of diesel fuel is about $\$ 0.566$ per gallon ${ }^{4}$, the total annual quantity of fuel used by the tankers is found to be approximately 34.3 million gallons. The corresponding total annual distance traveled by the tankers is calculated to be 8.76 million $\mathrm{km}$. Dividing the total annual distance traveled by the total annual fuel used, gives a tanker fuel usage of 3.91 gallons per $\mathrm{km}$.

Given this calculated value of tanker fuel usage, it is possible to determine the $\mathrm{CO}_{2}$ emitted by the tankers. Diesel fuel has an energy content of around 137 million joule per gallon and a $\mathrm{CO}_{2}$ emissions factor of close to 70 milligrams per joule. Given that the fuel used by a tanker is 3.91 gallons per $\mathrm{km}$, the amount of $\mathrm{CO}_{2}$ emitted by a tanker per $\mathrm{km}$ traveled can be found to be 37,614 grams. The total annual distance traveled is calculated by multiplying the total number of round trips per year, equal to the number of hours in a year divided by the loading time of 27.5 hours, by the respective round-trip distance. The total distance traveled by the tankers is found to be $63,683 \mathrm{~km}$. Multiplying the amount of $\mathrm{CO}_{2}$ emitted per $\mathrm{km}$ by the total annual distance traveled gives a total annual amount of $\mathrm{CO}_{2}$ emitted of 2,395 tonnes.

The amount of $\mathrm{CO}_{2}$ emitted due to boil off is estimated as one percent per day of the amount of $\mathrm{CO}_{2}$ transported by tanker based on industry experience with $\mathrm{CO}_{2}$ truck tankers. It is important to note that the calculation assumes that the $\mathrm{CO}_{2}$ is in the tanker, and therefore undergoing boil off, for only one half the number of hours taken for a round trip. This $\mathrm{CO}_{2}$ quantity is then multiplied by 365 days to give the amount of $\mathrm{CO}_{2}$ emitted per year. The annual quantity of $\mathrm{CO}_{2}$ emitted is calculated to be 53,362 tonnes.

\subsubsection{Cost Calculations}

The total capital cost of the tanker ocean $\mathrm{CO}_{2}$ storage option comprises the capital cost of the three required tankers, the offshore floating platform, the port facility, and a 2,000-m long, 8inch diameter ( 0.20 meter) vertical pipe. The capital cost of the tankers is found using McDermott's cost estimate of $\$ 55.3$ million for a single 22,000- $\mathrm{m}^{3}$ tanker. For the offshore floating platform, the capital cost of \$200 million also given in the McDermott report is used. In the case of the port facility, for which no cost estimate was provided, a capital cost of $\$ 50$ million is assumed. Next, based on cost data in the report, the capital cost of the vertical pipe is calculated. The vertical pipe's capital cost is taken to include $\$ 351,445 / \mathrm{in} / \mathrm{km}$ $(\$ 566,847 / \mathrm{in} / \mathrm{mi})$ for pipe marshalling and the attaching of buoys and corrosion anodes, a $\$ 0.3$ million cost for towing the pipe to the offshore structure and a $\$ 3$ million cost for pipe upending, securing, and anchoring. Finally, a 30 percent surcharge is added to all capital 
expenses to cover costs associated with general facilities, engineering, permitting, and contingencies.

The total O\&M cost is calculated as the sum of the non-fuel and fuel O\&M costs. From e-mail communications with Hamid Sarv ${ }^{3,4}$, it was learned that the total annual O\&M cost in the case studies was estimated as the sum of 5.6 percent and 0.02 percent of the total tanker and non-tanker capital costs, respectively, where the fuel cost comprised 16.5 percent of the tanker O\&M cost. The non-fuel O\&M cost is calculated in the model as 4.7 percent of the total tanker capital cost, thus excluding the fuel cost, plus 0.02 percent of the total non-tanker capital costs. The fuel O\&M cost is determined as the product of the total annual fuel usage, found from multiplying the tanker fuel usage by the total annual distance traveled, and a diesel fuel price of $\$ 0.566$ per gallon.

The capital and O\&M cost estimation factors are summarized in Table 9-1.

Table 9-1

Capital and O\&M cost estimation factors

\begin{tabular}{|c|c|c|}
\hline Parameter & Unit & Value \\
\hline \multicolumn{3}{|l|}{ CAPITAL COSTS } \\
\hline Tanker & $\$ /$ tanker & $55,263,000$ \\
\hline Offshore Platform & $\$$ & $200,000,000$ \\
\hline Onshore Port Facility & $\$$ & $50,000,000$ \\
\hline \multicolumn{3}{|l|}{ Vertical Pipeline: } \\
\hline Construction & $\$ / \mathrm{in} / \mathrm{km}$ & 351,445 \\
\hline Towing to Offshore Structure & $\$$ & 300,000 \\
\hline Upending, Securing \& Anchoring & $\$$ & $3,000,000$ \\
\hline $\begin{array}{l}\text { General Facilities, } \\
\text { Engineering, Permitting etc. }\end{array}$ & $\$$ & $\begin{array}{l}\text { 0.3*(Tanker_capital_cost }+ \\
\text { Offshore_platform_capital_cost }+ \\
\text { Onshore_port_facility_capital_cost }+ \\
\text { Vertical_pipeline_capital_cost) }\end{array}$ \\
\hline \multicolumn{3}{|l|}{ O\&M COSTS } \\
\hline Non-fuel & $\$ / y r$ & $\begin{array}{l}\left.\text { (Tanker_capital_cost }{ }^{\star} 0.047\right)+ \\
\text { ((Offshore_platform_capital_cost + } \\
\text { Onshore_port_facility_capital_cost }+ \\
\left.\text { Vertical_pipeline_capital_cost })^{\star} 0.02\right)\end{array}$ \\
\hline Fuel & $\$ /$ gal & 0.566 \\
\hline
\end{tabular}

1 inch $=0.0254$ meters 


\subsection{Design Basis}

\subsubsection{System Design}

The methodology described in Section 9.4.1 through Section 9.4.3 was used to calculate the required number of tankers, the diameter of the vertical pipeline, and the $\mathrm{CO}_{2}$ emissions from the tankers and due to boil off. Table 9-2 shows the results.

Table 9-2

Design basis for ocean storage via tanker

\begin{tabular}{|c|c|c|}
\hline Parameter & Unit & $\begin{array}{c}\text { Ocean Tanker } \\
\text { Base Case }\end{array}$ \\
\hline Offshore Distance & $\mathrm{km}$ & 100 \\
\hline Injection Depth & $\mathrm{m}$ & 2,000 \\
\hline Tanker Volume & $\mathrm{m}^{3}$ & 22,000 \\
\hline Tanker Pressure & bar & 7 \\
\hline Tanker Temperature & $\operatorname{deg} C$ & -50 \\
\hline Tanker $\mathrm{CO}_{2}$ Capacity & $\mathrm{kg} / \mathrm{m}^{3}$ & 25,410 \\
\hline Loading Time & $\mathrm{h}$ & 27.5 \\
\hline Unloading Time & $\mathrm{h}$ & 6 \\
\hline Tanker Speed & $\mathrm{km} / \mathrm{h}$ & 33 \\
\hline Time Taken for Round Trip & $\mathrm{h}$ & 39.6 \\
\hline Number of Tankers & & 3 \\
\hline Vertical Pipe Inlet Pressure & $\mathrm{MPa}$ & 15.2 \\
\hline Vertical Pipe Outlet Pressure & $\mathrm{MPa}$ & 20.0 \\
\hline Gravity Head & $\mathrm{MPa}$ & 19.4 \\
\hline $\begin{array}{l}\text { Pressure Drop per Unit } \\
\text { Length }\end{array}$ & $\mathrm{Pa} / \mathrm{m}$ & 7,281 \\
\hline Vertical Pipe Diameter & inches & 6.5 \\
\hline Nominal Vertical Pipe Size & inches & 8 \\
\hline Tanker Fuel Usage & $\mathrm{gal} / \mathrm{km}$ & 3.91 \\
\hline Diesel Energy Content & million joule/gal & 137 \\
\hline Diesel $\mathrm{CO}_{2}$ Emissions Factor & $\mathrm{mg} /$ joule & 70 \\
\hline $\begin{array}{l}\text { Total Annual Distance } \\
\text { Traveled }\end{array}$ & $\mathrm{km} / \mathrm{y}$ & 63,683 \\
\hline Total Annual Fuel Usage & $\mathrm{gal} / \mathrm{y}$ & 249,001 \\
\hline $\mathrm{CO}_{2}$ Emitted by Tankers & $t / y$ & 2,395 \\
\hline Boil Off & $\% / d$ & 1 \\
\hline $\mathrm{CO}_{2}$ Emitted by Boil Off & $t / y$ & 53,362 \\
\hline
\end{tabular}

1 inch $=0.0254$ meters, 1 gal $=3.79$ liters 


\subsubsection{Capital and O\&M Cost Inputs}

The capital and O\&M costs of ocean storage via tanker for the base case were calculated using the methodology described in Section 9.4.4. The results are shown in Table 9-3.

Table 9-3

Capital and O\&M cost inputs for the ocean tanker base case

\begin{tabular}{|c|c|c|}
\hline Parameter & Unit & $\begin{array}{c}\text { Ocean Tanker } \\
\text { Base Case }\end{array}$ \\
\hline Number of Tankers & & 3 \\
\hline Vertical Pipeline Diameter & inches & 6.5 \\
\hline Total Annual Fuel Usage & $\mathrm{gal} / \mathrm{y}$ & 249,001 \\
\hline \multicolumn{3}{|l|}{ CAPITAL COSTS } \\
\hline Tanker & $\$$ & $166,000,000$ \\
\hline Offshore Floating Platform & $\$$ & $200,000,000$ \\
\hline Onshore Port Facility & $\$$ & $50,000,000$ \\
\hline \multicolumn{3}{|l|}{ Vertical Pipeline: } \\
\hline Construction & $\$$ & $4,580,000$ \\
\hline Towing to Offshore Structure & $\$$ & 300,000 \\
\hline $\begin{array}{l}\text { Upending, Securing \& } \\
\text { Anchoring }\end{array}$ & $\$$ & $3,000,000$ \\
\hline $\begin{array}{l}\text { General Facilities, } \\
\text { Engineering, Permitting etc. }\end{array}$ & $\$$ & $127,000,000$ \\
\hline Subtotal & $\$$ & $550,880,000$ \\
\hline \multicolumn{3}{|l|}{ O\&M COSTS } \\
\hline Non-fuel & $\$$ & $12,900,000$ \\
\hline Fuel & $\$$ & 140,935 \\
\hline Subtotal & $\$$ & $13,040,935$ \\
\hline
\end{tabular}

1 inch $=0.0254$ meters

\subsection{Model Results}

This section presents costs for $\mathrm{CO}_{2}$ capture and storage for the base case described in Section 9.5. The storage costs comprise transaction, transportation, injection and monitoring costs. These costs are combined with capture costs from an IGCC power plant. The results are given on several bases as described in Chapter 2. Appendix B provides a detailed description of these spreadsheets. 
The Process Input sheet for the ocean tanker base case is presented in Table 9-4.

Table 9-4

Process input sheet for the ocean tanker base case

\section{Ocean Tanker Storage Input Variables}

\begin{tabular}{|c|c|}
\hline \multicolumn{2}{|l|}{$\begin{array}{l}\text { Design Basis } \\
\text { IGCC Plant }\end{array}$} \\
\hline $\begin{array}{l}\text { Capacity Factor } \\
\text { Pipeline Distance }\end{array}$ & $\begin{array}{r}80 \% \\
100 \mathrm{~km}\end{array}$ \\
\hline $\begin{array}{l}\text { Pipeline Distance } \\
\text { Nominal pipe size (in) }\end{array}$ & $\begin{array}{r}62 \text { miles } \\
12\end{array}$ \\
\hline $\mathrm{CO}_{2}$ Storage & \\
\hline Injection Depth (m) & 2000 \\
\hline Offshore Distance & $100 \mathrm{~km}$ \\
\hline Offshore Distance & 62 miles \\
\hline Tanker $\mathrm{CO}_{2}$ boil off rate (\%/day) & $1.0 \%$ \\
\hline $\begin{array}{l}\text { Nominal vertical pipe size (in) } \\
\text { Number of tankers needed }\end{array}$ & $\begin{array}{l}8 \\
3\end{array}$ \\
\hline
\end{tabular}

\begin{tabular}{|lr|}
\hline Economic & \\
IGCC Plant (Case 3a) & \\
$\mathrm{CO}_{2}$ Capture Cost (\$/tonne captured) & $\$ 14.55$ \\
$\mathrm{COE}$ Including $\mathrm{CO}_{2}$ Capture Cost $(\$ / \mathrm{MWh})$ & $\$ 55.08$ \\
IGCC Plant \& $\mathrm{CO}_{2}$ Storage & \\
After-Tax Discount Rate & \\
Levelized Carrying Charge Factor & \\
& \\
& \\
\end{tabular}


The Summary sheet for the ocean tanker base case is presented in Table 9-5.

Table 9-5

Summary sheet for the ocean tanker base case

\section{Ocean Tanker Storage Summary}

\begin{tabular}{|lcrr}
\hline Process Description & & & \\
& & & \\
Pileline Distance & $100 \mathrm{~km}$ & $\mathrm{CO}_{2}$ Stored (M tonne/yr) & 6.473 \\
Injection Depth (m) & 2,000 & $\mathrm{CO}_{2}$ Avoided (M tonne/yr) & 5.411 \\
Offshore Distance & $100 \mathrm{~km}$ & LC Avoided GHG (M tonne/yr) & 6.408 \\
& & LC Avoided GHG (M tonne/yr) & 5.358 \\
& & \\
Economic Description & $6.09 \%$ & \\
After-Tax Discount Rate & &
\end{tabular}

Cost of $\mathrm{CO}_{2}$ Capture \& Storage

1. Levelized Annual $\mathrm{CO}_{2}$ Storage Costs (years 1-20)

$$
\begin{array}{r}
\mathrm{CO}_{2} \text { Captured Basis } \\
113.03 \\
6.47 \\
\hline 17.46
\end{array}
$$

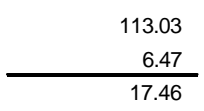

$\mathrm{CO}_{2}$ Storage Cost, $\mathrm{M} \$ / \mathrm{yr}$

$\mathrm{CO}_{2}$ Stored or Avoided, $\mathrm{M}$ tonne/yr

Storage Cost, $\$ /$ tonne $\mathrm{CO}_{2}$

2. Levelized Annual $\mathrm{CO}_{2}$ Capture and Storage Costs (years 1-20)

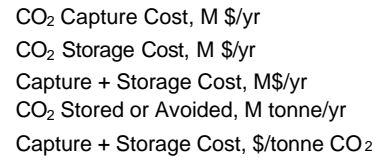

3. $\mathrm{CO}_{2}$ Capture and Storage Costs, NPV Basis (years 1-100)

NPV of $\mathrm{CO}_{2}$ Capture Costs, M\$

$\mathrm{NPV}$ of $\mathrm{CO}_{2}$ Storage Costs, M\$

NPV of Capture + Storage Costs, M\$

$\mathrm{NPV}$ of $\mathrm{CO}_{2}$ Stored or Avoided, M tonne

Capture + Storage Cost (NPV Basis), $\$ /$ tonne $\mathrm{CO}_{2}$

$\mathrm{CO}_{2}$ Captured Basis

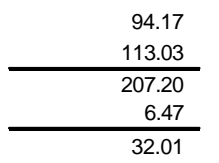

$\mathrm{CO}_{2}$ Captured Basis

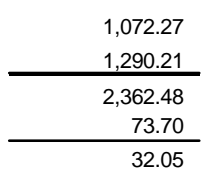

$\mathrm{CO}_{2}$ Avoided Basis

LC Avoided GHG Basis

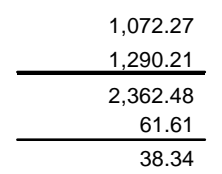

$1,072.27$

$1,290.21$

$2,362.48$

60.93

4. Cost of Electricity, $\$ / M W h$

$\begin{array}{lr}\text { Reference Plant (no capture) } & 43.98 \\ \text { Capture Costs (years 1-20) } & 11.10 \\ \text { Storage Costs (years 1-20) } & 13.32 \\ \text { Storage Costs, Monitoring, etc. (years 21-100) } & 0.03 \\ \text { Total Cost of Electricity } & 68.44\end{array}$




\subsection{Sensitivity Analysis}

The sensitivity of the $\mathrm{CO}_{2}$ storage cost for the ocean tanker option is determined for four key parameters: pipeline and offshore distance, boil off and diesel price. It can be seen in Figure 9-2 that increases in pipeline and offshore distance, boil off and diesel price all increase the storage cost. More noteworthy, the figure shows that changes in pipeline distance have the greatest effect on storage cost.

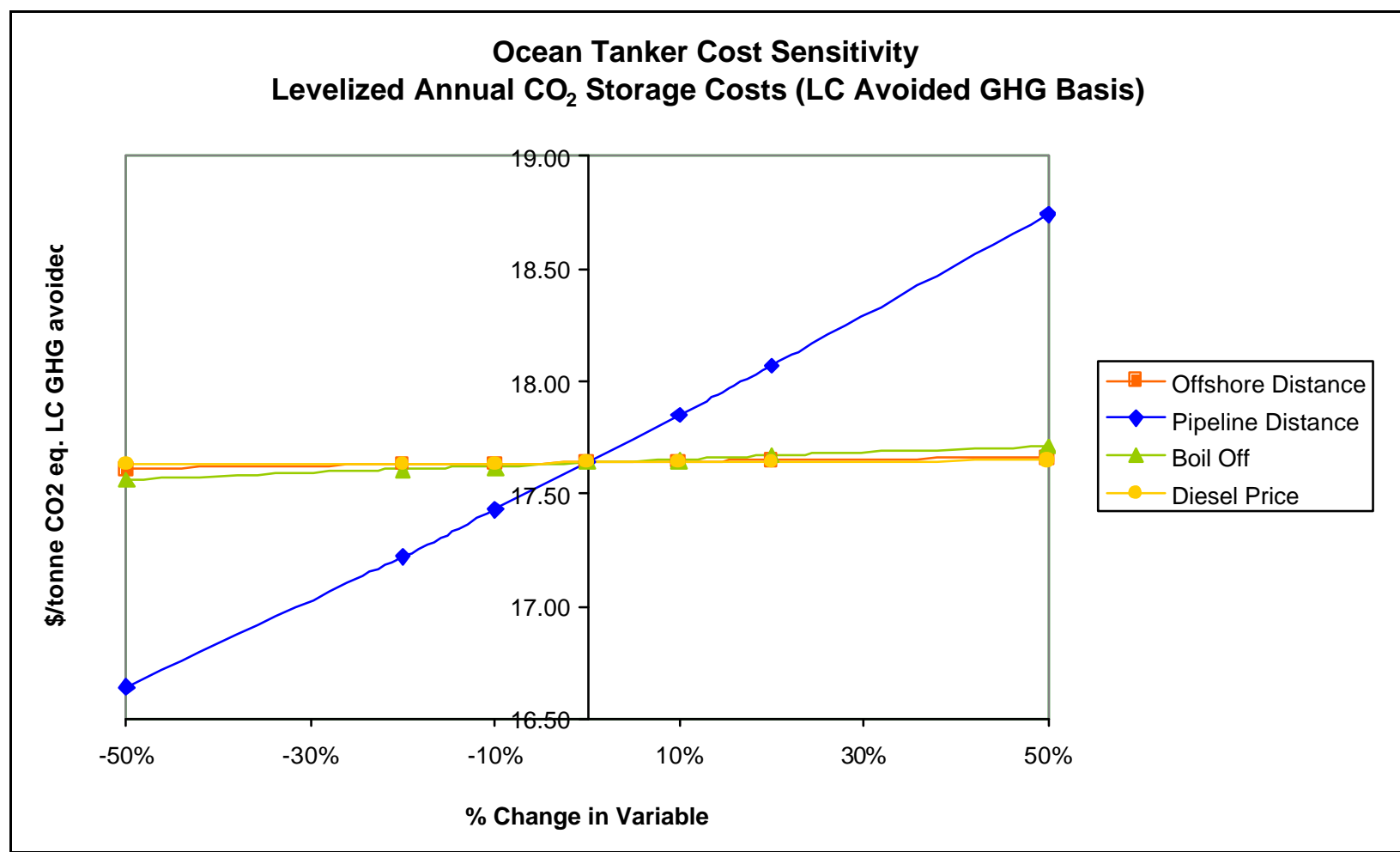

Figure 9-2

Sensitivity analysis for ocean tanker

High and low cost cases have been chosen for the depleted gas reservoir option, and are presented together with the base case in Table 9-6. For the high and low cost values for each of the four key parameters, the percentage change in the value from the base case is shown. This is done to illustrate the fact that the range in the values of some parameters is expected to be greater than for others. 
Table 9-6

Ocean tanker base, high cost and low cost cases

\begin{tabular}{|l|c|c|c|c|c|c|}
\hline Parameter & Units & $\begin{array}{c}\text { Ocean Tanker } \\
\text { Base Case }\end{array}$ & \multicolumn{2}{|c|}{$\begin{array}{c}\text { Ocean Tanker } \\
\text { High Cost Case }\end{array}$} & \multicolumn{2}{c|}{$\begin{array}{c}\text { Ocean Tanker } \\
\text { Low Cost Case }\end{array}$} \\
\hline Pipeline Distance & $\mathrm{km}$ & 100 & 300 & $+200 \%$ & 0 & $-100 \%$ \\
\hline Offshore Distance & $\mathrm{km}$ & 100 & 300 & $+200 \%$ & 50 & $-50 \%$ \\
\hline Boil Off & $\% / \mathrm{day}$ & 1 & 2 & $+100 \%$ & 0.5 & $-50 \%$ \\
\hline Diesel Price & $\$ / \mathrm{gal}$ & 0.566 & 0.8 & $+41 \%$ & 0.45 & $-20 \%$ \\
\hline
\end{tabular}

The results for the high and low cost cases as well as the base case are given in Table 9-7. The $\mathrm{CO}_{2}$ storage cost for the depleted gas reservoir option varies very little for the high and low cost cases.

Table 9-7

Results for ocean tanker base, high cost and low cost cases

\begin{tabular}{|l|c|c|c|c|}
\hline Parameter & Units & $\begin{array}{c}\text { Ocean Tanker } \\
\text { Base Case }\end{array}$ & $\begin{array}{c}\text { Ocean Tanker } \\
\text { High Cost } \\
\text { Case }\end{array}$ & $\begin{array}{c}\text { Ocean Tanker } \\
\text { Low Cost } \\
\text { Case }\end{array}$ \\
\hline Number of Tankers & & 3 & 3 & 3 \\
\hline Total Annual Fuel Usage & $\mathrm{gal} / \mathrm{yr}$ & 249,001 & 747,004 & 124,501 \\
\hline $\mathbf{C O}_{2}$ Emitted by Tankers & $\mathrm{t} / \mathrm{yr}$ & 2,395 & 7,186 & 1,198 \\
\hline $\mathbf{C O}_{2}$ Emitted by Boil Off & $\mathrm{t} / \mathrm{yr}$ & 53,362 & 139,415 & 24,638 \\
\hline $\begin{array}{l}\text { Levelized Annual } \mathbf{C O}_{2} \\
\text { Storage Cost }\end{array}$ & $\begin{array}{c}\$ / \text { tonne } \\
\mathrm{CO} \text { Eq. LC } \\
\mathrm{GHG} \\
\text { avoided }\end{array}$ & 17.64 & 22.79 & 15.76 \\
\hline
\end{tabular}

\subsection{Comparison to Literature}

There is no cost data in the literature with which to make a comparison. 


\subsection{References}

1 Sarv, $\mathrm{H}$., "Large-scale $\mathrm{CO}_{2}$ transportation and deep ocean sequestration," McDermott Technology Inc., Ohio. Tech. Rep. DE-AC26-98FT40412, Mar. 1999.

2 Sarv, $\mathrm{H}$., "Large-scale $\mathrm{CO}_{2}$ transportation and deep ocean sequestration - Phase II final report,” McDermott Technology Inc., Ohio. Tech. Rep. DE-AC26-98FT40412, 2001.

3 Sarv, H., e-mail communication, Feb. 4, 2002.

4 Sarv, H., e-mail communication, Feb. 20, 2002. 


\section{0 \\ $\mathrm{CO}_{2}$ SINK ENHANCEMENT IN FORESTS-BASIS AND APPROACH}

\subsection{Introduction}

From a utility perspective, the cost of GHG emission offsets (\$/tonne C equivalent GHG avoided) from forestry sink enhancement options depends on the following: (1) levels of $\mathrm{CO}_{2}$ sink enhancement, (2) changes in GHG emissions other than from $\mathrm{CO}_{2}$ sink enhancement (e.g., from methane and nitrous oxide emissions), (3) reimbursement of forest management companies for net costs of changes in forest land area and/or management, (4) transaction costs for aggregating and brokering GHG credits, and (5) monitoring costs for assuring that contractual obligations are fulfilled. These aspects are addressed below.

The IEA Greenhouse Gas R\&D Programme (IEA GHG), in consultation with the Edinburgh Centre for Carbon Management (ECCM), provided the following data on the economics of forestry $\mathrm{CO}_{2}$ sink enhancement options. Most of this information relates to developing countries, because that is where the greatest amount of forestry $\mathrm{CO}_{2}$ sink enhancement is likely to occur, but some information is also provided on carbon sequestration in U.S. forests.

\subsection{Study Basis}

\subsubsection{Overall Basis}

Some forestry carbon sink enhancement projects have already been implemented on a voluntary basis. A brief summary of the extent and costs of these projects is provided as background information in Appendix $\mathrm{C}$, but the costs of these pioneer projects cannot be compared directly to the costs of other sink enhancement techniques because they have been derived using a variety of economic conventions and the price of carbon credits has been greatly affected by supply and demand. In this study, costs of sink enhancement are calculated from the quantities and timing of carbon stored and costs of forest establishment, maintenance, land, and timber revenue.

The performances and costs of forestry sequestration cover a very wide range, depending on local factors such as existing land uses, climate, soil conditions, the type of sequestration scheme, types of trees, land values and labor costs. It is not possible to cover all of these factors in a study such as this. Instead, information is provided for a diverse range of seven forestry sequestration cases, described in Section 10.3 and Chapters 11-17. These cases cover afforestation, reforestation, and avoidance of deforestation, developed and developing countries, and temperate and tropical climates. 


\subsubsection{Carbon Sink Enhancement}

When a forest grows, it removes $\mathrm{CO}_{2}$ from the atmosphere and sequesters carbon in trees and other above ground biomass, litter, humus, roots and soil. Eventually the forest reaches a dynamic equilibrium when the rate of new sequestration of carbon is equal to the rate of natural conversion of carbon back to $\mathrm{CO}_{2}$. The amount of carbon sequestered in forests can be increased by planting new forests (afforestation), restoring degraded forests (reforestation) or avoiding the destruction of existing forests (deforestation).

Carbon is sequestered in forests in above-ground biomass (stems and foliage) and in roots, litter on the forest floor, humus and soil. This study considers carbon stored in above-ground biomass, the most easy to verify, and carbon stored below ground.

Greenhouse gas emissions can also be reduced beyond the forest itself. Wood can be harvested sustainably from forests and converted into useful products such as timber for buildings, furniture, paper etc. Some of the carbon in these products will be quickly converted back to $\mathrm{CO}_{2}$ but some will remain sequestered as carbon for many decades. Carbon stored in wood products is included in this study.

Further information on carbon sequestration is given in Section 10.3.

\subsubsection{Reduction in Emissions Resulting from Use of Wood and Biomass}

Wood products can displace materials such as steel or concrete which generate significant amounts of $\mathrm{CO}_{2}$ during their production. Reductions in emissions of greenhouse gases from production of materials which are displaced by wood are beyond the scope of this study.

Wood and other forest biomass can be used as fuel, displacing fossil fuels. Production and use of biomass fuels is beyond the scope of this study.

\subsubsection{Non- $\mathrm{CO}_{2}$ Greenhouse Gases}

Forests and other land-uses emit significant quantities of non- $\mathrm{CO}_{2}$ greenhouse gases, particularly $\mathrm{N}_{2} \mathrm{O}$. Emissions of $\mathrm{N}_{2} \mathrm{O}$ and $\mathrm{CH}_{4}$ are taken into account in this study but emissions of other nongreenhouse gases and particulates which can indirectly affect the climate are not. Further information on non- $\mathrm{CO}_{2}$ greenhouse gases is given in Section 10.3.

\subsubsection{Ancillary Benefits}

Forestry projects have many benefits in addition to those related to greenhouse gases. Natural forests, usually have high biodiversity, so preserving existing forests can be especially beneficial. Forest plantations can negatively affect biodiversity if they replace biologically rich native grasslands or wetland habitat but they can be designed to enhance biodiversity by stimulating restoration of natural forests. 
By reducing run-off, forests can conserve water resources and reduce the risk of flooding. They can also control erosion which can reduce siltation of rivers and protect fisheries and investment in hydro-electric power facilities.

Forests tend to have a higher landscape value than alternative land uses such as scrub and agricultural land and they have more potential for recreational activities. These benefits are likely to be greatest in areas which are accessible to large numbers of people and which currently have little variation in land form.

The overall philosophy of this study is that ancillary costs and benefits, such as those described previously, are not taken into account in the economic assessment. The reasons for this are:

- Attempting to quantify these costs and benefits involves a large amount of work that is beyond the scope of this study.

- The costs and benefits are very uncertain. They depend greatly on small scale local factors and the values of many of the benefits, for example preservation of biodiversity, are very subjective.

- The economic mechanisms do not usually exist to enable ancillary benefits or costs to accrue to the owners and operators of forest projects.

\subsubsection{Concerns and Uncertainties}

There are several concerns and uncertainties about forestry sequestration as a greenhouse gas abatement technique, including additionality, baselines, leakage, security and effects on the climate other than those due to greenhouse gases. To allow for these concerns, a tonne of carbon sequestered in forests is sometimes assumed to be not equivalent to a tonne of carbon emissions avoided by other means. It has been proposed that credit should be claimed for only a fraction of the carbon thought to be sequestered in forests, to allow for the concerns mentioned above. Such reductions in carbon credits are highly subjective and may be influenced by political factors, so they are not used in this study. However, when comparing costs and performances it should be recognized that international climate treaties, regulators and the public may regard a tonne of carbon sequestered in forests as not of equal value to a tonne of carbon emissions permanently avoided.

\subsubsection{Additionality}

Additionality essentially means "would the project have occurred anyway, regardless of carbon sequestration subsidies." Large areas of forests are already being planted for commercial production of wood and also large areas of existing non-commercial forests are not being destroyed, despite the absence of carbon sequestration subsidies. Project developers need to demonstrate that their project would not have occurred without carbon sequestration credits. The probability that the project would have occurred anyway is greatest for projects that are economically attractive without carbon sequestration credits. However, just because a project is economically viable without carbon credits does not mean that it would have gone ahead anyway. There are many potential barriers; capital may not be available, risks may be too high, 
infrastructure may be inadequate, legal or technological barriers may exist etc. Overcoming these barriers may enable a project to go ahead.

\subsubsection{Leakage}

In the context of forestry sequestration, leakage means the indirect impact that a targeted activity in a certain place at a certain time has on carbon storage at another place or time. Leakage in this sense should not be confused with physical leakage of $\mathrm{CO}_{2}$ from an underground or ocean storage reservoir due to geological faults, ocean currents etc.

Leakage can be induced through several different mechanisms, particularly activity shifting and demand displacement. Activity shifting tends to arise around the boundaries of the project and is related to socio-economic conditions of the surrounding population. For example, local people may be using land for agriculture and grazing purposes. If this land is then reforested or afforested, the local people may be forced to move to other areas where they will clear forest resulting in emissions that would not have arisen if the project were not implemented.

Market based leakage occurs when a forest protection or plantation project reduces the supply of a marketed product, either wood or agricultural products, resulting in increased felling of trees elsewhere to satisfy the demand for the product. This occurs in a diffuse way through global markets. Output from plantations that are subsidized for their carbon sequestration benefits can increase the supply, and hence reduce the price, of wood. This would tend to make forests that cannot claim carbon sequestration credits less economically attractive, so the amount of nonsubsidized plantations may decrease, resulting in less carbon sequestration. A study of the impacts on timber markets of 50 million ha of sequestration forests ${ }^{1}$ predicted that the impacts on the net quantity of carbon sequestered would be fairly small, about 10 percent. If forests were planted on agricultural land, this would tend to reduce the supply of food. The price of food would therefore increase, making conversion of forest elsewhere to agricultural land more attractive.

The only way to address leakage resulting from unfulfilled demand for wood or agricultural products is to invest in the supply chain elsewhere or reduce demand for products. For example, some of the revenue from a sequestration project could be invested in intensification of agriculture, to enable the same amount of food to be produced from a smaller area or land. This intensification of agriculture may affect greenhouse gas emissions, for example $\mathrm{CO}_{2}$ emitted during production of fertilizers and increased emissions of $\mathrm{N}_{2} \mathrm{O}$ from agricultural land. These effects are beyond the scope of this study.

\subsubsection{Security}

In common with most sequestration options, there is a potential for carbon stored in forests to be converted to $\mathrm{CO}_{2}$ and emitted to the atmosphere. Losses of carbon from forests could be classified as permanent or non-permanent. Non-permanent losses include forest fires and pest infestations. In most cases forests would re-grow naturally or they could be re-planted after such occurrences. There would be a temporary emission of $\mathrm{CO}_{2}$ but in the long term the carbon 
sequestration at the site could be restored, although there would be an economic cost of reestablishing the forest.

Permanent loss of sequestration could occur due to social and political factors or climate change. Climate change could mean that some areas could become no longer suitable for forests because of changes in temperature and rainfall. For example, some global climate modelling has predicted that vast areas of tropical forests in northern Brazil will die back around the middle of this century because of anthropogenic climate change ${ }^{2}$. Temperate grasslands are also expected to expand into regions of Europe and North America that are currently dominated by temperate or coniferous forests. Areas suitable for forests are predicted to expand northwards in North America and Asia and there are even suggestions that climate change may enable forests to grow in the Sahara region ${ }^{3}$. It may therefore be possible to replace sequestration forests lost due to climate change by planting or encouraging the natural growth of forests in other regions but this would involve disruption and economic costs. It is very difficult to predict these risks of forest loss because of the large uncertainties in predictions of regional impacts of climate change.

Forests can be lost due to social factors, for example population growth leading to increased requirements for agricultural and urban land. It is important that forest projects are structured to provide benefits to local inhabitants to reduce the risks of forest loss. The legal status of forests in some countries, where land ownership or tenure is less secure, may result in an increased risk of forest loss.

\subsubsection{Non-Greenhouse Gas Effects}

Vegetation cover can have a significant impact on the albedo (reflectivity) of the Earth. Dark green forests tend to absorb more solar energy than crop lands. The greatest effect is during the winter months when large unforested areas are covered in highly reflective snow. In a coniferous forest the snow tends to fall to the ground and the dark surface of the treetops is exposed and absorbs more solar energy. Recent work using global climate models ${ }^{4}$ has indicated that in some parts of the world, including large parts of Canada and the Russian Far East, the extra solar energy absorbed would more than offset the greenhouse gas benefits of carbon sequestered by forests. Even in the US South, the albedo effect is predicted to offset around 1020 percent of the carbon sequestration benefits of forests. These estimates are subject to many uncertainties, notably the predictions of snow amount and surface reflectivity and they are based on the current climate. However, they do show that solar reflectivity could have a significant impact on the climate change impacts of forests. Non-greenhouse has effects are beyond the scope of this study.

\subsection{Sequestration Cases}

\subsubsection{Descriptions}

The seven forestry sequestration cases assessed in this study are summarized in Table 10-1 and are described in detail in Chapters 11-17. 
Table 10-1

Summary of forestry sequestration cases

\begin{tabular}{|l|l|l|l|}
\hline Case & Type of management & Type of trees & Country/region \\
\hline 1 & Plantation & Loblolly pine & USA (South) \\
\hline 2 & Plantation & Douglas fir & USA (Pacific North-west) \\
\hline 3 & Plantation & Spanish Cedar & Mexico \\
\hline 4 & Restoration & Pine-oak & Mexico \\
\hline 5 & Restoration & Miombo & Southern Africa \\
\hline 6 & Agro-forestry & Mango-tamarind & India (South) \\
\hline 7 & Avoidance of deforestation & Various & Mexico \\
\hline
\end{tabular}

In the case studies, descriptions of the ecology, economics and management of these forestry systems are provided and case 7 (avoided deforestation) contains a description of the methodology to be applied to derive factors to parameterize the deforestation model.

The information provided in the case studies provides an indication of the costs and performances of forestry sequestration projects but it should be recognized that the results depend on many local factors. Actual carbon uptake and economic performance of forestry systems will depend upon local factors, such as micro-climate, soil conditions and rainfall patterns that require on the ground assessment and monitoring of conditions. Individual site / project inspections will also be necessary to determine factors such as potential leakage of project benefits, what the baseline level of carbon storage is likely to be and whether the project implementers actually have the technical skill, equipment, legal rights, financial and management capabilities to implement a project, as proposed.

In developing countries the social context for forestry projects is extremely important. Forestry systems are but one of a number of components that form the basis for rural livelihoods.

\subsubsection{Quantities of Carbon Sequestered}

The quantity of carbon sequestered depends on the site productivity. For some of the cases, information on the quantities of carbon sequestered is provided for high, medium and low productivity sites. For other cases, because of limited available information, information is only provided for typical sites. 


\subsubsection{Above-Ground Carbon}

The quantities of carbon sequestered in above ground biomass in each of the cases, and how they vary with time, are summarized in Figure 10-1. This information is for medium productivity sites.

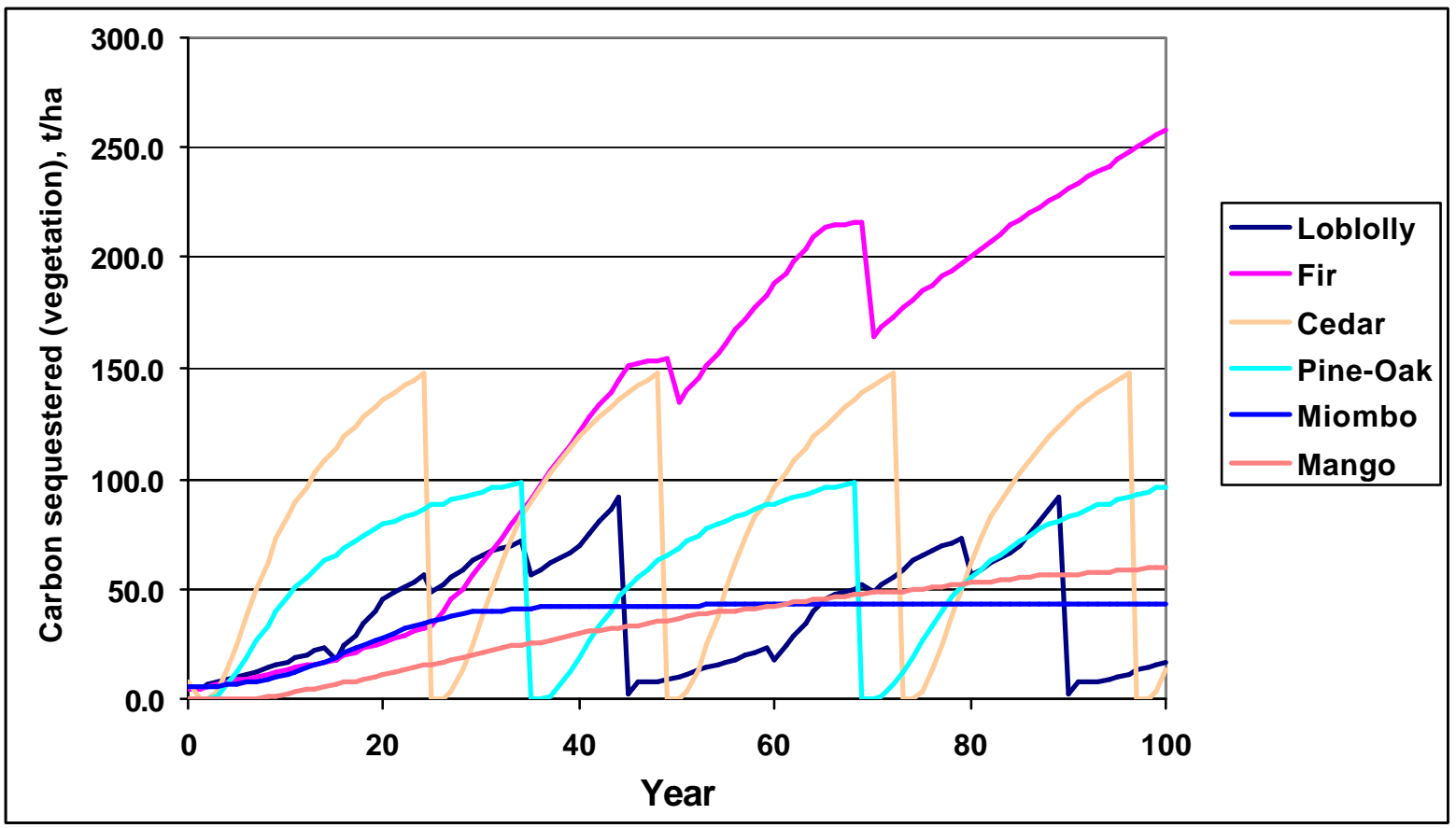

Figure 10-1

Quantities of carbon sequestered (medium productivity sites)

It can be seen that the quantities differ substantially between the cases, in terms of both carbon sequestration rate and the maximum quantity of carbon sequestered per hectare. The cases which give the fastest sequestration rates in early years do not necessarily sequester the largest quantities of carbon in the long term.

The quantities of carbon stored increase until the time when wood is harvested. If wood were not harvested the quantities of carbon stored may increase further but would then begin to decline, due to increased mortality. Harvesting wood and replanting has the benefit of producing revenue which offsets some of the costs of planting and maintaining the forests. Providing revenue and products for local use can be particularly important for developing countries, to maintain the support of local communities and reduce the risks of human induced forest loss.

The quantity of carbon sequestered depends on the site productivity. An example of this, for the Spanish Cedar plantations case, is shown in Figure 10-2. The quantities of carbon sequestered differ significantly between different site productivities but, in general the differences are less than between the different forest cases. 


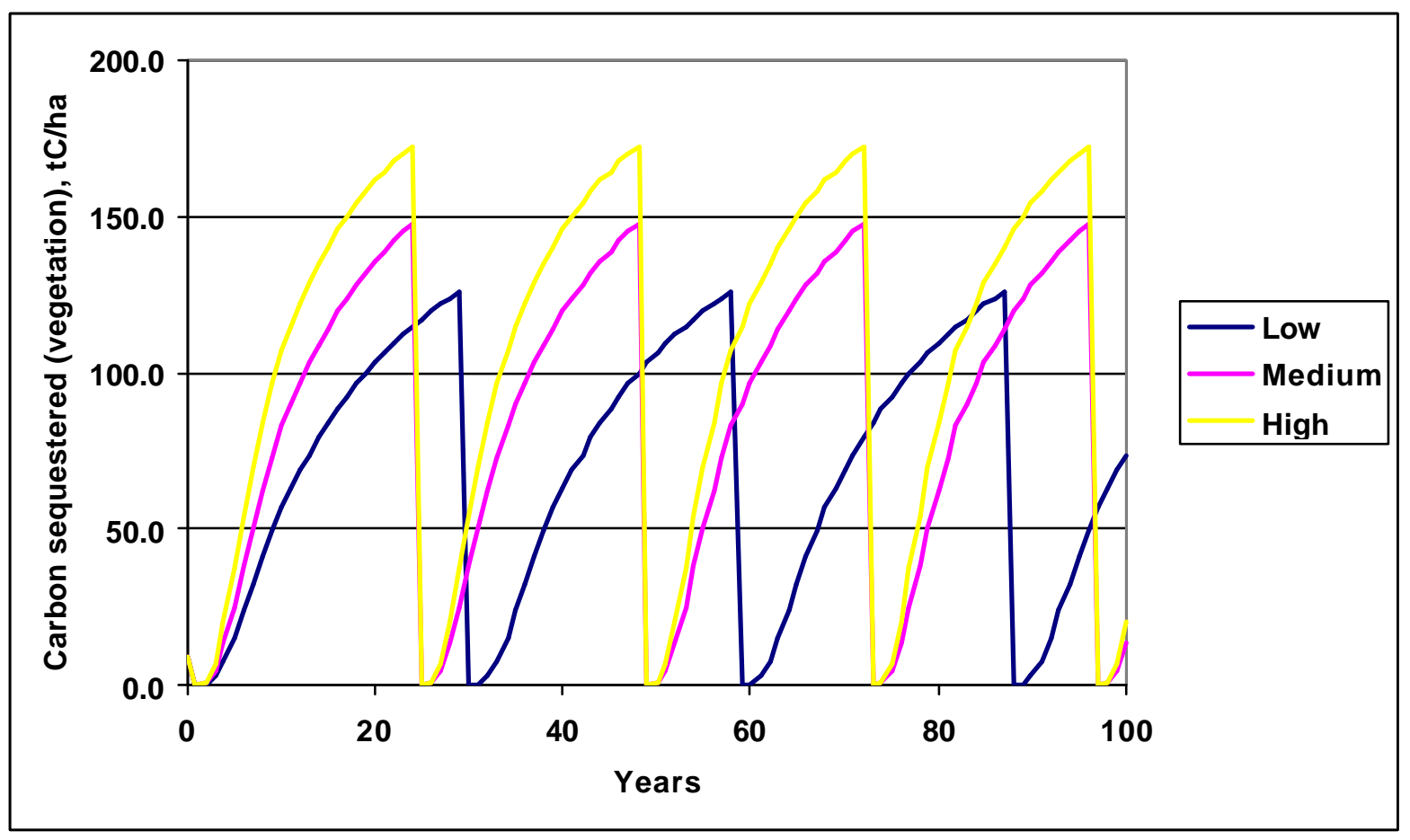

Figure 10-2

Carbon sequestered in Spanish Cedar plantations at different site productivities

\subsubsection{Below-Ground Carbon}

It is relatively easy to monitor and verify carbon stored in above-ground trees. Carbon sequestration credits are often based only on above ground carbon. Carbon in soils can be measured but it is more uncertain and many more measurements are required. This study includes both above-ground and carbon stored in soils. The base case economic assessments include both above ground carbon and carbon in soil, roots.

\subsubsection{Wood Products}

Carbon stored in products made from harvested wood is also considered in this study. Some wood products, e.g., paper, have short lifetimes, but others, e.g., wood used in buildings, can have lives of up to 100 years or more. Carbon stored in wood products is sometimes included in assessments of carbon sequestration but there are many uncertainties and there is no simple way to verify the quantity of carbon stored.

The quantities of carbon sequestered in above ground vegetation, soil (including roots, litter and, humus) and timber products in the medium productivity Spanish Cedar case are shown in Figure 10-3. The quantities of carbon shown in Figure 10-3 are in addition to those already existing at the start of the project. The figure illustrates the characteristic pattern of carbon stored in wood products. 


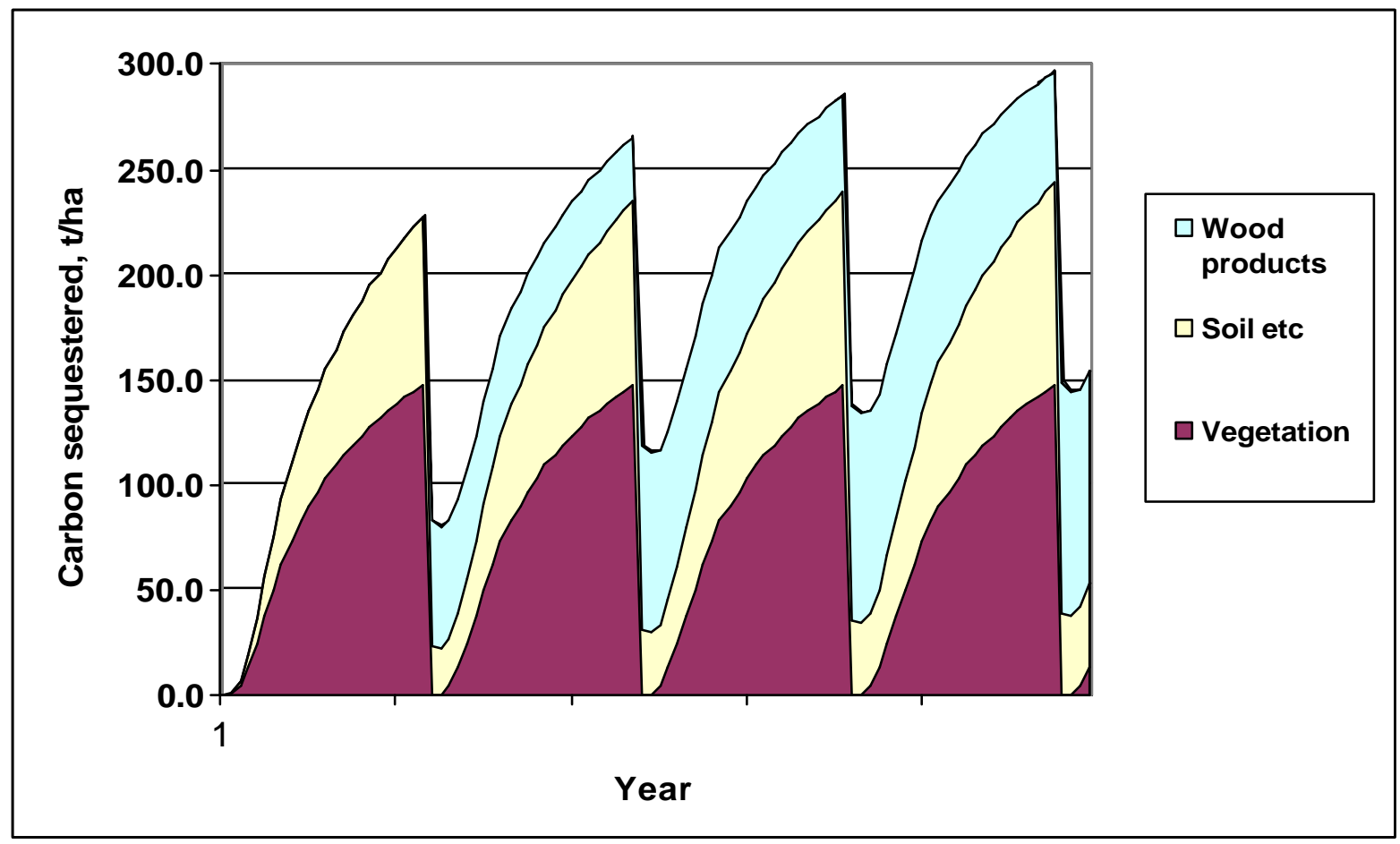

Figure 10-3

Carbon sequestered in vegetation, soil etc. and timber products (Spanish Cedar)

Wood products can displace other products, including steel and concrete. Significant amounts of greenhouse gases are emitted during their production, so substitution by wood products can result in substantial greenhouse gas benefits. The quantity of carbon sequestered in wood products can reach saturation, as the rate of decomposition equals the rate of creation of new products but the benefits of reduced emissions from production of alternative materials continues. A material substitution effect of $0.28 \mathrm{tC} / \mathrm{m}^{3}$ of final wood product has been suggested $^{5}$. Although this estimate is highly uncertain, it is possible that the substitution impact for wood products is greater than the sequestration impact. Material substitution effects are beyond the scope of this study.

Harvested wood can also be used as fuel, reducing greenhouse gas emissions from use of fossil fuels. The scope of this study was limited to carbon sequestration. Biomass fuel production is a broad subject in its own right and is beyond the scope of this study.

\subsubsection{Non- $\mathrm{CO}_{2}$ Greenhouse Gases}

Greenhouse gases other than $\mathrm{CO}_{2}$ are emitted and absorbed by forests. Forests are one of the main sources of nitrous oxide and they can be a source or sink for methane. Greenhouse gases may also be released during land clearance prior to planting of forests and during deforestation.

Little information is available on non- $\mathrm{CO}_{2} \mathrm{GHG}$ emissions from forests. Non- $\mathrm{CO}_{2}$ greenhouse gases are not normally included in assessments of forestry sequestration schemes. Including 
non- $\mathrm{CO}_{2}$ GHGs would greatly increase data requirements and monitoring costs. In this study, non- $\mathrm{CO}_{2}$ greenhouse gases are included as a sensitivity to indicate whether they are likely to be significant compared to carbon sequestration.

\subsubsection{Nitrous Oxide from Forests and Baseline Land Uses}

Global $\mathrm{N}_{2} \mathrm{O}$ sources related to land-use are summarized in Table 10-2 ${ }^{6}$. The carbon equivalents of these emissions, based on a 100 year global warming potential, are also shown in Table 10-2. The estimated emissions of $\mathrm{N}_{2} \mathrm{O}$ from natural forests are $1.1 \mathrm{Gt}$ carbon-equivalent per year, equivalent to about 18 percent of current emissions of $\mathrm{CO}_{2}$ from fossil fuel use. Emissions of $\mathrm{N}_{2} \mathrm{O}$ are enhanced under warm and wet conditions, e.g., those present in the soils of moist tropical forests, and when nitrogen is applied as fertilizer. The uncertainty in $\mathrm{N}_{2} \mathrm{O}$ emissions from forests is large, particularly for temperate forests, where the range of uncertainty is a factor of 16.

Table 10-2

Global $\mathrm{N}_{2} \mathrm{O}$ sources

\begin{tabular}{|c|c|c|c|c|}
\hline & \multicolumn{2}{|c|}{ Mt $\mathrm{Ny}^{-1}$} & \multicolumn{2}{|c|}{ Gt $C$ eq. $y^{-1}$} \\
\hline & $\begin{array}{l}\text { Central } \\
\text { Estimate }\end{array}$ & Range & $\begin{array}{l}\text { Central } \\
\text { Estimate }\end{array}$ & Range \\
\hline Forest soils - wet tropical forests & 3 & $2.2-3.7$ & 0.8 & $0.6-1$ \\
\hline - temperate forests & 1 & $0.1-2$ & 0.3 & $0.03-0.5$ \\
\hline Natural savanna soils & 1 & $0.5-2$ & 0.3 & $0.1-0.5$ \\
\hline Natural temperate grassland soils & 1 & $0.5-2$ & 0.3 & $0.1-0.5$ \\
\hline Cultivated soils & 3.5 & $1.8-5.3$ & 0.9 & $0.5-1.4$ \\
\hline Biomass burning & 0.5 & $0.2-1$ & 0.1 & $0.05-0.3$ \\
\hline Livestock & 0.4 & $0.2-0.5$ & 0.1 & $0.05-0.13$ \\
\hline Total & 10.4 & & 2.8 & \\
\hline
\end{tabular}

\subsubsection{Methane from Forests and Baseline Land Uses}

Although the overall global emission of methane is relatively well known, the magnitude of individual sources and the likely changes in methane sources and sinks associated with changes in land use and other modifications or terrestrial ecosystems are uncertain ${ }^{6}$. Tropical wetlands and termites emit methane but microbial activity in soils is a significant sink for atmospheric methane. Overall net emissions of methane from forests compared to alternative land uses are estimated to be an order of magnitude less significant than emissions of $\mathrm{N}_{2} \mathrm{O}$. 


\subsubsection{Net Emissions of Nitrous Oxide and Methane From Forestry}

Estimating the impacts on $\mathrm{N}_{2} \mathrm{O}$ and methane emissions of forestry sequestration depends on the emissions from the baseline land use. Forests are large emitters of $\mathrm{N}_{2} \mathrm{O}$ and in some circumstances are also emitters of methane, but alternative uses of the land would also emit significant amounts of these gases. In this study it is assumed that planted forests will replace pasture or abandoned farmland. If forests were planted on croplands there could be a significant reduction in emissions because croplands often have higher emissions than forests. However, if an area of cropland was forested, another area of land elsewhere may be converted to cropland to maintain food production, so the benefits would be illusory.

The net emissions of forests and baselines used in this study are shown in Table $10-3^{7,8}$

Table 10-3

Forest and baseline $\mathrm{N}_{2} \mathrm{O}$ And $\mathrm{CH}_{4}$ emissions

\begin{tabular}{|l|c|c|c|}
\hline & $\begin{array}{c}\text { U.S. afforestation / } \\
\text { deforestation }\end{array}$ & $\begin{array}{c}\text { Non-U.S. afforestation / } \\
\text { deforestation }\end{array}$ & $\begin{array}{c}\text { Avoidance of } \\
\text { deforestation }\end{array}$ \\
\hline $\mathrm{CH}_{4}$ emissions, $\mathrm{kg} \mathrm{ha}^{-1} \mathrm{y}^{-1}$ & & -1.1 & \\
\hline Baseline & -1.1 & -3.5 & -3.5 \\
\hline Forests & -1.2 & -2.4 & -1.1 \\
\hline $\mathrm{Net}$ & -0.1 & & 2.4 \\
\hline $\mathrm{N}_{2} \mathrm{O}$ emissions, $\mathrm{kg} \mathrm{ha}^{-1} \mathrm{y}^{-1}$ & & 0.4 & \\
\hline Baseline & 0.4 & 2.2 & 2.2 \\
\hline Forests & 1.2 & 1.8 & 0.4 \\
\hline Net & 0.8 & 0.13 & -1.8 \\
\hline Overall emissions, tCeq ha ${ }^{-1} \mathrm{y}^{-1}$ & 0.06 & -0.13 \\
\hline
\end{tabular}

Note: emissions for avoidance of deforestation are per hectare of land deforested

\subsubsection{Emissions From Biomass Burning}

Deforestation often involves open burning of biomass and some biomass is also often burned when ground is cleared prior to planting of forests. When vegetation is burned about 10 percent of the carbon contained in the biomass is converted to charcoal, which will remain stored in the soil for a very long time ${ }^{9}$. Most of the rest is oxidized and released to the atmosphere as $\mathrm{CO}_{2}$. Some methane and $\mathrm{N}_{2} \mathrm{O}$ are also produced during open burning of biomass and their total greenhouse gas effect is estimated to be about $0.1 \mathrm{tC}$ equivalent/ $\mathrm{tC}$ burned, based on 100 year global warming potentials and emissions data ${ }^{9}$. The carbon equivalent of methane and nitrous oxide missions from open burning of biomass appears to be approximately equal to the quantity of carbon that is converted to charcoal and therefore not emitted as $\mathrm{CO}_{2}$. For this study it is therefore assumed that, in effect, all of the carbon released during deforestation and ground clearance prior to planting of forests is released as $\mathrm{CO}_{2}$. 


\subsubsection{Other Atmospheric Emissions}

Vegetation emits large quantities of volatile organic compounds (VOC) to the atmosphere, substantially more than are emitted from use of fossil fuels (5). VOC is also emitted during biomass burning, along with $\mathrm{CO}$ and $\mathrm{NO}_{\mathrm{x}}\left(\mathrm{NO}\right.$ and $\left.\mathrm{NO}_{2}\right)$. These gases have only a small direct impact on radiative forcing but they have a large indirect effect, as they affect formation of ozone, which is an important greenhouse gas, and $\mathrm{OH}$, which affects the atmospheric burden of methane. Particulates are emitted during biomass burning and they too can have a significant impact on the climate. The climate impacts of these emissions are highly uncertain and Global Warming Potentials of these gases have not been agreed. They have therefore not been included in this study.

\subsubsection{Costs}

Cost information for each of the forestry cases has been provided by ECCM, based on published information and direct experience within developing countries. Details are given in Chapters 11-17. The costs provided by ECCM are within the ranges of costs quoted in published references. Costs from a variety of published references are given in Appendix $\mathrm{C}$ for comparison.

\subsubsection{Establishment and Maintenance}

Establishment costs provided by ECCM range from 100 to $700 \$ /$ ha. The costs provided by ECCM are within the ranges of costs quoted in published references. Costs from a variety of published references are given in Appendix D for comparison. Costs tend to be higher in developed countries because of higher labor costs.

\subsubsection{Land Costs}

Land costs are based on typical marginal costs of alternative land uses. The costs range from zero, where the land would not otherwise be used, to $1750 \$ /$ ha.

Large-scale application of carbon sequestration would affect the balance of supply and demand, and hence the price of fertile land. The cost of forestry carbon sequestration would therefore increase as the extent of sequestration forests increases. In some places, particularly developing countries, land owners may be reluctant to convert their land to sequestration forests because of uncertainties about making long term commitments, social and cultural attachments to current agricultural practices, a wish to ensure production of subsistence agricultural products and concerns about land ownership rights. The price paid for land for forestry sequestration may need to be greater than the current marginal value, to encourage land owners to change to sequestration forestry. No attempt is being made in this study to produce cost-supply curves for any of the sequestration options. These issues are therefore beyond the scope of this study. 


\subsubsection{Timber Revenues}

Forests produce useful products, particularly timber and fuel wood and also in some cases food, medicinal and other types of plants. Revenue from the sale of timber is included as in the economic assessment. Other products are mainly used locally and their value is assumed to help ensure the long term maintenance of the forests.

In the model, timber prices in the future are assumed to be the same as at present. A similar assumption is made in the EOR and ECBM cases, where oil and gas prices are assumed to remain constant. However, it is recognized that future timber prices are uncertain and large scale adoption of sequestration forestry could itself significantly affect timber prices. This report therefore presents sequestration costs with and without timber revenues.

\subsubsection{Monitoring}

The change in carbon stocks of stands of forest trees over a 5-year period can be assessed with good precision through standard inventory methods. Carbon stocks in soils have been determined by standard sampling techniques but large numbers of samples are required to achieve adequate precision ${ }^{6}$. Third party organizations offer independent carbon verification services, to give increased confidence to purchasers of carbon credits. A combination of remote satellite monitoring and on-the-ground measurements is normally used.

The costs of measuring and monitoring carbon sequestration in forests are a function mainly of the desired level of precision, which may vary by the type of project activities, the size of the project and the natural variation within the various carbon pools. The level of precision has a very large effect on the costs, for example variable costs for a precision of \pm 5 percent may be a factor of a hundred greater than for a precision of \pm 30 percent $^{6}$. If projects could only claim carbon credits for the lower bound of the confidence interval and the value of carbon credits was high, it would be worthwhile monitoring to a high level of precision.

A few data are available to provide preliminary estimates of the costs of measuring and monitoring of carbon in forestry projects. Based on available information ${ }^{6}$, an annual monitoring cost of $\$ 5 /$ ha has been assumed for this study.

\subsubsection{Financial Parameters}

The same financial parameters were used for forestry options as for $\mathrm{CO}_{2}$ capture and storage options included in this project. The rationale is that we assume that funding for both types of projects would come from an energy company seeking to receive credits for reducing GHG emissions. An energy company likely would use the same financial parameters for evaluating GHG abatement investments regardless of whether the investments involve $\mathrm{CO}_{2}$ capture and storage or $\mathrm{CO}_{2}$ sink enhancement. Costs were estimated on a constant-dollar basis using an interest rate of 5.83 percent, income tax rate of 38 percent, and after-tax discount rate of 6.09 percent (see the Section 2.4 for more details and rationale). Land, initial transaction, and establishment costs were levelized over the first 20 years using a 5.83 percent interest rate. 
Taxable income was based on revenues from a given harvest minus expenses that accumulated to that point. If accumulated expenses were greater than accumulated revenues at a given harvest, then expenses that were not yet offset by revenues were carried over to the next harvest for calculating taxes.

Costs of GHG mitigation (\$/tonne life-cycle avoided C equivalents) were calculated on an NPV basis as described in detail in Section 2.4. An after-tax discount rate of 6.09 percent was used to calculate NPV's. Costs calculated on this basis can be compared with costs from other $\mathrm{CO}_{2}$ storage or sink enhancement options that differ in timing of costs and in timing and permanence of GHG mitigation.

\subsection{References}

1 IEA Greenhouse Gas R\&D Programme, Carbon sequestration by forestry - effects of timber markets, IEA GHG report PH3/10, June 1999.

2 UK Met. Office Hadley Centre for Climate Prediction and Research, Climate change and its impacts, November 1998.

3 New Scientist, 21 July 2001, p.4-5.

4 UK Met Office, 2001, www.met-office.gov.uk

5 IPCC (Intergovernmental Panel on Climate Change), Climate change 2001, the scientific basis, published by Cambridge University Press, 2001, ISBN 0521807670.

6 IPCC (Intergovernmental Panel on Climate Change), Land use, land-use change, and forestry, published by Cambridge University Press, 2000, ISBN 0521800838.

7 Ambus P. and Christensen S., Atmospheric pollutants and trace gases - spatial and seasonal nitrous oxide and methane fluxes in Danish forest, grassland, and agroecosystems, J.Environ. Qual. 24:993-1001 (1995).

8 Weitz A.M. et.al., Nitrous oxide, nitric oxide and methane fluxes from soils following clearing and burning of tropical secondary forest, J.Geophysical Research, 103 (D21), p.28,047-28,058, Nov 20, 1998.

9 UNEP/OECD/IEA/IPCC 1997, Revised IPCC Guidelines for National GHG Inventories Vol. 3: GHG Inventory Reference Manual, IPCC, Bracknell, UK. 


\section{CASE 1: SOUTHERN U.S. LOBLOLLY PINE PLANTATIONS}

\subsection{Introduction}

Loblolly pine (Pinus taeda) is a versatile, fast-growing softwood species that thrives in much of central and eastern US. It is the most important timber species in the United States, withan estimated growing stock of 1.4 billion $\mathrm{m}^{3}$ across approximately 13.4 million ha, with around 2.4 million ha of loblolly pine plantations. In some States there has been a threefold increase in the area for Loblolly pine plantations since the 1970s.

\subsection{Ecology}

Loblolly pine grows in a variety of conditions; its natural range extends across several States, from $28^{\circ} \mathrm{N}$ in Florida, Texas and Oklahoma to $39^{\circ} \mathrm{N}$ in Delaware, New Jersey and Maryland. East-west its range stretches from $75-97^{\circ} \mathrm{W}$. It is found naturally between the flat Atlantic coastal plains up to altitudes of $1520 \mathrm{~m}$ in the Appalachian Highlands. Mean annual rainfall is between $1020-1520 \mathrm{~mm}$ per year and the mean annual temperature is $13-24^{\circ} \mathrm{C}$. It will grow on a variety of soils but grows best on moderately acid soils with imperfect to poor drainage. It does not normally thrive on base-rich soils with high $\mathrm{pH}$.

\subsection{Management Operations}

Typical management operations are described in the following subsections.

\subsubsection{Establishment}

Establishment of Loblolly pine plantations usually involves high intensity site preparation using mechanical methods to remove above-ground biomass, scarification and bedding of soils and application of fertilizer. Herbicides may be used to control vegetation on low productivity sites but are less effective on high productivity sites. Planting normally takes place between December and March, depending on adequate soil moisture availability. Planting density is between 625 and 1,100 stems per ha ( $4 \times 4$ to $3 \times 3 \mathrm{~m})$. For sites under 50 ha the unit costs of mechanical operations and fencing may be uneconomic. 


\subsubsection{Maintenance}

Maintenance of Loblolly pine plantations consists of:

- control of competing vegetation, in particular during the early years

- control of hardwoods

- application of $\mathrm{P}$ and $\mathrm{N}$ fertilizers that can significantly improve growth (no fertilizer assumed in this study)

\subsubsection{Harvesting}

Thinning can take place in years 15,25 , and 35 to remove saleable trees which would not survive to the end of the rotation and to release higher quality trees. Final clearcut takes place at 45 years.

\subsubsection{Re-establishment}

Planting of nursery grown seedlings is the most common method of re-establishment. Artificial regeneration by direct seeding may also be considered as a cheaper option but is less likely to produce good regeneration.

\subsubsection{Classification of Productivity}

Productivity on the southern coastal plains is generally relatively high and declines in the shale and sandstone regions of the highlands. Site indices are used to indicate site quality and potential growth, classified by height at a reference age (usually 25 for plantations, 50 for natural stands). Table 11-1 shows the two productivity levels for Loblolly pine.

\section{Table 11-1}

Productivity classes for Loblolly Pine in the southern United States

\begin{tabular}{|c|c|l|c|}
\hline Productivity & Site Index & \multicolumn{1}{|c|}{ Conditions } & Production \\
\hline High & $21-32$ & Loam hills and plains & $\begin{array}{c}220 \mathrm{~m}^{3} \\
45 \text { years }\end{array}$ \\
\hline Medium & $20-23$ & Sand hills and plains (deep sands) & $\begin{array}{c}190 \mathrm{~m}^{3} \\
45 \text { years }\end{array}$ \\
\hline Low & $18-24$ & Mixed sandstone shale & n.a. \\
\hline
\end{tabular}




\subsection{Carbon Sequestration Potential}

\subsubsection{Baseline}

The following are the initial assumptions for existing stored carbon at the site based on ECCM information.

- Vegetation: $5 \mathrm{tC} / \mathrm{ha}$.

- Soils: approximately $24 \mathrm{tC} / \mathrm{ha}$ under cropland

\subsubsection{Carbon Uptake and Storage by Pinus Taeda}

Pinus taeda is a fast growing species with maximum annual growth from 15 to 30 years. Rotations vary but a 45-year cycle is common, with earlier thinnings to produce some income. Values selected for this case are shown in Table 11-2.

Table 11-2

Expected carbon storage from Loblolly Pine plantations over 100 years

\begin{tabular}{|c|c|c|c|}
\hline Productivity & Low & Medium & High \\
\hline Rotation length (years) & n.a. & 45 & 45 \\
\hline Maximum above ground carbon ( $\left.\mathrm{tC} \mathrm{ha}^{-1}\right)$ & n.a. & 92 & 95 \\
\hline Average above-ground carbon ( $\mathrm{tC} \mathrm{ha}^{-1}$ ) & n.a. & 40 & 53 \\
\hline Average soil etc. carbon ( $\mathrm{tC} \mathrm{ha}^{-1}$ ) & n.a. & 67 & 72. \\
\hline
\end{tabular}

\subsection{Costs}

\subsubsection{Establishment and Maintenance}

Site preparation costs for intensive management can range from $\$ 370-\$ 480 /$ ha with chemical treatments ranging from $\$ 136-\$ 395 /$ ha. The overall average cost has been assumed to be $\$ 690 /$ ha for this study. Establishment grants are available in many US states but they have not been included in this study. The amount of grant aid available varies between states.

The main post-establishment costs are associated with weed control (particularly in high-rainfall areas). The main weeds are competing broadleaved, hardwood trees; these will be treated with herbicides annually for the first 3 to 5 years, depending on the site concerned. The cost of each treatment will be $\$ 40$ to $\$ 60$ per hectare. A cost of $\$ 40$ per year for the first 4 years has been assumed for this study. 


\subsubsection{Land Costs}

Most new plantations are likely to be established on marginal agricultural or range land, where the profitability of existing production (usually cattle grazing) is relatively low. Since the market for land in the southern US is fairly liquid, the price of land would appear to be a reasonable indicator of the net present value of income foregone. Land prices for medium quality range land and moderate to poor quality grazing land in the states of Missouri, Tennessee, Eastern Texas and Louisiana are in the range of $\$ 1000$ to $\$ 2,500$ per hectare. At the lower end of this range one would probably obtain below average yields of timber and carbon storage, with the exception of waterlogged river valleys, which are poor for cattle but could be highly productive as plantations.

\subsubsection{Potential Income}

Plantations are likely to turn out around $200 \mathrm{~m}^{3}$ timber at the end of the rotation. At $\$ 22 / \mathrm{m}^{3}$, this gives an income of around $\$ 4,400$, depending on site productivity.

\subsection{Summary of Model Inputs and Results}

A summary of input variables for the base case (medium productivity) Loblolly pine is presented in Table 11-3. The cost of $\mathrm{CO}_{2}$ sink enhancement (\$/tonne $\mathrm{C}$ ) is presented on several accounting bases in Table 11-4. Cumulative changes in carbon sequestered (tonne $\mathrm{C} / \mathrm{ha}$ ) and costs (\$/ha) are presented below Table 11-4 for the medium productivity case. For the high productivity case, the timber yield at the end of the rotation is $220 \mathrm{~m}^{3} /$ ha and other input variables are the same as for the medium productivity case. Costs of $\mathrm{CO}_{2}$ sink enhancement (\$/tonne C) are presented for the high productivity case on several accounting bases in Table 11-5. Cumulative changes in carbon sequestered (tonne $\mathrm{C} / \mathrm{ha}$ ) and costs (\$/ha) are presented below Table 11-5 for the high productivity case. Data were unavailable for a low productivity case for Loblolly pine.

Costs in Tables 11-4 and 11-5 were calculated on an NPV basis as described in Chapter 2, and can be compared with costs for $\mathrm{CO}_{2}$ capture and storage and other sink enhancement options calculated on the same NPV basis. The same establishment, land, maintenance, and harvesting costs were assumed for medium and high productivity cases in Tables 11-4 and 11-5. This assumption likely resulted in a slight underestimation of costs for the high productivity case but the general comparison is still considered valid. 
Table 11-3

Forestry input variables for Loblolly Pine

\section{Forestry: Input Variables}

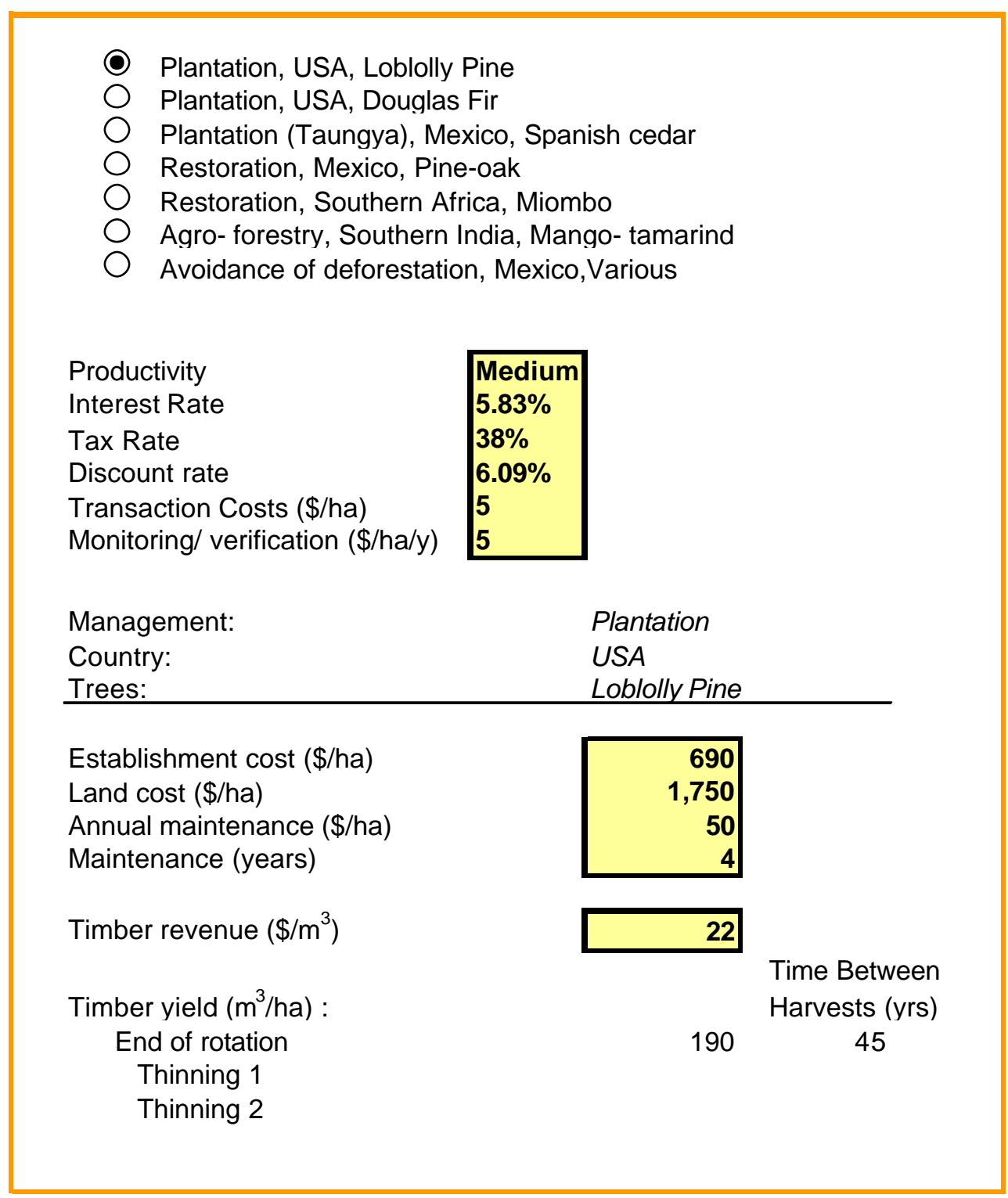


Table 11-4

Forestry summary of results for Loblolly Pine medium productivity case

Forestry: Summary of Results (Single System)

Medium Productivity

$\mathrm{CO}_{2}$ Sink Enhancement, NPV Basis (years 1-100)

Management:

Country/Region:

Plantation

Trees:

USA

Loblolly Pine

Carbon accounting basis (\$/tonne C Equivalent)

Above ground carbon

Above \& below ground carbon

Above \& below ground \& timber product carbon

Above \& below ground carbon \& non-COn GHGs

64.62

Above ground carbon with timber revenues

59.24

66.28

Above \& below ground carbon, non- $\mathrm{CO}_{2}$ GHGs, with timber products \& revenues $(A / I)^{*}$

115.94

${ }^{*}$ C Equivalent LC GHG Avoided Basis
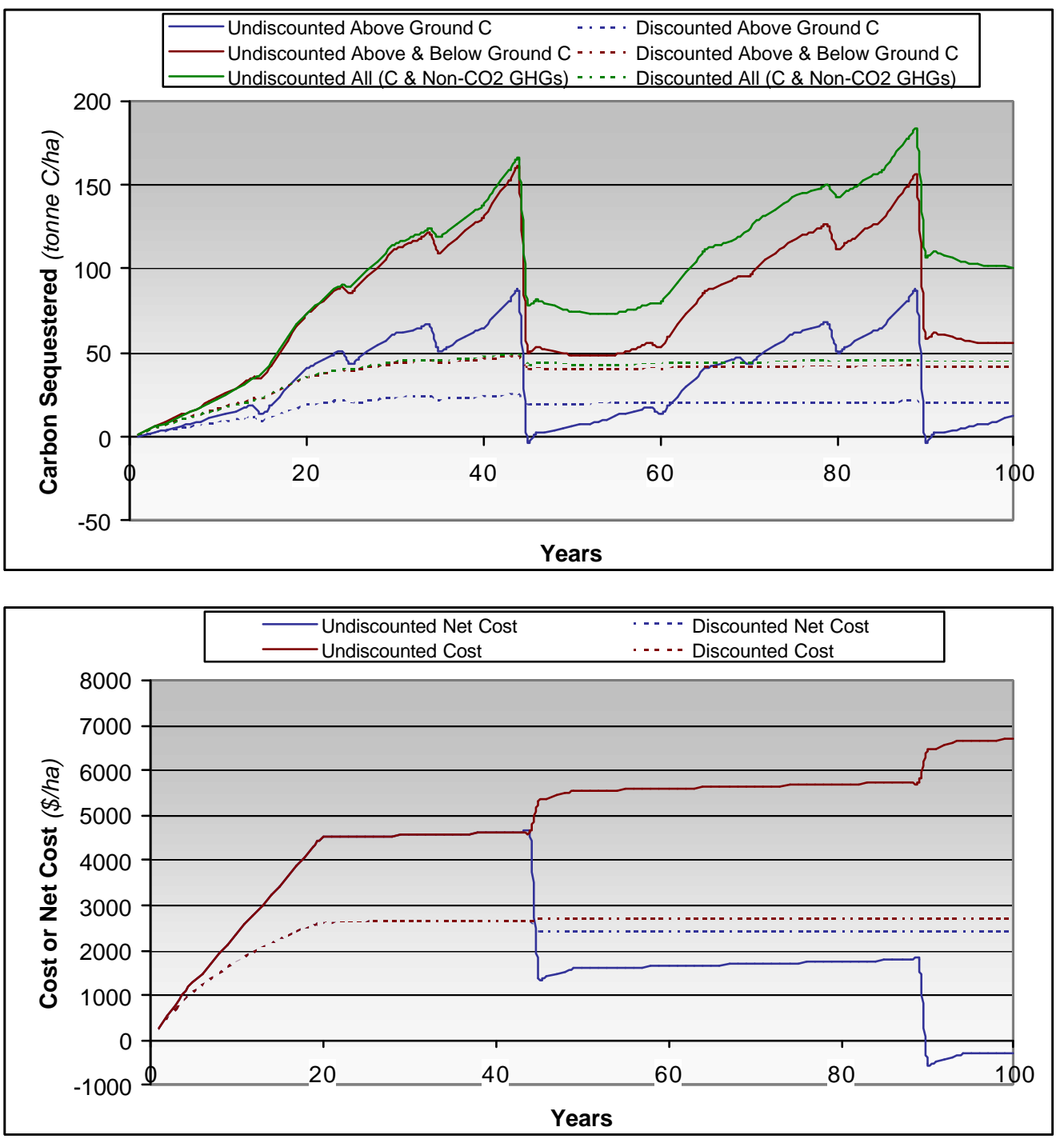
Table 11-5

Forestry summary of results for Loblolly Pine high productivity case

\section{Forestry: Summary of Results (Single System) High Productivity}

$\mathrm{CO}_{2}$ Sink Enhancement, NPV Basis (years 1-100)

Management:

Country/Region:

Trees:

Carbon accounting basis (\$/tonne C Equivalent)

Above ground carbon

Above \& below ground carbon

Above \& below ground \& timber product carbon

Above \& below ground carbon \& non- $\mathrm{CO}_{2}$ GHGs

Above ground carbon with timber revenues

Above \& below ground carbon, non- $\mathrm{CO}_{2}$ GHGs, with timber products \& revenues $(A / I)^{\star}$

* $C$ Equivalent LC GHG Avoided Basis
Plantation

USA

Loblolly Pine
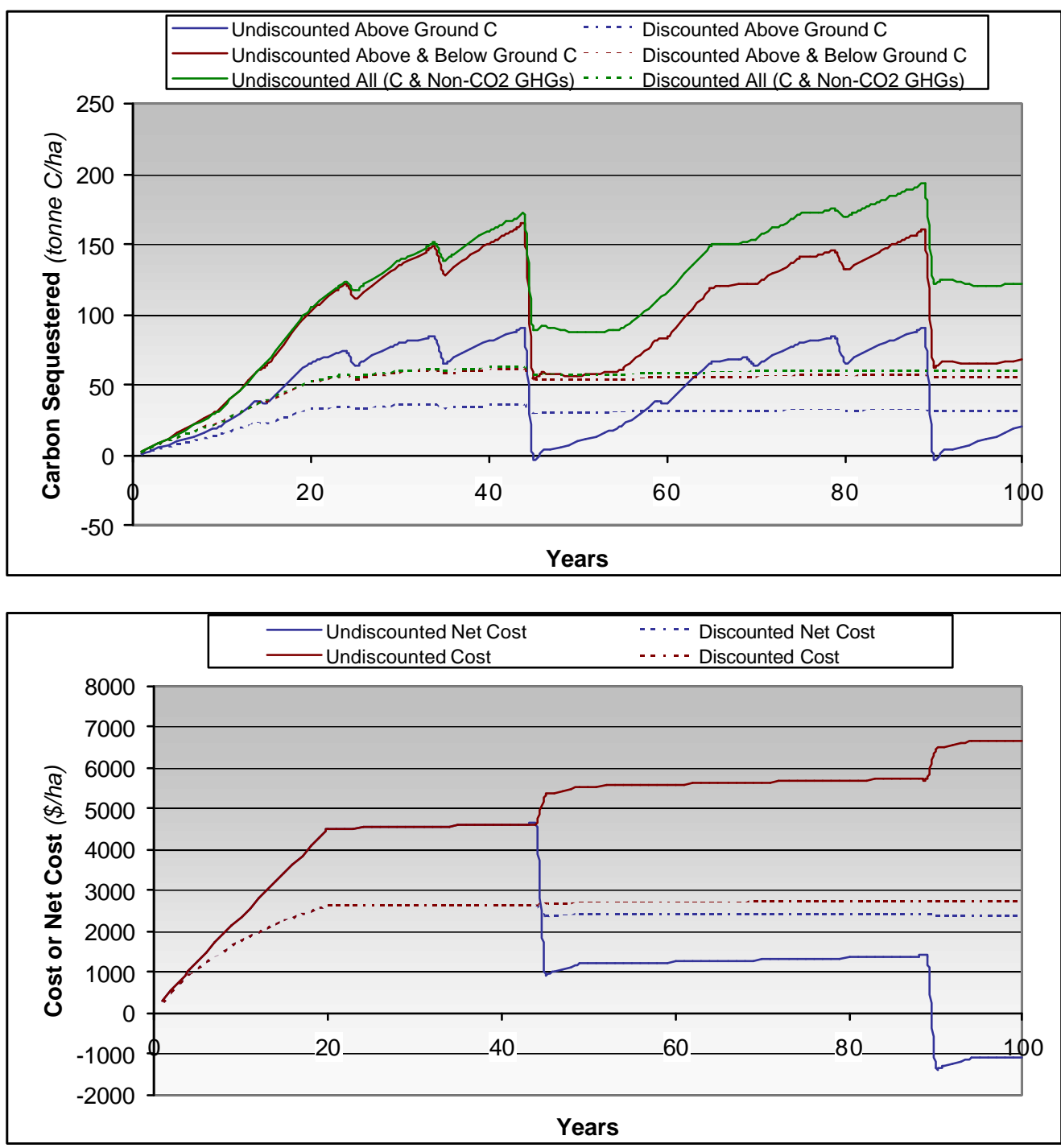


\subsection{References}

These references are not indicated specifically in the body of the chapter and instead represent background for the information presented in this chapter.

1 Birdsey, Richard, A. 1996. Carbon Storage for Major Forest Types and Regions in the Conterminous United States, in Forests and Global Change: Vol. 2. Forest Management Opportunities for Mitigating Carbon Emissions. American Forests, Washington, DC.

2 Burns, Russell M., and Barbara H. Honkala, (tech. ords.) 1990. Silvics of North America: Vol.1. Conifers. Agriculture Handbook 654. U.S. Department of Agriculture, Forest Service, Washington, DC.

3 LDAF. 2000. Quarterly Report of Forest Products.

4 Howard, James L. 1999. U.S. Timber Production, Trade, Consumption and Price Statistics 1965-1997. General Technical Report GPL-GTR-116. U.S. Department of Agriculture, Forest Service, Washington, DC.

5 Schultz, Robert P. 1997. Loblolly pine: the ecology and culture of loblolly pine (Pinus taeda L.). Agriculture Handbook 713. U.S. Department of Agriculture, Forest Service, Washington DC.

6 Timber-Mart South - Market Newsletter. University of Georgia, Athens, GA. http://www.forestry.uga.edu/warnell/tmart/ 


\section{2 \\ CASE 2: PACIFIC NORTHWEST DOUGLAS FIR PLANTATIONS}

\subsection{Introduction}

Douglass fir (Pseudotsuga menziesii) occurs naturally across a large area of western North America. Coastal Douglas fir is a valuable timber tree, with very high yields over long rotations and has been planted extensively. Old-growth stands are of considerable amenity and biodiversity value. Douglas fir plantations have the potential to sequester large amounts of carbon, and new planting may help protect old-growth forests under threat of exploitation.

\subsection{Ecology}

Pseudotsuga menziesii is a highly valuable timber tree, which has been extensively planted outside its natural range in western North America. There are two varieties, Rocky Mountain Douglas fir ( $P$. menziesii var. glauca) and Coastal Douglas fir (P. menziesii var. menziesii). The latter extends from central British Columbia, southwards to a latitude of $34^{\circ} 44^{\prime} \mathrm{N}$. It is the most dominant tree species in the Pacific West and occurs from near sea level up to $1,500 \mathrm{~m}$, often in pure stands. It grows best on well-aerated, deep soils with a $\mathrm{pH}$ between 5-6. It does not do well on poorly drained, oligotrophic soils. The Pacific Northwest has a maritime climate characterised by mild wet winters and cool dry summers, with annual average temperatures of 9$13^{\circ} \mathrm{C}$ and annual rainfall between $380-3,000 \mathrm{~mm}$. Douglas fir will not tolerate frost below $-10^{\circ} \mathrm{C}$ for periods longer than a week. It is initially relatively slow growing and attains the largest height increments between 20-30 years. It can however maintain relatively rapid rates of growth for over a century. Long rotation times of up to 100 years can produce high yields and high quality timber. Douglas fir timber has a variety of uses including timbers, pilings, railroad ties, posts and poles, flooring, veneers, pulp and furniture.

\subsection{Management Operations}

Typical management operation practices are described in the following subsections.

\subsubsection{Establishment}

Douglas fir plantations are most readily established using nursery-grown seedlings. Light shade improves survival of first-year seedlings but thereafter control of competing vegetation is 
essential. Planting is at densities between 750 and 1,500 stems per hectare $(3.6 \times 3.6$ to $2.6 \mathrm{x}$ 2.6m spacing).

\subsubsection{Maintenance}

Maintenance of Douglas fir plantations includes:

- weed control

- fertiliser application

\subsubsection{Harvesting}

Rotations are 100 years + , i.e., beyond the timescale of this study. Pre-harvest thinnings at 50 and 70 years will allow improved growth of remaining trees and provide interim income.

\subsubsection{Re-establishment}

Regeneration is usually by planting of nursery-stock, due to the requirements by forest laws for prompt regeneration of harvested areas.

\subsection{Classification of Productivity}

Productivity is classified by site index, according to height at a base year (usually 50 or 100 for Douglas fir)

Table 12-1

Productivity classes for Douglas Fir in pacific northwest USA

\begin{tabular}{|l|c|l|c|}
\hline Productivity & Site Index & \multicolumn{1}{|c|}{ Conditions } & Production \\
\hline High & $25+$ & Annual precipitation: $>1500 \mathrm{~mm}$ & $>1000 \mathrm{~m}^{3}$ \\
& & Soils: well-aerated, deep soils & 100 years \\
\hline Medium & $18-24$ & Intermediate & $>700 \mathrm{~m}^{3}$ \\
& & & 100 years \\
\hline Low & $\mathrm{n} / \mathrm{a}$ & Annual precipitation: $<1000 \mathrm{~mm}$ & Not available \\
& & Soils: poorly drained, nutrient poor soils & \\
\hline
\end{tabular}




\subsection{Carbon Sequestration Potential}

\subsubsection{Baseline}

It is assumed that plantations will be established on grassland or open ground. However, for actual projects, caution should be taken to assess whether sites are part of an established plantation cycle. The following are the initial assumptions for existing stored carbon at the site based on ECCM information.

- Vegetation: $5 \mathrm{tC} / \mathrm{ha}$.

- Soils: approximately $37 \mathrm{tC} / \mathrm{ha}$ under cropland

\subsubsection{Carbon Uptake and Storage by Pseduotsuga Menziesii}

Values selected for this case are shown in Table 12-2.

Table 12-2

Expected carbon storage from Douglas Fir plantations over 100 years

\begin{tabular}{|l|c|c|c|}
\hline Productivity & Low & Medium & High \\
\hline Rotation length (years) & n.a. & 100 & 100 \\
\hline Maximum above ground carbon $\left(\mathrm{tC} \mathrm{ha}^{-1}\right)$ & n.a. & 258 & 352 \\
\hline Average above-ground carbon (tC ha $\left.{ }^{-1}\right)$ & n.a. & 132 & 181 \\
\hline Average soil etc. carbon (tC ha-1) & n.a. & 137 & 147 \\
\hline
\end{tabular}

\subsection{Costs}

\subsubsection{Establishment and Maintenance}

Establishment costs for Douglas fir plantations are around $\$ 400$ per hectare. However, where there is a strong presence of Himalayan blackberry, Scotch broom or other weeds, the forest manager may well incur weeding costs of $\$ 200$ to $\$ 300$ per hectare over and above the planting costs. An establishment cost of $\$ 500$ per hectare has been assumed for this study.

The maintenance costs for Douglas fir are considerably lower than for Southern pines. A cost of $\$ 20 /$ ha per year over 4 years has been assumed for this study.

\subsubsection{Land}

A net present opportunity cost of around $\$ 800$ per hectare was selected for this case based on judgment and available existing information. 


\subsubsection{Potential Income}

High quality Douglas fir timber is a valuable commodity. Thinnings at 50 and 70 years can produce a total of about $350 \mathrm{~m}^{3} / \mathrm{ha}$, giving an income of $\$ 33,000-\$ 80,000$ at current prices, with a final felling generating $\$ 200,000-\$ 400,000$.

\subsection{Summary of Model Inputs and Results}

A summary of input variables for the base case (medium productivity) Douglas fir is presented in Table 12-3. The cost of $\mathrm{CO}_{2}$ sink enhancement (\$/tonne $\mathrm{C}$ ) is presented on several accounting bases in Table 12-4. Cumulative changes in carbon sequestered (tonne $\mathrm{C} / \mathrm{ha}$ ) and costs (\$/ha) are presented below Table 12-4 for the medium productivity case. For the high productivity case, the timber yields are 175 and $225 \mathrm{~m}^{3}$ /ha for thinnings 1 and 2, respectively, and other input variables are the same as for the medium productivity case. Costs of $\mathrm{CO}_{2}$ sink enhancement (\$/tonne $\mathrm{C}$ ) are presented for the high productivity case on several accounting bases in Table 125. Cumulative changes in carbon sequestered (tonne $\mathrm{C} / \mathrm{ha}$ ) and costs $(\$ / \mathrm{ha})$ are presented below Table 12-5 for the high productivity case. Data were unavailable for a low productivity case for Douglas fir.

Costs in Tables 12-4 and 12-5 were calculated on an NPV basis as described in Chapter 2, and can be compared with costs for $\mathrm{CO}_{2}$ capture and storage and other sink enhancement options calculated on the same NPV basis. The same establishment, land, maintenance, and harvesting costs were assumed for medium and high productivity cases in Tables 12-4 and 12-5. This assumption likely resulted in a slight underestimation of costs for the high productivity case but the general comparison is still valid. 
Table 12-3

Forestry input variables for Douglas Fir

Forestry: Input Variables

Plantation, USA, Loblolly Pine

- Plantation, USA, Douglas Fir

Plantation (Taungya), Mexico, Spanish cedar

$\bigcirc$ Restoration, Mexico, Pine-oak

Restoration, Southern Africa, Miombo

Agro- forestry, Southern India, Mango- tamarind

Avoidance of deforestation, Mexico,Various

Productivity

Interest Rate

Tax Rate

Discount rate

Transaction Costs (\$/ha)

Monitoring/ verification (\$/ha/y)

\begin{tabular}{|l|}
\hline Medium \\
$5.83 \%$ \\
$38 \%$ \\
$6.09 \%$ \\
5 \\
5 \\
\hline
\end{tabular}

\begin{tabular}{ll} 
Management: & Plantation \\
Country: & USA \\
Trees: & Douglas Fir \\
\hline
\end{tabular}

Establishment cost (\$/ha)

Land cost (\$/ha)

Annual maintenance ( $\$ / \mathrm{ha})$

Maintenance (years)

500

800

20

4

Timber revenue $\left(\$ / \mathrm{m}^{3}\right)$

150

Timber yield $\left(\mathrm{m}^{3} / \mathrm{ha}\right)$ :

Time Between

Harvests (yrs)

End of rotation

Thinning 1

Thinning 2 
Table 12-4

Forestry summary of results for Douglas Fir medium productivity case

\section{Forestry: Summary of Results (Single System) Medium Productivity}

$\mathrm{CO}_{2}$ Sink Enhancement, NPV Basis (years 1-100)

\section{Management: \\ Country/Region: \\ Trees:}

Carbon accounting basis (\$/tonne C Equivalent)

Above ground carbon

Above \& below ground carbon

Above $\&$ below ground $\&$ timber product carbon

Above \& below ground carbon \& non- $\mathrm{CO}_{2} \mathrm{GHGs}$

Above ground carbon with timber revenues

Above \& below ground carbon, non- $\mathrm{CO}_{2} \mathrm{GHGs}$, with timber products \& revenues $(A / I)^{*}$

${ }^{*}$ C Equivalent LC GHG Avoided Basis
Plantation

USA

Douglas Fir

47.58

23.21

22.79

23.61

14.01

6.83
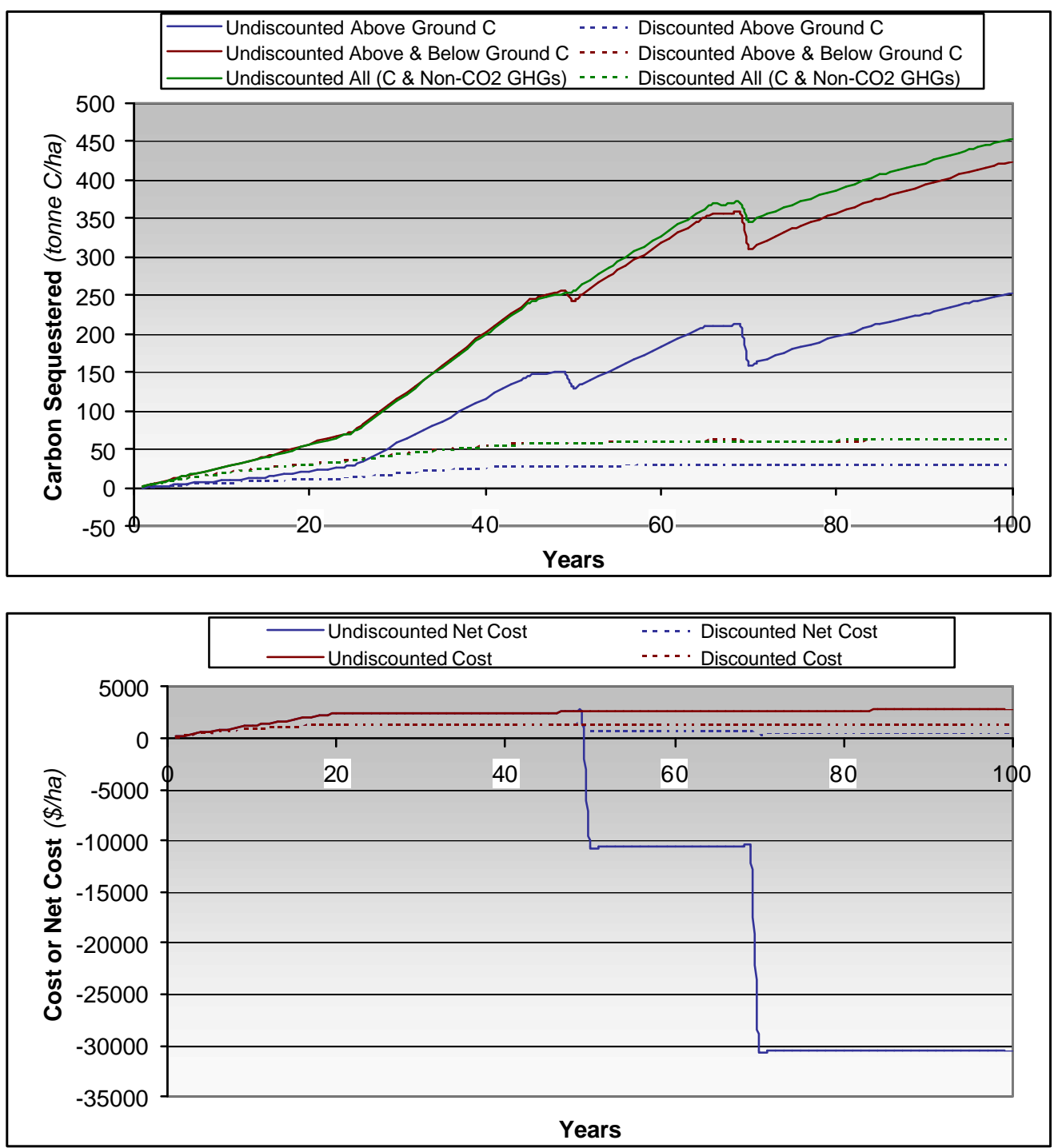
Table 12-5

Forestry summary of results for Douglas Fir high productivity case

\section{Forestry: Summary of Results (Single System) \\ High Productivity}

$\mathrm{CO}_{2}$ Sink Enhancement, NPV Basis (years 1-100)

\section{Management: \\ Country/Region: \\ Trees:}

Carbon accounting basis (\$/tonne C Equivalent)

Above ground carbon

Above \& below ground carbon

Above $\&$ below ground $\&$ timber product carbon

Above \& below ground carbon \& non- $\mathrm{CO}_{2} \mathrm{GHGs}$

Above ground carbon with timber revenues

Above \& below ground carbon, non- $\mathrm{CO}_{2} \mathrm{GHGs}$, with timber products \& revenues $(A / I)^{*}$

* C Equivalent LC GHG Avoided Basis
Plantation

USA

Douglas Fir
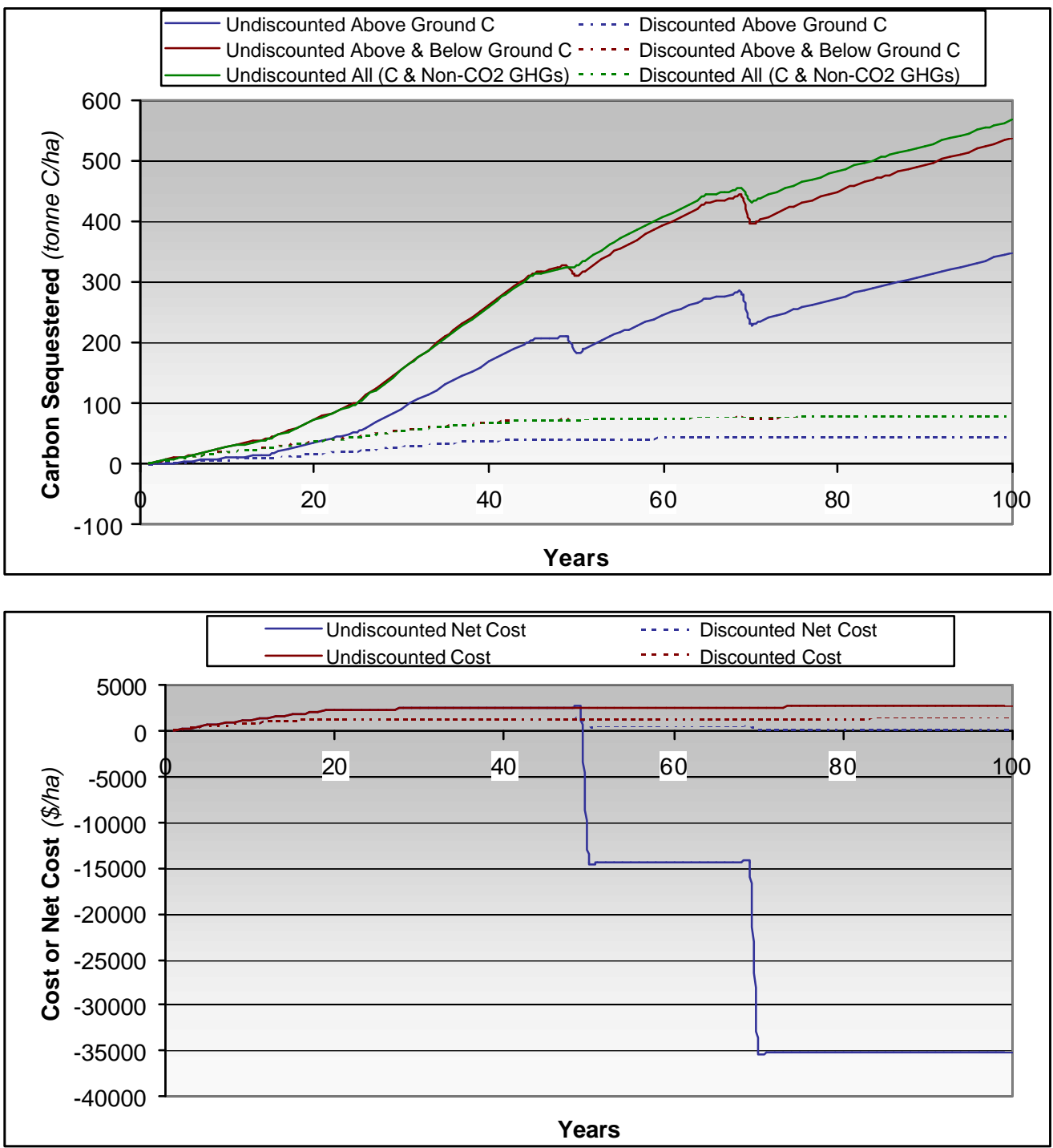


\subsection{References}

These references are not indicated specifically in the body of the chapter and instead represent background for the information presented in this chapter.

1 Birdsey, Richard, A. 1996. Carbon Storage for Major Forest Types and Regions in the Conterminous United States, in Forests and Global Change: Vol. 2. Forest Management Opportunities for Mitigating Carbon Emissions. American Forests, Washington, DC.

2 Burns, Russell M., and Barbara H. Honkala, (tech. ords.) 1990. Silvics of North America: Vol.1. Conifers. Agriculture Handbook 654. U.S. Department of Agriculture, Forest Service, Washington, DC.

3 Howard, James L. 1999. US Timber Production, Trade, Consumption and Price Statistics 1965-1997. General Technical Report GPL-GTR-116. US Department of Agriculture, Forest Service, Washington, DC. 


\section{3 \\ CASE 3: SPANISH CEDAR PLANTATIONS IN MEXICO USING THE TAUNGYA SYSTEM}

\subsection{Introduction}

The "Taungya system" for establishing plantations of Spanish cedar or "cedro" (Cedrela odorata) reduces the opportunity costs of plantation establishment by allowing the farmer to grow annual crops between the trees during the initial years. The annual crops provide some additional income and the saplings benefit from the maintenance of the crops. Furthermore, as the planting density is lower than in a mono-culture plantation, the cost of buying seedlings is reduced. After 3-4 years the tree will shade-out the annual crops. This system is best suited to areas of higher rainfall where competition for water is not a problem, and where there is sufficient labor to carry out the cropping and tree maintenance activities by hand.

\subsection{Ecology}

Cedrela odorata is a fast-growing, high- value timber tree that is native to large areas of Central and South America from southern Mexico to Bolivia, $28^{\circ} \mathrm{S}-26^{\circ} \mathrm{N}$. It is found naturally at altitudes between 0 and $1500 \mathrm{~m}$, where mean annual rainfall is between 1200-3000 mm per year, and where the mean annual temperature is $20-32^{\circ} \mathrm{C}$. It will grow on light, medium or heavy soils but thrives on free draining, fertile soils. Cedrela odorata is a light demanding species that develops best in open spaces or large clearings in the highly diverse tropical broadleaved forests but in much of its native range the gene pool has been severely depleted due to the high demand for its valuable timber. Cedrela odorata is grown as a plantation tree throughout the tropics.

\subsection{Management Operations}

The primary objective of the Taungya system is timber production. Crop yields (maize for this study) during the first few years will help cover planting costs. Thinning is used to liberate selected individuals of good form. Cedrela odorata produces a very high quality, valuable timber for which there is a ready market. Although plantations have lower biodiversity value, the production of this species may lessen pressure on surviving populations in native forests. Soil conservation is improved on steep slopes. Typical management operations are described in the following subsections. 


\subsubsection{Establishment}

Techniques used for planting maize are used to prepare the site for establishing the tree crop / maize mixture. Although these techniques vary with location the following activities are undertaken:

- Clearing weeds and other vegetation

- Sowing maize (according to local practices)

- Making holes for seedlings - large holes $30 \mathrm{~cm}$ diameter and depth produce better conditions for root development, the topsoil is more fertile and should be placed in the bottom of the hole for better rooting.

- In very compact soils holes may be dug after the start of the rains.

It is important to obtain good quality planting stock, which should be ready for planting at the beginning of the rainy season. Planting a mixture of species as well as Cedrela odorata may help reduce the occurrence of the shoot borer Hypsipyla grandela. Note if other species used have similar growth rates or account for not more than 20 percent of the crop, carbon estimates will not be significantly affected. Planting density should be between 1100 and 625 stems per ha ( $3 \times 3$ to $4 \times 4 \mathrm{~m})$. The roots of seedlings should be pruned just prior to planting to help root development

\subsubsection{Maintenance}

- Weeding should be carried out at least twice per year until canopy closure.

- Pruning is vital to maintain tree form, whenever is there is evidence of attack by Hypsipyla grandela

The most important pest of Cedrela odorata and one of the most important factors in establishment is the shoot borer Hypsipyla grandela. The larvae of the moth develop in the apical bud of young trees causing the shoot to die. This does not kill the tree but leads to the growth of several subsidiary shoots. If not pruned this will lead to forking of the main stem and drastically reduce the value of the timber. However if all but the strongest, straightest shoots that result are removed the tree will continue to grow with good form and the length of saleable timber will be much increased. Pruning of subsidiary shoots must take place within one or two years of Hypsipyla attack as the removal of older branches will put the tree at risk of disease. One means of reducing the occurrence of the shoot borer is to use a mixture of species.

Although not conclusively proven, inter-planting of other fast growing species with the Cedrela may help prevent infestation through reducing the chances of the moth finding its host in the plantation. Chemical and biological means of control do exist but the cost might make these unfeasible. The great advantage in small- scale plantations is that the farmer can quickly spot damaged trees and prune the shoots where necessary during routine maintenance. After approximately 5 years the trees become less susceptible to the shoot borer. It is extremely important that farmers are given training in pruning trees if they are to realize the full value of this species. 


\subsubsection{Harvesting}

Harvesting should take place in year 25 , however in poorer sites the rotation length may be up to 30 years.

\subsubsection{Re-establishment}

Two methods of re-establishment may be used in subsequent rotations:

1. Shelterwood: 25 to 30 trees/ha (approx. 20x20m) may be retained as seed trees when the main crop is felled to provide seed for the new crop. Regeneration should be maintained by regular weeding.

2. Repetition of the taungya system: if the crop is clear felled then the taungya system of establishment with annual crops may be repeated.

\subsection{Classification of Productivity}

Productivity is classified on three levels (low, medium and high): according to the altitude, rainfall and soil conditions shown in Table 13-1. Production figures are in cubic metres of timber harvested at the end of the specified rotation.

Table 13-1

Productivity classes for Spanish Cedar in central America

\begin{tabular}{|c|c|c|c|}
\hline Productivity & Conditio & & Production \\
\hline High & $\begin{array}{l}\text { Altitude: } \\
\text { Rainfall: } \\
\text { Soil: }\end{array}$ & $\begin{array}{l}300-1200 \mathrm{~m} \\
1450-3000 \mathrm{~mm} / \mathrm{y} \\
\text { Well-drained, brown-black }\end{array}$ & $\begin{array}{c}450 \mathrm{~m}^{3} \\
25 \mathrm{y}\end{array}$ \\
\hline Medium & $\begin{array}{l}\text { Altitude: } \\
\text { Rainfall: } \\
\text { Soil: }\end{array}$ & $\begin{array}{l}<300 \text { or }>1200 \mathrm{~m} \\
<1450 \mathrm{~mm} / \mathrm{y} \\
\text { Heavy clays; sandy }\end{array}$ & $\begin{array}{c}400 \mathrm{~m}^{3} \\
25 \mathrm{y}\end{array}$ \\
\hline Low & $\begin{array}{l}\text { Altitude: } \\
\text { Rainfall: } \\
\text { Soil: }\end{array}$ & $\begin{array}{l}<300 \text { or }>1200 \mathrm{~m} \\
<1450 \mathrm{~mm} / \mathrm{y} \\
\text { Stony, compacted or oxidised clays }\end{array}$ & $\begin{array}{c}350 \mathrm{~m}^{3} \\
30 \mathrm{y}\end{array}$ \\
\hline
\end{tabular}

\subsection{Carbon Sequestration Potential}

\subsubsection{Baseline}

The baseline conditions for Taungya systems in Central America vary considerably: most are established on land that is marginal for agricultural crops, where the land is cultivated sporadically, perhaps 2 years out of 10 using slash and burn methods. For most of the interim 
period the land is covered with a low, tangled thicket, containing a mixture of herbs, shrubs, and small trees with the occasional large or very large tree.

Because of this diversity it is necessary to assess the conditions in each plot individually. Table 13-2 gives a rapid method for assessing the components of baseline carbon-density prior to establishment of Taungya on individual plots.

Table 13-2

Components of baseline carbon stock (tC)

\begin{tabular}{|l|c|c|c|c|}
\hline Vegetation & $\begin{array}{c}\text { None } \\
<10 \% \text { cover }\end{array}$ & $\begin{array}{c}\text { Few } \\
10-20 \% \text { cover }\end{array}$ & $\begin{array}{c}\text { Moderate } \\
20-60 \% \text { cover }\end{array}$ & $\begin{array}{c}\text { Abundant } \\
>60 \% \text { cover }\end{array}$ \\
\hline Herbs & 0 & 0.4 & 1.2 & 2.0 \\
\hline Shrubs & 0 & 0.8 & 2.4 & 4.0 \\
\hline Small trees 1-5m & 0 & 1.4 & 4.2 & 12.0 \\
\hline Medium trees 5-10m & 0 & 2.4 & 7.2 & 18.0 \\
\hline Large trees 10-20m & & \multicolumn{5}{|c|}{3 tC per tree } \\
\hline Very large trees $>20 \mathrm{~m}$ & \multicolumn{5}{|c|}{} \\
\hline
\end{tabular}

For the purposes of this assessment the baseline vegetation carbon content was assumed to be $8.6 \mathrm{tC} / \mathrm{ha}$.

\subsubsection{Carbon Uptake and Storage by Cedrela Odorata}

Following the first 3 years of establishment, the system will accumulate carbon rapidly at 8 to 15 $\mathrm{tC} \mathrm{ha}^{-1} \mathrm{y}^{-1}$ during most of the 25-30 year rotation. Carbon storage for different productivity classes will be approximately as shown in Table 13-3:

Table 13-3

Expected carbon storage from Spanish Cedar over 100 years

\begin{tabular}{|l|c|c|c|}
\hline Productivity & Low & Medium & High \\
\hline Rotation length (years) & 30 & 25 & 25 \\
\hline Maximum above ground carbon $\left(\mathrm{tC} \mathrm{ha}{ }^{-1}\right)$ & 126 & 148 & 173 \\
\hline Average above-ground carbon $\left(\mathrm{tC} \mathrm{ha}{ }^{-1}\right)$ & 68 & 82 & 102 \\
\hline Average soil etc. carbon ( $\left.\mathrm{tC} \mathrm{ha}^{-1}\right)$ & 121 & 132 & 147 \\
\hline
\end{tabular}




\subsection{Costs}

\subsubsection{Establishment and Maintenance}

The cost of implementation by small farmers in Chiapas, southern Mexico (2000) was estimated at $\$ 385 /$ ha. In the first three years most of the weeding costs are paid for by the cultivation of maize between the young trees. The only other significant cost is pruning of trees attacked by shoot borer. The cost depends upon the severity of the attack and could be anything from zero in unaffected plantations to $\$ 50$ per hectare per year up to year 7 on severely affected plots. A cost of $\$ 25 /$ ha for 7 years was assumed for this study.

\subsubsection{Land Cost}

These systems are generally established on marginal agricultural land, where slope or soil conditions are sub-optimal for maize production. The opportunity cost (lost production from land) is estimated at \$0-1350/ha, depending upon site quality (agricultural production on poor quality sites has virtually zero opportunity cost). An average value of $\$ 675 /$ ha was chosen for this study.

\subsubsection{Potential Income}

Potential income from timber production of $400 \mathrm{~m}^{3} /$ ha at a price of $\$ 100 / \mathrm{m}^{3}$ gives a total of \$40k \$/ha per rotation.

\subsection{Summary of Model Inputs and Results}

A summary of input variables for the base case (medium productivity) Spanish cedar is presented in Table 13-4. The cost of $\mathrm{CO}_{2}$ sink enhancement (\$/tonne $\mathrm{C}$ ) is presented on several accounting bases in Table 13-5. Cumulative changes in carbon sequestered (tonne $\mathrm{C} / \mathrm{ha}$ ) and costs (\$/ha) are presented below Table 13-5 for the medium productivity case. For the low productivity case, the timber yield at the end of the rotation is $350 \mathrm{~m}^{3} / \mathrm{ha}$, time between harvest is 30 years, and other input variable s are the same as for the medium productivity case. Costs of $\mathrm{CO}_{2}$ sink enhancement (\$/tonne $\mathrm{C}$ ) are presented for the low productivity case on several accounting bases in Table 13-6. Cumulative changes in carbon sequestered (tonne $\mathrm{C} / \mathrm{ha}$ ) and costs (\$/ha) are presented below Table 13-6 for the high productivity case. For the high productivity case, the timber yield at the end of the rotation is $450 \mathrm{~m}^{3} / \mathrm{ha}$, time between harvest is 25 years, and other input variables are the same as for the medium productivity case. Costs of $\mathrm{CO}_{2}$ sink enhancement (\$/tonne C) are presented for the high productivity case on several accounting bases in Table 13-7. Cumulative changes in carbon sequestered (tonne $\mathrm{C} / \mathrm{ha}$ ) and costs (\$/ha) are presented below Table 13-7 for the high productivity case.

Costs in Tables 13-5 to13-7 were calculated on an NPV basis as described in Chapter 2, and can be compared with costs for $\mathrm{CO}_{2}$ capture and storage and other sink enhancement options calculated on the same NPV basis. The same establishment, land, maintenance, and harvesting 
costs were assumed for medium, low, and high productivity cases in Tables 13-5 to 13-7. This assumption likely resulted in a slight overestimation of costs for the low productivity case and a slight underestimation of costs for the high productivity case but the general comparison is still valid.

In the graphs associated with Tables 13-5 to 13-7, the change in aboveground carbon becomes negative at the beginning of the accounting period. The initial negative change in aboveground carbon is due to clearing of some existing vegetation in preparation for establishment of the Spanish Cedar plantation. The cumulative change in aboveground carbon becomes positive as the new tree growth more than compensates for the clearing of vegetation before planting.

Table 13-4

Forestry input variables for Spanish Cedar

Forestry: Input Variables

$\begin{array}{ll}\bigcirc & \text { Plantation, USA, Loblolly Pine } \\ \bigcirc & \text { Plantation, USA, Douglas Fir } \\ \bigcirc & \text { Plantation (Taungya), Mexico, Spanish cedar } \\ \bigcirc & \text { Restoration, Mexico, Pine-oak } \\ \bigcirc & \text { Restoration, Southern Africa, Miombo } \\ \bigcirc & \text { Agro- forestry, Southern India, Mango- tamarind } \\ \bigcirc & \text { Avoidance of deforestation, Mexico,Various }\end{array}$

Productivity

Interest Rate

\begin{tabular}{|l|}
\hline Medium \\
$5.83 \%$ \\
$38 \%$ \\
$6.09 \%$ \\
5 \\
5 \\
\hline
\end{tabular}

Management:

Country:

Plantation (Taungya)

Trees:

Mexico

Spanish cedar

Establishment cost (\$/ha)

Land cost (\$/ha)

Annual maintenance (\$/ha)

Maintenance (years)

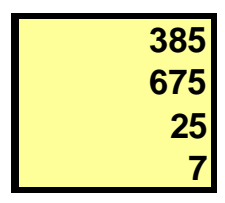

Timber revenue $\left(\$ / \mathrm{m}^{3}\right)$

100

Timber yield $\left(\mathrm{m}^{3} / \mathrm{ha}\right)$ :

End of rotation

Thinning 1

Thinning 2

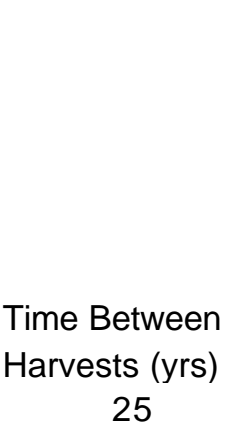

400

25 
Table 13-5

Forestry summary of results for Spanish Cedar medium productivity case

\section{Forestry: Summary of Results (Single System) Medium Productivity}

$\mathrm{CO}_{2}$ Sink Enhancement, NPV Basis (years 1-100)

\section{Management: \\ Country/Region: \\ Trees:}

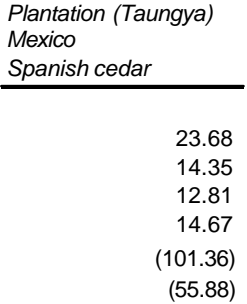

Plantation (Taungya)

Mexico

Carbon accounting basis (\$/tonne C Equivalent)

Above ground carbon

Above \& below ground carbon

Above \& below ground \& timber product carbon

Above \& below ground carbon \& non- $\mathrm{CO}_{2}$ GHGs

Above ground carbon with timber revenues

Above \& below ground carbon, non- $\mathrm{CO}_{2} \mathrm{GHG}$, with timber products \& revenues $(A / l)^{\star}$

${ }^{*}$ C Equivalent LC GHG Avoided Basis
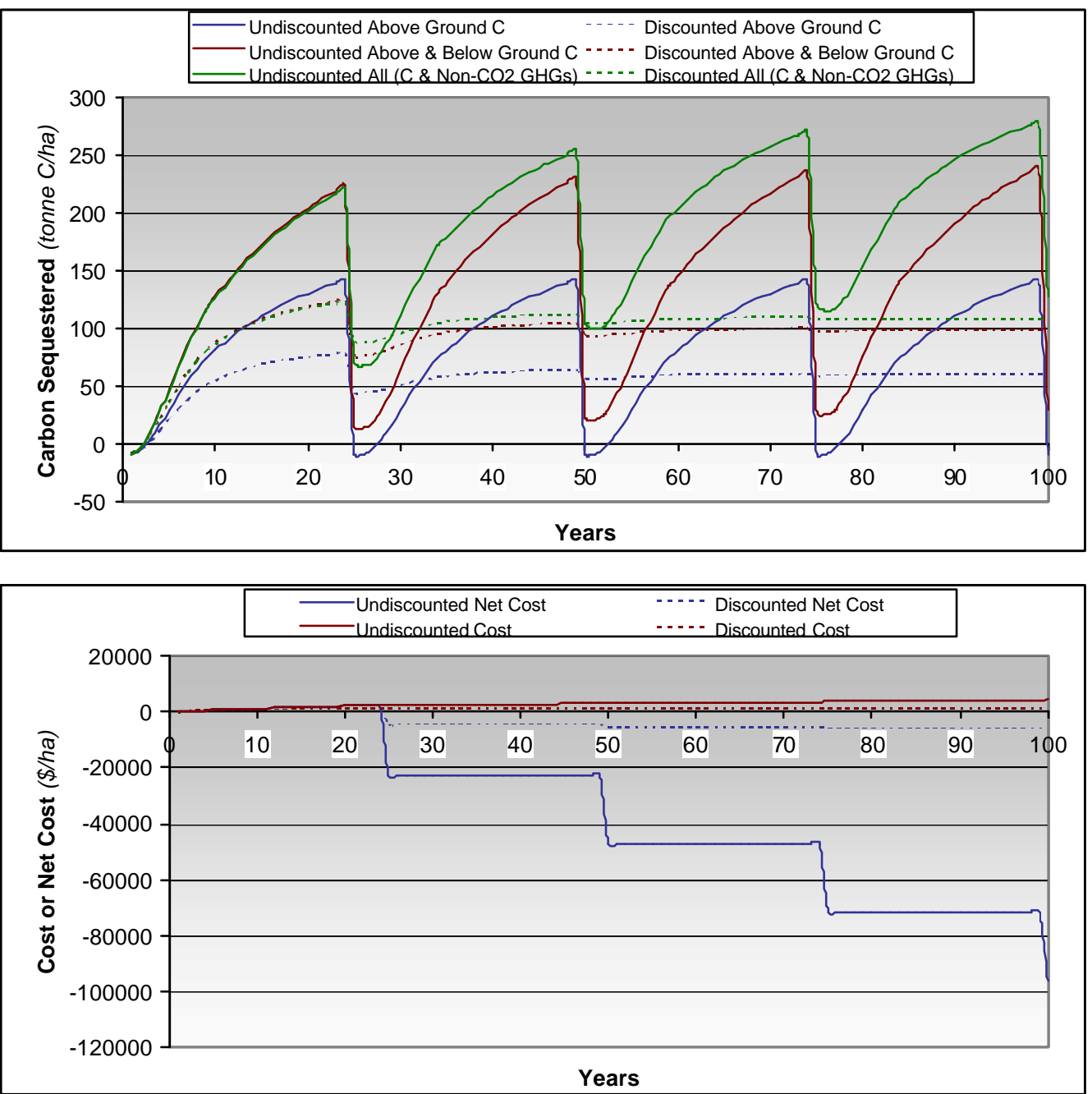
Table 13-6

Forestry summary of results for Spanish Cedar low productivity case

Forestry: Summary of Results (Single System)

Low Productivity

$\mathrm{CO}_{2}$ Sink Enhancement, NPV Basis (years 1-100)

\section{Management: \\ Country/Region: \\ Trees:}

Plantation (Taungya)

Mexico

Spanish cedar

Carbon accounting basis (\$/tonne C Equivalent) Above ground carbon

Above \& below ground carbon

Above \& below ground \& timber product carbon

Above \& below ground carbon \& non- $\mathrm{CO}_{2}$ GHGs

Above ground carbon with timber revenues

Above \& below ground carbon, non- $\mathrm{CO}_{2} \mathrm{GHGs}$, with timber products \& revenues $(A / l)^{*}$

* C Equivalent LC GHG Avoided Basis
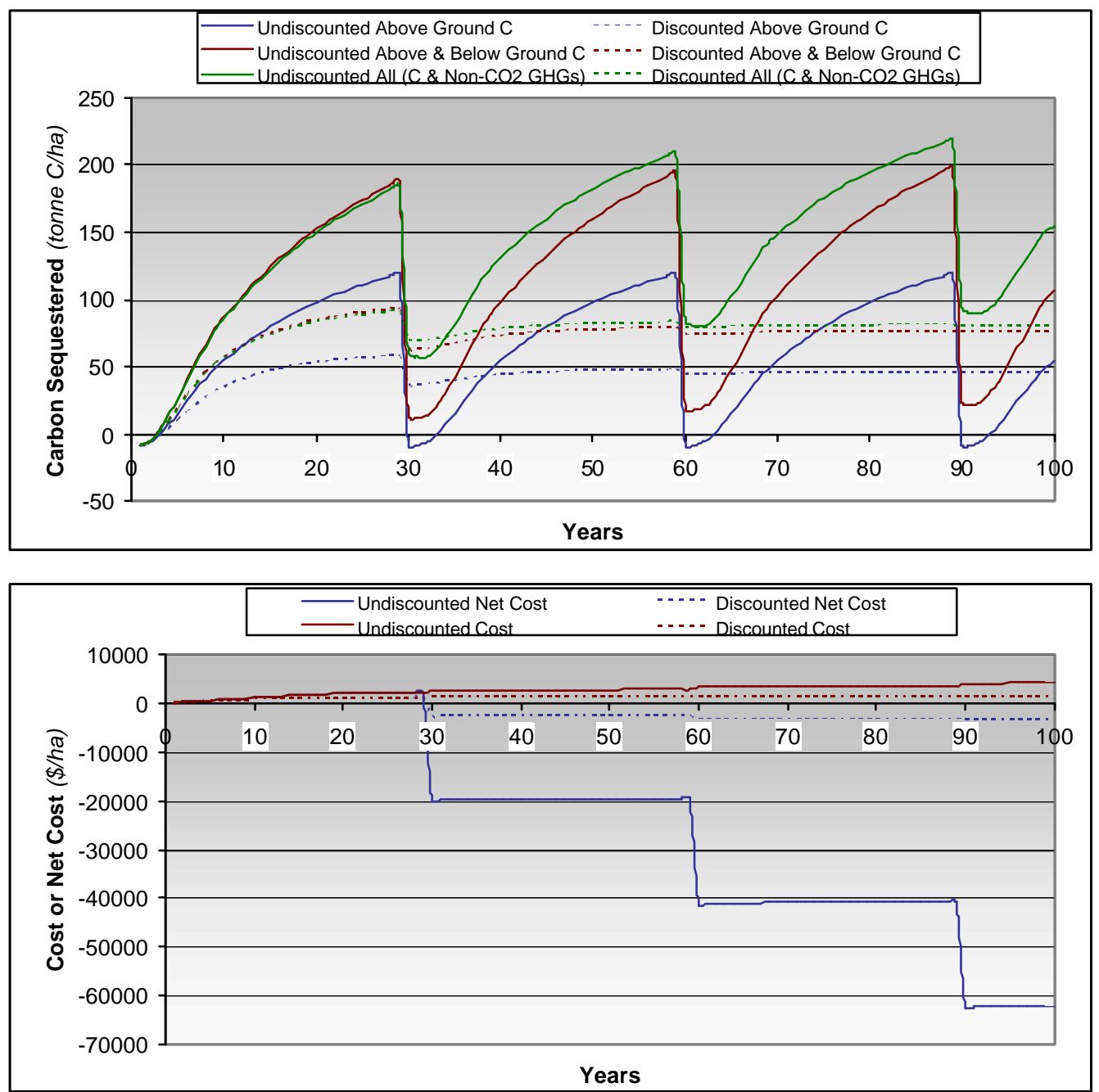
Table 13-7

Forestry summary of results for Spanish Cedar high productivity case

\section{Forestry: Summary of Results (Single System) \\ High Productivity}

$\mathrm{CO}_{2}$ Sink Enhancement, NPV Basis (years 1-100)

\section{Management: \\ Country/Region: \\ Trees:}

\begin{tabular}{l} 
Plantation (Taungya) \\
Mexico \\
Spanish cedar \\
\hline \\
\\
\\
\\
18.42 \\
11.22 \\
10.11 \\
11.41 \\
$(90.70)$ \\
$(50.55)$
\end{tabular}

(50.55)

Carbon accounting basis (\$/tonne C Equivalent) Above ground carbon

Above \& below ground carbon

Above \& below ground \& timber product carbon

Above \& below ground carbon \& non- $\mathrm{CO}_{2}$ GHGs

Above ground carbon with timber revenues

Above \& below ground carbon, non- $\mathrm{CO}_{2}$ GHGs, with timber products \& revenues $(A I I)^{*}$

* C Equivalent LC GHG Avoided Basis
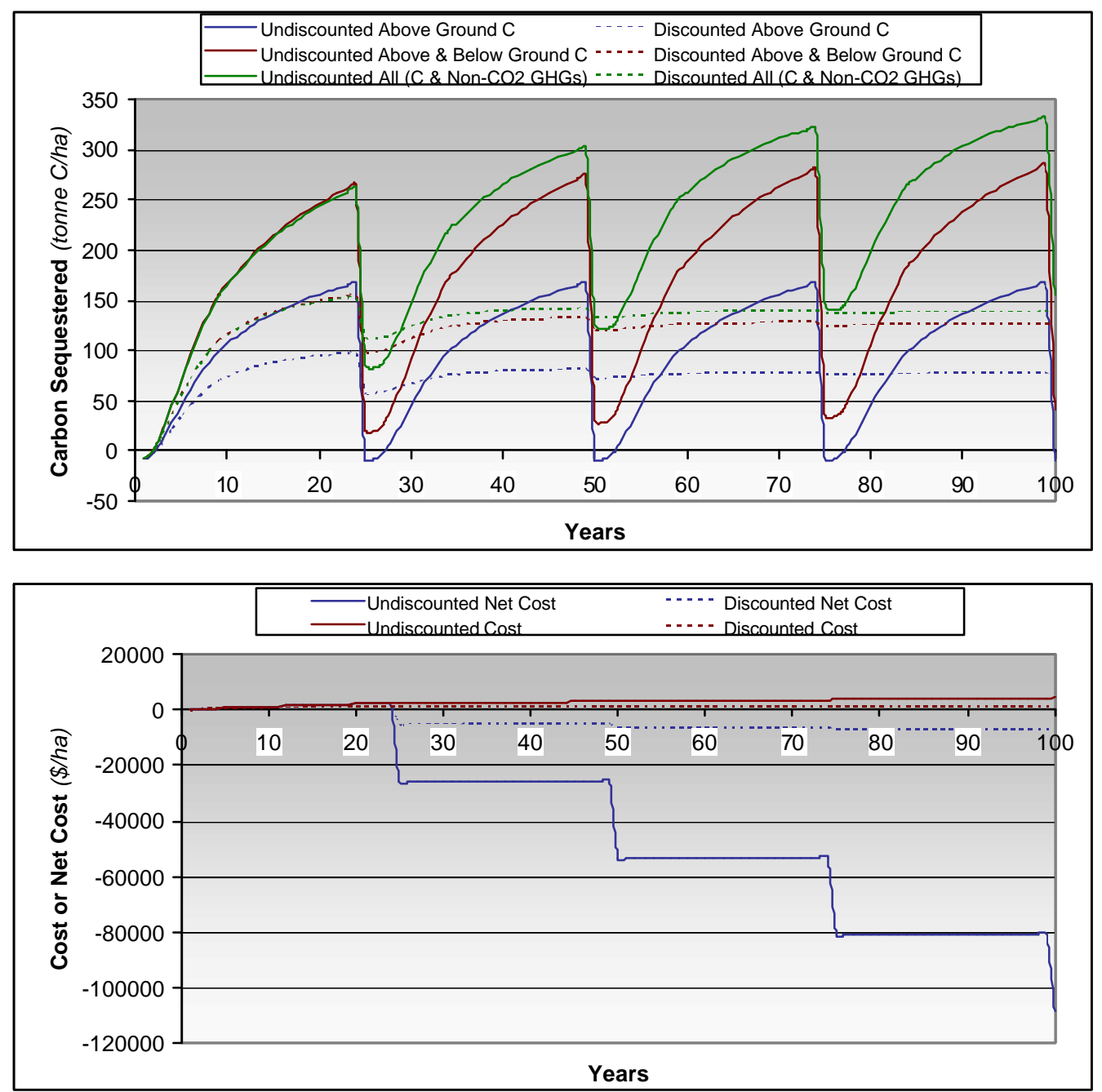


\subsection{Reference}

These references are not indicated specifically in the body of the chapter and instead represent background for the information presented in this chapter.

1 Mayhew J.E. and Newton A.C. (1998) The Silviculture of Mahogany. CABI Publishing, Wallingford, UK.

2 Webb D.B., Wood P.J., Smith J.P. and Henman G.S. (1984) A Guide to Species Selection for Tropical and Subtropical Plantations. Tropical Forestry Paper 15, Oxford, UK.

3 CABI Forestry Compendium.

4 ECCM technical note for classifying productivity in the absence of yield class information

5 Data adapted from Tipper R., de Jong B., Ochoa-Gaona S., Soto-Pinto M., Castillo-Santiago M., Montoya-Gomez G. and March-Mifsut I. (1999) Assessment of the cost of large scale forestry for $\mathrm{CO} 2$ sequestration: evidence from Chiapas, Mexico. IEA Greenhouse Gas R\&D Programme.

6 de Jong unpublished data.

7 Montoya G., Soto L., de Jong B., Nelson K., Farias P., Taylor J. and Tipper R. (1995) Desarrollo forestall sustenable: captura de carbono en las zones tzeltal y tojolabal del estado de Chiapas. Cuadernos de Trabajo 4, Instituto Nacional de Ecología, Mexico.

8 Cibrian 1995. 


\section{4 \\ CASE 4: RESTORATION OF DEGRADED PINE-OAK WOODLAND IN CHIAPAS, MEXICO THROUGH ENRICHMENT PLANTING WITH PINUS OOCARPA}

\subsection{Introduction}

This case is based on a system used in the central highlands of Chiapas, Mexico. It involves the management of secondary pine/oak vegetation for the production of timber, fuelwood and other products through enrichment planting with Pinus oocarpa and liberation thinning to encourage the growth of naturally regenerating oak (Quercus sp).

Pinus oocarpa produces good quality timber. There is a ready market for both round and sawn wood, and it is also used locally for house construction. Oak trees of good form can produce a high value timber and it is also the preferred species for fuelwood. Other species present are used for various purposes including poles, stakes, fruits and flowers. Regenerating pine/oak forest has a high biodiversity value due to the variety of tree species and other flora and fauna present. Soil conservation is improved on steep slopes.

\subsection{Ecology $y^{1,2,3,4}$}

Pine-oak forest occurs naturally in temperate to sub-tropical mountain regions of Central America. The composition of pine-oak forests is extremely varied and different mixtures of at least 5 species of oak, the most common, and economically important of which are $Q$. segouiensis (roble) and Q. crispipilis (chicinb), and 4 species of pine occur in different locations in the highlands of southern Mexico. Well-preserved areas of forest are noted for their diverse flora and fauna, including bromeliads, orchids and hummingbirds. However, these highland areas are among the most densely populated regions of Central America and the composition and structure of these forests are heavily influenced by human activities, such as slash and burn agriculture, timber harvesting browsing by sheep and goats and the collection of firewood. In many cases the forests have been severely degraded, such that only scrubby vegetation remains.

Pinus oocarpa is one of the native pine species of the region. It occurs over a wide range of altitude, $250-2500 \mathrm{~m}$, and rainfall, $700-3000 \mathrm{~mm} / \mathrm{yr}$. It grows best between 700 and $2000 \mathrm{~m}$ and with 1200-2000 mm rain/yr on free draining soils ${ }^{1}$ and will tolerate shallow or infertile soils and steep slopes. The mean annual temperature in its natural range is $13-21^{\circ} \mathrm{C}$ with a mean range of $8-32^{\circ} \mathrm{C}$ from the hottest to coldest month. 


\subsection{Management Operations}

Typical management operations are described in the following subsections.

\subsubsection{Establishment}

Planting lines at $2 \mathrm{~m}$ widths are cleared through the existing secondary vegetation to reduce competition for light. It is recommended to cut these lines on an east-west axis to maximize the available sunlight. The planting lines are cleared of all herbaceous and shrubby vegetation and all overhanging branches are cut back; planting lines may be diverted around larger trees to save labour.

Holes are dug for seedlings (30 cm depth and 30cm diameter) - large holes produce better conditions for root development. Seedlings are planted at a density between 5-700 stems /ha ( $7 \times 2$ to $7 \times 3 \mathrm{~m})$. The roots of seedlings are pruned just prior to planting to help root development. It is important to obtain good quality planting stock, which should be ready for planting at the beginning of the rainy season.

\subsubsection{Maintenance}

Weeding is carried out twice per year until canopy closure. Pruning is carried out when necessary to prevent forking and to reduce lateral branching. Planting lines are maintained clear of overhanging branches until the pine trees reach the height of surrounding secondary vegetation.

\subsubsection{Harvesting}

The harvest takes place in year 30-35 when the trees have a diameter of $40 \mathrm{~cm}$.

\subsubsection{Re-establishment}

Two methods of re-establishment may be used in subsequent rotations:

1. Shelterwood: 25 to 30 trees per ha (approx. $20 \times 20 \mathrm{~m}$ ) may be retained as seed trees when the main crop is felled to provide seed for the new crop. Regeneration should be maintained by regular weeding.

2. Re-establishment through the taungya system. An increase in soil fertility may make the plot suitable for replanting with pine seedlings combined with cultivation of maize for the first 3-4 years. 


\subsection{Classification of Productivity}

In Table 14-1, productivity is classified according to climatic and soil conditions ${ }^{1}$; site productivity is classified by soil characteristics (under development) and the production of maize $^{5}$.

\section{Table 14-1 \\ Productivity classes for Pinus Oocarpa in Chiapas, Mexico}

\begin{tabular}{|l|l|l|}
\hline Productivity & Conditions & Production \\
\hline High & Altitude: $700-2000 \mathrm{~m}$ & $320 \mathrm{~m}^{3}$ \\
& Rainfall: $1500-2000 \mathrm{~mm}$ & $30 \mathrm{y}$ \\
& Soil: Well-drained sandy loams, $>30 \mathrm{~cm}$ depth & \\
\hline \multirow{2}{*}{ Medium } & Altitude: $700-2000 \mathrm{~m}$ & $280 \mathrm{~m}^{3}$ \\
& Rainfall: $1200-1500 \mathrm{~mm}$ & $35 \mathrm{y}$ \\
& Soil: Intermediate & $220 \mathrm{~m}^{3}$ \\
& Altitude: $<700$ or $>2000 \mathrm{~m}$ & $35 \mathrm{y}$ \\
& Rainfall: $<1200 \mathrm{~mm} / \mathrm{y}$ & \\
\hline
\end{tabular}

\subsection{Carbon Sequestration Potential}

\subsubsection{Baseline}

Since the condition of the forest resource at the start of a project will vary from place to place it is important to assess the baseline carbon storage at each site. Table 14-2 provides a rapid method for estimating baseline carbon density at year 0 . 
Table 14-2

Components of baseline carbon stock (tC)

\begin{tabular}{|l|c|c|c|c|}
\hline Vegetation & $\begin{array}{c}\text { None } \\
<\mathbf{1 0 \%} \text { cover }\end{array}$ & $\begin{array}{c}\text { Few } \\
\mathbf{1 0 - 2 0 \%} \text { cover }\end{array}$ & $\begin{array}{c}\text { Moderate } \\
\mathbf{2 0 - 6 0 \%} \text { cover }\end{array}$ & $\begin{array}{c}\text { Abundant } \\
\mathbf{6 0} \% \text { cover }\end{array}$ \\
\hline Herbs & 0 & 0.4 & 1.2 & 2.0 \\
\hline Shrubs & 0 & 0.8 & 2.4 & 4.0 \\
\hline Small trees 1-5m & 0 & 1.4 & 4.2 & 12.0 \\
\hline Medium trees 5-10m & 0 & 2.4 & 7.2 & 20.0 \\
\hline Large trees 10-20m & & \multicolumn{5}{|c|}{$0.8 \mathrm{tC}$ per tree } \\
\hline Very large trees $>20 \mathrm{~m}$ & \multicolumn{5}{|c|}{$2.5 \mathrm{tC}$ per tree } \\
\hline
\end{tabular}

For the purposes of this study the baseline vegetation carbon content was assumed to be $20.6 \mathrm{tC} / \mathrm{ha}$.

Since most semi-degraded pine-oak forests in the central highlands of Chiapas are in a process of gradual deterioration, it is reasonable to expect further loss of biomass in the baseline scenario, of at least 1 percent per year. This rate of loss could be exceeded in areas where there is a high level of population pressure and ease of access. However, it is recommended that rates of loss of carbon stocks in excess of 1 percent per year should be substantiated using an objectively verifiable methodology such as a regional risk matrix model (RRM) as discussed for Case 7 (avoidance of deforestation).

\subsubsection{Carbon Uptake by the Regenerating Forest}

Following the first 4 years of establishment, the system will accumulate carbon at 5 to $12 \mathrm{tC} \mathrm{ha}^{-1} \mathrm{y}^{-1}$ during most of the 30-35 year rotation. Carbon storage for different productivity classes will be approximately as shown in Table 14-3:

\section{Table 14-3}

Expected carbon storage from Pine-Oak forest enriched with Pinus Oocarpa over 100 years

\begin{tabular}{|l|c|c|c|}
\hline Productivity & Low & Medium & High \\
\hline Rotation length (years) & 35 & 35 & 30 \\
\hline Maximum above ground carbon $\left(\mathrm{tC} \mathrm{ha}^{-1}\right)$ & 73 & 98 & 112 \\
\hline Average above-ground carbon $\left.(\mathrm{tC} \mathrm{ha})^{-1}\right)$ & 44 & 61 & 67 \\
\hline Average soil etc. carbon (tC ha $\left.{ }^{-1}\right)$ & 99 & 114 & 121 \\
\hline
\end{tabular}




\subsection{Costs:}

\subsubsection{Establishment and Maintenance}

The cost of initial establishment has been estimated at $\$ 290$ per hectare followed by annual maintenance costs of around $\$ 60$ per year for a further 6 to 8 years, depending on the state of the vegetation into which the pine is introduced. From then on any maintenance costs are likely to be covered by the value of fuelwood, fenceposts, and other minor forest products.

\subsubsection{Land}

The net present opportunity cost of land associated with this system is generally near to zero, since the alternative use would be marginal grazing on the degraded forest with perhaps the occasional crop of maize in patches of bare ground. A conservatively low value of $\$ 200 / \mathrm{ha}$ was chosen for this study.

\subsubsection{Potential Income}

$300 \mathrm{~m}^{3}$ of pine timber/ha could be produced, at a price of $\$ 30 / \mathrm{m}^{3}$, giving a total income of $\$ 9000 /$ ha at end of rotation plus additional benefits from fuelwood and other products. The volume of timber is estimated from the average reported yield ${ }^{2}$.

\subsection{Summary of Model Inputs and Results}

A summary of input variables for the base case (medium productivity) Pine oak is presented in Table 14-4. The cost of $\mathrm{CO}_{2}$ sink enhancement (\$/tonne $\mathrm{C}$ ) is presented on several accounting bases in Table 14-5. Cumulative changes in carbon sequestered (tonne C/ha) and costs ( $\$ /$ ha) are presented below Table 14-5 for the medium productivity case. For the low productivity case, the timber yield at the end of the rotation is $220 \mathrm{~m}^{3} / \mathrm{ha}$, time between harvest is 35 years, and other input variables are the same as for the medium productivity case. Costs of $\mathrm{CO}_{2}$ sink enhancement (\$/tonne $\mathrm{C}$ ) are presented for the low productivity case on several accounting bases in Table 14-6. Cumulative changes in carbon sequestered (tonne $\mathrm{C} / \mathrm{ha}$ ) and costs $(\$ / \mathrm{ha})$ are presented below Table 14-6 for the high productivity case. For the high productivity case, the timber yield at the end of the rotation is $320 \mathrm{~m}^{3} / \mathrm{ha}$, time between harvest is 30 years, and other input variables are the same as for the medium productivity case. Costs of $\mathrm{CO}_{2}$ sink enhancement (\$/tonne $\mathrm{C}$ ) are presented for the high productivity case on several accounting bases in Table 14-7. Cumulative changes in carbon sequestered (tonne C/ha) and costs (\$/ha) are presented below Table 14-7 for the high productivity case.

Costs in Tables 14-5 to 14-7 were calculated on an NPV basis as described in Chapter 2, and can be compared with costs for $\mathrm{CO}_{2}$ capture and storage and other sink enhancement options calculated on the same NPV basis. The same establishment, land, maintenance, and harvesting costs were assumed for medium, low, and high productivity cases in Tables 14-5 to 14-7. This assumption likely resulted in a slight overestimation of costs for the low productivity case and a 
slight underestimation of costs for the high productivity case but the general comparison is still considered valid.

Table 14-4

Forestry input variables for Pine-Oak

Forestry: Input Variables

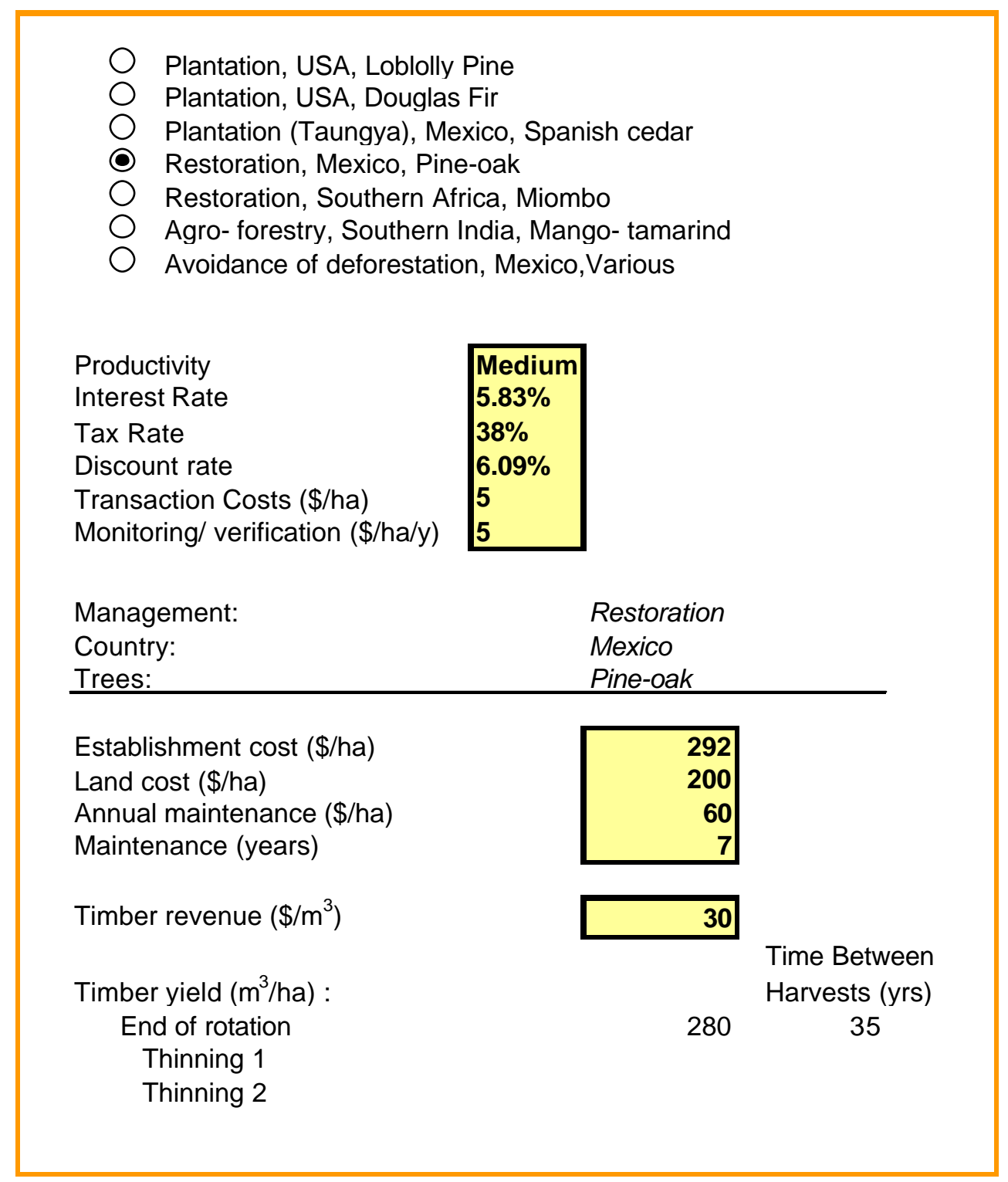


Table 14-5

Forestry summary of results for Pine-Oak medium productivity case

Forestry: Summary of Results (Single System)

Medium Productivity

$\mathrm{CO}_{2}$ Sink Enhancement, NPV Basis (years 1-100)

Management:

Country/Region:

Trees:

Carbon accounting basis (\$/tonne C Equivalent)

Above ground carbon

Above \& below ground carbon

Above \& below ground \& timber product carbon

Above \& below ground carbon \& non- $\mathrm{CO}_{2}$ GHGs

Above ground carbon with timber revenues

Above \& below ground carbon, non- $\mathrm{CO}_{2} \mathrm{GHGs}$, with timber products \& revenues $(A / l)^{*}$

* C Equivalent LC GHG Avoided Basis
Restoration

Mexico

Pine-oak

20.47

12.68

12.20

13.03

3.54

2.17
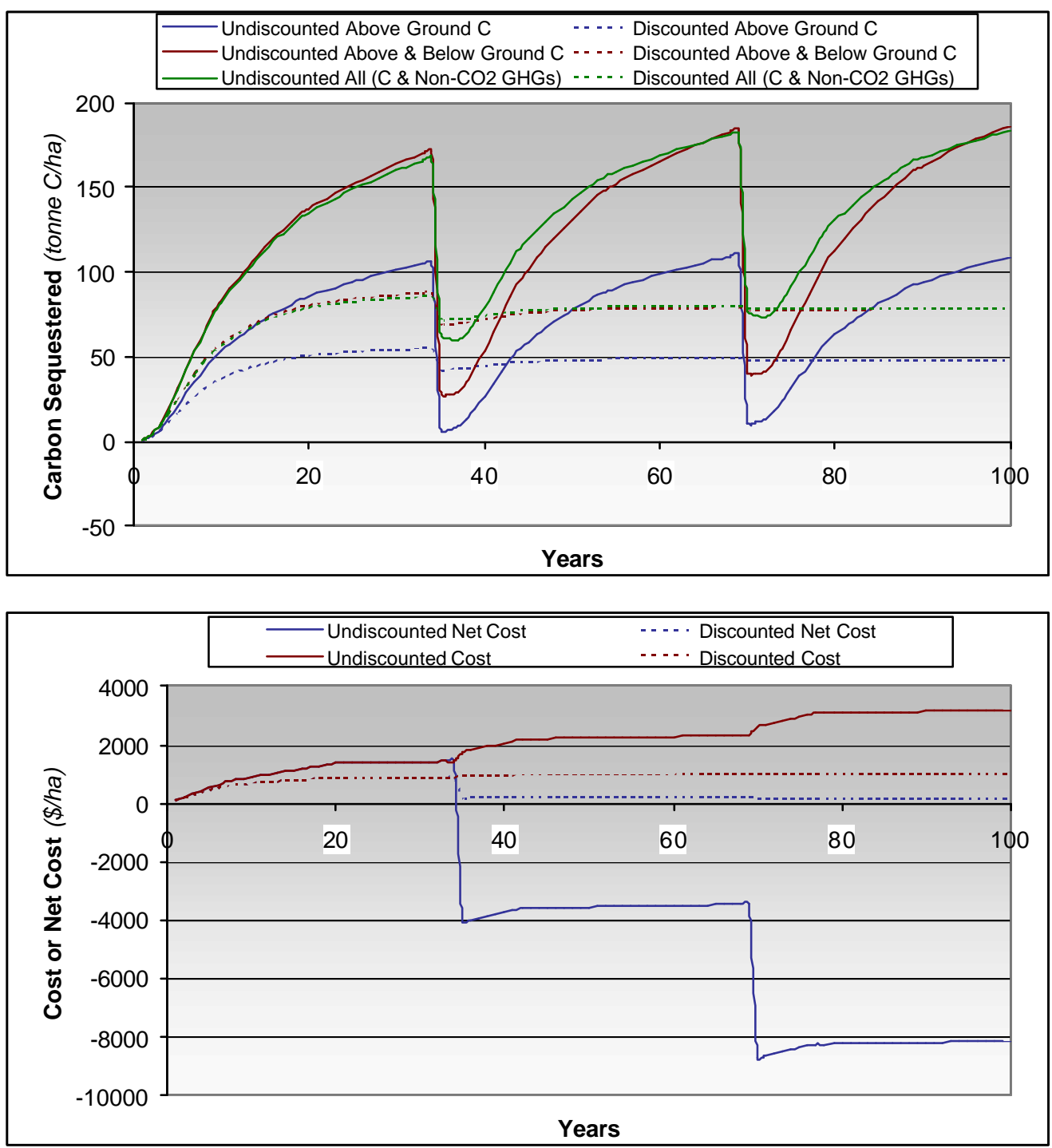
Table 14-6

Forestry summary of results for Pine-Oak low productivity case

\section{Forestry: Summary of Results (Single System) Low Productivity}

$\mathrm{CO}_{2}$ Sink Enhancement, NPV Basis (years 1-100)

\section{Management: \\ Country/Region: \\ Trees:}

Carbon accounting basis (\$/tonne C Equivalent)

Above ground carbon

Above \& below ground carbon

Above \& below ground \& timber product carbon

Above \& below ground carbon \& non- $\mathrm{CO}_{2} \mathrm{GHGs}$

Above ground carbon with timber revenues

Above \& below ground carbon, non- $\mathrm{CO}_{2} \mathrm{GHGs}$, with timber products \& revenues $(A / I)^{*}$

${ }^{*}$ C Equivalent LC GHG Avoided Basis

\section{Restoration \\ Mexico \\ Pine-oak}

\subsection{6}

18.32

17.55

19.07

9.68

6.07
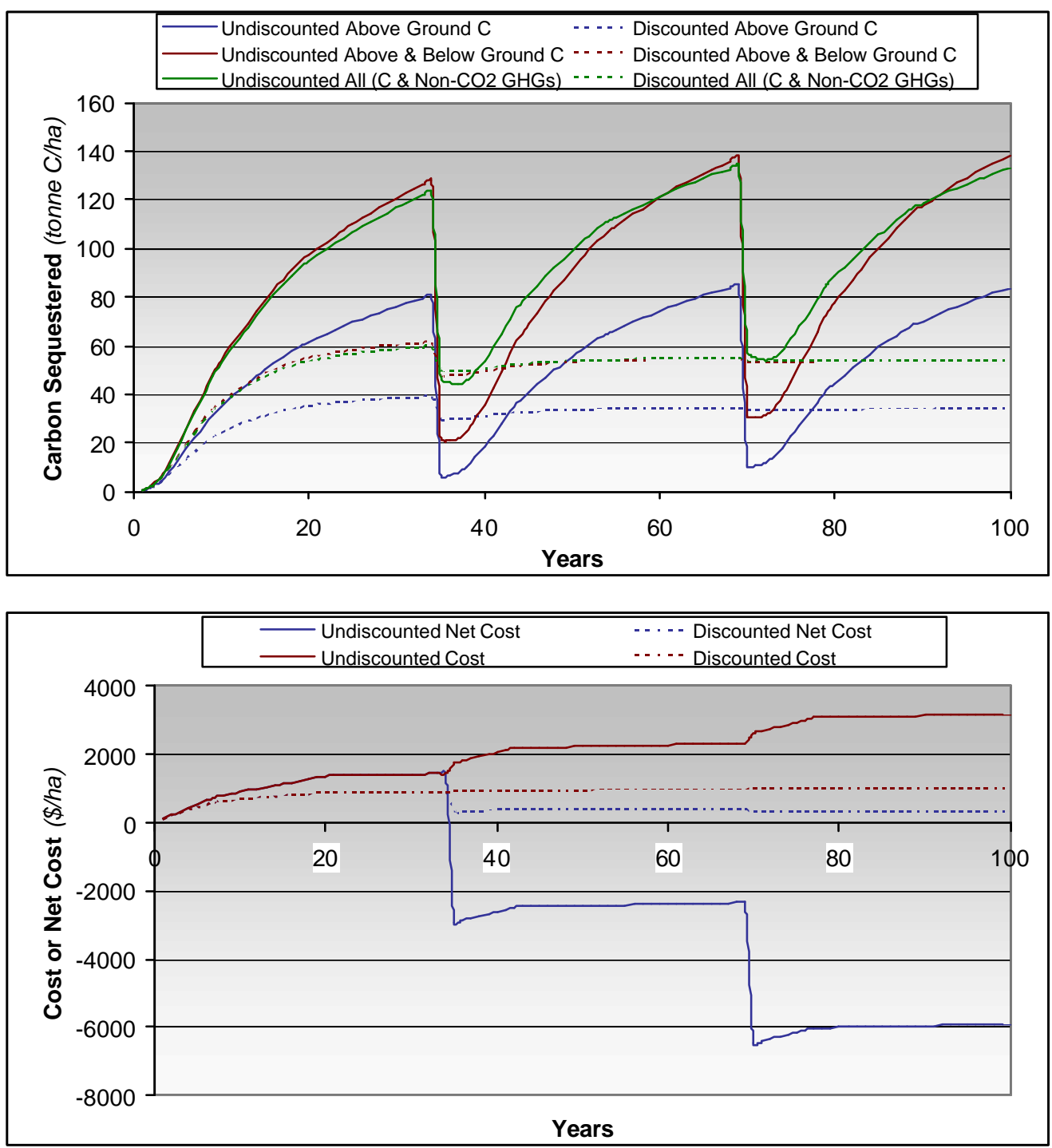
Table 14-7

Forestry summary of results for Pine-Oak high productivity case

\section{Forestry: Summary of Results (Single System) High Productivity}

$\mathrm{CO}_{2}$ Sink Enhancement, NPV Basis (years 1-100)

\section{Management: \\ Country/Region: \\ Trees:}

Carbon accounting basis (\$/tonne C Equivalent)

Above ground carbon

Above \& below ground carbon

Above \& below ground \& timber product carbon

Above \& below ground carbon \& non- $\mathrm{CO}_{2} \mathrm{GHGs}$

Above ground carbon with timber revenues

Above \& below ground carbon, non- $\mathrm{CO}_{2} \mathrm{GHGs}$, with timber products \& revenues $(A / I)^{*}$

* C Equivalent LC GHG Avoided Basis

\section{Restoration \\ Mexico \\ Pine-oak}

\subsection{7}

10.86

10.33

11.11

(5.00)

(2.97)
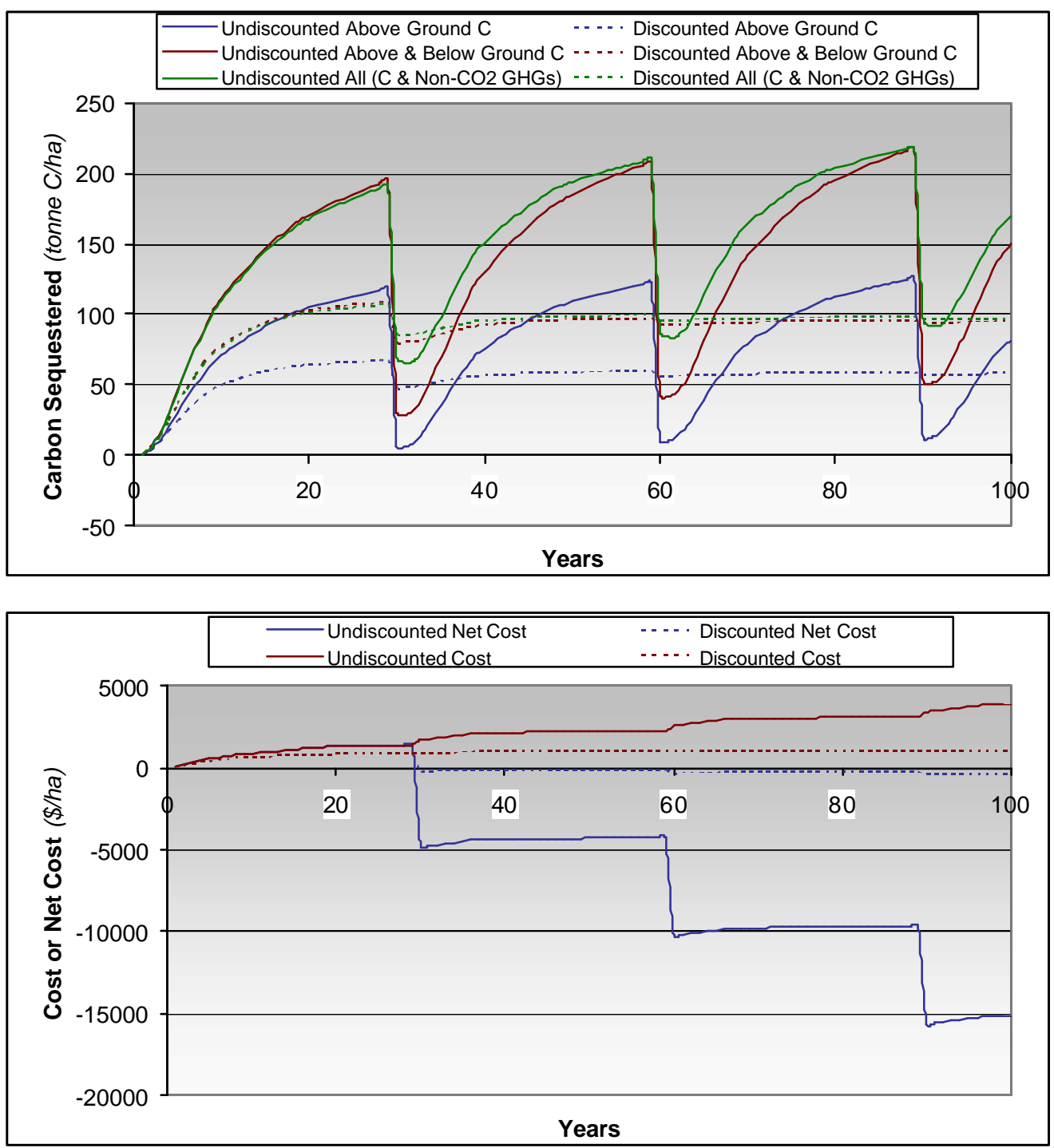


\subsection{References}

Some of these references are not indicated specifically in the body of the chapter and instead represent background for the information presented in this chapter.

1 Greaves A. (1982) Pinus oocarpa. [Review Article]. Forestry Abstracts 43(9) 503-526

2 Webb D.B., Wood P.J., Smith J.P. and Henman G.S. (1984) A Guide to Species Selection for Tropical and Subtropical Plantations. Tropical Forestry Paper 15, Oxford, UK

3 CABI Forestry Compendium

4 Hellier A., Newton A.C., Ovhoa Gaona S. (1999) Use of indigenous knowledge for rapidly assessing trends in biodiversity: a case study from Chiapas, Mexico. Biodiversity and Conservation 8: 869-889

5 ECCM technical note for classifying productivity in the absence of yield class information.

6 de Jong per. comm.

7 Montoya G., Soto L., de Jong B., Nelson K., Farias P., Taylor J. and Tipper R. (1995) Desarrollo forestall sustenable: captura de carbono en las zones tzeltal y tojolabal del estado de Chiapas. Cuadernos de Trabajo 4, Instituto Nacional de Ecología, Mexico 


\section{5 \\ CASE 5: RESTORATION OF DEGRADED DRY MIOMBO WOODLAND IN SOUTHERN AFRICA}

\subsection{Introduction}

Miombo woodland is found in central, southern and eastern Africa, and is typified by the dominance of the genera Brachystegia, Julbernardia and/or Isoberlinia. It is an ecologically and economically important ecosystem, providing a valuable source of timber, fuelwood and game for a population of around 40 million people. Large areas of miombo have been seriously degraded due to extraction of precious hardwoods, fuelwood and charcoal. The degradation of miombo woodland causes severe problems for local populations, for erosion control and maintaining water quality. Restoration through enrichment planting with native species combined with the development of sustainable agroforestry could provide a sustainable resource for local communities and prevent degradation of the environment, as well as provide carbon sequestration benefits. In many cases restoration of miombo woodlands will be part of a larger community-based programme for agricultural and environmental improvement.

\subsection{Ecology}

Miombo is the term used to describe woodlands of the south subhumid tropical zone in Africa, which are distinguished by the dominance of the genera Brachystegia, Julbernardia and Isoberlinia. Miombo occurs across approximately 2.8 million $\mathrm{km}^{2}$ in Southern Africa and contains over 8000 species of higher plants. Mean annual rainfall within its range is between $710-1365 \mathrm{~mm}$ with mean temperatures of $18-23^{\circ} \mathrm{C}$. In most areas, 95 percent of the rainfall occurs in a 5-7 month wet-season. Soils are generally nutrient poor and acidic with low organic matter ( $<3$ percent). In more nutrient rich area or areas with higher rainfall and deeper soils, miombo woodland grades into other vegetation types. It is thought that the presence of root ecto-mycorrhizae possessed by miombo species may allow them to exploit the porous and infertile soils. Dry miombo woodland occurs in areas with $<1000 \mathrm{~mm}$ annual rainfall, such as central and northern Mozambique. Dry miombo is less floristically diverse than wet miombo and has a lower biomass.

\subsection{Management Operations}

Typical management operations are described in the following subsections. 


\subsubsection{Establishment}

Establishment involves planting of nursery-grown seedlings consisting of a mosaic of species, possibly supplemented by natural regeneration. Species include Brachystegia spiciformis, Julbernadia globiflora, Millettia stuhlmanii, Pterocarpus angolensis, Dhalbergia melanoxylon, Afzelia quanzensis, Acacia nigrenscens, Swatzia madascariensis, Combretum imberbe, Khaya nyassicca, Albizzia veriscolour, Erthrophleoum suavolens and others. Land is game-fenced and firebreaks established. Planting of pioneer species in the initial stages allows quick establishment of the woodland.

\subsubsection{Maintenance}

Fire is an important factor in miombo woodland. Control of fire, particularly of anthropogenic origin for hunting or to create new grazing areas, will be an important part of management for carbon. Control of herbivores, including damage by elephants, is also important.

\subsubsection{Harvesting}

Thinnings take place firstly in years 5-7 to produces poles for traditional housing as well as fuelwood. Sustainable timber extraction occurs with harvests of around $30 \mathrm{~m}^{3} / \mathrm{ha}$ over a 30 -year period.

\subsubsection{Re-establishment}

Natural regeneration of small areas is considered suitable, with planting of nursery-grown seedlings where required.

\subsection{Classification of Productivity}

There is little information on relative productivity of miombo woodlands though it has been found that above-ground biomass increases with increasing rainfall. Productivity can range from 55 t/ha of above ground biomass in old-growth dry miombo woodland to about $90 \mathrm{t} / \mathrm{ha}$ in mature wet miombo. As discussed above, on deeper, more nutrient rich soils, vegetation will grade into evergreen or semi-evergreen forest.

\subsection{Carbon Sequestration Potential}

\subsubsection{Baseline}

The following are the initial assumptions for existing stored carbon at the site based on ECCM information.

- Vegetation: $6 \mathrm{tC} / \mathrm{ha}$ 
- Soils: $5 \mathrm{tC} / \mathrm{ha}$ (to $30 \mathrm{~cm}$ depth)

\subsubsection{Carbon Uptake and Storage in Miombo Woodland}

Expected carbon storage is shown in Table 15-1.

Table 15-1

Expected carbon storage from restoration of Miombo woodland over 100 years

\begin{tabular}{|l|c|c|c|}
\hline \multicolumn{1}{|c|}{ Productivity } & Low & Medium & High \\
\hline Rotation length (years) & n.a. & $\begin{array}{c}\text { Continuous } \\
\text { cover }\end{array}$ & n.a. \\
\hline Maximum above ground carbon $\left(\mathrm{tC} \mathrm{ha}{ }^{-1}\right)$ & n.a. & 43 & n.a. \\
\hline Average above-ground carbon ( $\left.\mathrm{tC} \mathrm{ha}^{-1}\right)$ & n.a. & 36 & n.a. \\
\hline Average soil etc. carbon ( $\left.\mathrm{tC} \mathrm{ha}^{-1}\right)$ & n.a. & 25 & n.a. \\
\hline
\end{tabular}

\subsection{Costs}

\subsubsection{Establishment and Maintenance}

Establishment costs are estimated at approximately $\$ 100 /$ ha including nursery establishment and training of local staff in forest management and timber utilisation techniques.

Maintenance costs following establishment will be very low. Activities that are carried out, including selective harvesting and hunting, will generate small net income or benefits.

\subsubsection{Land}

The opportunity costs of land associated with restoration of the woodland are zero, since there is no change of use and the productivity of the degraded system is virtually zero.

\subsubsection{Potential Income}

There is potential income from forest products manufactured from sustainable timber harvesting. While the growth rates of miombo are low (around $1 \mathrm{~m}^{3}$ per hectare per year) some of the species produce very valuable timber (fetching between $\$ 500$ and $\$ 1000 / \mathrm{m}^{3}$ on international markets). Other major benefits of restoration of miombo woodland are reduction in soil erosion and further environmental degradation, hydrological benefits and provision of a local resource for hunting, house building and fuel. 


\subsection{Additional Information}

It should be noted that most rural populations in the areas where miombo woodland occurs are 90 percent dependent on fuelwood or charcoal for their energy requirements. Significant amounts of wood are exported to towns. If the current rate of miombo degradation and deforestation continues then both urban and rural populations will become dependent upon fossil fuels (typically kerosene) for domestic energy. The $\mathrm{CO}_{2}$ benefits of avoiding future dependence on fossil fuels have not been included in this study.

\subsection{Summary of Model Inputs and Results}

A summary of input variables for the base case (medium productivity) Miombo is presented in Table 15-2. The cost of $\mathrm{CO}_{2}$ sink enhancement (\$/tonne $\mathrm{C}$ ) is presented on several accounting bases in Table 15-3. Cumulative changes in carbon sequestered (tonne $\mathrm{C} / \mathrm{ha}$ ) and costs (\$/ha) are presented below Table 15-3 for the medium productivity case. Data were unavailable for low and high productivity cases for Miombo.

Costs in Table 15-3 were calculated on an NPV basis as described in Chapter 2, and can be compared with costs for $\mathrm{CO}_{2}$ capture and storage and other sink enhancement options calculated on the same NPV basis. 
Table 15-2

Forestry input variables for Miombo

\section{Forestry: Input Variables}

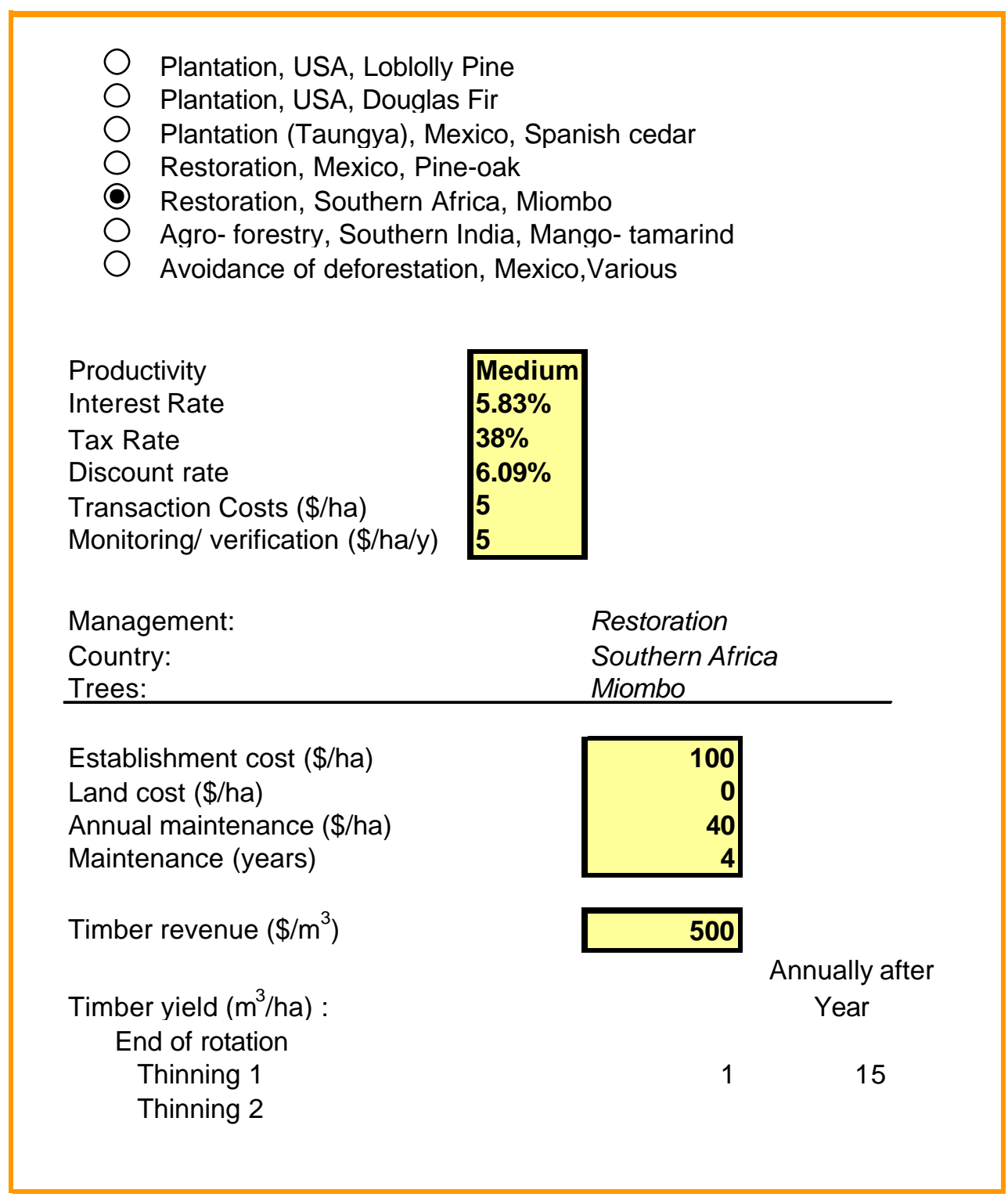


Table 15-3

Forestry summary of results for Miombo medium productivity case

\section{Forestry: Summary of Results (Single System) Medium Productivity}

$\mathrm{CO}_{2}$ Sink Enhancement, NPV Basis (years 1-100)

\section{Management: \\ Country/Region: \\ Trees:}

Carbon accounting basis (\$/tonne C Equivalent)

Above ground carbon

Above \& below ground carbon

Above \& below ground \& timber product carbon

Above \& below ground carbon \& non- $\mathrm{CO}_{2} \mathrm{GHG}$

Above ground carbon with timber revenues

Above \& below ground carbon, non- $\mathrm{CO}_{2} \mathrm{GHGs}$, with timber products \& revenues $(A / l)^{*}$

${ }^{*}$ C Equivalent LC GHG Avoided Basis
Restoration

Southern Africa

Miombo

22.98

13.33

13.02

14.62

(139.74)

(86.65)
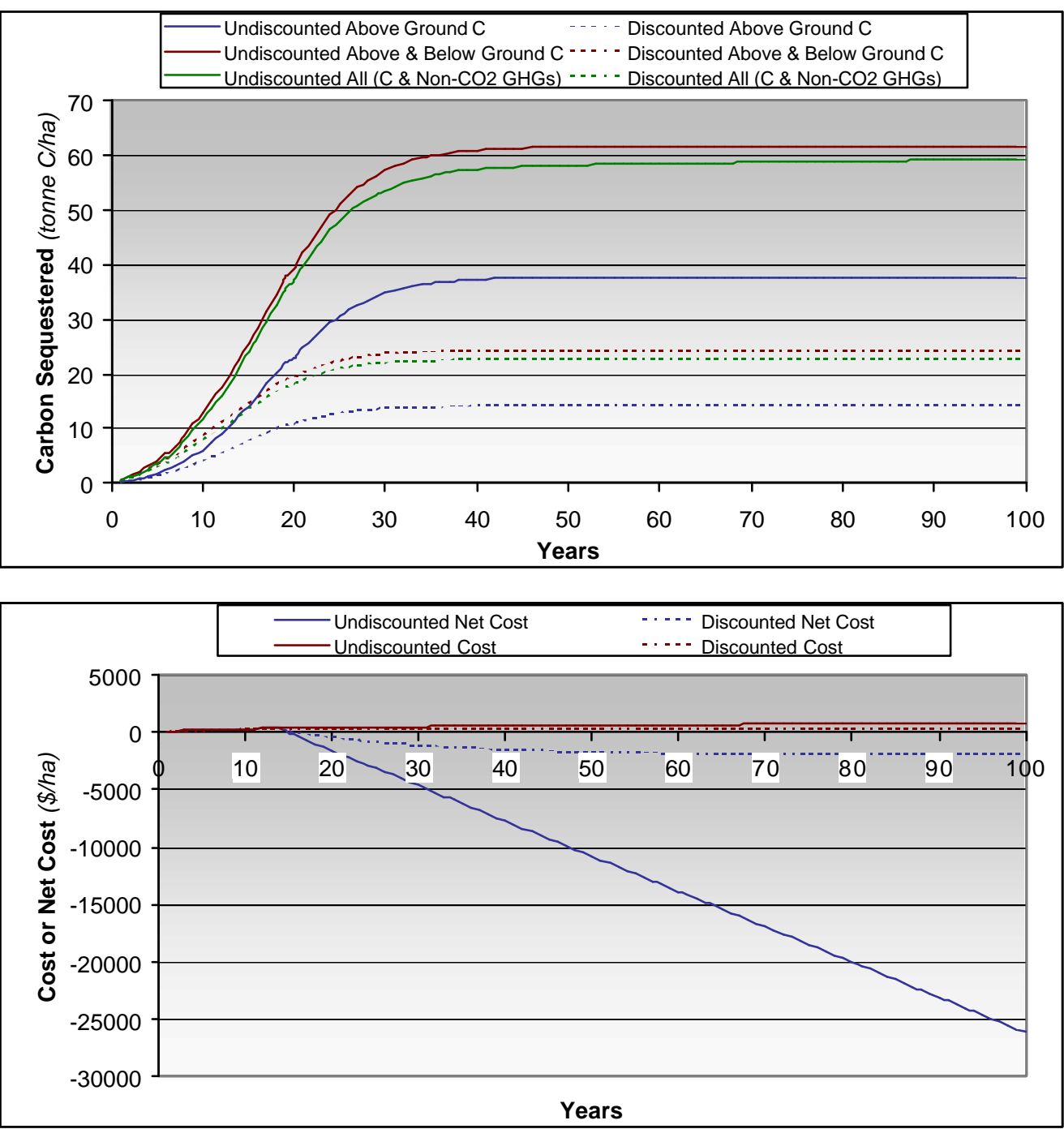


\subsection{References}

These references are not indicated specifically in the body of the chapter and instead represent background for the information presented in this chapter.

1 Campbell, B. 1996. The Miombo in Transition: Woodlands and Welfare in Africa. Centre for International Forestry Research (CIFOR), Bogor, Indonesia.

2 Desanker, P.V. Frost, P.G.H., Frost, C.O., Justice, C.O. and Scholes, R.J. 1997. The Miombo Network: Framework for a Terrestrial Transect Study of Land-Use and LandCover Change in the Miombo Ecosystems of Central Africa. IGBP Report 41. The Interational Geosphere-Biosphere Programme (IGBP), Stockholm, Sweden.

3 McGhee, W. personal communication.

4 Schwartz, A. personal communication.

5 White, F. 1983. The Vegetation of Africa. Unesco, Switzerland. 


\section{CASE 6: AGRO-FORESTRY: MANGO AND NATIVE FRUIT ORCHARDS IN SEMI-ARID AREAS OF SOUTHERN INDIA}

\subsection{Introduction}

Agroforestry is the combination of tree growing and crop and livestock production within the same farming system, such that the total output is greater than could be achieved by the implementation of a single component. In the extensive dry-land areas of southern India, such as North Kolar District, Karnataka, agro-forestry is a suitable system of land management. Small farmers can grow fruit trees and fast growing fuel wood species as wind breaks on water collection bunds. Depending on the soil type, soil depth, water availability for the particular plot, and management capability of the farming family, various fruit trees may be introduced to supplement income and nutrition. This case involves agro-forestry: Mango and native fruit orchards (Tamarind, Jackfruit, Jamun, Pongemia) in semi-arid areas of southern India

\subsection{Ecology}

Trees are selected on the basis of multiple attributes, including their contribution to water conservation, soil fertility, fruit quality, fuelwood production and shade effect. Native fruit orchards are a viable option for areas such as the Kolar district of Karnataka in southern India (600-1200 masl), where rainfall is highly seasonal, with 80 percent of the annual rainfall of 800 to $1200 \mathrm{~mm}$ falling in a 2-3 month period and where temperatures range from $10^{\circ} \mathrm{C}$ to $45^{\circ} \mathrm{C}$. Local varieties of Mango and Tamarind are likely to be the main components of the orchards. Other trees such as Jack Fruit, Jamun, Pongemia, Neem, and Acacia auriculiformis may also be introduced as windbreak trees for fuelwood, timber and fodder for browsing by small livestock. Intercropping with groundnuts or beans is carried out for the first 12 years. These species fit well with the existing farming systems, where water management is critical. Villages are encouraged to dig ponds and bunds (low mounds and ditches) for catching the 4 - 5 annual flash floods which bring up to half the annual rainfall on their plots. Once the ponds dry out, farmers become dependent upon bore-wells for water to irrigate their plots. Tree orchards help to reduce the runoff and peak stream flows after sudden downpours and the deep root systems that do not compete strongly with the staple crops, they also provide out-of-season income from fruits that keep families going in the lean months.

Timber extraction and charcoal production have ruined many of the old Tamarind stands in the Kolar district. Farm trees are often in poor form due to indiscriminate lopping for fuelwood but good examples of individual Mango trees and Tamarind "toops" (stands) may still be found. 


\subsection{Classification of Productivity}

Shown in Table 16-1 are the important parameters for productivity for the chosen species:

Table 16-1

Productivity factors for mixed orchards of Tamarind and Mango

\begin{tabular}{|c|c|c|}
\hline Productivity & Conditions & $\begin{array}{l}\text { Production } \\
\text { (mango fruit) }\end{array}$ \\
\hline High & $\begin{array}{l}600-1200 \mathrm{~m} \text {; deep, well-drained loamy soil, good sub- } \\
\text { soil ; temp } 10-38^{\circ} \mathrm{C} \text {, rainfall }>1000 \mathrm{~mm} / \mathrm{y} \text {, with good } \\
\text { rains from June to September followed by a more or } \\
\text { less dry spell. The quantum of rainfall is not as } \\
\text { important as its distribution. }\end{array}$ & $\begin{array}{l}10 \mathrm{tha}^{-1}(5 \mathrm{y}) \\
20 \mathrm{tha}^{-1}(10 \mathrm{y}) \\
30 \mathrm{tha}^{-1}(20 \mathrm{y})\end{array}$ \\
\hline Medium & Intermediate & $\begin{array}{c}8 \mathrm{t} \mathrm{ha}^{-1}(5 \mathrm{y}) \\
15 \mathrm{tha}^{-1}(10 \mathrm{y}) \\
25 \mathrm{tha}^{-1}(20 \mathrm{y})\end{array}$ \\
\hline Low & $\begin{array}{l}\text { Stony soils with temperatures exceeding } 40^{\circ} \mathrm{C} \text { for } \\
\text { prolonged periods, rainfall during flowering and fruit- } \\
\text { setting (February - April). }\end{array}$ & $\begin{array}{c}5 \text { t ha }^{-1}(5 y) \\
10 \text { tha }^{-1}(10 y) \\
15 \text { tha }^{-1}(20 y)\end{array}$ \\
\hline
\end{tabular}

\subsection{Management Operations}

Typical management operations are described in the following subsections.

\subsubsection{Establishment}

Planting pits are dug and filled with red earth, sand and manure. Irrigation channels are dug and wind-breaks should have been planted one or two years before. Irrigation, training, hoeing, weeding and staking to protect against high winds have to be carried out at regular intervals. Grafted plants are kept free of branching up to at least $75 \mathrm{~cm}$ height, with as little pruning as possible being done. Inter-cultivation is necessary to control Mango mealy bug in November and December. Mangos grow well even in poor soils due to their deep root system but during the non-bearing period, N P K fertilizer should be applied.

Between the trees in the centre of the plot, legumes, millet and groundnuts are planted in rows up to the $12^{\text {th }}$ year. Thereafter inter-cropping will probably cease. As Tamarind does not allow such annual crops to come up under its shade, Tamarind is placed at the edge and the corners of the field. The suitable hybrid varieties of Mango are Ratnagiri Alfonso, Benisha, H 13, and Mallika. Suitable Hybrid Tamarind varieties are Urigam, and local Red Tamarind varieties. The 
Jack Fruit and Jamun trees are placed suitably in the centre of a hexagon of Mangos, and the Old Variety Mangos are planted on the bund between the Neem and Pongemia and left to grow to their natural massive height.

220 Mango trees, 20 Tamarind trees, 20 Jack Fruit, 20 Jamun and 20 old variety Mango are planted per hectare. Ponge mia, Neem, and Acacia Auriculiformis are planted as windbreak trees for fuel and fodder at $2.5 \mathrm{~m}$ spacing in 2 rows along the bunds.

\subsubsection{Harvesting/Replanting}

The trees are replaced in the following cycles:

$\begin{array}{ll}\text { Mango grafted } & 100 \% \text { every } 40 \text { years } \\ \text { Tamarind } & 100 \% \text { every } 40 \text { years } \\ \text { Jack } & 100 \% \text { every } 80 \text { years } \\ \text { Jamun } & 100 \% \text { every } 30 \text { years } \\ \text { Old Variety Mango } & 100 \text { years }+\end{array}$

Neem, Pongemia and Acacia Auriculiformis will be coppiced for fuel wood, and the leaves and twigs cut for mulch.

\subsection{Carbon Sequestration Potential}

\subsubsection{Baseline}

The baseline vegetation for most new orchards will be a sparse covering of shrubs and small trees. Estimated above-ground carbon density is around $8 \mathrm{tC} \mathrm{ha}^{-1}$. Soil carbon is estimated to be $20 \mathrm{tC} \mathrm{ha}^{-1}$.

\subsubsection{Carbon Uptake and Storage by Orchards}

Carbon uptake by the vegetation is constrained by the availability of moisture during much of the year and while groves of old Tamarind trees have been estimated to contain over $300 \mathrm{tC} \mathrm{ha}^{-1}$ based on data from the Centre of Ecological Science ${ }^{4}$.

Mean carbon storage figures for sites of different productivity levels are not yet available. However, it is estimated that the typical carbon storage over 100 years from establishment will be as shown in Table 16-2. 
Table 16-2

Expected carbon storage from Mango-Tamarind agro-forestry over 100 y

\begin{tabular}{|l|c|c|c|}
\hline Productivity & Low & Medium & High \\
\hline Rotation length (years) & n.a. & $\begin{array}{c}\text { Continuous } \\
\text { cover }\end{array}$ & n.a. \\
\hline Maximum above ground carbon $\left(\mathrm{tC} \mathrm{ha}^{-1}\right)$ & n.a. & 60 & n.a. \\
\hline Average above-ground carbon $\left(\mathrm{tC} \mathrm{ha}^{-1}\right)$ & n.a. & 33 & n.a. \\
\hline Average soil etc. carbon $\left(\mathrm{tC} \mathrm{ha}^{-1}\right)$ & n.a. & 33 & n.a. \\
\hline
\end{tabular}

\subsection{Costs}

\subsubsection{Establishment and Maintenance}

It is estimated that the costs of establishment are between $\$ 100$ and $\$ 300$ per hectare in the first year.

In addition to the establishment, the mango-tamarind orchard will require considerable labor input, for watering and weed control during the establishment phase. The actual cost will depend upon the water requirement of the growing seedlings and the availability / proximity of a reliable water supply. For sites where there is an existing network of bunds, and water retention facilities, the maintenance costs during the first 5 years will be $\$ 100$ to $\$ 150$ per hectare per year, depending on the availability of labor and inputs. In much of southern India the price of farm labor is extremely low - less than $\$ 1$ per day.

Where the construction of water tanks, boreholes or other water retaining features are required the initial establishment costs could be significantly higher - in the order of $\$ 1000$ per hectare per year during the first 5 years. However, for the farmers / communities this investment will also see a considerable increase in the value of the land.

\subsubsection{Land}

The main alternative land use will be cultivation for groundnuts. Yields are sporadic, depending upon the rainfall and the returns per hectare will range from almost zero to $\$ 150 /$ year. On improved land (with bunds for water retention and fertilizer input) the returns will be higher. An annual opportunity cost of $\$ 60$ to $\$ 120$ per hectare was selected. This corresponds to a land cost of about $\$ 900$ per hectare (ten times the average opportunity cost) at establishment.

\subsubsection{Potential Income}

The system is managed primarily for fruit, with mango being the main cash crop. A mixed orchard will produce $\$ 200$ to $\$ 600$ per hectare depending on age, productivity class and the 
mixture of species. Inter-cropped legumes and groundnuts are also harvested for the first 10 years, or so. Fuelwood, fodder, and some fence-posts are assumed not to make a substantial difference to the total standing biomass or the carbon flows of the plot.

Other products from the orchards will include fodder from the leaves of Neem and cooking oils for Pongemia and Neem seeds.

\subsection{Additional Comments}

While the carbon uptake and storage potential of forestry / agroforestry systems in semi-arid conditions is relatively low, the costs of establishment and the associated benefits in terms of long term benefits to the rural economy make this an attractive option.

The carbon benefits of these systems can be further enhanced by utilising woody biomass for electricity generation. Many villages in the region referred to are dependent upon electrical or diesel pumps for extracting water from bore-wells. A number of promising examples of biofuelled generators and water pumps have been established.

\subsection{Summary of Model Inputs and Results-}

A summary of input variables for the base case (medium productivity) Mango-tamarind is presented in Table 16-3. The cost of $\mathrm{CO}_{2}$ sink enhancement (\$/tonne $\mathrm{C}$ ) is presented on several accounting bases in Table 16-4. Cumulative changes in carbon sequestered (tonne $\mathrm{C} / \mathrm{ha}$ ) and costs (\$/ha) are presented below Table 16-4 for the medium productivity case. Data were unavailable for low and high productivity cases for Mango-tamarind. Costs in Table 16-4 were calculated on an NPV basis as described in Chapter 2, and can be compared with costs for $\mathrm{CO}_{2}$ capture and storage and other sink enhancement options calculated on the same NPV basis. 
Table 16-3

Forestry input variables for Mango-Tamarind

\section{Forestry: Input Variables}

Plantation, USA, Loblolly Pine

Plantation, USA, Douglas Fir

Plantation (Taungya), Mexico, Spanish cedar

Restoration, Mexico, Pine-oak

Restoration, Southern Africa, Miombo

- Agro- forestry, Southern India, Mango- tamarind

$\bigcirc$ Avoidance of deforestation, Mexico,Various

Productivity

Interest Rate

\begin{tabular}{|l|}
\hline Medium \\
$5.83 \%$ \\
$38 \%$ \\
$6.09 \%$ \\
5 \\
5 \\
\hline
\end{tabular}

Tax Rate

Discount rate

Transaction Costs (\$/ha)

Monitoring/ verification (\$/ha/y)

5

\begin{tabular}{ll} 
Management: & Agro-forestry \\
Country: & Southern India \\
Trees: & Mango-tamarind \\
\hline
\end{tabular}

Establishment cost (\$/ha)

Land cost (\$/ha)

Annual maintenance ( $\$ / h a)$

Maintenance (years)

200

900

125

Timber revenue $\left(\$ / \mathrm{m}^{3}\right)$

$400 \$ / y$ fruit

Timber yield $\left(\mathrm{m}^{3} / \mathrm{ha}\right)$ :

End of rotation

Thinning 1

Thinning 2 
Table 16-4

Forestry summary of results for Mango-Tamarind medium productivity case

\section{Forestry: Summary of Results (Single System) \\ Medium Productivity}

$\mathrm{CO}_{2}$ Sink Enhancement, NPV Basis (years 1-100)

\section{Management:}

Country/Region:

Trees:

Carbon accounting basis (\$/tonne C Equivalent)

Above ground carbon

Above \& below ground carbon

Above \& below ground \& timber product carbon

Above \& below ground carbon \& non- $\mathrm{CO}_{2}$ GHGs

Above ground carbon with timber revenues

Above \& below ground carbon, non- $\mathrm{CO}_{2} \mathrm{GHG}$, with timber products \& revenues $(A I l)^{*}$

* C Equivalent LC GHG Avoided Basis
Agro- forestry

Southern India

Mango-tamarind
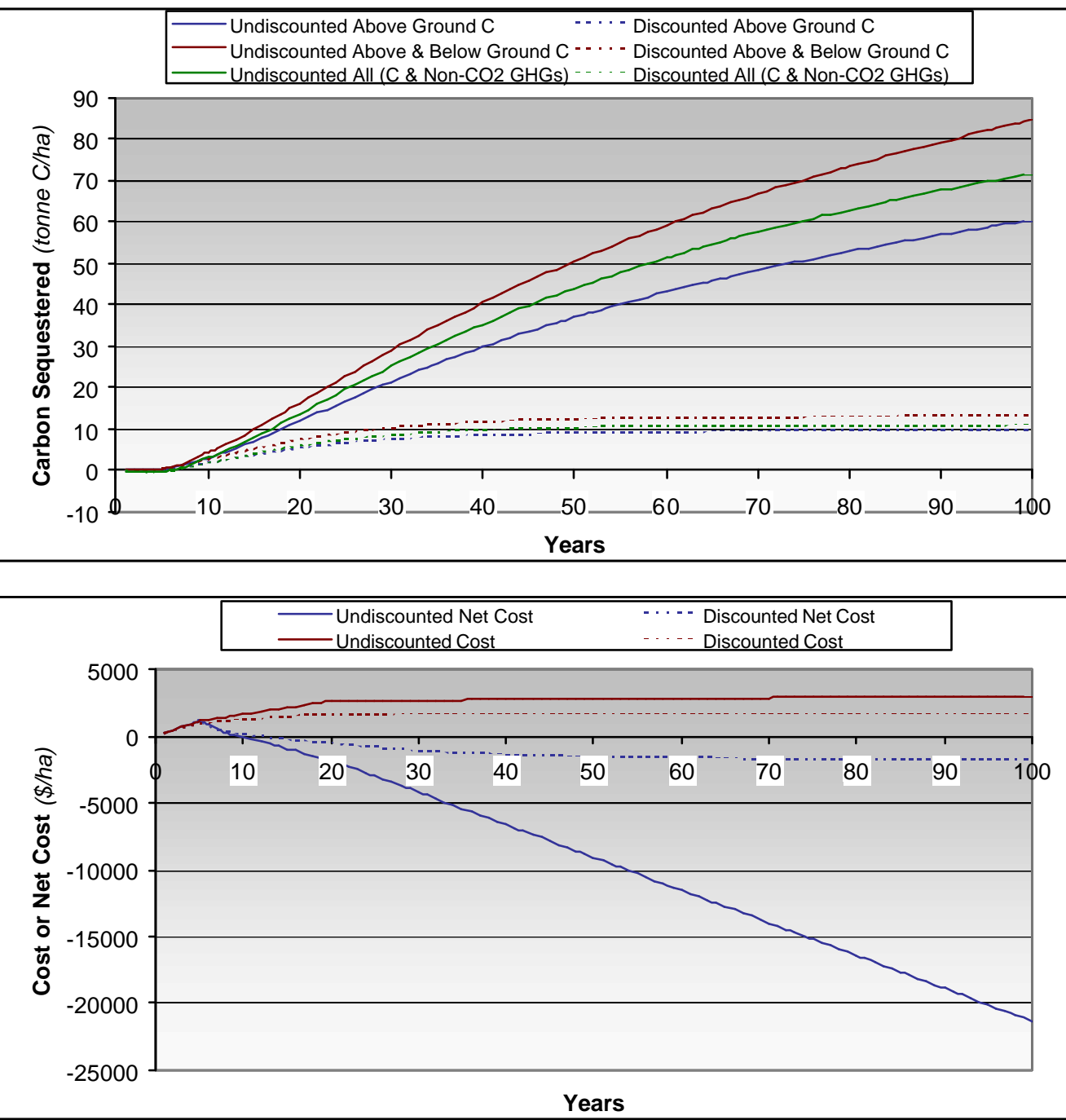


\subsection{References / Information Sources}

Some of these references are not indicated specifically in the body of the chapter and instead represent background for the information presented in this chapter.

1 Agro-ecological information was compiled from farmers in the North Kolar District, Karnataka.

2 Economics of establishment: Anandi Sharan of WSD, Bangalore.

3 Management of mango plantations: Fruit Growing, J.S. Bal, Kalyani Publ., New Delhi, 1997.

4 Carbon uptake estimates supplied by Dr. Nagraj of Centre of Ecological Science, Bangalore 2000. 


\section{7 \\ CASE 7: AVOIDANCE OF DEFORESTATION IN CHIAPAS, MEXICO}

\subsection{Introduction}

Deforestation, particularly in tropical regions, is one of the largest sources of anthropogenic greenhouse gas emissions. Carbon emissions from deforestation in the tropics during the 1990s range from 1.1 to $1.7 \mathrm{GtC} / \mathrm{y}$, with a best estimate of $1.6 \mathrm{GtC} / \mathrm{y}^{1}$. In tropical countries with large areas of remaining forest, reduction of deforestation has much greater potential climate benefits than other forestry options. Reduction of deforestation also usually produces more complementary benefits, such as maintaining biodiversity. On the other hand, quantifying the direct benefits of a programme of avoiding deforestation is much more difficult than quantifying the direct effects of more discrete activities.

The rates and causes of deforestation vary by region and scale. Conversion of forests to pasture and cropland has been the most direct cause of tropical deforestation. Non-sustainable logging has been the leading factor in parts of South-east Asia, whereas excessive harvest of wood fuel has been important only in specific sub-country regions and in some African countries.

The avoidance of deforestation cases in this study are based on information from the Chiapas region of southern Mexico, although conditions are similar is many other Central and South American countries.

\subsection{Ecology}

Three types of forest, which account for a large proportion of the existing native forest in Chiapas, are included in this case:

- Pine-oak forest

- Moist tropical forest

- Montane cloud forest

Pine-oak forest occurs naturally in temperate to sub-tropical mountain regions. Further details are given in Chapter 14.

Moist tropical forests consist of communities that reach up to $30 \mathrm{~m}$ high and contain a great diversity of canopy species. They occur mainly at altitudes of $<500 \mathrm{~m}$ and rainfall of $>2000 \mathrm{~mm} / \mathrm{y}$. 
The canopy of the mountain forest is dominated by various species of oak and can reach up to $40 \mathrm{~m}$ high. It occurs at altitudes of $>1500 \mathrm{~m}$ and rainfall of $>1000 \mathrm{~mm} / \mathrm{y}$.

The forests of Chiapas exhibit important characteristics in common with many regions of Latin America. The Altos or Central Highlands displays land use patterns that can be recognized in highland settings in Guatemala, Peru, Colombia and Ecuador as well as other areas of Mexico. Such areas contain established, traditionally managed agricultural systems and high population densities. The Lowland region, in common with many areas of extensive moist tropical forest in Latin America, is subject to rapid colonization, both by subsistence farmers and ranchers.

\subsection{Carbon Sequestration Potential}

The carbon sequestration potential depends on the expected rate of deforestation in the baseline, i.e., without any additional forest preservation measures. There are a number of issues associated with setting baselines for projects that purport to avoid emissions by preventing deforestation. The key issues are:

- How can project developers be prevented from skewing the results in their favor (overestimating the probable loss of forest)?

- How can an objective measurement of the risk of emissions be derived?

- How can we the error associated with predicted emissions be measured?

- How can a consistent methodology be applied to different projects within the same region?

In response to these questions, the Edinburgh Centre for Carbon Management (ECCM) has developed a standardized, objective method for setting baselines for deforestation prevention projects, using a risk-assessment approach, which relates the probability of future loss of terrestrial carbon to key driving factors that exist within a particular region ${ }^{2}$. This method, called the Regional Risk Matrix (RRM) method, produces a baseline map that allows any project within the region studied to be given an indicative figure for \% loss of above-ground carbon over a specific (approx. 20 year) period into the future. A simplified version of this method is used in this study.

The RRM method consists of the following steps that were applied, to a study area of 2.8 million ha in southern Mexico by ECCM and El Colegio de la Frontera Sur:

1. A series of satellite images of the area, showing vegetation changes over a 20 year period were analyzed: around 15 types of vegetation were identified and mapped, and changes in vegetation cover over a 20 years were calculated and mapped.

2. Estimates of above-ground biomass for each vegetation type were combined with the land use change data to provide estimates of emissions over a 20 -year period.

3. Maps of agricultural land use, roads and population densities were digitized for the study area and were compared with the maps of land use change. 
4. A number of probability matrices describing the relationship between emissions per unit of above ground biomass and key "driving and predisposing" factors of land use change were derived.

5. These matrices were then used to drive a model of future emissions, based upon the assumption that the land use change processes remain similar. This produced a map of probable future emissions for the next 20 years.

6. The prediction errors of different matrices were measured by comparison against the map of historical emissions (the predicted map was overlain upon the historic map to give a spatially explicit measure of the errors).

Further refinement of the RRM is undertaken in iterations, involving:

7. Division and re-calibration of the matrix for sub-regions, as appropriate to reduce prediction error.

Two of the main driving factors for deforestation are the population density and the distance from a road. Figure 17-1 shows the percentage loss of above ground carbon in 2.8 million ha of Chiapas, Mexico between 1976 and 1996 and Figure 17-2 shows the population densities and distances from roads. The emissions were derived from a series of vegetation maps and biomass estimates. Total emissions during this period were approximately 140 million tC. 


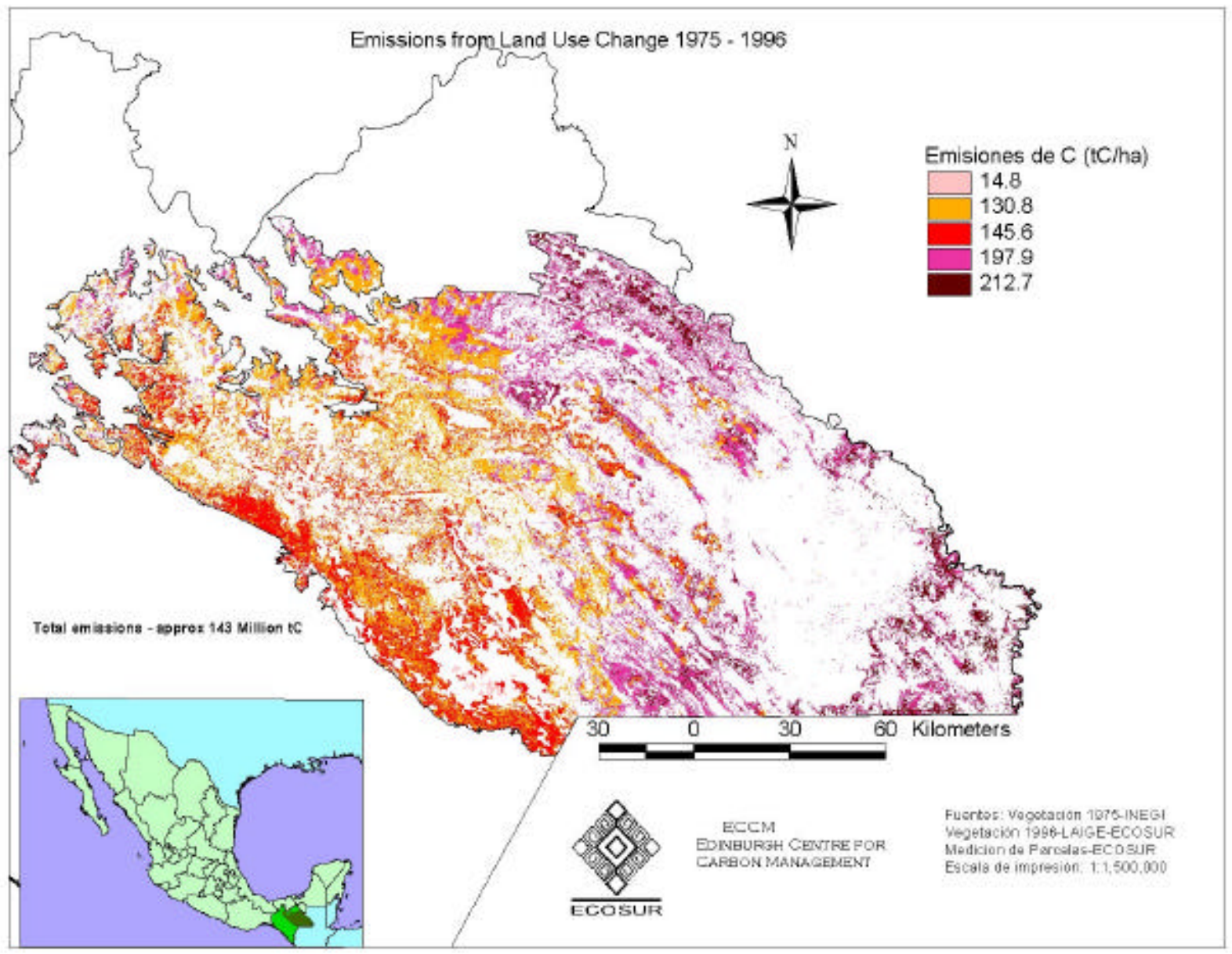

Figure 17-1

Emissions from land use change in Chiapas, Mexico, over 20 years from the mid-1970's. 


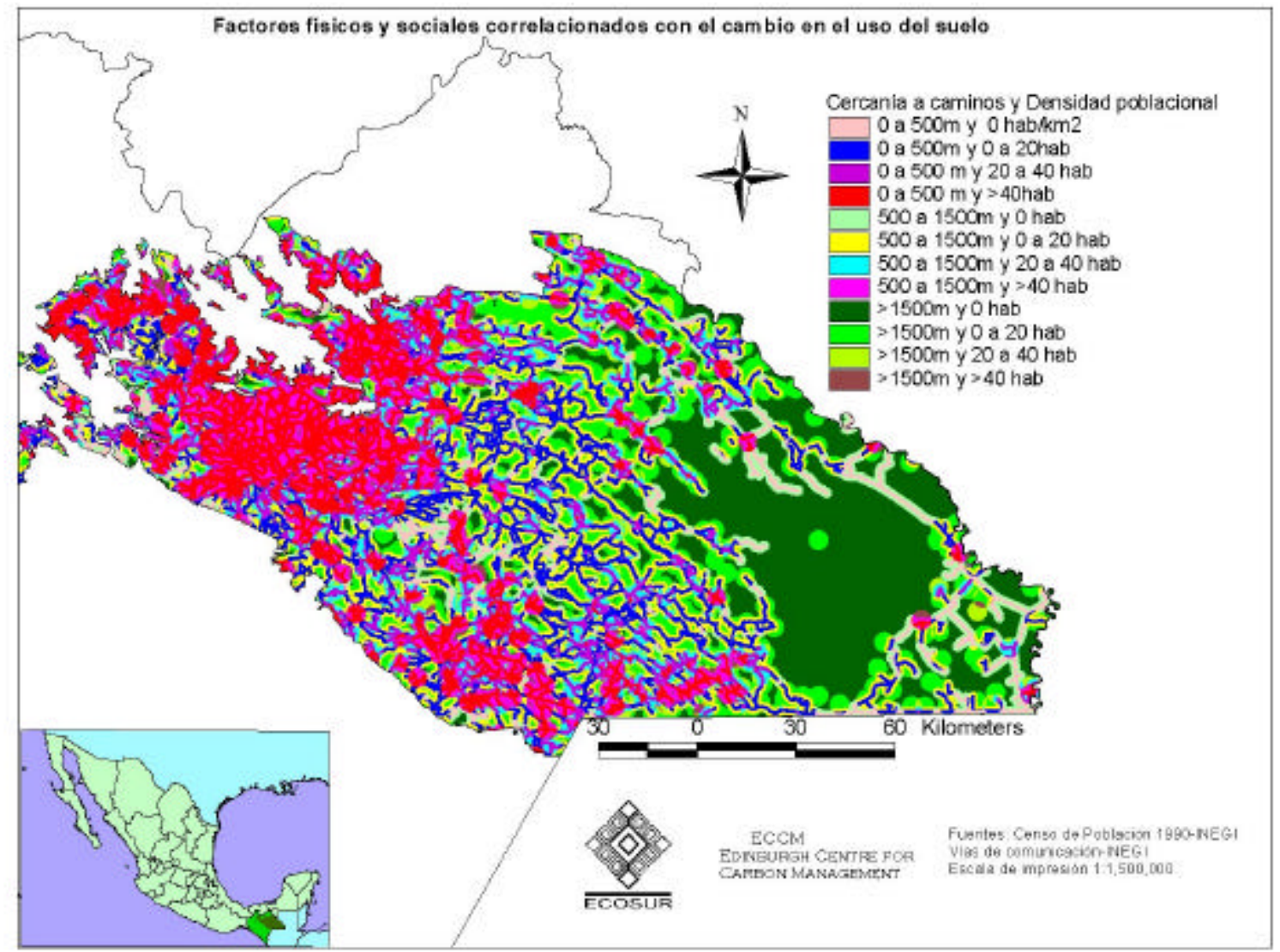

Figure 17-2

Map of two key causal factors in land-use change: Distance to roads and tracks and population density

Note that the red area to the west of the map corresponds to the densely populated central highlands and the green area to the east corresponds to the lowland tropical forests.

The relationship between the quantity of above ground carbon lost between 1976 and 1996 and population density and distance from roads and tracks is summarized in Table 17-1.

\section{Table 17-1}

Percentage of above-ground carbon lost from 1976 to 1996.

\begin{tabular}{|l|c|c|c|}
\hline \multirow{2}{*}{$\begin{array}{l}\text { Population density } \\
\left(\text { person } / \mathbf{k m}{ }^{2} \text { ) }\right.\end{array}$} & \multicolumn{3}{|c|}{ Distance to road (m) } \\
\cline { 2 - 4 } & $\mathbf{5 0 0}$ & $\mathbf{5 0 0 - 1 5 0 0}$ & $\mathbf{1 5 0 0}$ \\
\hline$>40$ & 63 & 55 & 41 \\
\hline $20-40$ & 56 & 46 & 37 \\
\hline $0-20$ & 46 & 35 & 25 \\
\hline 0 & 41 & 28 & 8 \\
\hline
\end{tabular}


Predictions of the quantities of carbon that are expected to be lost over the next 20 years for the 2.8 million ha study area are shown in Figure 17-3. The expected emissions over this period are around 90 million tC. The quantities of carbon lost range from 12 to $150 \mathrm{tC} / \mathrm{ha}$. The current matrix models are able to provide baselines with an average site-specific error of $+/-20$ percent and an aggregate error for the region as a whole of $+/-5$ percent.

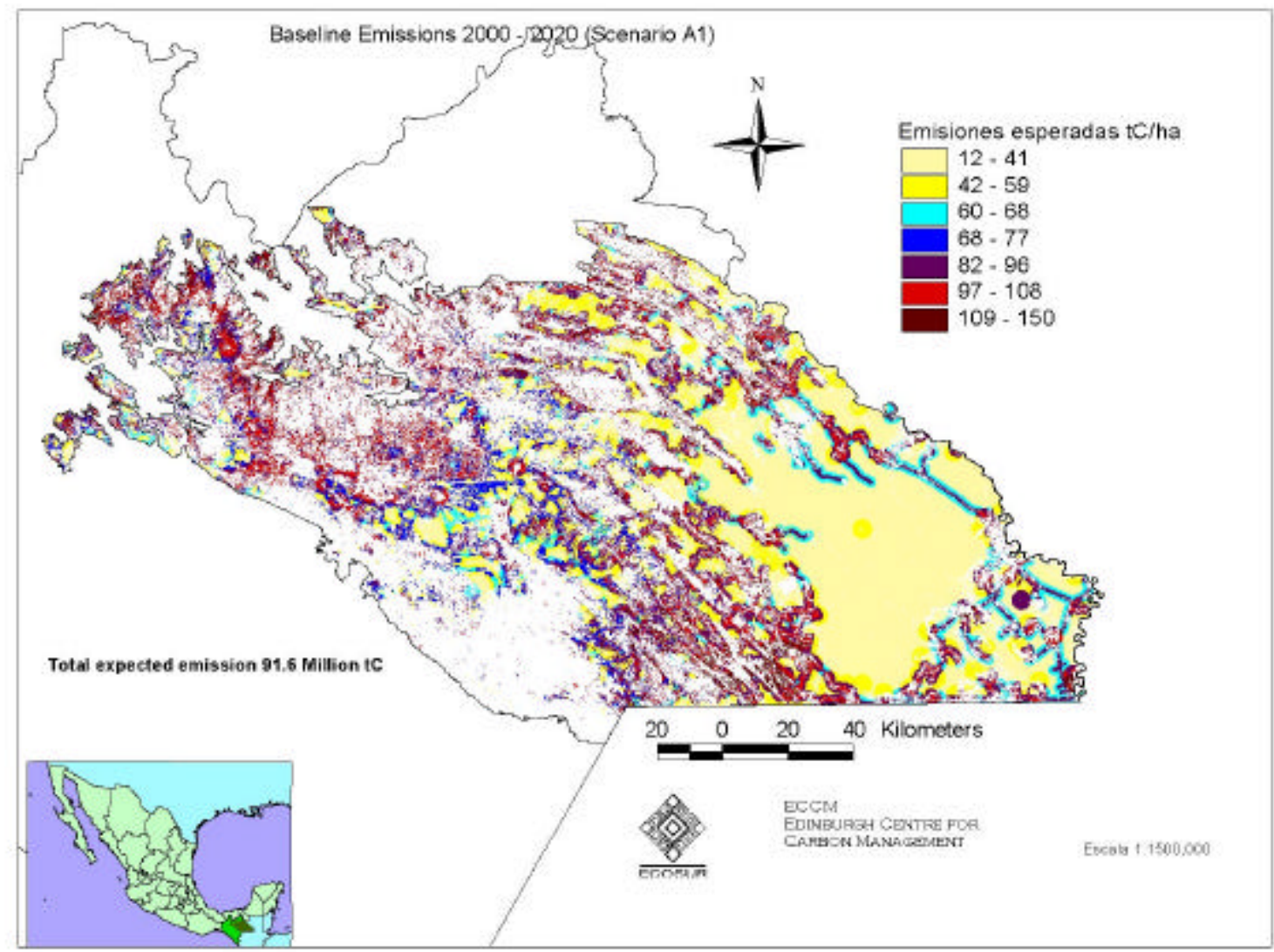

Figure 17-3

Regional baseline for 2000 to 2020, showing expected emissions tc/ha

For the purposes of this study a simplified version of the methodology derived by ECCM has been used. The rate of deforestation is assumed to depend on three factors:

- Base rate

- Vulnerability

- Pressure

Pressure is linked to the population density and vulnerability is linked to the distance to roads and tracks. Each of these parameters can be defined as low, medium or high and the model predicts an annual rate of deforestation. The predicted rates of deforestation are shown in Table 17-2 
Table 17-2

Predicted annual rate of deforestation (\%).

\begin{tabular}{|l|l|c|c|c|}
\hline \multirow{2}{*}{ Base rate } & \multirow{2}{*}{$\begin{array}{l}\text { population } \\
\text { pressure }\end{array}$} & \multicolumn{3}{|c|}{ Vulnerability } \\
\cline { 3 - 5 } & & Low & Medium & High \\
\hline \multirow{2}{*}{ Low } & Low & 0.39 & 0.6 & 0.84 \\
\hline & Medium & 0.65 & 1.00 & 1.40 \\
\hline Medium & High & 0.84 & 1.30 & 1.82 \\
\hline & Low & 1.09 & 1.68 & 2.35 \\
\hline & Medium & 1.82 & 2.80 & 3.92 \\
\hline High & High & 2.37 & 3.64 & 5.10 \\
\hline & Low & 1.37 & 2.10 & 2.94 \\
\hline & Medium & 2.27 & 3.50 & 4.90 \\
\hline & High & 2.96 & 4.55 & 6.37 \\
\hline
\end{tabular}

The baseline quantity of carbon stored depends on the type of forest; 180 t/ha for pine-oak forest, $240 \mathrm{t} / \mathrm{ha}$ for moist tropical forest, and $350 \mathrm{t} / \mathrm{ha}$ for montane cloud forest.

For this study it is assumed that the rate of deforestation will be constant over the next 100 years but it should be recognised that over such long time spans the performances of projects that avoid deforestation are subject to greater uncertainty than afforestation projects. The benefits of afforestation projects depend on the rate of carbon accumulation, which can be predicted with reasonable accuracy provided the forest continues to be maintained. The benefits of projects that avoid deforestation depend mainly on the baseline rate of deforestation, which is very uncertain more than 20 years into the future.

\subsection{Costs}

\subsubsection{Establishment and Maintenance}

A large proportion of the forests in Chiapas are legally held by communities rather than individuals or the public sector. Any management regime needs approval and consensus at the local level if it is to succeed. The total cost of establishment, including the socio-technical costs associated with obtaining local consensus, would nevertheless be relatively low and is estimated to be $\$ 270 /$ ha. An additional allowance of $\$ 25 /$ ha for the first four years is also included.

\subsubsection{Land Costs}

Accessible pine-oak and mountain forests would have substantial opportunity costs due to the value of charcoal and bromeliads that are currently extracted at significantly higher rates than the 
apparent level of sustainable yield. Some areas of the rainforests would have a relatively high opportunity costs associated with the available stocks of high value hardwoods, particularly mahogany. The annual opportunity cost is estimated to be about $\$ 300 /$ ha.

\subsubsection{Potential Income}

Some products for local use such as bromeliads, firewood and tree bark could be extracted on a sustainable basis from preserved forests. As in the other cases in this study, it is assumed that these minor products for local use would not be taken into account in the economic evaluation.

\subsection{Summary of Model Inputs and Results}

A summary of input variables for the base case (moist tropical forest, medium vulnerability, population pressure and medium productivity) avoidance of deforestation is presented in Table 17-3. The cost of $\mathrm{CO}_{2}$ sink enhancement (\$/tonne $\mathrm{C}$ ) is presented on several accounting bases in Table 17-4. Cumulative changes in carbon sequestered (tonne $\mathrm{C} / \mathrm{ha}$ ) and costs $(\$ / \mathrm{ha})$ are presented below Table 17-4. Costs in Table 17-4 were calculated on an NPV basis as described in Chapter 2, and can be compared with costs for $\mathrm{CO}_{2}$ capture and storage and other sink enhancement options calculated on the same NPV basis. 
Table 17-3

Forestry input values for avoidance of deforestation

\section{Forestry: Input Variables}

Plantation, USA, Loblolly Pine

Plantation, USA, Douglas Fir

Plantation (Taungya), Mexico, Spanish cedar

$\bigcirc$ Restoration, Mexico, Pine-oak

$\bigcirc$ Restoration, Southern Africa, Miombo

$\bigcirc$ Agro- forestry, Southern India, Mango- tamarind

( ) Avoidance of deforestation, Mexico,Various

Productivity

Interest Rate

Tax Rate

Discount rate

Transaction Costs $(\$ /$ ha $)$

Monitoring/ verification (\$/ha/y)

\begin{tabular}{|l|}
\hline Medium \\
$5.83 \%$ \\
$38 \%$ \\
$6.09 \%$ \\
5 \\
5 \\
\hline
\end{tabular}

Base case carbon (tC/ha) Annual rate of deforestation
Management:

Country:

Trees:

Establishment cost (\$/ha)

Land cost (\$/ha)

Annual maintenance (\$/ha)

Maintenance (years)

Timber revenue $\left(\$ / \mathrm{m}^{3}\right)$

Timber yield $\left(\mathrm{m}^{3} / \mathrm{ha}\right)$ :

End of rotation

Thinning 1

Thinning 2
Avoidance of deforestation

Mexico

Various

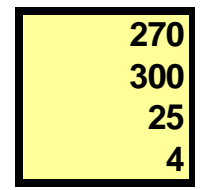


Table 17-4

Forestry summary of results for Avoidance of Deforestation medium productivity case

Forestry: Summary of Results (Single System) Medium Productivity

$\mathrm{CO}_{2}$ Sink Enhancement, NPV Basis (years 1-100)

\section{Management: \\ Country/Region: \\ Trees:}

Carbon accounting basis (\$/tonne $C$ Equivalent)

Above ground carbon

Above \& below ground carbon

Above \& below ground \& timber product carbon

Above \& below ground carbon \& non- $\mathrm{CO}_{2} \mathrm{GHGs}$

Above ground carbon with timber revenues

Above \& below ground carbon, non- $\mathrm{CO}_{2} \mathrm{GHGs}$, with timber products \& revenues $(A / I)^{*}$

${ }^{*}$ C Equivalent LC GHG Avoided Basis
Avoidance of deforestation

Mexico

Various
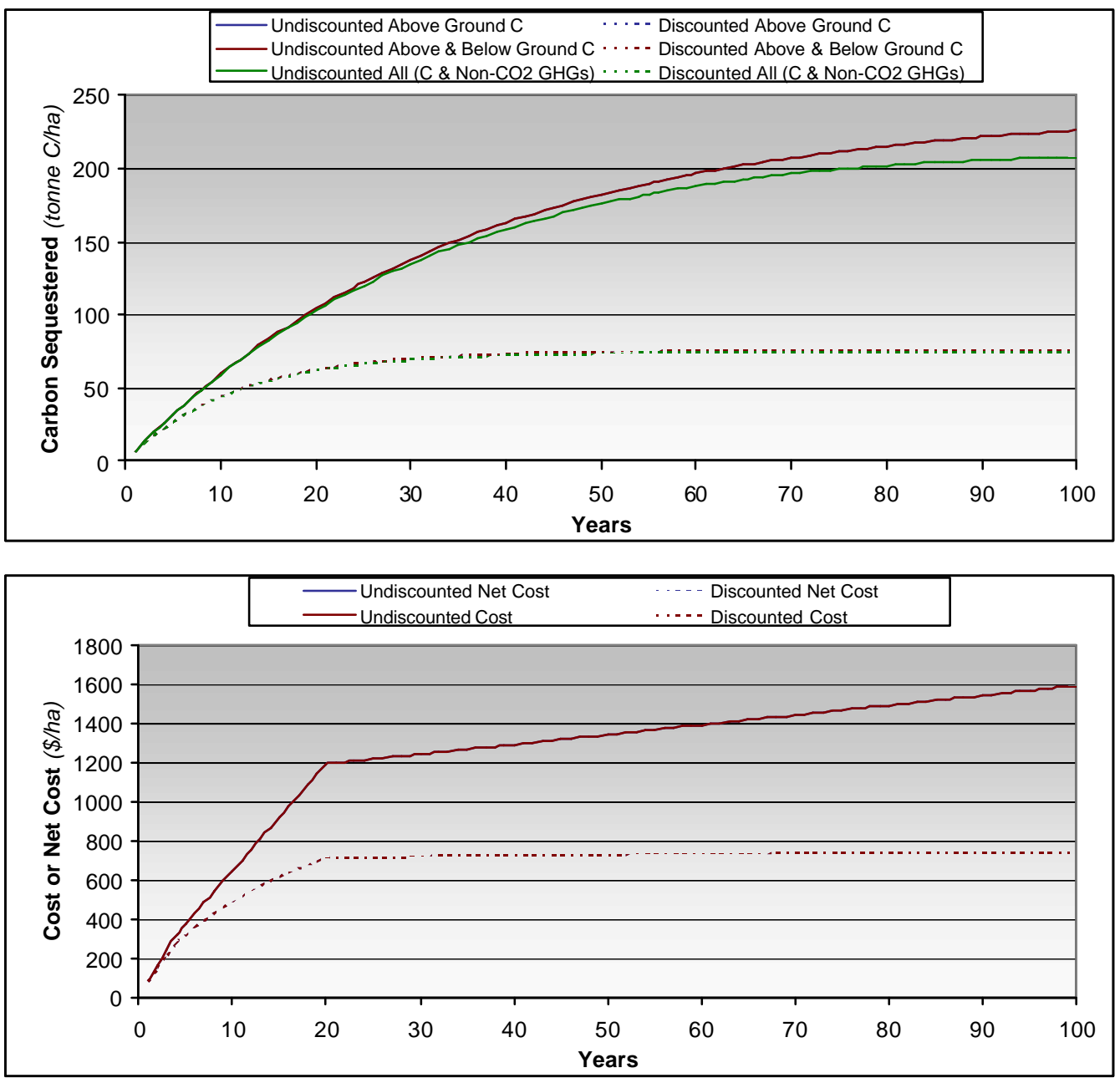


\subsection{References}

1 IPCC (Intergovernmental Panel on Climate Change), Climate change 2001, the scientific basis, published by Cambridge University Press, 2001, ISBN 052180767

2 Edinburgh Centre for Carbon Management, 2001, forthcoming paper. 


\section{8 \\ ECONOMICS OF $\mathrm{CO}_{2}$ SINK ENHANCEMENT VIA REDUCING TILLAGE ON U.S. CROPLAND-BASIS AND APPROACH}

\subsection{Introduction}

Reducing the amount of tillage and associated improvements in residue management beyond that already achieved account for about one-half of the potential (75-208 million tonnes of carbon/year) for $\mathrm{CO}_{2}$ sink enhancement in U.S. croplands ${ }^{1}$. The $\mathrm{CO}_{2}$ sink enhancement in croplands is the result of increased carbon storage in soil organic matter. The remaining one-half of the potential for $\mathrm{CO}_{2}$ sink enhancement on U.S. croplands is highly fragmented and beyond the scope and resources of this project.

The main purpose of the cropland component of this project is to estimate, from an energy company perspective, the cost of GHG emission offsets (\$/tonne carbon equivalent GHG avoided) from reducing tillage on U.S. croplands. This involves estimating the following aspects of reducing tillage over time: (1) levels of $\mathrm{CO}_{2}$ sink enhancement, (2) changes in $\mathrm{GHG}$ emissions other than from $\mathrm{CO}_{2}$ sink enhancement (e.g., from fuel use for tillage operations and from nitrous oxide emissions), (3) adoption incentives a company would have to pay to get farmers to adopt reduced-tillage practices, (4) transaction costs for aggregating and brokering GHG credits, and (5) monitoring costs for assuring that contractual obligations are fulfilled. A second purpose of this section is to estimate the hectares of reduced-tillage required to offset specified quantities of power plant GHG emissions.

\subsection{Tillage-System Definitions}

Research, development, demonstration, and deployment of reduced-tillage systems has been a major agricultural initiative over roughly the last forty years. Significant levels of adoption began to occur in the 1970's. In addition to $\mathrm{CO}_{2}$ sink enhancement, there are many benefits of reducing tillage such as fuel, labor, and equipment savings, improved soil quality, and reduced soil erosion by both water and wind ${ }^{2}$. Reductions in soil erosion are highly correlated with the percent of the soil surface covered by crop residues at the time of planting. For this reason, reduced-tillage systems are commonly characterized by the percent of the soil surface covered by crop residues at the time of planting and are commonly called conservation-tillage systems.

Tillage-system definitions published by the Conservation Tillage Information Center ${ }^{3}$ are used in this report. These definitions are as follows: 


\section{Conservation Tillage Types (30 percent or more crop residue left on the soil surface after planting):}

These types include any tillage and planting system that covers 30 percent or more of the soil surface with crop residue, after planting, to reduce soil erosion by water. Where soil erosion by wind is the primary concern, any system that maintains at least 1,000 pounds per acre of flat, small grain residue equivalent on the surface throughout the critical wind erosion period.

No-till/strip-till-The soil is left undisturbed from harvest to planting except for strips up to $1 / 3$ of the row width (strips may involve only residue disturbance or may include soil disturbance). Planting or drilling is accomplished using disc openers, coulter(s), row cleaners, in-row chisels or roto-tillers. Weed control is accomplished primarily with crop protection products (herbicides). Cultivation may be used for emergency weed control. Other common terms used to describe no-till include direct seeding, slot planting, zero-till, row-till, and slot-till.

Ridge-till-The soil is left undisturbed from harvest to planting except for strips up to $1 / 3$ of the row width. Planting is completed on the ridge and usually involves the removal of the top of the ridge. Planting is completed with sweeps, disk openers, coulters, or row cleaners. Residue is left on the surface between ridges. Weed control is accomp lished with crop protection products (frequently using banded application) and/or cultivation. Ridges are rebuilt during row cultivation.

Mulch-till-Full-width tillage involving one or more tillage trips which disturb all of the soil surface and is done prior to and/or during planting. Tillage tools such as chisels, field cultivators, disks, sweeps or blades are used. Weed control is accomplished with crop protection products and/or cultivation.

\section{Other Tillage Types:}

Reduced-till (15-30 percent residue)—Full-width tillage involving one or more tillage trips which disturb all of the soil surface and is performed prior to and/or during planting. There is 15-30 percent residue cover after planting or 500 to 1,000 pounds per acre of small grain residue equivalent throughout the critical wind erosion period. Weed control is accomplished with crop protection products and/or row cultivation.

Conventional-till or intensive-till-Full-width tillage which disturbs all of the soil surface and is performed prior to and/or during planting. There is less than 15 percent residue cover after planting, or less than 500 pounds per acre of small grain residue equivalent throughout the critical wind erosion period. Generally involves plowing or intensive (numerous) tillage trips. Weed control is accomplished with crop protection products and/or row cultivation.

The case studies reported later in this report rely heavily on county- and state-level estimates of carbon stored in soils and crop residues as affected by tillage system. These estimates have been published for Iowa ${ }^{4}$, Indiana ${ }^{5}$, and Nebraska ${ }^{6}$ for intensive-till, moderate-till, and no-till systems. In these reports, moderate-till includes mulch-till and ridge-till systems and no-till systems with intermittent intensive-tillage. 


\subsection{Effects of Tillage-System on the Amount of Carbon Stored in Soil Organic Matter}

The production of crop residues (crop stalks and roots) removes $\mathrm{CO}_{2}$ from the atmosphere and incorporates the $\mathrm{CO}_{2}$ into crop residues via photosynthesis (Figure 18-1). As the crop residues decompose, they release $\mathrm{CO}_{2}$ back into the atmosphere. When crop residues decompose at a slower rate than they are added to the soil, the amount of soil organic matter increases and the amount of carbon stored in soil organic matter increases proportionally. A key effect of reducing tillage is that crop residues decompose more slowly but the amount of crop residues added to the soil remains about the same. This results in an increase in the amount of carbon stored in soil organic matter. In addition to increasing the soil organic matter of non-eroded soil, conservation-tillage systems also significantly reduce the potential for soil erosion and loss of $\mathrm{CO}_{2}$ from eroded soil.

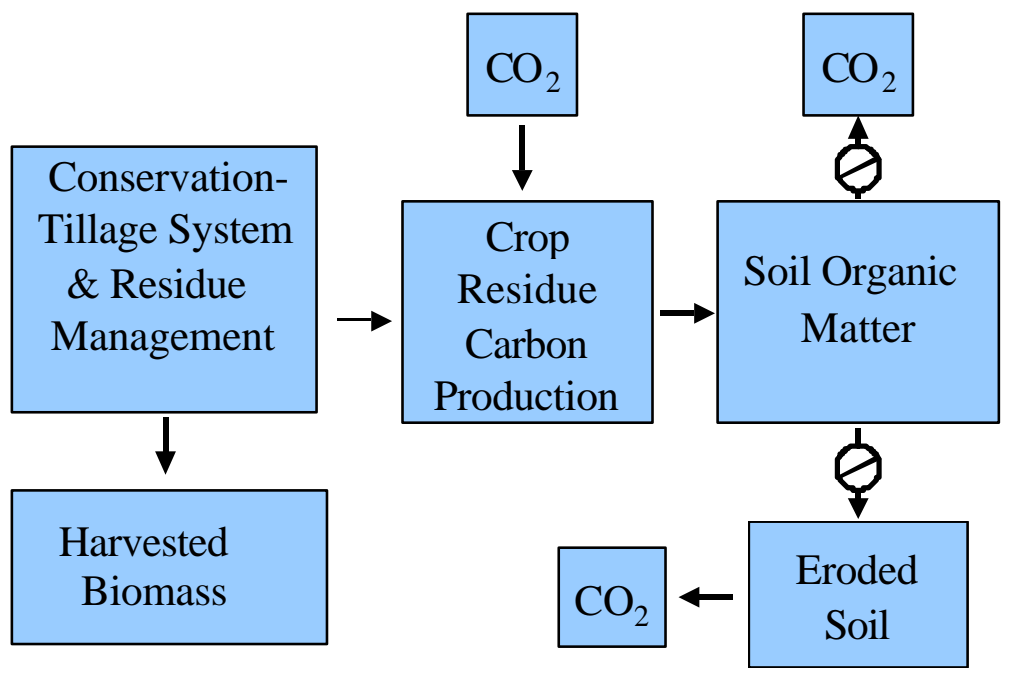

Figure 18-1

Mechanisms by which conservation-tillage systems affect the amount of carbon that remains stored in soil organic matter

Reducing tillage slows the rate of soil organic matter decomposition for several reasons ${ }^{7}$. One key reason is that the soil tends to be more aggregated and soil organic matter contained inside the aggregates is less exposed to soil oxygen, slowing the rate of organic matter decomposition. Another key reason is that crop residues on the soil surface reflect sunlight and result in significantly lower soil temperatures, further slowing the rate of organic matter decomposition. Also, less mixing of crop residues with the soil reduces exposure of the residues to soil moisture and nutrients required for rapid decomposition.

After switching from intensive- to conservation-tillage, the increase in soil organic matter becomes smaller each year and soil organic matter levels eventually build up to a point that the rate of organic matter decomposition equals the rate of crop residue addition. Once this new steady-state is reached, no additional carbon is stored in soil organic matter as a result of 
reducing tillage. An example of reaching a new steady-state level of soil organic carbon (? SOCs) is illustrated in Figure 18-2. The data points for 0, 10, and 20 years are model predictions from the Iowa Carbon Storage Project ${ }^{4}$ and the response curve is from a best-fit quadratic curve for the 1,10, and 20-year data points. In this example, the predicted number of years (Ys) to reach the new steady-state level of SOC was 29. Results from the Iowa and Indiana Carbon Storage Projects indicate that when intensive-till systems are switched to no-till, Ys in these states will typically be between 25 and 35 years.

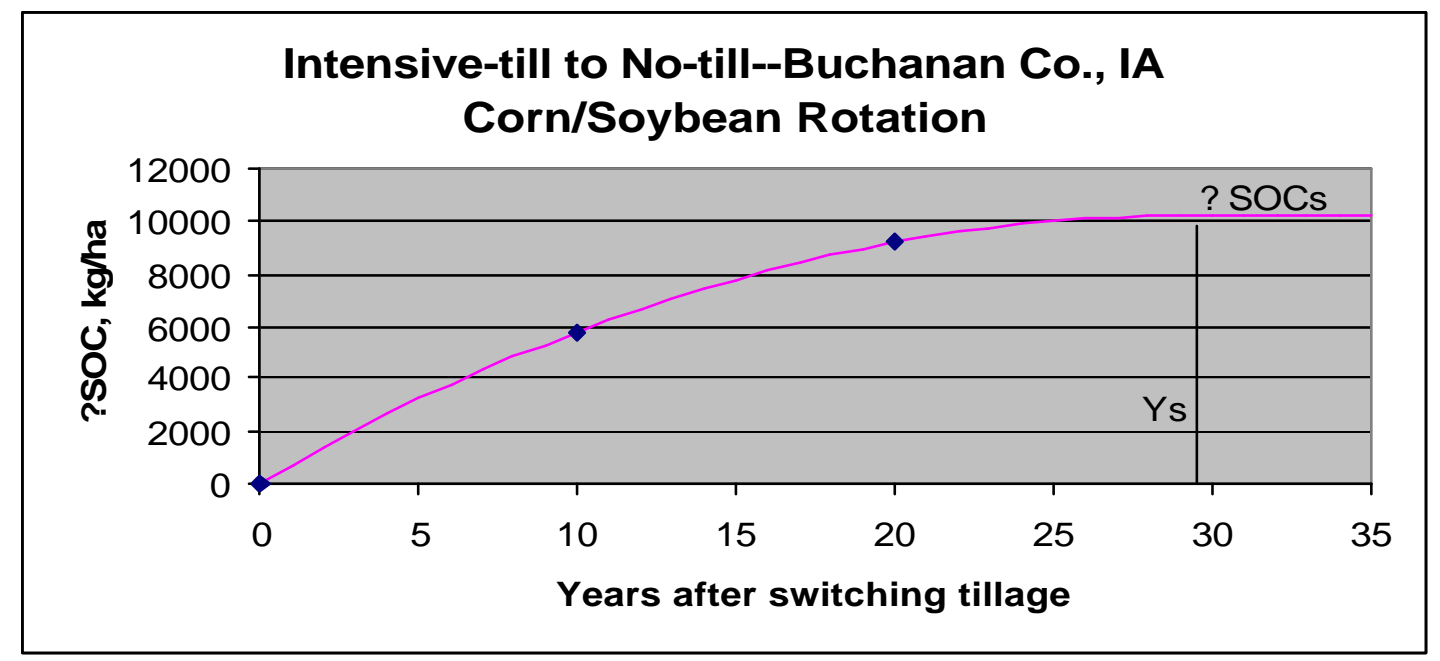

Figure 18-2

Increases in soil organic carbon (SOC) via switching from intensive-till to no-till

The native vegetation for U.S. cropland was primarily grass in the drier areas and trees in the more humid areas. Soil organic matter levels were much higher under native vegetation than they are today after several decades of cultivation. When the grasslands and forests were converted to cropland with intensive tillage systems, soil organic matter levels declined steadily until a new steady-state level was reached. The general decline in SOC for the central Corn Belt is illustrated in Figure 18-3 ${ }^{8}$. From the early 1900's until about 1950, SOC levels declined steadily and then remained at a new steady-state level until about 1970. With the advent of conservation-tillage practices in the 1970's, the general SOC levels in the central Corn Belt began to rise. Further adoption of conservation-tillage practices will help to restore part of the SOC that existed under natural vegetation. 


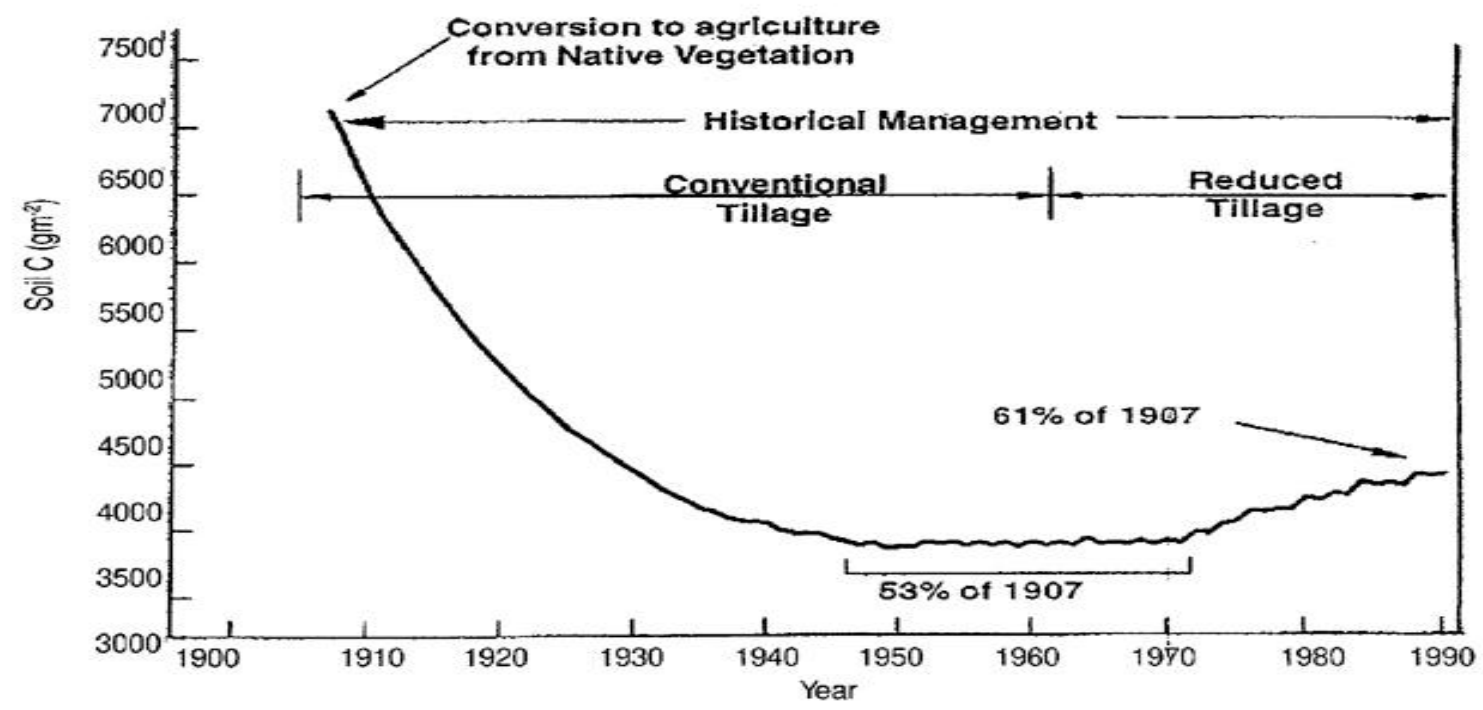

Figure 18-3

Trends in soil organic carbon (SOC) in the central corn belt

\subsection{Regions With Greatest Potential for Increasing Soil Organic Carbon}

Regions with the greatest potential for increasing SOC via reducing tillage are regions with large amounts of cropland and large per hectare increases in SOC as a result of reducing tillage. Counties with 20,000 or more hectares of cropland are presented in Figure 18-4 ${ }^{9}$. These counties meet the criteria of relatively large amounts of cropland. Most of this cropland is east of the Rocky Mountains. Generally, SOC levels increase moving east from the Rocky Mountains through the Great Plains and into the Corn Belt, mainly because of increasing precipitation levels and the associated increase in crop production and amount of crop residues added to the soil ${ }^{7}$.

Likewise, the potential per hectare increases in SOC that can occur as a result of reducing tillage will be greater moving east from the Rocky Mountains through the Great Plains and into the Corn Belt, mainly because of increasing precipitation levels and the associated increase in crop production and amount of crop residues added to the soil. 


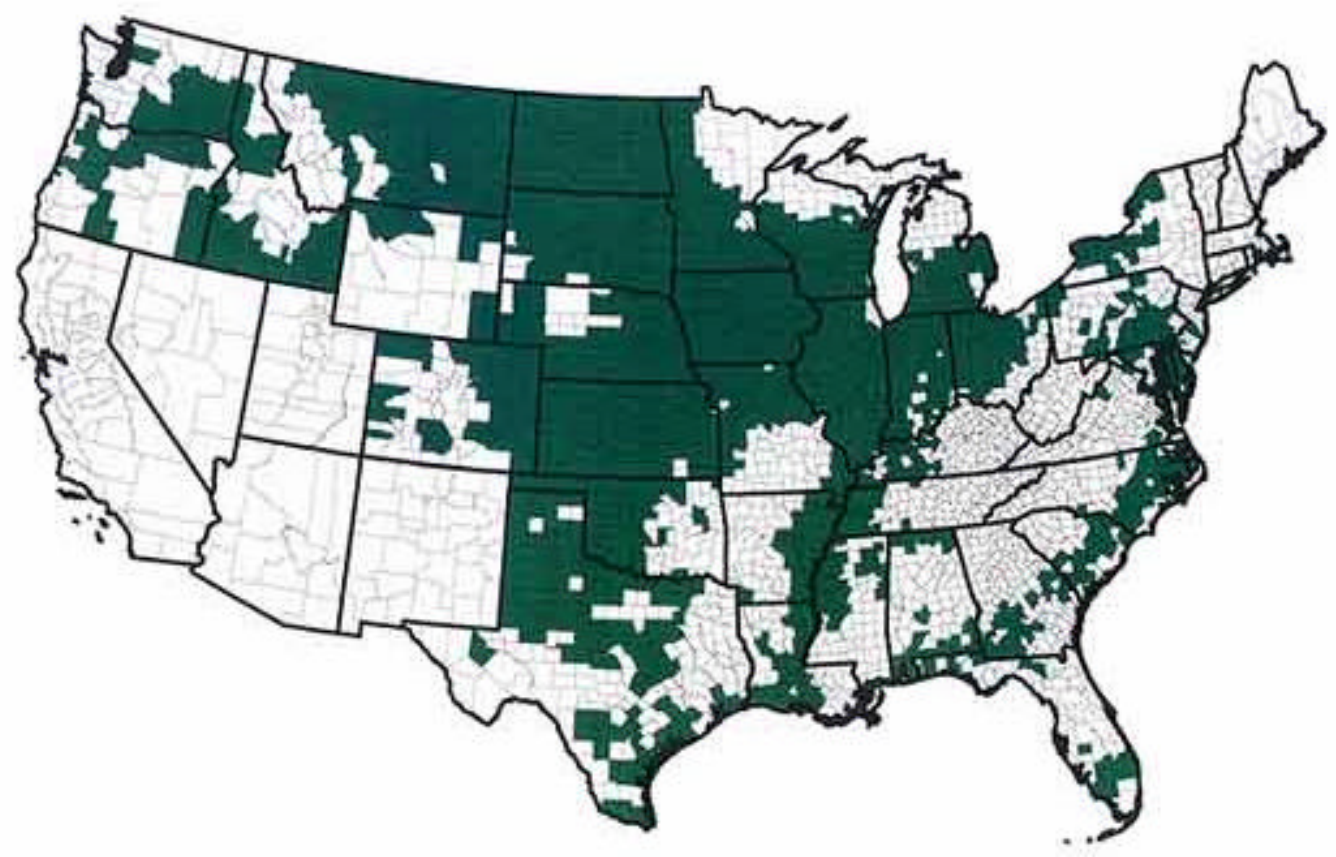

Figure 18-4

Counties with more than 20,000 hectares of cropland

The region comprising roughly the western third of the Great Plains states of North Dakota, South Dakota, Nebraska, Kansas, Oklahoma, and Texas and counties on west to the Rocky Mountains produces predominantly dry land small grains (mainly wheat). Crop production levels and associated residue production levels in this region are severely limited by the amount of rainfall. The traditional cropping system in this region is a wheat/fallow rotation. A crop is grown every two years and the land is left fallow in the alternate years to store soil moisture for the next crop. In traditional wheat-fallow systems in this region, crop residues are added back to the soil only every other year and soil organic matter levels are continuing to decline from levels under native vegetation. Switching to no-till wheat/fallow maintains current soil organic matter levels but does not result in a significant increase in soil organic matter. These relationships are presented for an eastern Colorado location in Figure 18-5 which is based on model simulations ${ }^{10}$. Switching to no-till in the traditional wheat/fallow region holds promise for conserving enough additional soil moisture to enable growing two crops out of three years or three crops out of four years, in which case moderate additional increases in soil organic matter levels can be achieved over that with no-till wheat/fallow ${ }^{11}$. 


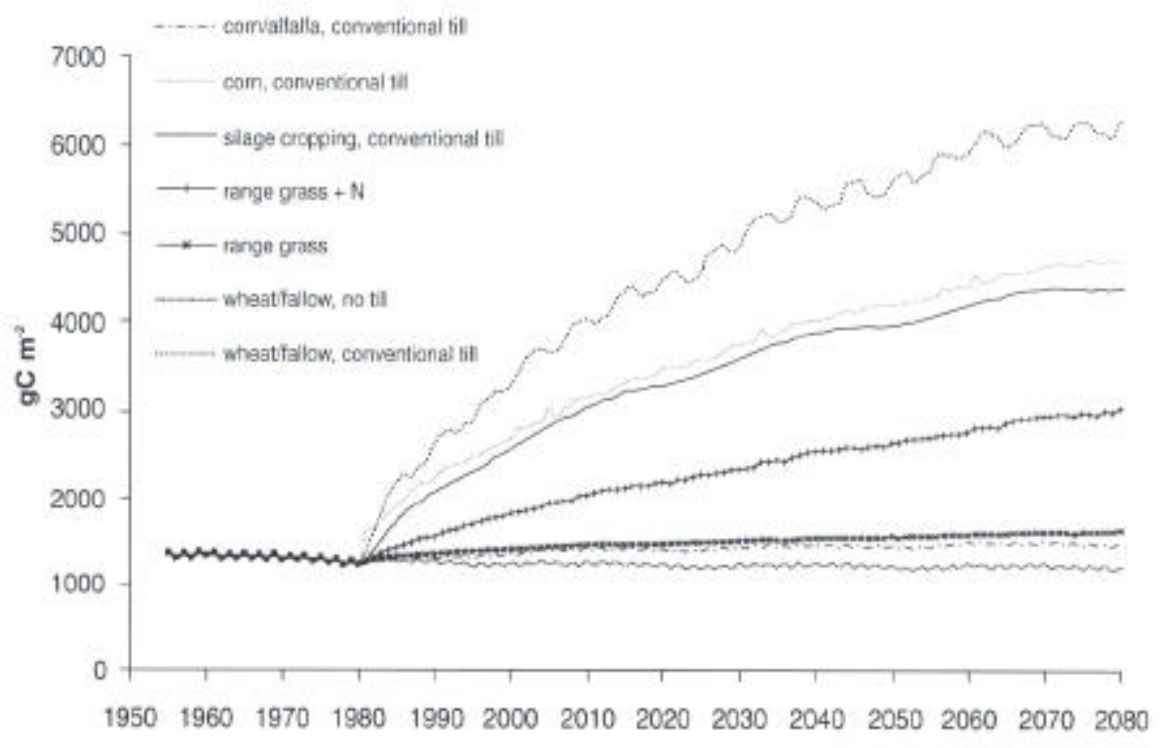

Figure 18-5

Simulated changes in soil organic carbon (SOC) as affected by tillage and cropping systems in eastern Colorado

The silage corn, corn, and corn/alfalfa curves in Figure 18-5 are for irrigated, conventionallytilled systems in which crop production is not limited by moisture. The large increase in SOC in these cropping systems compared to the curves for dryland wheat illustrates the extremely important impact of crop productivity and crop residue production levels on SOC levels. Even greater increases in SOC could be achieved in the irrigated systems by using conservation tillage instead of conventional tillage.

Roughly the eastern two-thirds of the Great Plains states mentioned above receives enough precipitation to enable growing a crop every year. Therefore, crop residues are added to the soil each year and this region has the potential to achieve greater increases in soil organic matter via reducing tillage than does the region discussed in the previous paragraph.

The Corn Belt states of Iowa, Illinois, Indiana, Ohio, Minnesota, Wisconsin, Michigan, and Missouri receive more rainfall than the Great Plains states and produce significantly more crop residues/hectare than the Great Plains. Most of the cropland in these states is in a corn/soybean rotation. In these states, there is a slightly larger area in corn than soybeans. Most of the "excess" corn area is in continuous corn or is rotated with crops in addition to soybeans (mainly wheat). Typical increases in SOC due to switching from intensive-till to no-till at a central Indiana location are presented in Figure $18-6^{10}$. Based on acreage and SOC increases per hectare, Corn/soybean rotations in the Corn Belt offer the greatest potential in the United States for increasing SOC via reducing tillage. 


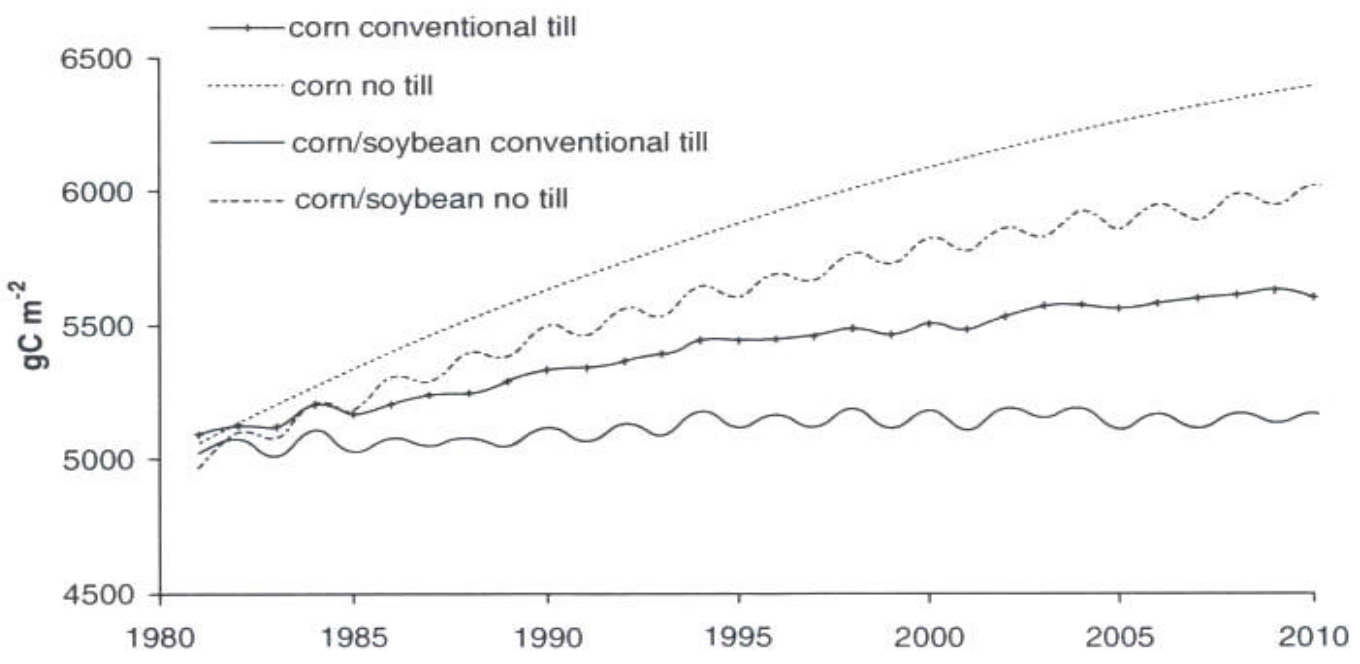

Figure 18-6

Simulated changes in soil organic carbon (SOC) as affected by tillage and cropping systems in central Indiana

Counties with more than 20,000 hectares in the Mississippi corridor to the south of the Corn Belt (Figure 18-4) also have significant potential for increasing SOC via reducing tillage. Cotton and soybeans are major crops in these counties. Crop productivity and amounts of crop residues added to the soil tend to be lower than in the Corn Belt and, due to higher temperatures, the rate of crop residue decomposition tends to be higher than in the Corn Belt. These factors result in less potential on a per hectare basis for increasing SOC via reducing tillage than occurs in the Corn Belt.

\subsection{Current Levels of Conservation-Tillage Adoption}

\subsubsection{Corn and Soybeans in the Corn Belt}

The hectares of corn and soybeans and adoption of conservation-tillage in a north-south transect in the eastern Corn Belt are presented in Table 18-1 ${ }^{12}$. Two trends are evident in Table 18-1. First, conservation-tillage adoption levels are much higher for soybeans than corn. Adoption levels are higher for soybeans than corn mainly because soybeans are better adapted to conservation-tillage and pose less risk of reduced income to the farmer. Since almost all soybeans are rotated with corn, Table 18-1 implies that there is a significant amount of the cropland in which soybeans are in conservation-tillage and corn is in intensive tillage. For example, in Indiana, 59+15=74 percent of the full season soybeans are in conservation tillage and $21+8=29$ percent of the corn is conservation-tillage. This implies that roughly 45 percent 
(74-29 percent) of the land in conservation-till soybeans is not in conservation-till corn. The second trend is that conservation-tillage adoption levels increase going from north to south. One of the challenges of conservation tillage is that leaving more crop residues on the soil surface causes soils to warm and dry more slowly in the spring. This can delay planting in the spring or at least slow growth in the spring and increase the risk of yield reductions with conservation tillage. The risk reduces going from north to south as reflected by the conservation-tillage adoption levels.

Table 18-1

Adoption of conservation-tillage practices in the eastern corn belt and mid-south U.S.

\begin{tabular}{lllllll} 
& & & \multicolumn{2}{c}{ Conservation-till } & \multicolumn{2}{c}{ Intensive-till } \\
\hline \multirow{2nnnyyy}{*}{ State } & & Crop & M hectares & \multicolumn{4}{c}{ No-till } & Mulch-till & $15-30 \%$ & $0-15 \%$ \\
\cline { 4 - 7 } MI & Corn (FS) & 1.1 & 14 & 12 & 20 & 54 \\
MI & SB (FS) & 0.8 & 39 & 9 & 16 & 36 \\
\hline IN & Corn (FS) & 2.3 & 21 & 8 & 19 & 53 \\
IN & SB (FS) & 2.2 & 59 & 15 & 11 & 15 \\
IN & SB (DC) & 0.1 & 80 & 13 & 2 & 5 \\
\hline KY & Corn (FS) & 0.5 & 56 & 16 & 12 & 16 \\
KY & SB (FS) & 0.3 & 56 & 15 & 11 & 19 \\
KY & SB (DC) & 0.2 & 86 & 11 & 2 & 1 \\
\hline TN & Corn (FS) & 0.2 & 54 & 11 & 16 & 19 \\
TN & SB (FS) & 0.3 & 50 & 7 & 18 & 25 \\
TN & SB (DC) & 0.1 & 85 & 5 & 5 & 5 \\
\hline FS=full season; DC=double crop & & & & \\
\hline
\end{tabular}

The hectares of corn and soybeans and adoption of conservation-tillage in a north-south transect in the western Corn Belt are presented in Table 18-2 $2^{12}$. The same trends are evident as were discussed above for Table 18-1. 
Table 18-2

Adoption of conservation-tillage practices in the western corn belt

\begin{tabular}{|c|c|c|c|c|c|c|}
\hline \multirow[b]{3}{*}{ State } & \multirow[b]{3}{*}{ Crop } & \multirow[b]{3}{*}{$\mathrm{M}$ hectares } & \multicolumn{2}{|c|}{ Conservation-till } & \multicolumn{2}{|c|}{ Intensive -till } \\
\hline & & & No-till & Mulch-till & $15-30 \%$ & $0-15 \%$ \\
\hline & & & \multicolumn{4}{|c|}{$\%$ of hectares } \\
\hline MN & Corn (FS) & 2.9 & 2 & 23 & 1 & 74 \\
\hline MN & SB (FS) & 2.8 & 4 & 42 & 2 & 51 \\
\hline IA & Corn (FS) & 4.8 & 18 & 27 & 34 & 21 \\
\hline IA & SB (FS) & 4.3 & 27 & 50 & 16 & 7 \\
\hline $\mathrm{MO}$ & Corn (FS) & 1.1 & 24 & 11 & 24 & 41 \\
\hline $\mathrm{MO}$ & SB (FS) & 1.9 & 37 & 16 & 17 & 30 \\
\hline MO & SB (DC) & 0.2 & 58 & 9 & 11 & 21 \\
\hline
\end{tabular}

\subsubsection{Small Grains}

Adoption of conservation-tillage practices in the major small grain producing states in year 2000 is presented in Table 18-3 $3^{12}$. A majority of the small grains are still intensively tilled. In the traditional stubble-mulch wheat-fallow systems, seven or more tillage operations are performed during the fallow period between wheat crops. Sweep undercutters and rod weeders are commonly used in these systems. These implements don't invert the soil and leave more crop residues on the soil surface than disks or chisel plows, but after seven or more operations during the fallow period, less than 30 percent residue cover is left in most of the traditional wheatfallow systems. 
Table 18-3

Adoption of conse rvation-tillage practices in major small grain states in year 2000

\begin{tabular}{llccccc} 
& & & \multicolumn{2}{c}{ Conservation-till } & \multicolumn{2}{c}{ Intensive -till } \\
\hline & & & No-till & Mulch-till & $15-30 \%$ & $0-15 \%$ \\
\cline { 3 - 7 } State & Crop & M hectares & \multicolumn{4}{c}{$\%$ of hectares } \\
\hline WA & SSSG & 0.4 & 17 & 20 & 34 & 29 \\
& FSSG & 0.8 & 7 & 19 & 40 & 34 \\
\hline MT & SSSG & 3.4 & 9 & 34 & 32 & 25 \\
& FSSM & 0.8 & 15 & 38 & 32 & 14 \\
\hline ND & SSSG & 5.4 & 10 & 16 & 28 & 43 \\
& FSSG & 0.6 & 8 & 10 & 22 & 60 \\
\hline SD & SSSG & 0.8 & 16 & 15 & 34 & 35 \\
& FSSG & 0.6 & 19 & 10 & 42 & 29 \\
\hline NE & FSSG & 0.6 & 7 & 14 & 18 & 60 \\
KS & FSSG & 4.4 & 6 & 15 & 25 & 53 \\
CO & FSSG & 1.5 & 4 & 35 & 28 & 34 \\
OK & FSSG & 2.4 & 5 & 18 & 25 & 51 \\
TX & FSSG & 2.7 & 3 & 28 & 26 & 42 \\
\hline SSSG=Spring seeded small grains; FSSG=fall seeded small grains. & \\
\hline
\end{tabular}

\subsubsection{Cotton}

Adoption of conservation-tillage practices in the major cotton producing states in year 2000 is presented in Table 18-4 ${ }^{12}$. Until recently, adoption of conservation-tillage in cotton has been slow. With the advent of herbicide resistant cotton, adoption of no-till cotton has occurred more rapidly in some states such as Alabama and Tennessee. 
Table 18-4

Adoption of conservation-p in major cotton states in year 2000

\begin{tabular}{lcccccc} 
& & & \multicolumn{2}{c}{ Conservation-till } & \multicolumn{2}{c}{ Intensive -till } \\
\hline \multirow{2}{*}{ State } & Crop & M hectares & No-till & Mulch-till & $15-30 \%$ & $0-15 \%$ \\
\cline { 3 - 7 } MO & Cotton & 0.1 & 5 & 3 & 3 & 66 \\
AK & Cotton & 0.4 & 4 & 1 & 7 & 84 \\
LA & Cotton & 4.8 & 18 & 27 & 34 & 21 \\
TN & Cotton & 0.2 & 45 & 1 & 7 & 47 \\
MS & Cotton & 0.8 & 7 & 4 & 18 & 70 \\
AL & Cotton & 0.2 & 35 & 4 & 2 & 11 \\
TX & Cotton & 2.8 & 1 & 2 & 10 & 86 \\
\hline
\end{tabular}

\subsection{GHG Effects in Addition to Carbon Storage in Soil Organic Matter}

Reducing tillage has several important effects on GHG emissions in addition to increasing the amount of carbon stored in soil organic matter. These include changes in GHG emissions from the following:

- Fuel use for field operations

- Machinery manufacturing, transportation, and repair

- Nitrogen $(\mathrm{N})$ fertilizer use

- Herbicide use

- Nitrous oxide $\left(\mathrm{N}_{2} \mathrm{O}\right)$ emissions from soil

These changes in GHG emissions due to reducing tillage continue indefinitely, even after a steady-state level of SOC has been attained. The net effect of the changes in these emissions and the increase in SOC due to reducing tillage is referred to in the case studies as avoided GHG emissions. Avoided GHG emissions will be estimated for a 100-year planning horizon. An overview of factors affecting GHG emissions by means other than carbon storage in SOM is presented below. More details are provided in the case studies.

\subsubsection{Fuel Use}

Reducing the number and intensity of tillage operations reduces fuel use and the associated $\mathrm{CO}_{2}$ emitted from fuel use. 


\subsubsection{Machinery Required}

Reducing tillage reduces the number of implements and tractors and the size of tractors required. This reduces emissions from machinery manufacture, transportation, and repair.

\subsubsection{N Fertilizer Use}

Reducing tillage increases the potential for $\mathrm{N}$ losses from the soil and for $\mathrm{N}$ tie-up in soil organic matter, but this potential is not necessarily realized if $\mathrm{N}$ is managed well. If greater $\mathrm{N}$ losses and/or more $\mathrm{N}$ tie-up do occur, more $\mathrm{N}$ fertilizer is required to produce a crop. Production of $\mathrm{N}$ fertilizer requires large quantities of fossil fuel to provide hydrogen and process energy for production of anhydrous ammonia and downstream $\mathrm{N}$ fertilizers such as urea and ureaammonium nitrate solutions. Additional energy is required to store, distribute, and apply $\mathrm{N}$ fertilizer. Therefore, any increase in $\mathrm{N}$ fertilizer use translates to significant increases in $\mathrm{CO}_{2}$ emissions. The amount of $\mathrm{N}$ fertilizer recommended for conservation-till systems is generally the same as for intensive-till systems in the Corn Belt. However, $\mathrm{N}$ rate recommendations are higher for conservation-till systems in some other regions. More details will be provided in the case studies.

\subsubsection{Herbicide Use}

Herbicide manufacture and use require some fossil energy but not nearly as much as required for $\mathrm{N}$ fertilizer manufacture and use. Reducing tillage results in somewhat more herbicide use but the increase in herbicide use is becoming minimal. As herbicide prices decrease and herbicide tolerate crops become more widespread, intensive-till and conservation-till systems rely on herbicide use to about the same extent. The main difference is that virtually all no-till systems use a burn-down contact herbicide before planting whereas intensive-till systems don't use a burndown herbicide before planting.

\subsection{5 $\mathrm{N}_{2} \mathrm{O}$ Emissions From Soil}

Increases in $\mathrm{N}_{2} \mathrm{O}$ emissions can have a large impact on the overall amount of GHG avoided by reducing tillage. Small differences in $\mathrm{N}_{2} \mathrm{O}$ emissions can be important because $\mathrm{N}_{2} \mathrm{O}$ is 296 times more potent (weight basis) than $\mathrm{CO}_{2}$ as a GHG. Reducing tillage increases the potential for increased $\mathrm{N}_{2} \mathrm{O}$ emissions from the soil, but this potential is not necessarily realized if these systems are well managed. Emission of $\mathrm{N}_{2} \mathrm{O}$ from soils results from both denitrification and nitrification (more details about these processes in the next paragraph). In general, the amount of $\mathrm{N}_{2} \mathrm{O}$ emitted increases with the amount of $\mathrm{N}$ fertilizer applied; this must be considered when reducing tillage increases the amount of $\mathrm{N}$ fertilizer required. However, even when more $\mathrm{N}$ fertilizer is not applied with reduced tillage, more $\mathrm{N}_{2} \mathrm{O}$ may be emitted when tillage is reduced. This is because, in some cases, soil conditions with reduced tillage are more conducive to $\mathrm{N}_{2} \mathrm{O}$ emissions from denitrification and nitrification. Therefore, both the amount of $\mathrm{N}$ fertilizer applied and soil factors must be considered in estimating the effects of reducing tillage on $\mathrm{N}_{2} \mathrm{O}$ emissions. 
Denitrification is a microbial process in which nitrate nitrogen is converted to gases, mainly $\mathrm{N}_{2}$ and $\mathrm{N}_{2} \mathrm{O}$, under limited oxygen conditions ${ }^{13}$. Nitrous oxide is usually a minor portion of the $\mathrm{N}$ lost via denitrification. In addition to a supply of nitrate and low oxygen conditions, a source of biologically available carbon is required as an energy source for the denitrifying microbes. Low oxygen conditions occur in soil mainly when soils are excessively wet and soil pores contain sufficient water to restrict movement of air into the soil; this can result in a depletion of soil oxygen levels as oxygen is used to support plant and microbial growth. In some cases, excessively wet conditions and more biologically available carbon occur more extensively in conservation-till than intensive-till systems, leading to more $\mathrm{N}_{2} \mathrm{O}$ emissions with conservationtill $^{14}$. More specifics will be provided in the case studies.

Nitrification is the microbial conversion of ammonium to nitrate. Most $\mathrm{N}$ fertilizers are applied in an ammonium form and $\mathrm{N}$ from soil organic matter is released as ammonium. In cropland, most of the $\mathrm{N}$ supplied from fertilizers and from soil organic matter is ultimately present as ammonium and then converted to nitrate via nitrification. Nitrification is a less important source of $\mathrm{N}_{2} \mathrm{O}$ than is denitrification and effects of reducing tillage on $\mathrm{N}_{2} \mathrm{O}$ emissions from nitrification are less well understood than the effects of reducing tillage on $\mathrm{N}_{2} \mathrm{O}$ emissions from denitrification $^{13}$.

\subsection{Costs of Reducing Tillage as a Means of Offsetting Utility GHG Emissions}

The costs of reducing tillage as a means of offsetting energy company GHG emissions are of three types: (1) adoption incentives an energy company would have to pay to get farmers to switch from intensive-tillage to conservation-tillage practices on additional land, (2) transaction costs for aggregating and brokering GHG credits, and (3) monitoring costs to assure that contractual obligations are fulfilled.

In general, crop production costs are less for conservation-tillage systems than for intensivetillage systems and average yields are not significantly affected by tillage system (See Appendix $\mathrm{E}$ for more details). This means that, in general, farmers' long-term incomes are not greatly affected by switching from intensive till to conservation till. The big economic difference when switching to conservation-tillage is greater yield variability and greater risk of reduced income in a given year ${ }^{15}$. Therefore, the main cost of achieving increased adoption of conservation tillage is an adoption incentive to compensate the farmer for accepting increased risk, especially in the first few years after adoption of reduced tillage. The increased risk with conservation-tillage systems is usually greatest during the first few years after switching to conservation tillage ${ }^{16}$. This is partly because farmers have to learn how to adapt conservation-tillage systems to their specific soils, climate, and financial resources and partly because benefits of improved soil quality from conservation tillage may not be significant until several years after switching to conservation tillage. Once significant soil quality improvements have occurred, they usually translate into higher crop yields. In most cases, the higher crop yields will provide sufficient economic incentive to continue the reduced-tillage practices without an external incentive. However, in some cases, farmers may have to be compensated for a lower average income over 
the long term; in these cases, adoption incentives will compensate for lost average income in addition to increased risk.

In addition to adoption incentives, other costs of $\mathrm{CO}_{2}$ sink enhancement via reducing tillage are transaction costs for aggregating and brokering $\mathrm{CO}_{2}$ credits and monitoring costs to verify that contractual obligations are fulfilled. These costs are not well defined because of lack of actual implementation projects. Costs will be based on related experiences such as in forestry sink enhancement projects.

A key question is how long adoption incentives will have to be paid to a farmer to get him to maintain the switch to conservation tillage. There are not definitive answers to this question. As indicated in Figures 18-2, 18-5, and 18-6, after switching from intensive-till to conservation-till, the annual increases in SOC decrease with time and eventually become zero, usually within 20 to 40 years after switching to conservation tillage. Will adoption incentives be required for the entire 20 to 40 years that SOC is increasing, or even longer? Since the greatest financial risk to the farmer occurs in the early years after switching to conservation tillage, it is likely that incentive payments will only be necessary for the first 5 to 20 years after switching tillage. After that time, higher crop yields with conservation tillage are expected to provide adequate incentive to continue conservation-tillage practices. Our analyses in the case studies will assume a range of 5 to 20 years for adoption incentive payments.

Another key question is how to handle situations in which a farmer must intensively till occasionally (e.g., in one or two years out of 20) to overcome some production problem that develops such as the need to incorporate lime or severe rutting of fields because of harvesting when the soils were too wet. This project uses a 100-year planning horizon for the economic analyses. With this length of planning horizon, we assume that if intensive tillage is used occasionally, the SOC le vel will have time to rebound to the steady-state level under conservation tillage before the end of the 100-year planning horizon.

Another key question is how to estimate costs of $\mathrm{CO}_{2}$ abatement from an energy company perspective if farmers were to permane ntly switch back to intensive tillage after adoption incentives are no longer paid (as discussed above, this is not expected to be the usual case). As discussed in Section 2.4, we use an approach that accounts for the timing of both $\mathrm{CO}_{2}$ abatement and $\mathrm{CO}_{2}$ abatement costs. This approach was selected to enable comparison of $\mathrm{CO}_{2}$ storage and sink enhancement options that vary greatly in the timing and permanence of $\mathrm{CO}_{2}$ abatement and timing of $\mathrm{CO}_{2}$ abatement costs. We treat removals and emissions/leaks of $\mathrm{CO}_{2}$ as separate events. The basic idea is that when a company removes or pays for removal of a ton of $\mathrm{CO}_{2}$, the company receives the going price of $\mathrm{CO}_{2}$. When a ton of $\mathrm{CO}_{2}$ is released, the owner of this $\mathrm{CO}_{2}$ (in this case the company) must then purchase a credit from elsewhere at the going price. With this approach, a breakeven $\mathrm{CO}_{2}$ price $\left(\$ /\right.$ tonne of $\left.\mathrm{CO}_{2}\right)$ is calculated as the price at which the sum of discounted $\mathrm{CO}_{2}$ revenues (both positive and negative) equals the sum of discounted costs of $\mathrm{CO}_{2}$ sink enhancement. This breakeven price is the long-term cost of $\mathrm{CO}_{2}$ abatement. See Section 2.4 for calculating costs of storing captured $\mathrm{CO}_{2}$ for more details on calculating the breakeven $\mathrm{CO}_{2}$ price. 
A 6.09 percent after-tax discount rate was used in calculating breakeven $\mathrm{CO}_{2}$ prices for $\mathrm{CO}_{2}$ sink enhancement via reducing tillage on U.S. croplands. This is the same discount rate (constant dollar basis) as used for calculating costs of storing captured $\mathrm{CO}_{2}$, and is applicable for calculating $\mathrm{CO}_{2}$ abatement costs from an energy company perspective. An energy company likely would use the same financial parameters for evaluating GHG abatement investments regardless of whether the investments involve $\mathrm{CO}_{2}$ capture and storage or $\mathrm{CO}_{2}$ sink enhancement.

\subsection{Cropland Case Studies Included in This Project}

The following cropland case studies are included in this project, the goal being to both (1) include cases representing the greatest amount of avoided GHG emissions that could be achieved by reducing tillage and (2) illustrate the range of amounts per hectare and costs of avoided GHG emissions that could be achieved by reducing tillage.

1. Chapter19: Corn/soybean rotations in the Corn Belt being converted from intensive-till to either no-till or moderate-till. This case includes best-case and worst-case scenarios concerning effects of reducing tillage on $\mathrm{N}$ fertilizer requirements and on $\mathrm{N}_{2} \mathrm{O}$ emissions.

2. Chapter 20: Continuous corn cropping systems in the Corn Belt being converted from intensive-till to either no-till or moderate-till. This case includes best-case and worst-case scenarios concerning effects of reducing tillage on $\mathrm{N}$ fertilizer requirements and on $\mathrm{N}_{2} \mathrm{O}$ emissions.

3. Chapter 21: Wheat/fallow rotations in the western Great Plains being converted from intensive-till to no-till. This case includes variations in the amount of SOC sequestered and amount of $\mathrm{N}_{2} \mathrm{O}$ emissions due to reducing tillage.

4. Chapter 22: Intensive-till cotton to no-till cotton in the southeastern U.S. This case includes variations in the amount of SOC sequestered and amount of $\mathrm{N}_{2} \mathrm{O}$ emissions due to reducing tillage. 


\subsection{References}

1 Lal, R., J.M. Kimble, R.F. Follett, and C.V. Cole. 1999. U.S. cropland's overall potential to mitigate the greenhouse effect. p. 81-87. In R. Lal., J.M. Kimble, R.F. Follett, and C.V. Cole (eds.) The potential of U.S. cropland to sequester carbon and mitigate the greenhouse effect. Lewis Publishers. Washington D.C.

2 CTIC (Conservation Tillage Information Center). 1999. www.ctic.purdue.edu/Core4/Core4TechnicalManual.pdf

3 CTICa (Conservation Tillage Information Center a). 2002. www.ctic.purdue.edu/Core4/CT/Definitions.html

4 Brenner, J., K. Paustian, G. Bluhm, J. Cipra, M. Easter, E.T. Elliott, T. Kautza, K. Killian, J. Schuler and S. Williams. 2001. Quantifying the change in greenhouse gas emissions due to natural resource conservation practice application in Iowa. Final report to the Iowa Conservation Partnership. Colorado State University Natural Resource Ecology Laboratory and USDA Natural Resources Conservation Service, Fort Collins, CO, USA.

5 Smith, P., J. Brenner, K. Paustian, G. Bluhm, J. Cipra, M. Easter, E.T. Elliott, K. Killian, D. Lamm, J. Schuler and S. Williams. 2002. Quantifying the change in greenhouse gas emissions due to natural resource conservation practice application in Indiana. Final report to the Indiana Conservation Partnership. Colorado State University Natural Resource Ecology Laboratory and USDA Natural Resources Conservation Service, Fort Collins, CO, USA.

6 Brenner, J.K., K. Paustian, G. Bluhm, J. Cipra, M.Easter, R. Foulk, K. Killian, R. Moore, J. Schuler, P. Smith, and S. Williams. 2002. Quantifying the change in greenhouse gas emissions due to natural resource conservation practice application in Nebraska. Colorado State University Natural Resource Ecology Laboratory and USDA Natural Resources Conservation Service, Fort Collins, CO, USA.

7 Paustian, Keith, Harold P. Collins, and Eldor A. Paul. 1997. Management controls on soil carbon. p. 15-49. In E.A. Paul, K. Paustian, E.T. Elliott, and C.V. Cole (eds.) Soil organic matter in temperate agroecosystems: long-term experiments in North America.

8 Donigan, A.S. Jr., T.O. Barnwell, R.B. Jackson, A.S. Patwardhan, K.B. Weinreich, A.L. Roswell, R.V. Chinnaswamy, and C.V. Cole. 1994. Assessment of alternative management practices and policies affecting soil carbon in agroecosystems of the central United States. Publication No. EPA/600R-94/067. US-EPA, Athens, GA.

9 CTICb (Conservation Tillage Information Center b). 2002. http://www.ctic.purdue.edu/Core4/CT/transect/50KCroplandAcres.jpg 
10 Del Grosso, S.J. W.J. Parton, A.R. Mosier, M.D. Hartman, J. Brenner, D.S. Ojima, and D.S. Schimel. 2001. Simulated interaction of carbon dynamics and nitrogen trace gas fluxes using the DAYCENT model. P. 303-332. In M.J. Shaffer, Liwang Ma, and S. Hansen (eds.) Modeling carbon and nitrogen dynamics for soil management. Lewis Publishers. Washington, D.C.

11 Peterson, G.A., D.G Westfall, N.E. Toman, and R.L. Anderson. 1993. Sustainable dryland cropping systems: economic analysis. Technical BulletinTB93-3. Colorado State University.

12 CTIC (Conservation Tillage Information Center). 2000. http://www.ctic.purdue.edu/Core4/CT/ctsurvey/2000/NewsReleases.html

13 Hutchinson, G.I. and Davidson, Eric A. 1993. Processes for production and consumption of gaseous nitrogen oxides in soil. p. 79-93. In Dennis E. Rolston (ed.) Agricultural ecosystem effects on trace gases and global climate change. ASA Special Publication no. 55. ASA,CSSA, and SSSA, Madison, WI.

14 Mummey, Daniel L., Jeffrey L. Smith, and George Blum. 1998. Assessment of alternative soil management practices on N2O emissions from U.S. agriculture. Agriculture, Ecosystems, and Environment 70:79-87.

15 Kurkalova, Lyubov A., Catherine L. King, and Jinhua Zhao. 2001. The subsidy for adopting conservation tillage: estimation from observed behavior. http://www.card.iastate.edu/publications/texts/01wp286.pdf

16 CTICc (Conservation Tillage Information Center c). 2002. http://www.ctic.purdue.edu/Core4/MAX/1998/Page38.html 


\section{CORN/SOYBEAN ROTATIONS IN THE U.S. CORN BELT}

\subsection{Introduction}

As indicated in Chapter 18, corn/soybean rotations in the Corn Belt represent the largest potential for increasing SOC via reducing tillage in the United States. This is primarily because of the large land area in corn/soybean rotations. Also, corn and soybean yields, crop residue levels, and potential for per hectare increases in SOC are larger than for regions beyond the Corn Belt that use corn/soybean rotations. Base-case results for corn/soybean rotations are presented in Section 19.2. The base cases assume good $\mathrm{N}$ fertilizer management. Effects of poor $\mathrm{N}$ fertilizer management on amounts and costs of GHG credits from corn/soybean rotations are presented in Section 19.3.

\subsection{Corn/Soybean Rotation (Base Cases)}

A summary of effects of switching from intensive-till to no- or moderate-till on SOC, GHG emissions, and costs of avoided GHG emissions is presented in Table 19-1 for corn/soybean rotations in Indiana and Iowa. The bases for the results in Table 19-1 are discussed in the following sections using output from the corn/soybean spreadsheet model developed for this project.

The results in Table 19-1 are presented at a state level because, even with the relatively large land area of corn/soybean rotations in the Corn Belt states, additional adoption of conservationtillage will be required on a state scale to avoid the same quantity of GHG emissions as avoided in the $\mathrm{CO}_{2}$ capture and storage cases assessed in this project. For example, converting the basecase $425 \mathrm{MW}$ (net) integrated gasification combined cycle (IGCC) power plant to capture 90 percent of the $\mathrm{CO}_{2}$ produced and storing the captured $\mathrm{CO}_{2}$ via enhanced oil recovery (EOR) avoids 0.45 million tonnes CE of GHG per year on a life-cycle basis during the 20-year life time of the plant (see earlier section on EOR). This translates to 9.1 million tonnes CE of GHG avoided during the 20 year life of the plant. Converting from intensive-till to no-till in Iowa avoids 9.9 tonnes CE GHG emissions per hectare during the 100-year planning horizon used in this project (Table 19-1). This means that 9,100,000/9.9=919,000 hectares of intensive-till cropland converted to no-till will be required to equal the avoided GHG in the IGCC-EOR case. This amount of cropland ( 0.92 million hectares) is slightly less than the amount of intensively tilled soybeans in Iowa and about one-third of the intensively tilled corn in Iowa (Table 18-2). 


\section{Table 19-1}

Effects of switching from intensive-till to no- or moderate-till on SOC, GHG Emissions, and costs of life-cycle (LC) avoided GHG emissions--Indiana and lowa state averages for

Corn/Soybean rotation

State

Switching from intensive-till to:
Indiana

No-

lowa

No-till Moderate-till till Moderate-till

\section{Quadratic SOC response curve}

$\begin{array}{lrrrr}\Delta \text { SOCs, kg C/ha } & 7221 & 5159 & 9794 & 6520 \\ \text { E (slope factor) } & 53.1 & 37 & 68.3 & 45.6 \\ \text { Years to new steady state (Ys) } & 27 & 28 & 29 & 29 \\ \begin{array}{l}\text { Average annual increase in SOC (years 1 to } \\ \text { Ys), kg C/ha/yr }\end{array} & 267 & 184 & 338 & 225\end{array}$

GHG emissions from tillage-system inputs and $\mathrm{N}_{2} \mathrm{O}$ (years 1-100), $\mathrm{kg} \mathrm{CE} / \mathrm{ha} / \mathrm{y}$ :

\begin{tabular}{|c|c|c|c|c|}
\hline$\Delta$ Fuel use & -22.3 & -16.9 & -22.3 & -16.9 \\
\hline$\Delta$ Machinery maint., trans., and repair & -4 & -3 & -4 & -3 \\
\hline$\Delta N$ fertilizer use & 0 & 0 & 0 & 0 \\
\hline$\Delta$ Herbicide use & 3 & 0.8 & 3 & 0.8 \\
\hline$\Delta$ Total GHG emissions from inputs & -23.3 & -19.1 & -23.3 & -19.1 \\
\hline$\Delta \mathrm{N}_{2} \mathrm{O}$ emissions from soil & 30.3 & 30.3 & 30.3 & 30.3 \\
\hline$\Delta$ Total GHG emissions & 7.0 & 11.2 & 7.0 & 11.2 \\
\hline \multicolumn{5}{|l|}{ Average LC GHG avoided (kg CE/ha/y) } \\
\hline Years 1 to Ys & 260 & 173 & 331 & 214 \\
\hline Years Ys to 100 & -7 & -11 & -7 & -11 \\
\hline $\begin{array}{l}\text { Total LC GHG avoided (years } 1-100 \text { ), } \\
\text { tonne CE/ha }\end{array}$ & 6.5 & 4.0 & 9.9 & 5.4 \\
\hline \multicolumn{5}{|l|}{ NPV Total LC GHG avoided (years 1-100), } \\
\hline tonne CE/ha & 4.3 & 2.9 & 5.7 & 3.7 \\
\hline \multicolumn{5}{|l|}{ Costs, $\$ /$ ha/y } \\
\hline Transaction (year 1) & 5 & 5 & 5 & 5 \\
\hline Adoption incentive (years 1-20) & 25 & 12.5 & 25 & 12.5 \\
\hline Monitoring (years 1-100) & 1 & 1 & 1 & 1 \\
\hline Total costs (years $1-100), \$ /$ ha & 605 & 355 & 605 & 355 \\
\hline NPV Total costs (years $1-100$ ), $\$ /$ ha & 306 & 163 & 306 & 163 \\
\hline $\begin{array}{l}\text { Cost (NPV basis), \$/tonne CE LC GHG } \\
\text { avoided }\end{array}$ & 72 & 56 & 54 & 44 \\
\hline
\end{tabular}




\subsubsection{Increases in Soil Organic Carbon}

The increases in SOC due to switching from intensive-till to no-till or moderate-till (Table 19-1) are based on state- and county-level assessments for Iowa ${ }^{1}$ and Indiana ${ }^{2}$. Iowa and Indiana form a representative east-west transect across the mid-section of the Corn Belt states. Similar assessments are not available for the other Corn Belt states. The Iowa and Indiana assessments provide county-level estimates of increases in SOC for 10 and 20 years after switching corn/soybean rotations from intensive-till to no-till or moderate-till. These results were provided for several combinations of soil texture and internal drainage [non-hydric (i.e., well drained) or hydric (i.e., poorly drained)]. State-level estimates of increases in SOC were provided for 10 years after switching from intensive-till to no-till or moderate-till on both non-hydric and hydric soils. SOC response curves for counties representing the range and mean of SOC responses in Indiana and Iowa are presented in Appendix F. An interpolation procedure described in Appendix F was used to develop state-level SOC response curves for switching from intensive-till to no-till and moderate-till in Indiana and Iowa. Graphs of the four SOC response curves represented in Table 19-1 are presented in Figure 19-1.

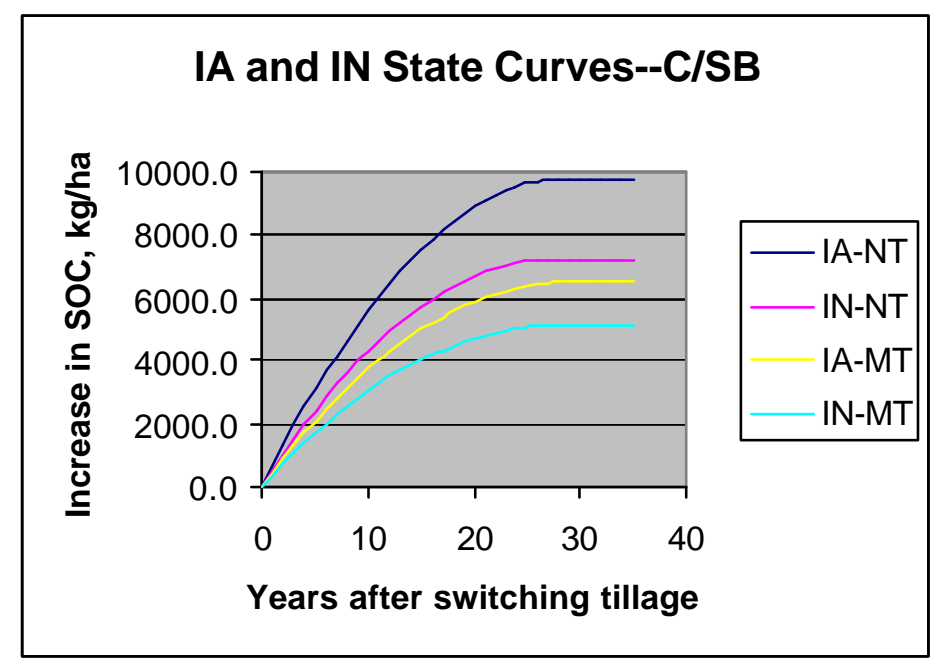

Figure 19-1

State SOC response curves for switching from intensive-till to no-till (NT) or moderate-till (MT) in lowa and Indiana

After completing county-level carbon storage estimates first in Iowa ${ }^{1}$ and then in Indiana ${ }^{2}$, results in Indiana were judged to be most representative of the Corn Belt (personal communication, John Brenner, NRCS). Eve et al. ${ }^{3}$ used the IPCC method of estimating firstapproximation regional increases in SOC due to reducing tillage. The IPCC method assumes a 20-year linear increase in SOC. Using the IPCC method, switching from intensive tillage to no tillage in the Corn Belt resulted in an estimated weighted mean increase in SOC of $480 \mathrm{~kg}$ $\mathrm{C} / \mathrm{ha} / \mathrm{yr}$ for a 20 -year period. This estimated increase in SOC should be representative for a corn/soybean rotation since it is the predominant cropping system in the Corn Belt. A best-fit linear/plateau curve for the Indiana state curve (intensive till to no till) in Figure 19-1 gave a linear SOC increase of $400 \mathrm{~kg} \mathrm{C} / \mathrm{ha} / \mathrm{yr}$ until the plateau was reached after 18 years. This is very similar to the IPCC estimate of $480 \mathrm{~kg} / \mathrm{ha} / \mathrm{yr}$ for a 20 -year period, further supporting use of the Indiana state curves as being more representative of the Corn Belt than are the Iowa state curves. 
West and Post ${ }^{4}$ summarized increases in SOC in the United States due to switching corn/soybean rotations from intensive tillage to no tillage for a period of 10 to 15 years; they estimated a mean increase in SOC of $900 \mathrm{~kg} \mathrm{C} / \mathrm{ha} / \mathrm{yr}$. This is much higher than the estimates by either Eve et al. ${ }^{3}$ using IPCC methodology or Brenner et al. ${ }^{1}$ on which the curves in Figure 19-1 are based. The higher values from West and Post ${ }^{4}$ appear to be due at least partially to the fact that most of the studies they summarized are for a shorter time period (10-15 years) after switching to no tillage, thereby reflecting a steeper portion of the SOC response curve.

Example spreadsheet inputs for calculating increases in SOC due to switching from intensive-till to no-till in Indiana (first column of Table 19-1) are presented in Table 19-2.

Table 19-2

Example process and economic input variables for switching from intensive-till to no-till for corn/soybean rotation in Indiana

Cropland: Two-Year Corn/Soybean Rotation (Changes Due to Switching from Intensive-Till to No-Till)

Indiana

\begin{tabular}{|c|}
\hline \multicolumn{1}{|c|}{ Indiana } \\
\hline
\end{tabular}

\section{Process}

$$
\text { Alternative Tillage System: No-till }
$$

Calculation Method for Sequestering Soil Organic Carbon (SOC)

Quadratic Plateau Linear Plateau

Efficiency or Slope Index $(E)$

SOC Increase to New Steady State ( $\Delta$ SOCs)

Years until New Steady State (Ys)

53.1

$7221.0 \mathrm{~kg} / \mathrm{ha}$

27 years

No-till time period

SOC Release Rate after no-till time period

100 years

$1500 \mathrm{~kg} \mathrm{C} / \mathrm{ha} / \mathrm{yr}$

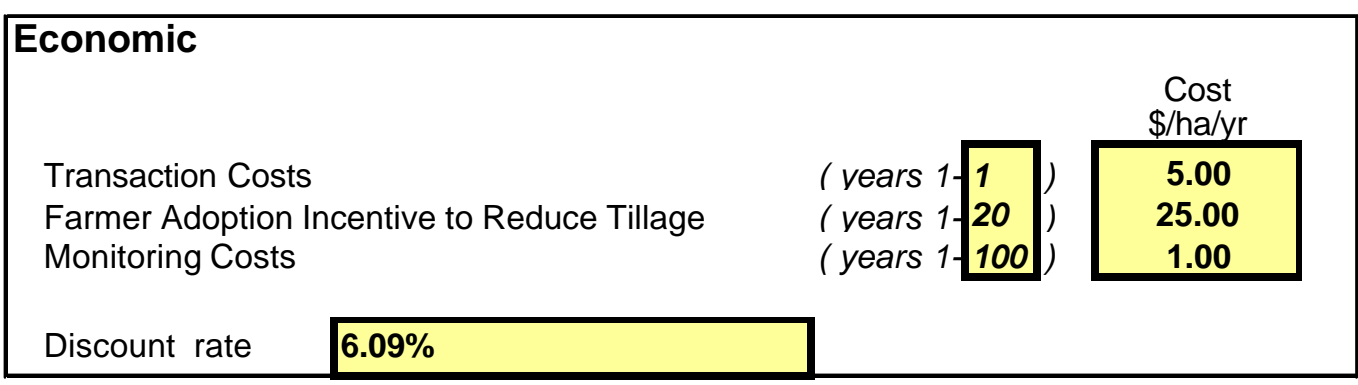




\subsubsection{Costs}

Example cost inputs are presented in Table 19-2. Experience with conservation-tillage adoption programs indicates that an adoption incentive of at least $\$ 25 / \mathrm{ha} /$ year for corn/soybean rotations will be required to achieve additional adoption from intensive-till of no-till in the Corn Belt (personal communication, Dan Towery, Conservation Tillage Information Center). For example, the Environmental Quality Incentives Program (EQIP) in Illinois is providing an incentive of $\$ 50 / \mathrm{ha} / \mathrm{yr}$ for switching corn from intensive tillage to no tillage and is providing no incentive for switching soybeans from intensive tillage to no tillage. This results in an average incentive of $\$ 25 / \mathrm{ha} / \mathrm{yr}$ for corn/soybean rotations. Conservation-tillage adoption incentives are estimated in Appendix E and ranged from $\$ 20$ to 25/ha/year for switching from intensive-till to no-till corn/soybean rotations. A value of $\$ 25 /$ ha/year was used for the case studies in this chapter. As a first approximation, we assume an adoption incentive of $\$ 12.50 / \mathrm{ha} / \mathrm{yr}$ will be required to achieve additional adoption of corn/soybean rotations from intensive-till to moderate till. Transaction costs are based on experience with forestry projects and are estimated at $\$ 5 / \mathrm{ha}$. Monitoring costs are assumed to be less than for forestry $(\$ 5 / \mathrm{ha})$, assuming that cropland monitoring will be based mainly on monitoring practices that have been correlated with changes in SOC rather than direct measurements of SOC in each field. Monitoring costs of $\$ 1 / \mathrm{ha} / \mathrm{year}$ were assumed.

\subsubsection{GHG Effects in Addition to Carbon Storage in Soil Organic Matter}

\subsubsection{Fuel Use}

Reductions in fuel use and associated carbon emissions by switching from intensive-till to no-till in a corn/soybean rotation are presented in Table 19-3. Fuel usage rates are from Langemeier and Taylor ${ }^{5}$. Reductions in fuel use and associated carbon emissions by switching from intensive-till to moderate-till in a corn/soybean rotation are presented in Table 19-4. 
Table 19-3

Reductions in fuel use and associated carbon emissions by switching from intensive-till to no-till in a corn/soybean rotation

Cropland: Two-Year Corn/Soybean Rotation

Indiana

Fuel Use for tillage, planting, and herbicide operations
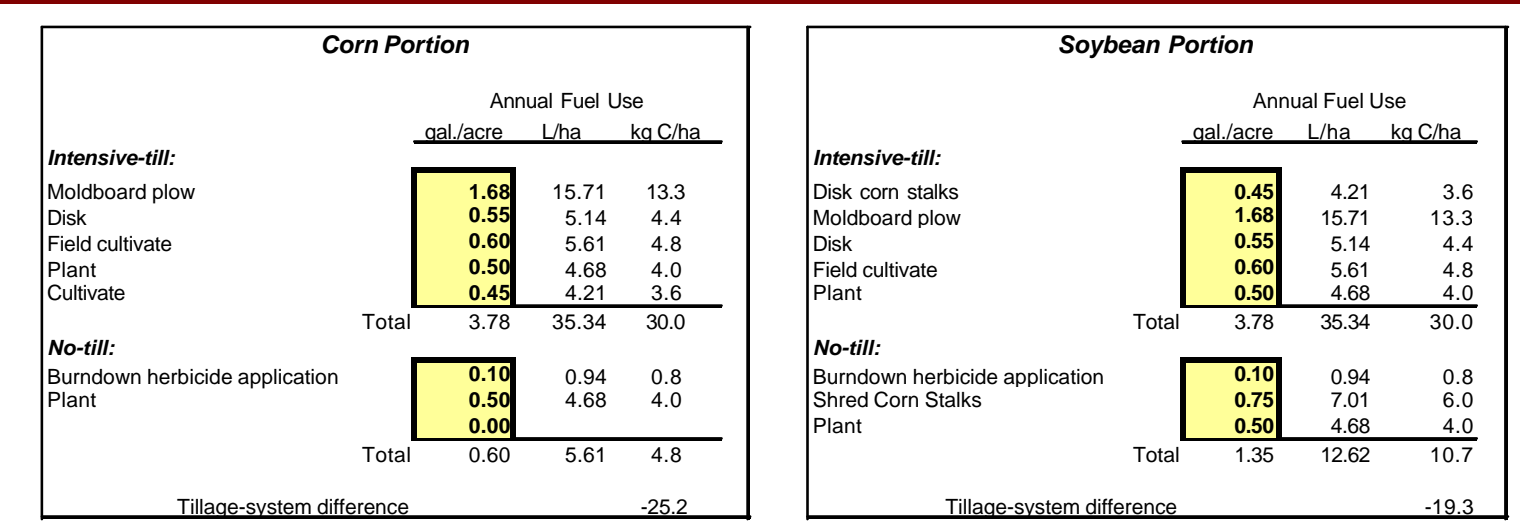

Mean annual tillage-system difference (years 1- 100 ) $\quad-22.3 \mathrm{~kg} \mathrm{C/ha}$

Energy Savings Embodied in Machinery Manufacturing,

Transportation, \& Repair (MTR)

Annual machinery MTR saving from reducing tillage (years 1- 100 ) $-4.0 \mathrm{~kg} \mathrm{C} / \mathrm{ha}$

\subsubsection{Machinery Manufacture, Transportation, and Repair}

Reductions in machinery manufacture, transportation, and repair (MTR) and associated carbon emissions by switching from intensive-till to no-till or moderate-till in a corn/soybean rotation were calculated as 18 percent of the fuel savings (Tables 19-3 and 19-4). The 18 percent factor is based on ratios of tillage-system fuel use and machinery MTR in a national analysis of tillagesystem effects on GHG emissions ${ }^{6}$. 
Table 19-4

Reductions in fuel use and associated carbon emissions by switching from intensive-till to moderate-till in a corn/soybean rotation

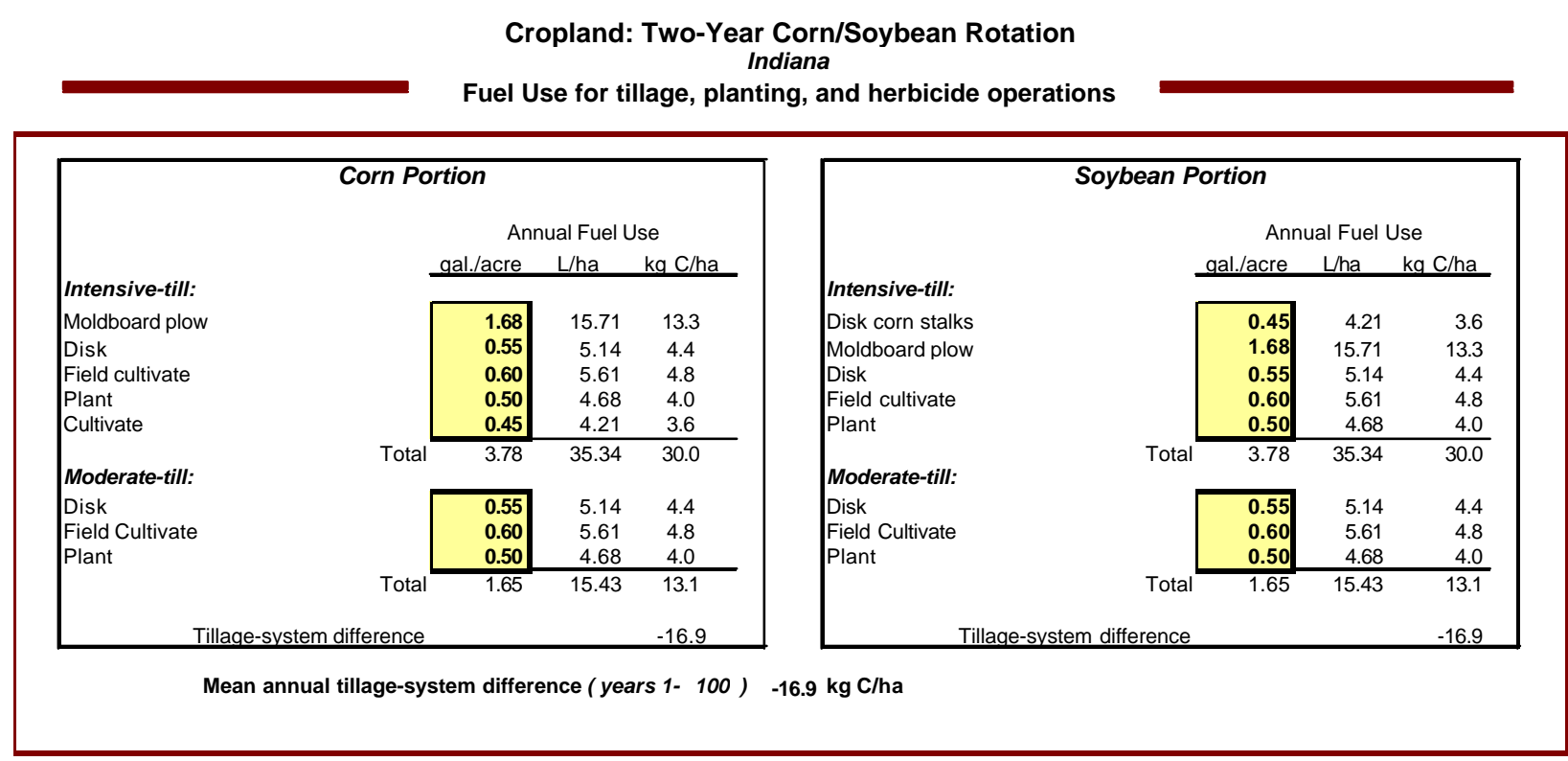

Energy Savings Embodied in Machinery Manufacturing, Transportation, \& Repair (MTR)

Annual fuel saving from reducing tillage

Annual machinery MTR savings

Annual machinery MTR saving from reducing tillage (years 1- 100 ) $\quad-3.0 \mathrm{~kg} \mathrm{C} / \mathrm{ha}$

\subsubsection{Nitrogen Fertilizer Use}

$\mathrm{N}$ fertilizers generally are not applied on soybeans because they are legumes. When inadequate soil $\mathrm{N}$ is available to legumes, they convert $\mathrm{N}_{2}$ from the atmosphere into forms available for plant nutrition, a process known as biological $\mathrm{N}$ fixation. Therefore, reducing tillage has no impact on the amount of $\mathrm{N}$ fertilizer used in the soybean portion of a corn/soybean rotation.

In addition to not requiring $\mathrm{N}$ fertilizer, soybeans generally leave more readily available $\mathrm{N}$ for the next crop than does corn. In the Corn Belt, it is common to reduce $\mathrm{N}$ fertilizer recommendations for corn following soybeans by about $30 \mathrm{~kg} \mathrm{~N} / \mathrm{ha}$ relative to recommendations for corn following corn ${ }^{7}$. This credit is not adjusted for tillage system.

In contrast to soybeans, corn generally requires significant quantities of $\mathrm{N}$ fertilizer for economically optimum production. There are several mechanisms by which more $\mathrm{N}$ can be lost from the soil when tillage is reduced, especially when $\mathrm{N}$ is poorly managed ${ }^{8,9}$. Reducing tillage conserves soil moisture. Higher soil moisture levels increase the potential for $\mathrm{N}$ leaching losses 
via downward movement with soil water, especially in highly permeable soils. No-till soils tend to develop more macro-pores that potentially can cause greater $\mathrm{N}$ leaching losses, especially when $\mathrm{N}$ is applied on the soil surface and $\mathrm{N}$ fertilizer moves directly into macro-pore openings at the soil surface. Higher soil moisture levels also increase the potential for $\mathrm{N}$ losses via denitrification, especially with wet conditions in soils with poor internal drainage (see Chapter 18 discussion of denitrification in the section about $\mathrm{N}_{2} \mathrm{O}$ losses via denitrification). More readily available organic matter near the soil surface in conservation-tillage systems also increases the potential for denitrification, especially when $\mathrm{N}$ is applied on the soil surface. The potential for denitrification can be greatly reduced by injecting $\mathrm{N}$ below the crop residues that are concentrated near the soil surface in conservation-till systems. The potential for both denitrification and leaching losses can be significantly reduced by applying $\mathrm{N}$ close to the time of crop need. When urea-containing fertilizers are applied on the soil surface without immediate incorporation, the potential for ammonia volatilization losses is much greater in conservation-till systems and especially in no-till systems. This problem is virtually eliminated when ureacontaining fertilizers are injected into the soil. In summary, the potential for $\mathrm{N}$ losses is greater with conservation tillage than with intensive tillage when $\mathrm{N}$ is poorly managed. With conservation tillage, it is more important that $\mathrm{N}$ be applied close to the time of crop need and that the $\mathrm{N}$ be injected below the decomposing crop residues.

Minimizing contact of $\mathrm{N}$ fertilizers with crop residues is especially critical in conservation-tillage systems ${ }^{10}$. In the Corn Belt, most of the $\mathrm{N}$ is applied as anhydrous ammonia and by necessity is injected well below the soil surface. Injection reduces the potential for denitrification and $\mathrm{N}$ tieup in organic matter in conservation-tillage systems. In contrast to urea or urea-ammonium nitrate solution, ammonia volatilization from anhydrous ammonia generally is not a significant problem and is not likely to differ by tillage system. With timely application of anhydrous ammonia, $\mathrm{N}$ leaching is not likely to be significantly greater in conservation-tillage systems than intensive-tillage systems. Outside the Corn Belt, anhydrous ammonia is not the dominant form of $\mathrm{N}$ fertilizer and surface applications of $\mathrm{N}$ fertilizer are more common. In some of these cases $\mathrm{N}$ rate recommendations are higher for conservation-till systems, especially no-till. An example is in Kentucky in which $\mathrm{N}$ rate recommendations are increased about $25 \mathrm{~kg} / \mathrm{ha}$ for no-till corn on soils that are not well drained ${ }^{11}$.

In addition to $\mathrm{N}$ losses, the amount of $\mathrm{N}$ released from crop residues and soil organic matter affects the amount of $\mathrm{N}$ fertilizer required. In general, $\mathrm{N}$ mineralization (conversion from organic to inorganic $\mathrm{N}$ ) is slower with conversation tillage than with intensive tillage, especially with cool wet conditions in the spring. When soil organic matter leve ls increase, more $\mathrm{N}$ as well as $\mathrm{C}$ is sequestered in the organic matter. Soil C:N ratios usually stabilize at about 11:1. This implies that if the SOC level increases $338 \mathrm{~kg} / \mathrm{ha} / \mathrm{yr}$ due to reducing tillage (see Iowa No-till example in Table 19-1), then the amount of $\mathrm{N}$ tied up in soil organic matter should increase by about $30 \mathrm{~kg} \mathrm{~N} / \mathrm{ha} / \mathrm{yr}$. In some cases, the added $\mathrm{N}$ tied up in soil organic matter with conservation tillage may be $\mathrm{N}$ that would have been lost had it not been tied up. In that case, the amount of $\mathrm{N}$ fertilizer required is not affected by $\mathrm{N}$ tie-up in organic matter. Also, it should be noted that if conservation-tillage corn residues mineralize less $\mathrm{N}$ to become available to the subsequent soybean crop, the soybean $\mathrm{N}$-fixation mechanism likely makes up for most or all of that deficit. 
Nitrogen rate recommendations generally are adjusted for yield levels expected to be achieved in a given cropping system. For individual farms and years, tillage system can significantly affect yields. However, averaged over a broad area (e.g., a state) and several years, tillage system is expected to have little impact on yields and associated $\mathrm{N}$ fertilizer rates.

In summary, the issue of amount of $\mathrm{N}$ fertilizer required by differing tillage systems is relevant for only the corn portion of a corn/soybean rotation and the soybean $\mathrm{N}$ fixation mechanism probably largely compensates for any reduced mineralization of soil organic matter following the corn crop. The principles discussed above indicate that when $\mathrm{N}$ is injected well below the decomposing crop residues and is applied close to when the crop needs the $\mathrm{N}$, then the amount of $\mathrm{N}$ fertilizer required for Corn in the Corn Belt should not be significantly affected by tillage system. However, with poorly managed $\mathrm{N}$, more $\mathrm{N}$ fertilizer will be required with conservation tillage than with intensive tillage.

The $\mathrm{N}$ fertilizer recommendations for Michigan, Ohio, and Indiana have been integrated into one system $^{7}$ and are representative of the Corn Belt. The recommended $\mathrm{N}$ rate is not adjusted for tillage system. However, the following adjustments are made for tillage system:

1. For soils with greater than 30 percent residue cover, the majority of applied $\mathrm{N}$ should be either:

a. Injected below the soil surface

b. Dribbled if using $\mathrm{N}$ solutions

c. Or broadcast only if the material contains no urea

2. No-till corn planted into cold, wet soils should receive some of the recommended $\mathrm{N}$ at planting banded near the row (20 to $40 \mathrm{~kg} \mathrm{~N} / \mathrm{ha}$ )

The National Agricultural Statistical Service reported the following average $\mathrm{N}$ rates for corn in the 10 major corn states as affected by tillage system and manure application (Table 19-5). Significantly less $\mathrm{N}$ fertilizer per hectare and more manure were applied in intensive-till systems involving plowing than in the other tillage systems reported. The lower mean $\mathrm{N}$ fertilizer rate for intensive-till systems involving plowing appears to be due to more manure being used in these systems, not because this tillage system requires less $\mathrm{N}$ fertilizer per se. Less $\mathrm{N}$ fertilizer is recommended on fields receiving manure, regardless of tillage system ${ }^{12}$.

Table 19-5

Mean $\mathrm{N}$ rates for corn in the ten major U.S. corn producing states-1995 ${ }^{13}$

\begin{tabular}{|l|c|c|c|c|}
\hline & $\begin{array}{c}\text { Intensive -till } \\
\text { with plow }\end{array}$ & $\begin{array}{c}\text { Intensive -till } \\
\text { without plow }\end{array}$ & Mulch-till & No-till \\
\hline $\mathrm{N}$ rate, kg/ha & 108 & 148 & 150 & 150 \\
\hline $\begin{array}{l}\text { \% of fields with } \\
\mathrm{N} \text { fertilizer }\end{array}$ & 93 & 98 & 97 & 98 \\
\hline $\begin{array}{l}\text { \% of fields with } \\
\text { manure }\end{array}$ & 38 & 15 & 14 & 8 \\
\hline
\end{tabular}


In this corn/soybean rotation case study, it was assumed that $\mathrm{N}$ rate is not affected by tillage system. This is because $\mathrm{N}$ rate recommendations are not adjusted for tillage system in the Corn Belt and the mean of actual $\mathrm{N}$ rates for corn after correcting for manure application, don't differ by tillage system.

Effects of applying more $\mathrm{N}$ fertilizer with no-till than with intensive-till, a case that is applicable when $\mathrm{N}$ fertilizer is poorly managed, is presented in Section 19-3.

\subsubsection{Herbicide Use}

The mean annual herbicide rates for intensive-till and no-till corn/soybean rotations were estimated from West and Marland ${ }^{6}$ as 1.92 and $2.56 \mathrm{~kg}$ active ingredient (a.i.)/ha, respectively. West and Marland ${ }^{6}$ estimated $4.70 \mathrm{~kg} \mathrm{C}$ emitted $/ \mathrm{kg}$ herbicide a.i. used. With these factors, carbon emissions were $3.0 \mathrm{~kg} \mathrm{C} / \mathrm{ha} / \mathrm{yr}$ more for no-till than intensive-till. The mean annual herbicide rate for moderate-till corn/soybean rotations was estimated from West and Marland ${ }^{6}$ as $2.09 \mathrm{~kg}$ a.i./ha. Multiplying (2.09-1.92 kg a.i./ha) by $4.70 \mathrm{~kg} \mathrm{C}$ emitted/ $\mathrm{kg}$ herbicide gave $0.8 \mathrm{~kg}$ $\mathrm{C} / \mathrm{ha} / \mathrm{yr}$ more for moderate-till than no-till. Example spreadsheet output is presented in Table 19-6.

Table 19-6

Example spreadsheet output for estimating herbicide carbon equivalent emissions for corn/soybean rotation

Cropland: Two-Year Corn/Soybean Rotation

Indiana

Annual Herbicide Use X Tillage System

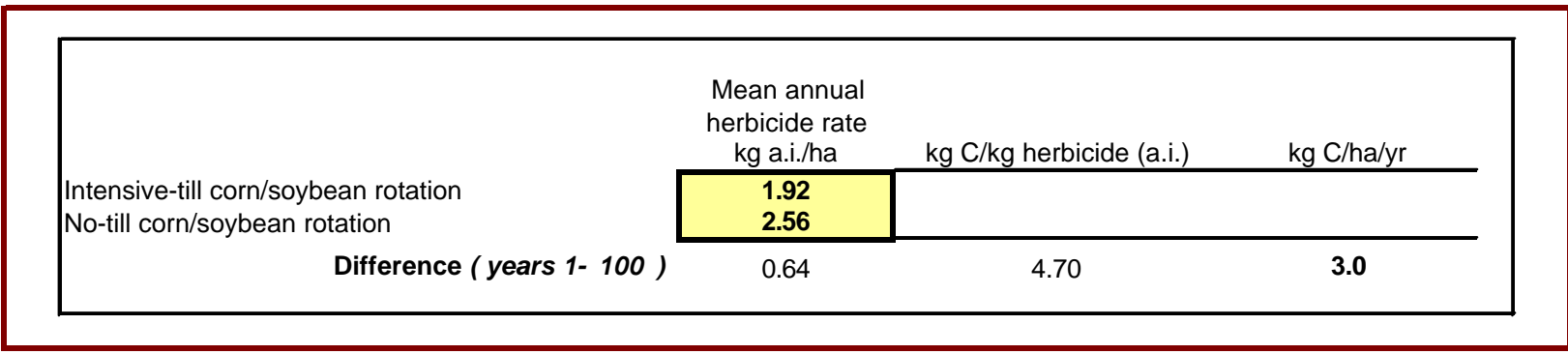

\subsubsection{5 $\mathrm{N}_{2} \mathrm{O}$ Emissions from Soil}

Background on $\mathrm{N}_{2} \mathrm{O}$ emissions from soil was provided earlier, indicating that $\mathrm{N}_{2} \mathrm{O}$ emissions are dependent on both soil conditions and amount of $\mathrm{N}$ fertilizer applied. In this Corn Belt corn/soybean rotation case, the amount of $\mathrm{N}$ fertilizer applied does not change with tillage system, but soil conditions do change as discussed earlier. Robertson et al. ${ }^{14}$ measured effects of switching from intensive-till to no-till in a corn/wheat/soybean rotation on a well drained soil in Michigan. The same $\mathrm{N}$ rate was used for both tillage systems and anhydrous ammonia was the primary N source. Switching to no-till increased $\mathrm{N}_{2} \mathrm{O}$ emissions from 141 to $152 \mathrm{~kg} \mathrm{CE} / \mathrm{ha} / \mathrm{yr}$. Del Grosso et al. ${ }^{15}$ modeled $\mathrm{N}_{2} \mathrm{O}$ emissions as affected by switching corn/soybean rotations from intensive-till to no-till on a well drained soil in Indiana. The same $\mathrm{N}$ fertilizer rate was assumed 
for both tillage systems. A specific placement (e.g., knifing or broadcast) of the $\mathrm{N}$ fertilizer was not indicated but broadcast placement is assumed. With these assumptions, $\mathrm{N}_{2} \mathrm{O}$ emissions were slightly lower with no-till than intensive-till in both a corn/soybean rotation and continuous corn. Mummey et al. ${ }^{16}$ modeled $\mathrm{N}_{2} \mathrm{O}$ emissions for intensive-till and no-till systems at 1035 sites for corn and 655 sites for soybeans. These sites represented the range of soil and environmental conditions for these crops in the United States. This modeling effort indicated that in the north central U.S. the mean $\mathrm{N}_{2} \mathrm{O}-\mathrm{N}$ emissions were $3.04 \mathrm{~kg} / \mathrm{ha}$ for intensive-till and $3.28 \mathrm{~kg} / \mathrm{ha}$ for notill. Taking the difference $\left(0.24 \mathrm{~kg} \mathrm{~N}_{2} \mathrm{O}-\mathrm{N} / \mathrm{ha}\right.$ ) times $126.4 \mathrm{~kg} \mathrm{~N}_{2} \mathrm{O} \mathrm{CE} / \mathrm{kg} \mathrm{N}_{2} \mathrm{O}-\mathrm{N}$ gives $30.3 \mathrm{~kg}$ $\mathrm{N}_{2} \mathrm{O}$ CE/ha/yr. This is a larger increase in $\mathrm{N}_{2} \mathrm{O}$ emissions due to switching to no-till than was found by Robertson et al. ${ }^{14}$ and Del Grosso et al. ${ }^{15}$, but the latter two studies were on well drained soils whereas the Mummey et al. ${ }^{16}$ study covered a range of soil and environmental conditions. On the other hand, Mummey et al. ${ }^{16}$ did not account for possible reductions in denitrification and $\mathrm{N}_{2} \mathrm{O}$ emissions with knifed $\mathrm{N}$ fertilizer applications that are common with anhydrous ammonia in the Corn Belt. The Mummey et al. ${ }^{16}$ estimates of increased $\mathrm{N}_{2} \mathrm{O}$ emissions due to switching from intensive-till to no-till in the north central U.S. were used as inputs to generate results in Table 19.1 for the corn/soybean Corn Belt case study (base scenario). Example spreadsheet output is presented in Table 19-7.

Table 19-7

Example spreadsheet output for carbon equivalent emissions from changes in $\mathrm{N}_{2} \mathrm{O}$ emissions for corn/soybean rotation when changing from intensive-till to no-till

\section{Cropland: Two-Year Corn/Soybean Rotation Indiana}

Annual Changes in $\mathrm{N}_{2} \mathrm{O}$ Emissions

Due to Tillage-Related Changes in Soil Properties \& Micro-Climate

Intensive-till corn/soybean rotation

No-till corn/soybean rotation

Difference ( years 1-100)

\begin{tabular}{|c|cc}
\multicolumn{1}{c}{$\begin{array}{l}\text { Annual } \\
\mathrm{kg} \mathrm{N} \text { O-N/ha }\end{array}$} & $\mathrm{kg} \mathrm{N}_{2} \mathrm{O}$ CE/kg N${ }_{2} \mathrm{O}-\mathrm{N}$ & $\mathrm{kg} \mathrm{N}$ O CE/ha/yr \\
\hline $\mathbf{3 . 0 4}$ & & \\
$\mathbf{3 . 2 8}$ & & 30.3 \\
\hline 0.24 & 126.4 & \\
\hline
\end{tabular}

Associated with Changes in N Application Rate

Intensive-till corn/soybean rotation

No-till corn/soybean rotation

\begin{tabular}{ccc}
$\begin{array}{c}\text { Mean annual } \\
\mathrm{N} \text { rate } \\
\mathrm{kg} \mathrm{N} / \mathrm{ha}\end{array}$ & $\begin{array}{c}\text { IPCC emission factor } \\
\mathrm{kg} \mathrm{N} \mathrm{O} \text { CE } / \mathrm{kg} \mathrm{N} \text { applied }\end{array}$ & $\mathrm{kg} \mathrm{N}$ O CE/ha/yr \\
\hline 75.0 & & \\
75.0 & 2.65 & 0.0
\end{tabular}




\subsubsection{Summary of Avoided GHG Emissions}

Example spreadsheet output summarizing changes in GHG emissions is presented in Table 19-8. This output corresponds to the first column in Table 19-1.

\section{Table 19-8}

Example spreadsheet output summarizing changes in GHG emissions for corn/soybean rotation when changing from intensive-till to no-till

\section{Cropland: Two-Year Corn/Soybean Rotation Indiana}

Life Cycle (LC) Avoided GHG Emissions

(Due to Switching from Intensive-Till to No-Till)

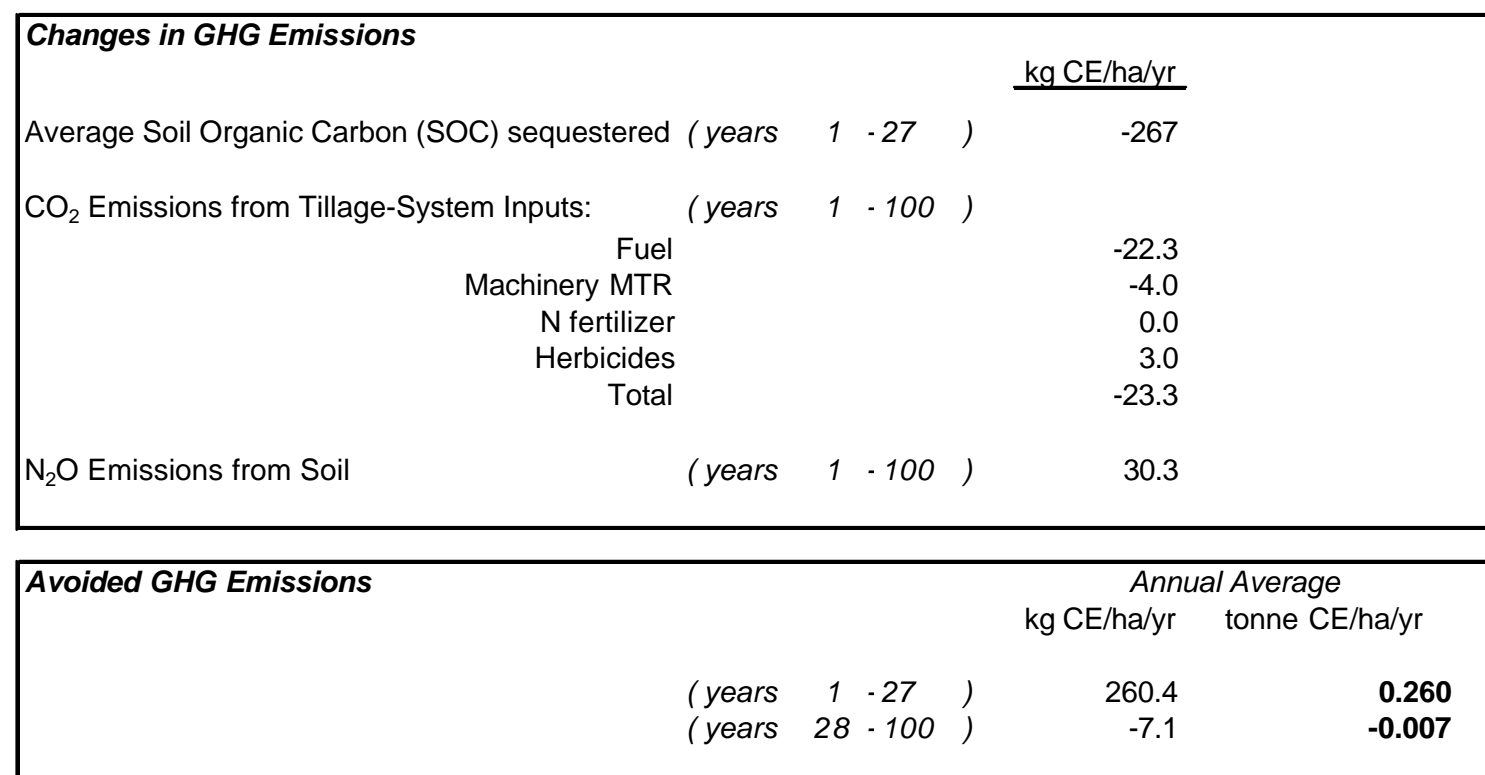

\subsubsection{Summary}

Example spreadsheet output summarizing costs and life-cycle (LC) avoided GHG on a carbon equivalent (CE) basis is presented in Table 19-9. This output corresponds to the first column in Table 19-1. 
Table 19-9

Example spreadsheet output summarizing costs and life-cycle (LC) avoided GHG on a carbon equivalent (CE) basis for corn/soybean rotation when changing from intensive-till to no-till

\section{Cropland: Two-Year Corn/Soybean Rotation} Indiana

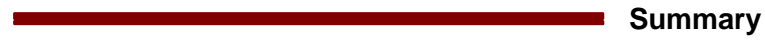

\begin{tabular}{|lccccc|}
\hline Process Description & & & & \\
& & & & \\
& & & & \\
Calculation Method for Sequestering SOC - Quadratic Plateau & No-till time period & 100 & years \\
Average SOC Sequestered & 267 & $\mathrm{~kg} \mathrm{C} / \mathrm{ha} / \mathrm{yr}$ & Release Rate after No-till & 1.5 & tonne CE/ha/yr \\
Time until Steady State & $27 \quad$ years & & & \\
\hline
\end{tabular}

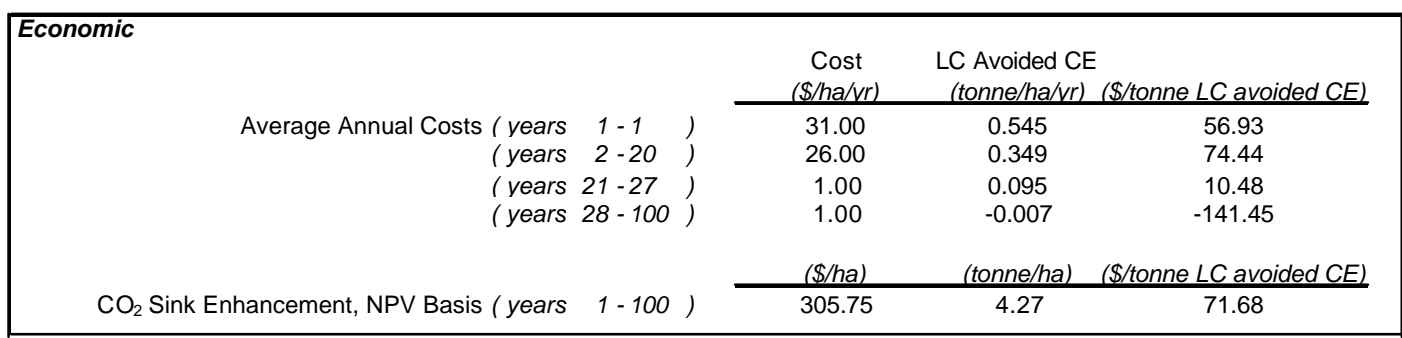
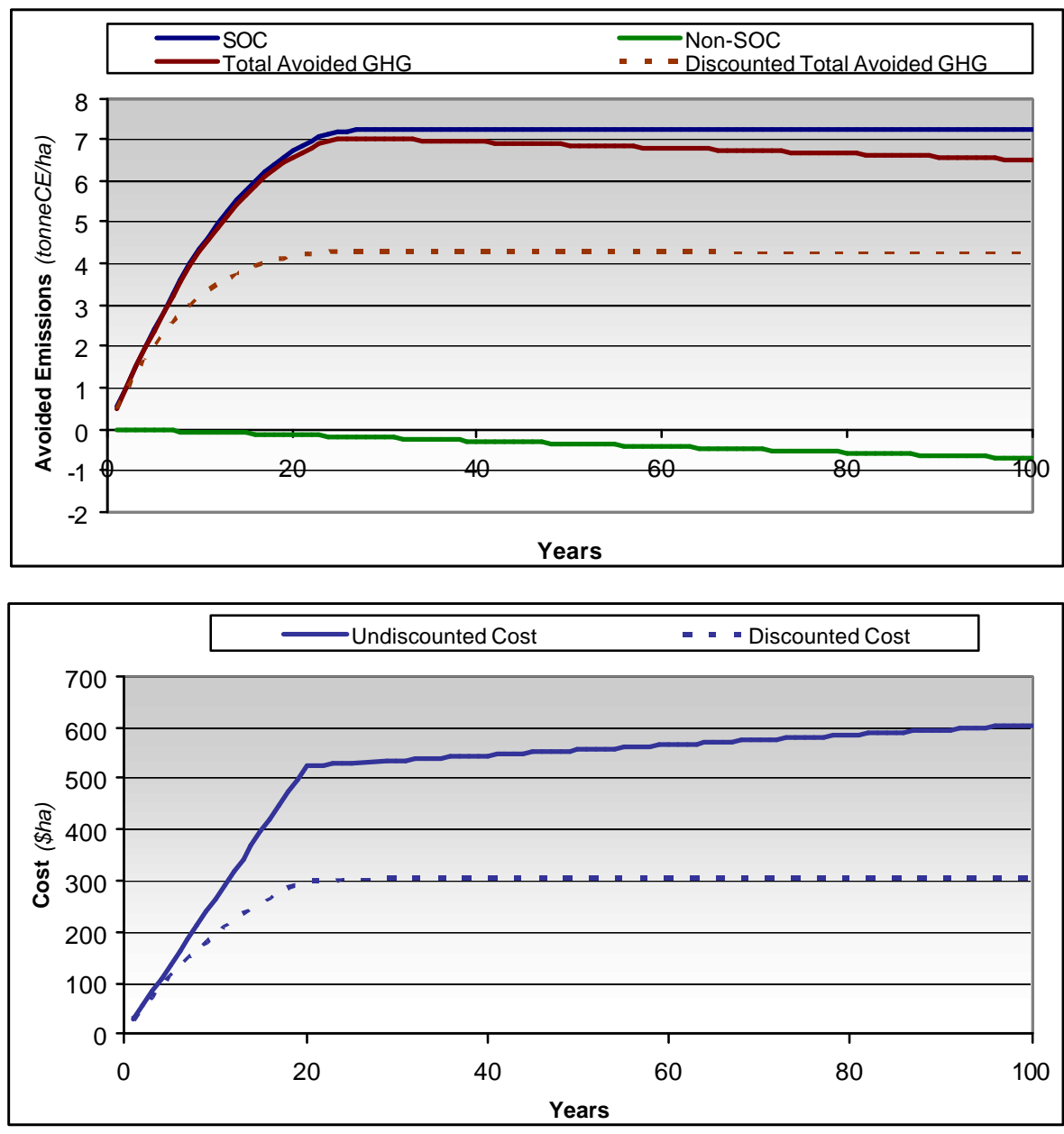


\subsubsection{Sensitivity Summary}

Example spreadsheet sensitivity summary output is presented in Table 19-10. This sensitivity output presents costs assuming adoption incentive payments for 5, 10, 15, and 20 years. These costs are presented assuming that no-till is maintained for the full 100-year planning horizon or for only as long as adoption incentives are paid to the farmer, after which the land is converted back to intensive-till. This analysis assumes that when no-till is switched back to intensive-till, SOC levels decrease at a rate of $1500 \mathrm{~kg} / \mathrm{ha} / \mathrm{yr}$. A base case of incentive payments for 10 years was selected for comparing costs with other $\mathrm{CO}_{2}$ sink enhancement or storage options. 
Table 19-10

Corn/soybean rotation sensitivity summary

\section{Cropland: Two-Year Corn/Soybean Rotation}

Indiana

Sensitivity Summary

\begin{tabular}{|rl|}
\hline Current Input Variable Values & \\
Calculation Method for Sequestering $\mathrm{CO}_{2}$ & Quadratic Plateau \\
Efficiency Index (Slope Factor) & 53.1 \\
SOC Increase to New Steady State $(\mathrm{kg} / \mathrm{ha})$ & 7221 \\
Time Until Steady State $(\mathrm{years})$ & 27 \\
SOC Release Rate after no-till time period (tonne C/ha/yr) & 1.5 \\
Farmer Adoption Incentive to Reduce Tillage $(\$ /$ ha/yr) & $\$ 25.00$ \\
Transaction Costs & $\$ 5.00$ \\
Transaction Time Period (years) & 1 \\
Monitoring Costs & $\$ 1.00$ \\
Monitoring Time Period (years) & 100 \\
After-Tax Discount Rate & $6.09 \%$ \\
\hline
\end{tabular}

Sensitivity Input

Farmer Adoption Incentive Time Period Viewed

5 years

10 years

15 vears

20 years

Push the adjacent button to update the sensitivity summary costs below.

Update

Values

$\mathrm{CO}_{2}$ Sink Enhancement Costs (100 year summation)

\begin{tabular}{ccc}
$\begin{array}{c}\text { No-till Time } \\
\text { Period } \\
\text { (years) }\end{array}$ & $\begin{array}{c}\text { Farmer Adoption Incentive } \\
\text { Time Period } \\
\text { (years) }\end{array}$ & $\begin{array}{c}\text { NPV Basis } \\
\text { LC avoided basis } \\
\text { (\$/tonne C equivalent) }\end{array}$ \\
\hline 5 & 5 & 358.50 \\
10 & 10 & 193.75 \\
15 & 15 & 146.75 \\
20 & 20 & 126.53 \\
100 & 5 & 29.57 \\
100 & 10 & 47.90 \\
100 & 15 & 61.53 \\
100 & 20 & 71.68
\end{tabular}




\subsection{Corn/Soybean Rotations (Poor N Management Scenario)}

This case is the same as the Indiana no-till base case in the last section except that poorer $\mathrm{N}$ management (broadcast application of urea) is assumed for the corn portion of the rotation, resulting in more $\mathrm{N}$ fertilizer being required with no-till corn than intensive-till corn. Using more $\mathrm{N}$ fertilizer increases $\mathrm{GHG}$ emissions associated with $\mathrm{N}$ fertilizer use and also increases $\mathrm{N}_{2} \mathrm{O}$ emissions in alternating years when corn is grown. This case assumes $150 \mathrm{~kg} \mathrm{~N} / \mathrm{ha}$ for intensive-till and $175 \mathrm{~kg} \mathrm{~N} / \mathrm{ha}$ or $200 \mathrm{~kg} / \mathrm{ha}$ for no-till. These $\mathrm{N}$ rates fall within the recommended rates for intensive-till and no-till corn in Kentucky ${ }^{11}$.

Table 19-11

Effects of switching from intensive-till using $150 \mathrm{~kg} \mathrm{~N} / \mathrm{ha}$ to no- till using 175 or $200 \mathrm{~kg}$ N/ha on GHG emissions and costs of life-cycle (LC) avoided GHG emissions_-Indiana Corn/Soybean rotations

\begin{tabular}{|c|c|c|c|}
\hline Switching from intensive-till to: & No-till & No-till & No-till \\
\hline $\mathrm{N}$ rate, $\mathrm{kg} / \mathrm{ha}$ & 150 & 175 & 200 \\
\hline \multicolumn{4}{|l|}{ Quadratic SOC response curve } \\
\hline$\Delta \mathrm{SOCs}, \mathrm{kg} \mathrm{C} / \mathrm{ha}$ & 7221 & 7221 & 7221 \\
\hline E (slope factor) & 53.1 & 53.1 & 53.1 \\
\hline Years to new steady state $(Y s)$ & 27 & 27 & 27 \\
\hline $\begin{array}{l}\text { Average annual increase in SOC (years } 1 \text { to } Y s \text { ), } \\
\mathrm{kg} \mathrm{C} / \mathrm{ha} / \mathrm{yr}\end{array}$ & 267 & 267 & 267 \\
\hline \multicolumn{4}{|c|}{ GHG emissions from tillage-system inputs and $\mathrm{N}_{2} \mathrm{O}$ (years $1-100$ ), $\mathrm{kg} \mathrm{CE} / \mathrm{ha} / \mathrm{y}$ : } \\
\hline$\Delta$ Fuel use & -22.3 & -22.3 & -22.3 \\
\hline$\Delta$ Machinery maintenance, trans., and repair & -4 & -4 & -4 \\
\hline$\Delta \mathrm{N}$ fertilizer use & 0 & 14.4 & 28.7 \\
\hline$\Delta$ Herbicide use & 3 & 3 & 3 \\
\hline$\Delta$ Total GHG emissions from inputs & -23.3 & -8.9 & 5.4 \\
\hline$\Delta \mathrm{N}_{2} \mathrm{O}$ emissions from soil & 30.3 & 63.5 & 96.6 \\
\hline$\Delta$ Total GHG emissions & 7.0 & 54.5 & 102 \\
\hline \multicolumn{4}{|l|}{ Average LC GHG avoided (kg CE/ha/y) } \\
\hline Years 1 to $Y s$ & 260 & 213 & 165 \\
\hline Years Ys to 100 & -7 & -55 & -102 \\
\hline Total LC GHG avoided (years 1-100), tonne CE/ha & 6.5 & 1.8 & -3.0 \\
\hline NPV Total LC GHG avoided (years 1-100), tonne & & & \\
\hline $\mathrm{CE} / \mathrm{ha}$ & 4.3 & 3.5 & 2.7 \\
\hline \multicolumn{4}{|l|}{ Costs, $\$ / h a / y$} \\
\hline Transaction (year 1) & 5 & 5 & 5 \\
\hline Adoption incentive (years 1-20) & 25 & 25 & 25 \\
\hline Monitoring (years 1-100) & 1 & 1 & 1 \\
\hline Total costs (years $1-100), \$ /$ ha & 605 & 605 & 605 \\
\hline NPV Total costs (years $1-100$ ), $\$ /$ ha & 306 & 306 & 306 \\
\hline Cost (NPV basis), \$/tonne CE LC GHG avoided & 72 & 88 & 113 \\
\hline
\end{tabular}


A summary of results is presented in Table 19-11. Increasing the $\mathrm{N}$ rate every other year for corn by $25 \mathrm{~kg} \mathrm{~N} /$ ha increased the cost of avoided GHG from $\$ 72$ to $\$ 88 /$ tonne CE LC avoided. Increasing the $\mathrm{N}$ rate for corn by $50 \mathrm{~kg} \mathrm{~N} /$ ha increased the cost of avoided GHG from $\$ 72 /$ tonne CE LC avoided to \$113/tonne CE LC avoided on an NPV basis. These increased costs are due to less avoidance of GHG emissions per dollar invested in adoption incentives and transaction and monitoring costs. Adding an additional $50 \mathrm{~kg} \mathrm{~N} /$ ha every other year for corn nearly doubled the cost per tonne CE LC avoided on an NVP basis and resulted in a negative avoidance of GHG emissions on a nondiscounted basis after 100 years (a decrease from 6.5 to -3.0 tonnes CE LC avoided). This emphasizes the importance of efficient $\mathrm{N}$ fertilizer management in cropping systems designed to reduce GHG emissions. Details of the effects of increased $\mathrm{N}$ fertilizer use on $\mathrm{GHG}$ emissions from $\mathrm{N}$ fertilizer manufacture, transportation, storage, and application and on $\mathrm{N}_{2} \mathrm{O}$ emissions are presented in the next two sections.

\subsubsection{Nitrogen Fertilizer Use}

Carbon emissions associated with important combinations of $\mathrm{N}$ source and placement are presented in Table 19-12. Emissions from $\mathrm{N}$ fertilizer use include ma nufacture ${ }^{17}$ and transportation and storage ${ }^{18}$. Emissions from $\mathrm{N}$ fertilizer application are from Langemeier and Taylor 5 . The manufacturing numbers assume that all energy is from natural gas, but a small undermined amount of energy is from electricity. The transportation, storage, and application numbers assume the energy is from diesel fuel.

Table 19-12

Corn/soybean carbon emissions associated with important combinations of $\mathbf{N}$ source and placement

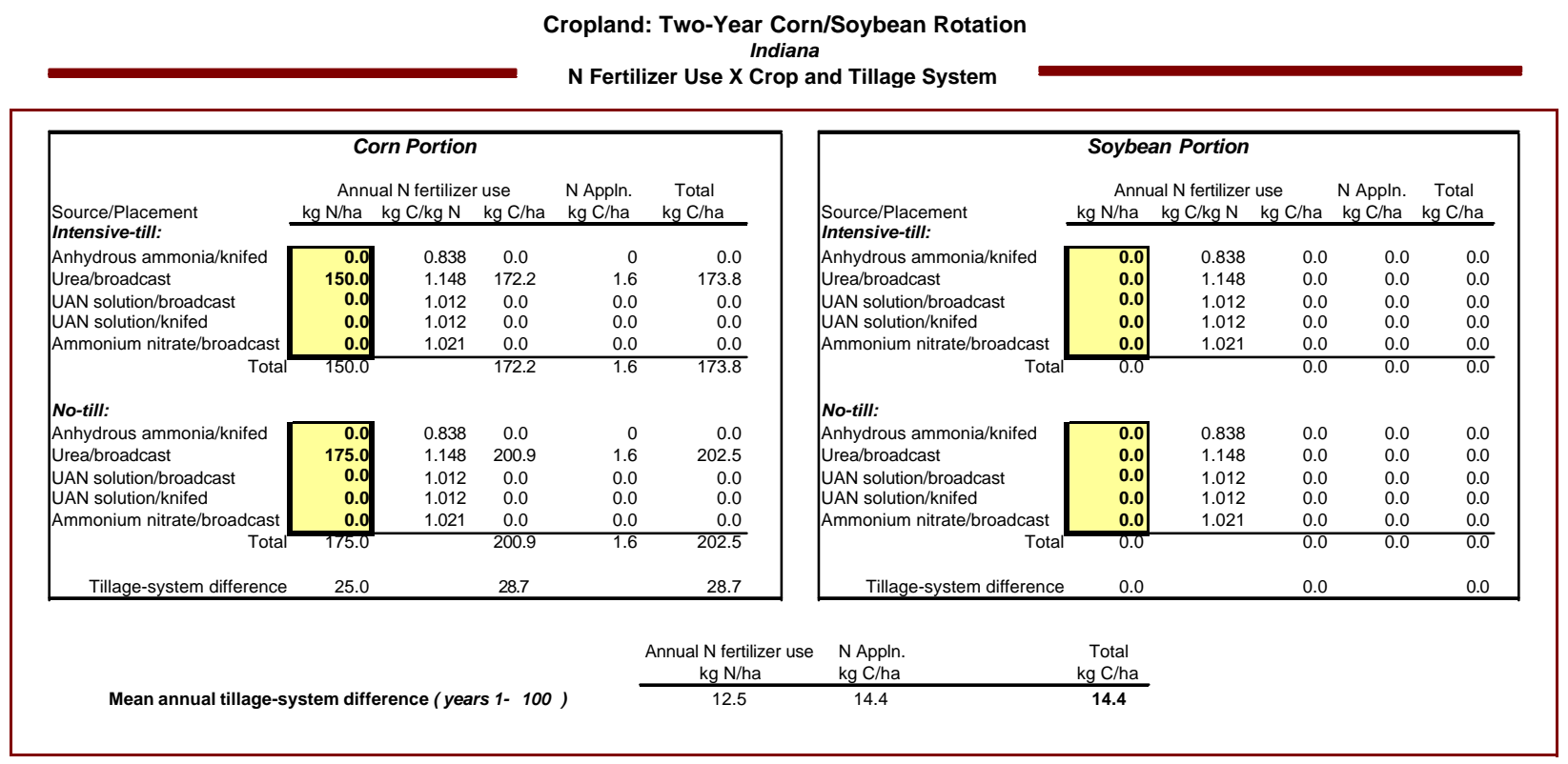

This case assumes that no $\mathrm{N}$ fertilizer is applied for soybeans and urea is broadcast for corn in both the intensive-till and no-till systems and that $150 \mathrm{~kg} \mathrm{~N} / \mathrm{ha}$ and $175 \mathrm{~kg} \mathrm{~N} / \mathrm{ha}$ are required for 
intensive-till and no-till corn, respectively. This resulted in an average annual increase in $\mathrm{N}$ fertilizer use of $12.5 \mathrm{~kg} \mathrm{~N} / \mathrm{ha}$.

The increase in $\mathrm{N}$ fertilizer use with no-till was assumed to increase $\mathrm{N}_{2} \mathrm{O}$ emissions from soils in accordance with the IPCC default $\mathrm{N}_{2} \mathrm{O}$ emission factor for commercial $\mathrm{N}$ fertilizer use ${ }^{19}$. The IPCC factor assumes the following:

- $\quad$ Direct $\mathrm{N}_{2} \mathrm{O}-\mathrm{N}$ emissions $=1.25$ percent of applied $\mathrm{N}$

- Indirect $\mathrm{N}_{2} \mathrm{O}-\mathrm{N}$ emissions from:

Volatilized $\mathrm{NH}_{3}$ and $\mathrm{NOx}=0.1$ percent of applied $\mathrm{N}$

Leached $\mathrm{N}=0.75$ percent of applied $\mathrm{N}$

- Total $\mathrm{N}_{2} \mathrm{O}-\mathrm{N}$ emission $=2.1$ percent of applied $\mathrm{N}$

(i.e., $0.021 \mathrm{~kg} \mathrm{~N} 2 \mathrm{O}-\mathrm{N} / \mathrm{kg}$ applied $\mathrm{N}$ )

The IPCC factor is converted to a carbon equivalent $(\mathrm{CE})$ radiative forcing basis as follows:

- $\quad 1.57 \mathrm{~N}_{2} \mathrm{O} / \mathrm{N}_{2} \mathrm{O}-\mathrm{N}$

- $296 \mathrm{CO}_{2}$ equivalent/ $\mathrm{N}_{2} \mathrm{O}$

- $\quad 0.272 \mathrm{C}$ equivalent $(\mathrm{CE}) / \mathrm{CO}_{2}$ equivalent

- $1.57 \times 296 \times .272 \mathrm{CE} / \mathrm{N}_{2} \mathrm{O}-\mathrm{N}$

$\left(126.4 \mathrm{CE} / \mathrm{N}_{2} \mathrm{O}-\mathrm{N}\right)$

Therefore, $1 \mathrm{~kg}$ applied $\mathrm{N}=0.021 \times 126.4 \mathrm{~kg} \mathrm{CE}$ from $\mathrm{N}_{2} \mathrm{O}$

$$
=2.65 \mathrm{~kg} \mathrm{CE} \text { from } \mathrm{N}_{2} \mathrm{O}
$$

The overall increase in $\mathrm{N}_{2} \mathrm{O}$ emissions due to both switching from intensive-till to no-till and increasing $\mathrm{N}$ fertilizer use was calculated as shown in Table 19-13. Increased $\mathrm{N}_{2} \mathrm{O}$ emissions due to tillage-related changes in soil properties and micro-climate (without changes in $\mathrm{N}$ fertilizer rate) are based on the same assumptions as in the previous case in which $\mathrm{N}$ fertilizer rate didn't change with tillage system. 
Table 19-13

Corn/soybean overall increase in $\mathrm{N}_{2} \mathrm{O}$ emissions due to both switching from intensive-till to no-till and increasing $\mathrm{N}$ fertilizer use

\section{Cropland: Two-Year Corn/Soybean Rotation Indiana}

Annual Changes in $\mathrm{N}_{2} \mathrm{O}$ Emissions

Due to Tillage-Related Changes in Soil Properties \& Micro-Climate

\begin{tabular}{|c|c|c|c|}
\hline & $\begin{array}{c}\text { Annual } \\
\mathrm{kg} \mathrm{N} \mathrm{N}_{2} \mathrm{O}-\mathrm{N} / \mathrm{ha}\end{array}$ & $\mathrm{kg} \mathrm{N}_{2} \mathrm{O} \mathrm{CE} / \mathrm{kg} \mathrm{N}_{2} \mathrm{O}-\mathrm{N}$ & $\mathrm{kg} \mathrm{N} \mathrm{N}_{2} \mathrm{O} \mathrm{CE} / \mathrm{ha} / \mathrm{yr}$ \\
\hline $\begin{array}{l}\text { Intensive-till corn/soybean rotation } \\
\text { No-till corn/soybean rotation }\end{array}$ & $\begin{array}{l}3.04 \\
3.28 \\
\end{array}$ & & \\
\hline Difference ( years 1-100) & 0.24 & 126.4 & 30.3 \\
\hline
\end{tabular}

\begin{tabular}{|c|c|c|c|}
\hline \multicolumn{4}{|c|}{ Associated with Changes in N Application Rate } \\
\hline & $\begin{array}{c}\text { Mean annual } \\
\mathrm{N} \text { rate } \\
\mathrm{kg} \mathrm{N} / \mathrm{ha}\end{array}$ & $\begin{array}{c}\text { IPCC emission factor } \\
\mathrm{kg} \mathrm{N}_{2} \mathrm{O} \text { CE } / \mathrm{kg} \mathrm{N} \text { applied }\end{array}$ & $\mathrm{kg} \mathrm{N} \mathrm{N}_{2} \mathrm{O} \mathrm{CE} / \mathrm{ha} / \mathrm{yr}$ \\
\hline Intensive-till corn/soybean rotation & 87.5 & & \\
\hline No-till corn/soybean rotation & 75.0 & & \\
\hline Difference ( vears 1-100) & 12.5 & 2.65 & 33.1 \\
\hline
\end{tabular}

Total Difference ( vears 1- 100 )

63.5

\subsubsection{Summary of Avoided GHG Emissions}

Example spreadsheet output summarizing changes in GHG emissions due to switching from intensive-till to no-till and increasing $\mathrm{N}$ fertilizer use by $25 \mathrm{~kg}$ N/ha is presented in Table 19-14. These results correspond to the second column in Table 19-11. Over the course of the 100-year planning horizon, the added $\mathrm{N}$ fertilizer use and associated increase in $\mathrm{N}_{2} \mathrm{O}$ emissions substantially reduced the amount of GHG emissions avoided (Table 19-15). 


\section{Table 19-14}

Corn/soybean example spreadsheet output summarizing changes in GHG emissions due to switching from intensive-till to no-till and increasing $\mathrm{N}$ fertilizer use

\section{Cropland: Two-Year Corn/Soybean Rotation \\ Indiana}

Life Cycle (LC) Avoided GHG Emissions

(Due to Switching from Intensive-Till to No-Till)

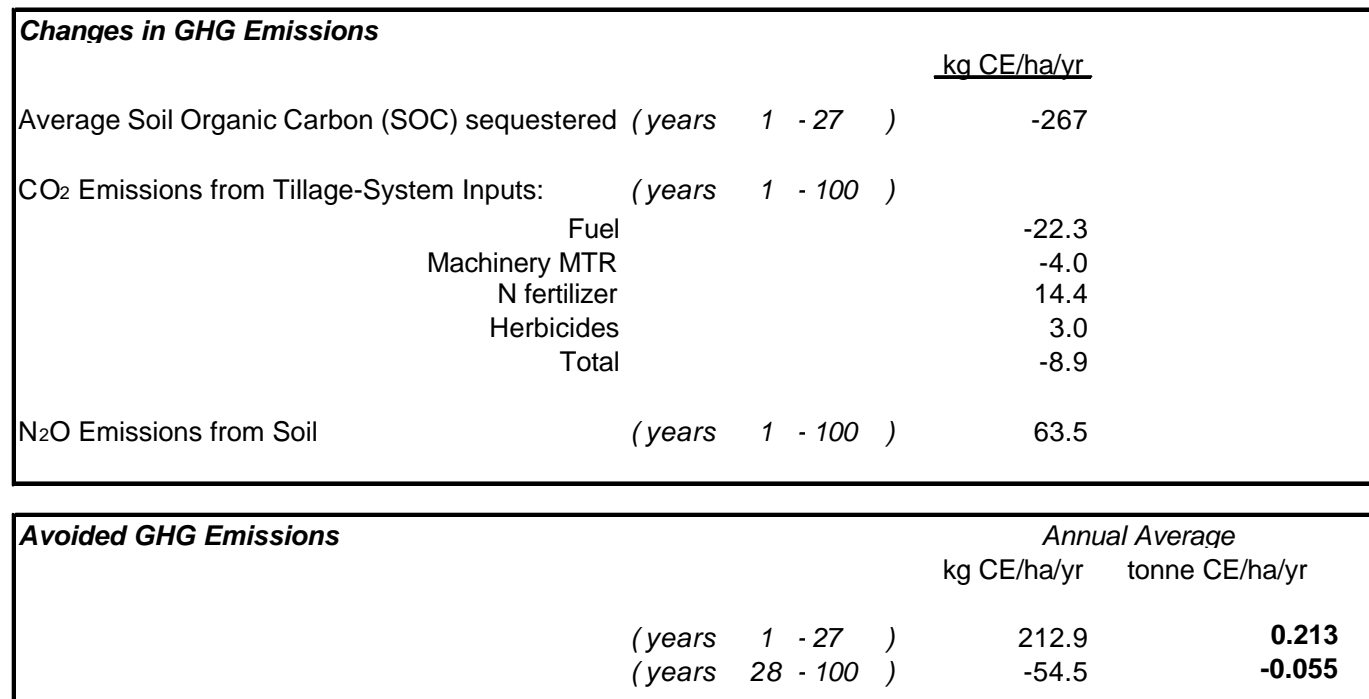

\subsubsection{Summary}

Example spreadsheet output summarizing costs and life-cycle (LC) avoided GHG on a carbon equivalent (CE) basis is presented in Table 19-15. This output corresponds to the second column in Table 19-11. 
Table 19-15

Corn/soybean example spreadsheet output summarizing costs and life-cycle (LC) avoided GHG on a carbon equivalent (CE) basis when changing from intensive-till to no-till and increasing $\mathbf{N}$ fertilizer use

\section{Cropland: Two-Year Corn/Soybean Rotation} Indiana

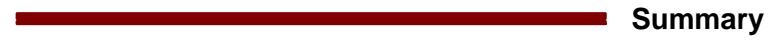

Process Description

Calculation Method for Sequestering SOC - Quadratic Plateau Average SOC Sequestered

No-till time period

100 years

Time until Steady State 27 years

Release Rate after No-till 1.5 tonne CE/ha/yr

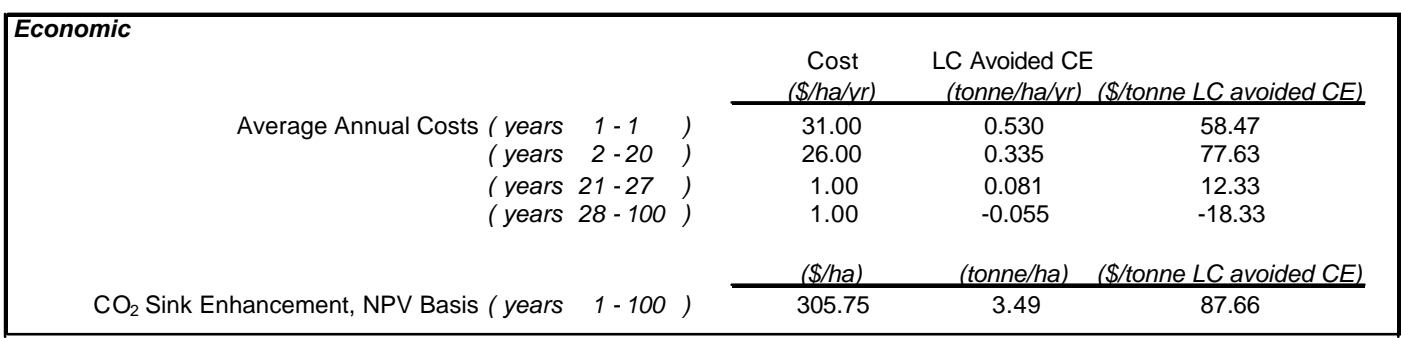
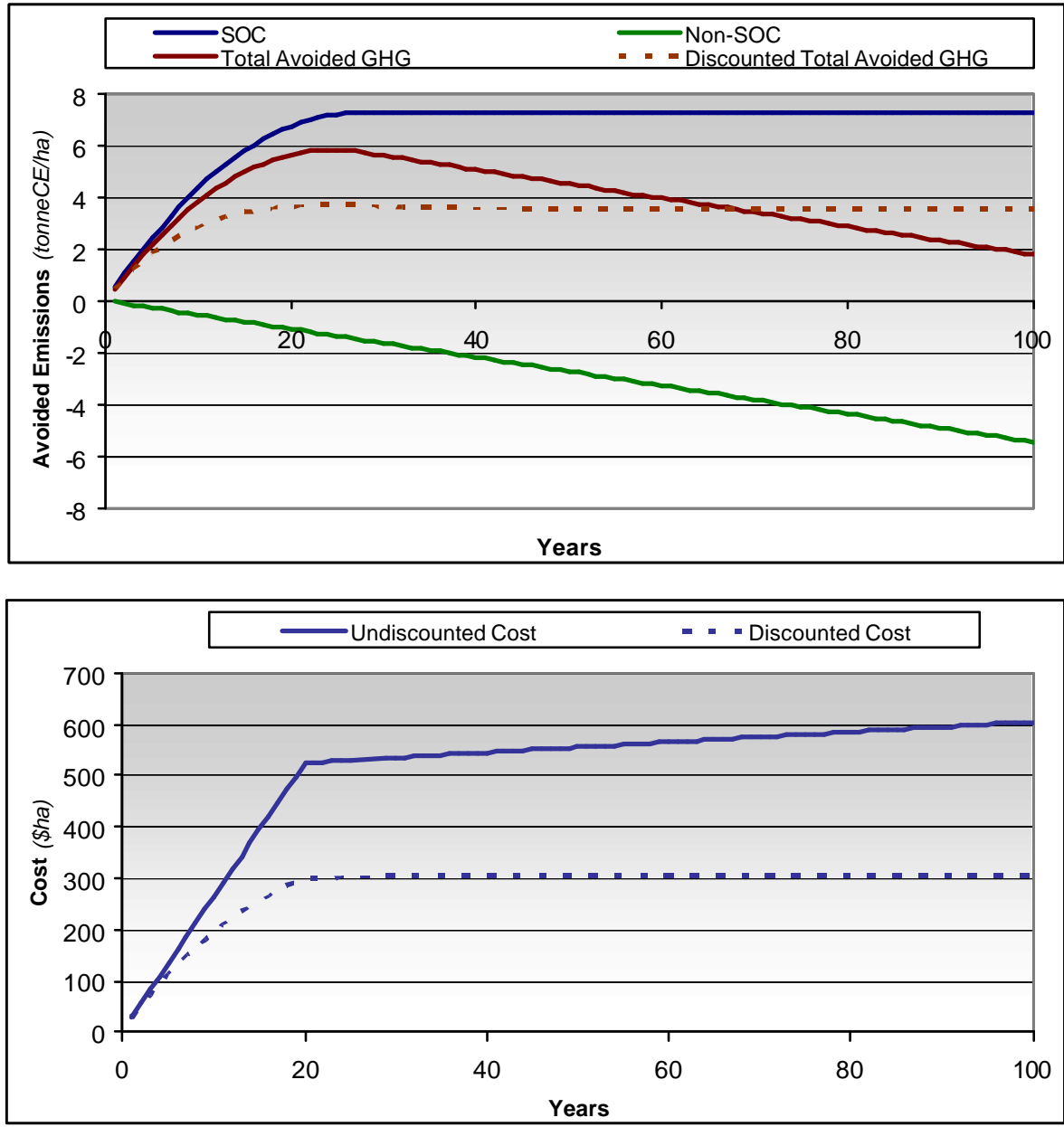


\subsubsection{Sensitivity Summary}

Example spreadsheet sensitivity summary output is presented in Table 19-16. This output corresponds to the second column in Table 19-11 and presents costs assuming adoption incentive payments for 5, 10, 15, and 20 years. These costs are presented assuming that no-till is maintained for the full 100-year planning horizon or for only as long as adoption incentives are paid to the farmer, after which the land is converted back to intensive-till. This analysis assumes that when no-till is switched back to intensive-till, SOC levels decrease at a rate of $1500 \mathrm{~kg} / \mathrm{ha} / \mathrm{yr}$. A base case of incentive payments for 10 years was selected for comparing costs with other $\mathrm{CO}_{2}$ sink enhancement or storage options. 
Table 19-16

Corn/soybean example spreadsheet sensitivity summary output when changing from intensive-till to no-till and increasing $\mathbf{N}$ fertilizer use

Cropland: Two-Year Corn/Soybean Rotation Indiana Sensitivity Summary

\section{Current Input Variable Values}

Calculation Method for Sequestering $\mathrm{CO}_{2}$

Efficiency Index (Slope Factor)

Quadratic Plateau

SOC Increase to New Steady State $(\mathrm{kg} / \mathrm{ha})$

Time Until Steady State (years)

SOC Release Rate after no-till time period (tonne C/ha/yr)

Farmer Adoption Incentive to Reduce Tillage ( $\$ / \mathrm{ha} / \mathrm{yr})$

Transaction Costs

Transaction Time Period (years)

Monitoring Costs

Monitoring Time Period (years)

After-Tax Discount Rate

53.1

7221

27

1.5

$\$ 25.00$

$\$ 5.00$

1

$\$ 1.00$

100

$6.09 \%$

Sensitivity Input

Farmer Adoption Incentive Time Period Viewed

5 vears

10 vears

15 vears

20 years

Push the adjacent button to update the sensitivity summary costs below.

Update

Values

$\mathrm{CO}_{2}$ Sink Enhancement Costs (100 year summation)

\begin{tabular}{ccc}
$\begin{array}{c}\text { No-till Time } \\
\text { Period } \\
\text { (years) }\end{array}$ & $\begin{array}{c}\text { Farmer Adoption Incentive } \\
\text { Time Period } \\
\text { (years) }\end{array}$ & $\begin{array}{c}\text { NPV Basis } \\
\text { LC avoided basis } \\
\text { (\$/tonne C equivalent) }\end{array}$ \\
\hline 5 & 5 & 827.87 \\
10 & 10 & 289.15 \\
15 & 15 & 197.32 \\
20 & 20 & 162.98 \\
100 & 5 & 36.16 \\
100 & 10 & 58.57 \\
100 & 15 & 75.25 \\
100 & 20 & 87.66
\end{tabular}


Examples of the large effects of $\mathrm{N}$ rate and $\mathrm{N}_{2} \mathrm{O}$ emissions on amount of GHG emissions avoided and cost per tonne of GHG avoided are presented in Table 19-17. The scenarios in Table 19-17 are for switching from intensive-till to no-till in a corn/soybean rotation in the Corn Belt. No significant change in $\mathrm{N}_{2} \mathrm{O}$ emissions due switching from intensive-till to no-till is a possibility with good $\mathrm{N}$ management, especially on well-drained soils. The increases in $\mathrm{N}$ rate and $\mathrm{N}_{2} \mathrm{O}$ emissions in Table 19-17 due to switching from intensive-till to no-till are possibilities with poor $\mathrm{N}$ management. Amounts of GHG avoided range from 9.6 tonnes $\mathrm{CE}$ LC GHG avoided/ha with a best-case $\mathrm{N}$ rate and $\mathrm{N}_{2} \mathrm{O}$ scenario to -3.0 tonnes CE LC GHG avoided/ha for a worst-case scenario. Costs on an NPV basis range from $\$ 64 /$ tonne CE LC GHG avoided with a best-case $\mathrm{N}$ rate and $\mathrm{N}_{2} \mathrm{O}$ scenario to $\$ 113 /$ tonne CE LC GHG avoided for a worst-case scenario. Differences between the best-case and worst-case scenarios regarding amount of GHG avoided are very large because the annual effects are manifested over the entire 100-year planning horizon. In order for reducing tillage on corn/soybean rotations to be a viable option for avoiding GHG emissions, $\mathrm{N}$ fertilizer will have to be managed efficiently so that the amount of $\mathrm{N}$ fertilizer used and the $\mathrm{N}_{2} \mathrm{O}$ emissions are not significantly increased.

Table 19-17

Effects of increases in $\mathrm{N}$ rate and $\mathrm{N}_{2} \mathrm{O}$ emissions on amounts and costs of avoided GHG via switching from intensive-till to no-till in a Corn/Soybean rotation

\begin{tabular}{|c|c|c|c|c|c|}
\hline \multicolumn{2}{|c|}{$\Delta \mathrm{N}$ rate } & $\Delta \mathrm{N}_{2} \mathrm{O}$ & Years 1-100 & \multicolumn{2}{|c|}{ NPV basis, years 1-100 } \\
\hline $\mathrm{kg} \mathrm{N} / \mathrm{ha} / \mathrm{yr}$ & $\mathrm{kg} / \mathrm{CE} / \mathrm{ha} / \mathrm{yr}$ & $\mathrm{kg} / \mathrm{CE} / \mathrm{ha} / \mathrm{yr}$ & $\begin{array}{c}\text { tonne CE LC } \\
\text { GHG } \\
\text { avoided/ha }\end{array}$ & $\begin{array}{c}\text { tonne CE LC } \\
\text { GHG } \\
\text { avoided/ha }\end{array}$ & $\begin{array}{c}\text { \$/tonne CE } \\
\text { LC GHG } \\
\text { avoided }^{1 /}\end{array}$ \\
\hline 0 & 0 & 0 & 9.6 & 4.8 & $64 \stackrel{2 !}{\prime}$ \\
\hline 0 & 0 & 30.3 & 6.5 & 4.3 & $72^{3 /}$ \\
\hline 25 & 14.4 & 63.5 & 1.8 & 3.5 & $88^{4 /}$ \\
\hline 50 & 28.8 & 96.6 & -3.0 & 2.7 & $113^{5 /}$ \\
\hline $\begin{array}{l}\text { 1/ Assumes in } \\
\text { 2/ Base case } \\
\text { 3/ Base case } \\
\text { 4/ Base case } \\
\text { column, Ta } \\
\text { 5/ Base case } \\
\text { (see third c }\end{array}$ & $\begin{array}{l}\text { tive payment } \\
\text { ept for no cha } \\
\text { e first column, } \\
\text { ept for an incr } \\
19-11 \text { ). } \\
\text { ept for an add } \\
\text { nn, Table 19- }\end{array}$ & $\begin{array}{l}\text { r } 20 \text { years. } \\
\text { in } \mathrm{N}_{2} \mathrm{O} \text { emiss } \\
\text { ble } 19-11 \text { ). } \\
\text { e in } \mathrm{N} \text { rate du } \\
\text { nal increase ir }\end{array}$ & to switching fro & $\begin{array}{l}\text { to no-till (see } \\
\text { ching from to } n\end{array}$ & ond \\
\hline
\end{tabular}




\subsection{References}

1 Brenner, J., K. Paustian, G. Bluhm, J. Cipra, M. Easter, E.T. Elliott, T. Kautza, K. Killian, J. Schuler and S. Williams. 2001. Quantifying the change in greenhouse gas emissions due to natural resource conservation practice application in Iowa. Final report to the Iowa Conservation Partnership. Colorado State University Natural Resource Ecology Laboratory and USDA Natural Resources Conservation Service, Fort Collins, CO, USA.

2 Smith, P., J. Brenner, K. Paustian, G. Bluhm, J. Cipra, M. Easter, E. T. Elliott, K. Killian, D. Lamm, J. Schuler and S. Williams. 2002. Quantifying the change in greenhouse gas emissions due to natural resource conservation practice application in Indiana. Final report to the Indiana Conservation Partnership. Colorado State University Natural Resource Ecology Laboratory and USDA Natural Resources Conservation Service, Fort Collins, CO, USA.

3 Eve, M.D., M. Sperow, K. Howerton, K. Paustian, and R.F. Follett. 2002. Predicted impact of management changes on soil carbon storage for each cropland region of the conterminous United States. J. Soil and Water Conservation. 57 (4) 196-204.

4 West, Tristram O. and Wlfred M. Post. 2002. Soil organic carbon sequestration rates for crops with reduced tillage and enhanced rotation. Submitted to Soil Science Society of America Journal.

5 Langemeier, L.N. and R.K. Taylor. 1998. A look at machinery cost. Kansas Farm Management Guide, MF-842. Kansas State University, Department of Agricultural Economics.

6 West, Tristram O. and Gregg Marland. 2002. A synthesis of carbon sequestration, carbon emissions, and net carbon flux in agriculture: comparing tillage practices in the United States. Agriculture, Ecosystems, and Environment (in press)

7 Vitosh. M.L., J.W. Johnson, and D.B. Mengel. 2000. Tri-state fertilizer recommendations for corn, soybeans, wheat, and alfalfa. www.agry.purdue.edu/ext/forages/publications/ay932.htm

8 Fox, R.H. and V.A. Bandel. 1986. Nitrogen utilization with no-tillage corn. p. 117-148. In (Milton A. Sprague and Glover B. Triplett, eds.) No-tillage and surface-tillage agriculture: the tillage revolution. John Wiley \& Sons. New York.

9 Thomas, Grant W. and Wilbur W. Frye. 1984. Fertilization and liming. P. 87-126. In (Ronald E. Phillips and Shirley H. Phillips, eds.) No-tillage agriculture: principles and practices. Van Nostrand Reinhold Company. New York.

10 Mengel, D.S. 1992. Fertilizing corn using conservation tillage.http://www.agcom.purdue.edu/AgCom/Pubs/AY/AY-268.html 
11 KY. 2001. 200-2001 lime and fertilizer

recommendations.www.ca.uky.edu/agc/pubs/agr/agr1/agr1.htm

12 Bock, B.R., K.R. Kelley, and J.J. Meisinger. 1992. Predicting N fertilizer needs for corn in humid regions: summary and future directions. p. 115-127. In (B.R. Bock and K.R. Kelley (eds.) Predicting $\mathrm{N}$ fertilizer needs in humid regions. Bull. Y-226. National Fertilizer Development Center. TVA. Muscle Shoals, AL.

13 USDA. 1995. Economic Research Service Agricultural Handbook 712. http://www.ers.usda.gov/publications/ah712/ah712_3.pdf

14 Robertson, G. Phillip, Eldor A. Paul, and Richard R. Harwood. 2001. Greenhouse gases in intensive agriculture: contributions of individual gases to the radiative forcing of the atmosphere. Science: 289 (5486): 1922-1925.

15 Del Grosso, S.J. W.J. Parton, A.R. Mosier, M.D. Hartman, J. Brenner, D.S. Ojima, and D.S. Schimel. 2001. Simulated interaction of carbon dynamics and nitrogen trace gas fluxes using the DAYCENT . P. 303-332. In M.J. Shaffer, Liwang Ma, and S. Hansen (eds.) Modeling carbon and nitrogen dynamics for soil management. Lewis Publishers. Washington, D.C.

16 Mummey, Daniel L., Jeffrey L. Smith, and George Blum. 1998. Assessment of alternative soil management practices on N2O emissions from U.S. agriculture. Agriculture, Ecosystems, and Environment 70:79-87.

17 Mudahar, Mohinder S. and Travis P. Hignett. 1987. Energy requirements, technology, and resources in the fertilizer sector. p. 25-61. In Z.R. Helsel (Ed.) Energy in World Agriculture. Vol. 2. Elsevier. New York.

18 Achorn, Frank P., David G. Salladay, and Jeffery L. Greenhill. 1980. Effects of high costs on fertilizer production. P. 5-12. Situation 80, TVA Fertilizer Conference. Kansas City, MO.

19 EPA. 2000. Inventory of U.S. greenhouse gas emissions and sinks: 1990-1998. EPA 236-R001. p. 5-17 to 5-19. 


\section{0 \\ CONTINUOUS CORN IN THE U.S. CORN BELT}

\subsection{Introduction}

As indicated in Chapter 18, continuous corn is produced on a much smaller land area in the United States than is corn rotated with soybeans. However, the amount of carbon sequestered per hectare is significantly larger for continuous corn than for corn/soybean rotations and a larger adoption incentive is required for continuous corn than for a corn/soybean rotation. Base-case results for continuous corn are presented in Section 20.2. The base cases assume good $\mathrm{N}$ fertilizer management. Effects of poor $\mathrm{N}$ fertilizer management on amounts and costs of GHG credits from continuous corn are presented in Section 20.3. Effects of N fertilizer management are greater for continuous corn than for corn/soybean rotations because $\mathrm{N}$ fertilizer is used every year for continuous corn and only every other year for corn/soybean rotations.

\subsection{Continuous Corn (Base Cases)}

A summary of effects of switching from intensive-till to no- or moderate-till on SOC, GHG emissions, and costs of avoided GHG emissions is presented in Table 20-1 for continuous corn in Indiana and Iowa. The bases for the results in Table 20-1 are discussed in the following sections using output from the continuous corn spreadsheet model developed for this project. 
Table 20-1

Effects of switching from intensive-till to no- or moderate-till on SOC, GHG emissions, and costs of life-cycle (LC) avoided GHG emissions--Indiana and lowa state averages for Continuous Corn

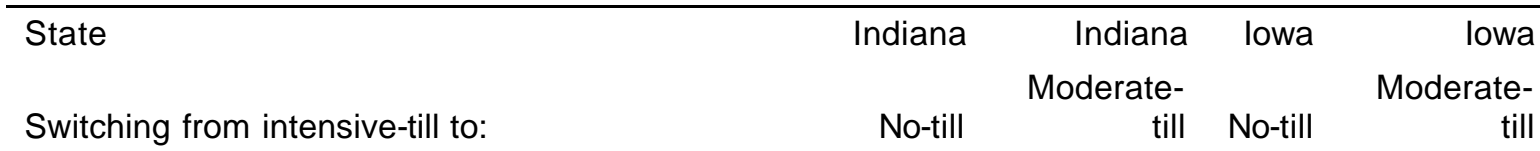

Quadratic SOC response curve

$\begin{array}{lrrrr}\Delta \text { SOCs, kg C/ha } & & 1335 & 5619 \\ \text { E (slope factor) } & 13104 & 10174 & 5 & 35.3 \\ \begin{array}{l}\text { Years to new steady state (Ys) } \\ \begin{array}{l}\text { Average annual increase in SOC (years 1 to Ys), } \\ \text { kg C/ha/yr }\end{array}\end{array} \quad 28 & 72.5 & 92.3 & 32 \\ \end{array}$

GHG emissions from tillage-system inputs and $\mathrm{N}_{2} \mathrm{O}$ (years 1-100), $\mathrm{kg} \mathrm{CE} / \mathrm{ha} / \mathrm{y}$ :

\begin{tabular}{lrrrr}
$\Delta$ Fuel use & -22.9 & -20.5 & -22.9 & -20.5 \\
$\Delta$ Machinery maint., trans., and repair & -4 & -4 & -4 & -4 \\
$\Delta$ N fertilizer use & 0 & 0 & 0 & 0 \\
$\Delta$ Herbicide use & 4 & 1.2 & 4 & 1.2 \\
\hline$\Delta$ Total GHG emissions from inputs & -22.7 & -23.0 & -22.7 & -23.0 \\
$\Delta \mathrm{N}_{2} \mathrm{O}$ emissions from soil & 30.3 & 30.3 & 30.3 & 30.3 \\
\hline$\Delta$ Total GHG emissions & 7.6 & 7.3 & 7.6 & 7.3
\end{tabular}

\section{Average LC GHG avoided (kg CE/ha/y)}

Years 1 to Ys

Years Ys to 100

$\begin{array}{rrrr}460 & 356 & 453 & 168 \\ -8 & -7 & -8 & -7\end{array}$

Total LC GHG avoided (years 1-100), tonne

CE/ha

NPV Total LC GHG avoided (years 1-100), tonne $\mathrm{CE} / \mathrm{ha}$

\section{Costs, $\$ / h a / y$}

Transaction (year 1)

Adoption incentive (years 1-20)

Monitoring (years 1-100)

Total costs (years 1-100), \$/ha

NPV Total costs (years 1-100), \$/ha

Cost (NPV basis), \$/tonne CE LC GHG avoided $\begin{array}{llll}12.3 & 9.4 & 12.6 & 4.9\end{array}$

$\begin{array}{llll}7.7 & 6.0 & 7.8 & 3.1\end{array}$

$\begin{array}{rrrr}5 & 5 & 5 & 5 \\ 50 & 25 & 50 & 25 \\ 1 & 1 & 1 & 1 \\ 1105 & 605 & 1105 & 605 \\ 590 & 306 & 590 & 306\end{array}$

$\begin{array}{llll}77 & 51 & 76 & 100\end{array}$




\subsubsection{Increases in Soil Organic Carbon}

The increases in SOC due to switching from intensive-till to no-till or moderate-till (Table 20-1) are based on state- and county-level assessments for Iowa ${ }^{1}$ and Indiana ${ }^{2}$. Iowa and Indiana form a representative east-west transect across the mid-section of the Corn Belt states. Similar assessments are not available for the other Corn Belt states. The Iowa and Indiana assessments provide county-level estimates of increases in SOC for 10 and 20 years after switching corn/soybean rotations from intensive-till to no-till or moderate-till. These results were provided for several combinations of soil texture and internal drainage [non-hydric (i.e., well drained) or hydric (i.e., poorly drained)]. State-level estimates of increases in SOC were provided for 10 years after switching from intensive-till to no-till or moderate-till on both non-hydric and hydric soils. SOC response curves for counties representing the range and mean of SOC responses in Indiana and Iowa are presented in Appendix F. An interpolation procedure described in Appendix F was used to develop state-level SOC response curves for switching from intensive-till to no-till and moderate-till in Indiana and Iowa. Graphs of the four SOC response curves represented in Table 20-1 are presented in Figure 20-1. After completing county-level carbon storage estimates first in Iowa ${ }^{1}$ and then in Indiana ${ }^{2}$, results from Indiana were judged to be most representative of the Corn Belt (personal communication, John Brenner, NRCS).

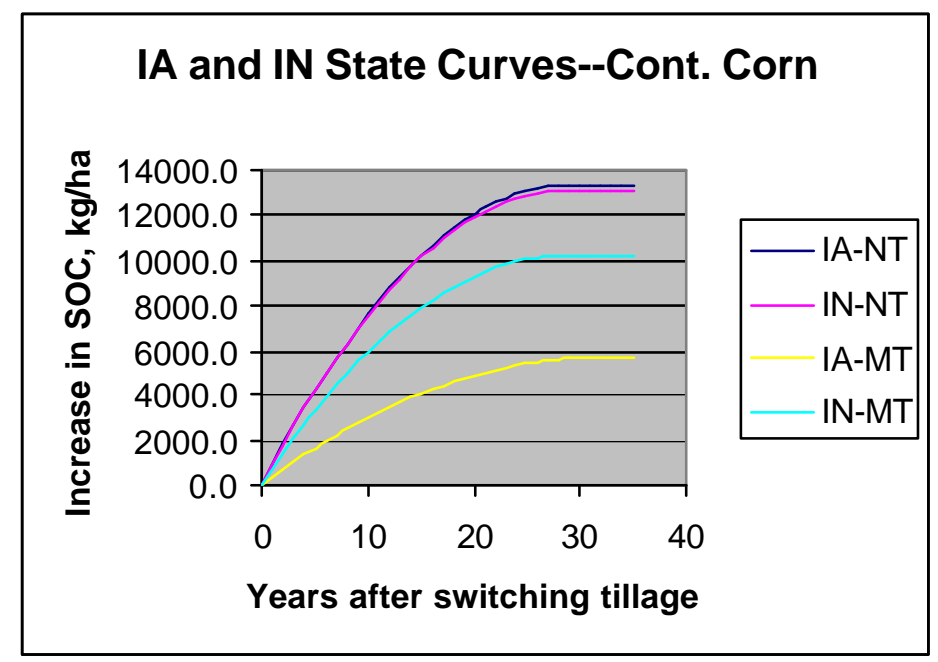

Figure 20-1

State SOC response curves for switching from intensive-till to no-till (NT) or moderate-till (MT) in lowa and Indiana 
Example spreadsheet inputs for calculating increases in SOC due to switching from intensive-till to no-till in Indiana (first column of Table 20-1) are presented in Table 20-2.

Table 20-2

Example process and economic input variables for switching from intensive-till to no-till for continuous corn in Indiana

\section{Cropland: Continuous Corn}

(Changes Due to Switching from Intensive-Till to No-Till)

\begin{tabular}{|c|}
\hline Indiana \\
\hline
\end{tabular}

\section{Process}

\section{Alternative Tillage System: $\quad$ No-till}

Calculation Method for Sequestering Soil Organic Carbon (SOC)

Quadratic Plateau

Linear Plateau

Efficiency or Slope Index (E)

(

Years until New Steady State $(\mathrm{Ys}) \quad 28$ years

No-till time period

SOC Release Rate after no-till time period

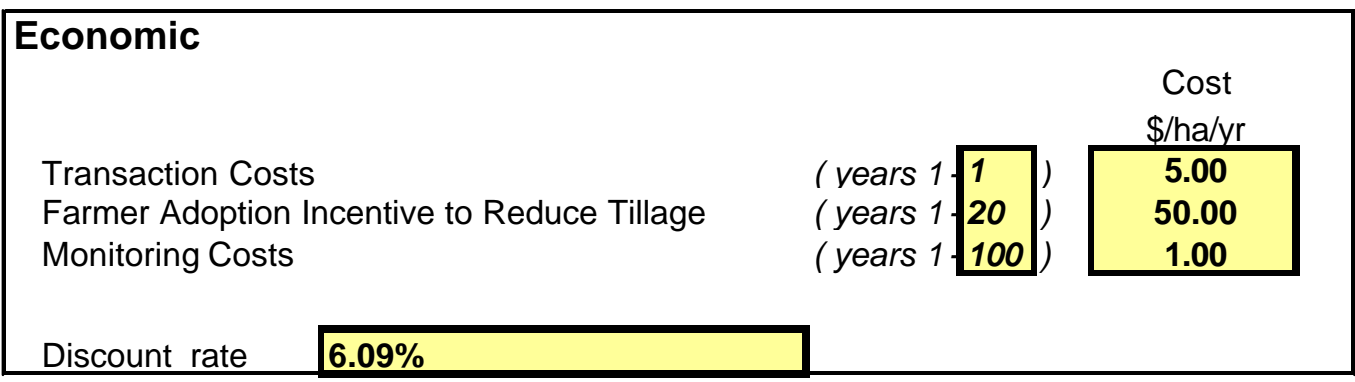




\subsubsection{Costs}

Example cost inputs are presented in Table 20-2. Experience with conservation-tillage adoption programs indicates that an adoption incentive of at least $\$ 50 /$ ha/year for continuous corn will be required to achieve additional adoption from intensive-till of no-till in the Corn Belt (personal communication, Dan Towery, Conservation Tillage Information Center). For example, the Environmental Quality Incentives Program (EQIP) in Illinois is providing an incentive of $\$ 50 / \mathrm{ha} / \mathrm{yr}$ for switching corn from intensive tillage to no tillage and is providing no incentive for switching soybeans from intensive tillage to no tillage. Conservation-tillage adoption incentives are estimated in Appendix E and ranged from $\$ 66$ to 100/ha/year for switching from intensivetill to no-till continuous corn. Risks of lower and more variable yields associated with no-till continuous corn have been lowered somewhat in recent years via improvements in technology and experience with no-till. As a first approximation, we assume an adoption incentive of $\$ 50 /$ ha/yr will be required to achieve additional adoption of continuous corn from intensive-till to no-till and that an adoption incentive of $\$ 25 / \mathrm{ha} / \mathrm{yr}$ will be required to achieve additional adoption of continuous corn from intensive-till to moderate-till. Transaction costs are based on experience with forestry projects and are estimated at $\$ 5 / \mathrm{ha}$. Monitoring costs are assumed to be less than for forestry ( $\$ 5 / \mathrm{ha}$ ), assuming that cropland monitoring will be based mainly on monitoring practices that have been correlated with changes in SOC rather than direct measurements of SOC in each field. Monitoring costs of $\$ 1 / \mathrm{ha} /$ year were assumed.

\subsubsection{GHG Effects in Addition to Carbon Storage in Soil Organic Matter}

\subsubsection{Fuel Use}

Reductions in fuel use and associated carbon emissions by switching from intensive-till to no-till in a corn/soybean rotation are presented in Table 20-3. Fuel usage rates are from Langemeier and Taylor ${ }^{3}$. Reductions in fuel use and associated carbon emissions by switching from intensive-till to moderate-till for continuous corn are presented in Table 20-4. Fuel usage rates are from Langemeier and Taylor ${ }^{3}$. 
Table 20-3

Reductions in fuel use and associated carbon emissions by switching from intensive-till to no-till in continuous corn

\section{Cropland: Continuous Corn Indiana}

Fuel Use for tillage, planting, and herbicide operations

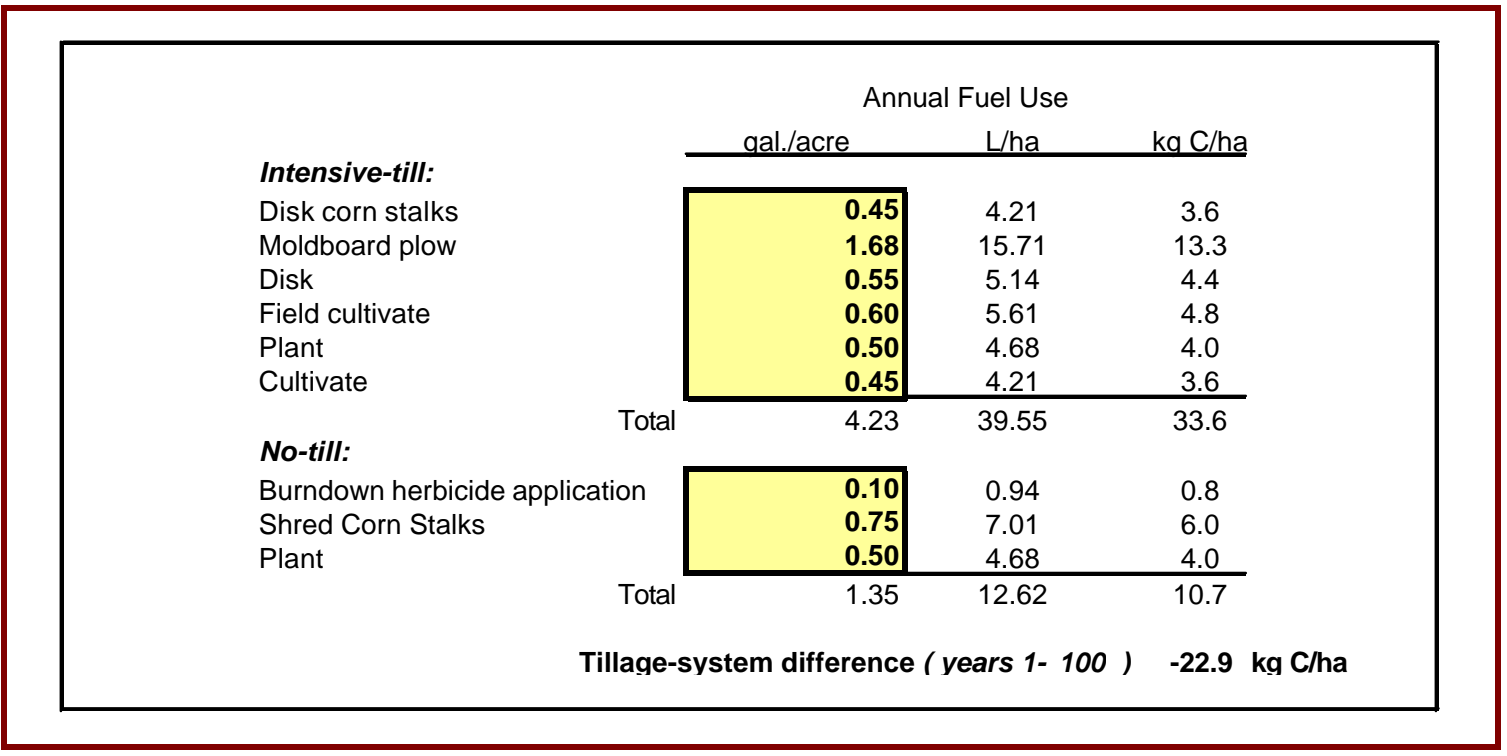

\section{Energy Savings Embodied in Machinery Manufacturing, Transportation, \& Repair (MTR)}

Annual fuel saving from reducing tillage

Annual machinery MTR savings
$-22.9 \mathrm{~kg} \mathrm{C} / \mathrm{ha}$

$18 \%$ of fuel savings

Annual machinery MTR saving from reducing tillage (years 1- 100 ) $\quad-4.1 \quad \mathrm{~kg} \mathrm{C} / \mathrm{ha}$

\subsubsection{Machinery Manufacture, Transportation, and Repair}

Reductions in machinery manufacture, transportation, and repair (MTR) and associated carbon emissions by switching from intensive-till to no-till or moderate-till for continuous corn were calculated as 18 percent of the fuel savings (Tables 20-3 and 20-4). The 18 percent factor is based on ratios of tillage-system fuel use and machinery MTR in a national analysis of tillagesystem effects on GHG emissions ${ }^{4}$. 
Table 20-4

Reductions in fuel use and associated carbon emissions by switching from intensive-till to moderate-till in continuous corn

\section{Cropland: Continuous Corn Indiana}

Fuel Use for tillage, planting, and herbicide operations

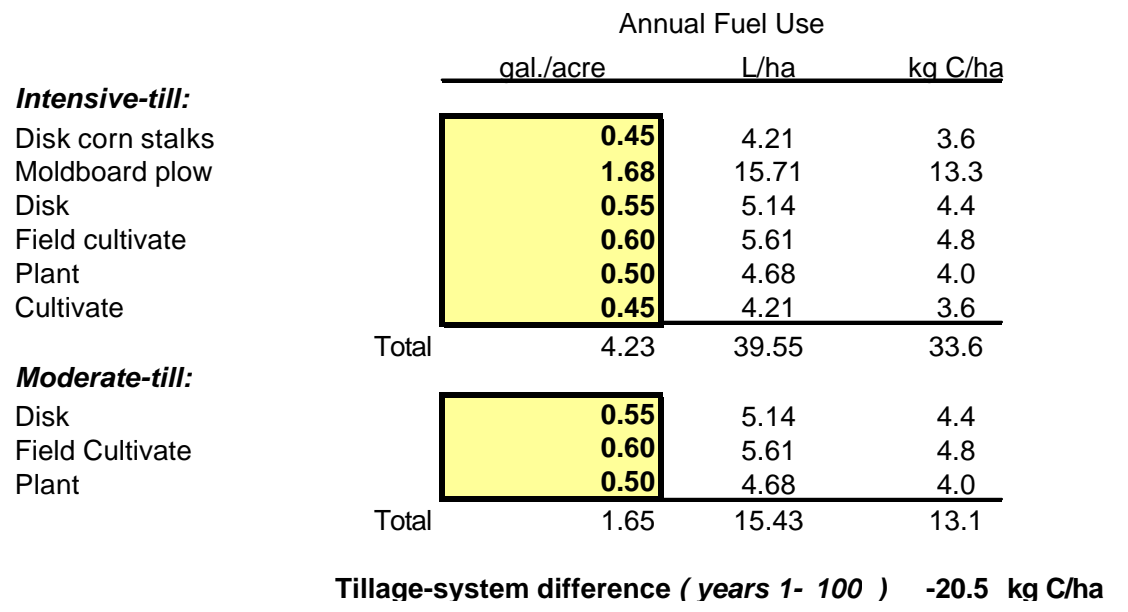

Energy Savings Embodied in Machinery Manufacturing, Transportation, \& Repair (MTR)

Annual fuel saving from reducing tillage

Annual machinery MTR savings
$-20.5 \mathrm{~kg} \mathrm{C} / \mathrm{ha}$

$18 \%$ of fuel savings

Annual machinery MTR saving from reducing tillage (years 1- 100 ) $\quad-3.7 \mathrm{~kg} \mathrm{C} / \mathrm{ha}$

\subsubsection{N Fertilizer Use}

Effects of reducing tillage on the amount of $\mathrm{N}$ fertilizer required for corn was discussed in Section 19.2.3.3. The conclusion was that when $\mathrm{N}$ is injected well below the decomposing crop residues and is applied close to when the crop needs the $\mathrm{N}$, then the amount of $\mathrm{N}$ fertilizer required for Corn in the Corn Belt should not be significantly affected by tillage system. However, with poorly managed $\mathrm{N}$, more $\mathrm{N}$ fertilizer will be required with conservation tillage than with intensive tillage. The base case for continuous corn summarized in Table 20-1 assumes that the amount of $\mathrm{N}$ fertilizer used in not affected by tillage system. Effects of applying more $\mathrm{N}$ fertilizer with no-till than with intensive-till, a case that is applicable when $\mathrm{N}$ fertilizer is poorly managed, is presented in Section 20-3. 


\subsubsection{Herbicide Use}

The mean annual herbicide rates for intensive-till and no-till continuous corn were estimated from West and Marland ${ }^{4}$ as 2.71 and $3.63 \mathrm{~kg}$ active ingredient (a.i.)/ha, respectively. West and Marland $^{4}$ estimated $4.70 \mathrm{~kg} \mathrm{C}$ emitted/kg herbicide a.i. used. With these factors, carbon emissions were $4.3 \mathrm{~kg} \mathrm{C} / \mathrm{ha} / \mathrm{yr}$ more for no-till than intensive-till. The mean annual herbicide rate for moderate-till corn/soybean rotations was estimated from West and Marland ${ }^{4}$ as $2.96 \mathrm{~kg}$ a.i./ha. Multiplying (2.96-2.71 kg a.i./ha) by $4.70 \mathrm{~kg} \mathrm{C}$ emitted/kg herbicide gave $1.2 \mathrm{~kg} \mathrm{C} / \mathrm{ha} / \mathrm{yr}$ more for moderate-till than no-till. Example spreadsheet output is presented in Table 20-5.

Table 20-5

Example spreadsheet output for estimating herbicide carbon equivalent emissions for continuous corn

\section{Cropland: Continuous Corn Indiana}
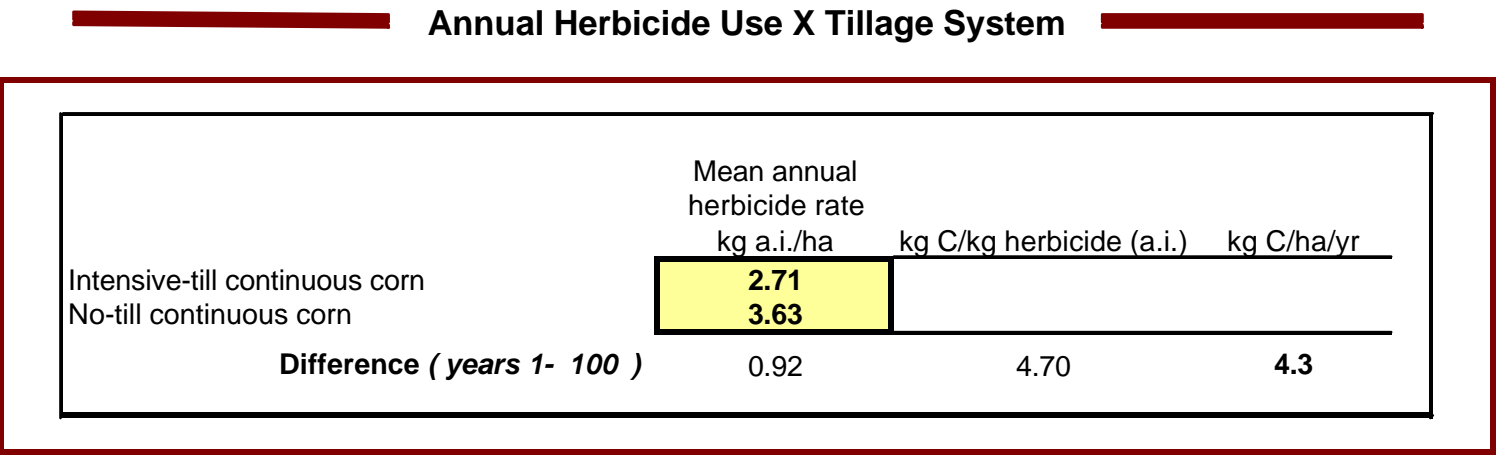

\subsubsection{5 $\mathrm{N}_{2} \mathrm{O}$ Emissions from Soil}

Background on $\mathrm{N}_{2} \mathrm{O}$ emissions from soil was provided earlier, indicating that $\mathrm{N}_{2} \mathrm{O}$ emissions are dependent on both soil conditions and amount of $\mathrm{N}$ fertilizer applied. In this Corn Belt continuous corn case, the amount of $\mathrm{N}$ fertilizer applied does not change with tillage system, but soil conditions do change as discussed earlier. Robertson et al. ${ }^{5}$ measured effects of switching from intensive-till to no-till in a corn/wheat/soybean rotation on a well drained soil in Michigan. The same $\mathrm{N}$ rate was used for both tillage systems and anhydrous ammonia was the primary $\mathrm{N}$ source. Switching to no-till increased $\mathrm{N}_{2} \mathrm{O}$ emissions from 141 to $152 \mathrm{~kg} \mathrm{CE} / \mathrm{ha} / \mathrm{yr}$. Del Grosso et al. ${ }^{6}$ modeled $\mathrm{N}_{2} \mathrm{O}$ emissions as affected by switching corn/soybean rotations from intensive-till to no-till on a well drained soil in Indiana. The same $\mathrm{N}$ fertilizer rate was assumed for both tillage systems. A specific placement (e.g., knifing or broadcast) of the $\mathrm{N}$ fertilizer was not indicated. With these assumptions, $\mathrm{N}_{2} \mathrm{O}$ emissions were slightly lower with no-till than intensive-till in both a corn/soybean rotation and continuous corn. Mummey et al. ${ }^{7}$ modeled $\mathrm{N}_{2} \mathrm{O}$ emissions for intensive-till and no-till systems at 1035 sites for corn and 655 sites for soybeans. These sites represented the range of soil and environmental conditions for these crops in the United States. This modeling effort indicated that in the north central U.S. the mean $\mathrm{N}_{2} \mathrm{O}-\mathrm{N}$ emissions were $3.04 \mathrm{~kg} / \mathrm{ha}$ for intensive-till and $3.28 \mathrm{~kg} / \mathrm{ha}$ for no-till. Taking the difference $\left(0.24 \mathrm{~kg} \mathrm{~N} \mathrm{~N}_{2} \mathrm{O}-\mathrm{N} / \mathrm{ha}\right.$ ) times $126.4 \mathrm{~kg} \mathrm{~N}_{2} \mathrm{O} \mathrm{CE} / \mathrm{kg} \mathrm{N}_{2} \mathrm{O}-\mathrm{N}$ gives $30.3 \mathrm{~kg} \mathrm{~N} \mathrm{~N}_{2} \mathrm{O} \mathrm{CE} / \mathrm{ha} / \mathrm{yr}$. This is a larger increase in $\mathrm{N}_{2} \mathrm{O}$ emissions due to switching to no-till than was found by Robertson et al. ${ }^{5}$ 
and Del Grosso et al. ${ }^{6}$, but the latter two studies were on well drained soils whereas the Mummey et al. ${ }^{7}$ study covered a range of soil and environmental conditions. On the other hand, Mummey et al. ${ }^{7}$ did not account for possible reductions in denitrification and $\mathrm{N}_{2} \mathrm{O}$ emissions with knifed $\mathrm{N}$ fertilizer applications that are common with anhydrous ammonia in the Corn Belt. The Mummey et al. ${ }^{7}$ estimates of increased $\mathrm{N}_{2} \mathrm{O}$ emissions due to switching from intensive-till to notill in the north central U.S. were used as inputs to generate results in Table 20.1 for the continuous corn Corn Belt base case. Example spreadsheet output is presented in Table 20-6.

Table 20-6

Example spreadsheet output for carbon equivalent emissions from changes in $\mathrm{N}_{2} \mathrm{O}$ emissions for continuous corn when changing from intensive-till to no-till

\section{Cropland: Continuous Corn Indiana}

Annual Changes in $\mathrm{N}_{2} \mathrm{O}$ Emissions

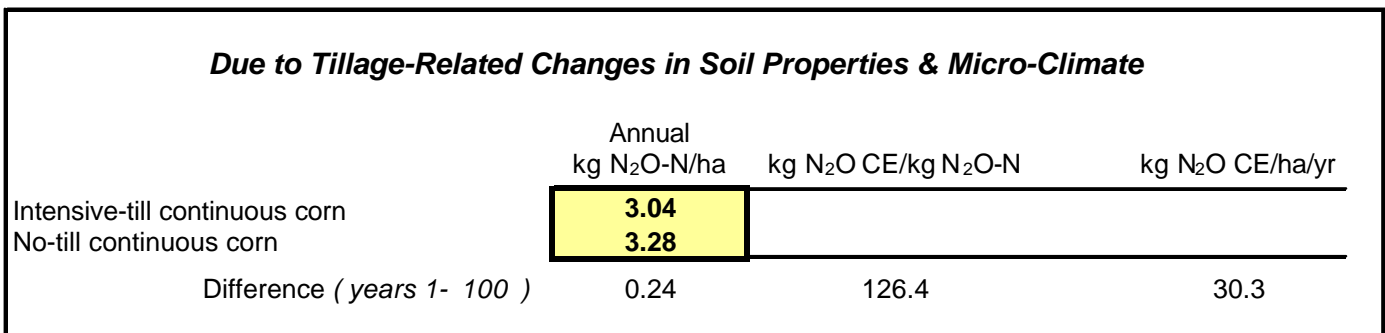

Intensive-till continuous corn

Associated with Changes in N Application Rate

No-till continuous corn

Difference ( years 1- 100)

\begin{tabular}{ccc}
$\begin{array}{c}\text { Mean annual } \\
\text { N rate } \\
\mathrm{kg} \mathrm{N} / \mathrm{ha}\end{array}$ & $\begin{array}{c}\text { IPCC emission factor } \\
\mathrm{kg} \mathrm{N}_{2} \mathrm{O} \text { CE } / \mathrm{kg} \mathrm{N} \text { applied }\end{array}$ & $\mathrm{kg} \mathrm{N}$ O CE/ha/yr \\
\hline 150.0 & & \\
150.0 & & 0.0 \\
\hline 0.0 & 2.65 & \\
\hline
\end{tabular}




\subsubsection{Summary of Avoided GHG Emissions}

Example spreadsheet output summarizing changes in GHG emissions is presented in Table 20-7. This output corresponds to the first column in Table 20-1.

Table 20-7

Example spreadsheet output summarizing changes in GHG emissions for continuous corn when changing from intensive-till to no-till

Cropland: Continuous Corn Indiana

Life Cycle (LC) Avoided GHG Emissions (Due to Switching from Intensive-Till to No-Till)

Changes in GHG Emissions

$\mathrm{kg} \mathrm{CE} / \mathrm{ha} / \mathrm{yr}$

Average Soil Organic Carbon (SOC) sequestered (years $\quad 1-28 \quad$ ) $\quad-468$

$\mathrm{CO}_{2}$ Emissions from Tillage-System Inputs: $\quad$ (years $1-100$ )

Fuel -22.9

Machinery MTR $\quad-4.1$

$\mathrm{N}$ fertilizer $\quad 0.0$

Herbicides $\quad 4.3$

Total -22.7

$\mathrm{N}_{2} \mathrm{O}$ Emissions from Soil $\quad$ (years $1-100$ ) 30.3

Avoided GHG Emissions

\begin{tabular}{|c|c|c|c|c|}
\hline & & & Ann & a Average \\
\hline & & & $\mathrm{kg}$ CE/ha/vr & tonne CE/ha/vr \\
\hline (years & $1-28$ & ) & 460.2 & 0.460 \\
\hline (years & $29-100$ & ) & -7.7 & -0.008 \\
\hline
\end{tabular}

\subsubsection{Summary}

Example spreadsheet output summarizing costs and life-cycle (LC) avoided GHG on a carbon equivalent (CE) basis is presented in Table 20-8. This output corresponds to the first column in Table 20-1. 
Table 20-8

Costs and life-cycle (LC) avoided GHG on a carbon equivalent (CE) basis for continuous corn when changing from intensive-till to no-till

Cropland: Continuous Corn

Indiana

Summary

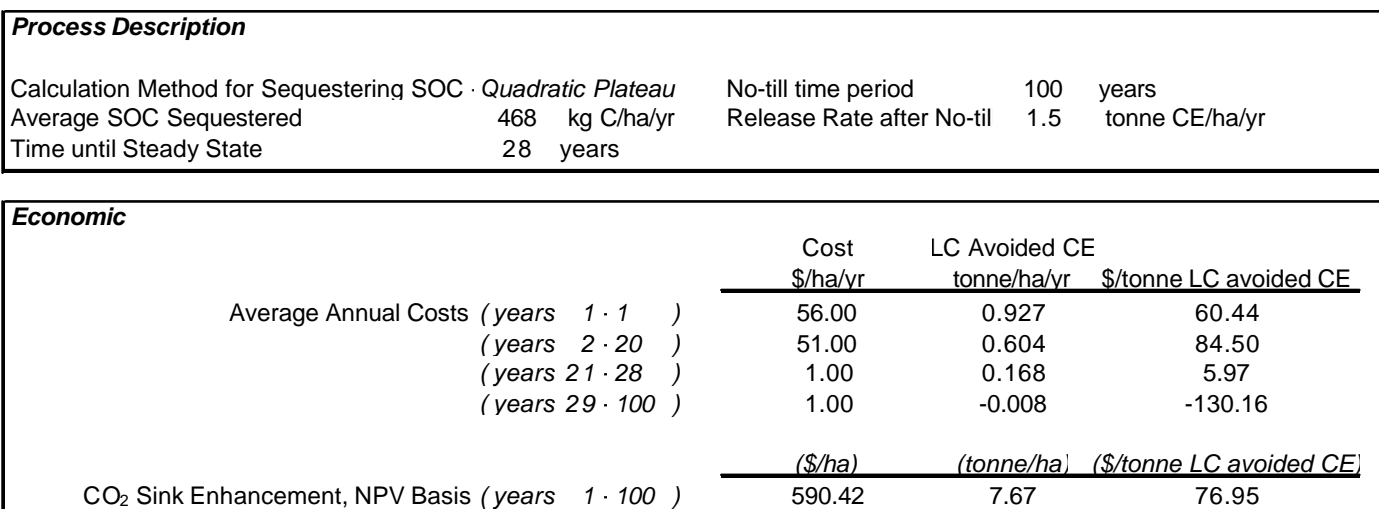
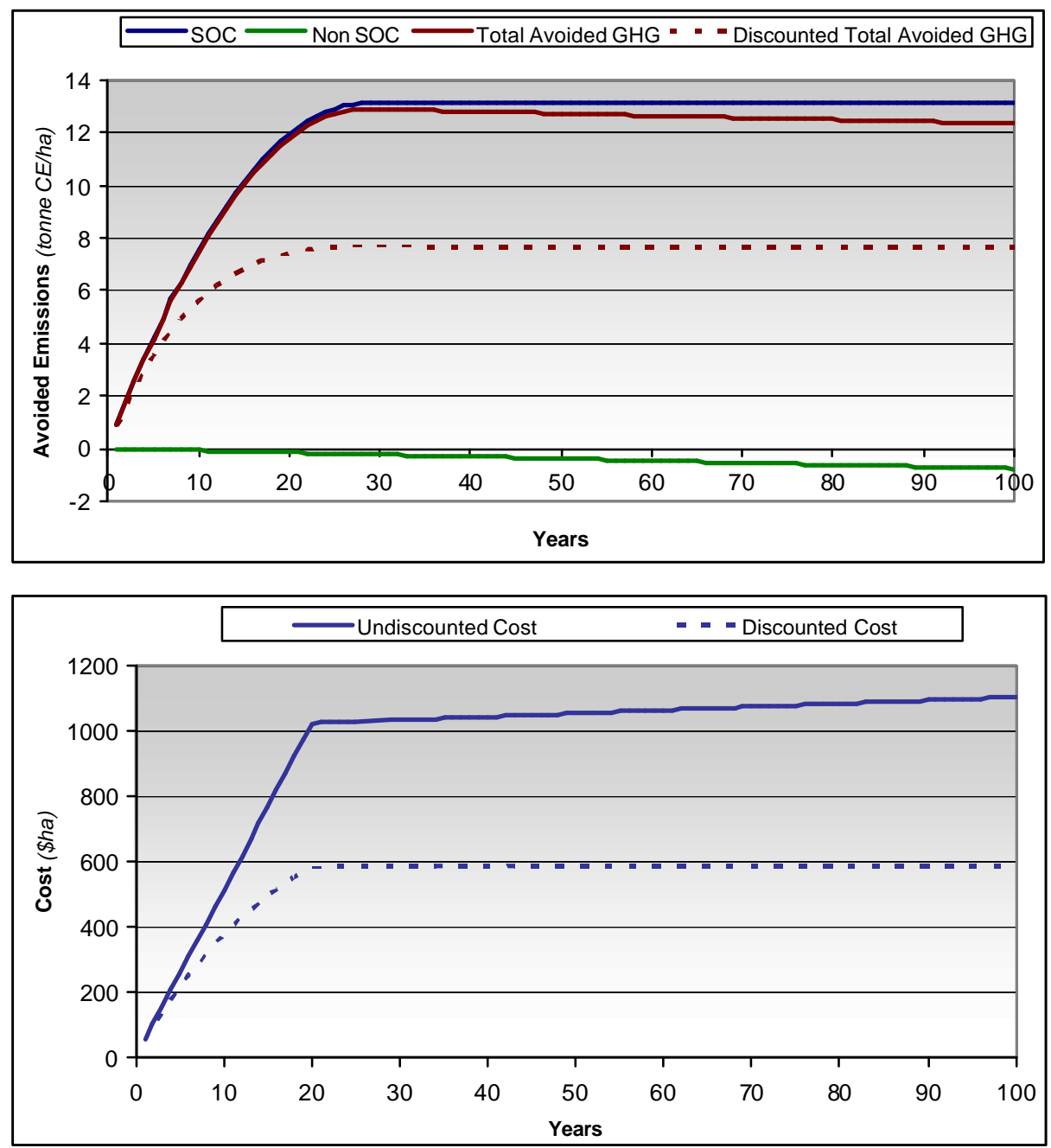


\subsubsection{Sensitivity Summary}

Example spreadsheet sensitivity summary output is presented in Table 20-9. This sensitivity output presents costs assuming adoption incentive payments for 5, 10, 15, and 20 years. These costs are presented assuming that no-till is maintained for the full 100-year planning horizon or for only as long as adoption incentives are paid to the farmer, after which the land is converted back to intensive-till. This analysis assumes that when no-till is switched back to intensive-till, SOC levels decrease at a rate of $1500 \mathrm{~kg} / \mathrm{ha} / \mathrm{yr}$. A base case of incentive payments for 10 years was selected for comparing costs with other $\mathrm{CO}_{2}$ sink enhancement or storage options. 
Table 20-9

Continuous corn sensitivity summary

\section{Cropland: Continuous Corn Indiana Sensitivity Summary}

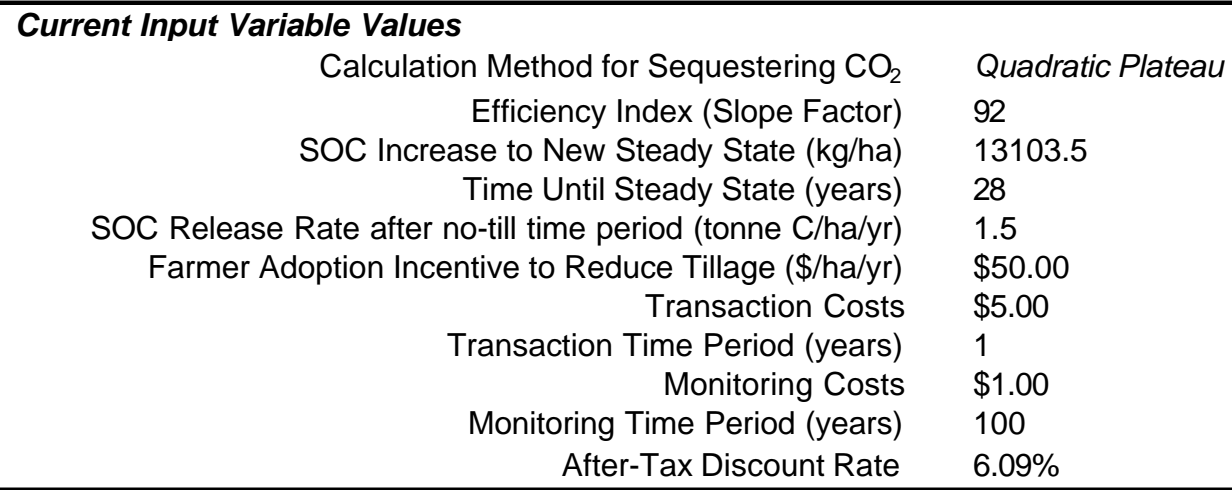

\section{Sensitivity Input}

Farmer Adoption Incentive Time Period Viewed

Push the adjacent button to update the sensitivity summary costs below.

$\mathrm{CO}_{2}$ Sink Enhancement Costs (years 1-100)

\begin{tabular}{ccc}
$\begin{array}{c}\text { No-till Time } \\
\text { Period } \\
\text { (years) }\end{array}$ & $\begin{array}{c}\text { Farmer Adoption Incentive } \\
\text { Time Period } \\
\text { (years) }\end{array}$ & $\begin{array}{c}\text { NPV Basis } \\
\text { LC avoided GHG basis } \\
\text { (\$/tonne C equivalent) }\end{array}$ \\
\hline 5 & 5 & 320.60 \\
10 & 10 & 142.87 \\
15 & 15 & 145.55 \\
20 & 20 & 128.82 \\
100 & 5 & 30.13 \\
100 & 10 & 50.51 \\
100 & 15 & 65.67 \\
100 & 20 & 76.95
\end{tabular}




\subsection{Continuous Corn (Poor N Management Scenario)}

This case is the same as the Indiana no-till base case in the last section except that poorer $\mathrm{N}$ management (broadcast application of urea) is assumed, resulting in more $\mathrm{N}$ fertilizer being required with no-till corn than intensive-till corn. Using more $\mathrm{N}$ fertilizer increases $\mathrm{GHG}$ emissions associated with $\mathrm{N}$ fertilizer use and also increases $\mathrm{N}_{2} \mathrm{O}$ emissions. This case assumes $150 \mathrm{~kg} \mathrm{~N} / \mathrm{ha}$ for intensive-till and $175 \mathrm{~kg} \mathrm{~N} / \mathrm{ha}$ or $200 \mathrm{~kg} / \mathrm{ha}$ for no-till. These $\mathrm{N}$ rates fall within the recommended rates for intensive-till and no-till corn in Kentucky ${ }^{8}$.

Table 20-10

Effects of switching from intensive-till Using $150 \mathrm{~kg} \mathrm{~N} / \mathrm{ha}$ to no- till Using 175 or $200 \mathrm{~kg}$ N/ha on GHG emissions and costs of life-cycle (LC) avoided GHG emissions-Indiana Continuous Corn

\begin{tabular}{|c|c|c|c|}
\hline $\begin{array}{l}\text { Switching from intensive-till to: } \\
\mathrm{N} \text { rate, } \mathrm{kg} / \mathrm{ha}\end{array}$ & $\begin{array}{r}\text { No-till } \\
150\end{array}$ & $\begin{array}{r}\text { No-till } \\
175\end{array}$ & $\begin{array}{r}\text { No-till } \\
200\end{array}$ \\
\hline \multicolumn{4}{|l|}{ Quadratic SOC response curve } \\
\hline$\Delta \mathrm{SOCs}, \mathrm{kg} \mathrm{C} / \mathrm{ha}$ & 13104 & 13104 & 13104 \\
\hline E (slope factor) & 92.0 & 92.0 & 92.0 \\
\hline Years to new steady state (Ys) & 28 & 28 & 28 \\
\hline \multicolumn{4}{|c|}{ Average annual increase in SOC (years 1 to $\mathrm{Ys}$ ), $\mathrm{kg} \mathrm{C} / \mathrm{ha} / \mathrm{yr}$} \\
\hline & 468 & 468 & 468 \\
\hline \multicolumn{4}{|c|}{ GHG emissions from tillage-system inputs and $\mathrm{N}_{2} \mathrm{O}$ (years $1-100$ ), $\mathrm{kg} \mathrm{CE} / \mathrm{ha} / \mathrm{y}:$} \\
\hline$\Delta$ Fuel use & -22.9 & -22.9 & -22.9 \\
\hline$\Delta$ Machinery maintenance, trans., and repair & -4 & -4 & -4 \\
\hline$\Delta \mathrm{N}$ fertilizer use & 0 & 21.0 & 57.4 \\
\hline$\Delta$ Herbicide use & 4 & 4 & 4 \\
\hline$\Delta$ Total GHG emissions from inputs & -22.7 & 6.0 & 34.7 \\
\hline$\Delta \mathrm{N}_{2} \mathrm{O}$ emissions from soil & 30.3 & 96.6 & 162.3 \\
\hline$\Delta$ Total GHG emissions & 7.6 & 102.6 & 197.0 \\
\hline \multicolumn{4}{|l|}{ Average LC GHG avoided (kg CE/ha/y) } \\
\hline Years 1 to Ys & 460 & 365 & 270 \\
\hline Years Ys to 100 & -8 & -103 & -198 \\
\hline Total LC GHG avoided (years 1-100), tonne CE/ha & 12.3 & 2.8 & -6.7 \\
\hline $\begin{array}{l}\text { NPV Total LC GHG avoided (years 1-100), tonne } \\
\text { CE/ha }\end{array}$ & 7.7 & 6.1 & 4.6 \\
\hline \multicolumn{4}{|l|}{ Costs, $\$ / h a / y$} \\
\hline Transaction (year 1) & 5 & 5 & 5 \\
\hline Adoption incentive (years 1-20) & 50 & 50 & 50 \\
\hline Monitoring (years 1-100) & 1 & 1 & 1 \\
\hline Total costs (years $1-100$ ), $\$ /$ ha & 1105 & 1105 & 1105 \\
\hline NPV Total costs (years $1-100$ ), $\$ /$ ha & 590 & 590 & 590 \\
\hline Cost (NPV basis), \$/tonne CE LC GHG avoided & 77 & 97 & 129 \\
\hline
\end{tabular}


A summary of results is presented in Table 20-10. Increasing the $\mathrm{N}$ rate every year for corn by $25 \mathrm{~kg}$ N/ha increased the cost of avoided GHG from \$77 to \$97/tonne CE LC avoided.

Increasing the $\mathrm{N}$ rate for corn by $50 \mathrm{~kg} \mathrm{~N} / \mathrm{ha}$ increased the cost of avoided GHG from $\$ 77 /$ tonne CE LC avoided to \$129/tonne CE LC avoided. These increased costs are due to less avoidance of GHG emissions per dollar invested in adoption incentives and transaction and monitoring costs. Adding an additional $50 \mathrm{~kg} \mathrm{~N} / \mathrm{ha}$ every year for corn nearly doubled the cost per tonne CE LC avoided on an NPV basis and resulted in a negative avoidance of GHG emissions on a nondiscounted basis after 100 years (a decrease from 12.3 to -6.7 tonnes CE LC avoided). This emphasizes the importance of efficient $\mathrm{N}$ fertilizer management in cropping systems designed to reduce GHG emissions. Details of the effects of increased $\mathrm{N}$ fertilizer use on GHG emissions from $\mathrm{N}$ fertilizer manufacture, transportation, storage, and application and on $\mathrm{N}_{2} \mathrm{O}$ emissions are presented in the next two sections.

\subsubsection{N Fertilizer Use}

Carbon emissions associated with important combinations of $\mathrm{N}$ source and placement are presented in Table 20-11. Emissions from $\mathrm{N}$ fertilizer use include manufacture ${ }^{9}$ and transportation and storage ${ }^{10}$. Emissions from $\mathrm{N}$ fertilizer application are from Langemeier and Taylor $^{3}$. The manufacturing numbers assume that all energy is from natural gas, but a small undermined amount of energy is from electricity. The transportation, storage, and application numbers assume the energy is from diesel fuel.

Table 20-11

Continuous corn carbon emissions associated with important combinations of $\mathbf{N}$ source and placement

Cropland: Continuous Corn Indiana N Fertilizer Use X Crop and Tillage System

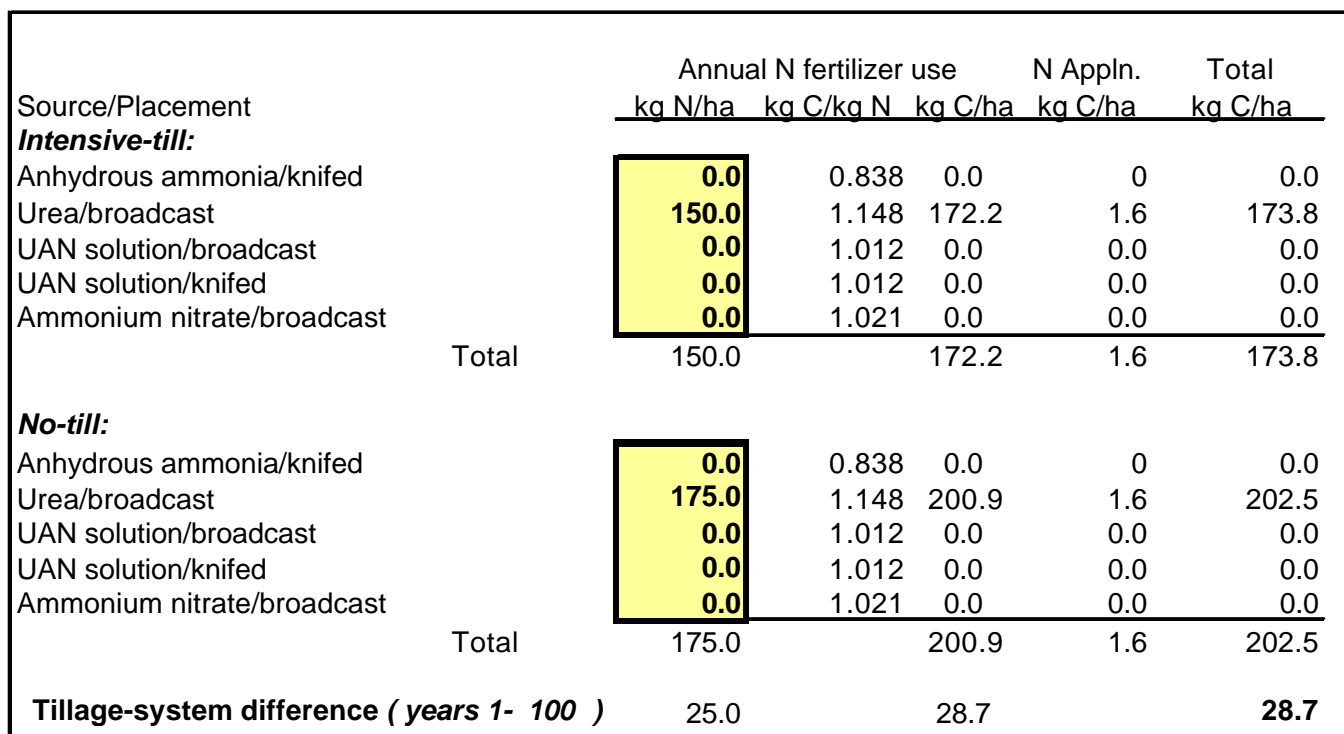


This case assumes that urea is broadcast for corn in both the intensive-till and no-till systems and that $150 \mathrm{~kg} \mathrm{~N} / \mathrm{ha}$ and $175 \mathrm{~kg} \mathrm{~N} / \mathrm{ha}$ are required for intensive-till and no-till corn, respectively. This resulted in an annual increase in $\mathrm{N}$ fertilizer use of $25 \mathrm{~kg} \mathrm{~N} / \mathrm{ha}$.

The increase in $\mathrm{N}$ fertilizer use with no-till was assumed to increase $\mathrm{N}_{2} \mathrm{O}$ emissions from soils in accordance with the IPCC default $\mathrm{N}_{2} \mathrm{O}$ emission factor for commercial $\mathrm{N}$ fertilizer use $\mathrm{e}^{11}$. The IPCC factor assumes the following:

- Direct $\mathrm{N}_{2} \mathrm{O}-\mathrm{N}$ emissions $=1.25$ percent of applied $\mathrm{N}$

- Indirect $\mathrm{N}_{2} \mathrm{O}-\mathrm{N}$ emissions from:

Volatilized $\mathrm{NH}_{3}$ and $\mathrm{NOx}=0.1$ percent of applied $\mathrm{N}$

Leached $\mathrm{N}=0.75$ percent of applied $\mathrm{N}$

- Total $\mathrm{N}_{2} \mathrm{O}-\mathrm{N}$ emission $=2.1$ percent of applied $\mathrm{N}$ (i.e., $0.021 \mathrm{~kg} \mathrm{~N} 2 \mathrm{O}-\mathrm{N} / \mathrm{kg}$ applied $\mathrm{N}$ )

The IPCC factor is converted to a carbon equivalent (CE) radiative forcing basis as follows:

- $\quad 1.57 \mathrm{~N}_{2} \mathrm{O} / \mathrm{N}_{2} \mathrm{O}-\mathrm{N}$

- $296 \mathrm{CO}_{2}$ equivalent/ $\mathrm{N}_{2} \mathrm{O}$

- $\quad 0.272 \mathrm{C}$ equivalent $(\mathrm{CE}) / \mathrm{CO}_{2}$ equivalent

- $1.57 \times 296 \times .272 \mathrm{CE} / \mathrm{N}_{2} \mathrm{O}-\mathrm{N}$ $\left(126.4 \mathrm{CE} / \mathrm{N}_{2} \mathrm{O}-\mathrm{N}\right)$

Therefore, $1 \mathrm{~kg}$ applied $\mathrm{N}=0.021 \times 126.4 \mathrm{~kg} \mathrm{CE}$ from $\mathrm{N}_{2} \mathrm{O}$

$$
=2.65 \mathrm{~kg} \mathrm{CE} \text { from } \mathrm{N}_{2} \mathrm{O}
$$

The overall increase in $\mathrm{N}_{2} \mathrm{O}$ emissions due to both switching from intensive-till to no-till and increasing $\mathrm{N}$ fertilizer use was calculated as shown in Table 20-12. Increased $\mathrm{N}_{2} \mathrm{O}$ emissions due to tillage-related changes in soil properties and micro-climate (without changes in $\mathrm{N}$ fertilizer rate) are based on the same assumptions as in the previous case in which $\mathrm{N}$ fertilizer rate didn't change with tillage system. 
Table 20-12

Continuous corn overall increase in $\mathrm{N}_{2} \mathrm{O}$ emissions due to both switching from intensivetill to no-till and increasing $\mathbf{N}$ fertilizer use

Cropland: Continuous Corn

Indiana

Annual Changes in $\mathrm{N}_{2} \mathrm{O}$ Emissions
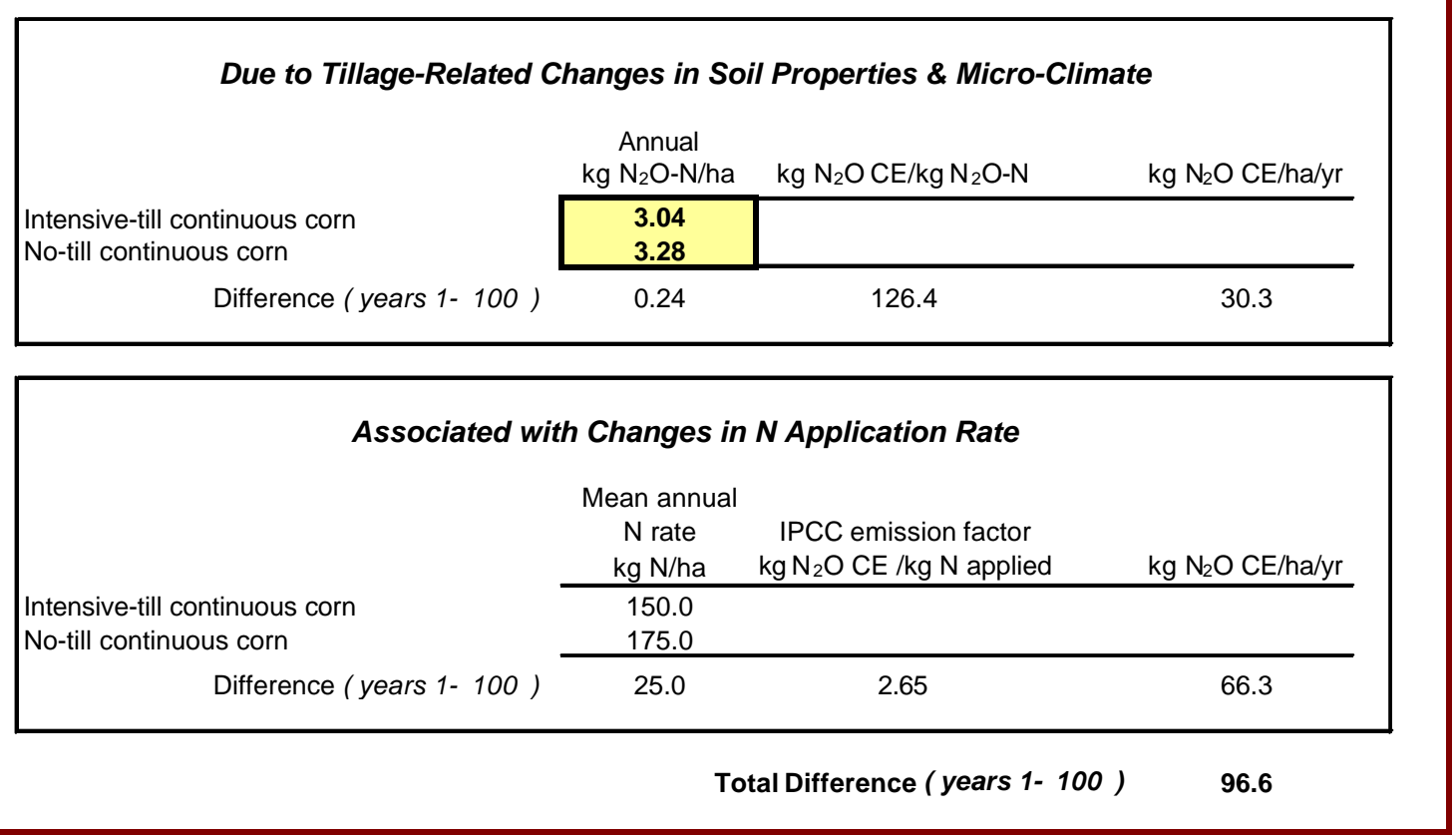

\subsubsection{Summary of Avoided GHG Emissions}

Example spreadsheet output summarizing changes in GHG emissions due to switching from intensive-till to no-till and increasing $\mathrm{N}$ fertilizer use by $25 \mathrm{~kg} \mathrm{~N} / \mathrm{ha}$ is presented in Table 20-13. These results correspond to the second column in Table 20-10. Over the course of the 100-year planning horizon, the added $\mathrm{N}$ fertilizer use and associated increase in $\mathrm{N}_{2} \mathrm{O}$ emissions substantially reduced the amount of GHG emissions avoided (Table 20-14). 
Table 20-13

Continuous sorn example spreadsheet output summarizing changes in GHG emissions due to switching from intensive-till to no-till and increasing $\mathbf{N}$ fertilizer use

Cropland: Continuous Corn

Indiana

Life Cycle (LC) Avoided GHG Emissions

(Due to Switching from Intensive-Till to No-Till)

Changes in GHG Emissions

kg CE/ha/yr

Average Soil Organic Carbon (SOC) sequestered (years $\quad 1-28 \quad$ ) $\quad-468$

$\mathrm{CO}_{2}$ Emissions from Tillage-System Inputs: $\quad$ (years $1-100$ )

$$
\text { Fuel } \quad-22.9
$$

Machinery MTR -4.1

$\mathrm{N}$ fertilizer $\quad 28.7$

Herbicides 4.3

Total 6.0

$\mathrm{N}_{2} \mathrm{O}$ Emissions from Soil $\quad$ (years $\quad 1-100$ ) 96.6

Avoided GHG Emissions

Annual Average

$\mathrm{kg} \mathrm{CE} / \mathrm{ha} / \mathrm{vr}$ tonne $\mathrm{CE} / \mathrm{ha} / \mathrm{vr}$

(years $1-28$ ) $\quad 365.2 \quad 0.365$

(years $29-100$ ) $\quad-102.6 \quad-\mathbf{0 . 1 0 3}$

\subsubsection{Summary}

Example spreadsheet output summarizing costs and life-cycle (LC) avoided GHG on a carbon equivalent (CE) basis is presented in Table 20-14. This output corresponds to the second column in Table 20-10. 
Table 20-14

Continuous corn costs and life-cycle (LC) avoided GHG on a carbon equivalent (CE) basis when changing from intensive-till to no-till and increasing $\mathbf{N}$ fertilizer use

\section{Cropland: Continuous Corn \\ Indiana}

Summary

\begin{tabular}{|lccccc|}
\hline Process Description & & & & \\
& & & & \\
& & & & \\
& & & \\
Calculation Method for Sequestering SOC $\cdot$ Quadratic Plateau & No-tilme period & years \\
Average SOC Sequestered & 468 & $\mathrm{~kg} \mathrm{C} / \mathrm{ha} / \mathrm{yr}$ & Release Rate after No-til & 1.5 & tonne CE/ha/yr \\
Time until Steady State & 28 years & & & \\
\hline
\end{tabular}

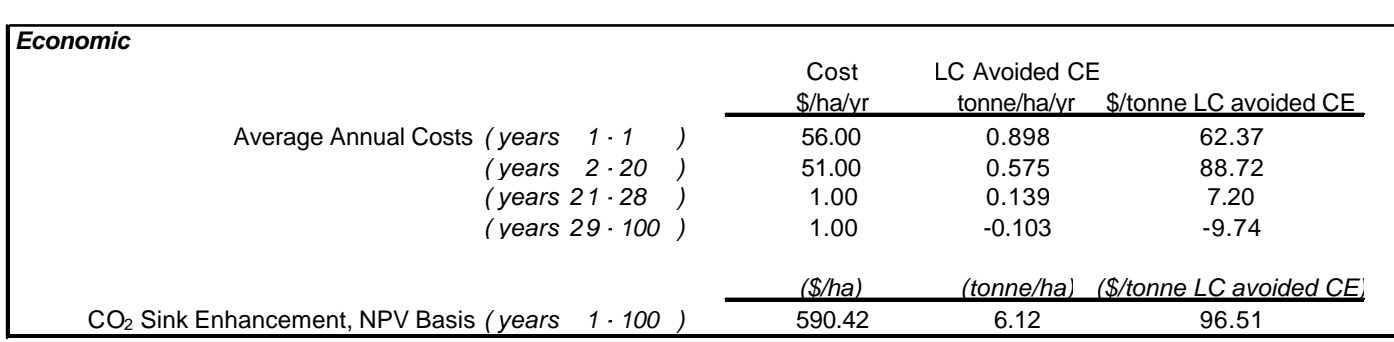
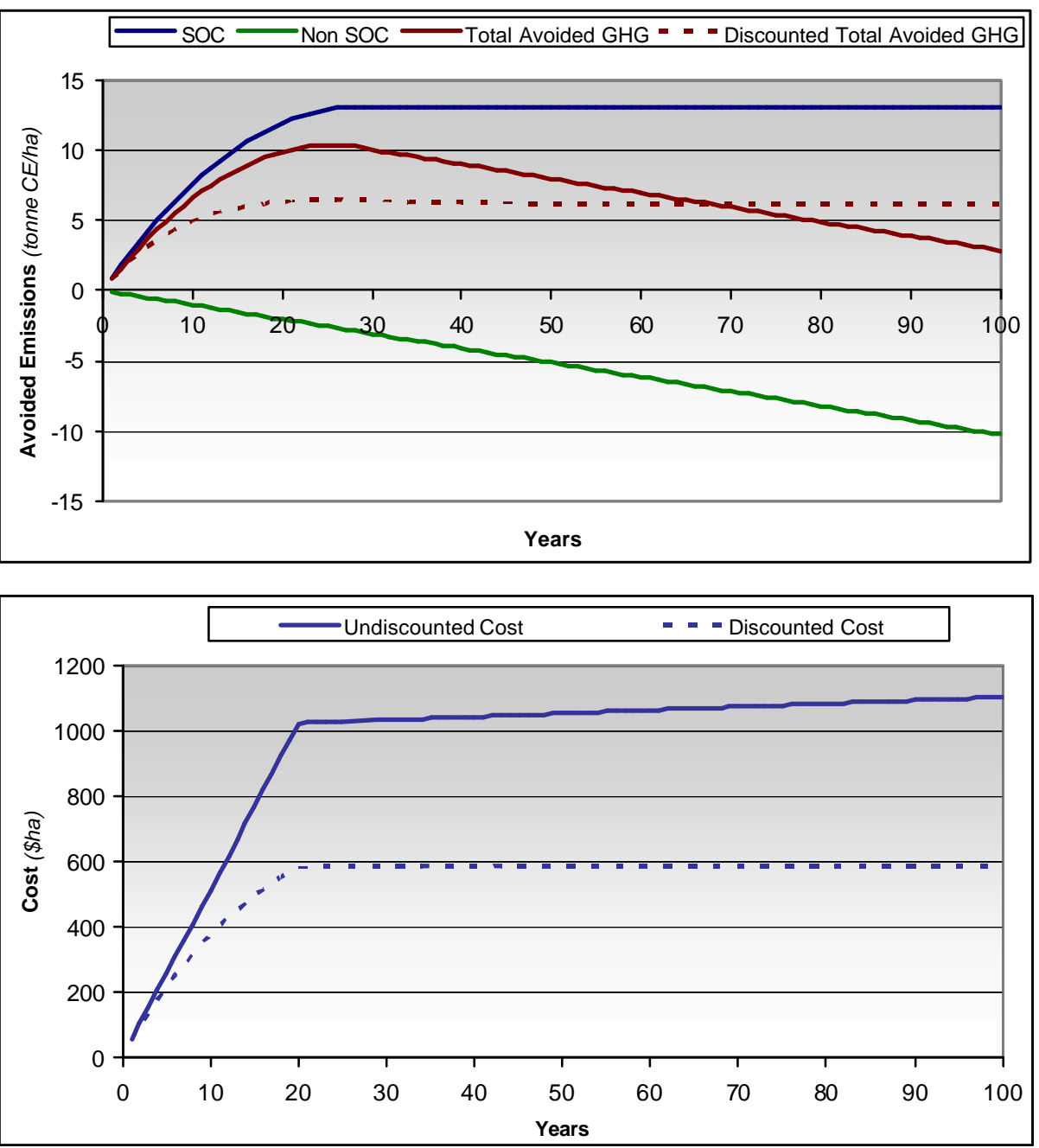


\subsubsection{Sensitivity Summary}

Example spreadsheet sensitivity summary output is presented in Table 20-15. This output corresponds to the second column in Table 20-10 and presents costs assuming adoption incentive payments for 5, 10, 15, and 20 years. These costs are presented assuming that no-till is maintained for the full 100-year planning horizon or for only as long as adoption incentives are paid to the farmer, after which the land is converted back to intensive-till. This analysis assumes that when no-till is switched back to intensive-till, SOC levels decrease at a rate of $1500 \mathrm{~kg} / \mathrm{ha} / \mathrm{yr}$. A base case of incentive payments for 10 years was selected for comparing costs with other $\mathrm{CO}_{2}$ sink enhancement or storage options. 
Table 20-15

Continuous corn example spreadsheet sensitivity summary output when changing from intensive-till to no-till and increasing $\mathbf{N}$ fertilizer use

\section{Cropland: Continuous Corn Indiana \\ Sensitivity Summary}

\section{Current Input Variable Values}

Calculation Method for Sequestering $\mathrm{CO}_{2}$

Efficiency Index (Slope Factor)

SOC Increase to New Steady State $(\mathrm{kg} / \mathrm{ha})$

Time Until Steady State (years)

SOC Release Rate after no-till time period (tonne $\mathrm{C} / \mathrm{ha} / \mathrm{yr}$ )

Farmer Adoption Incentive to Reduce Tillage (\$/ha/yr)

Transaction Costs

Transaction Time Period (years)

Monitoring Costs

Monitoring Time Period (years)

After-Tax Discount Rate

Quadratic Plateau

92

13103.5

28

1.5

$\$ 50.00$

$\$ 5.00$

1

$\$ 1.00$

100

$6.09 \%$

\section{Sensitivity Input}

Farmer Adoption Incentive Time Period Viewed

Push the adjacent button to update the sensitivity summary costs below.

$\mathrm{CO}_{2}$ Sink Enhancement Costs (years 1-100)

\begin{tabular}{ccc}
$\begin{array}{c}\text { No-till Time } \\
\text { Period } \\
\text { (years) }\end{array}$ & $\begin{array}{c}\text { Farmer Adoption Incentive } \\
\text { Time Period } \\
\text { (years) }\end{array}$ & $\begin{array}{c}\text { NPV Basis } \\
\text { LC avoided GHG basis } \\
\text { (\$/tonne C equivalent) }\end{array}$ \\
\hline 5 & 5 & 717.68 \\
10 & 10 & 192.17 \\
15 & 15 & 197.99 \\
20 & 20 & 168.59 \\
100 & 5 & 37.79 \\
100 & 10 & 63.35 \\
100 & 15 & 82.36 \\
100 & 20 & 96.51
\end{tabular}


Examples of the large effects of $\mathrm{N}$ rate and $\mathrm{N}_{2} \mathrm{O}$ emissions on amount of $\mathrm{GHG}$ emissions avoided and cost per tonne of GHG avoided are presented in Table 20-16. The scenarios in Table 20-16 are for switching from intensive-till to no-till continuous corn in the Corn Belt. No significant change in $\mathrm{N}_{2} \mathrm{O}$ emissions due switching from intensive-till to no-till is a possibility with good $\mathrm{N}$ management, especially on well-drained soils. The increases in $\mathrm{N}$ rate and $\mathrm{N}_{2} \mathrm{O}$ emissions in Table 20-16 due to switching from intensive-till to no-till are possibilities with poor $\mathrm{N}$ management. Amounts of GHG avoided range from 15.4 tonnes CE LC GHG avoided/ha with a best-case $\mathrm{N}$ rate and $\mathrm{N}_{2} \mathrm{O}$ scenario to -6.7 tonnes $\mathrm{CE}$ LC GHG avoided/ha for a worst-case scenario. Costs on an NPV basis range from \$72/tonne CE LC GHG avoided with a best-case $\mathrm{N}$ rate and $\mathrm{N}_{2} \mathrm{O}$ scenario to $\$ 129 /$ tonne CE LC GHG avoided for a worst-case scenario. Differences between the best-case and worst-case scenarios regarding amount of GHG avoided are very large because the annual effects are manifested over the entire 100-year planning horizon. In order for reducing tillage on continuous corn to be a viable option for avoiding GHG emissions, $\mathrm{N}$ fertilizer will have to be managed efficiently so that the amount of $\mathrm{N}$ fertilizer used and the $\mathrm{N}_{2} \mathrm{O}$ emissions are not significantly increased.

Table 20-16

Effects of increases in $\mathrm{N}$ rate and $\mathrm{N}_{2} \mathrm{O}$ emissions on amounts and costs of avoided GHG via switching from intensive-till to no-Continuous Corn

\begin{tabular}{|c|c|c|c|c|c|}
\hline \multicolumn{2}{|c|}{$\Delta \mathrm{N}$ rate } & $\Delta \mathrm{N}_{2} \mathrm{O}$ & Years 1-100 & \multicolumn{2}{|c|}{ NPV basis, years $1-100$} \\
\hline $\mathrm{kg} \mathrm{N} / \mathrm{ha} / \mathrm{yr}$ & $\mathrm{kg} / \mathrm{CE} / \mathrm{ha} / \mathrm{yr}$ & $\mathrm{kg} / \mathrm{CE} / \mathrm{ha} / \mathrm{yr}$ & $\begin{array}{c}\text { tonne CE LC } \\
\text { GHG } \\
\text { avoided/ha }\end{array}$ & $\begin{array}{c}\text { tonne CE LC } \\
\text { GHG } \\
\text { avoided/ha }\end{array}$ & $\begin{array}{l}\text { \$/tonne CE } \\
\text { LC GHG } \\
\text { avoided }^{1 /}\end{array}$ \\
\hline 0 & 0 & 0 & 15.4 & 8.2 & $72 \stackrel{2}{=}$ \\
\hline 0 & 0 & 30 & 12.3 & 7.7 & $77^{\stackrel{3}{ } /}$ \\
\hline 25 & 29 & 97 & 2.8 & 6.7 & $97^{4}$ \\
\hline 50 & 58 & 163 & -6.7 & 4.7 & $129^{5 /}$ \\
\hline $\begin{array}{l}\text { 1/ Assumes in } \\
\text { 2/ Base case } \\
\text { 3/ Base case } \\
\text { 4/ Base case } \\
\text { 5/ Base case } \\
\text { (see third c }\end{array}$ & $\begin{array}{l}\text { tive payments } \\
\text { ept for no cha } \\
\text { first column, } \\
\text { ept for an incr } \\
20-10 \text { ). } \\
\text { ept for an add } \\
\text { nn, Table 20- }\end{array}$ & $\begin{array}{l}20 \text { years. } \\
\text { in } \mathrm{N}_{2} \mathrm{O} \text { emis } \\
\text { ble } 20-10 \text { ). } \\
\text { ee in } \mathrm{N} \text { rate di } \\
\text { nal increase i }\end{array}$ & $\begin{array}{l}\text { to switching frc } \\
\text { Jate due to s }\end{array}$ & $\begin{array}{l}\text { ng to no-till. } \\
\text { to no-till (see } \\
\text { ching from to }\end{array}$ & ond \\
\hline
\end{tabular}




\subsection{References}

1 Brenner, J., K. Paustian, G. Bluhm, J. Cipra, M. Easter, E.T. Elliott, T. Kautza, K. Killian, J. Schuler and S. Williams. 2001. Quantifying the change in greenhouse gas emissions due to natural resource conservation practice application in Iowa. Final report to the Iowa Conservation Partnership. Colorado State University Natural Resource Ecology Laboratory and USDA Natural Resources Conservation Service, Fort Collins, CO, USA.

2 Smith, P., J. Brenner, K. Paustian, G. Bluhm, J. Cipra, M. Easter, E.T. Elliott, K. Killian, D. Lamm, J. Schuler and S. Williams. 2002. Quantifying the change in greenhouse gas emissions due to natural resource conservation practice application in Indiana. Final report to the Indiana Conservation Partnership. Colorado State University Natural Resource Ecology Laboratory and USDA Natural Resources Conservation Service, Fort Collins, CO, USA.

3 Langemeier, L.N. and R.K. Taylor. 1998. A look at machinery cost. Kansas Farm Management Guide, MF-842. Kansas State University, Department of Agricultural Economics.

4 West, Tristram O. and Gregg Marland. 2002. A synthesis of carbon sequestration, carbon emissions, and net carbon flux in agriculture: comparing tillage practices in the United States. Agriculture, Ecosystems, and Environment (in press)

5 Robertson, G. Phillip, Eldor A. Paul, and Richard R. Harwood. 2001. Greenho use gases in intensive agriculture: contributions of individual gases to the radiative forcing of the atmosphere. Science: 289 (5486): 1922-1925.

6 Del Grosso, S.J. W.J. Parton, A.R. Mosier, M.D. Hartman, J. Brenner, D.S. Ojima, and D.S. Schimel. 2001. Simulated interaction of carbon dynamics and nitrogen trace gas fluxes using the DAYCENT . P. 303-332. In M.J. Shaffer, Liwang Ma, and S. Hansen (eds.) Modeling carbon and nitrogen dynamics for soil management. Lewis Publishers. Washington, D.C.

7 Mummey, Daniel L., Jeffrey L. Smith, and George Blum. 1998. Assessment of alternative soil management practices on $\mathrm{N} 2 \mathrm{O}$ emissions from U.S. agriculture. Agriculture, Ecosystems, and Environment 70:79-87.

8 KY. 2001. 200-2001 lime and fertilizer recommendations. www.ca.uky.edu/agc/pubs/agr/agr1/agr1.htm

9 Mudahar, Mohinder S. and Travis P. Hignett. 1987. Energy requirements, technology, and resources in the fertilizer sector. p. 25-61. In Z.R. Helsel (Ed.) Energy in World Agriculture. Vol. 2. Elsevier. New York. 
10 Achorn, Frank P., David G. Salladay, and Jeffery L. Greenhill. 1980. Effects of high costs on fertilizer production. P. 5-12. Situation 80, TVA Fertilizer Conference. Kansas City, MO.

11 EPA. 2000. Inventory of U.S. greenhouse gas emissions and sinks: 1990-1998. EPA 236-R001. p. 5-17 to 5-19. 


\section{1 \\ WHEAT/FALLOW IN THE WESTERN GREAT PLAINS}

\subsection{Introduction}

As indicated in Chapter 18, wheat/fallow systems represent a large land area in the western Great Plains, but the amount of additional carbon sequestered per hectare via reducing tillage is much lower than for con/soybean rotations or continuous corn in the Corn Belt. On the other hand, reducing tillage on wheat/fallow rotations either reduces $\mathrm{N}_{2} \mathrm{O}$ emissions or has no significant effect on $\mathrm{N}_{2} \mathrm{O}$ emissions and a smaller adoption incentive is required to get farmers to switch from intensive-till to no-till. The net effect is that $\mathrm{CO}_{2}$ abatement costs per tonne CE LC avoided are not greatly different than for corn/soybean rotations or continuous corn. The base cases (Section 21.2) assume typical levels of carbon sequestration and a small decrease in $\mathrm{N}_{2} \mathrm{O}$ emissions due to reducing tillage and the sensitivity cases (Section 21.3) assume typical levels of carbon sequestration and no change in $\mathrm{N}_{2} \mathrm{O}$ emissions due to reducing tillage.

\subsection{Wheat/Fallow (Base Cases)}

A summary of effects of switching from intensive-till to no-till on SOC, GHG emissions, and costs of avoided GHG emissions is presented in Table 21-1 for wheat/fallow systems in the western Great Plains. The bases for the results in Table 21-1 are discussed in the following sections using output from the wheat/fallow spreadsheet model developed for this project. Base cases assuming a reduction in $\mathrm{N}_{2} \mathrm{O}$ emissions due to reducing tillage are presented in the first two columns of Table 21-1.

\subsubsection{Increases in Soil Organic Carbon}

Using the same SOC model for wheat/fallow rotations in Nebraska ${ }^{1}$ as for corn/soybean rotations and continuous corn in Iowa ${ }^{2}$ and Indiana ${ }^{3}$, switching from intensive-till to no-till was predicted to increase SOC an average of $240 \mathrm{~kg} \mathrm{C} / \mathrm{ha} /$ year in Nebraska for the first 10 years after switching from intensive-till to no-till. A Nebraska state average was only provided for the first ten years after switching to no-till but county averages were provided for 10 and 20 years after switching to no-till. For example, the average SOC increase in Kimball County on the western edge of Nebraska was estimated at $140 \mathrm{~kg} \mathrm{C} / \mathrm{ha} /$ year for the first 20 years after switching to no-till. Another approach for estimating regional increases in SOC due to switching from intensive-till to no-till is to use coefficients formulated by the IPCC ${ }^{4}$. These coefficients are for the first 20 years after switching from intensive-till to no-till. Using IPPC coefficients for the Mountain region which is representative of the drier western portion of the Great Plains with predominantly wheat/fallow rotations, switching from intensive-till to no-till resulted in an 
estimated weighted-mean increase in SOC of $200 \mathrm{~kg} \mathrm{C} / \mathrm{ha} /$ year. In contrast, a summary of wheat/fallow studies in the Great Plains indicated that switching from intensive-till to no-till resulted in negligible or no increases in $\mathrm{SOC}^{5}$. A model simulation ${ }^{6}$ indicated that switching from intensive-till to no-till on wheat/fallow systems in eastern Colorado stabilized SOC levels that otherwise were declining over time with intensive-till. Because of the variation in regional estimates of effects of reducing tillage on SOC levels, results are presented in Table 21-1 assuming increases of both 200 and $100 \mathrm{~kg} \mathrm{C} / \mathrm{ha} / \mathrm{year}$ for a 20 -year period due to switching from intensive-till to no-till in wheat/fallow systems; an increase of $200 \mathrm{~kg} \mathrm{C} / \mathrm{ha} / \mathrm{year}$ was chosen as the base case for cost comparisons with other $\mathrm{CO}_{2}$ sink enhancement or storage options.

Table 21-1

Effects of switching from intensive-till to no-till on SOC, GHG emissions, and costs of lifecycle (LC) avoided GHG emissions-Wheat/Fallow in the western great plains

\begin{tabular}{lcrrr}
\hline Linear SOC response curve & \multicolumn{2}{c}{ Base-case $\Delta \mathrm{N}_{2} \mathrm{O}$} & \multicolumn{2}{c}{ Zero $\Delta \mathrm{N}_{2} \mathrm{O}$} \\
$\mathrm{kg} \mathrm{C} / \mathrm{ha} / \mathrm{yr}$ & 200 & 100 & 200 & 100 \\
Years to new steady state $(\mathrm{Ys})$ & 20 & 20 & 20 & 20
\end{tabular}

GHG emissions from tillage-system inputs and $\mathrm{N}_{2} \mathrm{O}$ (years $1-100$ ), $\mathrm{kg} \mathrm{CE} / \mathrm{ha} / \mathrm{y}$ :

\begin{tabular}{lrrrr}
$\Delta$ Fuel use & -10.3 & -10.3 & -10.3 & -10.3 \\
$\Delta$ Machinery maintenance, trans., and repair & -1.9 & -1.9 & -1.9 & -1.9 \\
$\Delta$ N fertilizer use & 0 & 0 & 0 & 0 \\
$\Delta$ Herbicide use & 11.7 & 11.7 & 11.7 & 11.7 \\
\hline$\Delta$ Total GHG emissions from inputs & -0.5 & -0.5 & -0.5 & -0.5 \\
$\Delta$ N $_{2}$ O emissions from soil & -25.3 & -25.3 & 0 & 0 \\
\hline$\Delta$ Total GHG emissions & -25.8 & -25.8 & -0.5 & -0.5
\end{tabular}

\begin{tabular}{|c|c|c|c|c|}
\hline \multicolumn{5}{|l|}{ Average LC GHG avoided (kg CE/ha/y) } \\
\hline Years 1 to Ys & 226 & 126 & 201 & 101 \\
\hline Years Ys to 100 & 26 & 26 & -1 & -1 \\
\hline $\begin{array}{l}\text { Total LC GHG avoided (years 1-100), } \\
\text { tonne CE/ha }\end{array}$ & 6.6 & 4.6 & 4.1 & 2.1 \\
\hline $\begin{array}{l}\text { NPV Total LC GHG avoided (years 1-100), } \\
\text { tonne CE/ha }\end{array}$ & 2.7 & 1.6 & 2.3 & 1.2 \\
\hline \multicolumn{5}{|l|}{ Costs, \$/ha/y } \\
\hline Transaction (year 1) & 5 & 5 & 5 & 5 \\
\hline Adoption incentive (years 1-20) & 15 & 15 & 15 & 15 \\
\hline Monitoring (years 1-100) & 1 & 1 & 1 & 1 \\
\hline Total costs (years $1-100$ ), $\$ /$ ha & 405 & 405 & 405 & 405 \\
\hline NPV Total costs (years 1-100), \$/ha & 195 & 195 & 195 & 195 \\
\hline $\begin{array}{l}\text { Cost (NPV basis), \$/tonne CE LC GHG } \\
\text { avoided }\end{array}$ & 71 & 123 & 84 & 167 \\
\hline
\end{tabular}


Example spreadsheet inputs for calculating base-case increases in SOC due to switching from intensive-till to no-till in wheat/fallow systems in the western Great Plains (first column of Table 21-1) are presented in Table 21-2.

Table 21-2

Example process and economic input variables for switching from intensive-till to no-till for wheat/fallow rotation

\section{Cropland: Two-Year Wheat / Fallow Rotation \\ (Changes Due to Switching from Intensive-Till to No-Till)}

\begin{tabular}{|c|}
\hline Western Great Plains \\
\hline
\end{tabular}

Process

$$
\text { Alternative Tillage System: } \quad \text { No-till }
$$

Calculation Method for Sequestering Soil Organic Carbon (SOC)

Quadratic Plateau

Linear Plateau

SOC Sequestered until Steady State

Years until New Steady State

$200 \mathrm{~kg} \mathrm{C} / \mathrm{ha} / \mathrm{vr}$

20 years

No-till time period

SOC Release Rate after no-till time period

100 years

$70 \mathrm{~kg} \mathrm{C} / \mathrm{ha} / \mathrm{yr}$

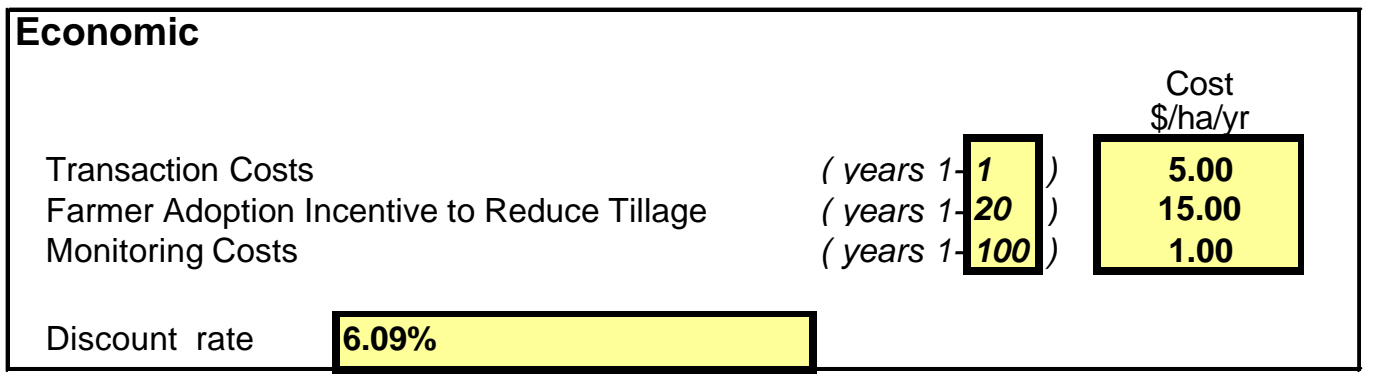

\subsubsection{Costs}

A theoretical basis for estimating conservation-tillage adoption incentives is overviewed in Appendix $\mathrm{E}$ and an adoption incentive of $\$ 15 / \mathrm{ha} /$ year is estimated for switching from intensivetill to no-till in wheat/fallow rotations in the western Great Plains. Transaction costs are based on experience with forestry projects and are estimated at $\$ 5 / \mathrm{ha}$. Monitoring costs are assumed to be less than for forestry $(\$ 5 / \mathrm{ha})$, assuming that cropland monitoring will be based mainly on monitoring practices that have been correlated with changes in SOC rather than direct measurements of SOC in each field. Monitoring costs of $\$ 1 /$ ha/year were assumed. 


\subsubsection{GHG Effects in Addition to Carbon Storage in Soil Organic Matter}

\subsubsection{Fuel Use}

Reductions in fuel use and associated carbon emissions by switching from intensive-till to no-till in a wheat/fallow rotation are presented in Table 21-3. Fuel usage rates are from Langemeier and Taylor?

Table 21-3

Reductions in fuel use and associated carbon emissions by switching from intensive-till to no-till in a wheat/fallow rotation

Cropland: Two-Year Wheat / Fallow Rotation Western Great Plains

Fuel Use for tillage, planting, and herbicide operations

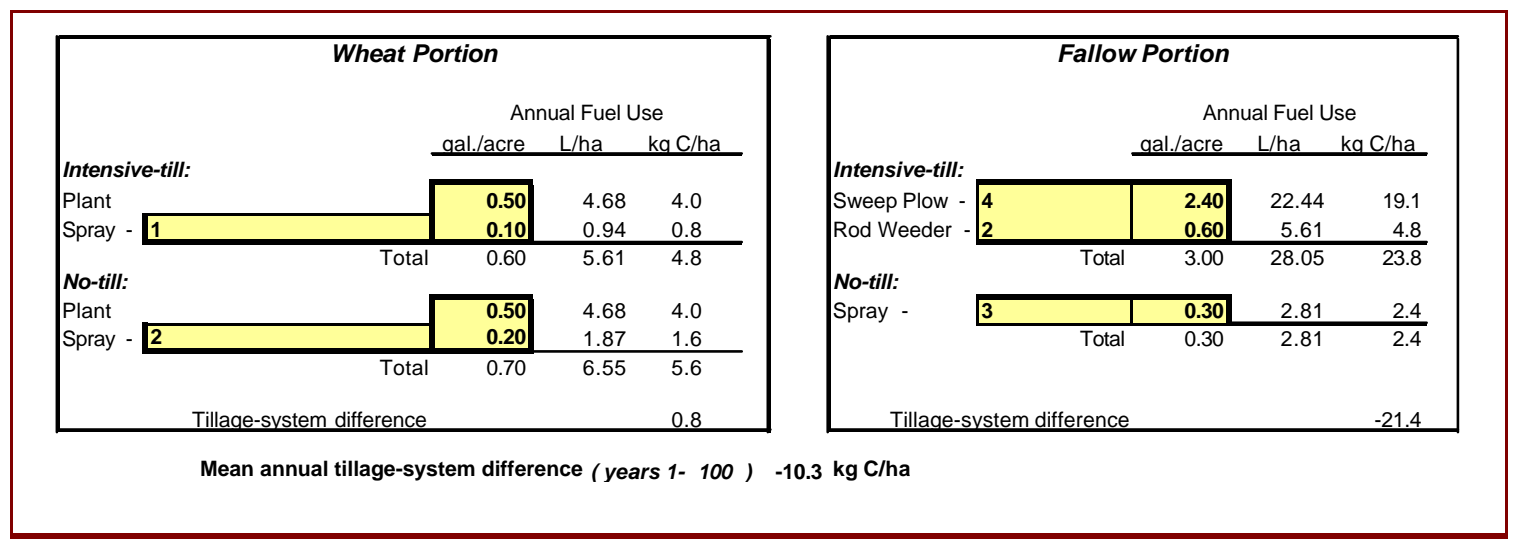

Energy Savings Embodied in Machinery Manufacturing, Transportation, \& Repair (MTR)

Annual fuel saving from reducing tillage

Annual machinery MTR savings

Annual machinery MTR saving from reducing tillage (years 1- 100 ) $\quad-1.9 \mathrm{~kg} \mathrm{C} / \mathrm{ha}$

\subsubsection{Machinery Manufacture, Transportation, and Repair}

Reductions in machinery manufacture, transportation, and repair (MTR) and associated carbon emissions by switching from intensive-till to no-till wheat/fallow rotations were calculated as 18 percent of the fuel savings (Tables 21-3). The 18 percent factor is based on ratios of tillagesystem fuel use and machinery MTR in a national analysis of tillage-system effects on GHG emissions $^{8}$. 


\subsubsection{N Fertilizer Use}

In drier climates such as the western Great Plains, reducing tillage has less potential for affecting the amount of $\mathrm{N}$ fertilizer required. Switching from intensive-till to no-till in wheat/fallow systems in the western Great Plains is assumed to have no effect on the amount of $\mathrm{N}$ fertilizer required.

\subsubsection{Herbicide Use}

In wheat/fallow systems, a switch from intensive-till to no-till involves substituting contact herbicide for tillage operations during the fallow period. A herbicide rate of $3.0 \mathrm{~kg}$ active ingredient/ha during the fallow period is assumed ${ }^{9}$. This translates to an average of $1.5 \mathrm{~kg}$ active ingredient/ha/year averaged over the entire wheat/fallow rotation. An estimate of $7.80 \mathrm{~kg} \mathrm{C}$ emitted/kg contact herbicide was used (personal communication, T.O. West, Oak Ridge National Laboratory). Example spreadsheet output is presented in Table 21-4.

\section{Table 21-4}

Example spreadsheet output for estimating herbicide carbon equivalent emissions for wheat/fallow rotation

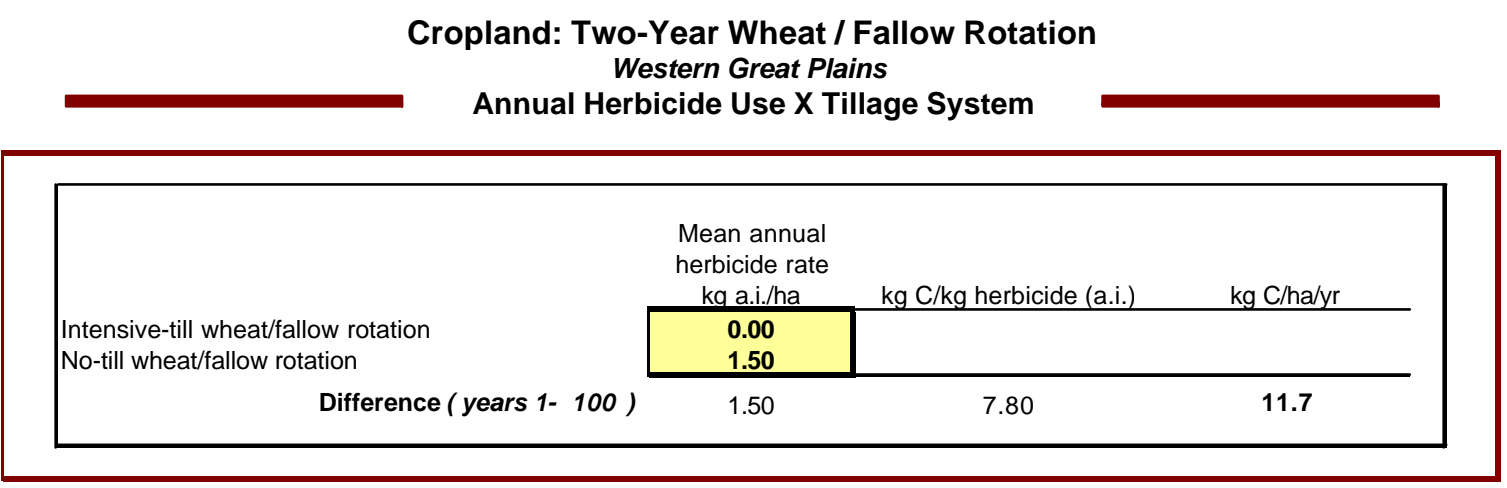

\subsubsection{5 $\mathrm{N}_{2} \mathrm{O}$ Emissions from Soil}

Background on $\mathrm{N}_{2} \mathrm{O}$ emissions from soil was provided earlier, indicating that $\mathrm{N}_{2} \mathrm{O}$ emissions are dependent on both soil conditions and amount of $\mathrm{N}$ fertilizer applied. In this western Great Plains wheat/fallow case, the amount of $\mathrm{N}$ fertilizer applied does not change with tillage system, but soil conditions do change as discussed Chapter 18. Del Grosso et al. ${ }^{6}$ modeled $\mathrm{N}_{2} \mathrm{O}$ emissions as affected by switching wheat/fallow rotations from intensive-till to no-till on a well drained soil in eastern Colorado. The same $\mathrm{N}$ fertilizer rate was assumed for both tillage systems. A specific placement (e.g., knifing or broadcast) of the $\mathrm{N}$ fertilizer was not indicated. With these assumptions, $\mathrm{N}_{2} \mathrm{O}$ emissions were slightly lower with no-till than intensive-till. Mummey et al. ${ }^{10}$ modeled $\mathrm{N}_{2} \mathrm{O}$ emissions for intensive-till and no-till wheat systems at 467 sites. These sites represented the range of soil and environmental conditions for wheat in the United States and wheat/fallow systems represent a significant portion of the wheat producing area. This modeling effort estimated mean $\mathrm{N}_{2} \mathrm{O}-\mathrm{N}$ emissions of $4.8 \mathrm{~kg} / \mathrm{ha} /$ year for intensive-till and 
$4.6 \mathrm{~kg} / \mathrm{ha} /$ year for no-till. Taking the difference $\left(-0.2 \mathrm{~kg} \mathrm{~N}_{2} \mathrm{O}-\mathrm{N} / \mathrm{ha} /\right.$ year) times $126.4 \mathrm{~kg} \mathrm{~N} \mathrm{~N}_{2} \mathrm{O}$ $\mathrm{CE} / \mathrm{kg} \mathrm{N} \mathrm{N}_{2} \mathrm{O}-\mathrm{N}$ gives $-25.3 \mathrm{~kg} \mathrm{~N}_{2} \mathrm{O} \mathrm{CE} / \mathrm{ha} /$ year. This estimate was used for the base cases in Table 21-1. Example spreadsheet output is presented in Table 21-5.

\section{Table 21-5}

Example spreadsheet output for carbon equivalent emissions from changes in $\mathrm{N}_{2} \mathrm{O}$ emissions for wheat/fallow rotation when changing from intensive-till to no-till

\section{Cropland: Two-Year Wheat / Fallow Rotation Western Great Plains \\ Annual Changes in $\mathrm{N}_{2} \mathrm{O}$ Emissions}

Due to Tillage-Related Changes in Soil Properties \& Micro-Climate

Intensive-till wheat/fallow rotation No-till wheat/fallow rotation

Difference ( years 1- 100)

\begin{tabular}{|c|c|c|}
\hline $\begin{array}{c}\text { Annual } \\
\mathrm{kg} \mathrm{N} \mathrm{N}_{2} \mathrm{O}-\mathrm{N} / \mathrm{ha}\end{array}$ & $\mathrm{kg} \mathrm{N}_{2} \mathrm{O}$ CE/kg N${ }_{2} \mathrm{O}-\mathrm{N}$ & $\mathrm{kg} \mathrm{N} \mathrm{N}_{2} \mathrm{O} \mathrm{CE} / \mathrm{ha} / \mathrm{yr}$ \\
\hline $\begin{array}{l}4.80 \\
4.60 \\
\end{array}$ & & \\
\hline-0.20 & 126.4 & -25.3 \\
\hline
\end{tabular}

Associated with Changes in N Application Rate

Intensive-till wheat/fallow rotation No-till wheat/fallow rotation

Difference ( years 1- 100)

\begin{tabular}{ccc}
$\begin{array}{c}\text { Mean annual } \\
\text { N rate } \\
\mathrm{kg} \mathrm{N} / \mathrm{ha}\end{array}$ & $\begin{array}{c}\mathrm{IPCC} \text { emission factor } \\
\mathrm{kg} \mathrm{N} \mathrm{O} \text { CE } / \mathrm{kg} \mathrm{N} \text { applied }\end{array}$ & $\mathrm{kg} \mathrm{N}$ O CE/ha/yr \\
\hline 35.0 & & \\
35.0 & & 0.0
\end{tabular}

Total Difference ( years 1- 100 )

$-25.3$

\subsubsection{Summary of Avoided GHG Emissions}

Example spreadsheet output summarizing changes in GHG emissions is presented in Table 21-6. This output corresponds to the first column in Table 21-1. 


\section{Table 21-6}

Example spreadsheet output summarizing changes in GHG emissions for wheat/fallow rotation when changing from intensive-till to no-till

\section{Cropland: Two-Year Wheat / Fallow Rotation Western Great Plains \\ Life Cycle (LC) Avoided GHG Emissions \\ (Due to Switching from Intensive-Till to No-Till)}

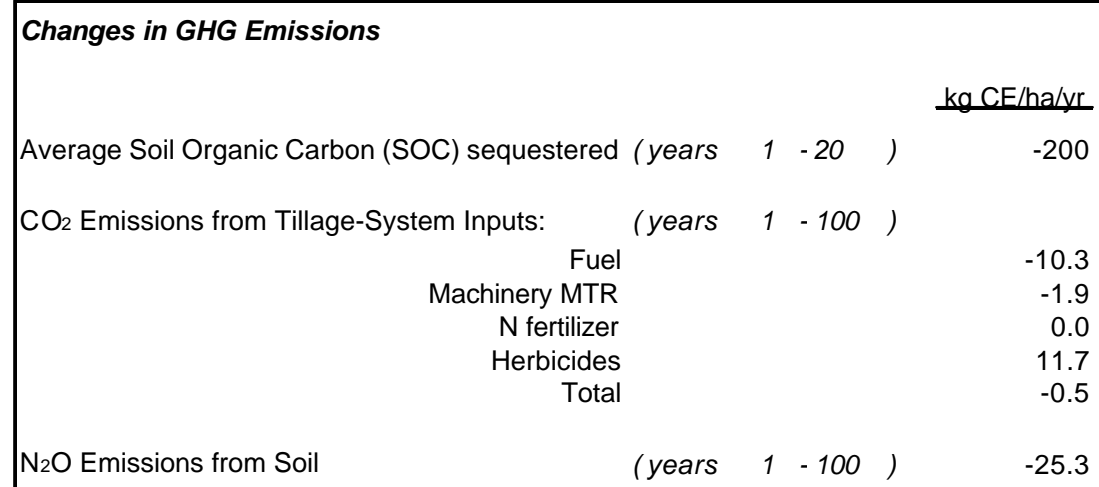

\subsubsection{Summary}

Example spreadsheet output summarizing costs and life-cycle (LC) avoided GHG on a carbon equivalent (CE) basis is presented in Table 21-7. This output corresponds to the first column in Table 21-1. 
Table 21-7

Example spreadsheet output summarizing costs and life-cycle (LC) avoided GHG on a carbon equivalent (CE) basis for wheat/fallow rotation when changing from intensive-till to no-till

\section{Cropland: Two-Year Wheat / Fallow Rotation} Western Great Plains

\section{cummary}

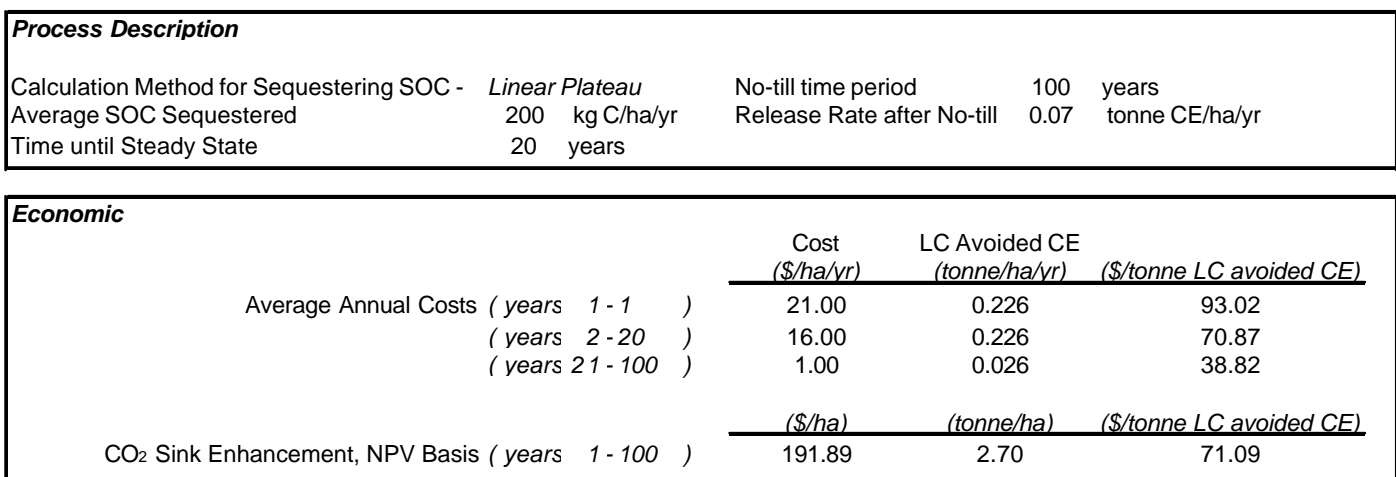
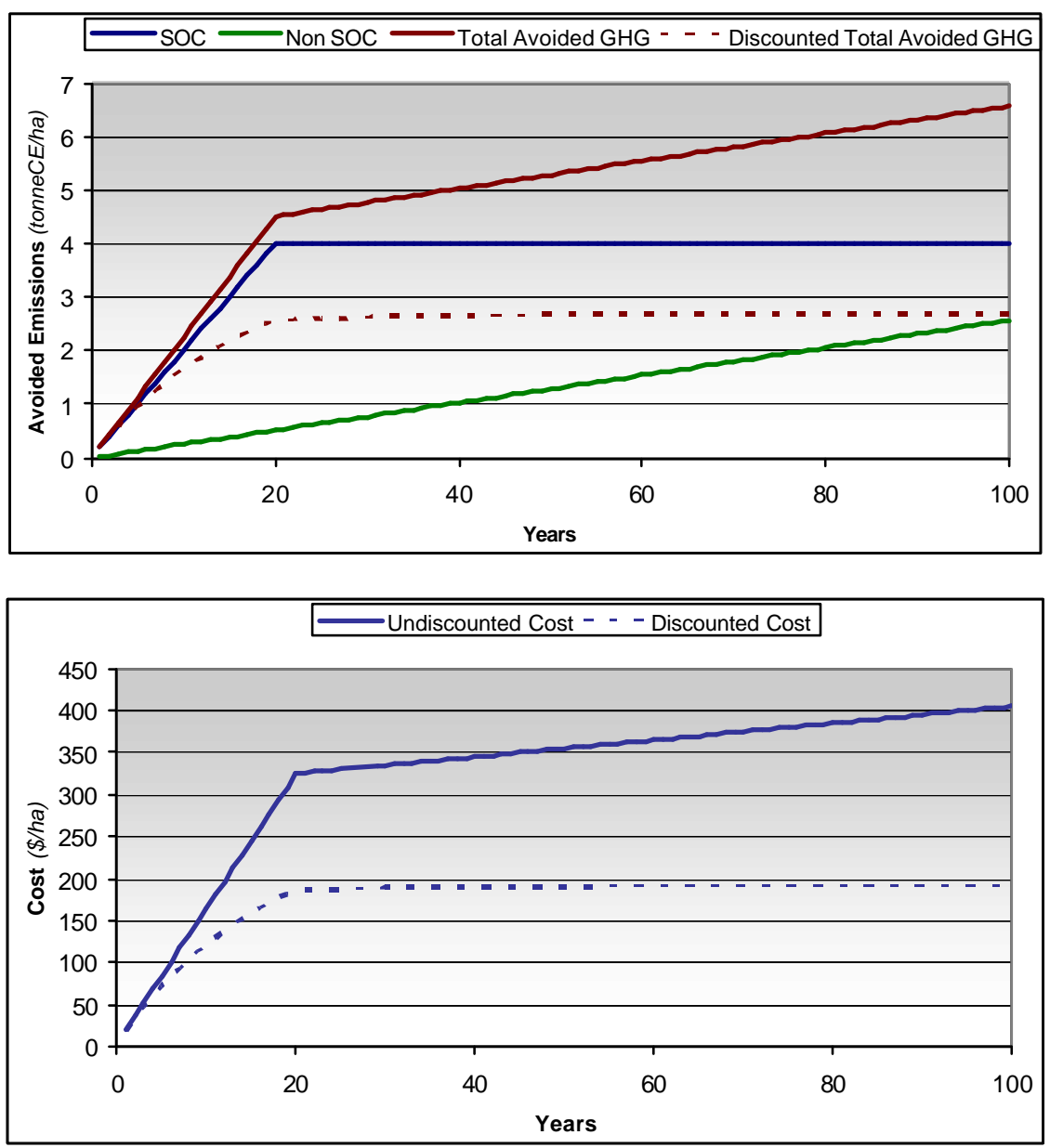


\subsubsection{Sensitivity Summary}

Example spreadsheet sensitivity summary output is presented in Table 21-8. This sensitivity output presents costs assuming adoption incentive payments for 5, 10, 15, and 20 years. These costs are presented assuming that no-till is maintained for the full 100-year planning horizon or for only as long as adoption incentives are paid to the farmer, after which the land is converted back to intensive-till. This analysis assumes that when no-till is switched back to intensive-till, SOC levels decrease at a rate of $70 \mathrm{~kg} / \mathrm{ha} / \mathrm{yr}$. A base case of incentive payments for 10 years was selected for comparing costs with other $\mathrm{CO}_{2}$ sink enhancement or storage options. 
Table 21-8

Wheat/fallow rotation sensitivity summary

\section{Cropland: Two-Year Wheat / Fallow Rotation \\ Western Great Plains \\ Sensitivity Summary}

\section{Current Input Variable Values}

Calculation Method for Sequestering $\mathrm{CO}_{2}$ SOC Sequestered until Steady State ( $\mathrm{kg} \mathrm{C} / \mathrm{ha} / \mathrm{yr})$

Time Until Steady State (years)

SOC Release Rate after no-till time period (tonne C/ha/yr)

Farmer Adoption Incentive to Reduce Tillage (\$/ha/yr)

Transaction Costs

Transaction Time Period (years)

Monitoring Costs

Monitoring Time Period (years)

After-Tax Discount Rate

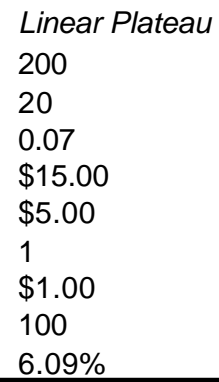

Sensitivity Input

Farmer Adoption Incentive Time Period Viewed

\begin{tabular}{|l|}
\hline 5 vears \\
10 years \\
15 vears \\
20 years \\
\hline
\end{tabular}

Push the adjacent button to update the sensitivity summary costs below.

$\mathrm{CO}_{2}$ Sink Enhancement Costs (100 year summation)

\begin{tabular}{ccc}
$\begin{array}{c}\text { No-till Time } \\
\text { Period } \\
\text { (years) }\end{array}$ & $\begin{array}{c}\text { Farmer Adoption Incentive } \\
\text { Time Period } \\
\text { (vears) }\end{array}$ & $\begin{array}{c}\text { NPV Basis } \\
\text { LC avoided basis } \\
\text { (\$/tonne C equivalent) }\end{array}$ \\
\hline 5 & 5 & 182.45 \\
10 & 10 & 115.36 \\
15 & 15 & 95.15 \\
20 & 20 & 86.04 \\
100 & 5 & 31.17 \\
100 & 10 & 48.54 \\
100 & 15 & 61.47 \\
100 & 20 & 71.09
\end{tabular}




\subsection{Wheat/Fallow (Sensitivity Cases with No Tillage Effect on $\mathrm{N}_{2} \mathrm{O}$ Emissions)}

These cases are the same as the western Great Plains wheat/fallow base cases in Section 21.2 except that no change in $\mathrm{N}_{2} \mathrm{O}$ emissions is assumed as a result of reducing tillage. These cases correspond to columns 3 and 4 of Table 21-1. Assuming no decrease in $\mathrm{N}_{2} \mathrm{O}$ emissions due to switching from intensive-till to no-till results in somewhat higher costs of $\mathrm{CO}_{2}$ abatement $\$ 84$ vs. \$71/tonne CE LC avoided in the $200 \mathrm{~kg}$ SOC/ha/year case and \$167 vs. \$123/tonne CE LC avoided in the $100 \mathrm{~kg} \mathrm{SOC} /$ ha/year case). The bases for the results in columns 3 and 4 in Table 21-1 are discussed in the following sections using output from the wheat/fallow spreadsheet model developed for this project.

\subsubsection{Summary of Avoided GHG Emissions}

Example spreadsheet output summarizing changes in GHG emissions due to switching from intensive-till to no-till wheat/fallow systems with no change in $\mathrm{N}_{2} \mathrm{O}$ emissions is presented in Table 21-9. These results correspond to the third column in Table 21-1.

Table 21-9

Wheat/fallow example spreadsheet output summarizing changes in GHG emissions due to switching from intensive-till to no-till with no change in $\mathrm{N}_{2} \mathrm{O}$ emissions

\section{Cropland: Two-Year Wheat / Fallow Rotation Western Great Plains \\ Life Cycle (LC) Avoided GHG Emissions \\ (Due to Switching from Intensive-Till to No-Till)}

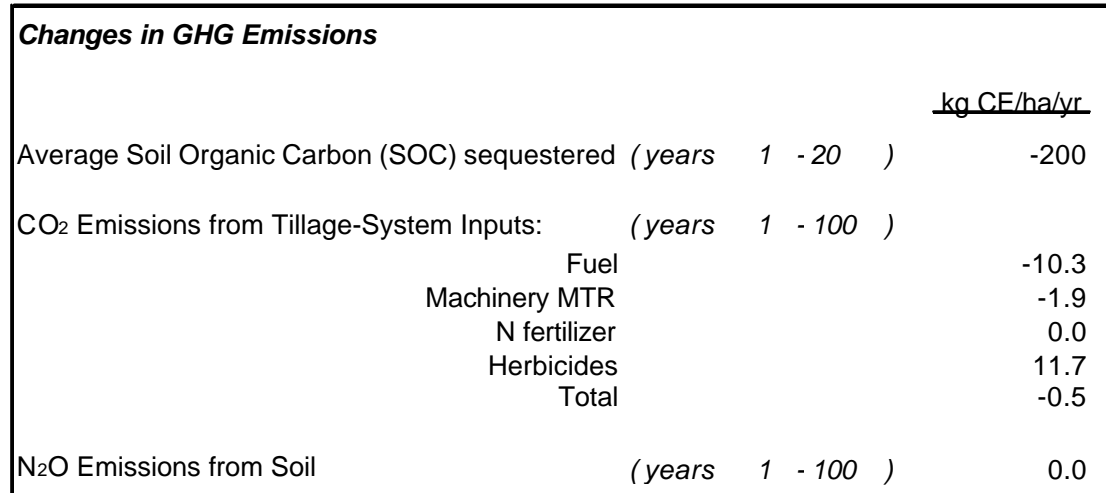

Avoided GHG Emissions

\begin{tabular}{ccccc} 
& & \multicolumn{2}{c}{ Annual Average } \\
& & & $\mathrm{kg} \mathrm{CE} / \mathrm{ha} / \mathrm{vr} \quad$ tonne CE/ha/yr \\
\cline { 3 - 4 } (years & $1-20$ & & \\
(years & $21-100)$ & 200.5 & $\mathbf{0 . 2 0 0}$ \\
& & 0.5 & $\mathbf{0 . 0 0 0}$
\end{tabular}




\subsubsection{Summary}

Example spreadsheet output summarizing costs and life-cycle (LC) avoided GHG on a carbon equivalent (CE) basis is presented in Table 21-10. This output corresponds to the third column in Table 21-1.

\subsubsection{Sensitivity Summary}

Example spreadsheet sensitivity summary output is presented in Table 21-11. This output corresponds to the third column in Table 21-1 and presents costs assuming adoption incentive payments for 5, 10, 15, and 20 years. These costs are presented assuming that no-till is maintained for the full 100-year planning horizon or for only as long as adoption incentives are paid to the farmer, after which the land is converted back to intensive-till. This analysis assumes that when no-till is switched back to intensive-till, SOC levels decrease at a rate of $70 \mathrm{~kg} / \mathrm{ha} / \mathrm{yr}$. A base case of incentive payments for 10 years was selected for comparing costs with other $\mathrm{CO}_{2}$ sink enhancement or storage options. 
Table 21-10

Wheat/fallow costs and life-cycle (LC) avoided GHG on a carbon equivalent (CE) basis when changing from intensive-till to no-till with no change in $\mathrm{N}_{2} \mathrm{O}$ emissions

\section{Cropland: Two-Year Wheat / Fallow Rotation} Western Great Plains

\section{Summary}

\begin{tabular}{|lcllll|}
\hline Process Description & & & & \\
& & & & \\
& & & & \\
Calculation Method for Sequestering SOC - - & Linear Plateau & No-time period & 100 & years \\
Average SOC Sequestered & $200 \quad \mathrm{~kg} \mathrm{C} / \mathrm{ha} / \mathrm{yr}$ & Release Rate after No-till & 0.07 & tonne CE/ha/yr \\
Time until Steady State & $20 \quad$ years & & & \\
\hline
\end{tabular}

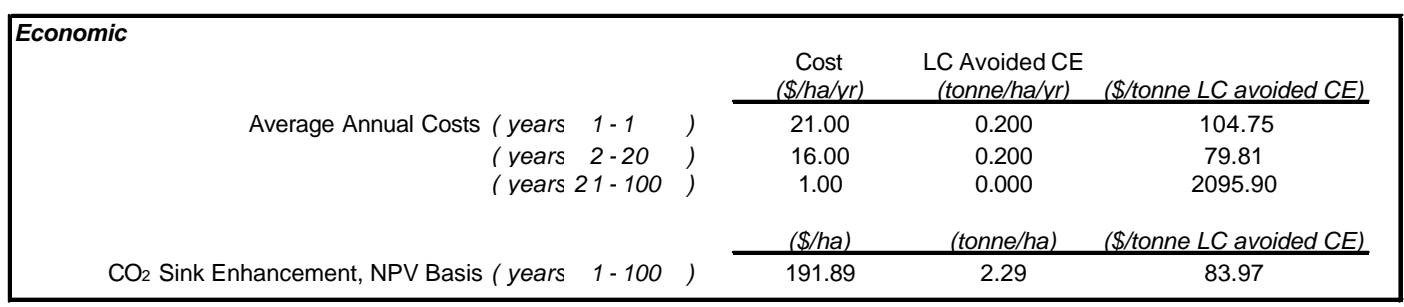
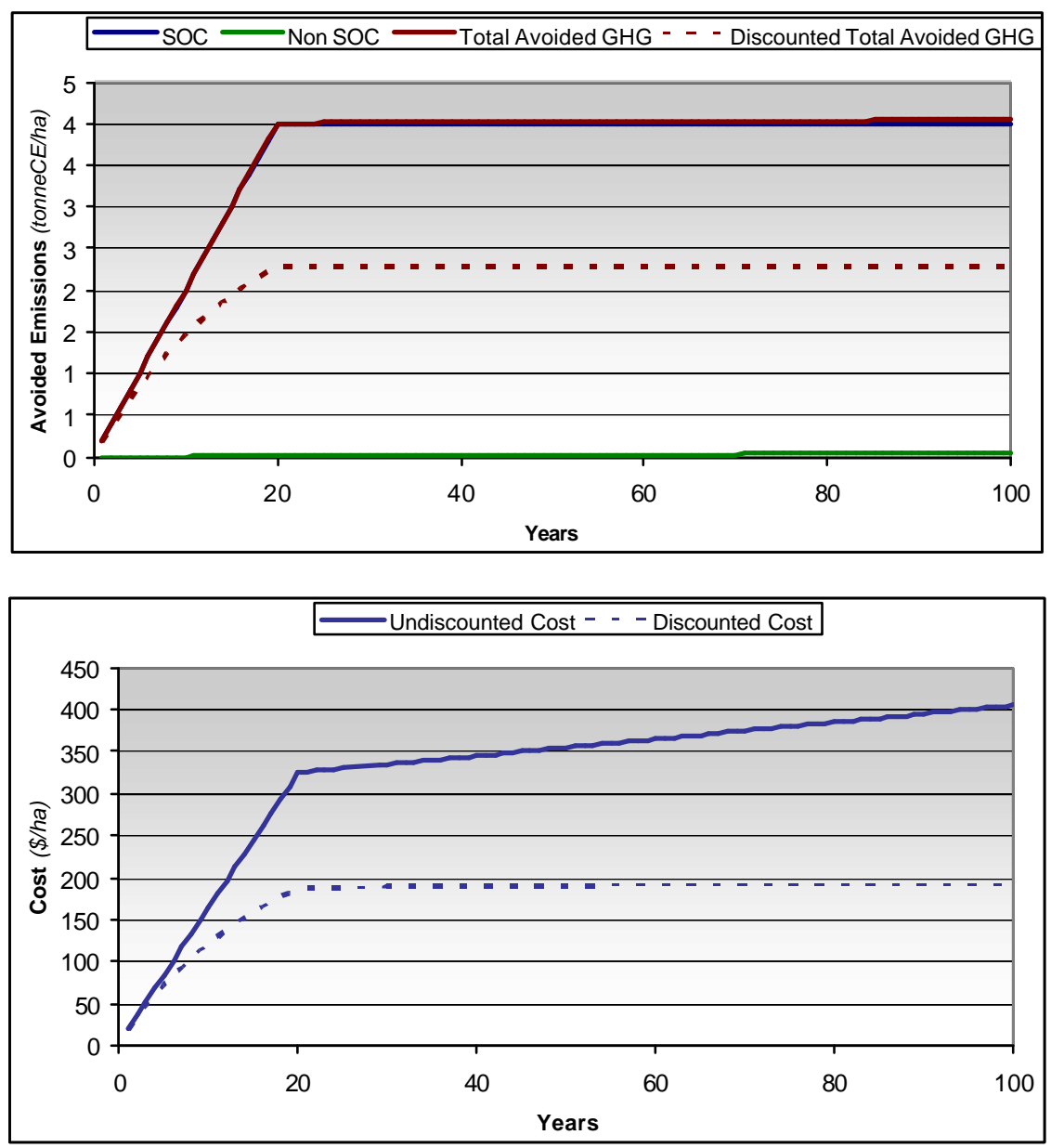
Table 21-11

Wheat/fallow example spreadsheet sensitivity summary output when changing from intensive-till to no-till with no change in $\mathrm{N}_{2} \mathrm{O}$ emissions

\section{Cropland: Two-Year Wheat / Fallow Rotation \\ Western Great Plains Sensitivity Summary}

\begin{tabular}{|rl|}
\hline Current Input Variable Values & \\
Calculation Method for Sequestering CO 2 & Linear Plateau \\
SOC Sequestered until Steady State $(\mathrm{kg} \mathrm{C} / \mathrm{ha} / \mathrm{yr})$ & 200 \\
Time Until Steady State (years) & 20 \\
SOC Release Rate after no-till time period (tonne C/ha/yr) & 0.07 \\
Farmer Adoption Incentive to Reduce Tillage (\$/ha/yr) & $\$ 15.00$ \\
Transaction Costs & $\$ 5.00$ \\
Transaction Time Period (years) & 1 \\
Monitoring Costs & $\$ 1.00$ \\
Monitoring Time Period (years) & 100 \\
After-Tax Discount Rate & $6.09 \%$ \\
\hline
\end{tabular}

Sensitivity Input

Farmer Adoption Incentive Time Period Viewed

5 vears 10 years

15 years

20 years

Push the adjacent button to update the sensitivity summary costs below.

Update

Values

$\mathrm{CO}_{2}$ Sink Enhancement Costs (100 year summation)

\begin{tabular}{ccc}
$\begin{array}{c}\text { No-till Time } \\
\text { Period } \\
\text { (years) }\end{array}$ & $\begin{array}{c}\text { Farmer Adoption Incentive } \\
\text { Time Period } \\
\text { (years) }\end{array}$ & $\begin{array}{c}\text { NPV Basis } \\
\text { LC avoided basis } \\
\text { (\$/tonne C equivalent) }\end{array}$ \\
\hline 5 & 5 & 182.45 \\
10 & 10 & 115.36 \\
15 & 15 & 95.15 \\
20 & 20 & 86.04 \\
100 & 5 & 31.17 \\
100 & 10 & 48.54 \\
100 & 15 & 61.47 \\
100 & 20 & 71.09
\end{tabular}




\subsection{References}

1 Brenner, J.K., K. Paustian, G. Bluhm, J. Cipra, M.Easter, R. Foulk, K. Killian, R. Moore, J. Schuler, P. Smith, and S. Williams. 2002. Quantifying the change in greenhouse gas emissions due to natural resource conservation practice application in Nebraska. Colorado State University Natural Resource Ecology Laboratory and USDA Natural Resources Conservation Service, Fort Collins, CO, USA.

2 Brenner, J., K. Paustian, G. Bluhm, J. Cipra, M. Easter, E.T. Elliott, T. Kautza, K. Killian, J. Schuler and S. Williams. 2001. Quantifying the change in greenhouse gas emissions due to natural resource conservation practice application in Iowa. Final report to the Iowa Conservation Partnership. Colorado State University Natural Resource Ecology Laboratory and USDA Natural Resources Conservation Service, Fort Collins, CO, USA.

3 Smith, P., J. Brenner, K. Paustian, G. Bluhm, J. Cipra, M. Easter, E.T. Elliott, K. Killian, D. Lamm, J. Schuler and S. Williams. 2002. Quantifying the change in greenhouse gas emissions due to natural resource conservation practice application in Indiana. Final report to the Indiana Conservation Partnership. Colorado State University Natural Resource Ecology Laboratory and USDA Natural Resources Conservation Service, Fort Collins, CO, USA.

4 Eve, M.D., M. Sperow, K. Howerton, K. Paustian, and R.F. Follett. 2002. Predicted impact of management changes on soil carbon storage for each cropland region of the conterminous United States. J. Soil and Water Conservation. 57 (4) 196-204.

5 West, Tristram O. and Wlfred M. Post. 2002. Soil organic carbon sequestration rates for crops with reduced tillage and enhanced rotation. Submitted to Soil Science Society of America Journal.

6 Del Grosso, S.J. W.J. Parton, A.R. Mosier, M.D. Hartman, J. Brenner, D.S. Ojima, and D.S. Schimel. 2001. Simulated interaction of carbon dynamics and nitrogen trace gas fluxes using the DAYCENT . P. 303-332. In M.J. Shaffer, Liwang Ma, and S. Hansen (eds.) Modeling carbon and nitrogen dynamics for soil management. Lewis Publishers. Washington, D.C.

7 Langemeier, L.N. and R.K. Taylor. 1998. A look at machinery cost. Kansas Farm Management Guide, MF-842. Kansas State University, Department of Agricultural Economics.

8 West, Tristram O. and Gregg Marland. 2002. A synthesis of carbon sequestration, carbon emissions, and net carbon flux in agriculture: comparing tillage practices in the United States. Agriculture, Ecosystems, and Environment (in press) 
9 Peterson, G.A., D.G Westfall, N.E. Toman, and R.L. Anderson. 1993. Sustainable dryland cropping systems: economic analysis. Technical BulletinTB93-3. Colorado State University.

10 Mummey, Daniel L., Jeffrey L. Smith, and George Blum. 1998. Assessment of alternative soil management practices on $\mathrm{N} 2 \mathrm{O}$ emissions from U.S. agriculture. Agriculture, Ecosystems, and Environment 70:79-87. 


\section{2 \\ COTTON IN THE SOUTHEASTERN UNITED STATES}

\subsection{Introduction}

Cotton is grown primarily in the southeastern United States. Switching from intensive-till to notill cotton results in somewhat greater increases in SOC than in wheat/fallow systems, primarily because with cotton there is no fallow period and cotton residues are added to the soil each year. However, primarily because of the warmer more humid climate in the southeast, switching from intensive-till to no-till cotton results in significant increases in $\mathrm{N}_{2} \mathrm{O}$ emissions in contrast to the slight decreases in $\mathrm{N}_{2} \mathrm{O}$ emissions for wheat/fallow. A larger adoption incentive is required to get farmers to switch from intensive-till to no-till cotton than is the case for wheat/fallow. The net effect of the above factors is that $\mathrm{CO}_{2}$ abatement costs per tonne CE LC avoided are significantly greater for cotton than for wheat/fallow. The base cases (Section 22.2) assume typical levels of carbon sequestration and a large increase in $\mathrm{N}_{2} \mathrm{O}$ emissions due to reducing tillage and the sensitivity cases (Section 22.3) assume typical levels of carbon sequestration and no change in $\mathrm{N}_{2} \mathrm{O}$ emissions due to reducing tillage.

\subsection{Cotton (Base Cases)}

A summary of effects of switching from intensive-till to no-till on SOC, GHG emissions, and costs of avoided GHG emissions is presented in Table 22-1 for cotton in the southeast. The bases for the results in Table 22-1 are discussed in the following sections using output from the cotton spreadsheet model developed for this project. Base cases assuming an increase in $\mathrm{N}_{2} \mathrm{O}$ emissions due to reducing tillage are presented in the first two columns of Table 22-1.

\subsubsection{Increases in Soil Organic Carbon}

A summary of cotton studies in the southeastern U.S. indicated that switching from intensive-till to no-till resulted in an average increase in SOC of about $300 \mathrm{~kg} / \mathrm{ha} / \mathrm{year}$ for the first 10 to 15 years after switching from intensive-till to no-till ${ }^{1}$. Using IPPC coefficients for the southeastern U.S., switching from intensive-till to no-till resulted in an estimated weighted-mean increase in SOC of $200 \mathrm{~kg} \mathrm{C} / \mathrm{ha} /$ year for the first 20 years after switching from intensive-till to no-till ${ }^{2}$. Cotton is a significant component of the cropping systems in the southeastern U.S. Using IPPC coefficients for the Mississippi Delta region of the United States which also includes a significant land area in cotton, switching from intensive-till to no-till resulted in an estimated weighted-mean increase in SOC of $520 \mathrm{~kg} \mathrm{C} / \mathrm{ha} /$ year for the first 20 years after switching from intensive-till to no-till ${ }^{2}$. Because of the variation in regional estimates of effects of reducing tillage on SOC levels, results are presented in Table 22-1 assuming increases of both 300 and 
$150 \mathrm{~kg} \mathrm{C} / \mathrm{ha} /$ year for a 20 -year period due to switching from intensive-till to no-till in cotton systems; an increase of $300 \mathrm{~kg} \mathrm{C} / \mathrm{ha} /$ year was chosen as the base case for cost comparisons with other $\mathrm{CO}_{2}$ sink enhancement or storage options.

Table 22-1

Effects of switching from intensive-till to no-till on SOC, GHG emissions, and costs of lifecycle (LC) avoided GHG emissions-Cotton in the southeastern United States

\begin{tabular}{lcrrr}
\hline Linear SOC response curve & \multicolumn{2}{c}{ Base-case $\Delta \mathrm{N}_{2} \mathrm{O}$} & \multicolumn{2}{c}{ Zero $\Delta \mathrm{N}_{2} \mathrm{O}$} \\
$\mathrm{kg} \mathrm{C} / \mathrm{ha} / \mathrm{yr}$ & 300 & 150 & 300 & 150 \\
Years to new steady state $(\mathrm{Ys})$ & 20 & 20 & 20 & 20
\end{tabular}

GHG emissions from tillage-system inputs and $\mathrm{N}_{2} \mathrm{O}$ (years 1-100), $\mathrm{kg} \mathrm{CE} / \mathrm{ha} / \mathrm{y}$ :

\begin{tabular}{|c|c|c|c|c|}
\hline$\Delta$ Fuel use & -23.8 & -23.8 & -23.8 & -23.8 \\
\hline$\Delta$ Machinery maint., trans., and repair & -4.3 & -4.3 & -4.3 & -4.3 \\
\hline$\Delta \mathrm{N}$ fertilizer use & 0.0 & 0.0 & 0.0 & 0.0 \\
\hline$\Delta$ Herbicide use & 0.0 & 0.0 & 0.0 & 0.0 \\
\hline$\Delta$ Total GHG emissions from inputs & -28.1 & -28.1 & -28.1 & -28.1 \\
\hline$\Delta \mathrm{N}_{2} \mathrm{O}$ emissions from soil & 63.2 & 63.2 & 0 & 0 \\
\hline$\Delta$ Total GHG emissions & 35.1 & 35.1 & -28.1 & -28.1 \\
\hline \multicolumn{5}{|l|}{ Average LC GHG avoided (kg CE/ha/y) } \\
\hline Years 1 to $\mathrm{Ys}$ & 265 & 115 & 328 & 178 \\
\hline Years Ys to 100 & -35.1 & -35.1 & 28.1 & 28.1 \\
\hline \multicolumn{5}{|l|}{ Total LC GHG avoided (years 1-100), } \\
\hline tonne CE/ha & 1.0 & -1.3 & 7.3 & 5.1 \\
\hline $\begin{array}{l}\text { NPV Total LC GHG avoided (years 1-100), } \\
\text { tonne CE/ha }\end{array}$ & 2.3 & 0.9 & 3.4 & 1.9 \\
\hline \multicolumn{5}{|l|}{ Costs, $\$ / h a / y$} \\
\hline Transaction (year 1) & 5 & 5 & 5 & 5 \\
\hline Adoption incentive (years 1-20) & 25 & 25 & 25 & 15 \\
\hline Monitoring (years 1-100) & 1 & 1 & 1 & 1 \\
\hline Total costs (years 1-100), \$/ha & 605 & 605 & 605 & 605 \\
\hline NPV Total costs (years $1-100$ ), \$/ha & 306 & 306 & 306 & 306 \\
\hline $\begin{array}{l}\text { Cost (NPV basis), \$/tonne CE LC GHG } \\
\text { avoided }\end{array}$ & 132 & 350 & 91 & 160 \\
\hline
\end{tabular}


Example spreadsheet inputs for calculating base-case increases in SOC due to switching from intensive-till to no-till in cotton in the southeastern U.S. (first column of Table 22-1) are presented in Table 22-2.

Table 22-2

Example process and economic input variables for switching from intensive-till to no-till for cotton

Cropland: Cotton

(Changes Due to Switching from Intensive-Till to No-Till) Southeastern United States Process and Economic Input Variables

\begin{tabular}{|c|c|}
\hline Process & \\
\hline Alternative Tillage System: & No-till \\
\hline Calculation Method for Sequestering Soil Or & Jarbon (SOC) \\
\hline $\begin{array}{ll}\text { Quadratic Plateau } & \bigcirc \\
\text { Linear Plateau } & \bigcirc\end{array}$ & \\
\hline SOC Sequestered until Steady State & $300 \mathrm{~kg} \mathrm{C} / \mathrm{ha} / \mathrm{yr}$ \\
\hline Years until New Steady State & 15 years \\
\hline No-till time period & 100 years \\
\hline SOC Release Rate after no-till time period & $100 \mathrm{~kg} \mathrm{C} / \mathrm{ha} / \mathrm{yr}$ \\
\hline
\end{tabular}

\begin{tabular}{|c|c|c|}
\hline \multicolumn{3}{|l|}{ Economic } \\
\hline & & Cost \\
\hline & & $\$ /$ ha/yr \\
\hline Transaction Costs & (years 1$]$ & 5.00 \\
\hline Farmer Adoption Incentive to Reduce Tillage & (years $1-20$ & 25.00 \\
\hline Monitoring Costs & (years $1-100$ & 1.00 \\
\hline Discount rate & & \\
\hline
\end{tabular}

\subsubsection{Costs}

A theoretical basis for estimating conservation-tillage adoption incentives is overviewed in Appendix $\mathrm{E}$ and an adoption incentive of $\$ 25 / \mathrm{ha} /$ year is estimated for switching from intensivetill to no-till cotton in the southeastern U.S. Transaction costs are based on experience with forestry projects and are estimated at $\$ 5 / \mathrm{ha}$. Monitoring costs are assumed to be less than for forestry $(\$ 5 / \mathrm{ha})$, assuming that cropland monitoring will be based mainly on monitoring practices that have been correlated with changes in SOC rather than direct measurements of SOC in each field. Monitoring costs of $\$ 1 /$ ha/year were assumed. 


\subsubsection{GHG Effects in Addition to Carbon Storage in Soil Organic Matter}

\subsubsection{Fuel Use}

Reductions in fuel use and associated carbon emissions by switching from intensive-till to no-till in cotton are presented in Table 22-3. Fuel usage rates are from Langemeier and Taylor ${ }^{3}$.

Table 22-3

Reductions in fuel use and associated carbon emissions by switching from intensive-till to no-till for cotton

\section{Cropland: Cotton}

Southeastern United States

Fuel Use for tillage, planting, and herbicide operations

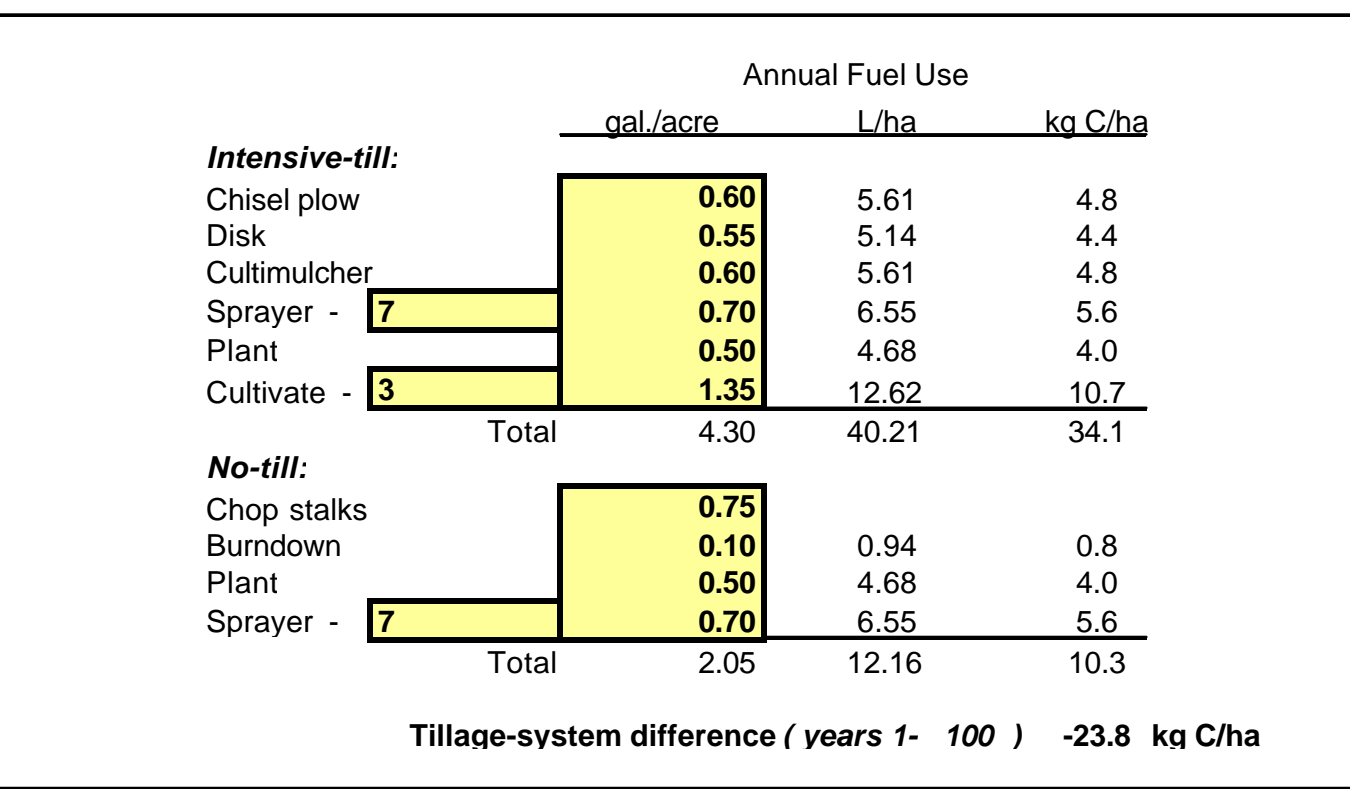

Energy Savings Embodied in Machinery Manufacturing, Transportation, \& Repair (MTR)

Annual fuel saving from reducing tillage

Annual machinery MTR savings

Annual machinery MTR saving from reducing tillage (years 1- 100 )
$-23.8 \mathrm{~kg} \mathrm{C} / \mathrm{ha}$

$18 \%$ of fuel savings 


\subsubsection{Machinery Manufacture, Transportation, and Repair}

Reductions in machinery manufacture, transportation, and repair (MTR) and associated carbon emissions by switching from intensive-till to no-till cotton were calculated as 18 percent of the fuel savings (Tables 22-3). The 18 percent factor is based on ratios of tillage-system fuel use and machinery MTR in a national analysis of tillage-system effects on GHG emissions ${ }^{4}$.

\subsubsection{N Fertilizer Use}

$\mathrm{N}$ rate recommendations for cotton generally are not adjusted for tillage system in the southeastern U.S. Switching from intensive-till to no-till cotton is assumed to have no effect on the amount of $\mathrm{N}$ fertilizer required.

\subsubsection{Herbicide Use}

With the advent of herbicide resistant cotton, herbicide use doesn't differ significantly with intensive-till and no-till cotton. Intensive-till and no-till cotton were assumed to involve the same herbicide usage as presented in Table 22-4.

Table 22-4

Example spreadsheet output for estimating herbicide carbon equivalent emissions for cotton

\section{Cropland: Cotton}

Southeastern United States

Annual Herbicide Use X Tillage System

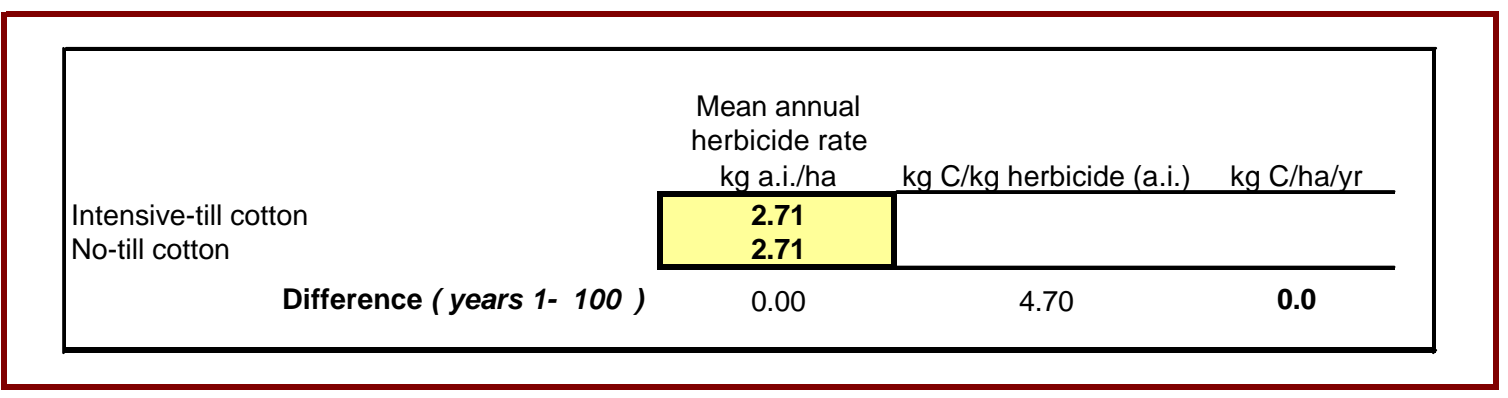

\subsubsection{5 $\mathrm{N}_{2} \mathrm{O}$ Emissions from Soil}

Background on $\mathrm{N}_{2} \mathrm{O}$ emissions from soil was provided earlier, indicating that $\mathrm{N}_{2} \mathrm{O}$ emissions are dependent on both soil conditions and amount of $\mathrm{N}$ fertilizer applied. In cotton, the amount of $\mathrm{N}$ fertilizer applied does not change with tillage system, but soil conditions do change as discussed Chapter 18. The relatively warm, humid climate in the southeastern U.S. is relatively conducive to $\mathrm{N}_{2} \mathrm{O}$ emissions. Mummey et al. ${ }^{5}$ modeled $\mathrm{N}_{2} \mathrm{O}$ emissions for intensive-till and notill cotton at 160 sites. These sites represented the range of soil and environmental conditions for cotton in the United States. This modeling effort estimated mean $\mathrm{N}_{2} \mathrm{O}-\mathrm{N}$ emissions of 
$6.5 \mathrm{~kg} / \mathrm{ha} /$ year for intensive-till and $7.0 \mathrm{~kg} / \mathrm{ha} /$ year for no-till. Taking the difference $(0.5 \mathrm{~kg}$ $\mathrm{N}_{2} \mathrm{O}-\mathrm{N} /$ ha/year) times $126.4 \mathrm{~kg} \mathrm{~N} \mathrm{~N}_{2} \mathrm{O} \mathrm{CE} / \mathrm{kg} \mathrm{N}_{2} \mathrm{O}-\mathrm{N}$ gives $63.2 \mathrm{~kg} \mathrm{~N}_{2} \mathrm{O} \mathrm{CE} /$ ha/year. This estimate was used for the base cases in Table 22-1. Example spreadsheet output is presented in Table 22-5.

Table 22-5

Example spreadsheet output for carbon equivalent emissions from changes in $\mathrm{N}_{2} \mathrm{O}$ emissions for cotton when changing from intensive-till to no-till

Cropland: Cotton

Southeastern United States Annual Changes in $\mathrm{N}_{2} \mathrm{O}$ Emissions
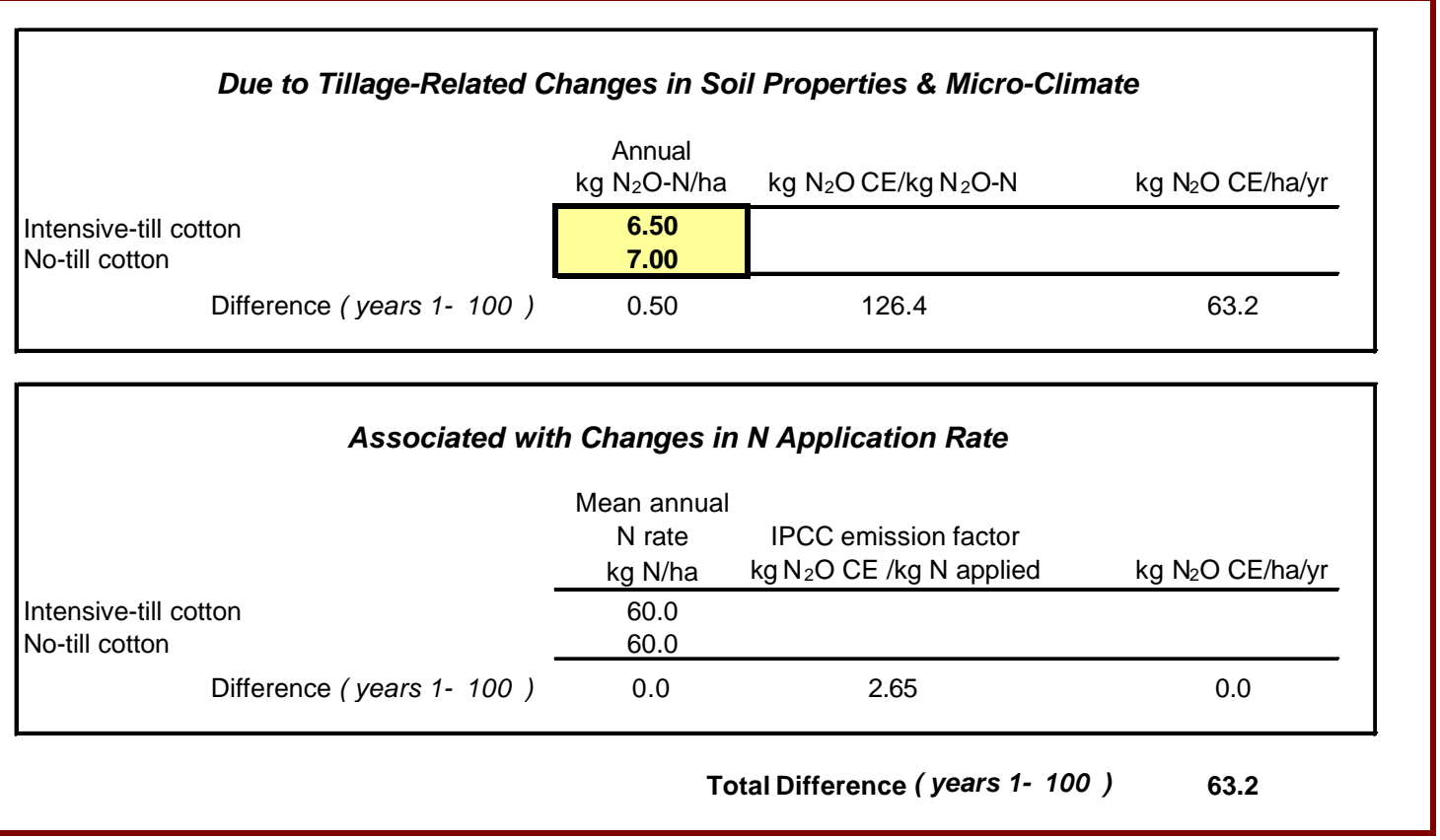

\subsubsection{Summary of Avoided GHG Emissions}

Example spreadsheet output summarizing changes in GHG emissions is presented in Table 22-6. This output corresponds to the first column in Table 22-1. 


\section{Table 22-6}

Example spreadsheet output summarizing changes in GHG emissions for cotton when changing from intensive-till to no-till

\section{Cropland: Cotton}

Southeastern United States

Life Cycle (LC) Avoided GHG Emissions

(Due to Switching from Intensive-Till to No-Till)

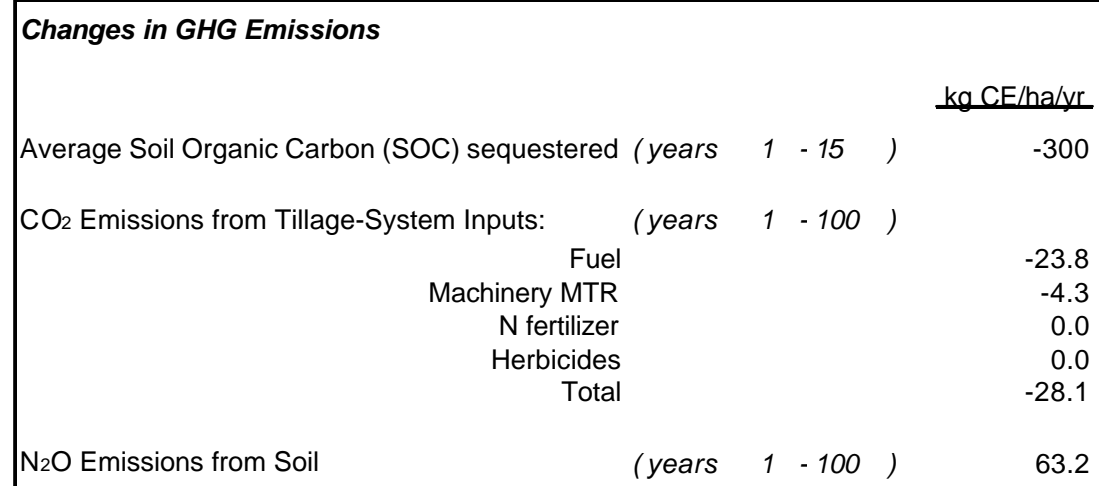

Avoided GHG Emissions

(years $1-100$ )

\begin{tabular}{cccr} 
& & \multicolumn{2}{c}{ Annual Average } \\
& & $\mathrm{kg} \mathrm{CE} / \mathrm{ha} / \mathrm{yr} \quad$ tonne CE/ha/yr \\
\cline { 3 - 3 } (years & $1-15$ & & \\
(years & $16-100)$ & 264.9 & 0.265 \\
& & -35.1 & -0.035
\end{tabular}

\subsubsection{Summary}

Example spreadsheet output summarizing costs and life-cycle (LC) avoided GHG on a carbon equivalent (CE) basis is presented in Table 22-7. This output corresponds to the first column in Table 22-1. 
Table 22-7

Example spreadsheet output summarizing costs and life-cycle (LC) avoided GHG on a carbon equivalent (CE) basis for cotton when changing from intensive-till to no-till

Cropland: Cotton

Southeastern United States

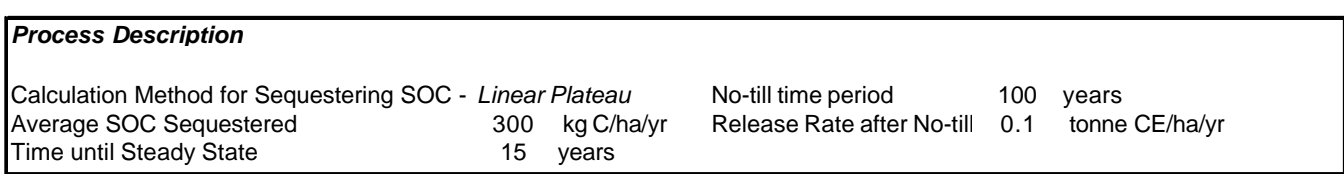

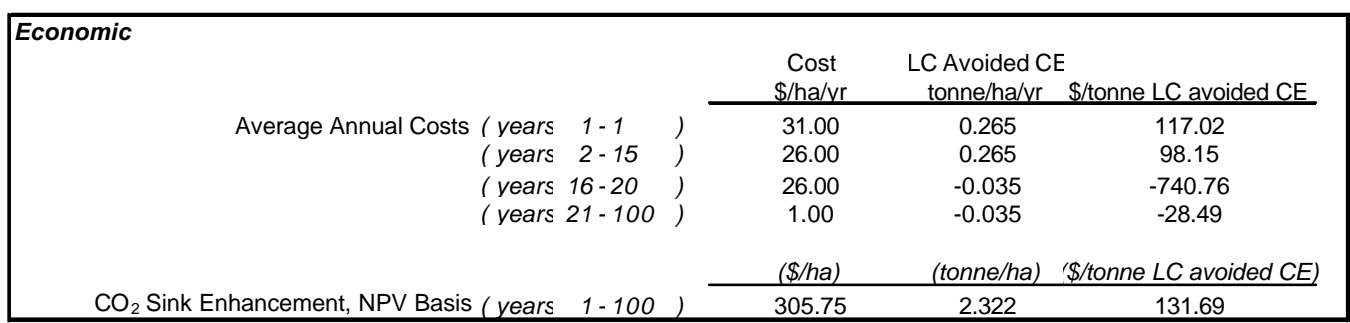
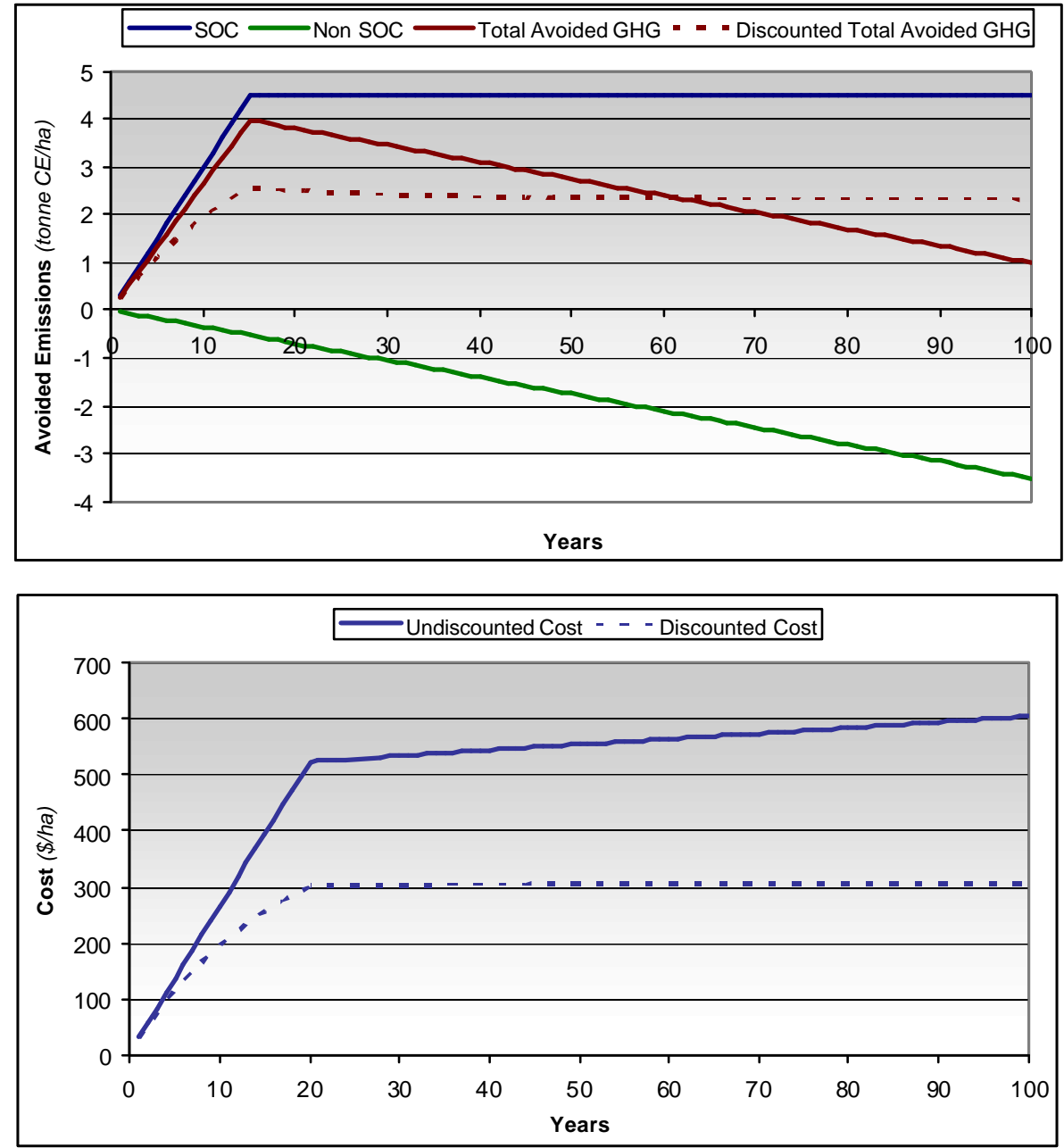


\subsubsection{Sensitivity Summary}

Example spreadsheet sensitivity summary output is presented in Table 22-8. This sensitivity output presents costs assuming adoption incentive payments for 5, 10, 15, and 20 years. These costs are presented assuming that no-till is maintained for the full 100-year planning horizon or for only as long as adoption incentives are paid to the farmer, after which the land is converted back to intensive-till. This analysis assumes that when no-till cotton is switched back to intensive-till, SOC levels decrease at a rate of $70 \mathrm{~kg} / \mathrm{ha} / \mathrm{yr}$. A base case of incentive payments for 10 years was selected for comparing costs with other $\mathrm{CO}_{2}$ sink enhancement or storage options. 
Table 22-8

Cotton rotation sensitivity summary

\section{Cropland: Cotton \\ Southeastern United States \\ Sensitivity Summary}

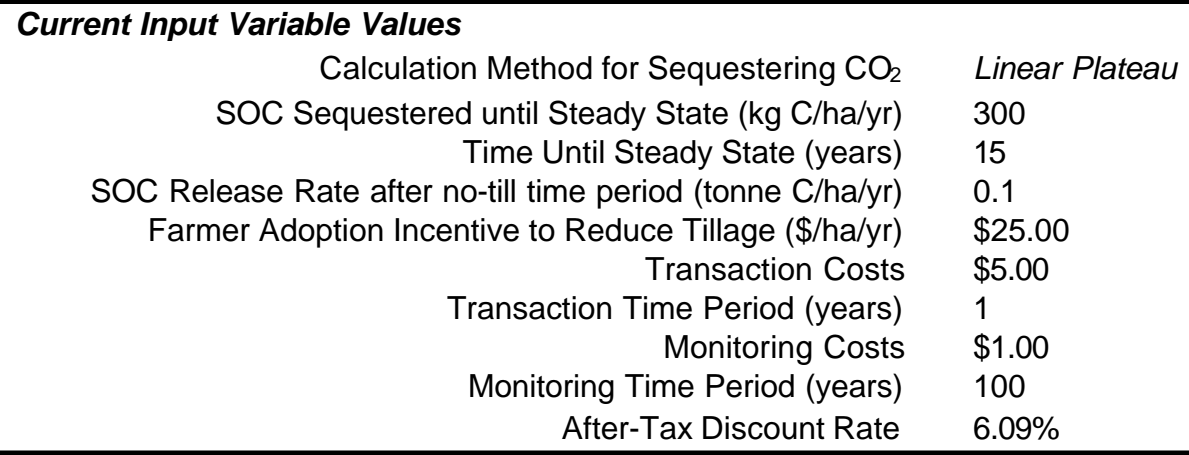

\section{Sensitivity Input}

Farmer Adoption Incentive Time Period Viewed

Push the adjacent button to update the sensitivity summary costs below.

$\mathrm{CO}_{2}$ Sink Enhancement Costs (years 1-100)

\begin{tabular}{ccc}
$\begin{array}{c}\text { No-till Time } \\
\text { Period } \\
\text { (years) }\end{array}$ & $\begin{array}{c}\text { Farmer Adoption Incentive } \\
\text { Time Period } \\
\text { (years) }\end{array}$ & $\begin{array}{c}\text { NPV Basis } \\
\text { LC avoided GHG basis } \\
\text { (\$/tonne C equivalent) }\end{array}$ \\
\hline 5 & 5 & 234.84 \\
10 & 10 & 172.19 \\
15 & 15 & 135.16 \\
20 & 20 & 149.97 \\
100 & 5 & 54.33 \\
100 & 10 & 87.99 \\
100 & 15 & 113.05 \\
100 & 20 & 131.69
\end{tabular}




\subsection{Cotton (Sensitivity Cases with No Tillage Effect on $\mathrm{N}_{2} \mathrm{O}$ Emissions)}

These cases are the same as the cotton base cases in Section 22.2 except that no change in $\mathrm{N}_{2} \mathrm{O}$ emissions is assumed as a result of reducing tillage. These cases correspond to columns 3 and 4 of Table 22-1. Assuming no increase in $\mathrm{N}_{2} \mathrm{O}$ emissions due to switching from intensive-till to no-till results in significantly lower costs of $\mathrm{CO}_{2}$ abatement (\$132 vs. \$91/tonne CE LC avoided in the $300 \mathrm{~kg} \mathrm{SOC} / \mathrm{ha} /$ year case and $\$ 350$ vs. \$160/tonne CE LC avoided in the $150 \mathrm{~kg}$ $\mathrm{SOC} / \mathrm{ha} / \mathrm{year}$ case). The bases for the results in columns 3 and 4 in Table 22-1 are discussed in the following sections using output from the cotton spreadsheet model developed for this project.

\subsubsection{Summary of Avoided GHG Emissions}

Example spreadsheet output summarizing changes in GHG emissions due to switching from intensive-till to no-till cotton with no change in $\mathrm{N}_{2} \mathrm{O}$ emissions is presented in Table 22-9. These results correspond to the third column in Table 22-1.

Table 22-9

Cotton example spreadsheet output summarizing changes in GHG emissions due to switching from intensive-till to no-till with no change in $\mathrm{N}_{2} \mathrm{O}$ emissions

Cropland: Cotton

Southeastern United States

Life Cycle (LC) Avoided GHG Emissions

(Due to Switching from Intensive-Till to No-Till)

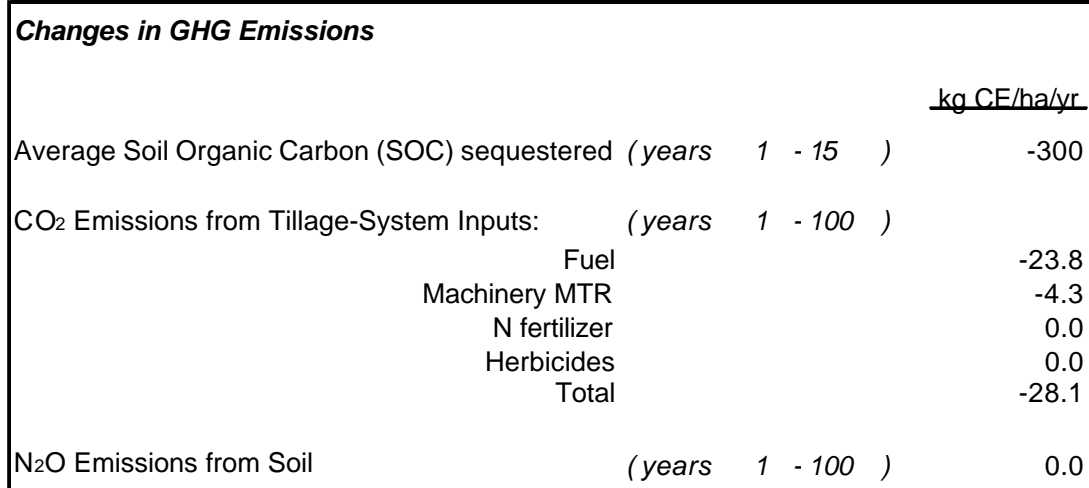

Avoided GHG Emissions

\begin{tabular}{ccrr} 
& & \multicolumn{2}{c}{ Annual Average } \\
& & $\mathrm{kg} \mathrm{CE} / \mathrm{ha} / \mathrm{yr} \quad$ tonne CE/ha/yr \\
\cline { 3 - 3 } (years & $1-15$ & & \\
(years & $16-100)$ & 328.1 & $\mathbf{0 . 3 2 8}$ \\
& & 28.1 & $\mathbf{0 . 0 2 8}$
\end{tabular}




\subsubsection{Summary}

Example spreadsheet output summarizing costs and life-cycle (LC) avoided GHG on a carbon equivalent (CE) basis is presented in Table 22-10. This output corresponds to the third column in Table 22-1.

\subsubsection{Sensitivity Summary}

Example spreadsheet sensitivity summary output is presented in Table 22-11. This sensitivity output corresponds to the third column in Table 22-1 and presents costs assuming adoption incentive payments for 5, 10, 15, and 20 years. These costs are presented assuming that no-till is maintained for the full 100-year planning horizon or for only as long as adoption incentives are paid to the farmer, after which the land is converted back to intensive-till. This analysis assumes that when no-till is switched back to intensive-till, SOC levels decrease at a rate of $70 \mathrm{~kg} / \mathrm{ha} / \mathrm{yr}$. A base case of incentive payments for 10 years was selected for comparing costs with other $\mathrm{CO}_{2}$ sink enhancement or storage options. 
Table 22-10

Cotton costs and life-cycle (LC) avoided GHG on a carbon equivalent (CE) basis when changing from intensive-till to no-till with no change in $\mathrm{N}_{2} \mathrm{O}$ emissions

Cropland: Cotton

Southeastern United States

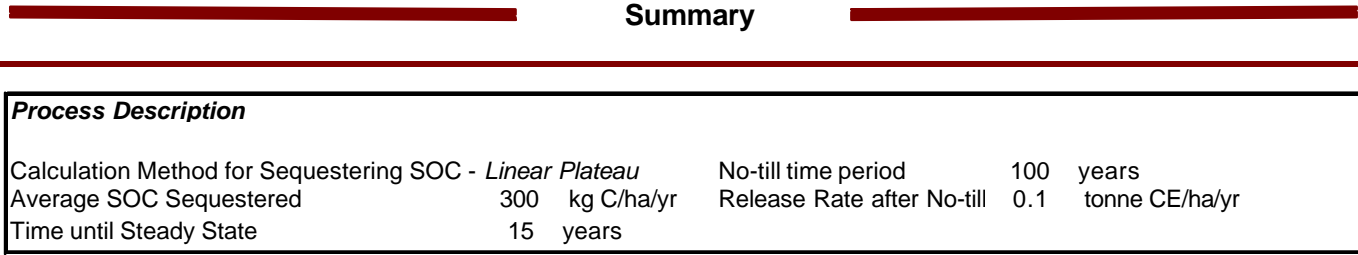

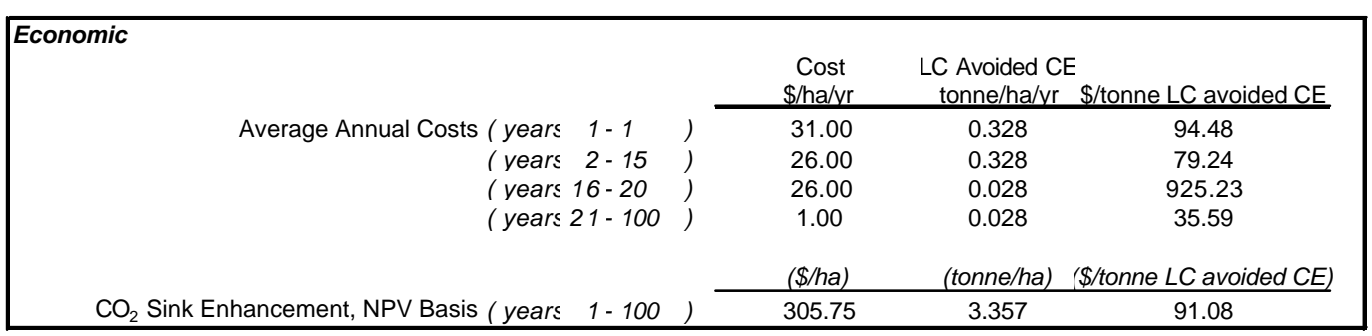
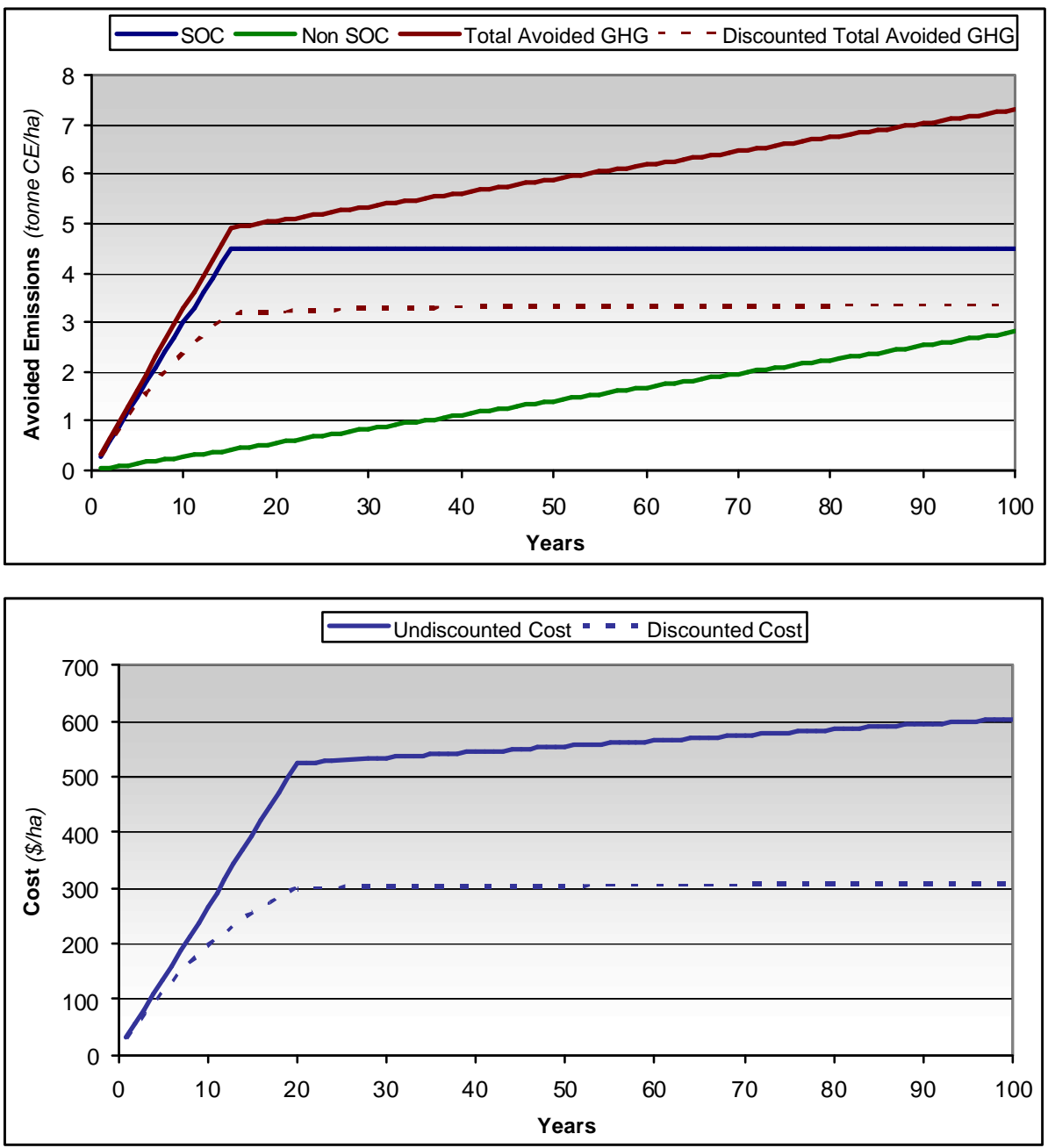
Table 22-11

Cotton example spreadsheet sensitivity summary output when changing from intensive-till to no-till with no change in $\mathrm{N}_{2} \mathrm{O}$ emissions

\section{Cropland: Cotton \\ Southeastern United States Sensitivity Summary}

\section{Current Input Variable Values}

Calculation Method for Sequestering $\mathrm{CO}_{2} \quad$ Linear Plateau SOC Sequestered until Steady State (kg C/ha/yr) 300

Time Until Steady State (years) 15

SOC Release Rate after no-till time period (tonne C/ha/yr) 0.1

Farmer Adoption Incentive to Reduce Tillage (\$/ha/yr) \$25.00

Transaction Costs $\$ 5.00$

Transaction Time Period (years) 1

Monitoring Costs $\$ 1.00$

Monitoring Time Period (years) $\quad 100$

After-Tax Discount Rate $\quad 6.09 \%$

\section{Sensitivity Input}

Farmer Adoption Incentive Time Period Viewed

20 years

Push the adjacent button to update the sensitivity summary costs below.

$\mathrm{CO}_{2}$ Sink Enhancement Costs (years 1-100)

\begin{tabular}{ccc}
$\begin{array}{c}\text { No-till Time } \\
\text { Period } \\
\text { (years) }\end{array}$ & $\begin{array}{c}\text { Farmer Adoption Incentive } \\
\text { Time Period } \\
\text { (years) }\end{array}$ & $\begin{array}{c}\text { NPV Basis } \\
\text { LC avoided GHG basis } \\
\text { (\$/tonne C equivalent) }\end{array}$ \\
\hline 5 & 5 & 157.14 \\
10 & 10 & 123.84 \\
15 & 15 & 102.84 \\
20 & 20 & 110.85 \\
100 & 5 & 37.58 \\
100 & 10 & 60.86 \\
100 & 15 & 78.19 \\
100 & 20 & 91.08
\end{tabular}




\subsection{References}

1 West, Tristram O. and Wlfred M. Post. 2002. Soil organic carbon sequestration rates for crops with reduced tillage and enhanced rotation. Submitted to Soil Science Society of America Journal.

2 Eve, M.D., M. Sperow, K. Howerton, K. Paustian, and R.F. Follett. 2002. Predicted impact of management changes on soil carbon storage for each cropland region of the conterminous United States. J. Soil and Water Conservation. 57 (4) 196-204.

3 Langemeier, L.N. and R.K. Taylor. 1998. A look at machinery cost. Kansas Farm Management Guide, MF-842. Kansas State University, Department of Agricultural Economics.

4 West, Tristram O. and Gregg Marland. 2002. A synthesis of carbon sequestration, carbon emissions, and net carbon flux in agriculture: comparing tillage practices in the United States. Agriculture, Ecosystems, and Environment (in press).

5 Mummey, Daniel L., Jeffrey L. Smith, and George Blum. 1998. Assessment of alternative soil management practices on $\mathrm{N} 2 \mathrm{O}$ emissions from U.S. agriculture. Agriculture, Ecosystems, and Environment 70:79-87. 


\section{3 \\ SUMMARY COMPARISONS AND CONCLUSIONS}

Presented in this chapter are comparisons among options evaluated in this project and between $\mathrm{CO}_{2}$ capture, transport and storage and indirect capture by forests and cropland via reducing tillage using the costs of capture from another EPRI study ${ }^{1}$.

\subsection{Transport and Storage}

Shown in Table 23-1 is a comparison of the transport and storage costs of captured $\mathrm{CO}_{2}$ developed in this study on a $\$ /$ tonne of $\mathrm{CO}_{2}$ and $\$$ tonne of $\mathrm{C}$ on a levelized annual equivalent life cycle greenhouse gas avoided basis rounded off to the nearest dollar. Bear in mind that the transport costs include a small portion of the compression costs normally included in the capture costs in many studies. This was necessitated by the use of the capture costs from the previous EPRI study which only compressed the $\mathrm{CO}_{2}$ to 83 bar (1200 psia) rather than the 153 bar (2200 psia) required at the pipeline inlet. This difference represents a small fraction of the costs of $\mathrm{CO}_{2}$ transport and storage ( $\$ 0.75 /$ tonne of $\mathrm{CO}_{2}$ or $\$ 2.7 /$ tonne of $\left.\mathrm{C}\right)$. Included are the base case and a range for each cost. These cases are intended to represent realistic ranges of the important variables and the details of the cases can be found in the appropriate chapter for each storage method. Plotted in Figure 23-1 are the values on a $\mathrm{CO}_{2}$ basis to visually represent the comparisons.

Table 23-1

$\mathrm{CO}_{2}$ transport and storage cost comparison on a levelized annual $\mathrm{CO}_{2}$ equivalent life cycle greenhouse gas avoided basis

\begin{tabular}{|l|c|c|c|c|c|c|}
\hline Case & Base Case & $\begin{array}{c}\text { High Cost } \\
\text { Case }\end{array}$ & $\begin{array}{c}\text { Low Cost } \\
\text { Case }\end{array}$ & $\begin{array}{c}\text { Base } \\
\text { Case }\end{array}$ & $\begin{array}{c}\text { High } \\
\text { Cost } \\
\text { Case }\end{array}$ & $\begin{array}{c}\text { Low } \\
\text { Cost } \\
\text { Case }\end{array}$ \\
\hline & $\begin{array}{c}\$ / \text { tonne } \\
\mathrm{CO}_{2}\end{array}$ & $\begin{array}{c}\$ / \text { tonne } \\
\mathrm{CO}_{2}\end{array}$ & $\begin{array}{c}\$ / \text { tonne } \\
\mathrm{CO}_{2}\end{array}$ & $\begin{array}{c}\$ / \text { tonne } \\
\mathrm{C}\end{array}$ & $\begin{array}{c}\$ / \text { tonne } \\
\mathrm{C}\end{array}$ & $\begin{array}{c}\$ / \text { tonne } \\
\mathrm{C}\end{array}$ \\
\hline EOR & $(12)$ & 74 & $(91)$ & $(45)$ & 271 & $(334)$ \\
\hline ECBMR & $(6)$ & 19 & $(26)$ & $(20)$ & 69 & $(94)$ \\
\hline $\begin{array}{l}\text { Depleted Gas } \\
\text { Res. }\end{array}$ & 5 & 19 & 1 & 18 & 71 & 4 \\
\hline Depleted Oil Res. & 4 & 11 & 1 & 14 & 41 & 4 \\
\hline Aquifer & 3 & 12 & 1 & 11 & 43 & 4 \\
\hline Ocean Pipeline & 6 & 14 & 3 & 20 & 52 & 11 \\
\hline Ocean Tanker & 18 & 23 & 16 & 65 & 84 & 58 \\
\hline
\end{tabular}




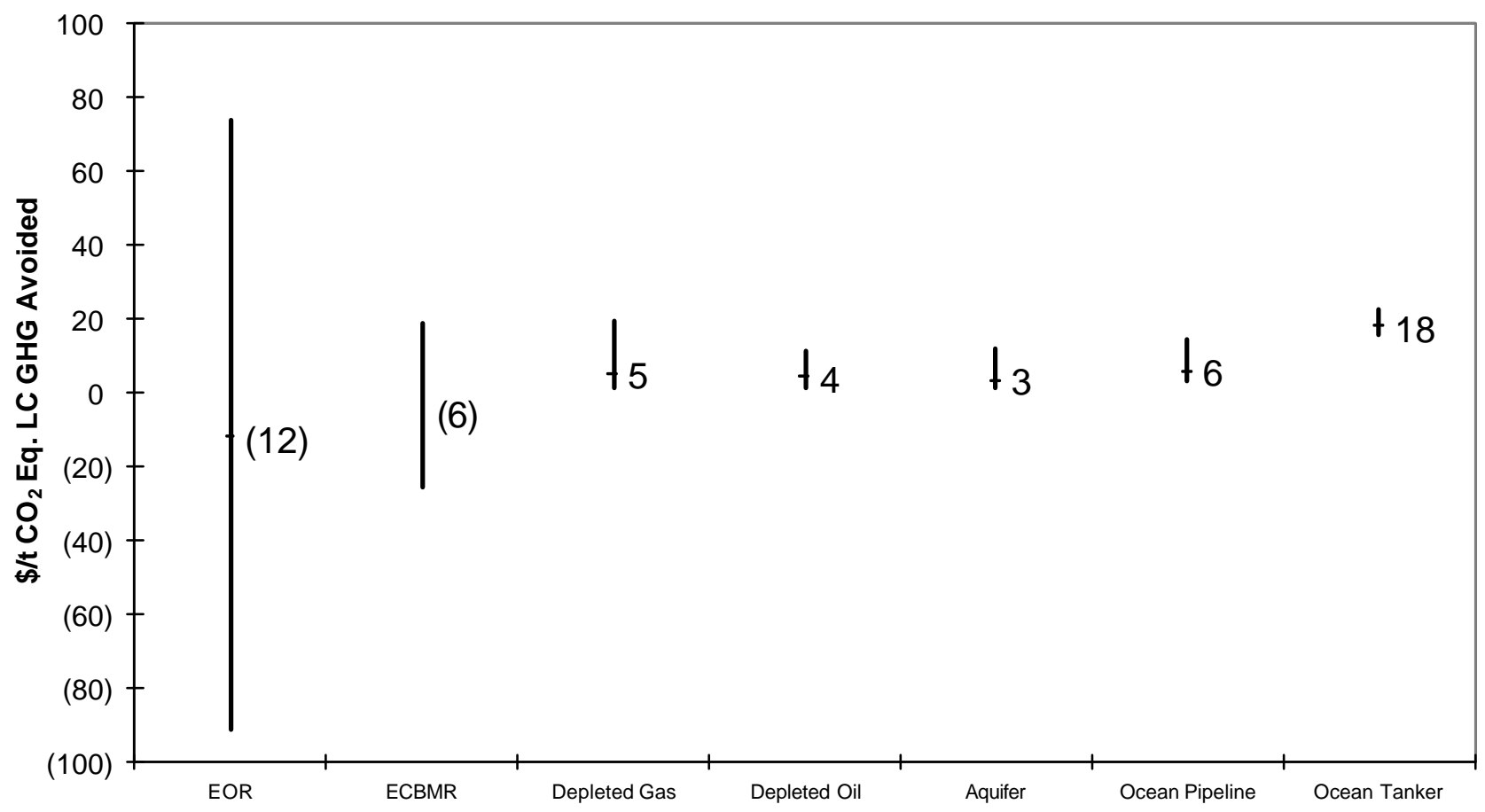

Figure 23-1

$\mathrm{CO}_{2}$ transport and storage cost comparison on a levelized annual $\$ / t$ of $\mathrm{CO}_{2}$ equivalent life cycle greenhouse gas avoided basis

In looking at the comparisons, the base case for EOR and ECBMR show a negative value base case and larger ranges than the other cases. This illustrates that, at the oil price used and no separate charge for $\mathrm{CO}_{2}$, these base cases operate at a profit. The large ranges show that the costs are very sensitive to changes in the variables. This illustrates how site specific these cases may be. The depleted gas, oil, aquifer and ocean pipeline are similar in value. Their ranges are more compressed although they still change by several factors. The tanker case evaluates as the most expensive and has the smallest range. This case is driven by the capital costs of the tanker, port, and platforms and the variables chosen in the high and low case only impact a small portion of the costs.

\subsection{Capture, Transport and Storage}

As discussed in Chapter 2, in order to compare capture, transport and storage with the indirect sequestration options, all of the cases have been put on a net present value (NPV) basis. This occurs because of the wide range of emissions and costs as a function of time over the 100-year span of the evaluation. Shown in Table 23.2 are the cases developed in this study on a $\$$ tonne of $\mathrm{CO}_{2}$ and $\$$ tonne of $\mathrm{C}$ on a NPV equivalent life cycle greenhouse gas avoided basis rounded off to the nearest dollar. A plot of the $\$ / t \mathrm{CO}_{2}$ information is shown in Figure 23.2. 
Table 23-2

$\mathrm{CO}_{2}$ capture, transport and storage cost comparison on a NPV equivalent life cycle greenhouse gas avoided basis

\begin{tabular}{lcc}
\hline Case & Base Case & Base Case \\
\hline EOR & $\begin{array}{c}\text { \$/tonne } \\
\mathrm{CO}_{2}\end{array}$ & $\$ /$ tonne C \\
\hline ECBMR & 4 & 15 \\
\hline Depleted Gas Res. & 11 & 41 \\
\hline Depleted Oil Res. & 23 & 86 \\
\hline Aquifer & 22 & 81 \\
\hline Ocean Pipeline & 21 & 77 \\
\hline Ocean Tanker & 24 & 89 \\
\hline
\end{tabular}

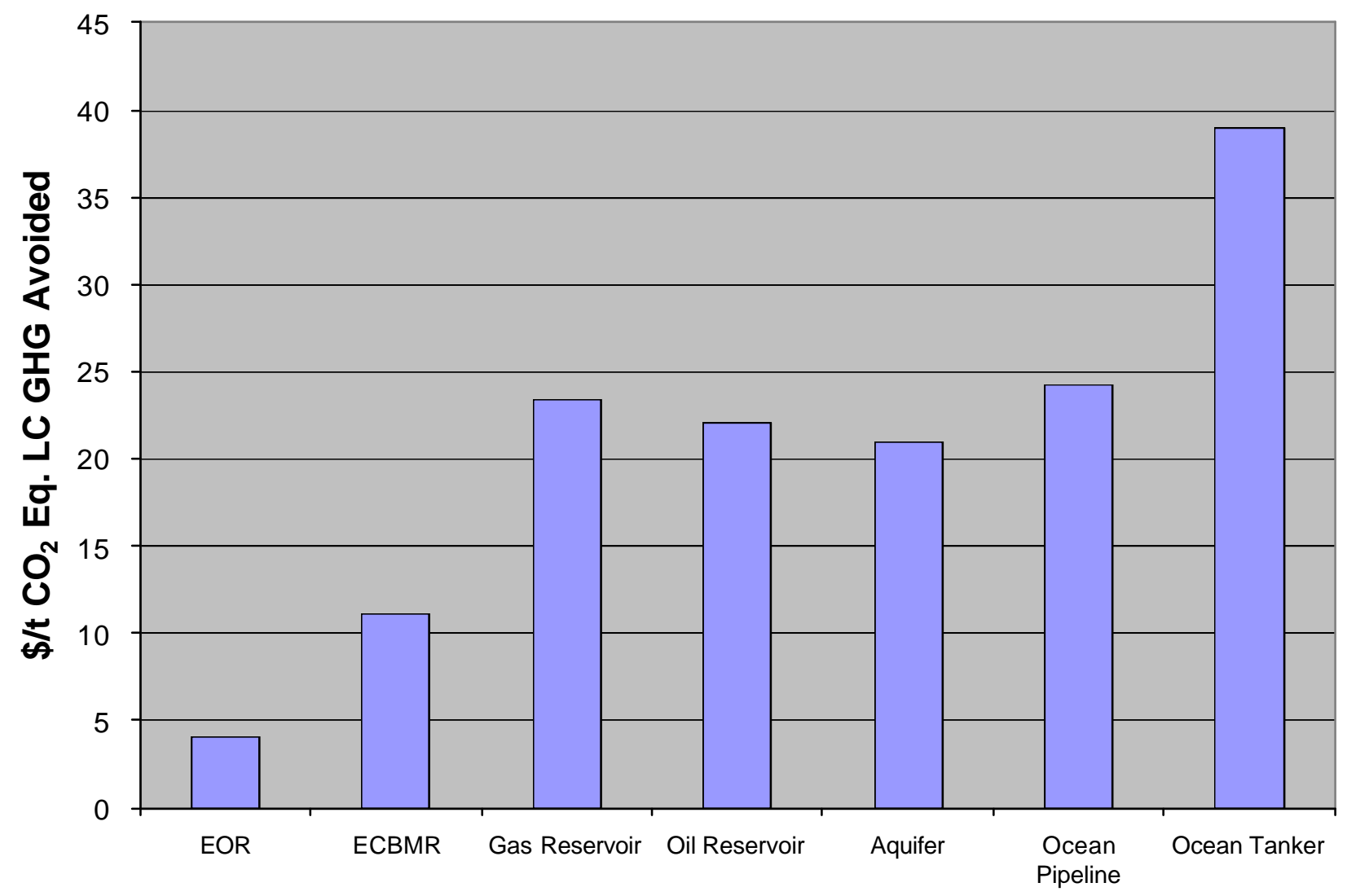

Figure 23-2

$\mathrm{CO}_{2}$ capture, transport and storage cost comparison on a NPV $\$ / t$ of $\mathrm{CO}_{2}$ equivalent life cycle greenhouse gas avoided basis 


\subsection{Forest management}

Shown in Table 23-3 is a comparison of the forestry cases developed in this study on a \$/tonne of $\mathrm{CO}_{2}$ and $\$$ /tonne of $\mathrm{C}$ on a NPV life cycle greenhouse gas avoided basis. Sensitivity to productivity are indicated where data was available to calculate the case. The information in this table is for forestry cases that include above and below ground carbon and timber products \& revenues.

Table 23-3

Forestry cases NPV cost comparison (LC equivalent greenhouse gas avoided, including above and below ground carbon and timber products \& revenues).

\begin{tabular}{|l|c|c|c|c|c|c|}
\hline Case & $\begin{array}{c}\text { Base Case- } \\
\text { Medium } \\
\text { Productivity }\end{array}$ & $\begin{array}{c}\text { Low Cost } \\
\text { Case-High } \\
\text { Productivity }\end{array}$ & $\begin{array}{c}\text { High Cost } \\
\text { Case-Low } \\
\text { Productivity }\end{array}$ & $\begin{array}{c}\text { Base Case- } \\
\text { Medium } \\
\text { Productivity }\end{array}$ & $\begin{array}{c}\text { Low Cost } \\
\text { Case-High } \\
\text { Productivity }\end{array}$ & $\begin{array}{c}\text { High Cost } \\
\text { Case-Low } \\
\text { Productivity }\end{array}$ \\
\hline & $\$$ /tonne $\mathrm{CO}_{2}$ & $\$$ /tonne $\mathrm{CO}_{2}$ & $\$$ /tonne $\mathrm{CO}_{2}$ & $\$ /$ tonne C & $\$$ /tonne C & $\$$ /tonne C \\
\hline US Pine & 15 & 11 & & 54 & 40 & \\
\hline US Fir & 2 & 1 & & 7 & 3 & \\
\hline Cedar & $(15)$ & $(14)$ & $(11)$ & $(56)$ & $(51)$ & $(39)$ \\
\hline Pine-Oak & 1 & $(1)$ & 2 & 2 & $(3)$ & 6 \\
\hline Miombo & $(24)$ & & & $(87)$ & & \\
\hline Mango & $(43)$ & & & $(158)$ & & \\
\hline Deforest & 3 & & & 10 & & \\
\hline
\end{tabular}

Where data was available, productivity (carbon stored/area), could affect costs significantly. Shown in Figure 23-3 is a bar chart of the \$/tonne $\mathrm{CO}_{2}$ costs from Table 26.2 to visually represent the comparisons. 


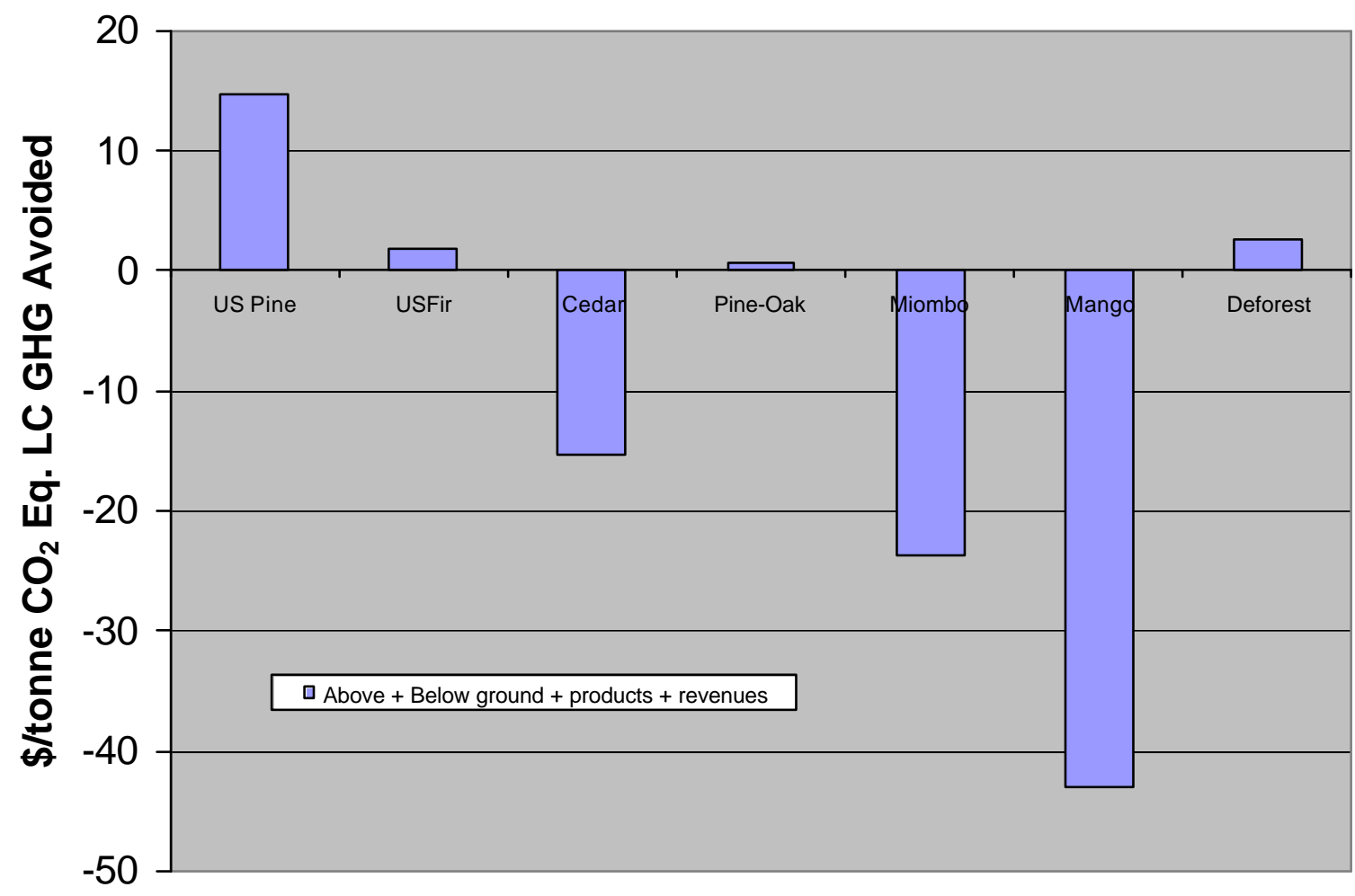

Figure 23-3

Forestry cost comparison on a NPV $\$ / t$ of $\mathrm{CO}_{2}$ equivalent life cycle greenhouse gas avoided basis

The only case with a significant cost is the US pine case and this is because the land costs are high and the timber revenues are not enough to offset them. US fir and Pine-Oak are generally revenue neutral and the Cedar, Miombo and Mango are negative costs due to the high value of their products. Prevention of deforestation is also a low-cost option.

\subsection{Cropland via Reducing Tillage}

Shown in Table 23-4 are the cases developed in this study for the cropland cases on a $\$$ tonne of $\mathrm{CO}_{2}$ and $\$$ /tonne of $\mathrm{C}$ on a NPV equivalent life cycle greenhouse gas avoided basis rounded off to the nearest dollar. A plot of the $\$ / t \mathrm{CO}_{2}$ information is shown in Figure 23-4. 
Table 23-4

Cropland cases NPV equivalent life cycle greenhouse gas avoided basis

\begin{tabular}{|l|c|c|c|c|c|c|}
\hline Case & $\begin{array}{c}\text { Base } \\
\text { Case-10 y } \\
\text { Incentive }\end{array}$ & $\begin{array}{c}\text { High Cost } \\
\text { Case- 20 y } \\
\text { Incentive }\end{array}$ & $\begin{array}{c}\text { Low Cost } \\
\text { Case-5 y } \\
\text { Incentive }\end{array}$ & $\begin{array}{c}\text { Base } \\
\text { Case-10 y } \\
\text { incentive }\end{array}$ & $\begin{array}{c}\text { High Cost } \\
\text { Case- 20 y } \\
\text { Incentive }\end{array}$ & $\begin{array}{c}\text { Low Cost } \\
\text { Case-5 y } \\
\text { Incentive }\end{array}$ \\
\hline $\begin{array}{c}\$ / \text { tonne } \\
\mathrm{CO}_{2}\end{array}$ & $\begin{array}{c}\$ \text { /tonne } \\
\mathrm{CO}_{2}\end{array}$ & $\begin{array}{c}\$ / \text { tonne } \\
\mathrm{CO}_{2}\end{array}$ & $\$ /$ tonne C & $\$$ /tonne C & $\$$ /tonne C \\
\hline $\begin{array}{l}\text { Continuous } \\
\text { corn }\end{array}$ & 13 & 20 & 8 & 48 & 72 & 30 \\
\hline Wheat/fallow & 13 & 19 & 8 & 51 & 77 & 30 \\
\hline $\begin{array}{l}\text { Continuous } \\
\text { cotton }\end{array}$ & 24 & 36 & 15 & 88 & 132 & 54 \\
\hline
\end{tabular}

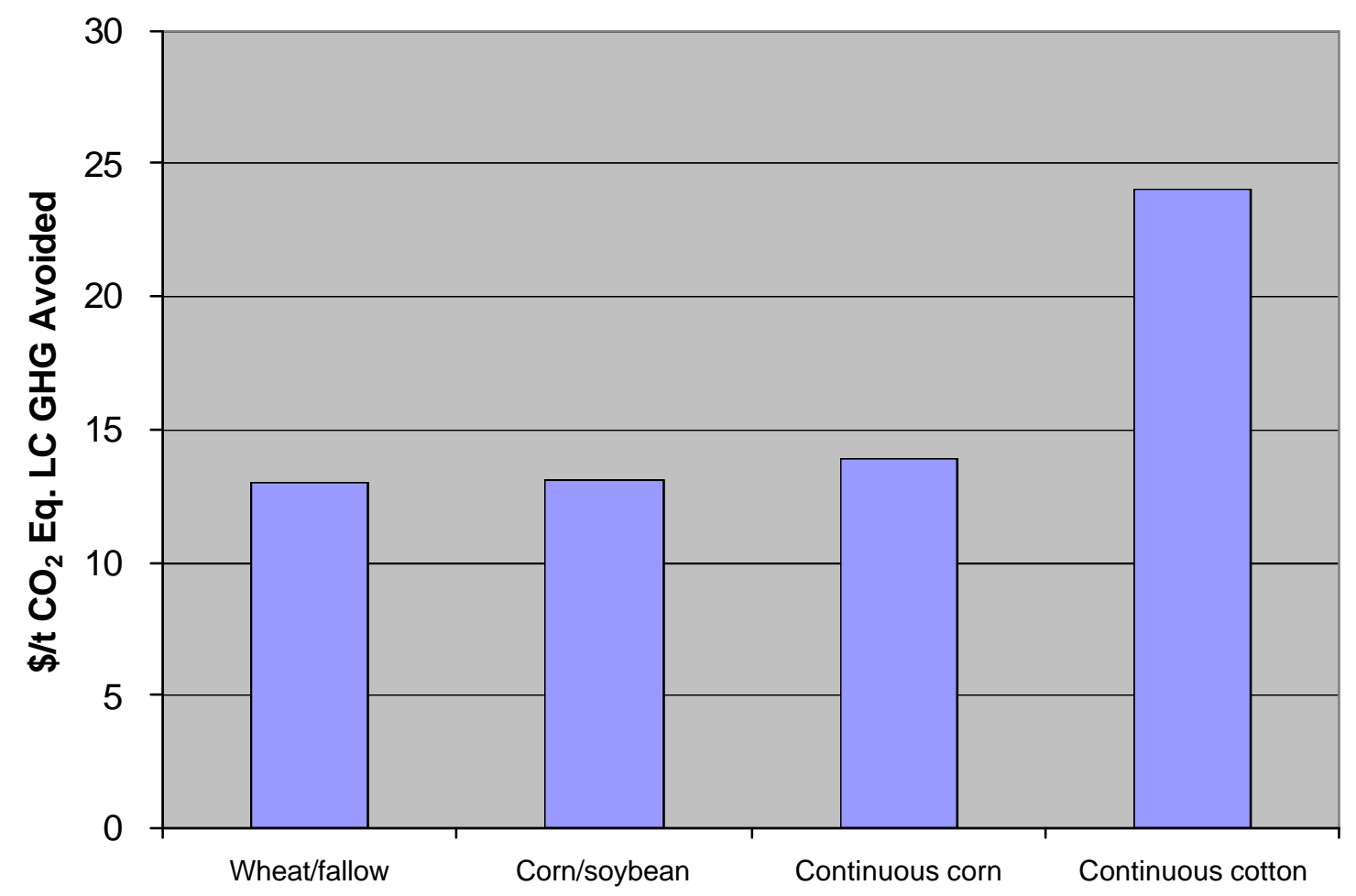

Figure 23-4

Cropland cases NPV $\$ / t \mathrm{CO}_{2}$ equivalent life cycle greenhouse gas avoided basis

All of these options are fairly expensive compared to the other options in the study. However, the length of time that the incentive has to be paid has a significant impact on the cost. 


\subsection{Direct Verses Indirect Sequestration}

Shown in Figure 23-5 is a comparison of all of the base case values in $\$ /$ tonne of $\mathrm{CO}_{2}$ equivalent LC GHG avoided on a net present value plotted from lowest to highest cost.

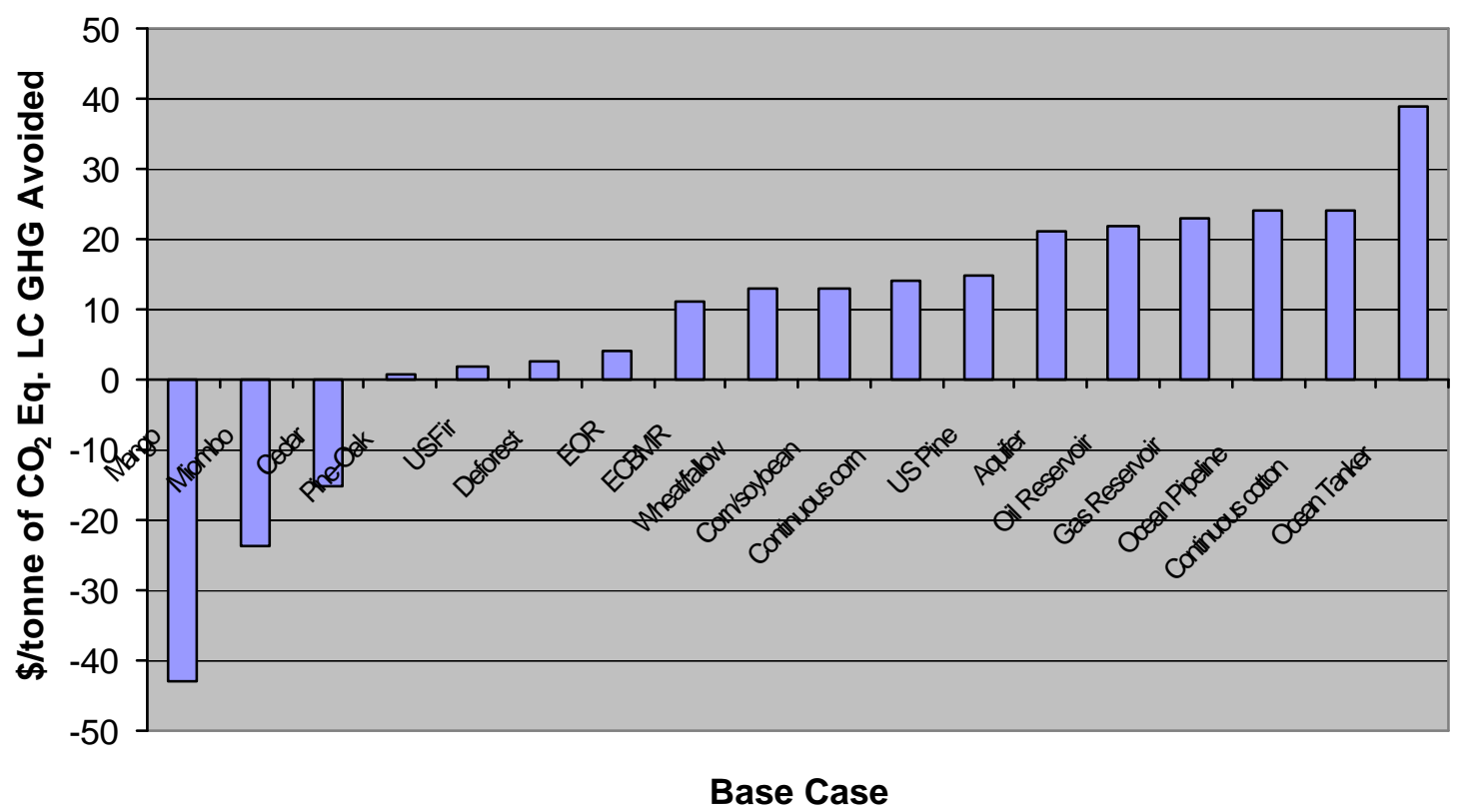

Figure 23-5

Comparison of direct and indirect sequestration cases.

As shown in Figure 23-5, all of the forestry options are the least expensive except for the US Pine case. Next are the EOR and ECBMR options followed by most of the cropland options. Figure 26-7 includes the available high and low cases. The main impact of these cases is on the cropland cases where the low cases would make them competitive with ECBMR and the high cases would make them about the same as the other geologic storage cases. 


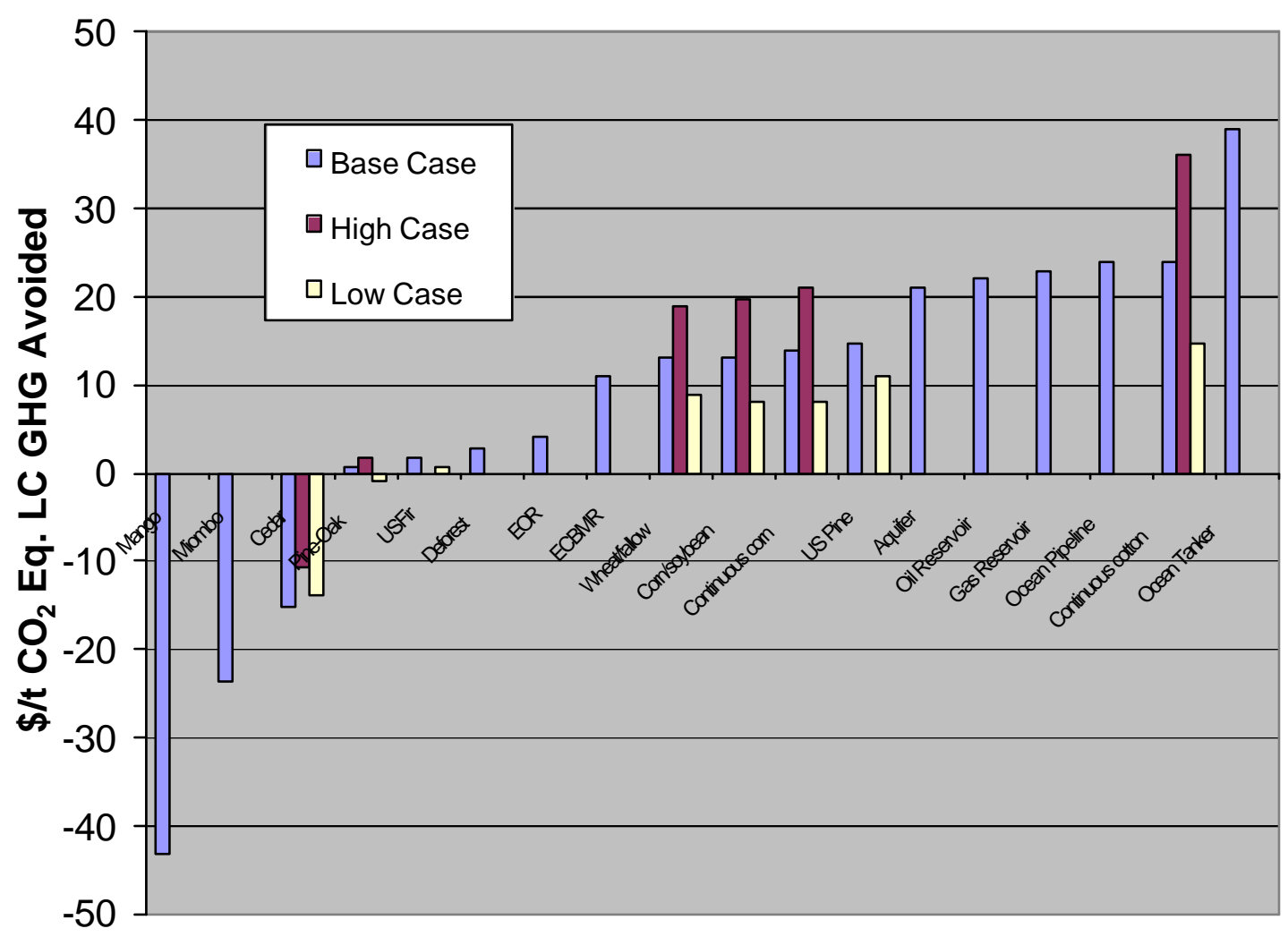

Figure 23-6

Comparison of direct and indirect sequestration cases including high and low cases.

Base-case forest and cropland areas required to offset LC GHG emissions avoided by base-case $\mathrm{CO}_{2}$ capture and storage options are presented in Table 23-5. These land area equivalents are for a 100-year planning horizon. The carbon equivalent (CE) LC GHG emissions avoided by the capture and storage options assume $\mathrm{CO}_{2}$ capture and injection into storage reservoirs during the 20-year book life of the capture and storage plants and storage of injected $\mathrm{CO}_{2}$ for another 80 years. For the ocean storage options, the $\mathrm{CE} \mathrm{LC} \mathrm{GHG}$ avoided is reduced for leakage of $\mathrm{CO}_{2}$ throughout the 100-year storage period. Zero $\mathrm{CO}_{2}$ leakage is assumed for the other $\mathrm{CO}_{2}$ storage options. The CE LC GHG emissions avoided by the forest and cropland options assume that the improved forestry or cropland practices are maintained for 100 years. Generally, ten times or more cropland than forest land is required to offset the $\mathrm{CO}_{2}$ storage options. 
Table 23-5

Base-case forest and cropland areas required to offset LC GHG emissions avoided by base-case $\mathrm{CO}_{2}$ capture and storage options.

Equivalent Forestry / Cropland Area Required to

Offset Geologic \& Ocean Options
LC Avoided GHG Basis (100 year summation,

\begin{tabular}{|c|c|c|c|c|c|c|c|c|c|c|c|c|c|c|c|}
\hline 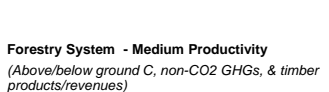 & 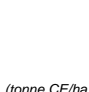 & Aquiter Storage & $\begin{array}{c}\text { Forestry/ Cropland } \\
\text { Areato Equal } \\
\infty_{2} \text { Capture \& Storage }\end{array}$ & Enhanced Oil & $\begin{array}{l}\text { Recovery } \\
\text { Forestry / Cropland } \\
\text { Aere to toqual } \\
\mathrm{CO}_{2} \text { Capture \& Storage }\end{array}$ & Depleted Oil Re & $\begin{array}{l}\text { Reservoris } \\
\text { Forestry / Cropland } \\
\text { AAreat Equal } \\
\mathrm{CO}_{2} \text { Capture \& Storage }\end{array}$ & Depleted Gas F & $\begin{array}{c}\text { Peserenoirs } \\
\text { Forestry / Cropland } \\
\text { Areat of Eqaal } \\
\infty_{2} \text { Capture \& S Storage }\end{array}$ & $\int^{\text {Coal Bed Meth }}$ & 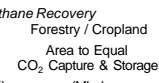 & $\left.\right|^{\text {ocean Pipelin }}$ & $\begin{array}{c}\text { ne Storage } \\
\text { Forosty / Cropland } \\
\text { Areat oqual } \\
\mathrm{CO}_{2} \text { Capture \& \& Storage }\end{array}$ & occan Tanker: & 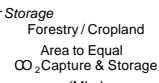 \\
\hline Plantation, USA, Loblolly Pine & 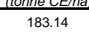 & $\frac{1}{9.81}$ & 0.05 & 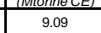 & 0.05 & HAOOnneCE & $\frac{05}{0.05}$ & 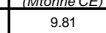 & \begin{tabular}{l|l} 
andat \\
0.05
\end{tabular} & $\frac{100 n \text { nec }}{9.54}$ & 0.05 & $\frac{1 \text { MonneCE }}{28.28}$ & 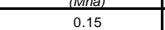 & $\frac{\text { Nitonne e }}{28.00}$ & $\frac{\text { Nhat }}{0.15}$ \\
\hline Plantation, USA, Douglas Fir & 452.65 & 9.81 & 0.02 & 9.09 & 0.02 & 9.81 & 0.02 & 9.81 & 0.02 & 9.54 & 0.02 & 28.28 & 0.06 & 28.00 & 0.06 \\
\hline Plantation (Taungya), Mexico, Spanish cedar & 277.40 & 9.81 & 0.04 & 9.09 & 0.03 & 9.81 & 0.04 & 9.81 & 0.04 & 9.54 & 0.03 & 28.28 & 0.10 & 28.00 & 0.10 \\
\hline Restoration, Mexico, Pine-oak & 183.39 & 9.81 & 0.05 & 9.09 & 0.05 & 9.81 & 0.05 & 9.81 & 0.05 & 9.54 & 0.05 & 28.28 & 0.15 & 28.00 & 0.15 \\
\hline Restoration, Southern Africa, Miombo & 59.26 & 9.81 & 0.17 & 9.09 & 0.15 & 9.81 & 0.17 & 9.81 & 0.17 & 9.54 & 0.16 & 28.28 & 0.48 & 28.00 & 0.47 \\
\hline Agro- forestry, Southerm India, Mango- tamarind & 71.53 & 9.81 & 0.14 & 9.09 & 0.13 & 9.81 & 0.14 & 9.81 & 0.14 & 9.54 & 0.13 & 28.28 & 0.40 & 28.00 & 0.39 \\
\hline Avoidance of deforesstation, Mexico, Various & 207.66 & 9.81 & 0.05 & 9.09 & 0.04 & 9.81 & 0.05 & 9.81 & 0.05 & 9.54 & 0.05 & 28.28 & 0.14 & 28.00 & 0.13 \\
\hline $\begin{array}{l}\text { Cropland System } \\
\text { Two Year Corr/Soybean Rotation } \\
\text { (Intensive-til to Novotil) }\end{array}$ & 6.51 & 9.81 & 1.51 & 9.09 & 1.39 & 9.81 & 1.51 & 9.81 & 1.51 & 9.54 & 1.46 & 28.28 & 4.34 & 28.00 & 4.30 \\
\hline $\begin{array}{l}\text { Continuous Corn } \\
\text { (Intensive-till to No-til) }\end{array}$ & 12.33 & 9.81 & 0.80 & 9.09 & 0.74 & 9.81 & 0.80 & 9.81 & 0.80 & 9.54 & 0.77 & 28.28 & 2.29 & 28.00 & 2.27 \\
\hline $\begin{array}{l}\text { Continuous Cotton } \\
\text { (Intensive-til to No-till) }\end{array}$ & 0.99 & 9.81 & 9.90 & 9.09 & 9.18 & 9.81 & 9.90 & 9.81 & 9.90 & 9.54 & 9.64 & 28.28 & 28.56 & 28.00 & 28.28 \\
\hline $\begin{array}{l}\text { Two Year Wheat / Fallow Rotation } \\
\text { (Intensive-till to No-til) }\end{array}$ & 6.58 & 9.81 & 1.49 & 9.09 & 1.38 & 9.81 & 1.49 & 9.81 & 1.49 & 9.54 & 1.45 & 28.28 & 4.30 & 28.00 & 4.26 \\
\hline
\end{tabular}




\subsection{Conclusions}

Making these comparisons was a challenge due to the differences between direct and indirect cases. The resulting numbers should only be used as a relative indication of cost. Site-specific characteristics could significantly change the outcome of the comparisons. In this study, the forestry options are very attractive along with capture using EOR for storage. Other factors, such as land availability and storage option location and capacity will also play a significant part in which options make the most sense at a given site.

The current work should only be considered a starting point. Better cost information and improvements to processes are likely to be developed and need to be incorporated into updates of this information. In addition, there are plans to update and add to portions of the current work to answer questions that arose but were beyond the scope of the current effort. For example, what happens to the costs if the power plant operates for longer than the plant book life? Also, how do the economics look for other power generation options? These and other questions will be evaluated in updates to this work.

\subsection{REFERENCES}

1 DOE/EPRI. 2000. Evaluation of innovative fossil fuel power plants with $\mathrm{CO} 2$ removal. EPRI, Palo Alto, California; U.S. Department of Energy-Office of Fossil Energy, Germantown, Maryland, and U.S. Department of Energy/NETL, Pittsburgh, Pennsylvania: 1000316. 


\section{$A$ \\ DETAILED LIFE-CYCLE GHG EMISSIONS AVOIDED VIA CAPTURING AND STORING $\mathrm{CO}_{2}$}

Detailed life-cycle (LC) GHG emissions avoided via capturing and storing $\mathrm{CO}_{2}$ in the base cases considered in this project are presented in Tables A-1 to A-7. Methodology for calculating these emissions is described in Chapters 2 and 3. 
Table A-1 EOR base case detailed analysis of LC GHG emissions avoided

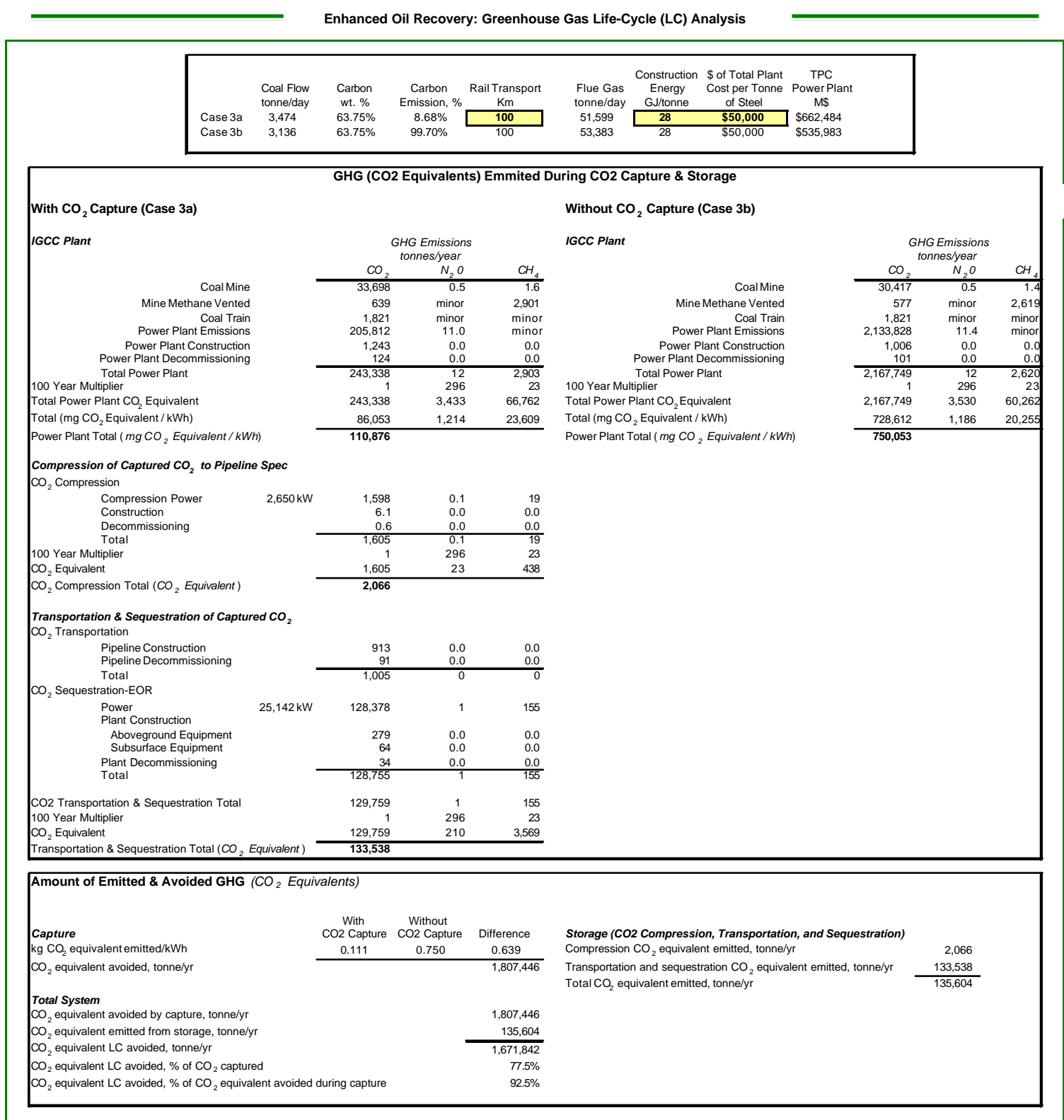


Table A-2

ECBMR base case detailed analysis of LC GHG emissions avoided

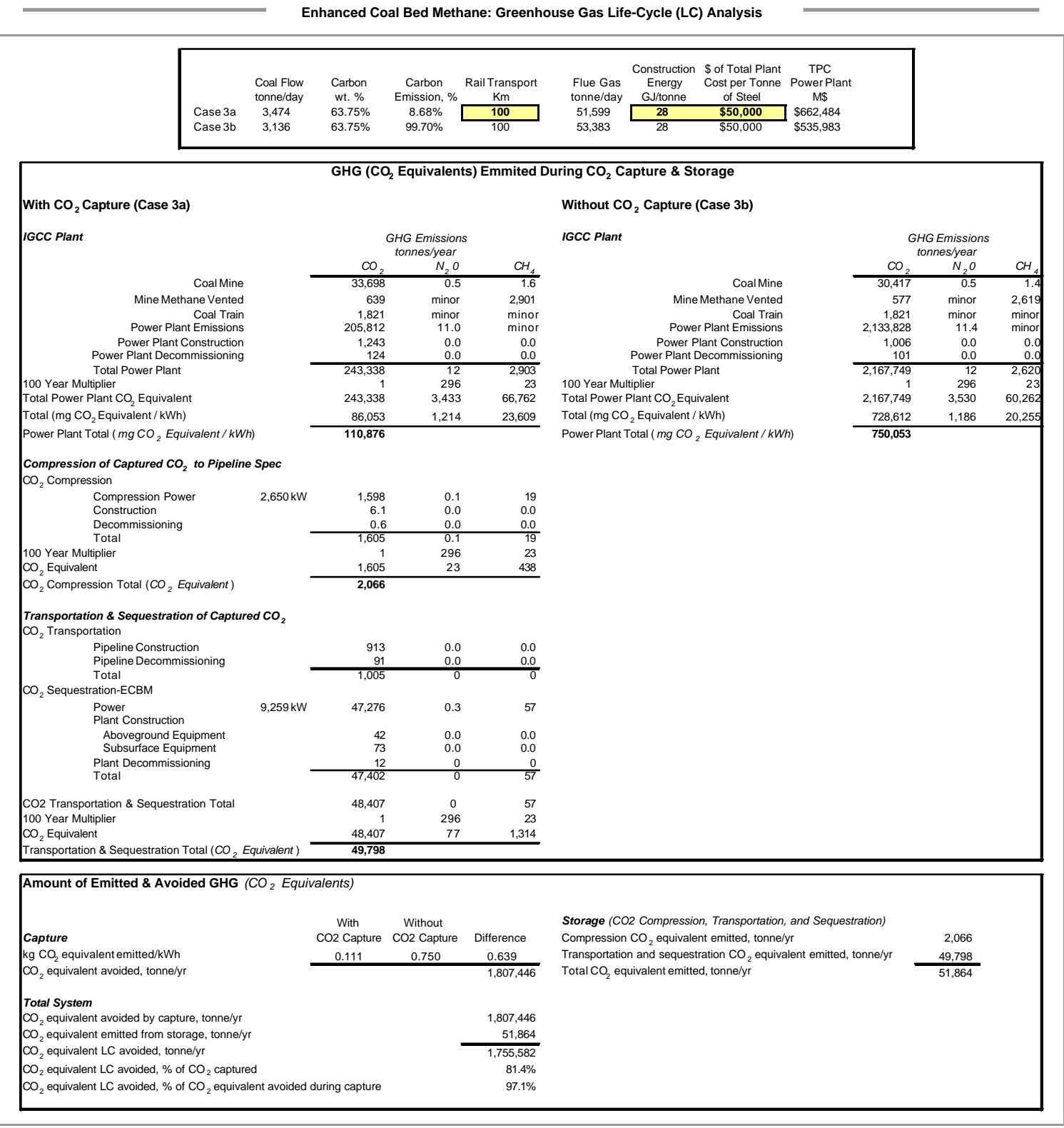


Table A-3

Aquifer storage base case detailed analysis of LC GHG emissions avoided

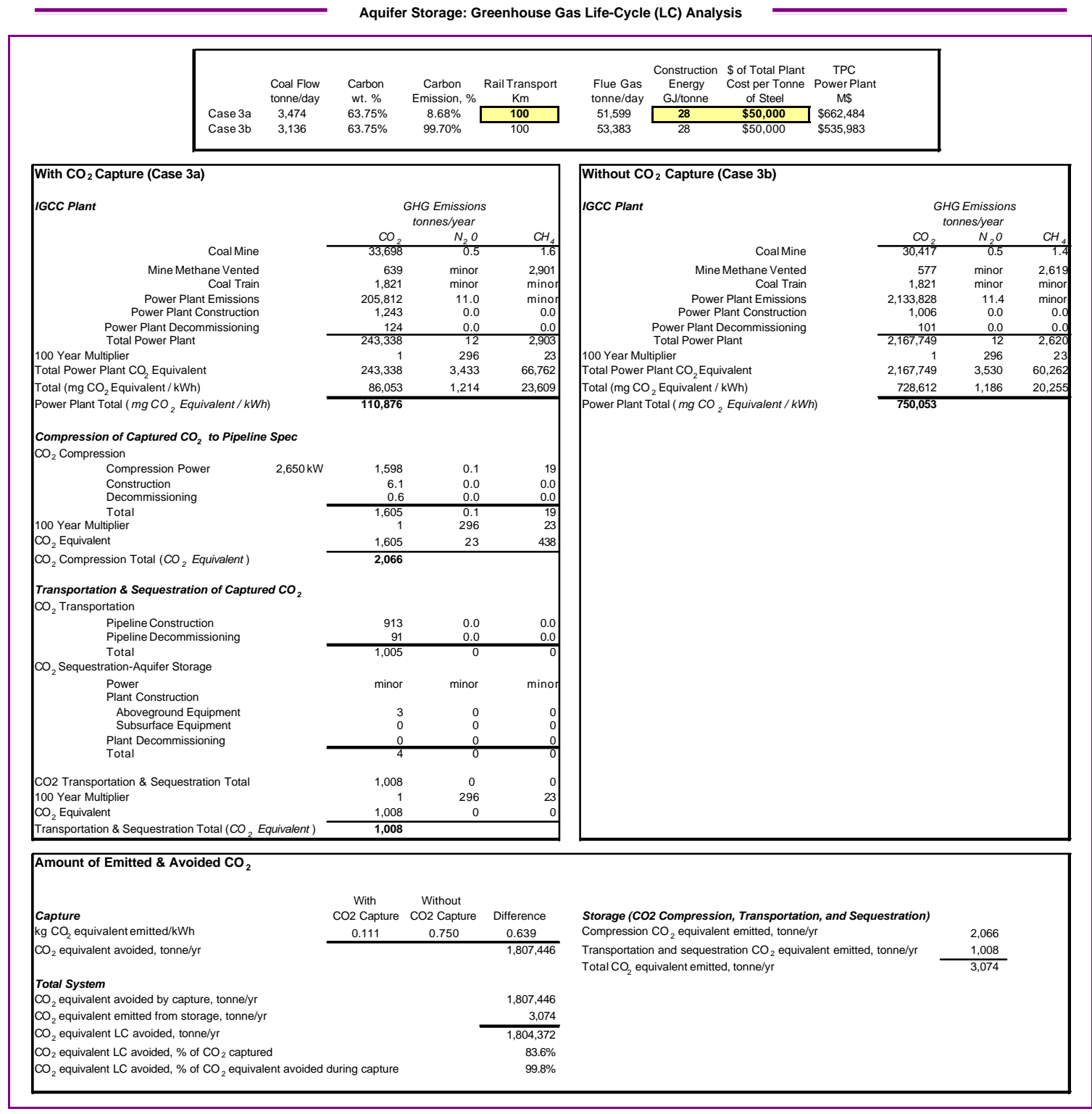


Table A-4

Depleted oil reservoir base case detailed analysis of LC GHG emissions avoided

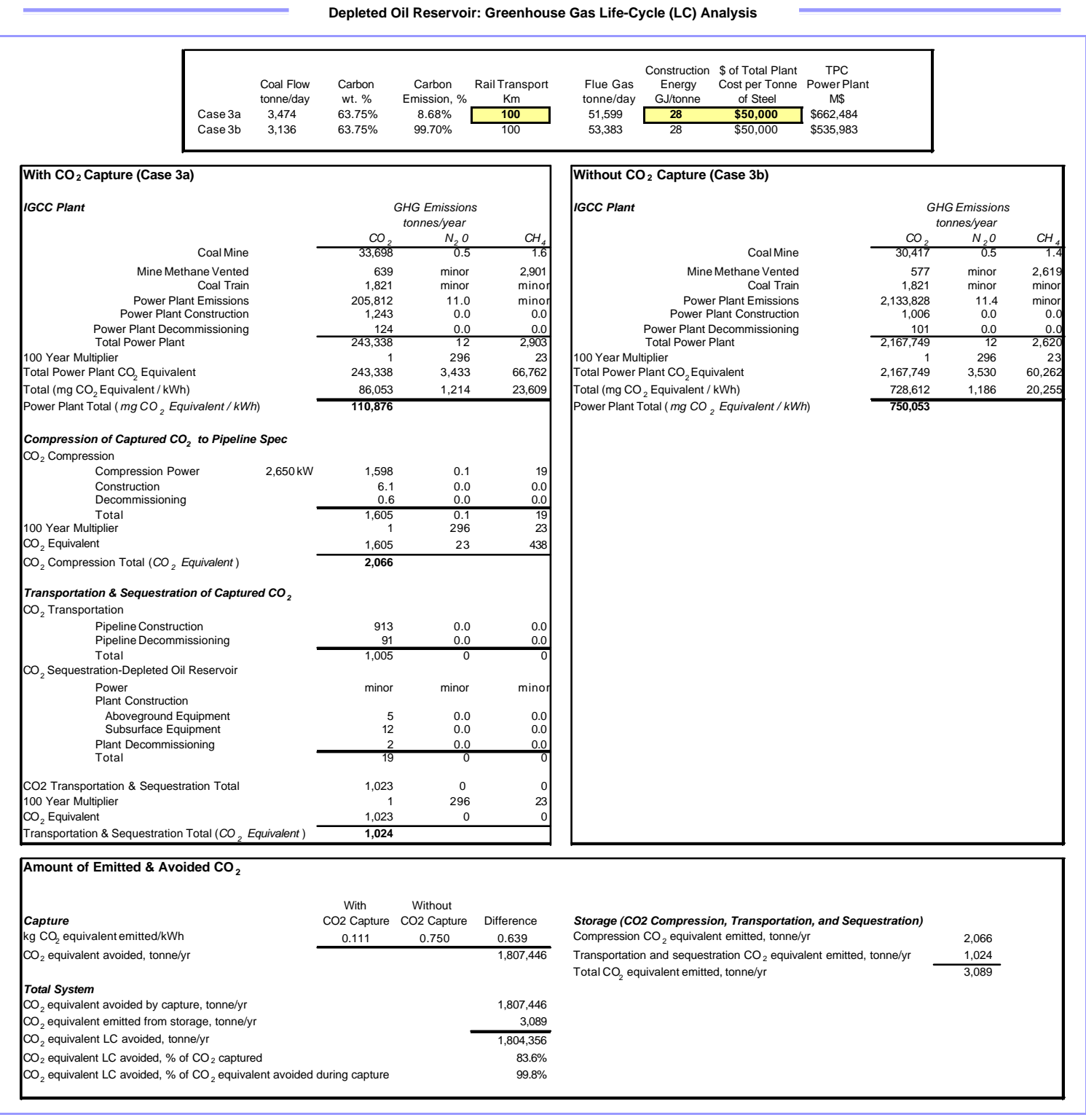


Table A-5

Depleted gas reservoir base case detailed analysis of LC GHG emissions avoided

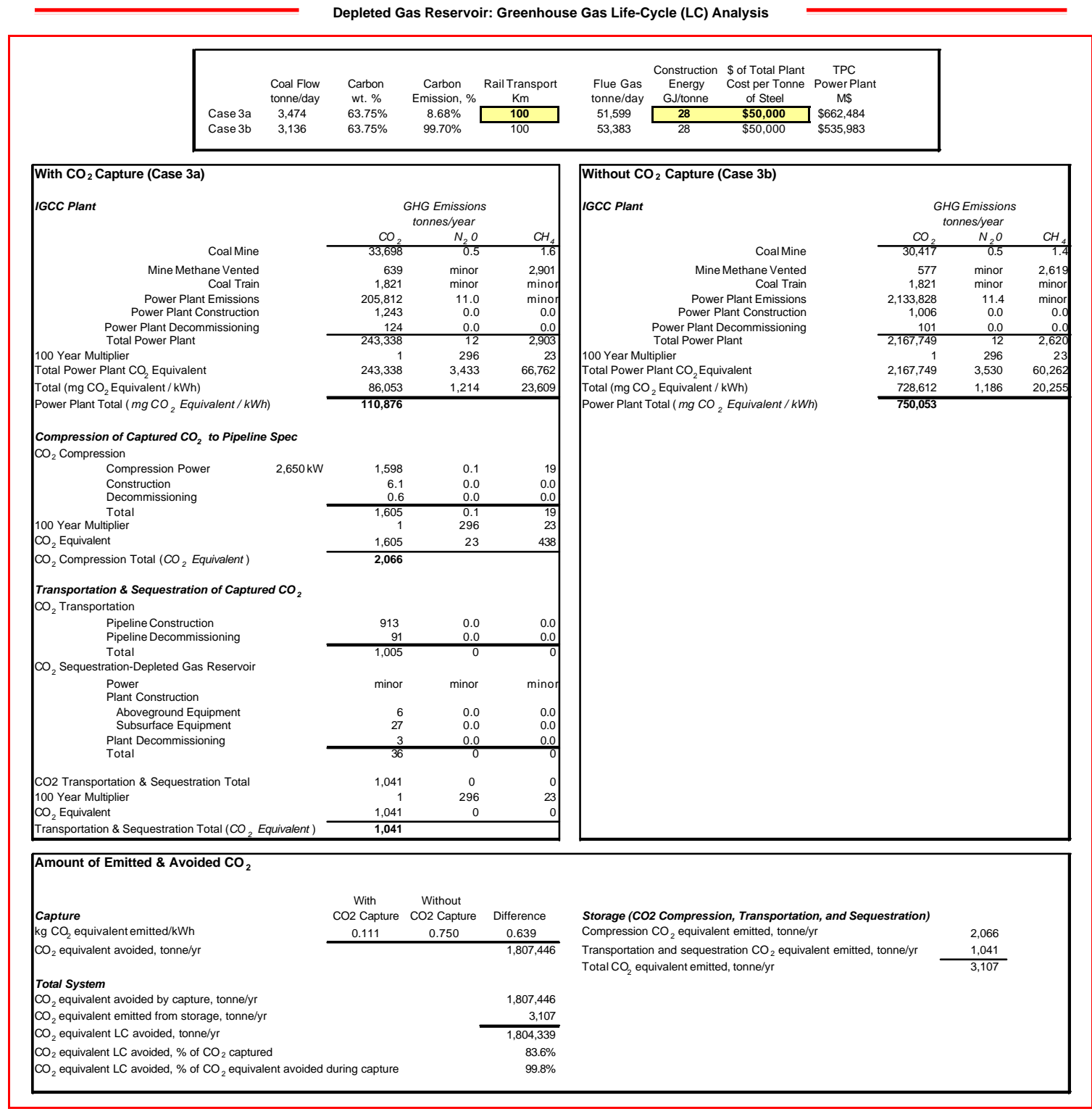


Table A-6

Ocean pipeline storage base case detailed analysis of LC GHG emissions avoided

Ocean Pipeline Storage: Greenhouse Gas Life-Cycle (LC) Analysis (without leakage)

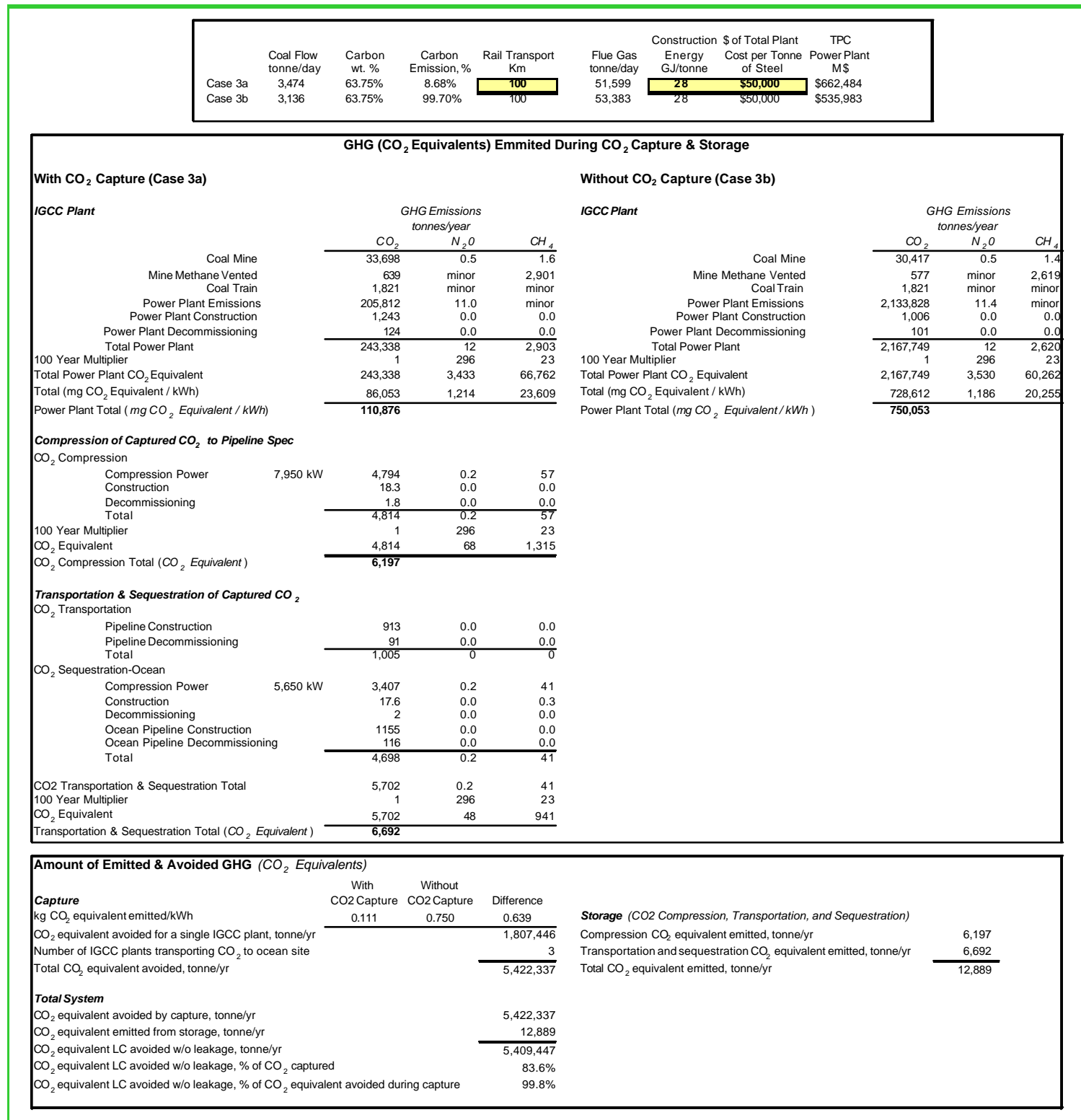


Table A-7

Ocean tanker storage base case detailed analysis of LC GHG emissions avoided

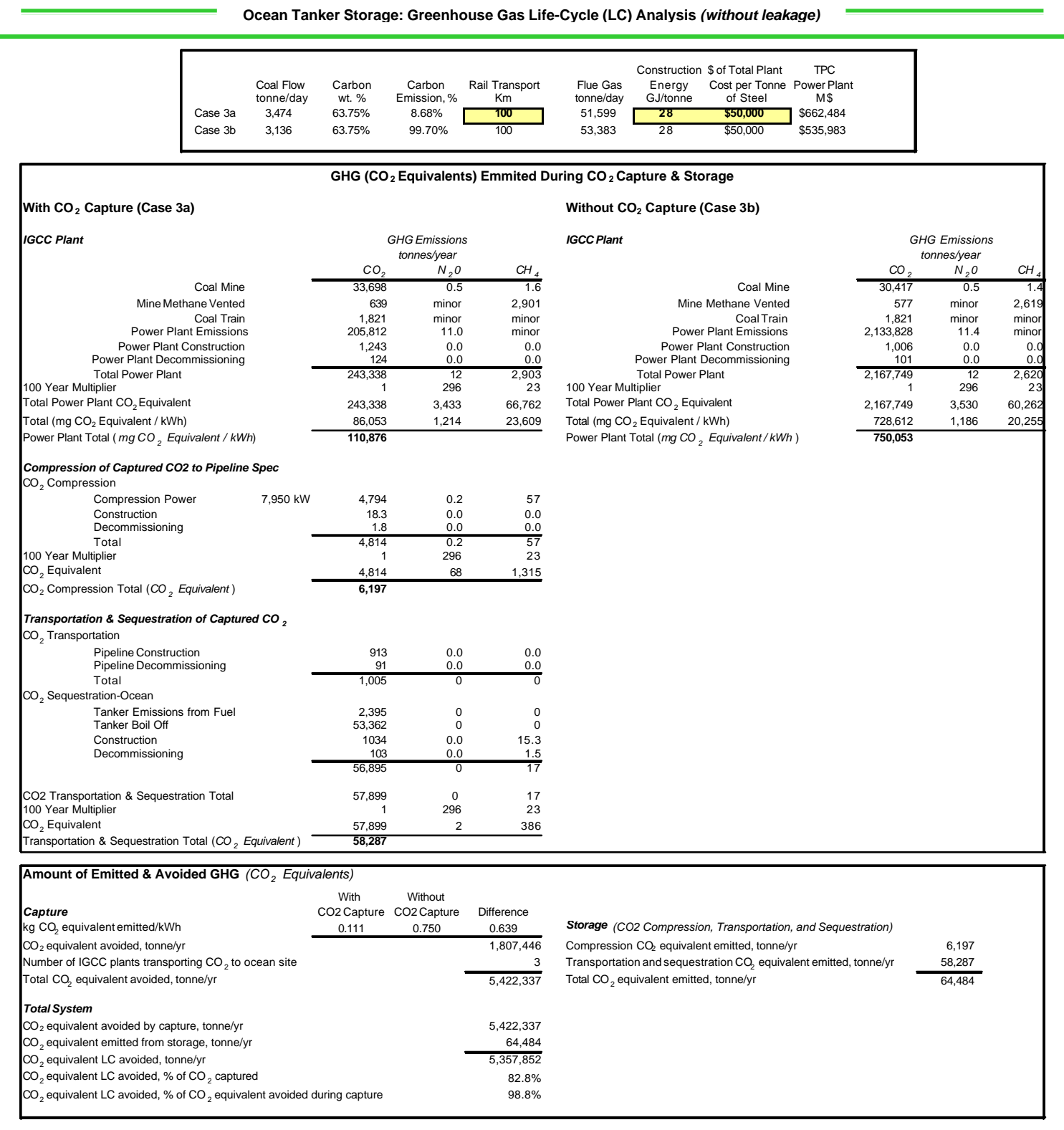




\section{EXPLANATION OF PROCESS INPUT AND SUMMARY SPREADSHEETS}

\section{Process Input sheet}

The Process Input sheet includes key physical and economic parameters for estimating $\mathrm{CO}_{2}$ storage costs. As for the entire spreadsheet, parameters in blue and contained in rectangular boxes can be varied by the user.

\section{Design Basis Section}

Definitions of these parameters can be found in the 'Methodology Used' section of the relevant chapter. Base-case estimates of these parameters are entered in the orientation version of the spreadsheet. The design basis assumes that one IGCC (Case $3 a) \mathrm{CO}_{2}$ capture plant provides the $\mathrm{CO}_{2}$ for the EOR, ECBMR, and geologic storage options. In the case of the ocean pipeline and ocean tanker storage options, however, it is assumed that the quantity of $\mathrm{CO}_{2}$ handled is equal to that supplied by three IGCC plants.

\section{Economic Section}

For the EOR and ECBMR options, the revenue generated from the enhanced production can offset or partially offset $\mathrm{CO}_{2}$ storage costs. In the case of the other storage options, however, there is no value-added product.

\section{EOR and ECBMR Storage Options Only}

The economic section of the Process Input sheet is structured the same for the EOR and ECBMR options. Therefore, the description that is given below, which directly relates to the EOR case, also applies to the ECBMR scenario.

For EOR, Wellhead Oil Price is the key economic parameter. The Wellhead Oil Price and the Oil Production rate (Design Basis section) determine the enhanced oil revenue from the EOR operation. The $\mathrm{CO}_{2}$ storage cost minus enhanced oil revenue gives the net cost of storing $\mathrm{CO}_{2}$. When oil revenue is greater than the $\mathrm{CO}_{2}$ storage cost, the net cost of storing $\mathrm{CO}_{2}$ is negative (i.e., a revenue). From the perspective of an EOR operation, a positive net storage cost equals the breakeven $\mathrm{CO}_{2}$ tipping fee. A negative net storage cost equals the breakeven $\mathrm{CO}_{2}$ purchase price. Note that a Breakeven Oil Price is provided in the Process Input sheet. This is the 
Wellhead Oil Price required for oil revenues to offset the cost of $\mathrm{CO}_{2}$ storage. Finally, the Oil Royalty is the percent of the Wellhead Oil price received by the owner of the oil rights and the Wellhead Oil Price minus the Oil Royalty gives the Oil Credit.

\section{All Storage Options}

The After-Tax Discount Rate (see Table 2-1 in Section 2.1.1) is used to calculate the net present value (NPV) of $\mathrm{CO}_{2}$ revenues (i.e., $\mathrm{CO}_{2}$ price times tonnes $\mathrm{CO}_{2}$ abated) and $\mathrm{CO}_{2}$ abatement costs to reflect the time-value of money. For regulated economics, the return on debt and equity is set by regulators and the discount rate equals the overall annual return to debt and equity. With assumptions in Table 2-1 of Section 2.1.1, the after-tax discount rate is 6.09 percent. Note that the carrying charge varies with discount rate because, in a regulated environment, the discount rate is the overall annual return to debt and equity, a parameter that is built into the carrying charge. A 6.09 percent After-tax Discount Rate gives a 15.0 percent Levelized Carrying Charge Factor.

\section{Summary Sheet}

The four sections in this sheet summarize the cost of capturing and storing $\mathrm{CO}_{2}$. The bottom- line costs in Summary sheet sections 1-3 are in units of $\$ /$ tonne $\mathrm{CO}_{2}$ captured or avoided. Costs in Summary sheet section 4 are in units of $\$ / \mathrm{MWh}$ and indicate incremental effects of $\mathrm{CO}_{2}$ capture, $\mathrm{CO}_{2}$ storage, and Year 21-100 storage costs on cost of electricity (COE).

\section{Summary Sheet Section 1-Levelized Annual $\mathrm{CO}_{2}$ Storage Costs (Years 1-20)}

Summary sheet section 1 provides results for a levelized annual storage cost analysis for years 120 , the book life of the storage operation.

Costs in Summary sheet section 1 are presented on a $\mathrm{CO}_{2}$ Captured Basis (column 1) and a LifeCycle (LC) Avoided GHG Basis for storage only (column 3). General approaches for calculating costs on these bases are described on in Sections 2.2 and 2.3.

\section{Summary Sheet Section 2-Levelized Annual $\mathrm{CO}_{2}$ Capture and Net Storage Costs (Years 1-20)}

This section is similar to Summary sheet section 1, but presents costs for capture and storage combined. Costs in this section are presented on $\mathrm{a} \mathrm{CO}_{2}$ Captured Basis (column 1), $\mathrm{CO}_{2}$ Avoided Basis for capture and storage combined (column 2) and a Life-Cycle (LC) Avoided GHG Basis for capture and storage combined (column 3). General procedures for calculating costs on these bases are described in Sections 2.2 and 2.3 of this report. 


\section{Summary Sheet Section 3- $\mathrm{CO}_{2}$ Capture and Storage Costs, NPV Basis (Years 1-100)}

The structure of this section is the same as for Summary sheet section 2 except that the first four lines contain net present values (NPVs) for years 1-100 instead of annual levelized values for years 1-20. The last line in Summary sheet section 3 contains costs in units of $\$ /$ tonne $\mathrm{CO}_{2}$; these bottom- line costs are calculated as the breakeven $\mathrm{CO}_{2}$ price required to offset $\mathrm{CO}_{2}$ capture and storage costs. Note that this breakeven $\mathrm{CO}_{2}$ price is constant over time. This is the price at which the NPV of $\mathrm{CO}_{2}$ revenues (i.e., $\mathrm{CO}_{2}$ price times $\mathrm{CO}_{2}$ stored or avoided) equals the NPV of costs for $\mathrm{CO}_{2}$ capture and storage combined. The theory for calculating the breakeven $\mathrm{CO}_{2}$ price is presented in Section 2.4. The same theory and procedures are used for the forestry and cropland $\mathrm{CO}_{2}$ sink enhancement options in this project. Using these procedures, the bottom-line costs (\$/tonne $\mathrm{CO}_{2}$ equivalent of GHG avoided on a life-cycle basis) in column 3 of Summary sheet section 3 can be compared with life-cycle costs for forestry and cropland sink enhancement options that differ greatly from $\mathrm{CO}_{2}$ capture/storage options in the timing of when costs occur and when $\mathrm{CO}_{2}$ is stored and/or leaks back to the atmosphere.

Equation (8) in Section 2.4 reduces to a ratio of total $\mathrm{CO}_{2}$ abatement costs to total $\mathrm{CO}_{2}$ abatement for cases in which annual $\mathrm{CO}_{2}$ storage costs and annual $\mathrm{CO}_{2}$ abatement change proportionally over time. For the $\mathrm{CO}_{2}$ capture and storage options in this project, $\mathrm{CO}_{2}$ abatement costs and $\mathrm{CO}_{2}$ abatement are levelized over time for years 1-20. This means that the bottom-line costs in Summary sheet section 3 (\$/tonne of $\mathrm{CO}_{2}$ ) are the same as in Summary sheet section 2 unless monitoring and/or transaction costs occur in years 21-100 without corresponding levels of $\mathrm{CO}_{2}$ abatement. The difference in bottom-line costs for Summary sheet sections 2 and 3 is also increased if $\mathrm{CO}_{2}$ leaks occur in years 21-100.

\section{Summary Sheet Section 4-Cost of Electricity, \$/MWh}

Costs in Summary sheet section 4 are in units of $\$ / \mathrm{MWh}$ and indicate incremental effects of $\mathrm{CO}_{2}$ capture (years 1-20), $\mathrm{CO}_{2}$ storage (years 1-20), and $\mathrm{CO} 2$ storage (years 21-100, e.g., monitoring and/or transaction costs) on COE. Procedures for calculating these incremental effects on COE are in Section 2.1.4. 


\section{STATUS AND COSTS OF EXISTING FORESTRY SEQUESTRATION PROJECTS}

The first forestry-based greenhouse gas offset projects took place in the early 1990s, as shown in Table $\mathrm{C}-1^{1}$. These were voluntary projects since there were no legal requirements to abate greenhouse gases. The voluntary aspect was somewhat reflected in the price paid for carbon sequestration, which averaged about $\$ 0.2 / \mathrm{t} \mathrm{C}$ based upon the costs to the investor. The signing of the UN Framework Convention on Climate Change in Rio de Janeiro in 1992 launched the concept of Joint Implementation to reduce greenhouse gas emissions. This led to an increase in investment in forestry sequestration. Between 1992 and the First Conference of the Parties (COP-1) in 1995, the average price paid for carbon sequestration is estimated to be about $\$ 2 / \mathrm{t}$, 10 times higher than before. At COP-1, developing countries' concerns about the concept of Joint Implementation resulted in a compromise that consisted of a pilot phase during which projects were called Activities Implemented Jointly (AIJ). These projects were conducted with the objective of establishing protocols and creating experiences but without allowing carbon crediting between developed countries. In this new environment where companies were faced with great uncertainty about the potential value of projects, there was a large reduction in investment in new sequestration projects and the willingness to pay for sequestration fell to $\$ 0.6 / t$ C. In the year preceding COP-3, in Kyoto in December 1997, there was great anticipation that binding commitments would be agreed, which would entail hard costs for industrialized countries. This led to an increase in the level of investment in forestry sequestration projects and the average price paid inc reased to $\$ 12 / \mathrm{tC}$. Following COP-3, there was even more interest in forestry sequestration and the price paid for carbon credits in some cases rose as high as $\$ 20-25 / t$ C. The supply of carbon offsets became more organized and more sophisticated. This is the case for the Costa Rican national program, which is the first producer-led carbon-offset initiative in the world and the first to utilize independent certification and insurance. 
Table C-1

Forestry sequestration projects initiated until mid-1998

\begin{tabular}{|c|c|c|c|c|c|c|}
\hline Project name & $\begin{array}{l}\text { Date } \\
\text { proposed / } \\
\text { initiated }\end{array}$ & $\begin{array}{l}\text { Carbon } \\
\text { offset } \\
(1000 \text { t C) }\end{array}$ & $\begin{array}{l}\text { Area } \\
\text { (ha) }\end{array}$ & $\begin{array}{l}\text { Host } \\
\text { country }\end{array}$ & $\begin{array}{l}\text { Investor } \\
\text { country }\end{array}$ & $\begin{array}{l}\text { Project } \\
\text { description }\end{array}$ \\
\hline AES-Care & 1990 & 10,500 & 186,000 & Guatemala & USA & Agroforestry \\
\hline Face Malaysia & 1992 & 4,250 & 25,000 & Malaysia & Netherlands & $\begin{array}{l}\text { Enrichment } \\
\text { planting }\end{array}$ \\
\hline Face-Kroknose & 1992 & 3,080 & 16,000 & Czech R. & Netherlands & Park rehabilitation \\
\hline Face Netherlands & 1992 & 885 & 5,000 & Netherlands & Netherlands & Urban forestry \\
\hline ICSB-NEP 1 & 1992 & 56 & 1,400 & Malaysia & USA & $\begin{array}{l}\text { Reduced impact } \\
\text { logging }\end{array}$ \\
\hline AES-Oxfam-Coica & 1992 & 15,000 & $1,500,000$ & South America & USA & Forest protection \\
\hline $\begin{array}{l}\text { ASS-Nature } \\
\text { Conservancy }\end{array}$ & 1992 & 15,380 & 58,000 & Paraguay & USA & Forest protection \\
\hline Face-Profafor & 1993 & 9,660 & 75,000 & Ecuador & Netherlands & $\begin{array}{l}\text { Small farmers } \\
\text { plantation forestry }\end{array}$ \\
\hline RUSAFOR-SAP & 1993 & 79 & 450 & Russia & USA & Plantation forestry \\
\hline Face Uganda & 1994 & 6,750 & 27,000 & Uganda & Netherlands & $\begin{array}{l}\text { Forest } \\
\text { rehabilitation }\end{array}$ \\
\hline Rio Bravo & 1994 & 1,300 & 87,000 & Belize & USA & $\begin{array}{l}\text { Forest protection } \\
\text { and management }\end{array}$ \\
\hline Carfix & 1994 & 2,000 & 91,000 & Costa Rica & USA & $\begin{array}{l}\text { Forest protection, } \\
\text { and management }\end{array}$ \\
\hline Ecoland/Tenaska & 1995 & 350 & 2,500 & Costa Rica & USA & $\begin{array}{l}\text { Forest } \\
\text { conservation }\end{array}$ \\
\hline ICSB-NEP 2 & 1996 & 39 & 980 & Malaysia & USA & $\begin{array}{l}\text { Reduced Impact } \\
\text { Logging }\end{array}$ \\
\hline Noel Kempif M. & 1996 & 14,000 & $1,000,000$ & Bolivia & UK/USA & $\begin{array}{l}\text { Forest } \\
\text { conservation and } \\
\text { management }\end{array}$ \\
\hline Klinki Forestry & 1997 & 1,600 & 87,000 & Costa Rica & USA & $\begin{array}{l}\text { Reforestation with } \\
\text { klinki }\end{array}$ \\
\hline Burkina Faso & 1997 & 67 & 300,000 & Burkina Faso & Denmark & $\begin{array}{l}\text { Fire wood } \\
\text { community } \\
\text { forestry }\end{array}$ \\
\hline Scolel Te & 1997 & 15 & 13,000 & Mexico & UK/France & $\begin{array}{l}\text { Community } \\
\text { forestry }\end{array}$ \\
\hline
\end{tabular}


Table C-1 (continued)

Forestry sequestration projects initiated until mid-1998

\begin{tabular}{|c|c|c|c|c|c|c|}
\hline $\begin{array}{l}\text { Project name } \\
\text { PAP OCIC }\end{array}$ & $\begin{array}{c}\text { Date } \\
\text { proposed / } \\
\text { initiated } \\
1997\end{array}$ & $\begin{array}{c}\text { Carbon } \\
\text { offset } \\
(1000 \text { t C) } \\
18,000\end{array}$ & $\begin{array}{l}\begin{array}{l}\text { Area } \\
\text { (ha) }\end{array} \\
570,000\end{array}$ & $\begin{array}{l}\text { Host } \\
\text { country } \\
\text { Costa Rica }\end{array}$ & $\begin{array}{l}\text { Investor } \\
\text { country } \\
\text { Norway, USA }\end{array}$ & $\begin{array}{l}\text { Project } \\
\text { description } \\
\text { Forest } \\
\text { conservation }\end{array}$ \\
\hline Norway-Costa Rica & 1997 & 230 & 4,000 & Costa Rica & Norway & $\begin{array}{l}\text { Forest } \\
\text { rehabilitation and } \\
\text { conservation }\end{array}$ \\
\hline Tesco 'green petrol' & 1998 & n.a. & n.a. & Undefined & UK & Forestry \\
\hline Green fleet initiative & 1997 & n.a. & n.a. & Australia & Australia & Reforestation \\
\hline AES—Ilha Bananal & 1998 & n.a. & 260,800 & Brazil & USA & $\begin{array}{l}\text { Forest } \\
\text { rehabilitation and } \\
\text { conservation }\end{array}$ \\
\hline NSWSF + utilities & 1998 & 1,300 & 10,000 & Australia & Australia & Reforestation \\
\hline $\begin{array}{l}\text { World Bank Prototype } \\
\text { Carbon Fund }\end{array}$ & 1998 & n.a. & n.a. & International & International & $\begin{array}{l}\text { Renewable } \\
\text { energy and } \\
\text { forestry }\end{array}$ \\
\hline ProNatura-Peugeot & 1999 & n.a. & n.a. & Brazil & France & $\begin{array}{l}\text { Forest } \\
\text { rehabilitation and } \\
\text { management }\end{array}$ \\
\hline TNC Guaraquecaba & 1999 & $\mathrm{n}$ a & $\mathrm{Na}$. & Brazil & USA & $\begin{array}{l}\text { Forest } \\
\text { conservation, } \\
\text { rehabilitation and } \\
\text { management }\end{array}$ \\
\hline Totals/average & & 104,541 & $4,239,930$ & & & \\
\hline
\end{tabular}




\section{References}

1 Moura Costa P. Forestry-based greenhouse gas mitigation: a short history of market evolution. Global Greenhouse Emissions Trader Issue 8, Sept. 2000, p. 2-3.

C-4 


\section{PUBLISHED COSTS OF FORESTRY CARBON SEQUESTRATION}

The following table is intended to give an indication of the range of published costs of forestry carbon sequestration and marginal values of land. In some of the references, best estimates or median costs are given along with ranges, which are shown here in brackets.

Table D-1

Published costs of forestry carbon sequestration

\begin{tabular}{|c|c|c|c|c|c|}
\hline Ref. & Description & Country & $\begin{array}{c}\text { Establishment } \\
\$ / \text { ha }\end{array}$ & $\begin{array}{c}\text { Maintenance } \\
\text { \$/ha y }\end{array}$ & Land \\
\hline 1 & $\begin{array}{l}\text { Tree planting } \\
\text { Pacific_pasture } \\
\text { —cropland } \\
\text { —-forest } \\
\text { South.East-pasture } \\
\text { —cropland } \\
\text { —-forest } \\
\text { Other regions-pasture } \\
\text { —cropland } \\
\text { —forest }\end{array}$ & USA & $\begin{array}{c}531 \\
445 \\
610 \\
166 \\
147 \\
299 \\
155-484 \\
141-373 \\
287-378 \\
\end{array}$ & & $\begin{array}{c}\$ / \mathrm{ha} / \mathrm{y} \\
31 \\
143 \\
11 \\
66 \\
126 \\
23 \\
31-69 \\
111-200 \\
11-30\end{array}$ \\
\hline 2 & $\begin{array}{l}\text { Afforestation } \\
\text { Reforestation }\end{array}$ & $\begin{array}{c}\text { Argentina } \\
\text { USA } \\
\text { Argentina } \\
\text { Australia } \\
\text { Brazil } \\
\text { Canada } \\
\text { China } \\
\text { Germany } \\
\text { India } \\
\text { Malaysia } \\
\text { Mexico } \\
\text { South Africa } \\
\text { USSR } \\
\text { USA }\end{array}$ & $\begin{array}{c}988 \\
255(39-373) \\
1684(662-1684) \\
347(306-740) \\
637(293-1207) \\
417(335-513) \\
393(329-410) \\
1391(442-3662) \\
477(220-1845) \\
303(285-309) \\
402(354-526) \\
952(910-993) \\
83(69-171) \\
256(53-346)\end{array}$ & & \\
\hline
\end{tabular}


Table D-2 (continued)

Published costs of forestry carbon sequestration

\begin{tabular}{|c|c|c|c|c|c|}
\hline Ref. & Description & Country & $\begin{array}{c}\text { Establishment } \\
\text { \$/ha }\end{array}$ & $\begin{array}{c}\text { Maintenance } \\
\text { \$/ha y }\end{array}$ & Land \\
\hline 3 & $\begin{array}{l}\text { Reforestation } \\
\text { Afforestation } \\
\text { Agroforestry }\end{array}$ & $\begin{array}{c}\text { Boreal } \\
\text { Temperate } \\
\text { Tropical } \\
\text { Temperate } \\
\text { Tropical }\end{array}$ & $\begin{array}{c}324(127-455) \\
357(257-911) \\
450(303-1183) \\
259(41-444) \\
454(255-699)\end{array}$ & & \\
\hline 4 & $\begin{array}{l}\text { Reforestation, public land } \\
\text { Reforestation, private land } \\
\text { Reforestation }\end{array}$ & $\begin{array}{c}\text { USA } \\
\text { USA } \\
\text { Tropical }\end{array}$ & $\begin{array}{l}680(230-996) \\
680(230-996) \\
395(153-680)\end{array}$ & & $\begin{array}{c}0 \\
84 \$ / \text { ha/y } \\
0\end{array}$ \\
\hline 5 & Plantations (softwood) & Australia & $\begin{array}{c}428 \text { establishment, } \\
232 \text { replanting after } \\
\text { harvest }\end{array}$ & $\begin{array}{l}17 \text { management } \\
+19 \text { fire insurance }\end{array}$ & $\begin{array}{c}250-1500 \\
\$ / \text { ha }\end{array}$ \\
\hline 6 & $\begin{array}{l}\text { Plantations - lowland } \\
\text { Plantations - upland }\end{array}$ & UK & $\begin{array}{l}1762 \\
3124\end{array}$ & $\begin{array}{l}42-49 \\
39-77\end{array}$ & $\begin{array}{c}2980 \$ / \mathrm{ha} \\
(950- \\
4750)\end{array}$ \\
\hline 7 & Plantations & $\begin{array}{l}\text { Industrialized } \\
\text { countries } \\
\text { Developing } \\
\text { countries }\end{array}$ & $\begin{array}{l}680 \\
400\end{array}$ & 20 & \\
\hline 9 & $\begin{array}{l}\text { Pasture land value } \\
\text { Cropland value } \\
\text { Pasture land value } \\
\text { Cropland value }\end{array}$ & USA & & & \\
\hline
\end{tabular}

Note: Exchange rate assumed to be 2 Aus\$/US\$

\section{References}

1 Moulton, R.J., and K.R. Richards. Costs of sequestering carbon through tree planting and forest management in the United States. USDA Forest Service General Technical Report WO-58. December 1990.

2 Winjum, J.K., R.K. Dixon, and P.E. Schroeder. Forest management and carbon storage: an analysis of 12 key forest nations. Water, Air and Soil Pollution 70: 239-257, 1993.

3 Sedjo, R.A., et. al. The economics of managing carbon via forestry: assessment of existing studies. Environmental and Resource Economics 6: 139-165, 1995.

4 Sanghi, A.K., and K.S. Michael. Carbon sequestering through reforestation: cost and potential for New York. Air \& Waste Management Association 84th Annual Meeting \& Exhibition, Vancouver, B.C., June 16-21, 1991. 
5 Bureau of Transport and Communication Economics. Costs of carbon sequestration through afforestation: greenhouse gas emissions Australian transport. Working Paper 23, Commonwealth of Australia, 1996, ISBN 0642245916.

6 ETSU. Full fuel-cycle study on power generation schemes incorporating the capture and disposal of carbon dioxide, volume 5: pulverised coal super-critical steam cycle with offset forestry $\mathrm{CO}_{2}$ mitigation. Report produced for the IEA Greenhouse Gas R\&D Programme, October 1994.

7 Huotari, J.,S. Helynen, and M. Flyktman. Indirect biofixation of $\mathrm{CO}_{2}$, VTT Finland, report CRE/CON 1424 produced for IEA Greenhouse Gas R\&D Programme. September 1993.

8 USDA agricultural land values. March 2000. www.usda.gov/nass/.

9 USDA agricultural cash rents. July 2000. www.usda.gov/nass/. 


\section{ESTIMATING ECONOMIC INCENTIVES REQUIRED TO ACHIEVE ADOPTION OF CONSERVATION-TILLAGE SYSTEMS IN SELECTED REGIONS OF THE UNITED STATES}

\section{Background}

The purpose of this appendix is to provide first-approximation regional estimates of economic incentives ( $\$ /$ hectare) necessary to induce farmers to adopt reduced-tillage practices in regionally important cropping systems.

This appendix indicates the likely range of incentives required to achieve adoption of conservation-tillage systems and estimates incentives for the four regional case studies listed below. The four case studies were selected to (1) represent regions and cropping systems with the greatest amount of avoided GHG emissions that could be achieved by reducing tillage, and

(2) illustrate the range of amounts per hectare and costs of avoided GHG emissions that could be achieved by reducing tillage.

1. Corn/soybean rotations in the Corn Belt being converted from intensive-till to either no-till or moderate-till. This case includes best-case and worst-case scenarios concerning effects of reducing tillage on $\mathrm{N}$ fertilizer requirements and on $\mathrm{N}_{2} \mathrm{O}$ emissions (Chapter19)

2. Continuous corn cropping systems in the Corn Belt being converted from intensive-till to either no-till or moderate-till. This case includes best-case and worst-case scenarios concerning effects of reducing tillage on $\mathrm{N}$ fertilizer requirements and on $\mathrm{N}_{2} \mathrm{O}$ emissions (Chapter 20)

3. Wheat/fallow rotations in the western Great Plains being converted from intensive-till to notill. This case includes variations in the amount of SOC sequestered and amount of $\mathrm{N}_{2} \mathrm{O}$ emissions due to reducing tillage (Chapter 21)

4. Intensive-till cotton to no-till cotton in the southeastern U.S. This case includes variations in the amount of SOC sequestered and amount of $\mathrm{N}_{2} \mathrm{O}$ emissions due to reducing tillage (Chapter 22)

Tillage-system budgets and yield distributions over time were used to estimate the incentive levels required to foster the adoption of conservation-tillage systems. 


\section{Budgeting Case Study Tillage Systems}

Regional budgets were developed for tillage and cropping systems within each case study. Consistent budgeting methodology was used across tillage and cropping systems and regions as follows. The chemical and fertilizer application rates, seed, drying, insurance, and miscellaneous costs were based on state Agricultural Extension Service budgets whenever possible. In instances where published costs were not found (for example, for no-tillage corn/soybean chemical use in Indiana), regional specialists were contacted for the application/cost information.

The various state Agricultural Extension Service budgets employ varying methods for estimating machine variable costs; therefore, in this study, pre-harvest machinery operating costs were estimated using the standardized methodology of the American Society of Agricultural Engineers (ASAE) reported by the AAEA Task Force on Commodity Costs and Returns ${ }^{1}$. ASAE methodology uses estimated engineering equations along with typical machinery hours, age, size, and type to estimate all costs associated with repair, maintenance, fuel, and lubrication. Machinery hours, repair costs, and fuel costs for each piece of machinery were included in the budget. Total variable costs include both repair and fuel costs. Labor hours were based on the sum of all machinery time. It has become common practice to custom hire the harvesting field operation; therefore, this study used the lower-bound custom hire estimates from published state Agricultural Extension Service publications. Cotton budgets were the one exception where the range of custom-hire costs is so wide that there is a high rate of error in using the custom rate. Therefore, cotton-harvest cost was based on ASAE agricultural engineering estimates. Interest on pre-harvest costs was calculated using a 7.5 percent interest rate and labor costs were calculated at $\$ 8 /$ hour for all regions. The sources of the individual budgets are listed in Attachment E-1 of Appendix E.

\section{Estimating the Incentives to Adopt Reduced-Tillage Practices}

Published research has shown that in many cases the mean net returns on reduced-tillage practices are equal to or greater than the returns from conventional tillage due to decreases in input costs, yet only 35 percent of agricultural lands have adopted conservation tillage practices ${ }^{2}$. One factor inhibiting the adoption of reduced tillage is the additional risk perceived by farmers and the perceived effects of these risks on net returns ${ }^{3,4,5,6}$. These risks include: the potential for reduced yields during initial years of adoption, the increased yield variability that reduced tillage practices may introduce, input use variability, and the human and/or physical capital investment that producers may incur. For this study, the impacts of these factors are represented in a probability distribution of net returns that farmers may perceive to be riskier than that associated with conventional practices. This study assumed that yield variation and production inputs are the primary factors of risk in cropland systems. The reduced tillage incentive must overcome the cost of net-returns variability before a risk adverse farmer will adopt reduced-tillage practices. Therefore, before finding the incentive level which will compel a switch to reduced tillage, farmer risk aversion behavior must be considered.

A methodological framework, referred to as the expected utility model ${ }^{7}$, provides a useful means for evaluating risk-return tradeoffs in agricultural production settings. In the expected utility 
model, the certainty equivalent (CE) for a risky decision is the return on a risk-free investment that makes the decision maker indifferent between the payoff from the risky decision and the payoff from the risk-free investment. The CE from one decision $(x)$ is greater than for another decision ( $y$ ) if, and only if, decision $x$ yields greater utility than decision $y$, hence making decision $x$ preferable over decision $y$ by a risk averse individual. This relationship allows inferences to be made about the risk rankings of alternative agricultural practices. Finally, the $\mathrm{CE}$ is calculated in monetary units, and thus, it can be used as an indicator of the economic differences between conventional and alternative practices. For example, in terms of reduced tillage, the CE of profit per unit of land area can be approximated using Equation $1^{8}$.

$$
\mathrm{CE}\left(\mathrm{NR}_{\mathrm{x}}\right)=\mathrm{E}\left(\mathrm{NR}_{\mathrm{x}}\right)-\lambda / 2 \operatorname{Var}\left(\mathrm{NR}_{\mathrm{x}}\right)
$$

Where $E\left(N_{x}\right)$ is the expected net return for tillage practice $\mathrm{x}$, ? is the value of the PrattArrow absolute risk aversion coefficient, and $\operatorname{Var}\left(\mathrm{NR}_{\mathrm{x}}\right)$ is the variance of net returns for tillage practice $\mathrm{x}$.

Freund ${ }^{9}$ has shown that the linear mean-variance objective function is consistent with the negative exponential utility function (assumes constant absolute risk aversion) and normally distributed profits. Thus, if $\mathrm{CE}\left(\mathrm{NR}_{\mathrm{x}}\right)>\mathrm{CE}\left(\mathrm{NR}_{\mathrm{y}}\right)$, then practice $\mathrm{x}$ is a risk efficient strategy for a risk averse farmer because it provides a higher expected utility and would be adopted by the farmer. The difference in the $\mathrm{CE}$ profit, $\mathrm{CEI}=\mathrm{CE}\left(\mathrm{NR}_{\mathrm{x}}\right)-\mathrm{CE}\left(\mathrm{NR}_{\mathrm{y}}\right)$, provides an estimated monetary value, or incentive, that a risk averse farmer would need to be compensated for in order to adopt alternative tillage practice $\mathrm{x}$.

Incentive levels for reduced-tillage practices were calculated using estimated certainty equivalents. The incentive level is defined as the monetary value that would make the producer indifferent between a certain choice (current practice) and a risky proposition (alternative tillage system).

\section{Analytical Procedure}

Incentive level estimation requires the estimation of the net returns of both the conventional tillage practices and the alternative reduced-tillage practices for each rotation and in each region. Total variable cost is given by the regional budgets for important combinations cropping and tillage systems. To estimate the gross revenue side of the equations, it is necessary to estimate the yield levels of the various regional cropping and tillage systems. Through an extensive literature and data search, 14 tillage experiments which studied the side-by-side yield effects of alternative tillage practices were identified which match the cases in this study. The most rigorous eight of these 14 studies were selected to represent the cases of interest. The reasons for the selection of these eight are reported in Attachment E- 2 of Appendix E. This analysis uses the selected regional tillage experiments to estimate the tillage-system effects on yield, and therefore, gross revenue. The mean yield, standard deviation, and coefficients of variation and variable costs for each cropping system, tillage system, and region are presented in Table E- 1 .

In some cases, budgets were altered to appropriately fit the tillage practices in individual experiments. For example, in the central Corn Belt region, one study used chisel plow for the 
conventional tillage practice while another experiment used disking for the conventional tillage practice. The regional rotation budget was altered to accurately represent the conventional tillage practice of each experiment.

All budget and yield sources are indicated in Attachment E-2. To make comparisons across differing rotation periods, the total variable costs and total net returns of all rotations were converted to annual average costs and revenues. Hence, final incentive levels were also computed on an annul basis.

Risk is a significant factor to include in analysis of an incentive level which would prompt farmers to switch to an alternative practice. To include risk, an empirical distribution of yields from each experiment was computed for each experiment. Attachment 3 includes histograms of the distributions of the tillage systems compared. Using randomly selected yield levels from the empirical distributions of each experiment and using them in conjunction with their specific production cost budgets, the net returns were simulated 300 times. This procedure provided a probability distribution of net returns for each cropping and tillage system and region. 
Table E-1

Yield mean, standard deviation, and coefficient of variation and variable costs at selected sites.

\begin{tabular}{|c|c|c|c|c|c|c|c|}
\hline Region & Rotation & Site \& Crop & Tillage & $\begin{array}{c}\text { Mean } \\
\text { (Mg/ha) }\end{array}$ & $\begin{array}{l}\text { St.Dev. } \\
\text { (Mg/ha) }\end{array}$ & $\begin{array}{l}\text { Coef. } \\
\text { Var. }\end{array}$ & $\begin{array}{c}\text { Variable } \\
\text { Cost }(\$ / \text { ha })\end{array}$ \\
\hline \multirow{22}{*}{ Corn Belt } & \multirow{16}{*}{$\begin{array}{l}\text { Corn/ } \\
\text { Soybean }\end{array}$} & \multirow{2}{*}{$\begin{array}{r}\text { IAAP- } \\
\text { corn }\end{array}$} & Intensive & 9.15 & 2.57 & 0.28 & 434.92 \\
\hline & & & No-Till & 8.76 & 2.19 & 0.25 & 436.67 \\
\hline & & \multirow{2}{*}{$\begin{array}{r}\text { IAAP- } \\
\text { soybean }\end{array}$} & Intensive & 2.92 & 0.31 & 0.11 & 285.51 \\
\hline & & & No-Till & 2.81 & 0.30 & 0.11 & 286.84 \\
\hline & & \multirow{3}{*}{$\begin{array}{r}\text { NERDF- } \\
\text { corn }\end{array}$} & Intensive & 9.93 & 1.57 & 0.16 & 434.92 \\
\hline & & & Reduced & 9.64 & 1.67 & 0.17 & 470.61 \\
\hline & & & No-Till & 9.71 & 1.85 & 0.19 & 436.67 \\
\hline & & \multirow{3}{*}{$\begin{array}{l}\text { NERDF- } \\
\text { soybean }\end{array}$} & Intensive & 3.03 & 0.60 & 0.20 & 285.51 \\
\hline & & & Reduced & 2.92 & 0.62 & 0.21 & 320.80 \\
\hline & & & No-Till & 2.96 & 0.62 & 0.21 & 286.84 \\
\hline & & \multirow{3}{*}{$\begin{array}{l}\text { ARC- } \\
\text { corn }\end{array}$} & Intensive & 11.96 & 1.73 & 0.14 & 445.98 \\
\hline & & & Reduced & 12.06 & 1.71 & 0.14 & 447.49 \\
\hline & & & No-Till & 11.61 & 1.74 & 0.15 & 413.53 \\
\hline & & \multirow{3}{*}{$\begin{array}{r}\text { ARC- } \\
\text { soybean }\end{array}$} & Intensive & 3.54 & 0.44 & 0.12 & 303.29 \\
\hline & & & Reduced & 3.39 & 0.46 & 0.14 & 311.47 \\
\hline & & & No-Till & 3.38 & 0.58 & 0.17 & 277.50 \\
\hline & \multirow{6}{*}{ Cont. Corn } & \multirow{3}{*}{$\begin{array}{r}\text { NERDF- } \\
\text { corn }\end{array}$} & Intensive & 8.88 & 2.04 & 0.23 & 488.17 \\
\hline & & & Reduced & 8.42 & 2.25 & 0.27 & 525.86 \\
\hline & & & No-Till & 8.18 & 2.11 & 0.26 & 491.93 \\
\hline & & \multirow{3}{*}{$\begin{array}{r}\text { ARC- } \\
\text { corn }\end{array}$} & Intensive & 11.21 & 1.86 & 0.17 & 484.69 \\
\hline & & & Reduced & 11.09 & 1.68 & 0.15 & 485.68 \\
\hline & & & No-Till & 9.68 & 1.88 & 0.19 & 453.22 \\
\hline \multirow{6}{*}{$\begin{array}{l}\text { Central } \\
\text { Great } \\
\text { Plains }\end{array}$} & \multirow{2}{*}{$\begin{array}{c}\text { Cont. } \\
\text { Sorghum }\end{array}$} & \multirow{2}{*}{$\begin{array}{r}\text { RMF- } \\
\text { sorghum }\end{array}$} & Intensive & 5.37 & 1.45 & 0.27 & 290.60 \\
\hline & & & No-Till & 5.24 & 1.32 & 0.25 & 320.95 \\
\hline & \multirow{4}{*}{$\begin{array}{l}\text { Sorghum/ } \\
\text { Soybean }\end{array}$} & \multirow{2}{*}{$\begin{array}{r}\text { RMF- } \\
\text { soybean }\end{array}$} & Intensive & 2.64 & 0.58 & 0.22 & 254.68 \\
\hline & & & No-Till & 2.78 & 0.65 & 0.23 & 265.48 \\
\hline & & \multirow{2}{*}{$\begin{array}{r}\text { RMF- } \\
\text { sorghum }\end{array}$} & Intensive & 7.83 & 1.31 & 0.17 & 273.06 \\
\hline & & & No-Till & 8.26 & 1.45 & 0.18 & 302.75 \\
\hline \multirow{6}{*}{$\begin{array}{c}\text { Western } \\
\text { Great } \\
\text { Plains }\end{array}$} & \multirow{2}{*}{$\begin{array}{l}\text { Wheat/ } \\
\text { Fallow }\end{array}$} & \multirow{2}{*}{$\begin{array}{r}\text { SWK1- } \\
\text { wheat }\end{array}$} & Intensive & 2.56 & 0.76 & 0.30 & 203.31 \\
\hline & & & No-Till & 2.74 & 0.75 & 0.27 & 249.94 \\
\hline & \multirow{4}{*}{$\begin{array}{l}\text { Wheat/ } \\
\text { Sorghum } \\
\text { /Fallow }\end{array}$} & \multirow{2}{*}{$\begin{array}{r}\text { SWK1- } \\
\text { wheat }\end{array}$} & Intensive & 2.19 & 0.96 & 0.43 & 203.31 \\
\hline & & & No-Till & 2.23 & 0.77 & 0.35 & 249.94 \\
\hline & & \multirow{2}{*}{$\begin{array}{l}\text { SWK1- } \\
\text { sorghum }\end{array}$} & Intensive & 3.59 & 1.24 & 0.34 & 273.06 \\
\hline & & & No-Till & 4.31 & 1.18 & 0.27 & 304.40 \\
\hline \multirow{6}{*}{$\begin{array}{l}\text { Mississippi } \\
\text { River } \\
\text { Corridor }\end{array}$} & \multirow{4}{*}{$\begin{array}{c}\text { Corn/ } \\
\text { Soybean }\end{array}$} & ALB- & Intensive & 8.15 & 1.52 & 0.19 & 377.22 \\
\hline & & corn & No-Till & 8.67 & 1.27 & 0.14 & 437.04 \\
\hline & & ALB- & Intensive & 2.40 & 0.53 & 0.22 & 253.84 \\
\hline & & soybean & No-Till & 2.33 & 0.39 & 0.16 & 268.37 \\
\hline & Cotton & MES- & Intensive & 8.94 & 3.03 & 0.34 & 694.34 \\
\hline & & cotton & No-Till & 9.07 & 2.65 & 0.29 & 706.32 \\
\hline
\end{tabular}


The distributions of net returns were analyzed using the SIMETAR@ software to estimate confidence premium levels under risk aversion ${ }^{10}$. A risk aversion coefficient of .02 was selected for the analysis after revie wing the literature of risk aversion in agriculture at the per hectare level $^{11,5,12}$. The confidence premium represents the payment that is necessary to equal the perceived net returns under risk aversion of the alternative practice; in other words, the risk premium is the incentive level necessary for producers to adopt the alternative practice. The estimated incentive levels by each case study region and rotation are presented in Table E- 2 .

Table E-2

Incentive levels under base yields and prices

\begin{tabular}{|c|c|c|c|c|c|}
\hline $\begin{array}{l}\text { Proposed } \\
\text { Switch }\end{array}$ & Region & $\begin{array}{c}\text { Site } \\
\text { Abbv.* } \\
\text { and } \\
\text { Drainage }\end{array}$ & $\begin{array}{c}\text { Conventional } \\
\text { Rotation }\end{array}$ & $\begin{array}{c}\text { Alternative } \\
\text { Rotation }\end{array}$ & $\begin{array}{l}\text { Incentive Level } \\
\text { Under Base } \\
\text { Yields and } \\
\text { Prices (\$/ha) }\end{array}$ \\
\hline \multirow{11}{*}{$\begin{array}{c}\text { Intensive Till } \\
\text { To } \\
\text { No-Till }\end{array}$} & \multirow{4}{*}{ Corn Belt } & $\begin{array}{l}\text { IAAP } \\
\text { Poor }\end{array}$ & Corn/Soybean & Corn/Soybean & 25.18 \\
\hline & & $\begin{array}{c}\text { NERDF } \\
\text { Well }\end{array}$ & Corn/Soybean & Corn/Soybean & 20.51 \\
\hline & & $\begin{array}{c}\text { NERDF } \\
\text { Well }\end{array}$ & Cont. Corn & Cont. Corn & 66.05 \\
\hline & & $\begin{array}{l}\text { ARC } \\
\text { Poor }\end{array}$ & Cont. Corn & Cont. Corn & 99.98 \\
\hline & \multirow{3}{*}{$\begin{array}{l}\text { Central Great } \\
\text { Plains }\end{array}$} & RMF & Cont. Soybean & Cont. Soybean & 6.84 \\
\hline & & RMF & Sorghum/Soybean & Sorghum/Soybean & 0.74 \\
\hline & & NAF & Cont. Sorghum & Cont. Sorghum & 36.1 \\
\hline & \multirow{2}{*}{$\begin{array}{c}\text { Western } \\
\text { Great Plains }\end{array}$} & SWK1 & Wheat/Fallow & Wheat/Fallow & 14.63 \\
\hline & & SWK1 & Wheat /Fallow & $\begin{array}{l}\text { Wheat/Sorghum/ } \\
\text { Fallow }\end{array}$ & 15.17 \\
\hline & \multirow{2}{*}{$\begin{array}{l}\text { Mississippi } \\
\text { River } \\
\text { Corridor }\end{array}$} & ALB & Corn/Soybean & Corn/Soybean & 19.67 \\
\hline & & MES & Cont. Cotton & Cont. Cotton & 23.2 \\
\hline \multirow{4}{*}{$\begin{array}{l}\text { Intensive Till } \\
\text { To } \\
\text { Reduced Till } \\
\text { (Ridge Till) }\end{array}$} & \multirow{4}{*}{ Corn Belt } & $\begin{array}{l}\text { ARC } \\
\text { Poor }\end{array}$ & Corn/Soybean & Corn/Soybean & 15.22 \\
\hline & & $\begin{array}{c}\text { NERDF } \\
\text { Well }\end{array}$ & Corn/Soybean & Corn/Soybean & 56.17 \\
\hline & & $\begin{array}{l}\text { ARC } \\
\text { Poor }\end{array}$ & Cont. Corn & Cont. Corn & 3.51 \\
\hline & & $\begin{array}{c}\text { NERDF } \\
\text { Well }\end{array}$ & Cont. Corn & Cont. Corn & 101.26 \\
\hline
\end{tabular}

* Note: Definition of site abbreviations can be found in Attachment E-2. 


\section{Discussion of Incentive Level Results}

One would expect that the incentive level for switching from intensive-till to no-till would be higher for poorly drained soils than for well-drained soils, and this is the result in the Corn Belt rotations of corn/soybean and continuous corn. The corn/soybean incentive is $\$ 25 /$ ha for poorly drained soil and $\$ 20 /$ ha for well-drained soil. The continuous corn incentive for poorly drained soils is $\$ 100 /$ ha and $\$ 66 /$ ha for well-drained soils. In the continuous corn rotation, no-till yields decline considerably, thereby making no-till continuous corn very uncompetitive and resulting in very high incentive levels. Risks of lower and more variable yields associated with no-till continuous corn have been lowered somewhat in recent years via improvements in technology and experience.

When looking at the switch from intensive to reduced tillage, we see that the incentive levels are much higher in the well-drained soil type than the poorly drained. The poor soil drainage studies saw little yield drop in the reduced-tillage system, and in some cases, even increased yield (corn in corn/soybean rotation, ARC site). The reduced tillage systems in well-drained soils lost yield in all sites. One hypothesis for this result is that the poorer soils are simultaneously reaping the advantages of both less tillage and better drainage. The reduced tillage system studied in these experiments is the ridge-till system, where a field cultivator is used to build high rows in which the crops are planted. This would give the needed drainage a minimum of tillage intrusion.

In the central Great Plains, the profitability of intensive- and no-tillage sorghum/soybean rotations are about the same, with only a $\$ 0.74 /$ ha incentive level estimated to bring no-till into production. Continuous sorghum has a very high incentive level of $\$ 36 /$ ha. The mean yields are fairly close, but the increased cost of no-till sorghum causes the high-incentive level in this case.

In the wheat/fallow and wheat/sorghum/fallow rotations of the western Great Plains, the yields with no-till were actually higher than with intensive-till and yield variations with no-till were less. The incentive level of around $\$ 15 /$ ha is a result of the higher cost of no-till in these systems.

In the Mississippi River Corridor Region, the experimental results show that the switch from corn/soybean to corn/soybean-wheat would take an incentive level of $\$ 74 /$ ha. The wheat yield of the analysis is from a separate continuous wheat rotation in the region and this results in a mean yield of 4 tonne/ha, which is very low. The poor returns from wheat combined with the extra cost of the added crop, lead to this very high-incentive level. It is assumed that this is a very extreme estimate of the incentive level. By leaving wheat out of the rotation, the analysis shows an incentive level of $\$ 20 /$ ha for switching to no-till corn/soybean.

The experimental yield results of continuous cotton in the Mississippi River Corridor Region show no-till slightly higher and with less variation. The $\$ 23 /$ ha incentive level is, therefore, the result of the higher cost (\$12/ha) and risk of no-till. 


\section{Sensitivity of Incentives to Changes in Revenue}

The incentive levels described above (Table E-2) are based on current prices and, therefore, revenue. As prices (and revenue) change, the incentive levels will also change. Revenue at four other levels (10 percent and 20 percent more and less than current prices) was estimated using the same methodology as above. This enables revenue sensitivity equations to be estimated, which represent the change in incentive as the level of revenue changes. All resulting equations are listed in Table E-5. As prices change, the percentage change in revenue from the baseline level of revenue can be computed as represented in Equation 2. The baseline yields and revenues are listed in Table E-3, and the baseline prices are reported in Table E-4. The new incentive level can then be estimated using the computed equations which follow the form of Equation 3 and are listed in Table E-5.

Equation 2: $\% \Delta \operatorname{Re}$ venue $=\left(\left(\sum_{i=1}^{n}\left(P_{i}^{*} Y_{i}\right) / J\right)-\right.$ Base Re venue $) /$ Base Re venue,

where $\boldsymbol{n}$ is the number of crops and $\boldsymbol{J}$ is the number of years in rotation.

Equation 3: Incentive level $=\beta_{0}+\beta_{1}(\% \Delta \operatorname{Re}$ venue $)$

Response of the various rotation incentive levels to changes in revenue varies considerably. Most follow the general trend that as revenues increase, incentive levels increase. But in seven rotations, incentive levels decrease as total revenue increases. This is due to two separate causes. In some cases, the variance in yields of conventional tillage is more than the variance of notillage yields. This causes the relative amount of revenues under conventional tillage to become more "risky" as revenues increase. Therefore, to a risk adverse producer, conventional tillage becomes less attractive. The other cause occurs in the comparisons to the conventional wheat/fallow rotation of the western Great Plains. The cost of the conventional wheat/fallow rotation is low compared to the alternative no-tillage practices. At low prices (revenue), the extra cost of the alternative practices is not offset by extra revenue, but as crop prices increase, the increase in mean expected total revenue offsets the higher cost of the rotation practice. This makes the alternative practices relatively more attractive at higher revenues; therefore, the incentive decreases.

The estimated incentive levels reported in Table E-2 are to be considered as the average incentives required by producers to adopt the alternative tillage system at baseline levels of commodity prices. However, more than likely the incentive would vary across farm sizes, types of operators, and other factors, all variables which are beyond the scope of this study. 
Table E-3

Base yields and revenues by experimental site and rotation.

\begin{tabular}{|c|c|c|c|c|c|c|}
\hline $\begin{array}{l}\text { Proposed } \\
\text { Switch }\end{array}$ & Region & $\begin{array}{c}\text { Site } \\
\text { Abbv. }\end{array}$ & $\begin{array}{l}\text { Rotation } \\
\text { and }\end{array}$ & \multicolumn{2}{|c|}{$\begin{array}{c}\text { Base Yields } \\
(\mathrm{Mg} / \mathrm{ha})\end{array}$} & $\begin{array}{l}\text { Base } \\
\text { Revenue } \\
\text { (\$/ha/yr) }\end{array}$ \\
\hline \multirow{15}{*}{$\begin{array}{c}\text { Intensive } \\
\text { Till } \\
\text { To } \\
\text { No-Till }\end{array}$} & \multirow{6}{*}{ Corn Belt } & \multirow[t]{2}{*}{ IAAP } & \multirow{2}{*}{$\begin{array}{l}\text { Corn/ } \\
\text { Soybeans: poor }\end{array}$} & Corn & 9.15 & \multirow[t]{2}{*}{646.41} \\
\hline & & & & Soybeans & 2.96 & \\
\hline & & \multirow[t]{2}{*}{ NERDF } & \multirow{2}{*}{$\begin{array}{l}\text { Corn/ } \\
\text { Soybeans: well }\end{array}$} & Corn & 9.95 & \multirow[t]{2}{*}{684.22} \\
\hline & & & & Soybeans & 3.03 & \\
\hline & & NERDF & Cont. Corn: well & Corn & 8.94 & 690.15 \\
\hline & & ARC & Cont. Corn: poor & Corn & 11.23 & 866.58 \\
\hline & \multirow{4}{*}{$\begin{array}{c}\text { Central } \\
\text { Great Plains }\end{array}$} & RMF & Cont. Soybeans & Soybeans & 2.69 & 533.74 \\
\hline & & \multirow[t]{2}{*}{ RMF } & \multirow{2}{*}{$\begin{array}{l}\text { Sorghum/ } \\
\text { Soybeans }\end{array}$} & Sorghum & 8 & \multirow[t]{2}{*}{560.92} \\
\hline & & & & Soybeans & 2.69 & \\
\hline & & NAF & Cont. Sorghum & Sorghum & 5.38 & 395.36 \\
\hline & Western & SWK1 & $\begin{array}{l}\text { Wheat/ } \\
\text { Fallow }\end{array}$ & Wheat & 1.95 & 102.13 \\
\hline & Great Plains & SWK1 & $\begin{array}{l}\text { Wheat/Sorghum/ } \\
\text { Fallow }\end{array}$ & Wheat & 1.95 & 102.13 \\
\hline & Mississippi & ALB & Corn/ & Corn & 8.2 & 556.72 \\
\hline & River & & Soybeans & Soybeans & 2.42 & \\
\hline & & MES & Cont. Cotton & Cotton & 0.97 & $1,107.18$ \\
\hline & & ARC & Corn/ & Corn & 12.04 & 818.02 \\
\hline & & & Soybeans: poor & Soybeans & 3.56 & \\
\hline Intensive & & NERDF & Corn/ & Corn & 9.95 & 684.22 \\
\hline Till & Corn Belt & & Soybeans: well & Soybeans & 3.03 & \\
\hline $\begin{array}{c}\text { To } \\
\text { Reduced }\end{array}$ & & ARC & Cont. Corn: poor & Corn & 11.23 & 886.58 \\
\hline & & NERDF & Cont. Corn: well & Corn & 8.94 & 690.15 \\
\hline
\end{tabular}

\footnotetext{
* Note: Definition of site abbreviations can be found in Attachment 2.
} 
Table E-4

Base prices

Table E-5

\begin{tabular}{|l|r|}
\hline \multicolumn{1}{|c|}{ Crop } & Price $(\$ / \mathrm{Mg})$ \\
\hline Corn & 77.16 \\
\hline Soybeans & 198.41 \\
\hline Wheat & 104.72 \\
\hline Sorghum & 73.49 \\
\hline Cotton & $1,144.62$ \\
\hline
\end{tabular}

\section{Revenue sensitivity equations}

\begin{tabular}{|c|c|c|c|c|c|}
\hline $\begin{array}{l}\text { Proposed } \\
\text { Switch }\end{array}$ & Region & $\begin{array}{l}\text { Site }{ }^{\star} \text { and } \\
\text { Drainage }\end{array}$ & $\begin{array}{l}\text { Conventional } \\
\text { Rotation }\end{array}$ & No-Till Rotation & Incentive-Level Equation \\
\hline \multirow{11}{*}{$\begin{array}{c}\text { Intensive Till } \\
\text { to } \\
\text { No-Till }\end{array}$} & \multirow{4}{*}{$\begin{array}{l}\text { Corn } \\
\text { Belt }\end{array}$} & $\begin{array}{l}\text { IAAP } \\
\text { Poor }\end{array}$ & Corn/Soybean & Corn/Soybean & $\begin{array}{r}25.18^{t}+0.067^{t}(\% \Delta \operatorname{Rev}) \\
r^{2}=.99 \\
\end{array}$ \\
\hline & & $\begin{array}{l}\text { NERDF } \\
\text { well }\end{array}$ & Corn/Soybean & Corn/Soybean & $\begin{array}{r}20.51^{\mathrm{t}}+0.533^{\mathrm{t}}(\% \Delta \operatorname{Rev}) \\
\mathrm{r}^{2}=.99\end{array}$ \\
\hline & & $\begin{array}{l}\text { NERDF } \\
\text { well }\end{array}$ & Cont. Corn & Cont. Corn & $\begin{array}{r}66.05^{\mathrm{t}}+0.681^{\mathrm{t}}(\% \Delta \operatorname{Rev}) \\
r^{2}=.99\end{array}$ \\
\hline & & $\begin{array}{l}\text { ARC } \\
\text { poor }\end{array}$ & Cont. Corn & Cont. Corn & $\begin{array}{r}99.98^{t}+1.525^{t}(\% \Delta \operatorname{Rev}) \\
r^{2}=.99\end{array}$ \\
\hline & \multirow{3}{*}{$\begin{array}{c}\text { Central } \\
\text { Great Plains }\end{array}$} & RMF & $\begin{array}{l}\text { Cont. } \\
\text { Soybeans }\end{array}$ & Cont. Soybean & $\begin{array}{r}6.84^{t}+0.00^{t}(\% \Delta R e v) \\
r^{2}=.99\end{array}$ \\
\hline & & RMF & $\begin{array}{l}\text { Sorghum/ } \\
\text { Soybean }\end{array}$ & $\begin{array}{l}\text { Sorghum/ } \\
\text { Soybean }\end{array}$ & $\begin{array}{r}0.74^{t}-0.163^{t}(\% \Delta R e v) \\
r^{2}=.99\end{array}$ \\
\hline & & NAF & Cont. Sorghum & Cont. Sorghum & $\begin{array}{r}36.10^{t}+0.052^{t}(\% \Delta \operatorname{Rev}) \\
r^{2}=.99\end{array}$ \\
\hline & \multirow[t]{2}{*}{$\begin{array}{l}\text { Western } \\
\text { Great Plains }\end{array}$} & SWK1 & $\begin{array}{l}\text { Wheat/ } \\
\text { Fallow }\end{array}$ & $\begin{array}{l}\text { Wheat/ } \\
\text { Fallow }\end{array}$ & $\begin{array}{r}14.63^{\mathrm{t}}-0.075^{\mathrm{t}}(\% \Delta \operatorname{Rev}) \\
r^{2}=.99\end{array}$ \\
\hline & & SWK1 & $\begin{array}{l}\text { Wheat/ } \\
\text { Fallow }\end{array}$ & $\begin{array}{l}\text { Wheat/Sorghum/ } \\
\text { Fallow }\end{array}$ & $\begin{array}{r}15.17^{\mathrm{t}}-0.684^{\mathrm{t}}(\% \Delta \operatorname{Rev}) \\
r^{2}=.99 \\
\end{array}$ \\
\hline & \multirow{2}{*}{$\begin{array}{l}\text { Mississippi } \\
\text { River } \\
\text { Corridor }\end{array}$} & ALB & $\begin{array}{l}\text { Corn/ } \\
\text { Soybean }\end{array}$ & $\begin{array}{l}\text { Corn/ } \\
\text { Soybean }\end{array}$ & $\begin{array}{r}19.67^{t}-0.216^{t}(\% \Delta \operatorname{Rev}) \\
r^{2}=.99\end{array}$ \\
\hline & & MES & Cont. Cotton & Cont. Cotton & $\begin{array}{r}23.2^{t}+0.708^{t}(\% \Delta \operatorname{Rev}) \\
r^{2}=.99\end{array}$ \\
\hline \multirow{4}{*}{$\begin{array}{l}\text { Intensive Till } \\
\text { to Reduced } \\
\text { Till }\end{array}$} & \multirow{4}{*}{$\begin{array}{l}\text { Corn } \\
\text { Belt }\end{array}$} & $\begin{array}{l}\text { ARC } \\
\text { Poor }\end{array}$ & Corn/Soybean & Corn/Soybean & $\begin{array}{r}15.22^{\mathrm{t}}+0.109^{\mathrm{t}}(\% \Delta \operatorname{Rev}) \\
r^{2}=.99\end{array}$ \\
\hline & & $\begin{array}{l}\text { NERDF } \\
\text { Well }\end{array}$ & Corn/Soybean & Corn/Soybean & $\begin{array}{r}56.17^{t}+0.200^{t}(\% \Delta \operatorname{Rev}) \\
r^{2}=.99\end{array}$ \\
\hline & & $\begin{array}{l}\text { ARC } \\
\text { Poor }\end{array}$ & Cont. Corn & Cont. Corn & $\begin{array}{r}3.51^{t}-0.068^{t}(\% \Delta R e v) \\
r^{2}=.99\end{array}$ \\
\hline & & $\begin{array}{l}\text { NERDF } \\
\text { Well }\end{array}$ & Cont. Corn & Cont. Corn & $\begin{array}{r}101.26^{t}+0.897^{t}(\% \Delta \operatorname{Rev}) \\
r^{2}=.99\end{array}$ \\
\hline
\end{tabular}

* Note: Definition of site abbreviations can be found in Attachment E-2.

$t=$ all coefficients significant at the 0.00 level of significance.

E-10 


\section{References Cited}

1 American Agricultural Economics Association (AAEA), 1998. Commodity Costs and Returns Estimation Handbook. A Report of the AAEA Task Force on Commodity Costs and Returns. Ames, Iowa.

2 Sandretto, C. 2001. Conservation tillage firmly planted in U.S. agriculture. Agricultural Outlook March 2001. Economic Research Service, U.S. Department of Agriculture, Washington, D.C.

3 Nowak, P. J., and P. F. Korsching. 1985. Conservation tillage: revolution or evolution? Journal of Soil and Water Conservation 40: 199-201.

4 Prato, T. 1990. Economic feasibility of conservation tillage with stochastic yields and erosion rates. North Central Journal of Agricultural Economics 12: 333-334.

5 Larson, J. A., R. K. Roberts, D. D. Tyler, B. N. Duck, and S. P. Slinsky. 1998. Nitrogen fixing winter cover crops and production risk: a case study for no tillage corn. Journal of Agricultural and Applied Economics 30: 163-174.

6 Larson, J. A., E. C..Jaenicke, R. K. Roberts, and D. D. Tyler. 2001. Risk effects of alternative winter cover crop, tillage, and nitrogen fertilization systems in cotton production. Journal of Agricultural and Applied Economics 33: 445-457.

7 Meyer, J. 2002. Expected utility model as a paradigm for decision making in agriculture. Chapter 1 in R. E. Just and R. Pope (eds.). The Role of Risk in Agriculture. Kluwer Academic Publishers, Norwell, MA.

8 Robison, L. J., and P. J. Barry. 1987. The Competitive Firm's Response to Risk. Macmillan Publishers, New York.

9 Freund,R. J. 1956. Introduction of risk into a programming model. Econometrica 24: 257263.

10 Richardson, James W. 2002. Simulation for Applied Risk Management, with an Introduction to the Software Package SIMETAR@: Simulation for Excel to Analyze Risk. Department of Agricultural Economics, Texas A\&M University.

11 Cochran, Mark J. "Stochastic Dominance: The state of the art in agricultural economics." Proceeding of a Seminar Sponsored by Southern Regional Project S-180, Tampa, Florida, March 23-26, 1986. Dept of Ag Economics, Washington State Univ. Pullman, Washington.

12 Williams, Jeffery R. "A Stochastic Dominance Analysis of Tillage and Crop Insurance Practices in a Semi-arid Region." American Journal of Agricultural Economics 70.1 (Feb 1988): 112-120. 
13 Sunding, D., and D. Zilberman. 2000. The Agricultural Innovation Process: Research and Technology Adoption in a Changing Agricultural Sector. Chapter 5, Handbook of Agricultural Economics, Vol. 1A: Agricultural Production, edited by B. L.Gardner and G. C. Rausser. Amsterdam: Elsevier Science Publications.

14 Kurkalova, Lyubov, Catherine King, and Junhua Zhao. 2001. The Subsidy for Adopting Conservation Tillage: Estimation from Observed Behavior. Working Paper 01-WP 286, CARD, Iowa State University. Paper Presented at the AAEA 2001 Annual Meeting in Chicago.

15 Griliches, Zvi. 1957. Hybrid Corn: An Exploration in the Economics of Technological Change. Econometrica 25.4 (October 1957): 501-522. 


\section{Attachment E-1 of Appendix E: Budget and Yield Sources}

\author{
Case\#1: Convent. corn/soybeans to no till \\ Case\#2: Convent. continuous corn to no-till \\ Budgets: \\ lowa: $\quad$ Ag Decision Maker, Mike Duffy, January 2002. \\ APAC Budgets \\ Indiana: Dobbins, C.L., et al. "2002 Purdue Crop Guide \\ Craig Dobbins, Purdue Ag Econ Dept. \\ Ohio State Crop Budgets \\ APAC Budgets \\ Indiana Custom Rates, D.H.Doster
}

\author{
Seed, Fert, insurance, misc, and Dry \\ Pre Harvest Machinery, chemicals \\ For conventional fertilizer app rates,drying insurance, mis \\ Herbicide \\ Herbicide \\ Pre-harvest Machinery \\ Harvest cost
}

\section{lowa}

NERDF, Nashua, IA

Data: Research Farm Manager, Ken Pecinovsky [kennethp@willowtree.com]

Site: $\quad$ North-East Research and Demonstration Farm, located near Nashua, lowa in the northeast corner of the state

Soil: $\quad$ Kenyon Loam, Tile Drained=Well Drained

Years: $\quad$ 1978-2001

\section{IAAP, Burlington, IA}

Data: $\quad$ Brown, H.J. "Tillage System Effects on Crop Growth and Production Costs for a Corn-Sobean Rotation", J.Prod.Agic. Vol 2 no 31989

Site: $\quad$ lowa Army Ammunition Plant near Burlington, IA, Southeastern part

Soil: $\quad$ Poorly drained Taintor/somewhat poorly drained Mahaska....silty clay loams

Years: $\quad$ 1980-1990

\section{SERDF, Crawfordsville, IA}

Data: $\quad$ Southeast Research and Demonstration Farm--2000 Annual Progress Reports, Farm Manager, Kevin VanDee 641

Site: $\quad$ Southeast Research and Demonstration Farm, Crawfordsville, IA,

Soil: $\quad$ Poory Drained Kalona Soil, 2) Well Drained Nira Soils

Years: $\quad$ 1980-2001

\section{Indiana}

\section{ARC, West Lafayette, IN}

Data: $\quad$ Cropping Systems Research Report 2001, T.D. West, T.J. Vyn, Department of Agronomy, Purdue Univesity

Site: $\quad$ Purdue Agronomy Research Center(ARC), West Lafayette, West-Central Indiana

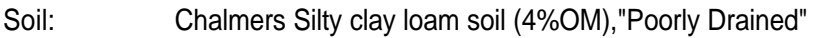

Years: $\quad$ 1975-2001

\section{PPAC, Wanatah, IN}

Data: $\quad$ Cropping Systems Research Report 2001, T.D. West, T.J. Vyn, Department of Agronomy, Purdue University

Site: $\quad$ Pinney-Purdue agricultural center(PPAC), Wanatah, IN, Northern Indiana

Soil: $\quad$ Sebewa Loam, "Very Poorly Drained"

Years: $\quad$ 1997-2001 


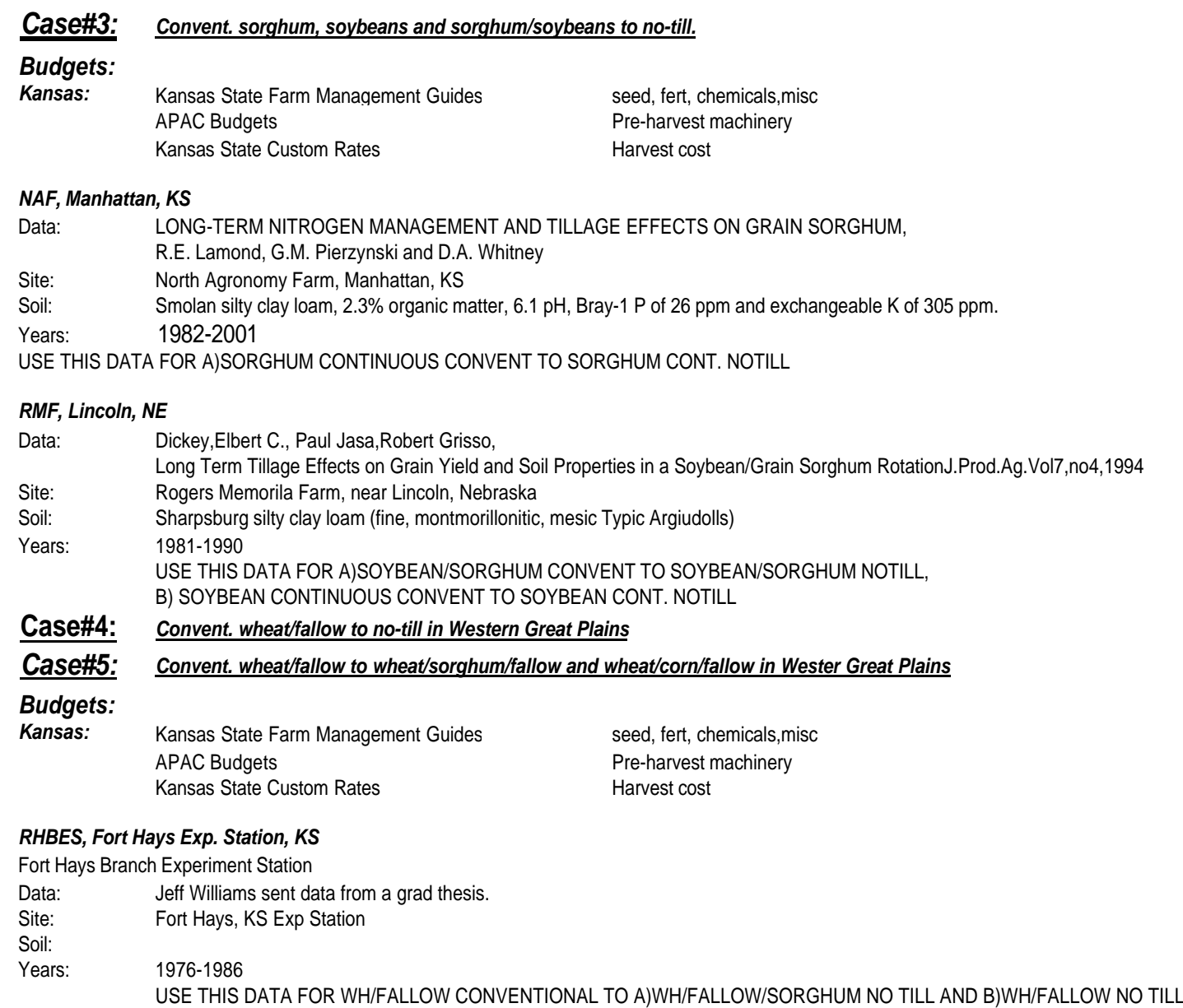

SWK1, Garden City, KS

Data: $\quad$ "Cropping System and Tillage Effects on Available Soil Water and Yield of Grain sorghum and Winter Wheat", Norwood,C.A. et al., J.Prod.Agric.,Vol.3,no.3.1990.87-91:

Norwood,"An Economic Comparisn of the wheat fallow and wheat sorghum fallow cropping systems"

Site: $\quad$ Southwest Kansas Res.-Extension Ctr.,Garden City, KS

Soil: $\quad$ Satanta loam(fine-loamy,mixed,mesic Aridic Agriustoll)ph of 7.0 , organ matter of $1.3 \%$

Years: $\quad$ 1979-1987

USE THIS DATA FOR A)WH/FALLOW CONVENT TO WH/FALLOW/SORGHUM NO TILL, B)WH/FALLOW CONVENT TO WH/FALLOW NOTILL

SWK2, Garden City, KS--not using now

Data: $\quad$ POST-HARVEST WEED CONTROL IN A WHEAT-FALLOW ROTATION,Alan Schlegel and Troy Dumler

Site: $\quad$ Southwest Kansas Res.-Extension Ctr.,Garden City, KS

Soil: $\quad$ Satanta loam(fine-loamy,mixed,mesic Aridic Agriustoll)ph of 7.0 , organ matter of $1.3 \%$

Years: 1996-2001

USE THIS DATA FOR A)WH/FALLOW CONVENT TO WH/FALLOW NOTILL 


\section{Case\#6: Convent Corn/Soybean to Corn/wheat-soybeans in Mid South \\ Budgets: \\ Tennessee: TN Field Crop Budgets, Ag. Ext. Service all but custom \\ TN Custom Rates,Ag. Ext. Service Harvest Costs}

\section{ALB--sovbean/corn}

Data: $\quad$ Edwards, J.H., D.L. Thurlow, and J.T. Eason. 1988. Influence of Tillage and Crop Rotation on Yields of Corn, Soybean, and Wheat. Agronomy Journal 80:76-80.

Site: $\quad$ Sand Mt Substation, Crossville, AL

Soil: $\quad$ fine sandy loam, well drained

Years: $\quad$ 1980-1984

\section{ALB--sovbean/corn}

Data: $\quad$ Tillage and wheat Production, Touchton, Joseph t., etal. Department of Agronomy, Auburn University.

Site: $\quad$ Monroeville, AL

Soil: $\quad$ Sumpter soil

Years: $\quad$ 1984-1992

\section{Case\#7: Convent Cotton to No-Till in Mid South.}

\section{Budgets:}

Tennessee:

TN Field Crop Budgets, Aq. Ext. Service

Not using custom rates for cotton.

MES, Milan, TN

Data:

Site:

Soil:

Years: pp.46-48;revised 01-25-95

Milan, Tennessee

Grenada Silt Loam

1981-1994 all

The custom price spread is too large and would lead to either severe over or under estimation.

Bradley,J.F. "Success with No-Till Cotton" in Arkansas Agricultural Experiment Station Special Publication 160, 


\section{Attachment E-2 of Appendix E: Site Selection}

\section{Corn Belt}

\section{Corn/Soybean Rotation Well-Drained Soil}

There are two experimental data sets from "well-drained soils," the NERDF and SERDF sites. Both NERDF and SERDF experiments are carried out in small test plots in Iowa. The "welldrained" soil in the SERDF experiment was on a 2-9 percent slope. The lesser slopes in this region are poorly drained. The NERDF experiment "well-drained" soils are on a 1-2 percent slope and may be more representative of "well-drained" soils for the region as a whole. NERDF has 24 years of data compared to SERDF's 11 years. For these reasons, the NERDF site is preferred as the representative for well-drained soils.

\section{Corn/Soybean Rotation}

Poorly drained Soil

There are four experimental data sets from "poorly drained soils": SERDF, IAAP, PPAC, and ARC. The PPAC site is excluded because it only has five years of data. The SERDF, ARC, and IAAP sites have 11, 24, and 10 years of data, respectively. Both the SERDF and ARC experiments were conducted on small test plots. The IAAP site is unique in that it was conducted on a 432 acre site; therefore, standard field equipment could be used. Although the ARC site has more years of data, the uniqueness of the scale of the IAAP site makes it preferable in the switch to no-tillage. The IAAP site has no reduced tillage data; therefore, we use the ARC site for the switch to reduced tillage.

\section{Continuous Corn}

\section{Well Drained Soil}

As mentioned above, the "well-drained" soil in the SERDF experiment was on a 2-9 percent slope. The lesser slopes in this region are poorly drained. The NERDF experiment "welldrained" soils are on a 1-2 percent slope and may be more representative of "well-drained" soils for the region as a whole. NERDF has 24 years of data compared to SERDF's 11 years. For these reasons, the NERDF site is preferred as the representative for well-drained soils.

\section{Continuous Corn}

\section{Poorly Drained Soil}

There are three continuous corn data sets from poorly drained soils, SERDF, PPAC and ARC sites. As stated above, an eastern experiment would be more preferred, as it may represent the more common poorly drained soils of the eastern part of the Corn Belt. The ARC site has 24 years of data compared to PPAC's five years of data. Also, the PPAC site is very far north and may not be representative of the region. For these reasons, the ARC site is preferred.

\section{Western Great Plains}

\section{Wheat/fallow and wheat/sorghum/fallow}

FHBES experiment data was sent from a graduate research paper. Much of the information concerning the experiment is missing, such as soil type, experiment plot size, and chemical use. The SWK1 site has more specific information. Additionally, the SWK1 site is further west, in Garden City, as opposed to Hays, Kansas. For these reasons, the SWK1 site is preferred. 


\section{Attachment E-3 of Appendix E: Yield Comparisons}

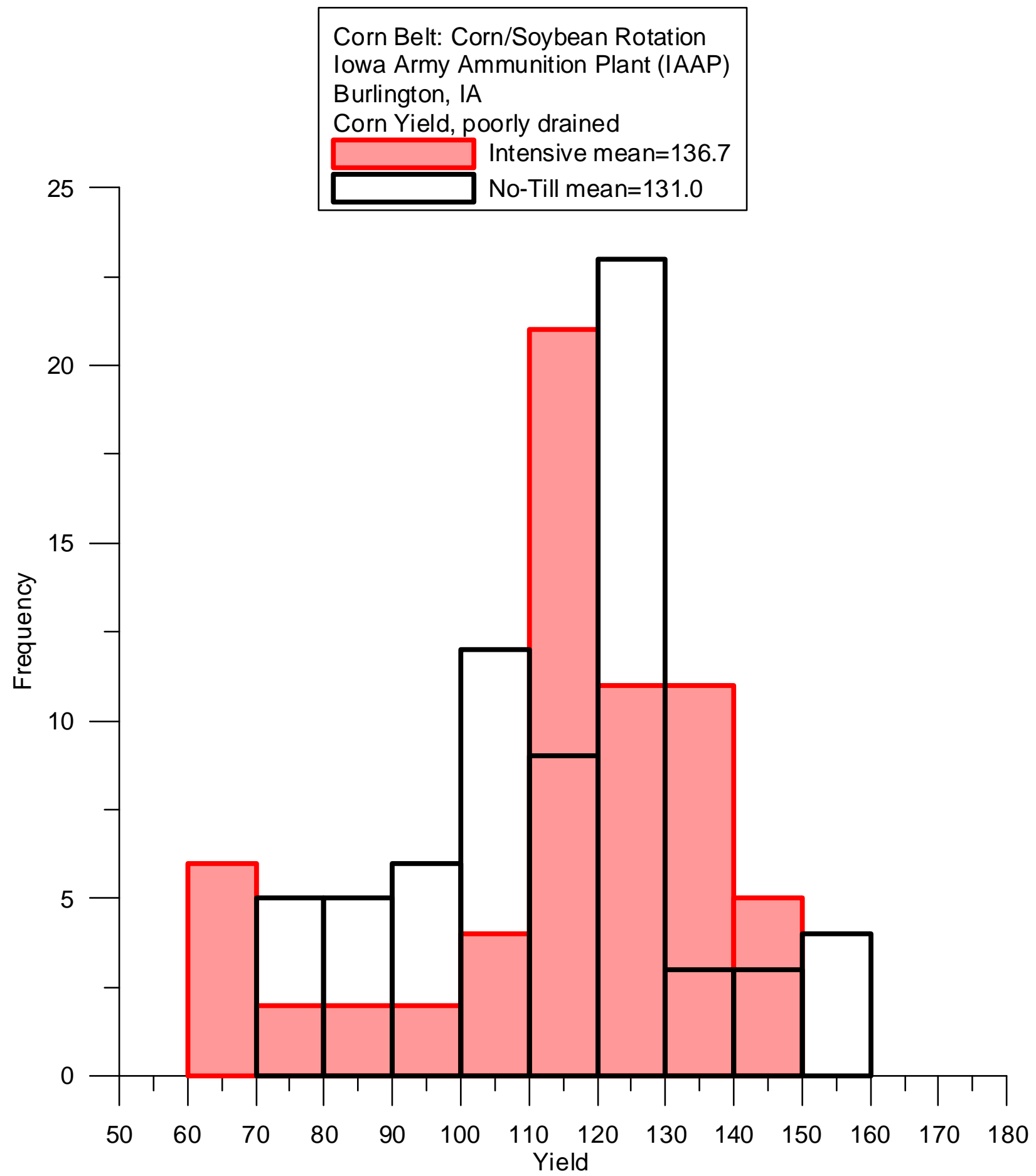




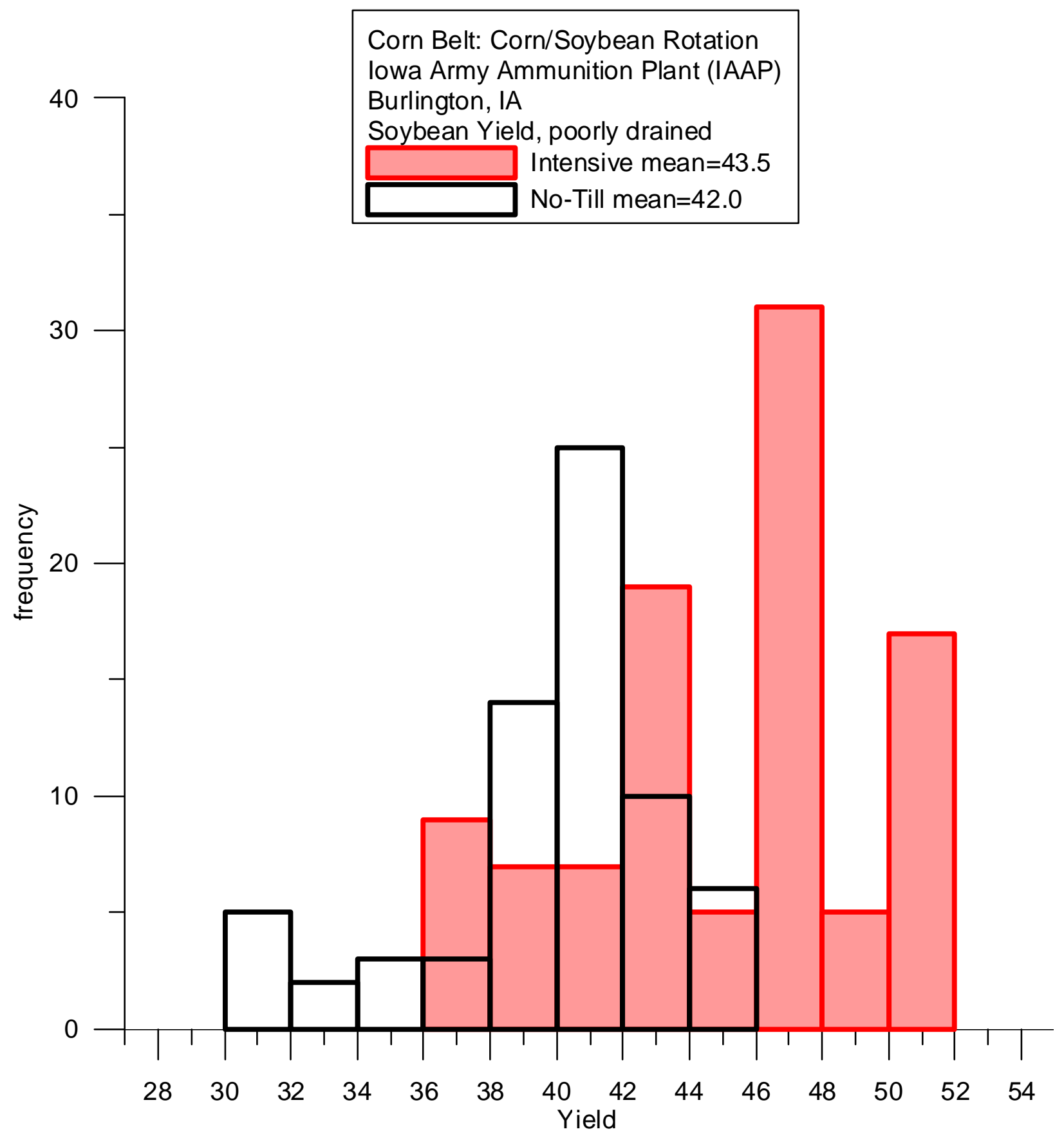

E-18 


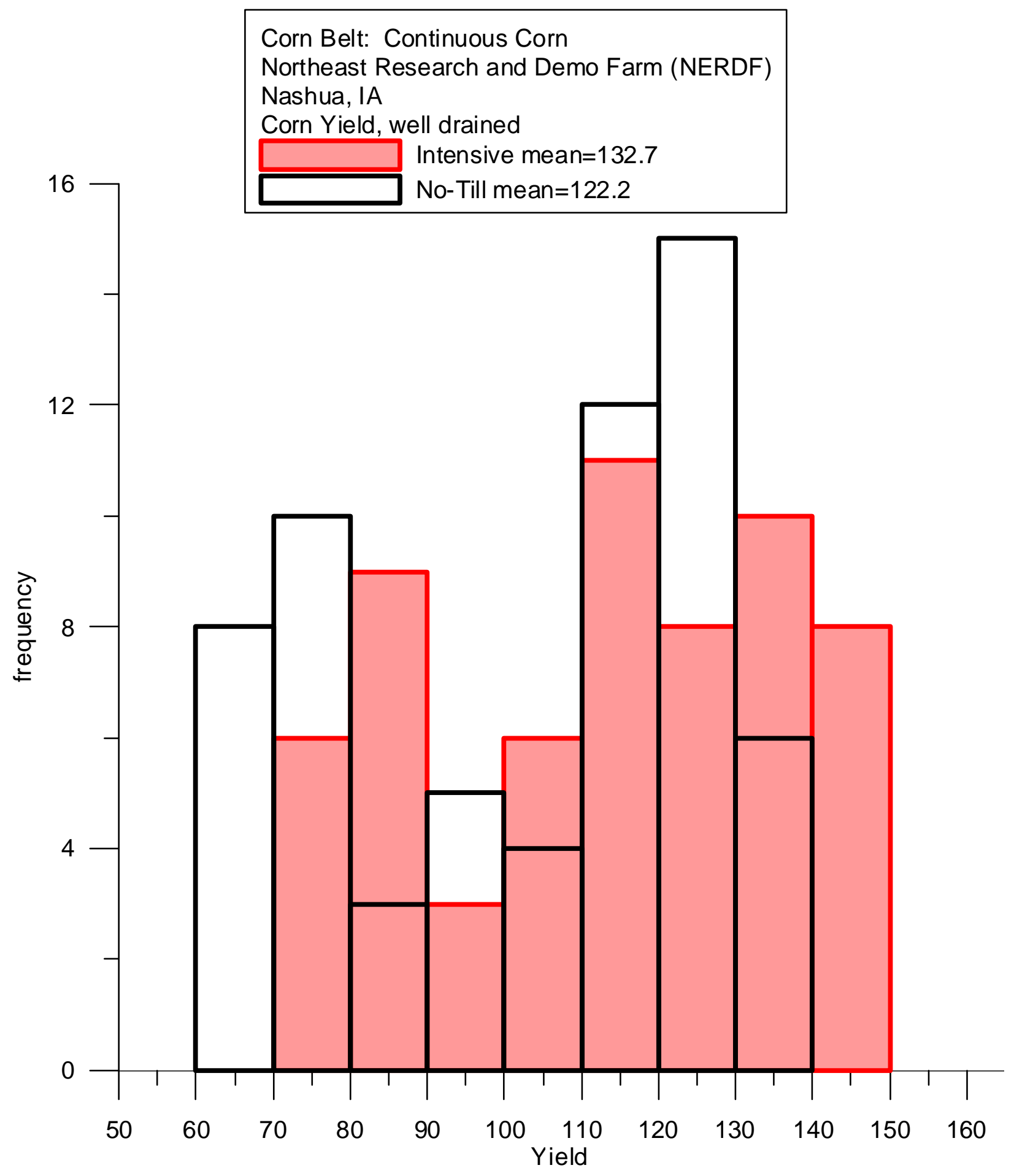




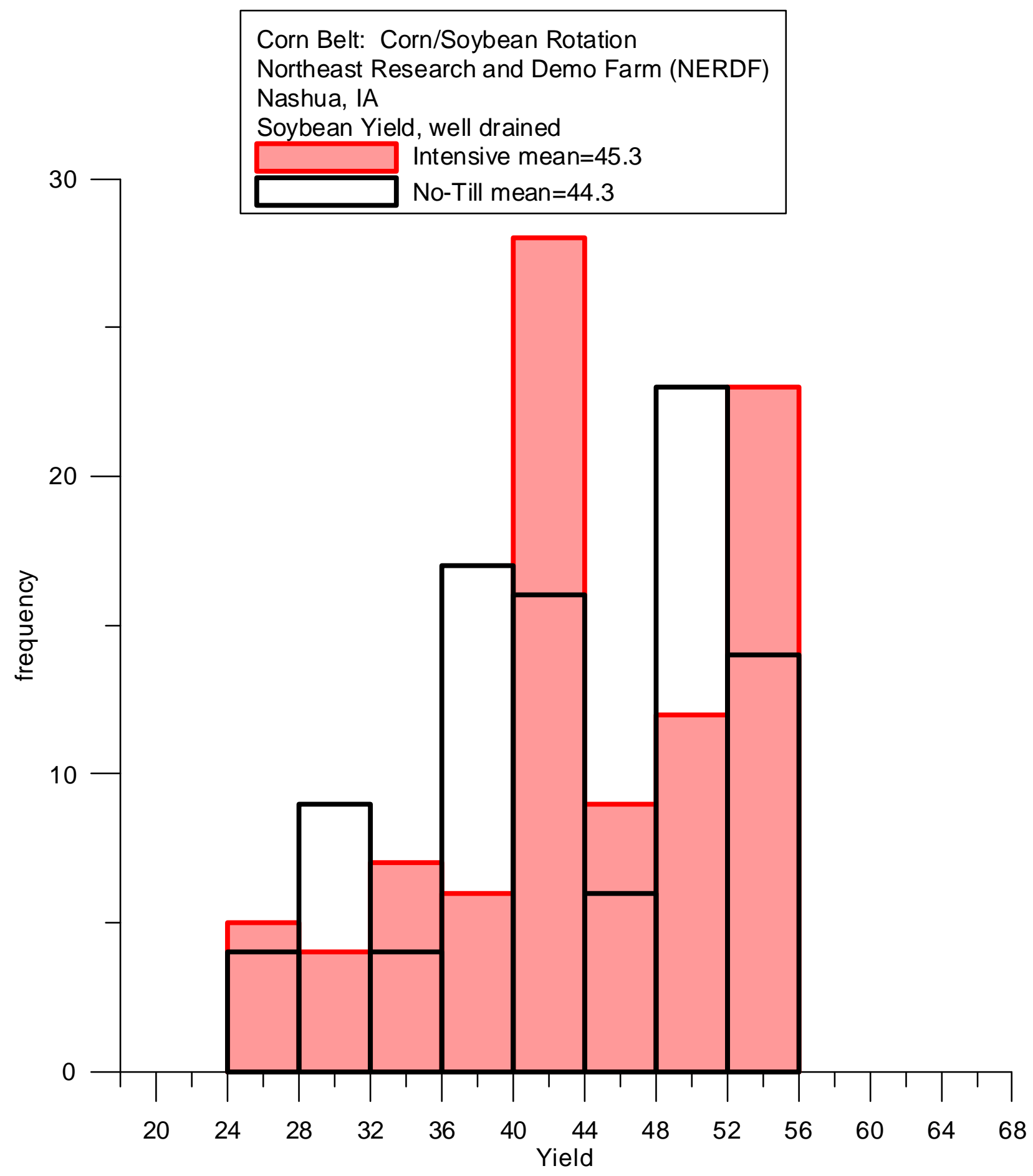




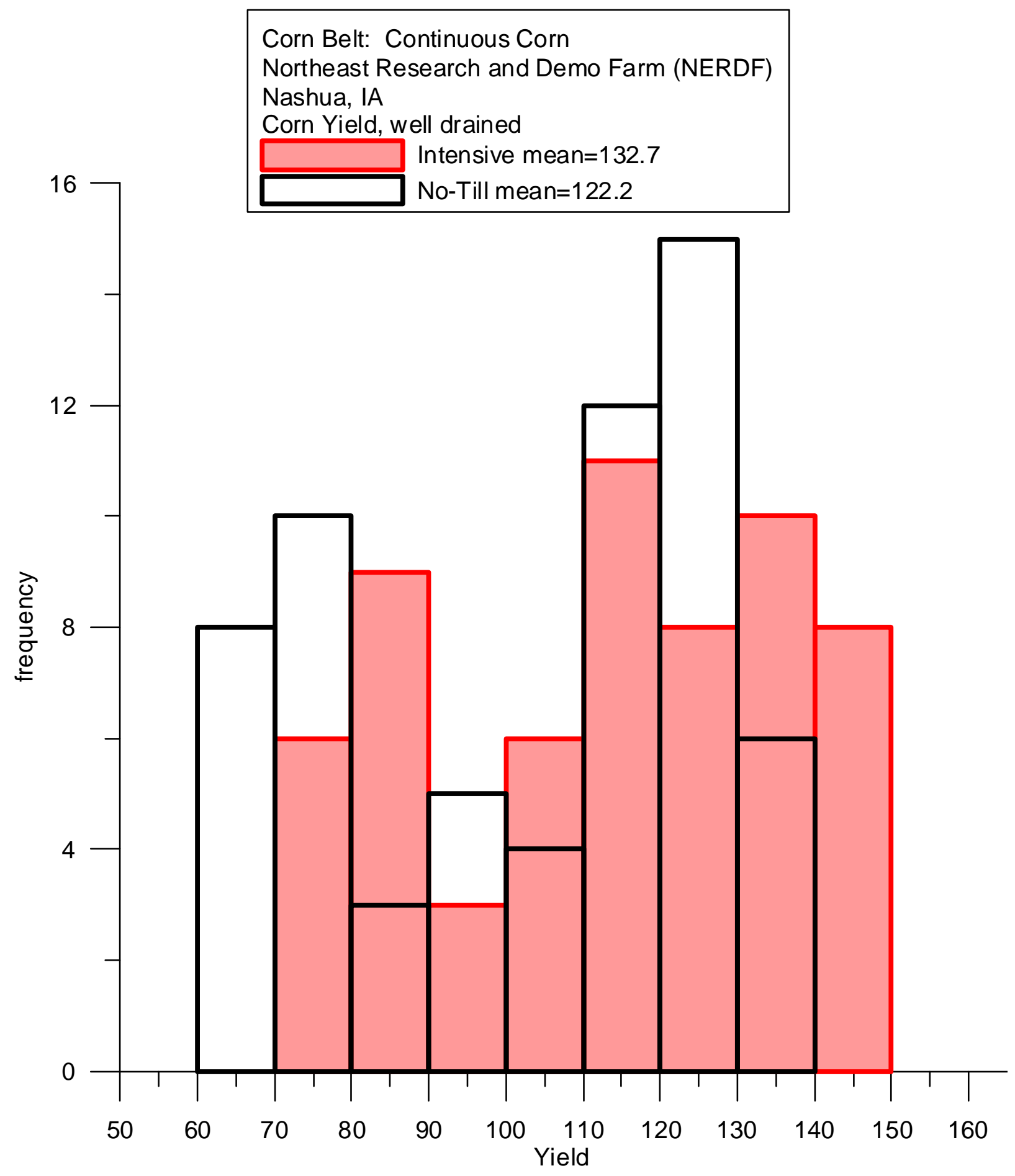




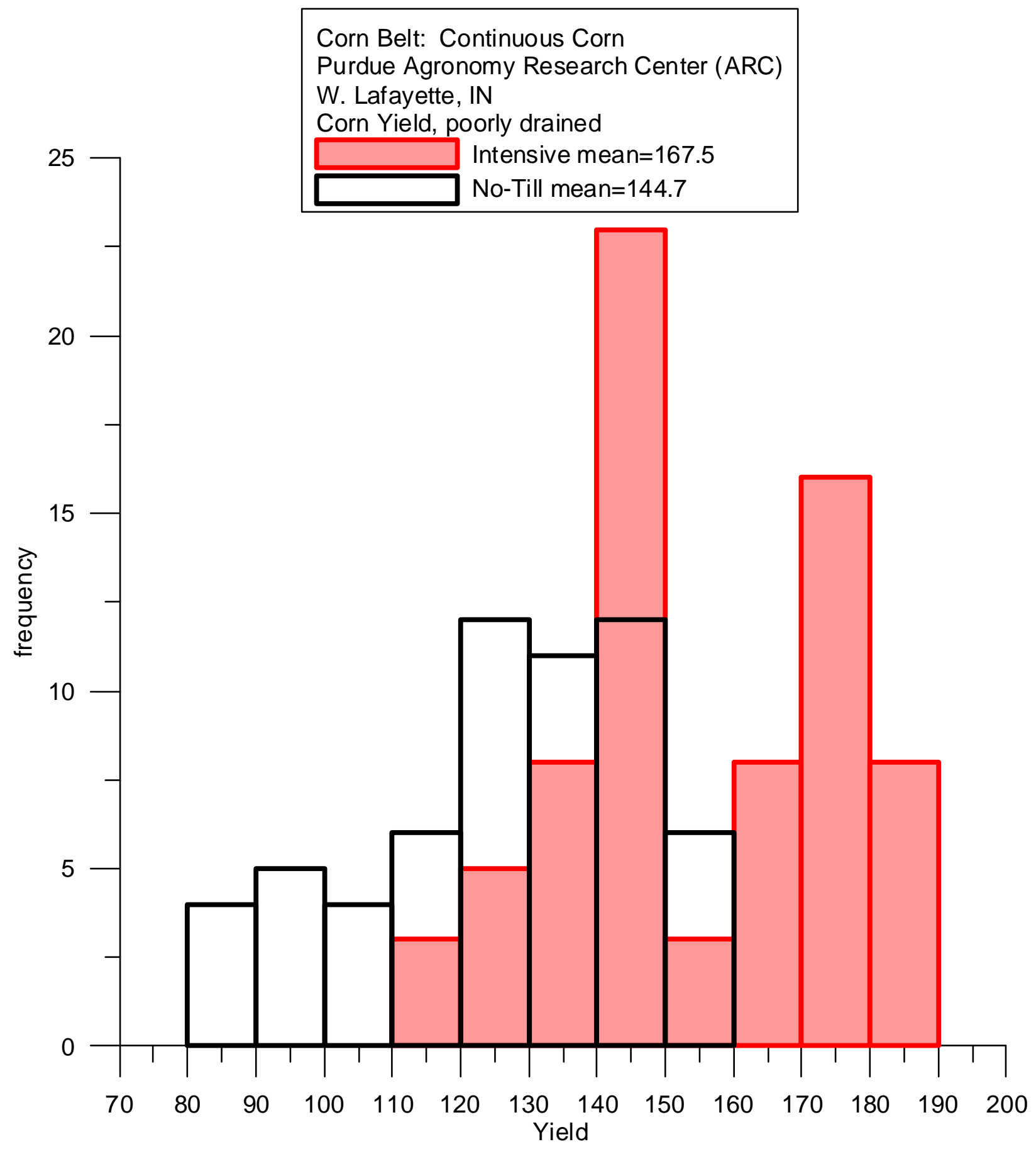




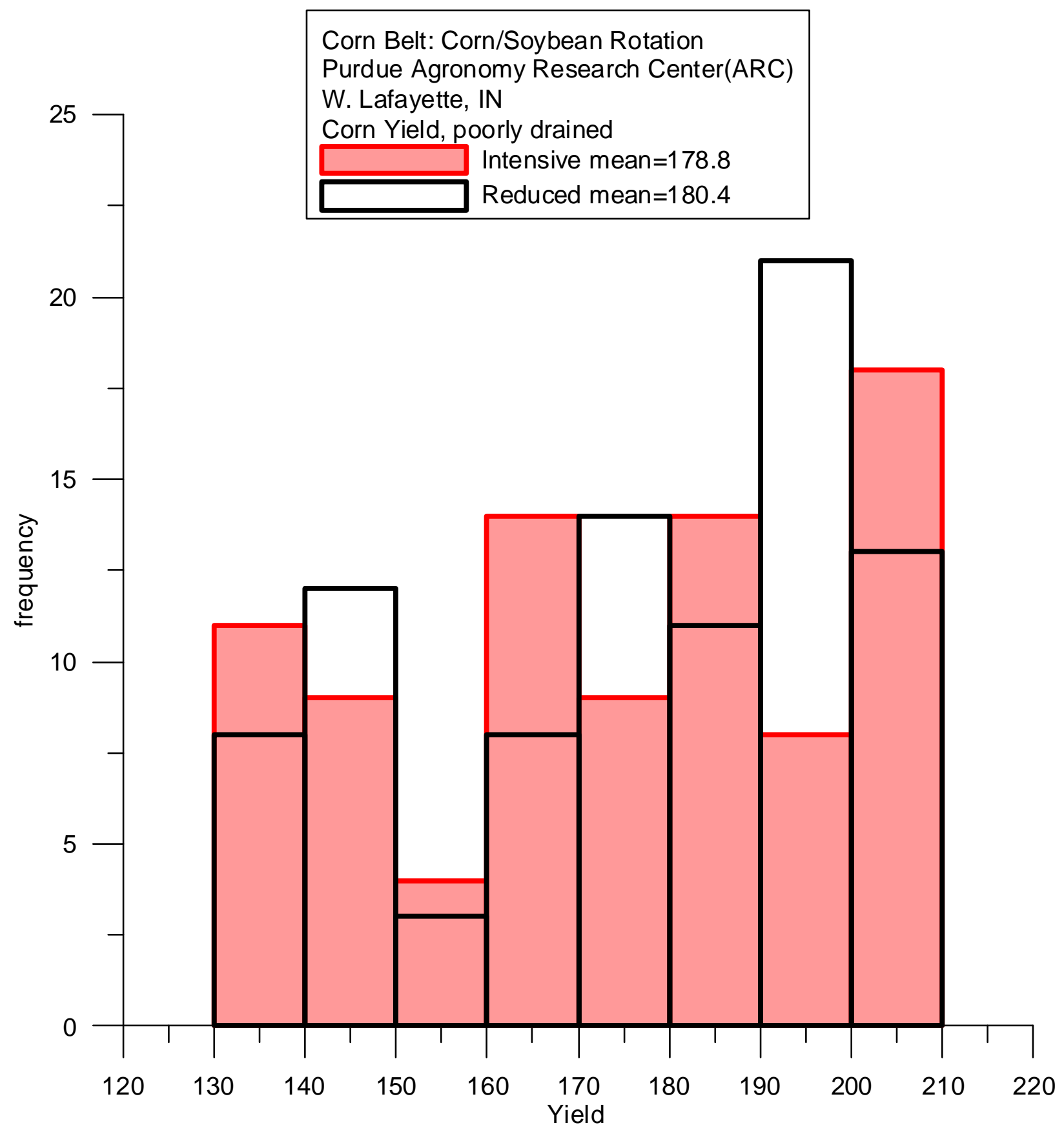




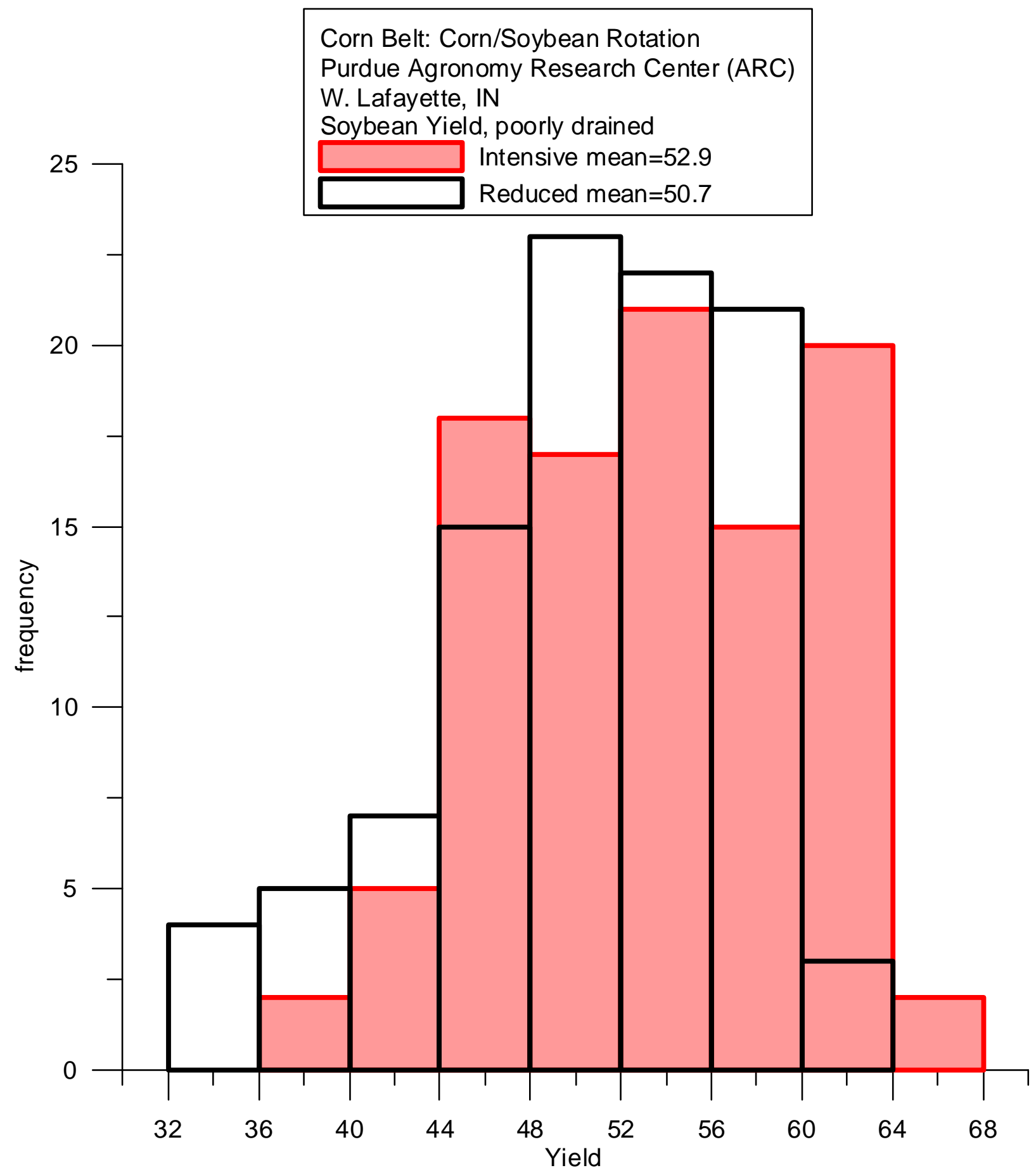




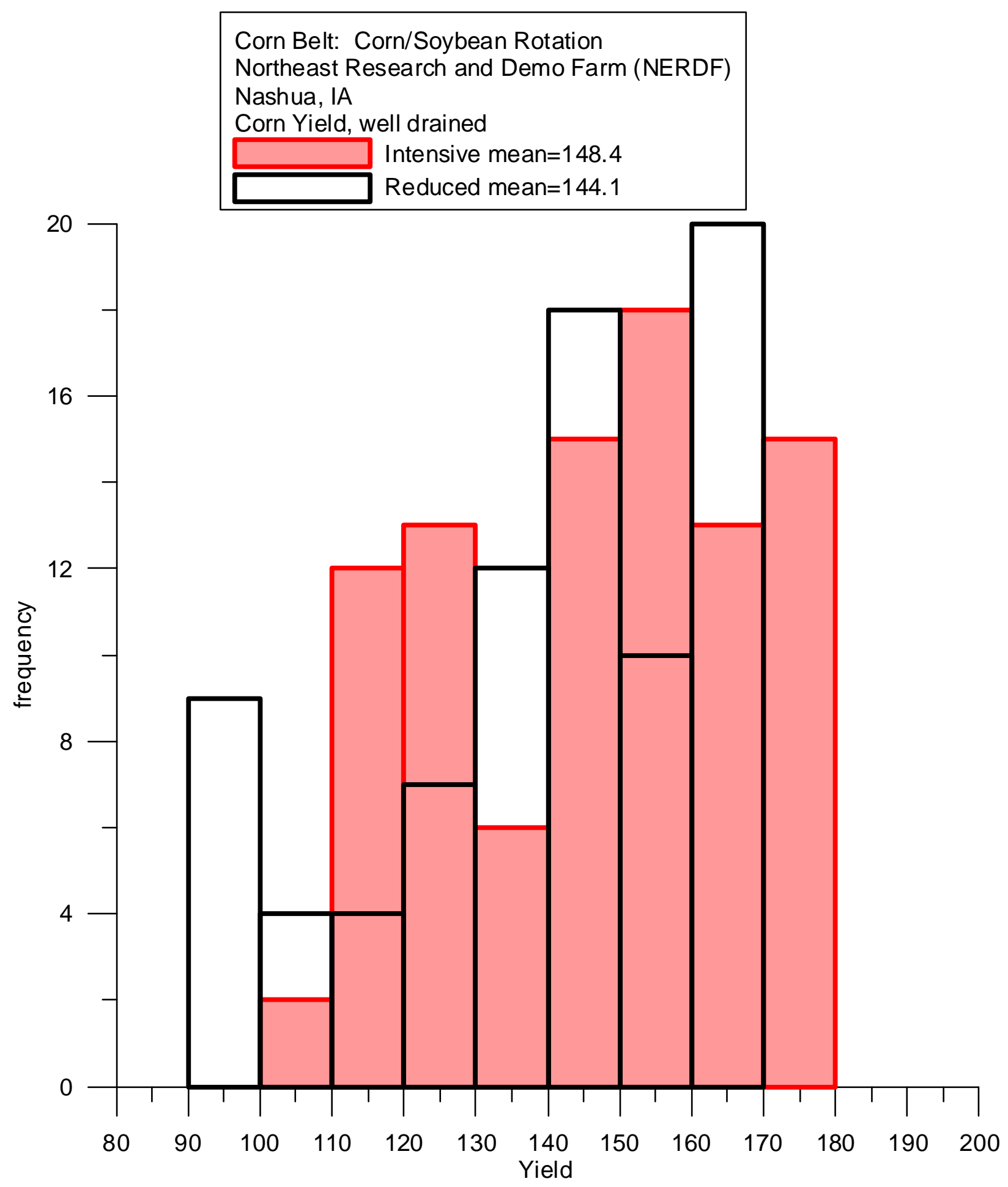




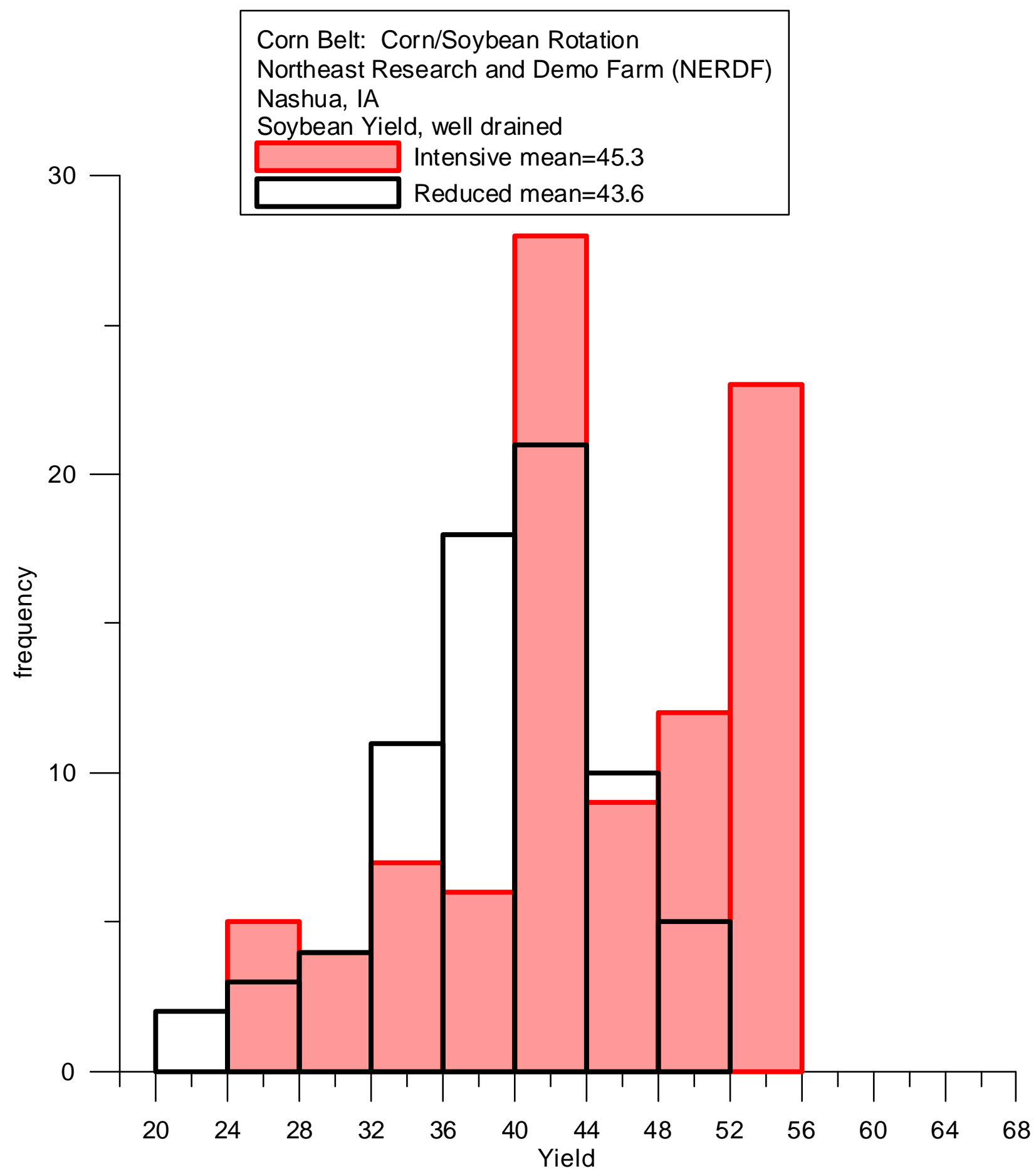




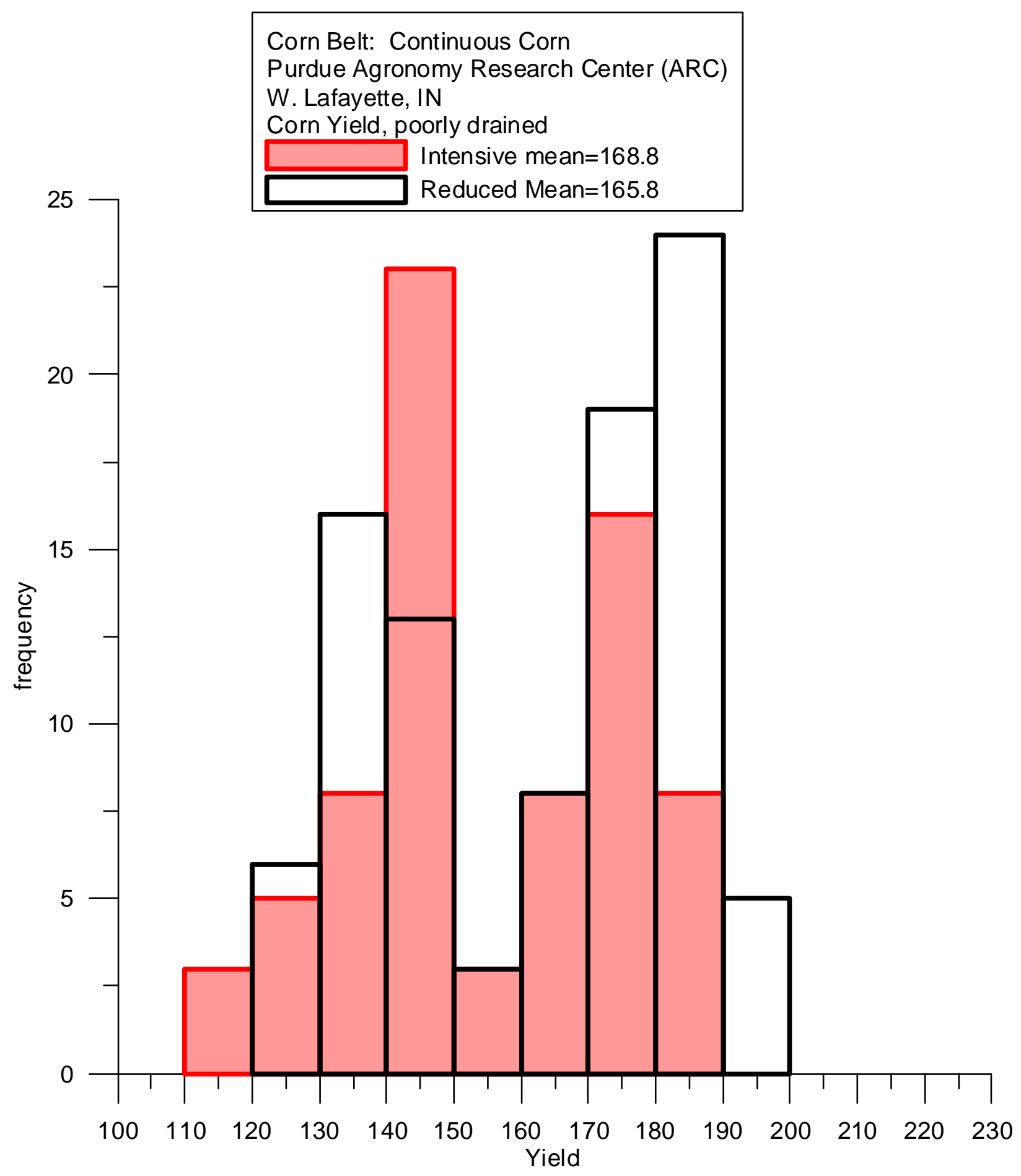




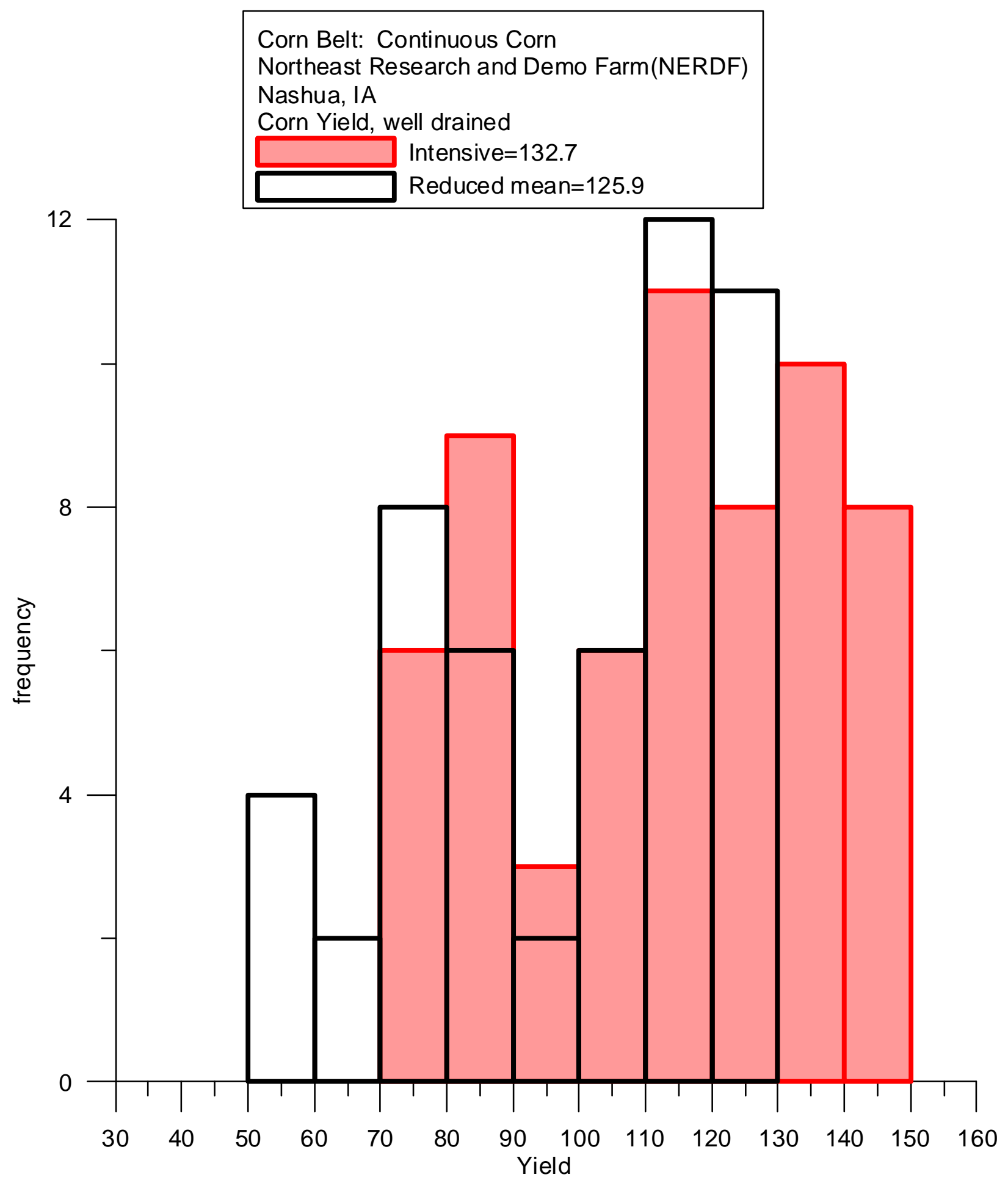




\section{ESTIMATING STATE-LEVEL SOC RESPONSES}

The purpose of this appendix is to describe how state-level SOC response curves were developed for Indiana and Iowa. The state curves were developed from carbon storage projects recently completed by Smith, et al. ${ }^{1}$, in Indiana, and Brenner, et al. ${ }^{2}$, in Iowa. These projects provided state- level estimates of increased SOC as a result of switching corn/soybean rotations from intensive-till to moderate-till or no-till. These were point estimates for 10 years after switching tillage-systems. These projects provided county-level point estimates for 10 and 20 years after switching tillage systems. At least two data points in addition to the zero-zero point are needed to characterize the nonlinear increase in SOC that results from reducing tillage. Therefore, county-level SOC response data (10- and 20-year data points) were selected from counties that represent the state-wide range of SOC responses and also provide a mean response that passes through the state-wide mean for 10 years after switching tillage. In Indiana, Allen and Gibson Counties represented the range of SOC responses and the mean of curves for Tippecanoe and Gibson Counties were used to represent the state mean (Table F-1). This interpolation process was performed for corn/soybean rotations switched from intensive-till to both moderate-till and no-till and resulted in state curves that passed through or very nearly through the state mean 10 -year data points for corn/soybean rotations. Curves for the same counties were used to develop state curves for continuous corn switched from intensive-till to both moderate-till and no-till.

More specifically, a quadric regression was performed for each county-level set of data points (i.e., for 0, 10, and 20 years). The quadratic responses were transformed as described by Bock, et al. $^{3}$, to provide SOC as a function of the maximum increase in SOC (? SOCs) and a slope or efficiency factor $(\mathrm{E})$. An example of this process for the first SOC response in Table F-1 is illustrated in Figure F-1.

For both Indiana (Figure F-2) and Iowa (Figure F-3), there was a linear relationship between E and ? SOCs for the range of curves generated. Therefore, the mean of two or more curves was calculated using the mean of E values for the curves being averaged and the mean of ? SOCs values for the curves being averaged.

Finally, state curves were calculated for corn/soybean rotations switched from intensive-till to moderate-till or no-till using weighted averages for the E and ? SOCs parameters for hydric and non-hydric soils. In Indiana, 79 percent of the soils are non-hydric and 21 percent of the soils are hydric (personal communication, John Brenner, NRCS). The same process was conducted for continuous corn. Results of these weighted averages are at the end of Table F-1.

The same overall process was performed for Iowa (Table F-2). Buchanan and Greene Counties were used to represent the range of responses in Iowa and the mean of curves from Buchanan, 
Pottawattamoe, and Greene Counties were used to represent the state mean. In Iowa, 77 percent of the soils are non-hydric and 23 percent of the soils are hydric (personal communication, John Brenner, NRCS).

\begin{tabular}{rccccc}
$\begin{array}{c}\text { State } \\
\text { IN }\end{array}$ & County & Rotation & Tillage & Hydric & Texture \\
Year & Allen & C/SB & No & N & L \\
0 & \multicolumn{2}{c}{0} & & \\
10 & \multicolumn{2}{c}{5100 from IN carbon storage project (Table 1) } \\
20 & \multicolumn{2}{c}{8100 from IN carbon storage project (Table 1) }
\end{tabular}
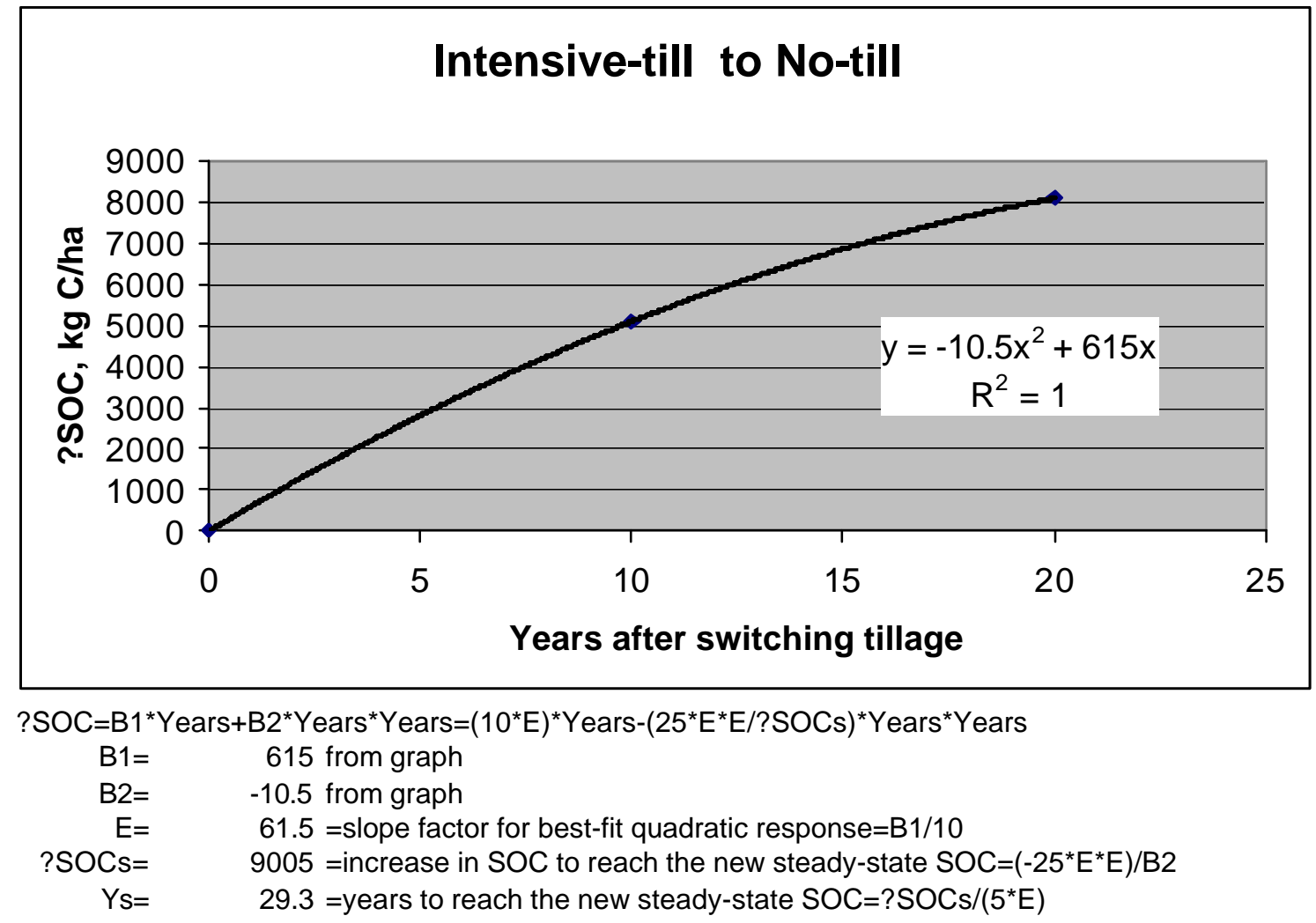

Figure F-1

Quadratic regression and transformation procedure for SOC response to reducing tillage 


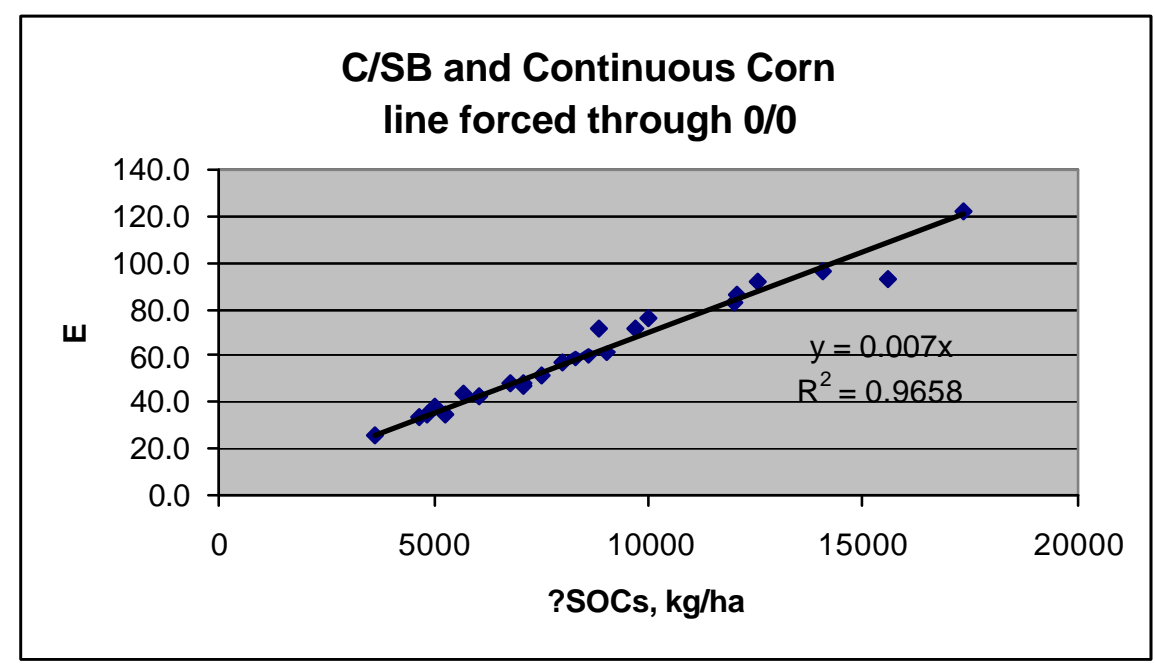

Figure F-2

Linear relationship between E and ?SOCs for the Indiana data from Table F-1

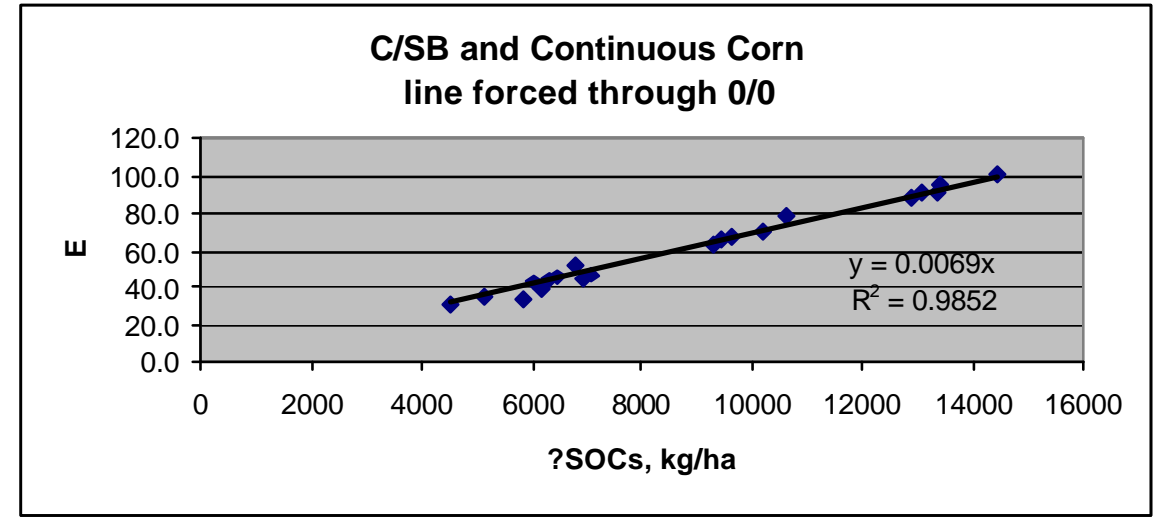

Figure F-3

Linear relationship between E and ?SOCs for the lowa data from Table F-2 
Table F-1

Increases in SOC due to switching from intensive-till to no-till or moderate till in Indiana

Table 1. Increases in SOC due to switching from intensive-till to no-till or moderate-till in counties selected to represent the range and mean of county-level responses in Indiana, Smith et al. (2002).

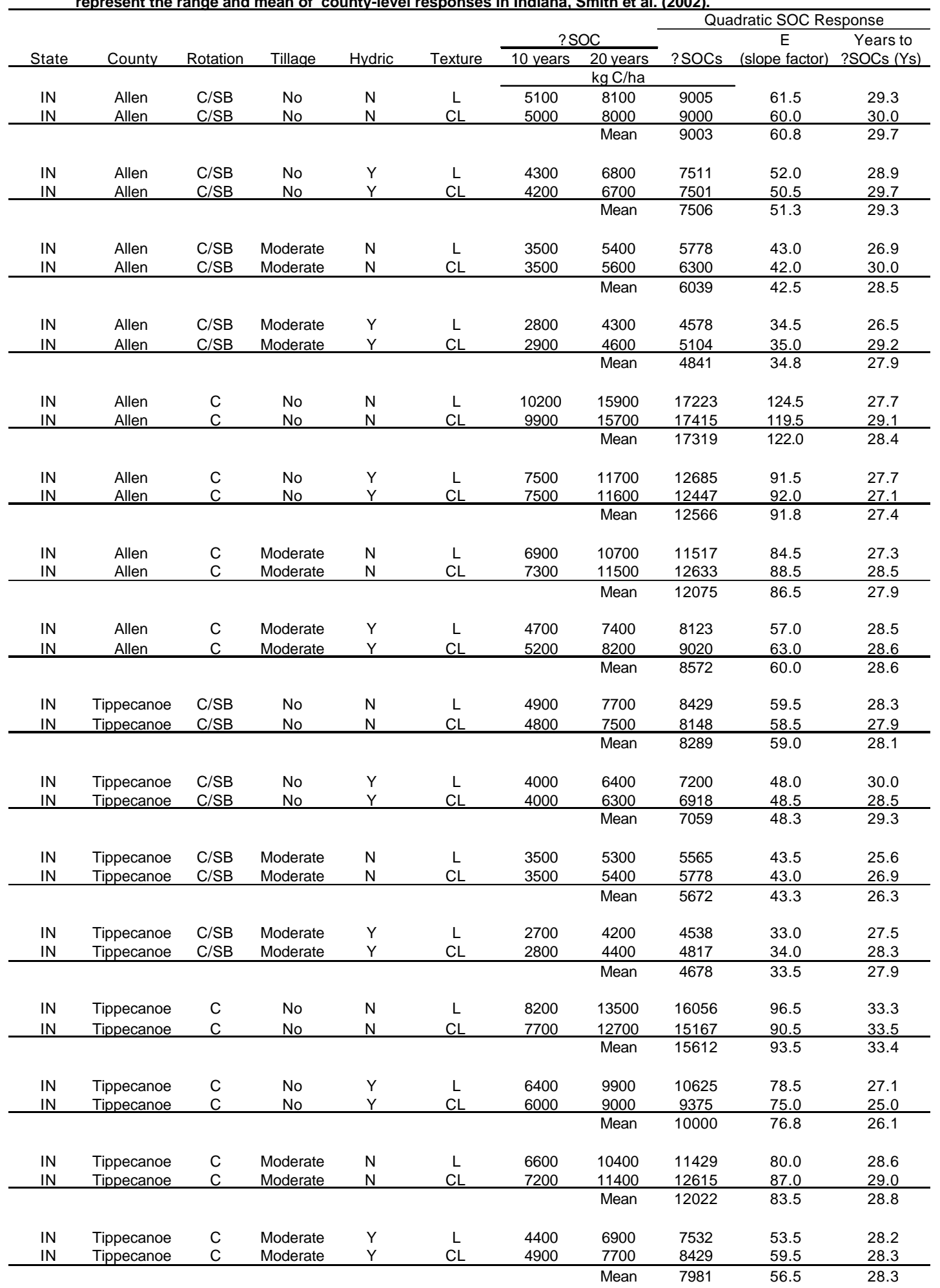




\begin{tabular}{|c|c|c|c|c|c|c|c|c|c|c|}
\hline $\begin{array}{l}\text { IN } \\
\text { IN }\end{array}$ & $\begin{array}{l}\text { Gibson } \\
\text { Gibson }\end{array}$ & $\begin{array}{l}\mathrm{C} / \mathrm{SB} \\
\mathrm{C} / \mathrm{SB} \\
\end{array}$ & $\begin{array}{l}\text { No } \\
\text { No } \\
\end{array}$ & $\begin{array}{l}\mathrm{N} \\
\mathrm{N} \\
\end{array}$ & $\begin{array}{c}\mathrm{L} \\
\text { SICL } \\
\end{array}$ & $\begin{array}{l}4300 \\
3600 \\
\end{array}$ & $\begin{array}{l}6700 \\
5700 \\
\end{array}$ & $\begin{array}{l}7253 \\
6308 \\
\end{array}$ & $\begin{array}{l}52.5 \\
43.5 \\
\end{array}$ & $\begin{array}{l}27.6 \\
29.0 \\
\end{array}$ \\
\hline \multirow{3}{*}{$\begin{array}{l}\text { IN } \\
\text { IN }\end{array}$} & & & & & & & Mean & 6781 & 48.0 & 28.3 \\
\hline & $\begin{array}{l}\text { Gibson } \\
\text { Gibson }\end{array}$ & $\begin{array}{l}\mathrm{C} / \mathrm{SB} \\
\mathrm{C} / \mathrm{SB} \\
\end{array}$ & $\begin{array}{l}\text { No } \\
\text { No }\end{array}$ & $\begin{array}{l}Y \\
Y\end{array}$ & $\begin{array}{c}L \\
S I C L \\
\end{array}$ & $\begin{array}{l}3500 \\
2600 \\
\end{array}$ & $\begin{array}{l}5400 \\
4000 \\
\end{array}$ & $\begin{array}{l}5778 \\
4267 \\
\end{array}$ & $\begin{array}{r}43.0 \\
32.0 \\
\end{array}$ & $\begin{array}{l}26.9 \\
26.7 \\
\end{array}$ \\
\hline & & & & & & & Mean & 5023 & 37.5 & 26.8 \\
\hline \multirow[t]{2}{*}{$\begin{array}{l}\text { IN } \\
\text { IN }\end{array}$} & $\begin{array}{l}\text { Gibson } \\
\text { Gibson }\end{array}$ & $\begin{array}{l}\mathrm{C} / \mathrm{SB} \\
\mathrm{C} / \mathrm{SB} \\
\end{array}$ & $\begin{array}{l}\text { Moderate } \\
\text { Moderate }\end{array}$ & $\begin{array}{l}\mathrm{N} \\
\mathrm{N}\end{array}$ & $\begin{array}{c}\mathrm{L} \\
\mathrm{SICL}\end{array}$ & $\begin{array}{l}2900 \\
2900 \\
\end{array}$ & $\begin{array}{l}4600 \\
4700 \\
\end{array}$ & $\begin{array}{l}5104 \\
5410 \\
\end{array}$ & $\begin{array}{l}35.0 \\
34.5 \\
\end{array}$ & $\begin{array}{l}29.2 \\
31.4 \\
\end{array}$ \\
\hline & & & & & & & Mean & 5257 & 34.8 & 30.3 \\
\hline \multirow[t]{2}{*}{$\begin{array}{l}\text { IN } \\
\text { IN }\end{array}$} & $\begin{array}{l}\text { Gibson } \\
\text { Gibson }\end{array}$ & $\begin{array}{l}\mathrm{C} / \mathrm{SB} \\
\mathrm{C} / \mathrm{SB}\end{array}$ & $\begin{array}{l}\text { Moderate } \\
\text { Moderate }\end{array}$ & $\begin{array}{l}Y \\
Y\end{array}$ & $\begin{array}{c}\mathrm{L} \\
\mathrm{SICL}\end{array}$ & $\begin{array}{l}2300 \\
1900 \\
\end{array}$ & $\begin{array}{l}3500 \\
3100\end{array}$ & $\begin{array}{l}3692 \\
3616 \\
\end{array}$ & $\begin{array}{l}28.5 \\
22.5 \\
\end{array}$ & $\begin{array}{l}25.9 \\
32.1\end{array}$ \\
\hline & & & & & & & Mean & 3654 & 25.5 & 29.0 \\
\hline \multirow[t]{2}{*}{$\begin{array}{l}\text { IN } \\
\text { IN }\end{array}$} & $\begin{array}{l}\text { Gibson } \\
\text { Gibson }\end{array}$ & $\begin{array}{l}\mathrm{C} \\
\mathrm{C}\end{array}$ & $\begin{array}{l}\text { No } \\
\text { No }\end{array}$ & $N$ & $\stackrel{L}{S I C L}$ & 8700 & $\begin{array}{l}13400 \\
11900\end{array}$ & $\begin{array}{l}14311 \\
13856\end{array}$ & $\begin{array}{l}107.0 \\
86.5\end{array}$ & 26.8 \\
\hline & & & & & & & Mean & 14084 & 96.8 & 29.4 \\
\hline \multirow{3}{*}{$\begin{array}{l}\text { IN } \\
\text { IN }\end{array}$} & Gibson & C & No & Y & L & 6400 & 9900 & 10625 & 78.5 & 27.1 \\
\hline & Gibson & C & No & Y & SICL & 5000 & 7000 & 7042 & 65.0 & 21.7 \\
\hline & & & & & & & Mean & 8834 & 71.8 & 24.4 \\
\hline \multirow[t]{2}{*}{$\begin{array}{l}\text { IN } \\
\text { IN }\end{array}$} & $\begin{array}{l}\text { Gibson } \\
\text { Gibson }\end{array}$ & $\begin{array}{l}\mathrm{C} \\
\mathrm{C} \\
\end{array}$ & $\begin{array}{l}\text { Moderate } \\
\text { Moderate }\end{array}$ & $\begin{array}{l}N \\
N\end{array}$ & $\begin{array}{c}\mathrm{L} \\
\mathrm{SICL}\end{array}$ & $\begin{array}{l}5900 \\
6100 \\
\end{array}$ & $\begin{array}{c}9100 \\
10700 ?\end{array}$ & 9734 & 72.5 & 26.9 \\
\hline & & & Mean & & & & & 9734 & 72.5 & 26.9 \\
\hline IN & Gibson & C & Moderate & Y & $\mathrm{L}$ & 3800 & 6000 & 6613 & 46.0 & 28.8 \\
\hline \multirow[t]{2}{*}{ IN } & Gibson & C & Moderate & Y & SICL & 4000 & 6500 & 7521 & 47.5 & 31.7 \\
\hline & & & & & & & Mean & 7067 & 46.8 & 30.3 \\
\hline
\end{tabular}

Interpolated state curves--means of Tippaconoe and Gibson County curves

\begin{tabular}{|c|c|c|c|c|c|c|c|c|c|c|}
\hline \multirow[b]{3}{*}{ State } & \multirow[b]{3}{*}{ County } & \multirow[b]{3}{*}{ Rotation } & \multirow[b]{3}{*}{ Tillage } & \multirow[b]{3}{*}{ Hydric } & \multirow[b]{3}{*}{ Texture } & \multirow{2}{*}{\multicolumn{2}{|c|}{$2 \mathrm{soc}$}} & \multicolumn{3}{|c|}{ Quadratic SOC Response } \\
\hline & & & & & & & & \multirow{3}{*}{ ? SOCs } & \multirow{2}{*}{$\begin{array}{c}E \\
\text { (slope factor) }\end{array}$} & \multirow{2}{*}{$\begin{array}{c}\text { Years to } \\
\text { ?SOCs (Ys) }\end{array}$} \\
\hline & & & & & & 10 years & 20 years & & & \\
\hline & & & & & & & $\mathrm{kg} \mathrm{C} / \mathrm{ha}$ & & & \\
\hline IN & Tippeconoe & $\mathrm{C} / \mathrm{SB}$ & No & $\mathrm{N}$ & Mean & & & 8289 & 59.0 & 28.1 \\
\hline \multirow[t]{3}{*}{ IN } & Gibson & $\mathrm{C} / \mathrm{SB}$ & No & $\mathrm{N}$ & Mean & & & 6781 & 48.0 & 28.3 \\
\hline & & & & \multirow{2}{*}{\multicolumn{2}{|c|}{$\begin{array}{l}\text { Interpolated state curve } \\
\text { nean--Smith et al. (2002) }\end{array}$}} & 4400 & 6901 & 7535 & 53.5 & 28.2 \\
\hline & & & State $\mathrm{n}$ & & & 4225 & not avail. & & & \\
\hline \multirow{4}{*}{$\begin{array}{l}\text { IN } \\
\text { IN }\end{array}$} & Tippeconoe & $\mathrm{C} / \mathrm{SB}$ & No & $\mathrm{Y}$ & Mean & & & 7059 & 48.3 & 29.3 \\
\hline & Gibson & $\mathrm{C} / \mathrm{SB}$ & No & $\mathrm{Y}$ & Mean & & & 5023 & 37.5 & 26.8 \\
\hline & & & & \multicolumn{2}{|c|}{ Interpolated state curve } & 3527 & 5532 & 6041 & 42.9 & 28.0 \\
\hline & & & State $\mathrm{n}$ & nean--Smit & t al. (2002) & 3500 & not avail. & & & \\
\hline \multirow{4}{*}{$\begin{array}{l}\text { IN } \\
\text { IN }\end{array}$} & Tippeconoe & $\mathrm{C} / \mathrm{SB}$ & Moderate & $\mathrm{N}$ & Mean & & & 5672 & 43.3 & 28.8 \\
\hline & Gibson & $\mathrm{C} / \mathrm{SB}$ & Moderate & $\mathrm{N}$ & Mean & & & 5257 & 34.8 & 30.3 \\
\hline & & & & \multirow{2}{*}{\multicolumn{2}{|c|}{$\begin{array}{l}\text { Interpolated state curve } \\
\text { nean--Smith et al. (2002) }\end{array}$}} & 3204 & 5016 & 5464 & 39.0 & 29.6 \\
\hline & & & State $\mathrm{n}$ & & & 3200 & not avail. & & & \\
\hline \multirow{4}{*}{$\begin{array}{l}\text { IN } \\
\text { IN }\end{array}$} & Tippeconoe & $\mathrm{C} / \mathrm{SB}$ & Moderate & Y & Mean & & & 4678 & 33.5 & 27.9 \\
\hline & Gibson & $\mathrm{C} / \mathrm{SB}$ & Moderate & Y & Mean & & & 3654 & 25.5 & 29.0 \\
\hline & & & & Interpolate & state curve & 2428 & 3811 & 4166 & 29.5 & 28.5 \\
\hline & & & State $\mathrm{n}$ & nean--Smi & t al. (2002) & 2400 & not avail. & & & \\
\hline \multirow{3}{*}{$\begin{array}{l}\text { IN } \\
\text { IN }\end{array}$} & Tippeconoe & c & No & $\mathrm{N}$ & Mean & & & 15612 & 93.5 & 33.4 \\
\hline & Gibson & $\mathrm{C}$ & No & $\mathrm{N}$ & Mean & & & 14084 & 96.8 & 29.4 \\
\hline & & & & \multicolumn{2}{|c|}{ Interpolated state curve } & 7989 & 12931 & 14848 & 95.1 & 31.4 \\
\hline IN & Tippeconoe & c & No & Y & Mean & & & 10000 & 76.8 & 26.1 \\
\hline \multirow[t]{2}{*}{ IN } & Gibson & C & No & $\mathrm{Y}$ & Mean & & & 8834 & 71.8 & 24.4 \\
\hline & & & & \multicolumn{2}{|c|}{ Interpolated state curve } & 5961 & 8995 & 9417 & 74.3 & 25.2 \\
\hline IN & Tippeconoe & C & Moderate & $\mathrm{N}$ & Mean & & & 12022 & 83.5 & 28.8 \\
\hline \multirow[t]{2}{*}{ IN } & Gibson & $\mathrm{C}$ & Moderate & $\mathrm{N}$ & Mean & & & 9734 & 72.5 & 26.9 \\
\hline & & & & \multicolumn{2}{|c|}{ Interpolated state curve } & 6402 & 10007 & 10878 & 78.0 & 27.9 \\
\hline & Tippeconoe & C & Moderate & Y & Mean & & & 7981 & 56.5 & 28.3 \\
\hline \multirow[t]{2}{*}{ IN } & Gibson & c & Moderate & Y & Mean & & & 7067 & 46.8 & 30.3 \\
\hline & & & & \multicolumn{2}{|c|}{ Interpolated state curve } & 4277 & 6783 & 7524 & 51.6 & 29.3 \\
\hline
\end{tabular}


Weighted state means assuming $79 \%$ non-hydric soils and $21 \%$ hydric soils

\begin{tabular}{cccccccccccc}
\multicolumn{10}{c}{ Weighted state means assuming $79 \%$ non-hydric soils and 21\% hydric soils } \\
\hline IN & State & C/SB & No & Mean & Mean & 4217 & 6614 & 7220.8 & 51.3 & 28.2 \\
IN & State & C/SB & Moderate & Mean & Mean & 3041 & 4763 & 5191.6 & 37.0 & 28.1 \\
IN & State & C & No & Mean & Mean & 7587 & 11942 & 13103.5 & 92.0 & 28.5 & \\
IN & State & C & Moderate & Mean & Mean & 5956 & 9331 & 10173.6 & 72.5 & 28.1
\end{tabular}


Table F-2

Increases in SOC due to switching from intensive-till to no-till or moderate-till in lowa

Table 2. Increases in SOC due to switching from intensive-till to no-till or moderate-till in counties selected to represent the range and mean of county-level responses in lowa, Brenner et al. (2001).

\begin{tabular}{|c|c|c|c|c|c|c|c|c|c|c|}
\hline \multirow[b]{3}{*}{ State } & \multirow[b]{3}{*}{ County } & \multirow[b]{3}{*}{ Rotation } & \multirow[b]{3}{*}{ Tillage } & \multirow[b]{3}{*}{ Hydric } & \multirow[b]{3}{*}{ Texture } & \multirow{2}{*}{\multicolumn{2}{|c|}{ ? SOC }} & \multicolumn{3}{|c|}{ Quadratic SOC Response } \\
\hline & & & & & & & & \multirow[b]{2}{*}{ ?SOCs } & \multirow{2}{*}{$\begin{array}{c}E \\
\text { (slope factor) }\end{array}$} & \multirow{2}{*}{$\begin{array}{c}\text { Years to } \\
\text { ?SOCs (Ys) }\end{array}$} \\
\hline & & & & & & 10 years & 20 years & & & \\
\hline & & & & & & & $\mathrm{kgC} / \mathrm{ha}$ & & & \\
\hline IA & Buchanan & $\mathrm{C} / \mathrm{SB}$ & No & $\mathrm{N}$ & $\mathrm{L}$ & 5800 & 9200 & 10208 & 70.0 & 29.2 \\
\hline \multirow[t]{2}{*}{ IA } & Buchanan & $\mathrm{C} / \mathrm{SB}$ & No & $\mathrm{N}$ & $\mathrm{CL}$ & 5800 & 9200 & 10208 & 70.0 & 29.2 \\
\hline & & & & & & & Mean & 10208 & 70.0 & 29.2 \\
\hline $\mathrm{IA}$ & Buchanan & $\mathrm{C} / \mathrm{SB}$ & No & Y & $\mathrm{L}$ & & & & & \\
\hline \multirow[t]{2}{*}{ IA } & Buchanan & $\mathrm{C} / \mathrm{SB}$ & No & Y & $\mathrm{CL}$ & 6400 & 9900 & 10625 & 78.5 & 27.1 \\
\hline & & & & & & & Mean & 10625 & 78.5 & 27.1 \\
\hline IA & Buchanan & $\mathrm{C} / \mathrm{SB}$ & Moderate & $\mathrm{N}$ & $\mathrm{L}$ & 3800 & 6100 & 6901 & 45.5 & 30.3 \\
\hline \multirow[t]{2}{*}{ IA } & Buchanan & $\mathrm{C} / \mathrm{SB}$ & Moderate & $\mathrm{N}$ & $\mathrm{CL}$ & 4000 & 6400 & 7200 & 48.0 & 30.0 \\
\hline & & & & & & & Mean & 7051 & 46.8 & 30.2 \\
\hline IA & Buchanan & $\mathrm{C} / \mathrm{SB}$ & Moderate & $Y$ & $\mathrm{~L}$ & & & & & \\
\hline \multirow[t]{2}{*}{ IA } & Buchanan & $\mathrm{C} / \mathrm{SB}$ & Moderate & $Y$ & $\mathrm{CL}$ & 4200 & 6400 & 6760 & 52.0 & 26.0 \\
\hline & & & & & & & Mean & 6760 & 52.0 & 26.0 \\
\hline $\mathrm{IA}$ & Buchanan & C & No & $\mathrm{N}$ & $\mathrm{L}$ & 7600 & 12100 & 13504 & 91.5 & 29.5 \\
\hline \multirow[t]{2}{*}{ IA } & Buchanan & $\mathrm{C}$ & No & $\mathrm{N}$ & $\mathrm{CL}$ & 7500 & 11900 & 13210 & 90.5 & 29.2 \\
\hline & & & & & & & Mean & 13357 & 91.0 & 29.4 \\
\hline IA & Buchanan & C & No & $Y$ & $\mathrm{~L}$ & & & & & \\
\hline \multirow[t]{2}{*}{ IA } & Buchanan & C & No & $Y$ & $\mathrm{CL}$ & 8300 & 13100 & 14429 & 100.5 & 28.7 \\
\hline & & & & & & & Mean & 14429 & 100.5 & 28.7 \\
\hline IA & Buchanan & C & Moderate & $\mathrm{N}$ & $\mathrm{L}$ & 3100 & 5000 & 5704 & 37.0 & 30.8 \\
\hline \multirow[t]{2}{*}{ IA } & Buchanan & $\mathrm{C}$ & Moderate & $\mathrm{N}$ & $\mathrm{CL}$ & 3500 & 5700 & 6624 & 41.5 & 31.9 \\
\hline & & & & & & & Mean & 6164 & 39.3 & 31.4 \\
\hline IA & Buchanan & $\mathrm{C}$ & Moderate & $Y$ & $\mathrm{~L}$ & & & & & \\
\hline IA & Buchanan & C & Moderate & $Y$ & $\mathrm{CL}$ & 3700 & 6000 & 6914 & 44.0 & 31.4 \\
\hline & & & & & & & Mean & 6914 & 44.0 & 31.4 \\
\hline IA & Greene & $\mathrm{C} / \mathrm{SB}$ & No & $\mathrm{N}$ & $\mathrm{L}$ & 5200 & 8200 & 9020 & 63.0 & 28.6 \\
\hline $\mathrm{IA}$ & Greene & $\mathrm{C} / \mathrm{SB}$ & No & $\mathrm{N}$ & $\mathrm{CL}$ & 5300 & 8500 & 9601 & 63.5 & 30.2 \\
\hline & & & & & & & Mean & 9311 & 63.3 & 29.4 \\
\hline IA & Greene & $\mathrm{C} / \mathrm{SB}$ & No & $Y$ & $\mathrm{~L}$ & 5400 & 8500 & 9327 & 65.5 & 28.5 \\
\hline IA & Greene & $\mathrm{C} / \mathrm{SB}$ & No & $Y$ & $\mathrm{CL}$ & 5500 & 8700 & 9614 & 66.5 & 28.9 \\
\hline & & & & & & & Mean & 9471 & 66.0 & 28.7 \\
\hline IA & Greene & $\mathrm{C} / \mathrm{SB}$ & Moderate & $\mathrm{N}$ & $\mathrm{L}$ & 3400 & 5300 & 5741 & 41.5 & 27.7 \\
\hline $\mathrm{IA}$ & Greene & $\mathrm{C} / \mathrm{SB}$ & Moderate & $\mathrm{N}$ & $\mathrm{CL}$ & 3600 & 5700 & 6308 & 43.5 & 29.0 \\
\hline & & & & & & & Mean & 6025 & 42.5 & 28.4 \\
\hline $\mathrm{IA}$ & Greene & $\mathrm{C} / \mathrm{SB}$ & Moderate & $Y$ & $\mathrm{~L}$ & 3500 & 5500 & 6021 & 42.5 & 28.3 \\
\hline IA & Greene & $\mathrm{C} / \mathrm{SB}$ & Moderate & $\mathrm{Y}$ & $\mathrm{CL}$ & 3700 & 5900 & 6601 & 44.5 & 29.7 \\
\hline & & & & & & & Mean & 6311 & 43.5 & 29.0 \\
\hline IA & Greene & C & No & $\mathrm{N}$ & $\mathrm{L}$ & 7300 & 11500 & 12633 & 88.5 & 28.5 \\
\hline IA & Greene & C & No & $\mathrm{N}$ & $C L$ & 7300 & 11700 & 13200 & 87.5 & 30.2 \\
\hline & & & & & & & Mean & 12917 & 88.0 & 29.4 \\
\hline $\mathrm{IA}$ & Greene & C & No & $Y$ & $\mathrm{~L}$ & 7600 & 11900 & 12964 & 92.5 & 28.0 \\
\hline IA & Greene & $\mathrm{C}$ & No & $Y$ & $\mathrm{CL}$ & 7500 & 11900 & 13210 & 90.5 & 29.2 \\
\hline & & & & & & & Mean & 13087 & 91.5 & 28.6 \\
\hline IA & Greene & C & Moderate & $\mathrm{N}$ & $\mathrm{L}$ & 2500 & 4000 & 4500 & 30.0 & 28.6 \\
\hline $\mathrm{IA}$ & Greene & C & Moderate & $\mathrm{N}$ & $\mathrm{CL}$ & 2500 & 4000 & 4500 & 30.0 & 28.6 \\
\hline & & & & & & & Mean & 4500 & 30.0 & 28.6 \\
\hline IA & Greene & C & Moderate & $Y$ & $\mathrm{~L}$ & 2800 & 4400 & 4817 & 34.0 & 28.3 \\
\hline $\mathrm{IA}$ & Greene & C & Moderate & $\mathrm{Y}$ & $\mathrm{CL}$ & 2900 & 4700 & 5410 & 34.5 & 34.1 \\
\hline & & & & & & & Mean & 5114 & 34.3 & 31.2 \\
\hline
\end{tabular}




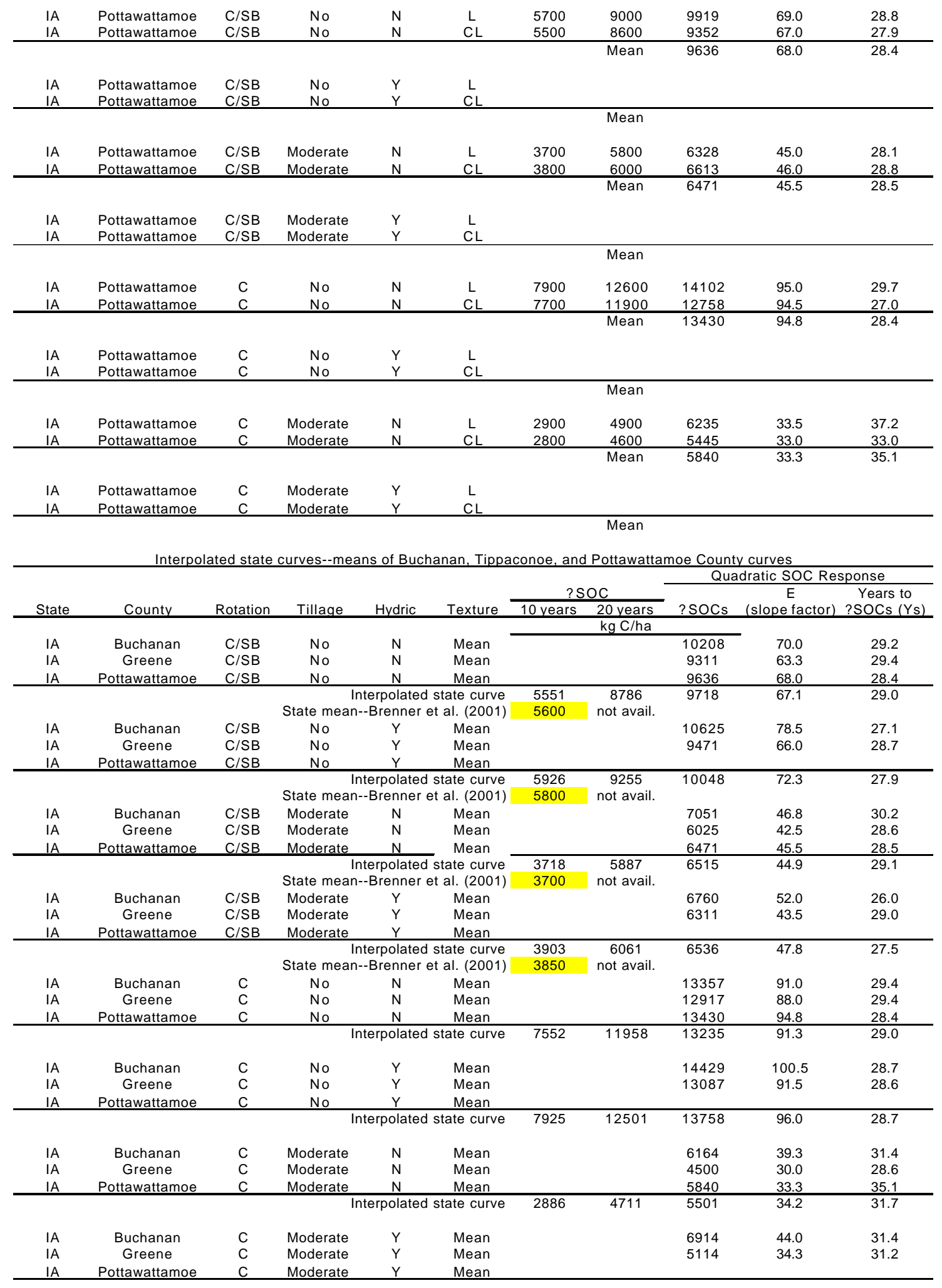


Weighted state means assuming $77 \%$ non-hydric soils and $23 \%$ hydric soils

\begin{tabular}{|c|c|c|c|c|c|c|c|c|c|c|}
\hline $\begin{array}{l}\text { IA } \\
\text { IA }\end{array}$ & $\begin{array}{l}\text { State } \\
\text { State }\end{array}$ & $\begin{array}{l}\mathrm{C} / \mathrm{SB} \\
\mathrm{C} / \mathrm{SB}\end{array}$ & $\begin{array}{c}\text { No } \\
\text { Moderate }\end{array}$ & $\begin{array}{l}\text { Mean } \\
\text { Mean }\end{array}$ & $\begin{array}{l}\text { Mean } \\
\text { Mean }\end{array}$ & $\begin{array}{l}5637 \\
3761\end{array}$ & $\begin{array}{l}8895 \\
5929\end{array}$ & $\begin{array}{l}9793.8 \\
6519.8\end{array}$ & $\begin{array}{l}68.3 \\
45.6\end{array}$ & $\begin{array}{l}28.7 \\
28.6\end{array}$ \\
\hline $\begin{array}{l}\text { IA } \\
\text { IA }\end{array}$ & $\begin{array}{l}\text { State } \\
\text { State }\end{array}$ & $\begin{array}{l}\mathrm{C} \\
\mathrm{C}\end{array}$ & $\begin{array}{c}\text { No } \\
\text { Moderate }\end{array}$ & $\begin{array}{l}\text { Mean } \\
\text { Mean }\end{array}$ & $\begin{array}{l}\text { Mean } \\
\text { Mean }\end{array}$ & $\begin{array}{l}7638 \\
2976\end{array}$ & $\begin{array}{c}12083 \\
4843\end{array}$ & $\begin{array}{c}13354.9 \\
5619.2\end{array}$ & $\begin{array}{l}92.3 \\
35.3\end{array}$ & $\begin{array}{l}28.9 \\
31.8\end{array}$ \\
\hline
\end{tabular}




\section{References}

1 Smith, P., J. Brenner, K. Paustian, G. Bluhm, J. Cipra, M. Easter, E.T. Elliott, K. Killian, D. Lamm, J. Schuler, and S. Williams. 2002. Quantifying the change in greenhouse gas emissions due to natural resource conservation practice application in Indiana. Final report to the Indiana Conservation Partnership. Colorado State University Natural Resource Ecology Laboratory and USDA Natural Resources Conservation Service, Fort Collins, Colorado, USA.

2 Brenner, J., K. Paustian, G. Bluhm, J. Cipra, M. Easter, E.T. Elliott, T. Kautza, K. Killian, J. Schuler, and S. Williams. 2001. Quantifying the change in greenhouse gas emissions due to natural resource conservation practice application in Iowa. Final report to the Iowa Conservation Partnership. Colorado State University Natural Resource Ecology Laboratory and USDA Natural Resources Conservation Service, Fort Collins, Colorado, USA.

3 Bock, B. R., F. J. Sikora, and G. W. Hergert. 1991. Approach for estimating yield response to nitrogen based on nitrogen-rate requirement parameters. p. 323-332. In: R.F. Follett and D.R. Keeney (eds.). Managing nitrogen for groundwater quality and farm profitability. ASA, Madison, Wisconsin. 